\title{
Muße und Moderne
}

Herausgegeben von

Tobias Keiling, Robert Krause und Heidi Liedke

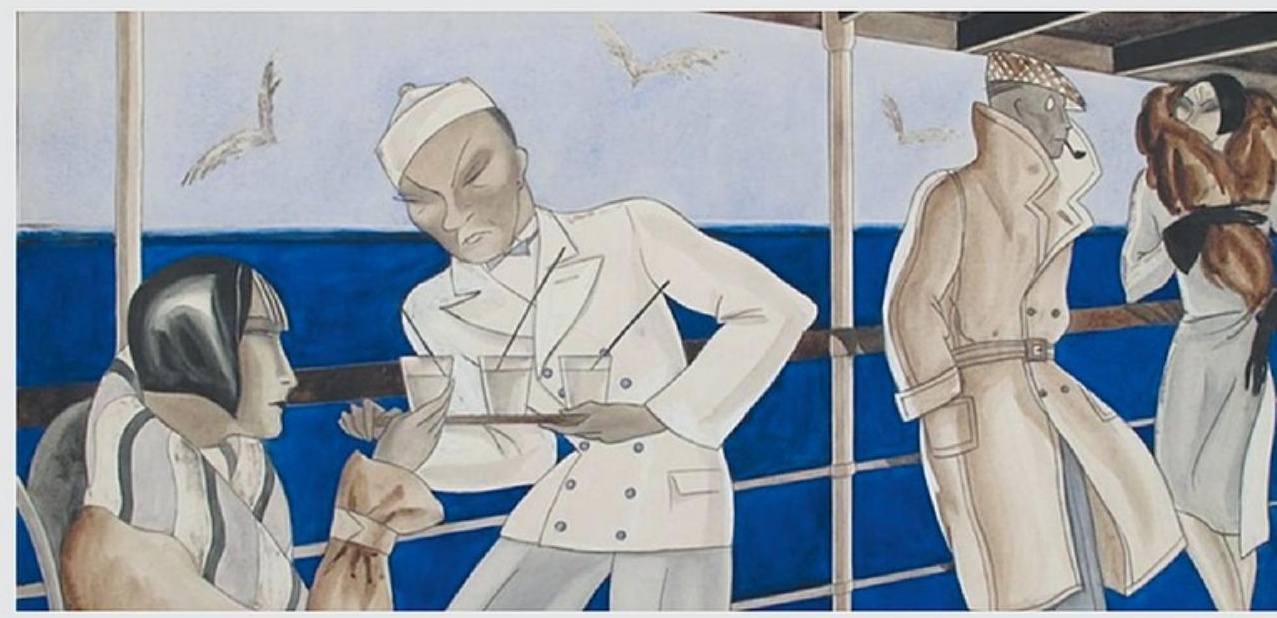

Otium.

Studien zur Theorie und Kulturgeschichte der Muße

Mohr Siebeck 


\section{Otium}

Studien zur Theorie und Kulturgeschichte der Muße

\section{Herausgegeben von}

Elisabeth Cheauré, Gregor Dobler, Monika Fludernik, Hans W. Hubert und Peter Philipp Riedl

\section{Beirat}

Barbara Beßlich, Christine Engel, Udo Friedrich, Ina Habermann, Richard Hunter, Irmela von der Lühe, Ulrich Pfisterer, Gérard Raulet, Gerd Spittler, Sabine Volk-Birke

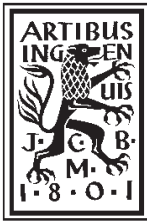





\section{Muße und Moderne}

Herausgegeben von

Tobias Keiling, Robert Krause und Heidi Liedke

Mohr Siebeck 
Tobias Keiling, Dr., PhD. Forschungsstipendiat am Human Dynamics Centre der JuliusMaximilians-Universität Würzburg; Studium der Philosophie, Soziologie und des Europaund Völkerrechts in Freiburg, Basel und Paris; 2013 PhD am Boston College, USA, und Promotion zum Dr. phil. an der Albert-Ludwigs-Universität Freiburg; 2013-2016 Wissenschaftlicher Mitarbeiter am Freiburger Sonderforschungsbereich 1015 „Muße“.

Robert Krause, Dr. Phil. Akademischer Mitarbeiter am Deutschen Seminar, Abteilung Neuere deutsche Literatur, der Albert-Ludwigs-Universität Freiburg; Assoziiertes Mitglied der Forschungsstelle „Nietzsche-Kommentar“ der Heidelberger Akademie der Wissenschaften; 2009 Promotion an der Universität Freiburg; 2012-2013 Postdoc-Stipendiat der Fritz Thyssen Stiftung; 2013-2014 Mitarbeiter am SFB 1015 „Muße“; Herbst 2016 Forschungsaufenthalt in Paris im Rahmen eines sozialwissenschaftlich ausgerichteten deutsch-französischen Kooperationsprogramms zum Thema, Arbeit' (WZB / FMSH).

Heidi Liedke, Dr. Feodor Lynen Postdoc-Stipendiatin der Alexander von Humboldt-Stiftung an der Queen Mary University of London, GB; 2013-2016 Wissenschaftliche Mitarbeiterin am Freiburger SFB 1015 „Muße“; 2016 Promotion zur Dr. phil. im Fach Englische Philologie an der Albert-Ludwigs-Universität Freiburg; seit 2017 Wissenschaftliche Mitarbeiterin im Fach Anglistik an der Universität Koblenz-Landau, Campus Landau.

Diese Publikation entstand im Rahmen des Sonderforschungsbereichs 1015 „Muße“ und wurde durch die Deutsche Forschungsgemeinschaft (DFG) gefördert.

ISBN 978-3-16-156337-9 / eISBN 978-3-16-156338-6

DOI 10.1628/978-3-16-156338-6

Die Deutsche Nationalbibliothek verzeichnet diese Publikation in der Deutschen Nationalbibliographie; detaillierte bibliographische Daten sind im Internet über $h t t p: / / d n b . d n b$. de abrufbar.

\section{(C) 2018 Mohr Siebeck Tübingen. www.mohrsiebeck.com}

Das Werk einschließlich aller seiner Teile ist urheberrechtlich geschützt. Jede Verwertung außerhalb der engen Grenzen des Urheberrechtsgesetzes ist ohne Zustimmung des Verlags unzulässig und strafbar. Das gilt insbesondere für die Verbreitung, Vervielfältigung, Übersetzung und die Einspeicherung und Verarbeitung in elektronischen Systemen.

Das Buch wurde von Computersatz Staiger in Rottenburg/N. aus der Minion gesetzt, von Gulde Druck in Tübingen auf alterungsbeständiges Werkdruckpapier gedruckt und von der Großbuchbinderei Spinner in Ottersweier gebunden.

Umschlagabbildung: Dodo, Trübe Ahnung/1929. @ akg-images.

Printed in Germany. 


\section{Vorwort}

Was kennzeichnet Muße in der Moderne? Dieser Frage gingen Philosophinnen und Philosophen, Literatur- und Kulturwissenschaftlerinnen und -wissenschaftler während einer Vorlesungsreihe des Freiburger Sonderforschungsbereichs (SFB) 1015 „Muße“ in den Jahren 2015 und 2016 nach. Ihre Vorträge sind hier in ausgearbeiteter Form versammelt sowie um weitere thematisch einschlägige Beiträge ergänzt. Eine Einleitung stellt unsere konzeptionellen Überlegungen zu den Leitbegriffen ,Muße und ,Moderne' dar.

Wir danken dem Vorstand des SFB, der unsere zweisemestrige Vorlesungsreihe und deren Publikation finanziell gefördert und organisatorisch mitgetragen hat. Ebenso danken wir den Herausgeberinnen und Herausgebern für die Aufnahme des Bandes in die Otium-Reihe, den anonymen Gutachterinnen und Gutachtern im Peer-Review-Verfahren für hilfreiche Hinweise und den Beiträgerinnen und Beiträgern für ihre Kooperation. Klaus Hermannstädter und Susanne Mang danken wir für Lektorat und Herstellung im Verlag Mohr Siebeck. 



\section{Inhaltsverzeichnis}

\section{Robert Krause}

Muße und Moderne. Zur Einführung

Jan Gerstner

Idyllische Arbeit und tätige Muße. Transformationen um 1800

Pia Florence Masurczak

'The opulent baboos [...] filling out [their] cellular tissue

with sebaceous deposits'. Körper als Aushandlungsorte von Müßiggang .

Nassima Sahraoui

Ent-Setzen, -Halten, -Stellen, -Rücken.

Drei Bemerkungen zur Zeitlichkeitsstruktur von Faulheit und Muße ....

Günter Figal

Muße und Einfachheit.

Henry David Thoreaus literarisches Lebensexperiment

Martin Jörg Schäfer

Ein „edel Ding um Musse und Müssiggehen“ und Nietzsches

Metaphorologie der Arbeit . .

\section{Annika Schlitte}

Kein Raum für Muße? Georg Simmel und die ,ruhelose Rhythmik

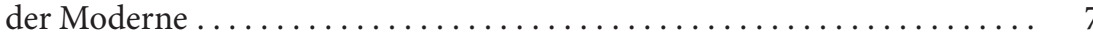

Peter Philipp Riedl

Die Muße des Flaneurs. Raum und Zeit in Franz Hessels

Spazieren in Berlin (1929) . . . . . . . . . . . . . . . . . . . . . . . . . . .

Robert Krause

Walter Benjamins Suche nach der „Schwelle [...], die den Müßiggang von der Muße trennt" 
Jan Wilm

Mußemöglichkeiten des Lesens und die frühen Gedichte

von Samuel Beckett

Kerstin Fest

Oberland und Bloomsbury. Städtische und ländliche Muße

in Dorothy Richardsons Pilgrimage

Tobias Keiling

Arbeit oder Muße. Über eine moderne, aber falsche Alternative

Georg Feitscher

Muße zur Selbstreflexion. Autobiographisches Erzählen in der Moderne . 195

Christoph Henning

Muße und Ungleichheit. Zur Dialektik eines modernen Problems

Heidi Liedke

Walking the (Open) City. Vom viktorianischen München

ins postmoderne New York

Antonia Egel

Freiträumen. Über Peter Handkes Schauspiel. Die Unschuldigen, ich und die Unbekannte am Rand der Landstraße mit Abstechern zu Wim Wenders' pina. Ein Film für Pina Bausch

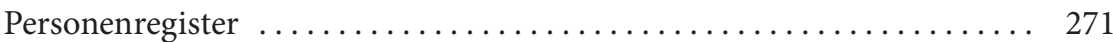

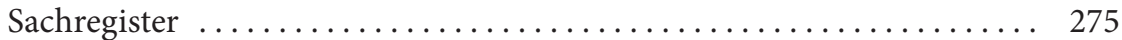




\title{
Muße und Moderne
}

\author{
Zur Einführung
}

\author{
Robert Krause
}

,Muße und Moderne stehen in einem spannungsreichen Verhältnis. Das zeigt die historische Rückschau, aber auch der Blick auf unsere, wohl eher spät- als postmoderne, Gegenwart. Die industriellen Revolutionen - von der Maschinisierung um 1800 über die Elektrifizierung um 1900 und die Automatisierung im 20. Jahrhundert bis zur anhaltenden Digitalisierung - haben große Teile der Lebens- und Arbeitswelt drastisch verändert und beschleunigt. ${ }^{1}$ Technische Neuerungen haben nicht nur Produktionsprozesse, sondern auch Transport- und Kommunikationswege verkürzt. ${ }^{2}$ Künstliches Licht lässt Tag und Nacht verschwimmen und vermeintlich 24 Stunden zur Verfügung stehen, Arbeit und Konsum sind jederzeit möglich, anders als Schlaf, der nicht länger ein festes Residuum der Ruhe darstellt. ${ }^{3}$ Daten werden rund um die Uhr und den Globus übertragen, mittlerweile sogar in Echtzeit. Der Kapitalismus hat sich weltweit als dominante Wirtschafts- und Gesellschaftsordnung etabliert, zwar mit Abstufungen, aber allen Anfechtungen sowie Wirtschafts- und Bankenkrisen zum Trotz. Aus der Arbeiterschicht, auf die Karl Marx und Friedrich Engels revolutionäre Hoffnungen setzten, gingen in der Zeit zwischen und nach den Weltkriegen mehr und mehr Angestellte ohne dezidiertes Klassenbewusstsein hervor; aus den Angestellten wurden an der Wende zum 21. Jahrhundert wiederum viele (Schein-)Selbständige und ein kreatives Prekariat, das seine nicht unbeträchtliche ökonomische Not bestenfalls zur Tugend erhebt und sich selbst zur neuen Boheme erklärt. ${ }^{5}$ Optimierung und Quantifizierung werden indes nicht nur pro-

${ }^{1}$ Dazu aus soziologischer und sozialphilosophischer Perspektive Harmut Rosa, Beschleunigung. Die Veränderung der Zeitstrukturen in der Moderne, Frankfurt a. M. 2005; Hartmut Rosa (Hg.), fast forward. Essays zur Zeit und Beschleunigung. Standpunkte junger Forschung, Hamburg 2005; Jérôme Lèbre, Vitesses, Paris 2011.

2 Vgl. Wolfgang Schivelbusch, Geschichte der Eisenbahnreise. Zur Industrialisierung von Zeit und Raum im 19. Jahrhundert, München u. a. 1977.

${ }^{3}$ Vgl. Jonathan Crary, 24/7: Late capitalism and the ends of sleep, London u. a. 2014.

4 Darauf hat Siegfried Kracauer bereits 1930 hingewiesen: Kracauer, „Die Angestellten. Aus dem neuesten Deutschland“, in: Soziologie als Wissenschaft. Der Detektiv-Roman. Die Angestellten, Schriften, Bd. I, hg. v. Inka Mülder-Bach, Frankfurt a. M. 1971, 205-304.

${ }_{5}$ Erinnert sei nur an das Manifest von Holm Friebe und Sasha Lobo, Wir nennen es 
pagiert, sondern auch internalisiert, wie das unlängst von Soziologen konstatierte „unternehmerische Selbst“6 und „metrische Wir" zeigen. ${ }^{7}$

Muße scheint dabei zum Anachronismus geworden, aber nie ganz verschwunden zu sein. Das bezeugt etwa die Tradition der Boheme, deren Vertreter im 19. und frühen 20. Jahrhundert das freie, künstlerisch inspirierte Leben jenseits sozialer und moralischer Konventionen und Marktmechanismen suchten. ${ }^{8}$ Dandy und Flaneur sind weitere prominente Sozialfiguren, die in der Gegenwartsliteratur und -Kultur wiederkehren und uns an beinahe vergessene Möglichkeiten des müßigen Lebens inmitten der schnelllebigen urbanen Moderne erinnern ${ }^{9}$, aber auch an dessen Grenzen angesichts hohen Verkehrsaufkommens, monotoner Einkaufsmeilen, bekannter Schnellrestaurants und von Sicherheitskräften kontrollierter Plätze. ${ }^{10}$

Der skizzierten Spannung zwischen ,Muße und Moderne' weiter nachzugehen und historisch fundiert nach der Muße in der Moderne zu fragen, lässt die Konturen der beiden Begriffe und Phänomene klarer hervortreten. ${ }^{11} \mathrm{Wie}$ bei interdisziplinärer Forschung üblich, greifen die Autoren der hier versam-

Arbeit: Die digitale Bohème oder: Intelligentes Leben jenseits der Festanstellung, München 2006, insbes. 21-41 (Kap. 1: „Das Prinzip Bohème“).

${ }^{6}$ Ulrich Bröckling, Das unternehmerische Selbst. Soziologie einer Subjektivierungsform, Frankfurt a. M. 2007.

7 Steffen Mau, Das metrische Wir. Über die Quantifizierung des Sozialen, Berlin 2017.

8 Vgl. Helmut Kreuzer, Die Boheme. Analyse und Dokumentation der intellektuellen Subkultur vom 19. Jahrhundert bis zur Gegenwart, Stuttgart 1971; Anne-Rose Meyer, Jenseits der Norm. Aspekte der Bohème-Darstellung in der französischen und deutschen Literatur; 1830-1910, Bielefeld 2001.

9 Vgl. Robert Krause, ,„dem müßigen Flaneur den angenehmsten Zeitvertreib gewähren'. Figurationen des Müßiggangs in Heines ,Briefen aus Berlin' und ,Lutezia', in: Thorsten Unger/Claudia Lillge/Björn Weyand (Hg.), Arbeit und Müßiggang in der Romantik, Paderborn 2017, 171-182; Robert Krause, „Dandysme. Zu einem Motiv aus Nietzsches Baudelaire-Exzerpten“, in: Katharina Grätz/Sebastian Kaufmann (Hg.), unter red. Mitarbeit v. Armin Thomas Müller/Milan Wenner, Nietzsche als Dichter. Lyrik - Poetologie - Rezeption, Berlin, Boston 2017, 401-420.

10 Eine durchaus ideologiekritische Sondierung des gegenwärtigen Stadtlebens bietet Hannelore Schlaffer, Die City. Straßenleben in der geplanten Stadt, Berlin 2013.

${ }^{11}$ Zum Muße-Begriff vgl. einführend Norbert Martin, „Muße“, in: Historisches Wörterbuch der Philosophie, hg. v. Joachim Ritter/Karlfried Gründer, Bd. 6, Basel 1984, 257-260; Hans-Joachim Gehrke/Martin Heimgartner, „Muße“, in: Der Neue Pauly. Enzyklopädie der Antike, hg. v. Hubert Cancik/Helmuth Schneider, Bd. 8, Stuttgart/Weimar 2000, 554-557; Albert Schirrmeister, „Muße“, in: Enzyklopädie der Neuzeit, hg. v. Friedrich Jaeger, Bd. 8, Darmstadt 2008, 977-979; Tobias Keiling, „Glossar: Muße“, in: Muße. Ein Magazin, 1 (2015), DOI: 10.6094/musse-magazin/1.2015.48; Jochen Gimmel/Tobias Keiling u. a., Konzepte der Muße, Tübingen 2016; Burkhard Hasebrink/Peter Philipp Riedl (Hg.), Muße im kulturellen Wandel. Semantisierungen, Ähnlichkeiten, Umbesetzungen, Berlin 2014; Günter Figal/Hans W. Hubert/Thomas Klinkert (Hg.), Die Raumzeitlichkeit der Muße, Tübingen 2016; außerdem Robert Krause, „Glossar: Müßiggang“, in: Muße. Ein Magazin, 2 (2015) DOI: 10.6094/musse-magazin/2.2015.47. 
melten Aufsätze aus Philosophie, Literatur- und Kulturwissenschaften durchaus unterschiedlich auf das gemeinsame Rahmenthema zu. Verbindendes Anliegen ist es, Muße als Phänomen zu konturieren und zu einem besseren Verständnis der Muße unter den spezifischen Bedingungen der Moderne beizutragen. Dabei zeichnen sich die Beiträge durch einen doppelten Charakter aus. Einerseits speisen sie bestimmte Autoren, Werke und Kontexte aus ihrer Fachperspektive oder ihren individuellen Forschungsschwerpunkten in den interdisziplinären Muße-Diskurs ein. Andererseits zeigen sie, dass und inwiefern die Untersuchung von Muße einen ,Mehrwert' für zentrale Fachdiskussionen besitzt. Die jeweiligen, durchaus voneinander divergierenden Annäherungen an Muße in der Moderne werden nicht nur theoretisch reflektiert, sondern auch in den Denkstilen, Argumentationsweisen und Referenzen performativ vorgeführt.

So können beispielsweise Muße-affine literarische Gattungen bzw. Untergattungen, wie die Idylle (vgl. Gerstner), autobiographische Prosa (vgl. Feitscher) und Flaneurtexte (vgl. Riedl), textnah und kontextbewusst untersucht, Begriffe und Vorstellungen von ,Muße' und ,Müßiggang' kulturgeschichtlich rekonstruiert und systematisiert (vgl. Krause) oder aber kolonialistische Körperpraktiken als Aushandlungen von Müßiggang (vgl. Masurczak) entziffert werden. Andere Beiträger hinterfragen die vermeintliche Alternative von Arbeit und Muße (Keiling), weisen auf die sozial ungleich verteilte Muße hin (Henning) oder erläutern und dekonstruieren die Theorien über den Mehrwert von Marx (Sahraoui). In diesen eher an theoretischen als literarischen Texten orientierten Beiträgen wird deutlich, wie die modernen Kultur- und Sozialphilosophien Bedeutung und Wert eines Handelns in Muße und dessen Unterschied zum Arbeiten reflektieren. Der gemeinsamen Leitfrage nach dem Verhältnis von Muße und Moderne liegt allerdings die Beobachtung zugrunde, dass Muße-Diskurse oftmals der modernetypischen Spezialisierung und wissenschaftlichen Ausdifferenzierung trotzen und sich womöglich mehr denn je an der Grenze von Literatur und Philosophie bewegen. ${ }^{12}$ Offenbar fungiert Muße in der Moderne als ein Schlüsselkonzept für die Ausbildung von Subjektivitäts-, Kunst- und Autorentwürfen (vgl. die Beiträge von Figal, Fest, Feitscher, Liedke). ${ }^{13}$ Daher wer-

12 Ähnliche Überschneidungen gibt es in der Vormoderne auch mit Theologie, Religionsphilosophie und mystischer Literatur, vgl. die Beiträge in Thomas Jürgasch/Tobias Keiling (Hg.), Anthropologie der Theorie, Tübingen 2017. Zur anthropologischen Dimension der Muße vgl. außerdem das von Christoph Wulf und Jörg Zirfas hg. Themenheft „Muße“: Paragrana. Internationale Zeitschrift für historische Anthropologie 16,1 (2007) sowie Tobias Keiling, „The Pleasure of the Non-Conceptual. Theory, Leisure and Happiness in Hans Blumenberg's philosophical anthropology", in: SATS. Northern European Journal of Philosophy (2016), 81-113.

13 Vgl. zu diesem „poetologischen Zusammenhang“: Thomas Klinkert, Muße und Erzählen. Ein poetologischer Zusammenhang, Tübingen 2016. Zur Rolle der Ästhetik vgl. Martin Jörg Schäfer, Die Gewalt der Muße. Wechselverhältnisse von Arbeit, Nichtarbeit, Ästhetik, 
den in einer kulturgeschichtlichen Perspektive literarische wie philosophische Texte gleichermaßen berücksichtigt, um Paradigmen des schreibenden Nachdenkens über und Erlebens von Muße vorzustellen und zu analysieren. Neben systematischen und überblicksartigen Beiträgen (von Masurczak, Sahraoui, Keiling, Henning, Liedke und Feitscher) stehen konkrete Analysen zu einzelnen Autoren (Henry David Thoreau, Friedrich Nietzsche, Georg Simmel, Walter Benjamin und Samuel Beckett) oder Werken (Franz Hessels Spazieren in Berlin, Dorothy Richardsons Pilgrimage, Peter Handkes Die Unschuldigen, ich und die Unbekannte am Rande der Landstraße).

Befunde zu den jeweiligen soziohistorischen und -kulturellen Gegebenheiten erweitern das thematische und methodische Spektrum des vorliegenden interdisziplinären Bands, der somit Impulse der sozial- und kulturgeschichtlich ausgerichteten Moderne-Forschung und Hinweise auf den gesellschaftlichen Nexus der Muße aufnimmt. ${ }^{14}$ Einige Beiträger verorten Muße im Kontext der Modernisierung der Arbeitswelt und deren philosophischer und literarischer Reflexion (z.B. Gerstner, Schäfer, Keiling) und begreifen damit die literarische und philosophische Moderne als Teil des sozioökonomischen Systems. Anderen (Wilm, Egel) erscheint die zivilisatorische Moderne, charakterisiert durch Ausdifferenzierung, Säkularisierung und „Entzauberung der Welt“15, schwerlich kompatibel mit der ästhetischen oder gar ästhetizistischen Moderne, welche die Muße als Leitbild kultiviert und gerade aus dem Nonkonformismus, der Absage an die Funktionalität, hervorgegangen ist. ${ }^{16}$ Diese Spannung zwischen ,Modernen' innerhalb derselben historischen Epoche wird radikalisiert, wenn als ,modern ' die Entdeckung eines einfachen Lebens verstanden wird, in dem die Abgrenzung zu vorhergehenden Epochen nicht mehr relevant ist (Figal). ${ }^{17}$

Der Band gibt damit einen Einblick in Muße-Konzepte in der modernen Philosophie, Literatur und Kultur anhand von ausgesuchten, deutschen, englischen und französischen Beispielen, darunter sowohl kanonische als auch weniger

Zürich/Berlin 2013; zur ästhetischen Opposition: Leonhard Fuest, Poetik des Nicht(s)tuns. Verweigerungsstrategien in der Literatur seit 1800, München 2008.

14 Vgl. Gregor Dobler/Peter Philipp Riedl (Hg.), Muße und Gesellschaft, Tübingen 2017.

15 Max Weber, „Die protestantische Ethik und der Geist des Kapitalismus“, in: Gesammelte Aufsätze zur Religionssoziologie, 3 Bde., Tübingen 1976 [1920], Bd. 1, 17-206, 35 u. $54-55$.

16 Zur kompensatorischen Funktion von Kunst und etwaigen Aporien des Ästhetizismus vgl. Annette Simonis, „Ästhetizismus und Avantgarde. Genese, wirkungsgeschichtlicher und systematischer Zusammenhang", in: Sabina Becker/Helmuth Kiesel (Hg.) unter Mitarbeit v. Robert Krause, Literarische Moderne. Begriff und Phänomen, Berlin 2007, 291-316.

$17 \mathrm{Zu}$ diesem am Paradigma architektonisch gestalteter Raumerfahrung entwickelten Verständnis von Moderne vgl. Günter Figal, Ando. Raum Architektur Moderne, Freiburg 2017, außerdem der Beitrag zu Thoreau in diesem Band. 
bekannte. ${ }^{18}$ Die ,Moderne', längst ein Forschungsfeld sui generis ${ }^{19}$, wird dabei denkbar weit verstanden, als Makro-Epoche, die mit der Klassischen Deutschen Philosophie und der Literatur der Klassik und Romantik um 1800 anfängt - sich sodann aber gegen die Vorgaben eines ,klassischen“ Muße-Verständnisses abzusetzen beginnt ${ }^{20}$, um das zu leisten, was Robert Musil „Beiträge zur geistigen Bewältigung der Welt“ genannt hat. ${ }^{21}$,Moderne erweist sich dabei als Differenzbegriff: „Modern ist, was im Kontrast zum Alten steht.“22 Sie erscheint weniger als klar datierbare Epoche, denn als Riss, als forciert herausgestellter Bruch ${ }^{23}$, in ihrer Vielfältigkeit und prinzipiellen Unabschließbarkeit. „Die Moderne ist sich am wenigsten gleich geblieben“, bemerkte Walter Benjamin schon 1938/3924, Jürgen Habermas hat sie „ein unvollendetes Projekt“ 25 genannt. Insofern dürften auch die Neubewertung und wechselnde ästhetische Modellierung der Muße Folgen oder gar konstituierende Kennzeichen von Modernisierungsprozessen sein. Moderne Erzähltechniken und ästhetische Formen, vor allem des Modernismus, wären damit auch als literarisch-künstlerische Mußepraktiken zu verstehen (vgl. Wilm, Fest, Liedke). In diesem Zusammenhang ist nochmals auf die Bedeutung des Flaneurs hinzuweisen, der als eine Leitfigur der urbanen Mo-

18 Dies bringt eine Einschränkung auf den europäischen oder westlichen Kulturraum mit sich. Eine interkulturelle Beschreibung von Muße wird in diesem Band nur von Pia Masurczak unternommen. Allgemein ist sie bisher nur sehr eingeschränkt geschehen, vgl. aber zu Russland Elisabeth Cheauré, Muße-Diskurse. Russland im 18. und 19. Jahrhundert, Tübingen 2017; zu China: Wolfgang Kubin, „Muße und Melancholie. Eine nicht nur chinesische Sicht", in: Hasebrink/Riedl (Hg.), Muße im kulturellen Wandel, 304-318; zu Japan: Rolf Elberfeld, „Zur Handlungsform der ,Muße‘. Ostasiatische Perspektiven jenseits von Aktivität und Passivität", in: Paragrana 16,1 (2007), 193-203.

19 Einen Überblick über Fachgeschichte und Ausrichtung der literaturwissenschaftlichen Moderne-Forschung vermitteln die einleitenden Bemerkungen von Becker/Kiesel samt Literaturhinweisen in Becker/Kiesel (Hg.), Literarische Moderne. Begriff und Phänomen, insbesondere 9-35.

20 Zum Verständnis von ,Muße', ,Müßiggang' und ,Arbeit' in der Literatur und Philosophie der Romantik vgl. Lillge/Unger/Weyand (Hg.), Arbeit und Müßiggang in der Romantik.

${ }^{21}$ Oskar Maurus Fontana, „Was arbeiten Sie? Gespräch mit Robert Musil“ (1926), in: Musil, Gesammelte Werke, Bd. II, hg. v. Adolf Frisé. Reinbek 1978, 939-942, 942. Zu „Muße und Müßiggang in Robert Musils Roman ,Der Mann ohne Eigenschaften“", vgl. die Studie dieses Titels von Heinrich Puppe (St. Ingbert 1991).

${ }^{22}$ Günter Figal, „Krise der Aufklärung - Freiheitsphilosophie und Nihilismus als geschichtliche Voraussetzungen der Moderne“, in: Silvio Vietta/Dirk Kemper (Hg.), Ästhetische Moderne in Europa. Grundzüge und Problemzusammenhänge seit der Romantik, Tübingen 1997, 57-69, 57.

${ }_{23}$ Dazu Werner Frick, „Avantgarde und longue durée. Überlegungen zum Traditionsverbrauch der klassischen Moderne“, in: Becker/Kiesel (Hg.), Literarische Moderne, 97-112.

${ }^{24}$ Walter Benjamin, „Charles Baudelaire. Ein Lyriker im Zeitalter des Hochkapitalismus“, in: Benjamin, Gesammelte Schriften, hg. v. Rolf Tiedemann/Hermann Schweppenhäuser, Bd. I/2, Frankfurt a. M. 1974, 509-653, 593.

25 Jürgen Habermas, „Die Moderne - ein unvollendetes Projekt“, in: Habermas, Kleine philosophische Schriften (I-IV), Frankfurt a. M. 1981, 444-464, 446. 
derne in mehreren vorliegenden Beiträgen thematisiert wird, wobei die besondere Aufmerksamkeit entweder Zeitkonzepten (bei Riedl), dem Übergang von Muße zu Müßiggang (bei Krause) oder der Parallele von Gehen und Sprechen (bei Liedke) gilt. Die räumliche und zeitliche Umgebung des Flaneurs und des Dandys ist die Großstadt, wie sie von Simmel analysiert worden ist (vgl. Schlitte).

Gerade durch ihre unterschiedlichen Perspektiven tragen die vorliegenden Untersuchungen von Muße-Konzepten, -Diskursen und -Praktiken aus über zwei Jahrhunderten dazu bei, die bis heute dominante Arbeitsgesellschaft mit ihren Aporien, aber auch ihre möglichen Alternativen kritisch zu hinterfragen. Es könnte sein, dass ,Muße eine anthropologische Kategorie ist, die in der modernen Arbeitsgesellschaft, dem modernen Verständnis von Subjektivität und Autorschaft und in Gestalt von Figuren wie dem Flaneur eine spezifische historische Form annimmt. Genau deshalb besitzt die Konstellation von Muße und Moderne aber auch in spät- oder gar postmodernen Zeiten besondere Relevanz: Die Beiträge reflektieren explizit oder implizit Bedeutungsnuancen und -verschiebungen des Arbeitsbegriffs, der sich derzeit wiederum wandelt und dadurch auch das gegenwärtige Muße-Verständnis vermutlich nicht unberührt lässt. Die Moderne ist jedenfalls die letzte Epoche, die wir mit gewissem historischem Abstand betrachten können. Aktuelle Debatten um das Verhältnis von Arbeitszeit und Freizeit, Vollzeit- und Teilzeittätigkeit, Lohnarbeit und Ehrenamt, Arbeitslohn und bedingungsloses Grundeinkommen, temporäre Auszeit und Renteneintrittsalter sind im Wissen um alte Traditionen und moderne Transformationen der Muße angemessener zu verstehen und zu führen. Dazu gehören neben den literarischen, philosophischen und theologischen auch soziokulturelle Dimensionen der Muße, die komplementär zur philosophisch nobilitierten Arbeit ${ }^{26}$ als Thema interdisziplinärer Forschung zu akzentuieren und als individueller und kollektiver Wert zur Diskussion zu stellen ist.

26 Vgl. die Kleine Philosophie der Faulheit, hg. v. David Dilmaghani/Nassima Sahraoui, Frankfurt a. M. 2012, und die jüngst erschienene Anthologie Philosophie der Arbeit. Texte von der Antike bis zur Gegenwart, hg. v. Michael S. Aßländer/Bernd Wagner, Berlin 2017. 


\title{
Idyllische Arbeit und tätige Muße
}

\author{
Transformationen um 1800
}

\author{
Jan Gerstner
}

„Der Mensch darf nicht in solcher idyllischen Geistesarmut hinleben, er muß arbeiten. ${ }^{\text {"I }}$ Hegels Urteil über die Idylle fasst eine Diskussion zusammen, die im letzten Drittel des 18. Jahrhunderts beginnt und, wie der Kollektivsingular andeutet, nicht nur eine literarische Gattung zum Gegenstand hat. Insofern die Idylle literarische Formen zur Ausgestaltung von Muße bereitstellt, werden im Kontext der anbrechenden Moderne um 1800 in der Diskussion der Gattung Konzepte von Muße, Arbeit und Müßiggang gegeneinander ausgespielt und ausgetauscht. Besonders prominent exponiert diese Problematik die spät- und nachaufklärerische Geschichtsphilosophie und Ästhetik, vor Hegel v. a. bei Kant und Schiller, wenngleich nicht immer in Einklang mit der Gattungsentwicklung. Diese ist - das soll im Folgenden v. a. an der Figuration des Landlebens bei Geßner, Hirschfeld und Garve gezeigt werden - vielmehr von einer komplexeren Verschachtelung von Arbeit und Muße gekennzeichnet. Hier, und darüber hinausweisend am Beispiel von Herders später Idyllentheorie sowie an Hegels Rezeption von Herrmann und Dorothea, lässt sich zeigen, wie idyllische Arbeit angesichts der Umordnung der Arbeitsverhältnisse in der kapitalistischen Moderne strukturell die Stelle der Muße einnimmt.

Wenn Hegel in den Vorlesungen über die Ästhetik in der Idylle die „höhere[n] Triebe“ des Menschen vermisst, die ihn zur Tätigkeit anstacheln und ihm „das Gefühl der innerlichen Kraft“ geben, „aus dem sich sodann auch die tieferen Interessen und Kräfte entwickeln können“2, dann gilt Arbeit als geschichts- und menschenbildende Potenz $z^{3}$, der die Idylle nicht genügen kann. Dort „befriedigt [...] dem Menschen die Natur jedes Bedürfnis, das sich in ihm regen mag", und dieser „begnügt [...] sich in seiner Unschuld mit dem, was Wiese, Wald, Herden, ein Gärtchen, seine Hütte ihm an Nahrung, Wohnung und sonstigen Annehm-

${ }^{1}$ Georg Wilhelm Friedrich Hegel, Vorlesungen über die Ästhetik I, Werke (=W), hg. v. Eva Moldenhauer und Karl Markus Michel, Frankfurt a. M. 1986, Bd. 13, 336.

2 Hegel, Vorlesungen über die Ästhetik I, W 13, 336.

3 Vgl. zur begriffsgeschichtlichen Entwicklung: Werner Conze, „Arbeit“, in: Geschichtliche Grundbegriffe, hg. v. Otto Brunner/Werner Conze/Reinhart Koselleck, Bd. 1, Stuttgart $1972,154-215$, v.a. $187 \mathrm{f}$. 
lichkeiten bieten können, indem alle Leidenschaften des Ehrgeizes oder der Habsucht [...] noch durchweg schweigen. " ${ }^{4}$ Die in diesem Setting fehlende Arbeit hat Joseph Vogl unter Bezug auf Hegels Formel von der "gehemmte[n] Begierde“5 in Abgrenzung zum Arbeitsbegriff der Aufklärung als Bezeichnung für ,jede Tätigkeit“ beschrieben, „die nicht mit der Befriedigung eines Bedürfnisses still-

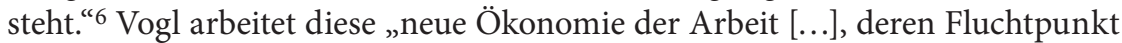
in einer Unabschließbarkeit des Tuns und in der Vergeblichkeit von Produktionen liegt" ${ }^{\text {"7 }}$, mit Goethes Faust II an einem Text heraus, der selbst wieder in einer problematischen Beziehung zur Idylle steht. Nach der groß angelegten Rekapitulation der alteuropäischen Arkadien-Tradition im dritten Akt tritt dort die Idylle mit der harmonischen Hütten-Existenz Philemons und Baucis' zur Eröffnung des fünften Akts als Restbestand auf, der durch seine schiere Existenz Fausts rastlosen Expansionsdrang reizt: „Die Alten droben sollten weichen,/Die Linden wünscht ich mir zum Sitz,/Die wenig Bäume, nicht mein eigen,/Verderben mir den Welt-Besitz." ${ }^{\text {" }}$ Die letztlich katastrophale Konfrontation von Idylle und Modernisierung durch Arbeit, wie sie exemplarisch Fausts Landgewinnungsprojekt verkörpert, spielt eine Konstellation durch, die um 1800 geläufig ist. Das Idyllische ist hier mehr als ein dramaturgischer oder narrativer Kontrastraum. Es ist als Entwurf müßigen Lebens (und die Unklarheit der adjektivischen Form zwischen Muße und Müßiggang ist hier passend) ein ,Gegenbild', an dem sich Literatur und Philosophie um 1800 abarbeiten.

Rund 50 Jahre vor Goethes und Hegels Bezügen auf die Idylle profiliert bereits Kant in den Ideen zu einer allgemeinen Geschichte in weltbürgerlicher Absicht den Fortschritt der Menschheit durch die ,an sich zwar nicht eben liebenswürdige Eigenschaft" des Egoismus, der „Ehrsucht, Herrschsucht oder Habsucht", mit dem kontrastierenden Bezug auf ein „arkadische[s] Schäferleben“, in welchem „bei vollkommener Eintracht, Genügsamkeit und Wechselliebe alle Talente auf ewig in ihren Keimen verborgen bleiben“.9 Bei Kant, der Muße mit „einer leeren Zeit" verbindet, vor der das „menschliche Gemüt Abscheu, Unmut, Ekel“ hat ${ }^{10}$,

${ }^{4}$ Hegel, Vorlesungen über die Ästhetik I, W 13, 335.

${ }^{5}$ Hegel, Phänomenologie des Geistes, W 3, 153.

6 Joseph Vogl, Kalkül und Leidenschaft. Poetik des ökonomischen Menschen, München $2002,339$.

7 Vogl, Kalkül und Leidenschaft, 336.

8 Johann Wolfgang Goethe, Faust, Frankfurter Ausgabe, Bd. 7/1, hg. v. Albrecht Schöne, Frankfurt a. M. 2005, 434. Vgl. zu diesem Zusammenhang: Peter Philipp Riedl, „Arbeit und Muße. Literarische Inszenierungen eines komplexen Verhältnisses“, in: Hermann Fechtrup/William Hoye/Thomas Sternberg (Hg.), Arbeit - Freizeit - Muße. Über eine labil gewordene Balance, Berlin 2015, 65-100, vor allem 69-76.

9 Immanuel Kant, „Idee zu einer allgemeinen Geschichte in weltbürgerlicher Absicht“, in: Werke $(=W)$, hg. v. Wilhelm Weischedel, Darmstadt 1983, Bd. 9, 31-50, 38, A 393.

10 Vgl. Immanuel Kant, Eine Vorlesung Kants über Ethik, hg. v. Paul Menzer, Berlin 1924, 201 f. Zum Zeitproblem bei Kant vgl. Martin Seel, „Rhythmen des Lebens. Kant über erfüllte und leere Zeit", in: Wolfgang Kersting/Claus Langbehn (Hg.), Kritik der Lebenskunst, 
ist die Vorstellung eines Zustands, in dem lediglich „arkadische Lieder gesungen, und die Schönheit der Natur betrachtet "11 würde, in individualpsychologischer wie menschheitsgeschichtlicher Hinsicht Metapher des Verfehlens menschlicher Bestimmungen.

Die metaphorische Verwendung der Idylle kann als Hinweis gelten für den Modellcharakter, den die Gattung im Hinblick auf eine bestimmte Form der Muße - und damit, bei Kant, auch die Muße allgemein - um 1800 zugeschrieben bekommt. Den prominentesten und weitreichendsten Reflex der geschichtsphilosophischen Problematisierung der Idylle im Bereich der Ästhetik formulierte Schiller in Über naive und sentimentalische Dichtung. Sein viel zitierter Versuch, die Idylle neu zu bestimmen als Form, die „den Menschen, der nun einmal nicht mehr nach Arkadien zurückkann, bis nach Elysium führt"12, setzt sich von der traditionellen (sentimentalischen) „Schäferidylle" ${ }^{13} \mathrm{ab}$, insofern diese einen $\mathrm{Zu}$ stand „[v]or dem Anfang der Kultur" darstelle, der "allzuwenig für den Geist“ habe: „Wir können sie daher nur lieben und aufsuchen, wenn wir der Ruhe bedürftig sind, nicht wenn unsere Kräfte nach Bewegung und Tätigkeit streben."14 Demgegenüber gelte es, in der Idylle einen „Zustand der Harmonie und des Friedens mit sich selbst und von außen“ als „letztes Ziel“15 der Kultur darzustellen, der das tätige Moment der Zivilisation in sich aufnehme:

Ruhe wäre also der herrschende Eindruck dieser Dichtungsart, aber Ruhe der Vollendung, nicht der Trägheit; eine Ruhe, die aus dem Gleichgewicht, nicht aus dem Stillstand der Kräfte, die aus der Fülle, nicht aus der Leerheit fließt und von dem Gefühl eines unendlichen Vermögens begleitet wird. ${ }^{16}$

Als Vorschein einer utopischen Zukunft partizipiert die ursprünglich räumlich begrenzte Idylle bei Schiller an jener „Verzeitlichung der Utopie“, die laut Reinhart Kosellecks Beobachtung ab der zweiten Hälfte des 18. Jahrhunderts eingesetzt hat. ${ }^{17}$ Zugleich soll sie die Härte der geschichtsphilosophischen Logik abmildern, indem sie im ästhetischen Spiel ermöglicht, was in der Tätigkeit des Lebens nicht erfahrbar ist. In diesem Sinne stellt Schiller in den Briefen zur ästhetischen Erziehung der "Sklavenarbeit“ gegenwärtiger Individuen bei

Frankfurt a.M. 2007, 181-200. Zum Problem der Muße: Marc Rölli, „Begründete Kritik, abgründige Zweifel. Zur Pathologie der Muße in der Philosophie der Aufklärung", in: $\mathrm{Pa}$ ragrana 16,1 (2007), 62-72, v. a. 68-72.

11 Kant, „Über Pädagogik“, in: W 10, 691-761, 730, A 76.

12 Friedrich Schiller, „Über naive und sentimentalische Dichtung“, in: Sämtliche Werke $(=S W)$, auf der Grundlage der Textedition von Herbert G. Göpfert hg. v. Peter-André Alt/ Albert Maier/Wolfgang Riedel, München 2004, Bd. 5, 694-780, 730.

13 Schiller, „Über naive und sentimentalische Dichtung“, in: SW 5, 748.

14 Schiller, „Über naive und sentimentalische Dichtung“, in: SW 5, 747.

15 Schiller, „Über naive und sentimentalische Dichtung“, in: SW 5, 746.

16 Schiller, „Über naive und sentimentalische Dichtung“, in: $S W$ 5, 751.

17 Vgl. Reinhart Koselleck, „Die Verzeitlichung der Utopie“, in: Koselleck: Zeitschichten. Studien zur Historik, Frankfurt a. M. 2003, 131-149. 
der „Ausbildung der menschlichen Natur“ im Sinne der Gattung den „seligen Müßiggang" „spätere[r] Geschlechter" gegenüber. ${ }^{18}$ Die Rede vom „Müßiggang“ ist hier alles andere als utopisch gemeint ${ }^{19}$, sondern unterstreicht die Diskrepanz zwischen den versagten Ansprüchen des Individuums und der aufgeschobenen Vollendung der Gattung. Anstelle des Müßiggangs derer, die das Produkt der leidvollen Arbeit ihrer Vorgänger genießen, soll durch den „phänomenalen und strukturellen Zusammenhang von Muße und ästhetischer Erfahrung ${ }^{\text {"20 }}$ in der Idylle der Vorschein des Ideals in der Wirklichkeit schon jetzt genossen werden. Der Unterschied von Muße und Müßiggang ist eine Frage geschichtsphilosophischen Ausgleichs (oder Palliativs).

Mit der Ablehnung der Schäferidylle wie des Müßiggangs und der Betonung der Tätigkeit ist Schillers Idyllen-Entwurf nicht nur „kritischer Reflex auf den historischen Siegeszug der vita activa in der prometheischen Welt der Moderne ${ }^{\text {"21 }}$, sondern auch Konsequenz dieser Entwicklung im Bereich der Idylle. Ebenso wie die anderen angeführten Beispiele, grenzt sich Schiller mit den Stichworten Arkadiens oder der Schäfer von einer Form der Idyllik ab, die um 1800 im Grunde weitgehend obsolet war. ${ }^{22}$ Auch die Form der Muße, wie sie die Idylle entwirft, hatte sich zum Ende des 18. Jahrhunderts geändert.

Entgegen der - nicht zu bestreitenden, aber sehr pauschalen - These, dass mit der bürgerlichen Arbeitsgesellschaft die Muße in eine Krise gerät, sich in „träumerische[n] Müßiggang “23 flüchtet, oder der Müßiggang sich in „seine aggressive Tendenz zur Verweigerung " zurückzieht, die „keine idyllischen Zustände“24 mehr zulässt, mithin mit der Muße auch die Idylle an ein Ende kommt, soll hier ein anderer Weg verfolgt werden. Wegen der Bedeutung der Muße für die Idylle lässt sich an dieser Gattung ebenso gut zeigen, wie die Freiräume, die vormals von einer bestimmten Konzeption von Muße besetzt waren, nun mit einer Arbeit gefüllt werden, die mit Muße nicht mehr nur negativ zusammenhängt.

18 Friedrich Schiller, „Über die ästhetische Erziehung des Menschen in einer Reihe von Briefen“, in: SW 5, 570-669, 588.

19 Vgl. dagegen Peter Philipp Riedl, „Die Kunst der Muße. Über ein Ideal in der Literatur um 1800", in: Publications of the English Goethe Society 80,1 (2011), 19-37, 25.

20 Riedl, „Die Kunst der Muße“, 26.

21 Riedl, „Die Kunst der Muße“, 26.

22 Die gemessen an der Gattungsentwicklung unzeitgemäße Kritik an der Idylle bei Kant und Hegel betont schon Gerhard Kaiser, Wandrer und Idylle. Goethe und die Phänomenologie der Natur in der deutschen Dichtung von Geßner bis Gottfried Keller, Göttingen $1977,101 \mathrm{f}$.

${ }^{23}$ Luigi Forte, „Lob der Faulheit. Muße und Müßiggang im 19. Jahrhundert“, in: Martin Huber/Konrad Feilchenfeldt (Hg.), Bildung und Konfession. Politik, Religion und literarische Identitätsbildung 1850-1918, Tübingen 1996, 79-93, $80 \mathrm{f}$.

${ }^{24}$ Leonhard Fuest, Poetik des Nicht(s)tuns. Verweigerungsstrategien in der Literatur seit 1800, München 2008, $21 \mathrm{f}$. 


\section{Ländliche Arbeit/ländliche Muße}

In der Bukolik, verstanden als Vorform der Idyllik, wie sie im 18. Jahrhundert sich herausbildet ${ }^{25}$, war die Muße an die Figur des Schäfers gebunden, denn - so das topische Argument - dessen Tätigkeit gewähre ihm ausreichend Gelegenheit zur Muße und damit zum Gesang. ${ }^{26}$ Um die Repräsentation ländlicher Lebensweisen ging es dabei bekanntlich nicht. ${ }^{27}$ Indem sie die Schäferei von ihrem ursprünglichen Tätigkeitsbereich abkoppelte und als „Mimesis von Dichtung“28 inszenierte, orientierte die traditionelle Bukolik das Schäferleben auf einen der Muße zugeordneten Bereich hin. Seit der frühen Aufklärung erscheint diese Artifizialität der Schäferdichtung zunehmend problematisch oder zumindest begründungsbedürftig. Gottsched betreibt so im Versuch einer Critischen Dichtkunst einen vergleichsweise großen Aufwand, um das poetische Schäferleben in einem Land, wo man „von schwerer Arbeit [...] eben so wenig“ weiß „als von Drangsalen und Kriegen“, vom „heutige[n] Schäferstand, zumal in unserm Vaterlande“ 29 , abzugrenzen.

Obgleich das Problem einer Darstellung schäferlicher Muße angesichts von ländlichen Zuständen, die durch harte und als niedrig eingestufte Arbeiten geprägt waren, nicht nur bei Gottsched ein wichtiger Diskussionsgegenstand ist, wurde die Bukolik im 18. Jahrhundert nicht bloß ihrer Wirklichkeitsferne we-

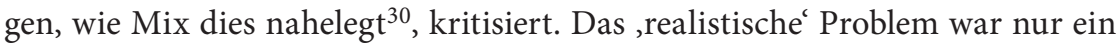
- oft durch Kompromissformeln gemilderter - Aspekt einer generellen Umschichtung der Idyllenpoetik im 18. Jahrhundert, die sich in der Nachfolge und Diskussion der Idyllen Geßners (1756 bzw. 1772) und dann besonders um 1800 intensivierte und in deren Zug die Muße andere Positionen zugewiesen bekam. So konnte zum Ende des 18. Jahrhunderts die Wahl von Fischern anstelle

25 Vgl. Günter Häntzschel, „Idylle“, in: Reallexikon der deutschen Literaturwissenschaft, hg. v. Klaus Weimar/Harald Fricke, 3. Aufl., Berlin 1997, Bd. II, 122-125, 123; Klaus Garber, „Bukolik“, in: Reallexikon der deutschen Literaturwissenschaft, Bd. I, 287-291, 288; kritisch zu dieser Aufteilung neuerdings: Jakob Christoph Heller, Masken der Natur. Zur Transformation des Hirtengedichts im 18. Jahrhundert, Paderborn 2018.

26 So etwa bei: Julius Caesar Scaliger, Poetices libri septem, Faks.-Neudr. d. Ausg. Leipzig von Lyon 1561, Stuttgart-Bad Cannstatt 1987, 6.

27 Vgl. Helmut J. Schneider, „Einleitung: Antike und Aufklärung. Zu den europäischen Voraussetzungen der deutschen Idyllentheorie“, in: Helmut J. Schneider (Hg.), Deutsche Idyllentheorien im 18. Jahrhundert, Tübingen 1988, 7-74, 25.

28 Wolfgang Iser, Das Fiktive und das Imaginäre. Perspektiven literarischer Anthropologie, Frankfurt a. M. 1993, 70.

${ }_{29}$ Johann Christoph Gottsched, Versuch einer Critischen Dichtkunst, 4. Aufl., Leipzig 1751 (Reprint: Darmstadt: Wissenschaftliche Buchgesellschaft 1962), 583, 582.

30 Vgl. York-Gothart Mix, „Idyllik, Anti-Idyllik, Aufklärung und Selbstaufklärung. Zur ästhetischen und philosophischen Kritik des Arkadien-Topos“, in: Nina Birkner/YorkGothart Mix (Hg.), Idyllik im Kontext von Antike und Moderne. Tradition und Transformation eines europäischen Topos, Berlin 2015, 206-222, 207-209. 
von Schäfern als Idyllenpersonal damit begründet werden, dass letztere „allzumüßig“, aber „Ruhe und Muße [...] ohne Arbeitsamkeit keine Züge des wahren Glücks"31 seien.

Mit der nicht nur in diesem Beispiel zu beobachtenden Abwendung von den Schäfern ging die Ausweitung der Idyllik auf einen allgemein ländlich orientierten Darstellungsbereich einher. Gattungshistorisch lässt sich die Idylle im moderneren Sinne als Konglomerat von Schäfer- und Landlebendichtung beschreiben. ${ }^{32}$ Die Darstellung von Arbeit hatte in der Landlebendichtung von jeher ihren Platz ${ }^{33}$, obgleich in der topischen Entgegensetzung von Land und Stadt bzw. Hof auch hier das Landleben als die weniger geschäftige Option figuriert.

Die Integration ländlicher Arbeiten in die Idyllik des späten 18. Jahrhunderts lässt sich in dem Zusammenhang nicht nur als Ersetzung der „Fundamentalkategorie der Gattung“, der Muße, durch die Arbeit beschreiben ${ }^{34}$, sondern ebenso als Transformation idyllischer Muße-Konzeptionen. In Ansätzen erkennbar ist dies bereits in den Idyllen Geßners, etwa, wenn in Der Wunsch, der letzten Idylle der Sammlung von 1756, ein ländlicher Muße-Raum entworfen wird. ${ }^{35}$ Die Sprecherinstanz dieses Texts träumt davon, dort „den Landmann, wenn er beym Furchenziehenden Pflug singt, oder die frohen Reihen der Schnitter, wenn sie ihre ländlichen Lieder singen “36, beobachten zu können, oder dem Gärtner, durch dessen „Fleiß zur Arbeit gelokt“, zur Hand zu gehen, „indeß daß er neben mir stühnde, der wenigern Kräfte lächelnd. " ${ }^{37}$ Arbeit ist ein Objekt der Betrachtung und allenfalls erbauliche Nebenbeschäftigung, deren tatsächliche Ausführung anderen überlassen bleibt.

31 Franz Xaver Bronner, Neue Fischergedichte und Erzählungen, Zweytes Bändchen, Zürich 1794, 8 f. Die Ersetzung der Hirten durch Fischer hat ihre Pointe darin, dass gerade Fischer in Idyllen ausgehend von einem Theokrit zugeschriebenen Idyll und von Sannazzaros eclogae piscatoriae ein traditionell umstrittener Gegenstand waren. Fontenelle lehnt sie in seinem im 18. Jahrhundert viel rezipierten Discours sur la Nature de l'Eclogue ab: ,j'y sens toujours que l'idée de leur travail dur me blesse." (Bernard Le Bovier de Fontenelle: „Discours sur la Nature de l'Eclogue“, in: Euvres diverses de M. de Fontenelle, Bd. 3, Den Haag 1773, 103-133, 114).

32 Vgl. Renate Böschenstein-Schäfer, Idylle, 2. Aufl., Stuttgart 1977, 4 f., 26, 74. Zur Unterscheidung beider Gattungen prägnant, wenn auch sehr auf Trennschärfe fokussiert: Anke-Marie Lohmeier, „Zur Bestimmung der deutschen Landlebendichtung des 17. und 18. Jahrhunderts", in: Wilhelm Voßkamp (Hg.), Schäferdichtung, Hamburg 1977, 123-140.

${ }^{33}$ Klaus Garber, Der Locus amoenus und der Locus terribilis. Bild und Funktion der Natur in der deutschen Schäfer- und Landlebendichtung des 17. Jahrhunderts, Köln 1974, 83.

34 Renate Böschenstein-Schäfer, „Arbeit und Muße in der Idyllendichtung des 18. Jahrhunderts“, in: Gerhart Hoffmeister (Hg.), Goethezeit. Studien zur Erkenntnis und Rezeption Goethes und seiner Zeitgenossen. Festschrift für Stuart Atkins, Bern u. a. 1981, 9-30, 27.

35 Vgl. dazu Riedl, „Arbeit und Muße“, 80.

36 Salomon Geßner, Idyllen. Kritische Ausgabe, hg. v. E. Theodor Voss, Stuttgart 1973, 69.

37 Geßner, Idyllen, 67. 
Deutlicher wird die bei Geßner angedeutete Relation von Muße, Landleben und körperlicher Arbeit in Christian Cay Lorenz Hirschfelds Das Landleben entfaltet. Die Bedeutung von Hirschfelds Landleben-Buch, das seit 1768 in mehreren Auflagen das Landleben als „malerische[ ] Idylle“38 preist, für die Umbruchszeit um 1800 zeigt sich u.a. in den extensiven Übernahmen daraus in den „Landleben“-Artikel von Johann Georg Krünitz' Oeconomischer Encyclopaedie. ${ }^{39}$ Bei Hirschfeld wird die Arbeit explizit als Hintergrund benannt, vor dem sich die Muße auf dem Land profiliert. Gegen die Verachtung der ländlichen Arbeit führt der Text neben dem Hinweis auf den Nutzen der Landwirtschaft an, „daß ihr Anblick, indem er uns an die Beschwerden unsrer Nebenmenschen erinnert, auch das Gefühl von unsrer eigenen Ruhe und Bequemlichkeit belebt “ ${ }^{40}$ Auf der anderen Seite grenzt sich der Text aber auch von den „vornehme[n] Müßiggänger[n]"41 ab, denen die Mußezeit auf dem Land nur Vorwand zum Nichtstun ist, obwohl sie dort von früh bis spät „,hundert Scenen der Arbeit sehen, und [dennoch] weder irgend eine der menschlichen Gesellschaft nützliche Beschäftigung vornehmen, noch den Geist mit einigen der Würde des Landlebens angemessenen Betrachtungen unterhalten" ${ }^{42}$ Die Beziehung von Muße, ländlicher Arbeit und Müßiggang ist offensichtlich komplex. Einerseits verrichtet der Muße-Genießende auf dem Land gerade keine körperliche Arbeit, andererseits soll deren Anblick verhindern, dass seine Muße zum Müßiggang wird.

Die Bedeutung idyllisierter Wahrnehmungen der Landarbeit für Muße-Konzepte um 1800 wird von einer anderen Seite her an einem Text wie Christian Garves Aufsatz Über die Muße ersichtlich, der in einer neueren Präsentation nicht von ungefähr als „ein am Pianoforte gespieltes Idyll“43 bezeichnet wird. Im Einklang mit der bis in die Antike zurückreichenden europäischen Tradition bestimmt Garve das Land als privilegierten Ort der Muße: „Wer könnte von der Muße reden, ohne des Landlebens und der Wissenschaften zu gedenken? An keinem Orte ist die Muße so erwünscht, als auf dem Lande: mit keinem Gegenstande kann sie so völlig ausgefüllt werden, als mit dem Anbaue der

38 Christian Cay Lorenz Hirschfeld, Das Landleben, 4. Aufl., Leipzig 1776, 23 (Hirschfeld zitiert hier Hagedorn).

39 Art. „Landleben“, in: Oeconomische Encyclopädie oder allgemeines System der Land-, Haus- und Staats-Wirthschaft in alphabetischer Ordnung, hg. v. Johann Georg Krünitz, Bd. 60 (1793), Berlin 1773-1858, 318-358, die unten zitierte Passage von Hirschfeld auf S. 320 .

40 Hirschfeld, Das Landleben, 38.

41 Hirschfeld, Das Landleben, 112.

42 Hirschfeld, Das Landleben, 114.

43 Michael Stolleis, „[Präsentation von:] Christian Garve: Über die Muße“, in: Ein solches Jahrhundert vergißt sich nicht mehr. Lieblingstexte aus dem 18. Jahrhundert, ausgewählt und vorgestellt v. Autorinnen und Autoren des Verlages C. H. Beck, München 2000, $577-578,577$. 
Wissenschaften. "44 Die topische Abgrenzung des Lands von der Stadt als dem Ort der „Gewerbsarbeiten, [...] der Regierungsgeschäfte, und der Zerstreuungen " 45 entspricht der doppelten Abgrenzung der Muße von der Arbeit als fremdbestimmter Tätigkeit einerseits und vom Müßiggang andererseits. Letzterer „ist Unthätigkeit; jener [sic - gemeint ist die Muße] ist die äußere Möglichkeit einer freywilligen, selbstgewählten, also der edelsten Thätigkeit.“46 Die Beschreibung der Muße als Tätigkeit, als „thätige[ ] Muße“47, ist bei Garve zentral, bis hin zur Bezeichnung der in der Muße ausgeübten Tätigkeiten als „Arbeit“" ${ }^{4}$, solange diese nur selbstbestimmt sind. Selbstverständlich ist nicht jede Tätigkeit dadurch zur Muße geeignet. Garve beschreibt mit der Muße geistige Tätigkeiten, setzt diese aber in Beziehung zur körperlichen Arbeit auf dem Land. Im Text schlägt sich dies auch sprachlich nieder. Die Rede vom „Anbaue der Wissenschaften“ in direkter Beiordnung zur Verortung auf dem Land wird später aufgegriffen, wenn die Fähigkeit zum Genuss des Landlebens jenen zugesprochen wird, die „entweder das Land selbst, welches sie bewohnen, oder an dessen Stelle das Feld der Wissenschaft und der Literatur anbauen. "49 Das Zeugma vom Anbau der Literatur und Wissenschaften oder der Äcker hält die Differenz von geistigem und landwirtschaftlichem Tätigkeitsfeld zwar aufrecht, nähert die Muße in der Metapher jedoch ebenso der Arbeit an. Denken und Schreiben unterscheiden sich von der Landwirtschaft zwar hinsichtlich ihres Betätigungsfelds, entsprechen ihr aber, indem sie an deren „Stelle“ treten können, in ihrem Charakter als Tätigkeit.

Während in der Schäferdichtung der Schäfer als Stellvertreter oder fiktionales Pendant zur Muße des Dichters diente, ist es hier nicht mehr die Muße, sondern die Arbeit der Landbevölkerung, die als zwar andere, aber homologe Tätigkeit die Spielräume der Muße v. a. in Abgrenzung zum Müßiggang beschreiben hilft. Die darin wirksame Aufspaltung der Arbeit in ein idyllisches Schauspiel für den in Muße Tätigen einerseits und eine durch gesellschaftliche Arbeitsteilung ausgelagerte Anstrengung andererseits ${ }^{50}$ verdankt sich nicht zuletzt einem Funktionswandel der Landlebenliteratur im Zuge ökonomischer Modernisierung:

${ }^{44}$ Christian Garve, „Über die Muße“, in: Sämmtliche Werke (=SW), hg. v. J. C. F. Manso/K. H. G. Schneider, Breslau 1801-1804, Bd. 5, 232-240, 237.

45 Garve, „Über die Muße“, in: SW 5, 237.

46 Garve, „Über die Muße“, in: SW 5, 234.

47 Garve, „Über die Muß“", in: SW 5, 236.

48 Garve, „Über die Muße“, in: SW 5, 236 (mit Zweckbestimmung „zum Besten der Welt arbeiten“, 239).

49 Garve, „Über die Muße“, in: SW 5, 239.

${ }^{50}$ Hier deutet sich bereits die von Christoph Henning in diesem Band beschriebene Dialektik von Muße und Ungleichheit an. 
Viele der literarischen Quellen der Zeit sagen uns, daß die Rede vom Landleben immer weniger die Praxis der landwirtschaftlichen Produktion und ihres Marktgeschehens meint, sondern vielmehr ein Reflexionsbegriff geworden ist, der im Spiegel einer bestimmten Daseinserfahrung Zustande [sic] des Geistes und der Seele zum Ausdruck bringt. ${ }^{51}$

Mit der Rationalisierung der Landwirtschaft und der Ablösung von Arbeit aus dem Ordnungszusammenhang des ,ganzen Hauses` im vormodernen Verständnis von Ökonomie wird das Bild vom Landleben aus dem Bereich der im praktischen Sinne weitgehend funktionslos werdenden ökonomischen Literatur abgelöst. Die Übernahmen von Passagen aus Hirschfelds Buch in die Oeconomische Encyclopädie zeugt noch von diesem früheren Zusammenhang, ebenso aber auch vom Zusammenhang von ästhetischer Wahrnehmung und ökonomischer Reform, bis diese schließlich ganz auf die Idealisierung verzichten konnte. Frühsorge weist darauf hin, dass in folgenden Nachschlagwerken ein Lemma „Landleben“ fehlt. 52

Die Transformation der Landlebenliteratur in der Idyllik um 1800 ist so ebenso als partielle Übertragung bukolischer Repräsentationsmuster auf den Bereich des Landlebens zu verstehen wie als Erweiterung des Themenkreises der Schäferdichtung. Nicht mehr der Schäfer, sondern die Vorstellung einer glücklichen Existenz auf dem Lande stellt eine künstlich stilisierte Lebensform dar, in der etwas möglich sein soll, was dem gesellschaftlichen Leben ebenso abgeht wie dem hier in artifizieller Überformung vermeintlich repräsentierten Referenzbereich. Mit der Zusammenführung unterschiedlicher Repräsentationsstrategien der jeweiligen Gattungen geht eine ,Hybridisierung' der traditionell damit verbundenen Wertigkeiten einher. Die durch die Schäfer vermittelte Muße wird durch die Verlegung in ein zwar stilisiertes, aber auf eine konkrete Lebensführung bezogenes Landleben zur , tätigen Muße‘.

\section{Produktion der Idylle}

Von hier ausgehend (und in der Idyllenpoetik des 18. Jahrhunderts diese Entwicklung begleitend) ist eine Abstraktion oder Formalisierung des Idyllischen möglich, die sich von inhaltlich-thematischen Festlegungen wie dem Landleben auch lösen kann. Herder bestimmt so die Idylle in der Adrastea denkbar allgemein als „Darstellung oder Erzählung einer menschlichen Lebensweise ihrem

${ }^{51}$ Gotthardt Frühsorge, Die Kunst des Landlebens. Vom Landschloss zum Campingplatz. Eine Kulturgeschichte, München u. a. 1993, 29.

52 Vgl. Gotthardt Frühsorge, „Landleben؛ Vom Paradies-Bericht zum Natur-Erlebnis. Entwicklungsphasen literarisierter Lebenspraxis“, in: Winfried Barner (Hg.), Tradition, Norm, Innovation. Soziales und literarisches Traditionsverhalten in der Frühzeit der deutschen Aufklärung, München 1989, 165-187, 165. 
Stande der Natur gemäß, mit Erhebung derselben zu einem Ideal von Glück und Unglück. "53 An die Stelle des Entwurfs eines glücklichen Lebens in einem abgegrenzten Bereich - der Muße auf dem Land -, der in sich einen weiteren Bereich - die Landarbeit - abgrenzt, in dem sich die Muße spiegelt, tritt die Ausweitung der Idylle auf die Darstellung einer ganzen Lebensform. Die mediale Funktion der Landarbeit, wie sie bei Geßner, Hirschfeld oder Garve noch beobachtet werden konnte, tritt damit zugunsten der - in der Kopplung von Muße und beobachteter Arbeit bereits angelegten - tätigen Herstellung des idyllischen Zustands zurück.

Aus unserm Herzen sprossend muß unser Verstand sich durch Kunst dies Lebens-Idyllion schaffen, durch Auswahl diese Lebensekloge vollenden.

Auf wie einen reinen Platz tritt hiemit das Idyll! Leere Beschreibungen der Natur, Schäfertändeleien, die nirgends existieren, verschwinden in ihm wie abgekommene Galanterieen; der ganze Kram einer uns fremden Bilderwelt, von dem unsre Phantasie so wenig als unsre Empfindung weiß, verschwindet. Dagegen tritt unsre Welt, nach Jedes Weise und Sitte in den schönen Glanz einer neuen Schöpfung; Geist und Herz, Liebe, Großmut, Fleiß, Tapferkeit, Sanftmut schaffen sich ein Arkadien in ihrer Welt, in ihrem Stande, es ordnend, genießend, gebrauchend. ${ }^{54}$

Die traditionelle Schäferidylle wird hier noch einmal aufgerufen, um sie vollends zu verabschieden. An die Stelle dieser „fremden Bilderwelt“ soll die Eigentümlichkeit einzelner Lebensformen treten, deren produktive Tätigkeit zur Herstellung des jeweiligen Zustands das Idyllische garantiert. Charakteristisch ist, wie sich in Herders Text die Ebene der ästhetischen Darstellung mit der des Dargestellten vermischt. Wie „durch Kunst“ das „Lebens-Idyllion“ geschaffen werden soll, so „schaffen sich“ die jeweiligen Bereiche „ein Arkadien in ihrer Welt“. Die Idylle übernimmt in der Darstellung die produktive Tätigkeit des Dargestellten als Prinzip der eigenen Poiesis. Während die Bukolik nach Iser „das Fingieren thematisiert und dadurch literarischer Fiktionalität zur Anschauung verholfen hat" ${ }^{\text {"55, }}$ überbrückt in Herders Idyllen-Konzept ein in Dichtung und ,Leben“ gleichermaßen wirksames Prinzip der Produktivität die Differenz zwischen beiden Bereichen.

Diese Produktivität ist freilich eine andere, als sie eingangs als Kennzeichen des modernen Arbeitsbegriffs skizziert wurde. Die Hinweise auf das ,Genießen und ,Gebrauchen' rufen vor dem Hintergrund des frühen Kapitalismus eine Form der Produktion auf, die sich mit der Bedürfnisbefriedigung zufriedengibt und am Gebrauchs- eher als am Tauschwert orientiert ist. Versteht man Muße als „in sich selbst gründendes Tun“, das als solches „definitiv in bestimmter Weise

53 Johann Gottfried Herder, „Idyll“, in: Adrastea (Auswahl), Werke (=W), Bd. 10, hg. v. Günter Arnold, Frankfurt a. M. 2000, 276-283, 281.

${ }^{54}$ Herder, „Idyll“, in: $W$ 10, $282 \mathrm{f}$.

55 Iser, Das Fiktive und das Imaginäre, 60. 
negativ auf Arbeit bezogen ist ${ }^{\text {"56, }}$, dann wird in dieser Form der Idyllik Arbeit (wenn man davon noch sprechen will) in einer, wenn man so will, ,obsoleten Weise konzipiert, die sie mindestens strukturell der Muße annähert, indem sie selbst negativ auf ein modernes Arbeitskonzept bezogen ist.

Angesichts der Modernisierung der Lebens- und Arbeitswelt im 19. Jahrhundert verschwindet das Idyllische damit nicht. Das „biedermeierliche Gattungsverständnis bzw. de[r] Assoziationskomplex vom Idyllischen, in das sich die Gattung mehr oder weniger im Laufe des 19. Jahrhunderts auflöste " 57 , wie es Helmut J. Schneider beim späten Herder vorgebildet sieht, steht schließlich im Versuch, „die belastende Komplexität der Welt und der Gesellschaft auf mehr Einfachheit, Natürlichkeit und Überschaubarkeit“ zu bringen, in einem „funktionale[n] Komplementärverhältnis“ zur „Modernisierungserfahrung“ ${ }^{58}$

In der Verklammerung von moderner Komplexität und idyllischer Autarkie liegt nach Hegel denn auch die ästhetische Berechtigung des Idyllischen. Das Modell hierzu sieht er im ,idyllischen Epos ${ }^{59}$ und hier insbesondere in Goethes Herrmann und Dorothea gegeben. Entscheidend ist auch hier, dass der dargestellte Zustand als Produkt der Arbeit erscheint:

So ist hier alles idyllisch, aber nicht in der begrenzten Weise, daß Erde, Flüsse, Meer, Bäume, Vieh usf. dem Menschen seine Nahrung darreichen und der Mensch dann vornehmlich nur in der Beschränkung auf diese Umgebung und deren Genuß erscheint; sondern innerhalb dieser ursprünglichen Lebendigkeit tun sich tiefere Interessen auf, in Verhältnis auf welche die ganze Äußerlichkeit nur als ein Beiwesen, als der Boden und das Mittel für höhere Zwecke da ist - als ein Boden jedoch und eine Umgebung, über welche jene Harmonie und Selbständigkeit sich verbreitet, die nur dadurch zum Vorschein kommt, daß alles und jedes menschlich hervorgebracht und benutzt, zugleich von dem Menschen selbst, der es braucht, bereitet und genossen wird. ${ }^{60}$

Indem Goethe mit dem Hintergrund der Revolutionskriege „den für sich beschränkten Stoff mit den weitesten, mächtigsten Weltbegebenheiten in Beziehung bringt“ ${ }^{\text {“ }}$, sind jene „tiefere[n] Interessen“ garantiert, zugleich bleibt die dargestellte Sphäre vor allem in ökonomischer Hinsicht geschlossen. Was gebraucht und genossen wird, ist in dieser Sphäre selbst produziert und ruft nicht - wie es

56 Volker Schürmann, Muße, Bielefeld 2001, 28.

57 Schneider, „Einleitung: Antike und Aufklärung“, 63.

58 Hans Ulrich Seeber, „Einleitung“, in: Hans Ulrich Seeber/Paul Gerhard Klussmann (Hg.), Idylle und Modernisierung in der europäischen Literatur des 19. Jahrhunderts, Bonn 1986, 7-12, 7 f. Solche Konzeptionen spielen auch in Thoreaus Rückzugsexperiment eine Rolle, vgl. dazu den Beitrag von Günter Figal in diesem Band.

59 Vgl. dazu Helmut J. Schneider, „Gesellschaftliche Modernität und ästhetischer Anachronismus. Zur geschichtsphilosophischen und gattungsgeschichtlichen Grundlage des idyllischen Epos", in: Seeber/Klussmann (Hg.), Idylle und Modernisierung in der europäischen Literatur des 19. Jahrhunderts, 13-24.

60 Hegel, Vorlesungen über die Ästhetik $I, W 13,338 \mathrm{f}$.

${ }^{61}$ Hegel, Vorlesungen über die Ästhetik I, W 13, 251. 
Hegel an der Erwähnung von Kaffee und Tabak in Voß' Luise bemängelt - die „mannigfache[n] Vermittlungen“ des Weltmarkts, „überhaupt der modernen Industrie“, auf. ${ }^{62}$ Insofern in der idyllischen „Beschränktheit privater häuslicher Zustände auf dem Lande und in der kleinen Stadt" noch die "Stoffe“ zu finden sind, „welche sich einer epischen Darstellung fügen könnten “63, bietet die Idylle ästhetische Möglichkeiten, die dem eigentlichen Epos ebenso wie dem Roman als der „modernen bürgerlichen Epopöe“64 mit ihrem Anspruch auf größere Totalität nicht mehr zur Verfügung stehen. Hier lässt sich Arbeit noch so darstellen, als diene sie rein dem Erhalt und der Sicherung eines selbstgenügsamen Zustands.

In der eigentümlichen Zwischenstellung zwischen Epos und überkommener Idylle ist das von Hegel beschriebene Idyllische als Kippfigur zwischen Neuorientierung und Verabschiedung der Idylle erkennbar. Dies entspricht durchaus dem Status der Muße im idyllischen Raum, der nicht mehr vom müßigen Hirten bevölkert, und doch nicht von moderner Arbeit erfüllt ist. Die hier verrichtete Arbeit verdrängt nicht einfach die Muße, sondern tritt an deren Stelle, indem sie aus dem Paradigma unbeschränkter Produktivität heraustritt. Sie ähnelt der Muße darin, dass sie wiederum als Gegenentwurf einer modernen Arbeit konzipiert ist und zugleich vom Müßiggang, zu dem nun auch die rein kontemplative Muße und ihr Statthalter, der poetische Schäfer, zählen, sich unterscheidet.

Diese Umbesetzung eröffnet aber auch den Spielraum für Experimente, die sich einer ästhetischen Form von Produktivität verschreiben und anstelle einer Kontamination von Muße und Arbeit auf die andere Option setzen, den Müßiggang. Schlegels „Idylle über den Müßiggang“ aus der Lucinde lässt sich in diesem Sinne als ,polemische Idylle ${ }^{65}$ lesen, die auf der Umbesetzung der bukolischen Muße aufbaut, deren Abwertung in der Idylle als Müßiggang ausbuchstabiert und diesen gerade als solchen für sich in Anspruch nimmt. Schlegels Kompendium unterschiedlichster Muße-Traditionen ${ }^{66}$ steht freilich, jenseits der hier mit der Figuration idyllischer Arbeit und dezidiert tätiger Muße beschriebenen Zusammenhänge, im Horizont der idealistischen Poetik Schillers, die er gezielt aufgreift und überschreitet ${ }^{67}$, um darin, ohne ihn zu nennen, den müßigen Hirten zu retten.

${ }^{62}$ Hegel, Vorlesungen über die Ästhetik I, W 13, 339.

63 Georg Wilhelm Friedrich Hegel, Vorlesungen über die Ästhetik III, W 15, 414.

${ }^{64}$ Hegel, Vorlesungen über die Ästhetik III, W 15, 392.

65 Vgl. Viktor Žmegač, „Polemische Idyllen. Utopische Vorstellungen vom Müßiggang in der deutschen Literatur", in: Žmegač, Tradition und Innovation. Studien zur deutschsprachigen Literatur seit der Jahrhundertwende, Wien 1993, 152-165.

66 Vgl. Martin Jörg Schäfer, Die Gewalt der Muße. Wechselverhältnisse von Arbeit, Nichtarbeit, Ästhetik, Zürich 2013, 36; Riedl, „Die Kunst der Muße“, 24.

67 Vgl. Mix, „Idyllik, Anti-Idyllik, Aufklärung und Selbstaufklärung“, 211; zu konkreten Bezügen in Schlegels Text auf Schiller vgl. John Hibberd, „The Idylls in Friedrich Schlegel's Lucinde“, in: Deutsche Vierteljahresschrift für Literaturwissenschaft 51 (1977), 222-246, $230-232$. 


\title{
,The opulent baboos [...] filling out [their] cellular tissue with sebaceous deposits
}

\author{
Körper als Aushandlungsorte von Müßiggang
}

Pia Florence Masurczak

\author{
1. Körperliche Konstitution \\ und prekäre koloniale Herrschaft
}

„Objectless and hopeless, with its ennui and intemperance and, at times, even despair! "1 So wird in The British Army in India das passive, langweilige Kasernenleben britischer Soldaten in Indien beschrieben. Als Julius Jeffreys nach rund 15 Jahren als Militärarzt in Indien 1858 seine fachlichen, aber auch persönlichen Beobachtungen unter diesem Titel veröffentlichte, muss er sich auf dem Höhepunkt einer Welle medizinisch-politischer Literatur gewähnt haben. 1857 waren die Briten von einem sich schnell ausbreitenden Aufstand der indischen Regimenter innerhalb der britischen Armee überrascht worden und konnten nur mit Mühe die Aufständischen besiegen. Diese Zäsur läutete formell eine neue Ära der Kolonialherrschaft ein, in der Indien nun vollständig der britischen Regierung unterstellt wurde. Insbesondere nach der Niederschlagung dieser ersten großen Rebellion gegen die Kolonialherrschaft erschienen zahllose Ratgeber, Studien und Traktate, die versuchten, die nun offenkundig gewordene Instabilität dieser Herrschaft über den Subkontinent zu erklären. Der Grund wurde von zahlreichen Autorinnen und Autoren in der Degeneration der Soldaten gefunden, so dass ein zentraler Ansatzpunkt die Wiederherstellung der körperlichen Stärke und die Tüchtigkeit der Britinnen und Briten im tropischen Klima Indiens war. Die ohnehin bedrohlich geringe Zahl der weißen Bevölkerung schien durch kranke Soldaten im Besonderen und wehrlose Männer allgemein nur unzureichend verteidigt. Vor dem Hintergrund der Erschütterung durch die Rebellion, drängt Jeffreys in The British Army in India nun auf eine wesentlich bessere Ausstattung und vor allem auf eine an modernen medizinischen Maßstäben ausgerichtete Lebensführung der Soldaten und Offiziere. Denn nach dem end-

1 Julius Jeffreys, The British Army in India. Its Preservation by an Appropriate Clothing, Housing, Locating, Recreative Employment, and Hopeful Encouragement of the Troops, London 1858, 175. 
gültigen Ende der Kämpfe, so Jeffreys, beginne wieder die bereits beschriebene Langeweile des Kasernenlebens. Die Eintönigkeit des Alltags und die fehlende Abwechslung körperlicher Betätigung sei einer der wichtigsten Gründe für den Verfall der britischen Armee. So erläutert Jeffreys:

The mortality amongst the European soldiery has hitherto been the most grievous contingency upon the tenure of India, [...] which would not prevail to so serious an extent were the active spirits and energy of Englishmen afforded a field for their exercise. It is a life of absolute idleness, worse to a spirited Englishman than the prospect of death, which makes any extremity often preferred by a soldier to a continuance in his present state. They who have the most mind and spirit, who are the farthest removed form [sic!, P.M.] Eastern apathy, can least endure that dormant state which is one of bliss to the native. ${ }^{2}$

Das Leben in „absolute idleness“, das Jeffreys hier beschreibt, ist aber gerade nicht für jeden so tödlich, sondern nur für diejenigen, deren Verstand und Geist am stärksten im Kontrast zur vermeintlichen orientalischen Apathie stehen. Es ist, mit anderen Worten, die besondere Konstitution des britischen Körpers und Geistes, die die Nachahmung indischen Müßiggangs zu einer solchen Qual macht.

Jeffreys schlägt also vor, die Soldaten in Friedenszeiten in handwerklichen „workshops" zu organisieren, um ihnen eine , sinnvolle“ Beschäftigung zu geben. Interessant ist dabei, dass Jeffreys nicht - wie andere Autoren - eine Bücherei zur Verfügung stellen oder eine verstärkte Präsenz der Kirche propagieren will. Es geht ihm also nicht um geistige Erbauung zur Aufrechterhaltung der Moral, sondern um die konkrete körperliche Verfasstheit, um geistige Aktivität, die sich in handwerklicher Arbeit ausdrückt, die den Körper fordert, aber auch diszipliniert. Das wird insbesondere deutlich, wenn Jeffreys später das Gegenbild zum betriebsamen, stets um Tätigkeit bemühten Briten zeichnet, also seine allgemeine Verdammung indischen Müßiggangs ausbuchstabiert. Der ,lazy native nimmt hier die Gestalt des „opulent baboo“ an, also des sich gehen lassenden, wohlhabenden und gebildeten Bengalen²:

As to the interests the natives have in the presence of the British soldier, [...] there cannot be a question that the comparative security with which [they, P.M.] have rested upon their pillows during the present century has been due to that presence. The opulent baboos of the Presidencies, the progressive filling out of whose cellular tissue with sebaceous deposits may be taken as the symbol and measure of the progressive filling up of their cellars

2 Jeffreys, The British Army in India, 183.

3 Der Begriff „baboo“ oder „babu“ ist eigentlich eine Ehrenbezeichnung im Sinne von ,Herr' und wird dem Namen vorangesetzt. Verwendet wurde der Begriff vor allem in Bengalen für (kleinere) Beamte und Schreiber, also für die Schicht, die oft eine Mittlerfunktion zwischen der indischen Bevölkerung und den Kolonialherren einnahm. Seine pejorative Konnotation nimmt er im Verlauf der britischen Herrschaft an. 
with Company's tissue and bullion deposits, would view with quaking hearts the departure of the last British soldier from India. ${ }^{4}$

Bereits in diesem kurzen Absatz evoziert Jeffreys Bilder von Fettsucht, Gier, Ausschweifungen und Verweiblichung und, diagnostiziert' als Arzt interessanterweise all dies als in den Körperzellen verankert. Der Körper des babu ist nicht nur sichtbar, also äußerlich degeneriert, sondern auch in seinem Kern verdorben. Die ,talgigen Ablagerungen“ - „sebaceous deposits“ - werden als Analogie zur Gier nach den Reichtümern der East India Company präsentiert, nach Reichtümern also, die aus Jeffreys' Perspektive erarbeitet wurden, während die Faulheit der babus als das exakte Gegenstück fungiert. Der damit implizierte Müßiggang ist also nicht nur eine ,Praxis', die von außen beobachtbar wäre, sondern ist dem Körper des ,Anderen' eingeschrieben. In Jeffreys' babu fallen die gängigen Bilder indischen Müßiggangs zusammen: Gier nach Luxus und Reichtümern, Verweiblichung und Feigheit angesichts roher körperlicher Gewalt und der sich um jede ehrliche Arbeit drückende, lazy nativé.

Die Präsenz britischer Soldaten in Indien ist in dieser Logik nötig zum Schutz jener, die einer physischen Auseinandersetzung nicht gewachsen wären. Die „opulent baboos" nämlich

know very well that it would be the signal for the descent upon them of armed bands from the interior [...]; that, to have the dagger of Ehud buried in their obese persons would be more considerate treatment they could hope for from beings whose minds, filled to the brim with thoughts of rapine, had no space left for any other; and who could not give them credit for having surrendered their last hoard until torture had done its worst upon their bodies. ${ }^{5}$

Jeffreys imaginiert hier eine Art von ,folgerichtiger' Verletzung, ja wortwörtlich Folter, des müßigen, faulen und fetten Körpers, die den Schutz der Einheimischen durch furchtlose und aktive britische Truppen geradezu erzwingt. Fast schon obsessiv kommt Jeffreys immer wieder auf die degenerierte physische Verfassung der babus, auf ihre Fettleibigkeit zurück, und immer wieder kontrastiert er sie mit einer ebenfalls als gegeben vorausgesetzten britischen Stärke:

To the [British soldiers, P.M.] also does every sleek effeminate baboo owe his personal safety and to him blissful opportunities of gathering riches year by year; while his brave protectors are accumulating, - not wealth, but disease! - are not adding to their substance, not fattening like him in purse and in person, but wasting away; many of them are leaking out their very blood; when not from wounds in the field, from their bowels in dysentery! ${ }^{6}$

${ }^{4}$ Jeffreys, The British Army in India, 229. Hervorhebungen im Original.

5 Jeffreys, The British Army in India, 229-230. Hervorhebung im Original.

6 Jeffreys, The British Army in India, 202. 
In Indien, so wird hier angedeutet, ist der britische Körper ständigen Gefahren ausgesetzt, sei es durch „wounds in the field“, durch Krankheiten wie die Ruhr oder eben durch schädlichen erzwungenen Müßiggang.

Will man den Diskurs der British Army in India zusammenfassen, lässt sich das in der Dichotomie von angeblich ,weibischen Einheimischen“ - „effeminate baboos“ - und ,tapferen Beschützern“ - „brave protectors“ - tun, die Jeffreys hier vornimmt. Während der Müßiggang, die Verweiblichung und die körperliche Degeneration der einen selbstverständlich ist, stellt sie bei den anderen eine dringend zu behandelnde ,Krankheit', einen durch äußere Umstände aufgezwungenen schädlichen Einfluss auf Geist und Physis dar. Was Jeffreys in beiden Fällen anhand von körperlichen Merkmalen diagnostiziert, ist bei den babus angelegt, und bei den britischen Soldaten pathologisch.

\section{Die Herausbildung von müßigen und tätigen Körpern}

Diese scheinbar einfache Trennung körperlicher Verfasstheit ist aber nicht völlig selbstverständlich; vielmehr bildet sie sich im Laufe des 19. Jahrhunderts erst heraus. Die Teilung in müßiggängerisch-faule und fleißig-aktive Körper, beziehungsweise Körperpraktiken, wird zum sichtbaren Merkmal kolonialer Herrschaft. Parallel dazu entwickelt sich auch eine praktische Trennung britischer und indischer Lebenswelten, die mit der Neudefinierung des anglo-indischen Körpers als ,Britisch ‘ beziehungsweise ,Englisch` einhergeht. Elizabeth Collingham beschreibt den Import von Lebensmitteln aus Großbritannien und von europäischer Kleidung, aber auch das Verschwinden der im 18. Jahrhundert noch relativ selbstverständlichen indischen Ehefrauen und Geliebten als Auswirkungen dieser ,Anglisierung.7 Im Rückzug der anglo-indischen Oberschicht in die hill stations - die eigens errichteten Kleinstädte in den Vorbergen des Himalaya und in rein weiße Stadtviertel manifestiert sich diese Trennung auch räumlich. ${ }^{8}$ Für Collingham stellt diese ,Anglisierung' das Zentrum einer sich ohnehin verschärfenden ideologischen Trennung zwischen der anglo-indischen und der indischen Bevölkerung dar, die den Charakter kolonialer Herrschaft im 19. Jahrhundert tiefgreifend verändert. Muße - im positiven Sinn konnotierte idleness außerhalb von Arbeits- oder Tätigkeitszwängen - findet in dieser diskursiven wie praktischen Dichotomie der Körper nur schwerlich Platz. ${ }^{9}$

7 Vgl. Elizabeth Collingham, Imperial Bodies. The Physical Experience of the Raj, $c$. 1800-1947, London 2001.

8 Vgl. Dane Kennedy, The Magic Mountains. Hill Stations and the British Raj, Berkeley 1996.

9 Vgl. hierzu auch den Artikel von Tobias Keiling in diesem Band. 
Wie hat sich dieser Prozess der Anglisierung des Körpers nun auf die Darstellung und Bewertung von Müßiggang ausgewirkt? Julius Jeffreys' Überlegungen sind für diesen Prozess beispielhaft, denn in The British Army in India sind im Grunde alle feineren Verästelungen der vorangehenden Jahrzehnte abgebildet: Die orientalistische Setzung, dass Müßiggang in Indien geradezu heimisch ist, aber auch die damit verwandten Topoi wie ausschweifender Luxus, Femininität, geistige wie körperliche Degeneration inklusive der entsprechenden Behandlungen und Präventionen, und die Auswirkungen des Klimas. Im kolonialen indischen Kontext des späten 18. und 19. Jahrhunderts, so meine These, hat all dies auch einen somatischen Aspekt; der Körper - egal ob der indische oder britische - fungiert also auch als Beschreibungs- und Aushandlungsort von Müßiggang. David Arnold beispielsweise beschreibt den Körper auch als „site of colonizing power and of contestation between the colonized and the colonizers "10; er ist also gleichermaßen Instrument und Objekt der Kolonisierungsbemühungen. Wie die Beispiele aus The British Army in India gezeigt haben, geht es dabei sowohl um die Körper der Kolonisierer wie die der Kolonisierten. Vereinfacht gesagt gilt es, ersteren zu erhalten und letzteren zu disziplinieren. Vom vermeintlich exzessiven Müßiggang der babus geht gewissermaßen eine Ansteckungsgefahr aus, der gegenüber der britische Körper abgeschirmt werden muss, sei es im ,europäischeren' Klima des Himalaya, durch Leibesübungen oder durch protektive Kleidung.

Beispielhaft für die frühen Körperdiskurse steht William Mackintoshs Reisebericht, der ins Calcutta des Jahres 1779 und damit zu seinem „Englishman in Bengal“ führt. Der Reisebericht entsteht zu einem Zeitpunkt, als die Debatte um den sogenannten nabob in Großbritannien ihren Zenit erreicht hat. Der nabob ist der britische Angestellte in der indischen Kolonialverwaltung. Diese Verwaltung wurde von der East India Company, der britischen Handelsgesellschaft, ausgeübt, die den Generalgouverneur stellte und bis 1813 das Monopol auf den Ostindienhandel hatte. Der nabob steht jedoch weniger für die in der zweiten Hälfte des 18. Jahrhunderts besonders erfolgreiche Ausdehnung dieses Gebiets. Vielmehr symbolisiert er für die Öffentlichkeit in Großbritannien alle negativen Aspekte der Company und ihrer Politik: Habsucht, Gier, sozial transgressive Ambitionen im Mutterland ${ }^{11}$ und, zentral für das negative Bild, eine Form des ,going native, also der Anverwandlung indischer Praktiken. Dieses ,going

10 David Arnold, Colonizing the Body. State Medicine and Epidemic Disease in Nineteenth-Century India, Berkeley/Los Angeles 1993, 7-8.

${ }^{11}$ Der nabob, das haben beispielsweise Tilman Nechtman und Christina Smylitopoulos gezeigt, fungiert in Großbritannien als Chiffre für den problematischen Aufstieg der Mittelschicht, die ohne den ,richtigen' kulturellen und sozialen Hintergrund und mit ihrem teilweise dubios erworbenen Vermögen in die politische Arena drängt. Vgl. hierzu Tilman Nechtman, Nabobs. Empire and Identity in Eighteenth-Century Britain, Cambridge 2010; Christina Smylitopoulos, „Rewritten and Reused. Imaging the Nabob through ,Upstart Iconography “', in: Eighteenth-Century Life 32,3 (2008), 39-59. 
native wird in Darstellungen wahlweise durch dunklere Haut, durch indische Kleidung oder dem Nachgehen indischer Freizeitbeschäftigungen wie dem Betrachten indischer Tänzerinnen oder dem Rauchen der Wasserpfeife sichtbar gemacht. Bei Mackintoshs Englishman kommt außerdem eine nahezu vollständige Untätigkeit hinzu, für die der Begriff ,Müßiggang fast schon zu positiv konnotiert ist: Der Englishman verweigert jede körperliche Anstrengung. Der Morgen beginnt für ihn, indem er von einer Schar Diener geweckt wird:

In about half an hour after undoing and taking off his long drawers, a clean shirt, breeches, stockings, and slippers are put upon his body, thighs, legs and feet, without any great exertion on his own part than if he was a statue. [...] The superior then walks in state to his breakfasting parlour in his waistcoat; is seated; the consumah makes and pours out his tea, and presents him with a plate of bread or toast. ${ }^{12}$

Mackintosh beschreibt genüsslich, wie vollständig regungslos der Tag für den nabob beginnt, in dessen Verlauf er in einer Sänfte zu verschiedenen gesellschaftlichen Terminen getragen wird und der in einem nachmittäglichen Nickerchen seinen vorläufigen Höhepunkt findet. Bei der Arbeit taucht er nur auf ,if business renders HIS PRESENCE ONLY necessary ${ }^{\text {"13 }}{ }^{3}$ Sogar die Begegnung mit der indischen Geliebten gestaltet sich im Passiv: „our hero is conducted to his bedroom, where he finds a female companion, to amuse him until the hour of seven or eight the next morning. "14

Alle körperlichen Anstrengungen, Verausgabungen oder auch nur Tätigkeiten sind Mackintoshs Figur fremd. Betrachtet man den letzten Satz dieses Briefes, werden die Analogien mit Julius Jeffreys' opulenten babus noch auffälliger, denn „with no greater exertions than these do the Company's servants amass the most splendid fortunes. ${ }^{\text {"15 }}$ Nicht nur in der Wahl seiner Geliebten, seines Fortbewegungsmittels und seiner feudal anmutenden Zahl von Dienern betreibt der ,Englishman' also eine Form des, going native', sondern explizit auch in der Nachahmung offenbar genuin indischen Müßiggangs. Verlässlich wiederkehrendes Symbol dafür ist das Rauchen der Wasserpfeife, also einer Art Einverleibung orientalischen Müßiggangs. Noch dazu werden Arbeiten hier von anderen am Körper verrichtet, nicht durch den eigenen Körper. Wenn man die komplette Passage betrachtet, fällt es sogar schwer, von einem hedonistischen Lebenswandel zu sprechen, denn offensichtlich empfindet der Protagonist keinerlei Freude oder auch nur gesteigertes Gefallen an den einzelnen Stationen seines Tages. Weder der Genuss von Essen und Tabak, noch der von Sexualität spielen eine Rolle. Der Körper selbst ist also nicht einmal Instrument des genussvollen Nichtstuns.

12 William Mackintosh, Travels in Europe, Asia, and Africa; Describing Characters, Customs, Manners, Laws, and Productions of Nature and Art. Containing Various Remarks on the Political and Commercial Interests of Great Britain, Bd. 2, London 1782, 215-216.

13 Mackintosh, Travels, 216.

14 Mackintosh, Travels, 219.

15 Mackintosh, Travels, 219. 
Während Jeffreys den Körper des Müßiggängers pathologisiert, entbehrt er bei Mackintosh nahezu jeder Funktion, wirkt geradezu lebensuntüchtig. Er scheint jedem Nützlichkeitsdiskurs entzogen und wird, sozusagen in ultimativer Abgrenzung, als ,indianisiert' gekennzeichnet und deutlich abgelehnt.

Interessant ist dabei, dass sich bei Mackintosh an keiner Stelle die gängige Rechtfertigung für solchen Müßiggang finden lässt. In vielen anderen Texten, seien es Fremdbeschreibungen oder Selbstzeugnisse, werden das Klima, die Hitze, die tropischen Verhältnisse und die ,hot season' herangezogen, um das eigene, manchmal auch nur vermeintliche, Nichtstun zu erklären. Das macht das Nichtstun des Englishman nur umso irritierender und verwerflicher, denn wesentlich häufiger sind Reiseberichte aus Indien wie dieser von Fanny Parks, die schreibt: "I knew not before the oppressive power of the hot winds, and find myself as listless as any Indian lady is universally considered to be; I can now excuse what I before condemned as indolence and want of energy - so much for experience." 16 Collingham hebt hervor, wie entscheidend der ständige Verweis auf das Klima ist für die Rechtfertigung ,indianisierter Körperpraktiken wie tägliches Baden inklusive Shampoonieren der Haare (der Begriff selbst stammt aus Indien und wird 1762 das erste Mal erwähnt), das Sitzen unter der punkah, dem Deckenfächer, und generell die intensivierte Körperhygiene. ${ }^{17}$ Auch der Mittagsschlaf des Englishman lässt sich so leichter rechtfertigen. Während aber solche - auch von britischen Ärzten zum Teil empfohlenen - Behandlungen stets die Wiederherstellung der Tatkraft des britischen Körpers zum Ziel haben, sind sie in Mackintoshs Bericht ebenso ziel- und nutzlos wie der gesamte Tagesablauf des Protagonisten. Die Hitze Bengalens und ihre Auswirkungen bleiben hier ganz außen vor.

Die Vorstellung, dass das Klima, oder allgemeiner die Umweltbedingungen, einen starken Einfluss auf die Gesundheit, menschliche Entwicklung und ,Rassen' haben, taucht natürlich nicht das erste Mal im Indien des 18. und 19. Jahrhunderts auf. Vermischt zunächst mit Resten der Vier-Säfte-Lehre und, später, den Anfängen der biologistischen Rassentheorie bekommt das Klima-Problem im Zuge der Konsolidierung britischer Herrschaft eine akute Dringlichkeit, die kaum zu überschätzen ist. Im Zentrum steht die Frage, ob und wie der Subkontinent überhaupt dauerhaft regiert und besiedelt werden kann, wenn der britische Körper dort vielleicht gar nicht als solcher erhalten werden kann. Mackintosh zeigt allerdings zweifelsohne, dass sein Englishman sicher nicht derjenige ist, der effizient und weitsichtig regieren und/oder verwalten kann.

Neben den eigentlichen epidemischen Erkrankungen, die bis ins späte 19. Jahrhundert für eine hohe Sterberate unter der anglo-indischen Bevölkerung verantwortlich sind, gelten auch Symptome wie Mattheit, Schläfrigkeit oder Apathie

16 Fanny Parks, Wanderings of a Pilgrim in Search of the Picturesque, Bd. 1, Karachi 1975, 26.

17 Collingham, Imperial Bodies, 24. 
als Auswirkungen des tropischen Klimas. Dane Kennedy findet in seiner Studie über Akklimatisierungsdiskurse eine gute Zusammenfassung für diese Debatte, wenn er schreibt:

[The climate debate, P.M.] provided commentary on the political choices and constraints of Western imperialism itself. It had this larger resonance because it spoke at one level to the deep-felt anxieties of colonists concerning their physical health and security, their cultural values, and the racial character of their economic and social privileges, and at a second level to the broader concerns of imperial policy makers about the very shape and future of European colonialism in the tropical world. At its core was a fundamental question: could white colonists thrive, reproduce, and sustain lasting communities whose ethnic and cultural identities remained intact in the tropics? For climatic theorists, the answer was problematic at best $[\ldots]^{18}$

Bedenken gegenüber einer möglichen (und angeblich immer wieder beobachteten) Degeneration des weißen Körpers unter dauerhaften tropischen Bedingungen äußern sich insbesondere in der Hervorhebung des vermeintlich ,nordisch-britischen' Prinzips der Aktivität und Tatkraft gegenüber dem ,orientalischen' der Passivität, oder, wie Collingham schreibt:

The steamy heat of Bengal was supposed to induce sloth of mind and body, while the fertility of the land provided little inducement to effort. This combined with the effects of the tyranny of Mughal government resulted in a stagnant society made up of apathetic effeminate individuals. Temperate climates, on the other hand, were believed to breed strong independent types, full of manly vigour. ${ }^{19}$

Für viele Kommentatoren scheint der Verfall körperlicher Tüchtigkeit und Leistungsfähigkeit der erschreckendste Ausblick jenseits akuter Bedrohungen durch Infektionen zu sein und wird in unterschiedlichen Formen spätestens ab Ende des 18. Jahrhunderts dauernd thematisiert. ${ }^{20}$

Ganz gleich, ob die Begründungen nun Umwelteinflüsse und Evolutionstheorien oder ,rassische Merkmale anführen, bleibt der britische Körper während der gesamten Kolonialzeit das fragile, bedrohte Objekt von Behandlungen, $\mathrm{Ku}$ ren und Schutzmaßnahmen. Das führt zu einer Art umgekehrter Exotisierung, die die Fremdheit des weißen Körpers in seiner neuen Umgebung unterstreicht, und ihn wiederum besonders prekär erscheinen lässt. Hier wird die von Homi Bhabha beschriebene grundlegende Ambivalenz kolonialer Diskurse ${ }^{21}$ sichtbar: der britische Körper ist einerseits von überlegener Physis und Tatkraft; so schreibt Jemima Kindersley 1777: „Ease with them is the greatest good; and no-

18 Dane Kennedy, „The Perils of the Midday Sun. Climatic Anxieties in the Colonial Tropics“, in: John MacKenzie (Hg.), Imperialism and the Natural World, Manchester/New York 1990, 118-140, 118-119.

19 Collingham, Imperial Bodies, 25.

$20 \mathrm{Vgl}$. bspw. Jemima Kindersley, Letters from the Island of Teneriffe, Brazil, the Cape of Good Hope, and the East-Indies, London 1777, 164-165.

21 Vgl. Homi K. Bhabha, The Location of Culture, London/New York 1994. 
thing surprizes the Indians so much as to see Europeans take pleasure in exercise; they are astonished to see people walking who might sit still." 22 Andererseits muss der britische Körper aber auch immer vor einem stets drohenden Verfall in orientalische Schwäche und Passivität geschützt werden, wie die unzähligen Ideen medizinischer Provenienz zeigen, für die Julius Jeffreys' Werk beispielhaft ist und auf die ich im dritten Teil noch eingehen werde.

Vor diesem Hintergrund wird auch jeder Äußerung von Unlust, Faulheit, Trägheit oder Müdigkeit besondere Aufmerksamkeit zuteil. Der ,Englishman` taugt also nicht nur wegen seiner ,Indianisierung' als Objekt von Mackintoshs Satire; vielmehr ist bereits die nahezu vollständige Abwesenheit jeder Körperlichkeit ein Symptom dieses skandalösen ,going native'. Diese Durchlässigkeit des britischen Körpers gegenüber der indischen Umgebung wird im 19. Jahrhundert extrem problematisiert und schließlich weitestgehend unterbunden.

Bereits in diesem Sinne deutlich ,europäisierter' erscheint dann die Figur des "Anglo-Bengalee“ aus Godfrey Charles Mundys Pen and Pencil Sketches von 1832. Ähnlich episodisch aufgebaut wie Mackintoshs Beschreibung unterscheiden sich die beiden Beschreibungen des gleichen Milieus deutlich. Anstatt sich nur in der Sänfte fortzubewegen, reitet der Anglo-Bengalee auch mal selbst. Und die Wasserpfeife, deren Genuss in den 1830ern bereits verpönt ist, taucht, anders als bei Mackintosh, nur noch beim Abendessen auf. Es scheint hingegen sozial erwünscht, mehr Wert auf die Erhaltung des eigenen Körpers zu legen:

In the hot weather - and nine months of the twelve are hot - the Anglo-Bengalee - unless he has been late at a party the night before, or loves his bed better than his health - is roused by the punctual warning of his bearer [...] and completing, by the assistance of the same domestic officer, a hasty toilette, he mounts his Arab, and by half-past four is taking his constitutional canter round the dew-freshened race-course. [...] During the months preceding the races, the training of the horses affords the sporting world of Calcutta an additional incitement to the healthful practice of early rising. ${ }^{23}$

Wie weit Anspruch und Wirklichkeit aber auseinanderklaffen, wird spätestens um sechs Uhr deutlich, wenn „the arch-enemy of European constitutions“, die aufgehende Sonne der Ertüchtigung ein Ende setzt:

and the „Qui hi“ who has any respect for the wellbeing of his liver, shrinks appalled from its increasing disk, sneaks home, delivers his reeking horse to the attendant syce, and, exhausted with the monstrous exertion he has undergone, creeps under his mosquito curtain, and dozes, a bearer fanning him, until half-past $8 .^{24}$

22 Kindersley, Letters, 182.

23 Godfrey Charles Mundy, Pen and Pencil Sketches, Being the Journal of a Tour in India, Bd. 2, London 1832, 292.

${ }^{24}$ Mundy, Pen and Pencil Sketches, 293. „Qui hi“ ist ein geläufiger Spitzname für die Angestellten der East India Company. Aus dem ursprünglich bengalischen Ruf nach einem Diener (etwa: ,Ist da jemand?'), wurde die Bezeichnung für die vergleichsweise wohlhabende (und vermeintlich verwöhnte) anglo-indische Oberschicht. 
Liest man weiter, zeigt sich, dass Mundys Anglo-Bengalee immer wieder eine Art Rückfall in vermeintlich indische Gewohnheiten erlebt: So folgt auf die Rückkehr ins Bett ein Frühstück mit Muffins und Pilau, einem indischen Reisgericht. Und auch das tägliche Bad, vielleicht das Symbol für indischen Müßiggang schlechthin, ist im Tagesablauf vorgesehen: „A bath - the greatest luxury in India - and perhaps shampooing wind him up for the breakfast" ${ }^{25}$ Anders als Mackintoshs Englishman hat Mundys Anglo-Bengalee zumindest ein deutlich erkennbares Interesse an seinem Körper. Hier bezieht sich die spöttische Darstellung eher auf die Oberflächlichkeit dieser Tätigkeiten, die Eitelkeiten der Figuren und vielleicht das flatterhafte Interesse und nicht, wie bei Mackintosh, auf die völlige Tatenlosigkeit. Der Referenzpunkt für die Figuren ist in den 1830ern und 1840ern also offenkundig zumindest partiell das britische Ideal körperlicher Ertüchtigung und tatkräftiger Männlichkeit, auch wenn der Anglo-Bengalee ihm nicht gerecht wird.

Mark Harrison hat ganz richtig angemerkt, dass es trotz allem aber natürlich keinen einheitlichen und widerstandslosen Abschied von zum Teil dankbar angenommenen indischen Körperpraktiken im 19. Jahrhundert gab. ${ }^{26}$ Wie die Passagen aus Mundys Reisebericht zeigen, bleiben manche Formen der Körperhygiene, aber auch generell der Anpassungsversuche an das indische Klima erhalten. Die Debatten um eine mögliche, mehr oder weniger dauerhafter Präsenz in Indien, so Harrison, zwang die Briten nämlich dazu, sich mit ihren eigenen Praktiken kritisch auseinanderzusetzen, insbesondere im Vergleich mit denen jener, die offenkundig besser mit den Umständen zurechtkamen. ${ }^{27}$ Etwas verkürzt könnte man also sagen, dass der nabob, wie ihn auch Mackintoshs Englishman darstellt, im 18. Jahrhundert indische Praktiken im Sinne sozialer Distinktion nachahmt. Einige der als aristokratisch und damit in Großbritannien sozial transgressiv wahrgenommenen Praktiken werden aber im 19. Jahrhundert im Sinne ihrer medizinischen Nützlichkeit mehr oder weniger stillschweigend akzeptiert oder sogar offensiv von den Ärzten der East India Company vertreten. Die punkah, ein großer Fächer, der von der Decke hängt, ist ein Beispiel hierfür: Bis spät ins 19. Jahrhundert gehört er - zusammen mit einem entsprechenden Bediensteten - zur Minimalausstattung der anglo-indischen Mittelschicht und verliert in diesem Kontext auch langsam die Konnotation von fast schon feudalem Müßiggang. Im Gegensatz zur punkah ist indische Kleidung bereits zu Beginn des 19. Jahrhunderts deutlich verpönt, obwohl auch hier die Vorteile für den Kreislauf und die Wärmezirkulation unter der Kleidung immer mal wieder hervorgehoben werden. Auch für die Zeit der Anglisierung des anglo-indischen

25 Mundy, Pen and Pencil Sketches, 293.

26 Vgl. Mark Harrison, „,The Tender Frame of Man': Disease, Climate, and Racial Difference in India and the West Indies, 1760-1860“, in: Bulletin of Historical Medicine 70,1 (1996), 68-93.

27 Harrison, „,The Tender Frame of Man“", 73. 
Körpers lässt sich also eine eklektische Aneignung bestimmter indischer Körperpraktiken beobachten.

\section{Praktische Vorkehrungen: hill stations und Hutmodelle}

Nichtsdestoweniger hat Elizabeth Collingham Recht, wenn sie in der Trennung anglo-indischer und indischer Lebenswelten der ersten Hälfte des Jahrhunderts zwei Verschiebungen zusammendenkt, nämlich einerseits die des Verständnisses von kolonialer Herrschaft und andererseits die des Körperbilds. Im dritten Teil möchte ich daher - auch anhand von Julius Jeffreys - einige dieser Maßnahmen genauer betrachten. Denn die Anglisierung des Körpers geht weit über das langsame Verschwinden indischer Praktiken hinaus. Der gegenüber indischen Einflüssen offene Körper wird nicht nur durch ein Ende dieser Hybridität zu schützen versucht, sondern auch durch eine scheinbar unendliche Auswahl von neuer Kleidung, Ideen zur Luftzirkulation, zu Essgewohnheiten und medizinischen Behandlungen. Man versucht also nicht nur, wieder zum europäischen Modell zurückzukehren, sondern entwickelt aktiv darüber hinausgehende, dem Klima angepasste Maßnahmen.

So diskutiert Jeffreys beispielsweise auf mehr als 60 Seiten die Vor- und Nachteile bestimmter Hutmodelle, außerdem Varianten von Kleidung und Ausrüstung. Er präsentiert sogar mehrere eigene Designs, wie beispielsweise für die Kopfbedeckungen der berittenen Truppen und ein den Rücken und das Rückenmark vor zu viel Wärme schützenden ,Vorhang“ („curtain“). Als besonders besorgniserregend gilt ihm die Sonneneinstrahlung, die nahezu jedes Material durchdringe und direkt auf den Körper wirke:

The eight layers of thick cotton cloth in the two flies of an officer's tent in India [...], fail to prevent the solar heat from penetrating. With such power is it projected down by the radiant cloth that it will often drive the inmate under the table for further shelter, unless he protect himself by a wetted cloth on the head. ${ }^{28}$

Kopf und Rückenmark sind, bei Jeffreys und anderen, besonders sensible Körperteile, die nicht nur akut vor zu viel Hitze geschützt werden müssen, sondern auch potentiell langfristige, sich auf das ganze Nervensystem auswirkende Schäden davontragen können. Gerade leichte Kleidung erscheint ihm ungenügend, ja geradezu gefährlich leichtsinnig, weil sie zu viel Strahlung durchlässt. Vor diesem Hintergrund wird verständlich, dass dem indischen Klima im Laufe des 19. Jahrhunderts nicht mehr mit leichter, nach indischen Modellen gefertigter Kleidung begegnet wird, sondern stattdessen mit Flanellunterwäsche, schwarzen Stoffen, dem sogenannten spine pad, einer Art Stoffpolster für das Rücken-

28 Jeffreys, The British Army in India, 24. 
mark, oder dem sola topi, dem Tropenhelm. Hoffnungen auf eine Art Akklimatisierung, eine Anpassung an die Umweltbedingungen durch Imitation und Aneignung indischer Praktiken verschwinden weitgehend im 19. Jahrhundert und werden durch eine dezidierte Abgrenzung des britischen Körpers ersetzt. Auch hier zeigen sich in der vermeintlichen Andersartigkeit des britischen Körpers wieder gleichzeitig eine Vorstellung von prinzipieller Überlegenheit und eine Fragilität, die symptomatisch für die britische Herrschaft in Indien sind.

Interessanterweise führt Jeffreys als Begründung für seine Kleidungsreform nicht nur den verständlichen Wunsch nach geringerer Sterblichkeits- und Krankheitsrate an, sondern verweist wieder auf das Gegenbild britischer Tatkraft:

[The natives, P.M.] differ nothing from mankind [...] plume themselves upon any advantages they possess over others, and especially upon the solitary advantage over us in possessing tropical constitutions. Man, everywhere, is likewise disposed to look upon that climate which suits him best, as the proper one, and declines in the former, as a poor creature' of a feeble constitution. The natives of India look upon us as white bears from the cold unhealthy North, ferociously brave, but of sickly constitutions, disabling us from occupying their country without their aid. ${ }^{29}$

Diesen Eindruck gilt es zu vermeiden, so Jeffreys weiter, wolle man nicht erneut Opfer von an die klimatischen Verhältnisse besser angepassten, hinterlistig auf genau diesen Unterschied, die einzige Schwäche der britischen Armee, spekulierenden Einheimischen werden.

Zunehmender Rückzug und Abgrenzung des Körpers gegenüber indischen Einflüssen prägen also die 1830 er bis 1850 er Jahre. Die vielleicht symbolträchtigste Manifestation dieses Prozesses stellen die hill stations dar, die ab den 1820ern vor allem im Norden, in den Vorbergen des Himalaya errichtet wurden. ${ }^{30}$ Die wohl bekannteste, Shimla, liegt auf einer Höhe von rund $2000 \mathrm{Me}$ tern und wird 1864 sogar die Sommerhauptstadt des indischen Kolonialreichs. Baulich, aber auch durch die Gestaltung der sozialen Ereignisse und der Zusammensetzung des gesellschaftlichen Milieus, versuchen sich die hill stations an einer Replikation des idealisierten englischen Landlebens. Hier geht es um die Kultivierung von, wie Collingham es nennt, „thoroughly English pursuits “31 wie Ausritten, Picknicks, Pflanzenzüchtung usw. Zentral für diese Imitation - und für die Wahl des Ortes - ist aber das ,europäischere' Klima mit den milden und nicht zu schwülen Sommern. ${ }^{32}$ Die Errichtung von Sommerhäusern, Sanatorien

29 Jeffreys, The British Army in India, 14.

30 Indien ist bei weitem nicht die einzige Kolonie, in der diese Erholungsorte entstehen. Auch in anderen Gebieten, vor allem in den britisch-beherrschten Teilen Asiens und Afrikas, werden ähnliche Siedlungen errichtet. Bis heute dienen sie teilweise als Urlaubsorte für die einheimische Bevölkerung.

31 Collingham, Imperial Bodies, 86.

32 Julius Jeffreys preist ebenfalls die klimatisch günstigen, sogar besseren Bedingungen 
und die zum Teil ärztlich angeordneten Erholungsaufenthalte verknüpfen in der Wahrnehmung der anglo-indischen Bevölkerung untrennbar Klima, ,Englishness' und körperliches Wohlbefinden miteinander. Sie sind Collingham zufolge auch Zeichen des Endes britischer Akklimatisierungsbemühungen. Reiseberichte verweisen oft auf den erfrischenden Effekt eines längeren Aufenthalts, der die eigenen Kräfte erneuere und die Tatkraft wiederherstelle. Fanny Parks macht 1830 diese Verknüpfung ganz offensichtlich:

With a westerly wind, and the thermometer at $65^{\circ}$, we Indians find it very cold, the contrast to the hot winds is so great. I have worn a shawl all the morning, and to-night, for the first time this year, we have begun fires; and have had the horse-shoe table placed in front of the fire-place, that we may enjoy the warmth during dinner-time. [...] I feel so English, without lassitude, so strong and well. My husband has just sallied out in his great coat to take a very long walk; and the little terrier is lying under the table, watching a musk rat, which has taken refuge in a hole under the grate. ${ }^{33}$

Obwohl Parks hier von sich selbst und ihrem Mann als „Indians“ spricht, adressiert sie direkt im nächsten Satz den alles überlagernden Unterschied zwischen Indien und England, ein Gefühl des Englischseins, das sich in der Abwesenheit von körperlicher Trägheit ausdrückt. Interessant ist auch, dass Parks nicht nur die ersehnte Rückkehr zu englischer Vitalität verkündet, sondern auch Symbole von viktorianischer Domestizität in das Bild einbringt: der brennende Kamin, der kleine Hund, und der lange Spaziergang ihres Mannes. In dieser Passage kommen physisches Erleben, nationale Identität und klimatische Verhältnisse zusammen. Trägheit, Faulheit und Mattigkeit stehen bei Parks für das Gegenteil englischer Körpererfahrung und sind überdeutlich dem kolonialen ,Anderen zugeordnet. Ihre Wahrnehmung von Vitalität und Aktivität ist also in den Reiseberichten nicht nur diskursives Element von nationaler Identität und Ethnizität, sondern kann als Teil der Herausbildung des kolonialen Körpers verstanden werden. Dieser bezieht sich eben nicht nur positiv auf das Idealbild tätiger Männlichkeit und häuslicher Weiblichkeit, sondern definiert sich insbesondere über die Abgrenzung gegenüber dem indisch-faulen Körper. Das zeigt sich auch bei Fanny Parks: Sie fühle sich englisch - also gerade nicht matt und träge. Erst nach dieser Definition ex negativo kommen die eigentlichen Attribute, nämlich „strong and well“. Vor diesem Hintergrund werden die hill stations in den 1830ern und 1840ern diskursiv zum einzig passenden Ort für den anglisierten Körper aufgeladen; ein Ort, dessen Klima es dem britischen Körper erlaubt, sich so natürlich wie möglich auszudrücken, also ohne der fremdartigen indischen

der Vorberge. Vgl. David Zuck, „Jeffreys, Julius (1800-1877)“, in: Oxford Dictionary of National Biography (Mai 2007), http://www.oxforddnb.com/view/article/14706 (abgerufen am 20.09.2016).

33 Parks, Wanderings of a Pilgrim, 169. Hervorhebung im Original. 
Trägheit unterworfen zu sein. In Shimla und anderen hill stations wird die Exotisierung des britischen Körpers in Indien so weit wie möglich zurückgedrängt.

Was bei Parks als Erleben indischer Trägheit durch die Aneignung und Anglisierung von Orten zu erreichen versucht wird - nämlich die Rückkehr englischer Vitalität - ist für Jeffreys' Soldaten durch Kleidungsvorschriften und eine milde Form von ,workhouse discipline“ vorgesehen. Grundsätzlich bietet der englische Körper $^{34}$ also mehr als eine Möglichkeit, Müßiggang und Nichtstun zu verhandeln. Anhand des müßigen Körpers werden Fragen nach dem sozialen Status und ,rassischer Reinheit' verhandelt, aber auch akutere politisch-militärische Anliegen. Die Anfälligkeit des Soldatenkörpers für Alkoholismus und Faulheit im Gegensatz zum betont verweiblichten, fast schon feudalen Nichtstun des nabob zeigt, dass zwar der Müßiggang an sich als verwerflich betrachtet wird, aber je nach Milieu, Klasse und Gender ganz andere Formen annimmt und unterschiedlich behandelt wird. ${ }^{35}$ In vielen Fällen aber spielt race die ,Trumpfkarte als Begründung für eine völlig unhaltbare Trennung zwischen dem indischen und dem britischen Körper:

It is very possible to show that, what to an Englishman would be a motive for exertion, is a motive to the Indian for sleeping - that, what the former would propose as an interesting amusement for the leisure of the day, is put off by the latter as a burdensome duty to an indefinite 'to-morrow, - that, what the former values as the first of earthly comforts, worthy of soul-wearying efforts for their attainment, are viewed by the latter with a calm indifference, as undeserving of a thought - that while 'to better his condition' is an ever powerful motive to an Englishman [...] wealth is very rarely sought by the native with the ultimate object of improving his condition. ${ }^{36}$

Anders als Jeffreys hier vorgibt, demonstrieren die Auszüge aus Mackintosh, Parks und Mundy, wie der britische und der indische Körper eigentlich Objekte gegenseitiger Formierung sind. Grenzziehungen zwischen ihnen stellen sich in diesen Beispielen als ausgesprochen fragil und porös dar. Der Blick hinter die

34 Hier soll angemerkt werden, dass es natürlich auch - performative wie konzeptionelle - Unterschiede in der Konstruktion englischer Körper gibt. So lässt sich die häuslich-aktive Parks als Angehörige der Mittelschicht nur bedingt mit den Soldaten aus Jeffreys' Abhandlung vergleichen. Gender- und Klassenaspekte sind in diesem Zusammenhang von enormer Bedeutung, aus ihnen folgen die unterschiedlichen Implikationen, die Müßiggang und Trägheit für die jeweiligen Körper haben. Vgl. hierzu Anne McClintock, Imperial Leather. Race, Gender and Sexuality in the Colonial Context, New York 1995, 161-168. Dennoch wird in beiden Fällen der Tatkraft und Vitalität des weißen Körpers eine besondere Rolle bei der Aufrechterhaltung kolonialer Herrschaft zugesprochen, aus der sich die Vergleichsperspektive ergibt.

35 Eine ganz eigene und in dieser Hinsicht noch nicht ausreichend betrachtete Gruppe stellen die sogenannten „Eurasians“ dar, also die Einwohner der Kolonien mit einem weißen und einem indischen Elternteil. Für erste Überlegungen hierzu vgl. Harald Fischer-Tiné, Low and Licentious Europeans. Race, Class and, White Subalternity' in Colonial India, New Delhi 2009, 54-60, 72-73.

36 Jeffreys, The British Army in India, 277-278. 
jeweiligen stereotypen Figuren des , lazy native, des degenerierten Soldaten oder des nabob zeigt, wie entscheidend nicht nur Körperbilder, sondern auch Körperwahrnehmungen für die fortschreitende Homogenisierung einer vitalen, kraftvollen und tätigen kolonialen ,Englishness' im 19. Jahrhundert sind. Der hier als spezifisch englisch konstruierte Körper steht gleichermaßen in einer Linie von unterschiedlichen, aber dezidiert als modern herausgestellten Körperbildern, für die sich tätige Männlichkeit als Ideal herausbildet. Das ,Gefühl', englisch zu sein - und auch nur englisch oder indisch sein zu können - wird tief im Körper verankert und ist besonders gut durch diesen auszudrücken. Ein Blick auf den müßigen Körper ist darüber hinaus ein Beispiel für die Vielgestaltigkeit ,rassischer Unterscheidungen: Diese kommen schon auf der Ebene des körperlichen Erlebens zum Tragen. 



\title{
Ent-Setzen, -Halten, -Stellen, -Rücken
}

\author{
Drei Bemerkungen zur Zeitlichkeitsstruktur \\ von Faulheit und Muße
}

\author{
Nassima Sahraoui
}

Über die Begriffe Faulheit und Müßiggang oder dessen große Schwester, die Muße, gibt es eine Vielzahl an Literatur. Manchmal handelt es sich hierbei um philosophische Überlegungen, wie sie seit der Antike immer wieder angestellt werden. Oder es handelt sich um wirkungsvolle literarische und poetische Versuche, Faulheit und Muße in ihren unterschiedlichsten Ausformungen textuell zu erfassen und darzustellen. Mitunter sind diese Versuche mit dem Ernst der Suche nach einem gelungenen Leben untermalt, bei einigen handelt es sich um Satiren, Polemiken oder Komödien, bei anderen wiederum um Dramen oder Tragödien über das Scheitern des Lebens und das Scheitern im Leben; und in manchen Fällen schließlich gilt vor allem die Faulheit gar als moderndes Teufelswerk, das gänzlich aus dem Leben verbannt werden sollte. Im Rahmen des vorliegenden Beitrags können selbstverständlich nicht sämtliche Aspekte dieser schillernden Begriffe definiert und interpretiert werden. Stattdessen möchte ich mich in folgenden Ausführungen auf ein grundlegendes Merkmal konzentrieren, das Faulheit und Muße offenbar gemeinsam ist, wenn auch in unterschiedlichen Ausformungen: ${ }^{1}$ Dieses grundlegende Merkmal besteht darin, dass

${ }^{1}$ Der Müßiggang nimmt eine gewisse Sonderrolle ein, die hier nicht weiter untersucht wird. Stattdessen wird er unter dem Begriff der Muße gefasst, obwohl dies natürlich eine Verkürzung darstellt. Über den Müßiggänger und den Müßiggang ist viel geschrieben worden. Exemplarisch genannt werden soll an dieser Stelle Friedrich Schlegels „Idylle über den Müßiggang" aus seinem Roman Lucinde. Bekenntnisse eines Ungeschickten. Ein Roman (Frankfurt a. M. 2011, 44-51) oder Robert Walsers Der Spaziergang (Frankfurt a. M. 2001) oder auch Walter Benjamins erhellende Analyse des Flaneurs in seinem Baudelaire-Buch. Siehe Walter Benjamin, „Charles Baudelaire. Ein Lyriker im Zeitalter des Hochkapitalismus", in: Gesammelte Schriften (= GS), Bd.I.2, hg. v. Rolf Tiedemann/Hermann Schweppenhäuser, Frankfurt a.M. 2000, 509-653, 537-569. Zum Flaneur siehe auch: Nassima Sahraoui, „The Flâneur and Socio-Economic Critique“, in: Madeleine Kasten/Rico Sneller u. a. (Hg.), Benjamin's Figures: Dialogues on the Vocation of the Humanities, Nordhausen 2018, 41-53. Dass Muße und Müßiggang nicht einfach gleichzusetzen seien, beschäftigte interessanterweise auch Benjamin: Der Müßiggänger, so Benjamin in einem Fragment seiner Passagenarbeit, unterscheide sich alleine schon dadurch vom Müßigen, dass er versuche „jeder Arbeit aus dem Wege zu gehen." (Benjamin, Passagen-Werk, GS V.2, hg. v. 
beide Handlungsformen sind, welche Auswirkungen auf die Gestaltung der individuellen Lebensführung haben, wodurch wiederum eine andere Zeitstruktur generiert wird als die geltende ökonomische. Die hier zu diskutierende These lautet daher wie folgt: Durch die Ausübung von ,aktiver' Faulheit und Muße ist es möglich, für einen Moment den geltenden ökonomischen Zeitvorstellungen und -strukturen zu widerstehen und diese vielleicht sogar zu entsetzen oder zumindest neu zu justieren. Dieser Widerstand liegt im Fall unserer Moderne im Wesentlichen darin, sich der schnelllebigen Geschäftigkeit und dem ökonomischen Treiben der Umgebung zu entziehen, um so gewissermaßen einen, anderen Takt' anzuschlagen.

Die Ausgangsthese wäre also, dass es sich bei Faulheit und Muße um Momente der Enthaltung und des Zurückweisens von der uns umgebenden ökonomischen - und damit auch lebensweltlichen - Taktung handelt. Mit dieser Ausgangsthese ist bereits die in diesen Momenten immanente Widerständigkeit angezeigt. Wäre es nun möglich, so können wir fragen, dass es Kraft dieser immanenten Widerständigkeit vielleicht gelingt, sich jenem stetigen Sog, der entlang der ökonomischen Zeitachse entsteht und der die subjektiven Kräfte absorbiert, zu enthalten und diese so zu entsetzen, zu entstellen und zu entrücken, wie schon der Titel dieses Beitrags andeutet? Wenn dem so ist, wie genau müssten die Begriffe Muße und Faulheit im Hinblick auf die ökonomische Zeit verstanden werden? Und inwiefern weisen die für den Moment der Widerständigkeit verwendeten Begriffe ,Entsetzen', ,Enthalten', Entstellen' und ,Entrücken' gleichzeitig auf eine räumliche Komponente und damit auf die potentielle Veränderbarkeit der Raumstrukturen qua Rückzug aus der ökonomischen Zeit hin?

Im Folgenden werden wir uns diesen komplexen Fragen und den Deutungen von Faulheit und Muße widmen, um zu demonstrieren, wie genau sie die Zeit - und eben den Raum - zu entsetzen vermögen. Die Zeit und den Raum zu entsetzen meint hierbei, sie nicht etwa im Sinne einer Hegel'schen Dialektik einfach ,aufzuheben', sondern deren lineare Verläufe für einen Augenblick zu unterbrechen. ${ }^{2}$ Bevor wir uns jedoch diesen Fragen und Deutungen zuwenden, ist darauf hinzuweisen, dass beide Begriffe zunächst einmal einer Differenzierung

Rolf Tiedemann/Hermann Schweppenhäuser, Frankfurt a. M. 1982, 964 f. („m 3, 1“). Zum Verhältnis von Muße und Müßiggang bei Benjamin siehe den Aufsatz von Robert Krause in vorliegendem Band. Einige Teile des vorliegenden Beitrages sind in dem von Konrad Paul Liesmann erschienenen Sammelband Mut zur Faulheit. Die Arbeit und ihr Schicksal (Wien 2018, 69-92) bereits erschienen.

2 Der Begriff des ,Entsetzens, v. a. in seiner Unterscheidung zum Begriff des ,Entstellens', lehnt sich an Walter Benjamins Verwendung derselben an und meint eine Unterbzw. Durchbrechung linearer oder auch ewig zyklischer Verläufe. Vgl. u. a. Walter Benjamin, „Zur Kritik der Gewalt“, GS II.1, hg. v. Rolf Tiedemann/Hermann Schweppenhäuser, Frankfurt a.M. 2002, 179-203, 202. Zum Unterschied zwischen ,Entsetzen' und ,Entstellen' bei Benjamin vgl. auch: Sami Khatib, „Teleologie ohne Endweck“. Walter Benjamins Ent-stellung des Messianischen, Marburg 2013, vor allem Kap. I.1. 
bedürfen, denn schließlich sind sie schon im alltäglichen Sprachgebrauch - vom philosophischen ganz zu schweigen - sehr unterschiedlich konnotiert: In der Regel wird die Faulheit sowohl als passive als auch als aktive Tätigkeit, nämlich als Regeneration durch Nichtvollzug von Arbeit, verstanden. Demgegenüber ist die Muße fast durchweg positiv konnotiert, denn bei der Muße handelt es sich - anders vielleicht als bei der Faulheit - um ein meditatives oder kontemplatives Moment der Ausklammerung äußerlicher Einflüsse, die im besten Fall zur mentalen und geistigen Erhebung führt.

Diesem Spannungsfeld möchte ich anhand von drei Bemerkungen nachspüren, in denen ich mich auf einige prägnante Stationen der europäischen und russischen Ideen- und Literaturgeschichte - wie der Antike, der Aufklärung und Industriellen Revolution und den damit verbundenen Kämpfen um die Verkürzung der Arbeitszeit einerseits und den Transformationen feudaler Gesellschaftsstrukturen - wie im 18. und 19. geschehen - andererseits, konzentriere. Erstens sollen hierbei die Unterschiede zwischen Muße und Faulheit sowie zwischen Muße als aktiver oder passiver Tätigkeit exemplarisch umrissen werden, wie sie sich durch die Lektüre einiger Passagen aus Iwan Gontscharows Oblomow und Immanuel Kants Anthrophologischen Schriften aufweisen lassen. Von dort aus werde ich zweitens eine besonders prägnante Passage aus den Theorien über den Mehrwert von Karl Marx philosophisch und philologisch deuten und zu dekonstruieren versuchen. Dabei werden die Begriffe Faulheit und Muße insofern synonym verwendet, als durch beide - zumindest für einen Moment - die ökonomische Zeit aus den Fugen gerät. Dieses Verrücken - oder besser: Entrücken - der gängigen Zeitlichkeitsstruktur wiederum ist Gegenstand der dritten Bemerkung. Im Rekurs auf die griechische Antike soll dort gezeigt werden, dass die Momente der Faulheit und der Muße ein kritisches Potential enthalten, durch das es möglich sein könnte, sich der geltenden ökonomischen Ordnung zu widersetzen, um so in letzter Instanz den Raum zur freien Entfaltung unserer Vermögen und Fähigkeiten zu öffnen.

\section{Bemerkung: Faulheit und Muße}

Ihr meint doch nicht, daß ich mit Musse und Müssiggehen auf euch ziele, ihr Faulthiere? Friedrich Nietzsche, Menschliches, Allzumenschliches

Seinen wohl exemplarischen Einzug in die Welt der Prosa erhielt der Versuch, Faulheit als passive Trägheit darzustellen, durch Iwan Gontscharows 1859 publizierten sozialkritischen Roman Oblomow. ${ }^{3}$ Meisterhaft wird hier der Protagonist Ilja Iljitsch Oblomow beschrieben, der als ein dem Landadel angehörender

${ }^{3}$ Iwan Gontscharow, Oblomow, übers. v. Josef Hahn, München 2011. Im Folgenden zitiere ich aus ebengenannter Ausgabe. 
Gutsbesitzer ein Leben im Überfluss führt und die Möglichkeit hat, nichts tun $z u$ müssen. Im Verlauf des Romans wird dem Leser sukzessive vor Augen geführt, wie jene passive Trägheit des Oblomow den Protagonisten peu à peu an den Rand seines Untergangs bringt, bis ihn die von ihm zelebrierte Kette von Handlungsunterlassungen letztlich in den finanziellen Ruin und körperlichen Tod führt: Oblomow verliert sein gesamtes Hab und Gut und stirbt schlussendlich an einem durch seine Trägheit ausgelösten Schlaganfall.

Der Roman besitzt einerseits eine moralisierende Pointe: dass es nämlich für das Gelingen eines guten Lebens nötig ist, aktiv in die Prozesse seiner Umwelt einzugreifen. Zugleich hat Gontscharow mit seiner überbordenden Darstellung dieses passiven Menschen, der sich für nichts in seiner Umwelt wirklich begeistern kann, offensichtlich auch eine sozialpolitische Kritik am untergehenden russischen Gutsherrentum des 19. Jahrhunderts im Sinn. Oblomow fällt damit unter die in der russischen Literatur jener Zeit populäre Figur des „überflüssigen Menschen“ - meist ein Adeliger, der sich nicht aktiv in das Gemeinwesen einbringt - und so zwischen dem Protest gegen die repressive Politik unter Zar Nikolaus I. und gegen die sich nach dessen Tod 1855 radikal modernisierende Gesellschaftsordnung mäandert. ${ }^{4}$ Zum Ausdruck bringt dies Oblomow, indem er im Gespräch mit wechselnden Personen wiederholt gegen den Verfall der Menschlichkeit philosophiert und provozierend hinterfragt, wo diese denn nun eigentlich bleibe. „Ihr wollt allein mit dem Kopf schreiben!“, ruft er aus, um gleich im Anschluss hinzuzufügen: „Glaubt ihr denn nicht, daß zum Denken auch Herz gehört?" ${ }^{5}$, um dann schließlich im Gespräch mit dem Penkin - einem Schriftsteller, dessen Name wohl nicht zufällig stark an Puschkin erinnert, der wiederum bekanntlich mit seinem Eugen Onegin ${ }^{6}$ den Prototyp des gelangweilten Dandys zeichnete - zu fordern: „Den Menschen, den Menschen gebt mir!“7

4 Vgl. Iwan Turgénew, „Tagebuch eines überflüssigen Menschen“, in: FünfErzählungen, übers. v. Herbert Wotte u. Dieter Pommerenke, Berlin 1983. Kein Adeliger, sondern ein Beamter ist die Hauptfigur in Dostojewskis exemplarischem Kurzroman Aufzeichnungen aus dem Kellerloch (übers. v. Swetlana Geier, Frankfurt a. M. 2011).

${ }^{5}$ Gontscharow, Oblomow, 36.

${ }^{6}$ Alexander Puschkin, Eugen Onegin. Ein Versroman, übers. v. Sabine Baumann, Frankfurt a.M. 2004.

7 Gontscharow, Oblomow, 37. Bei diesem Ausspruch Oblomows hört man bereits das Echo Nietzsches antworten: In Menschliches, Allzumenschliches heißt es „Zu Gunsten der Müssigen“: „Die Gelehrten schämen sich des otium. Es ist aber ein edel Ding um Musse und Müssiggehen. - Wenn Müssiggang wirklich der Anfang aller Laster ist, so befindet er sich also wenigstens in der nächsten Nähe aller Tugenden; der müssige Mensch ist immer noch ein besserer Mensch als der thätige. - Ihr meint doch nicht, dass ich mit Musse und Müssiggehen auf euch ziele, ihr Faulthiere?"Vgl. Friedrich Nietzsche, Menschliches, Allzumenschliches. Ein Buch für freie Geister, Sämtliche Werke. Kritische Studienausgabe (=KSA), Bd. 2, hg. v. Giorgio Colli/Mazzino Montinari, München 1999, 232. Ausführlicher mit Nietzsche beschäftigt sich Martin Jörg Schäfer in seinem Aufsatz im vorliegenden Band. 
Nebst einer Kritik an der Modernisierung sämtlicher Lebensbereiche, die in Oblomow wohl steckt, gelingt es Gontscharow in diesem Roman eine literarische Figur zu zeichnen, die in ihrem Rückzug in die Passivität des Faulseins zu einer bemitleidenswerten körperlichen und geistigen Lethargie verkümmert. Dabei meint jener Rückzug ins Nichtstun hier - trotz aller Gesten des Protests - explizit nicht jene spezifische Widerständigkeit, auf die in der Einleitung hingewiesen wurde, sondern eher eine Art Phlegma. Dieses Phlegma zeichnet sich im Wesentlichen dadurch aus, dass Oblomows Nichtstun in letzter Instanz um des Nichtstuns selbst willen erfolgt. Es handelt sich bei der Faulheit als passiver Trägheit folglich um eine tautologische Selbstreferentialität, von der aus keinerlei Relation zur Außenwelt hergestellt wird - im Gegenteil: Diese rein auf sich selbst gerichtete völlige Zurücknahme körperlicher und auch geistiger Tätigkeiten unterminiert jede Möglichkeit, aktiv in den ihn umgebenden Raum einzugreifen. Oblomow wird dadurch handlungsunfähig, wobei ,un-fähig' hier im wörtlichen und philosophischen Sinne als Negation des Vollzugs subjektiver Fähigkeiten oder als Vermögen verstanden werden muss.

Nicht nur entzieht sich Oblomow damit dem ihn umgebenden sozialen und räumlichen Gefüge, sondern durch diese passive Form der Faulheit wird ferner ersichtlich, dass hier per se an der Möglichkeit gerüttelt wird, die Faulheit selbst auch im positiven Sinn zu lesen. Dieser Eindruck wird dadurch verstärkt, dass Gontscharow dem trägen Protagonisten seinen charismatischen und energiegeladenen Freund Stolz beiseitestellt, der als verkörperte Arbeitstüchtigkeit stetig, jedoch erfolglos, versucht, den nostalgisch hinterherhinkenden Verweigerer Oblomow aus seiner Lethargie zu reißen. ${ }^{8}$

An Oblomow zeigt sich daher, wie sehr seine gesamte Haltung letztlich der Sinnlosigkeit einer sich selbst perpetuierenden Trägheit überantwortet wird, so dass er im Verlauf des Romans stetig verfällt, nach und nach alles verliert und schließlich stirbt. ${ }^{9}$ Faulheit in ihrer so konnotierten Form meint demzufolge einen Zustand der Trägheit, wie wir an Oblomow sehen: einen Zustand der Verdammnis, des Schlechten, der Amoralität oder gar des Verteufelten, einen Zustand der Fäulnis also, bei dem man förmlich mit der Nasenspitze auf die etymo-

8 Vgl. exemplarisch Gontscharow, Oblomow, 79-88.

9 Fernando Pessoa erweitert gewissermaßen in seinem Buch der Unruhe das Bild von Oblomow um eine wichtige Komponente. Denn Pessoa zeigt, wie die Trägheit als Existenzform des Geistes erst dessen Kräfte - d. h. hier die Vorstellungskraft - zu aktivieren vermag: „Untätigkeit tröstet über alles hinweg. Nicht handeln gibt uns alles. Sich etwas vorstellen ist alles, solange es nicht in Handeln ausartet. Niemand kann König der Welt sein, es sei denn im Traum. Und ein jeder von uns will, sofern er sich wirklich kennt, König der Welt sein." (Fernando Pessoa, Das Buch der Unruhe des Hilfsbuchhalters Bernardo Soares, übers. v. Georg Rudolf Lind, Frankfurt a. M. 2011, 184) Zur Unruhe siehe das kürzlich erschienene Wörterbuch der Unruhe von Ralf Konersmann (Frankfurt a. M. 2017). 
logische Ähnlichkeit zwischen Faulheit, Fäulnis und schließlich Faulen gestoßen wird. ${ }^{10}$

Etwas anders als bei der passiven Faulheit à la Oblomow sieht es bei der aktiven Form der Faulheit aus. Deren eigentliches Merkmal besteht darin, notwendig in Beziehung zur Ausübung einer Tätigkeit oder Arbeit zu stehen. Faulheit ist hier nicht mehr unmittelbar an die Selbstreferentialität einer autodestruktiven Trägheit gebunden, sondern hat eine im Verhältnis zum Vollzug einer Tätigkeit oder Arbeit stehende regenerative und erholsame Funktion.

Dass die Faulheit in einem intrinsischen Verhältnis zur Arbeit steht, wird innerhalb der Geschichte des Faulheitsbegriffs erst während der industriellen Revolution zum eigentlichen Thema: und zwar im Kampf um die Verkürzung der Arbeitszeit zugunsten der frei zur Verfügung stehenden Zeit. Historisch setzt diese Diskussion demnach in dem Augenblick ein, in dem gleichzeitig die sogenannte ,protestantische Ethik ${ }^{\text {c }}$ um es mit Max Weber zu formulieren - vollständig zum geistigen Ethos des Kapitalismus wird. ${ }^{11}$

Da nun mit der protestantischen Ethik und der industriellen Revolution schon die Schwelle zum 18. beziehungsweise 19. Jahrhundert übertreten wurde, wenden wir uns sogleich einer weiteren Definition von Faulheit zu, die beide Aspekte - also Faulheit als Trägheit und Faulheit als Erholung - der heutigen Diskussion vorwegnimmt. Noch vor der Blütezeit der Industrialisierung verkündete Immanuel Kant in einer Textstelle seiner anthropologischen Schriften von 1796/97:

Der größte Sinngenuß, der gar keine Beimischung von Ekel bei sich führt, ist, im gesunden Zustande, Ruhe nach der Arbeit. - Der Hang zur Ruhe ohne vorhergehende Arbeit in jenem Zustande ist Faulheit. - Doch ist eine etwas lange Weigerung, wiederum an seine Geschäfte zu gehen, und das süße far niente zur Kräftesammlung, darum noch nicht Faulheit; weil man (auch im Spiel) angenehm und doch zugleich nützlich beschäftigt sein kann, und auch der Wechsel der Arbeiten, ihrer spezifischen Beschaffenheit nach,

10 Wie sehr die Faulheit mit einer angewöhnten Trägheit durch Nicht-Vollzug von Arbeit zusammenhängt und diese wiederum mit dem tatsächlichen Verwesen von Körper und Geist, beschreibt auch Hegel sehr präzise in seiner Rechtsphilosophie ( $\$ 21$, Zusatz oder $\$ 197)$. Zum Zusammenhang zwischen Gewohnheit, Faulheit und Armut bei Hegel siehe auch Frank Rudas Studie zu Hegels Pöbel. Ruda zeigt hier, wie sich aus Hegels Rechtsphilosophie eine ,Theorie der Faulheit' ableiten lässt (Frank Ruda, Hegels Pöbel. Eine Untersuchung der „Grundlinien der Philosophie des Rechts“, Konstanz 2011, bes. 125 ff.)

11 Vgl. Max Weber, „Die protestantische Ethik und der Geist des Kapitalismus“, in: Weber, Gesammelte Aufsätze zur Religionssoziologie, 3 Bde., Tübingen 1976 [1920]. Die sich im Laufe der Jahrzehnte hieraus entwickelnden Diskussionen, bis hin zur sogenannten ,Freizeit- und Spaßgesellschaft', sind aus soziologischer und philosophischer Perspektive eine äußerst paradoxe Entwicklung aus der Moderne heraus, auf die an dieser Stelle nur hingewiesen werden kann. Die Fülle an wichtiger Literatur ist mittlerweile ausufernd. Siehe exemplarisch: Theodor W. Adorno/Max Horkheimer, „Dialektik der Aufklärung“, in: Max Horkheimer, Dialektik der Aufklärung und Schriften 1940-1950, Gesammelte Schriften, Bd. 5, Frankfurt 1987. 
zugleich so vielfältige Erholung ist: da hingegen an eine schwere unvollendet gelassene Arbeit wieder zu gehen ziemliche Entschlossenheit erfordert.

Unter den drei Lastern: Faulheit, Feigheit und Falschheit, scheint das erstere das verächtlichste zu sein. Allein in dieser Beurteilung kann man dem Menschen oft sehr unrecht tun. Denn die Natur hat auch den Abscheu für anhaltende Arbeit manchem Subjekt weislich in seinen für ihn sowohl als andere heilsamen Instinkt gelegt; weil dieses etwa keinen langen oder oft wiederholten Kräfteaufwand ohne Erschöpfung vertrug, sondern gewissen Pausen der Erholung bedurfte. ${ }^{12}$

Diese Textstelle illustriert eine interessante Ambivalenz: Denn wenn einerseits die Faulheit als Laster verdammt wird, können wir bei Kant gleichzeitig eine Art legitimierte Faulheit erkennen, die, positiv gewendet, der Erholung von und vor der Arbeit dient. Faulheit ist also hier einerseits passiv gedacht, nämlich im Sinne von Trägheit, wie wir sie eben schon bei Oblomow kennengelernt haben. Allerdings tritt nun andererseits ein weiterer Faktor hinzu, nämlich der einer durch vorhergegangene Arbeitsleistung legitimierten aktiven Faulheit. Faulheit wird an dieser Stelle somit nicht bloß in ihrer rein negativen Form - d. i. als passive Trägheit - gedacht, sondern auch als aktives Mittel zur Selbstoptimierung innerhalb der ökonomischen Dynamiken, oder wie Kant schreibt: als „süße[s] far niente zur Kräftesammlung “ ${ }^{13}$

Nun scheint es also einen intrinsischen Zusammenhang zwischen Faulheit und aktiver Tätigkeit oder Arbeit zu geben, bei dem Faulheit zur Rückzugsmöglichkeit vor der Routine und Geschäftigkeit des schnelllebigen marktwirtschaftlichen Rhythmus wird. Die Faulheit hat also, wie soeben dargelegt, eine doppelte Bedeutung und ist damit nicht mehr nur rein negativ konnotiert, sondern erhält ebenso die positive Funktion der Regeneration von und vor der Arbeit.

Die Idee eines positiven Begriffs derjenigen Momente, in denen wir unsere Kräfte sammeln und bündeln, ist selbstverständlich nicht neu; bereits seit der Antike fällt sie allerdings eher unter den Begriff der Muße. Die Bedeutungen von Muße oder Müßiggang unterscheiden sich jedoch in einem entscheidenden Aspekt von der Faulheit: zwar gehen beide mit einem Akt der Enthaltung und Ausklammerung - einer Art epochē - von äußeren Umständen und Dynamiken einher. Doch bei der Muße tritt im Gegensatz zur Faulheit ein weiteres Moment hinzu: das der Kontemplation. Mit Kontemplation ist eine konzentrierte innere Anschauung gemeint, die den Geist zu höherem und reinerem Denken ermächtigen soll. Nicht umsonst war schließlich der sogenannte bios theōrētikos oder die vita contemplativa, wie es in der lateinischen Übersetzung heißt, bei den alten

12 Immanuel Kant, Schriften zur Anthropologie, Geschichtsphilosophie, Politik und Pädagogik. Bd.2, Werke (=W), Bd.XII, hg. v. Wilhelm Weischedel, Frankfurt a. M. 1996, 613614.

13 Kant, Schriften zur Anthropologie, W XII, 614. 
Griechen - und insbesondere bei Aristoteles - eine Lebensform, die allen anderen Lebensformen hierarchisch übergeordnet sein sollte. ${ }^{14}$

Es besteht also ein Verhältnis zwischen Arbeit und Muße oder Faulheit als passives und aktives Moment der Zurücknahme oder der aktiven Ausklammerung. Damit erhalten wir bereits einen Vorboten von dem, was sich mit Beginn der Industrialisierung einerseits so schicksalhaft mit den marktwirtschaftlichen Rhythmen verquickte, und das andererseits wohl auch das Potential birgt, sich ebendiesen Rhythmen zu widersetzen und so deren schnelllebige Taktung zu entstellen.

Vom bisher Dargestellten aus kommen wir nun zur zweiten Bemerkung, welche um die Frage kreist, wie sich der Begriff der Zeit hier einfügt und wie aus den Momenten der aktiven Faulheit und Muße ein besonderer Mehrwert - oder zumindest ein anderer Mehrwert als der durch die Marktwirtschaft erzeugte entspringt.

\section{Bemerkung: Arbeit und die Verfügbarkeit von Zeit}

In einer kleinen Passage seiner Theorien über den Mehrwert ${ }^{15}$ - ein Konvolut von Manuskripten, bei denen es sich im Wesentlichen um Studien zu dem nie als solchem publizierten vierten Teil des Kapitals handelt - zitiert Karl Marx aus einem beeindruckenden Pamphlet, das im Jahre 1821 anonym in London kursierte. Die Urheberschaft jenes Pamphlets wurde einige Jahrzehnte später einem gewissen Charles Wentworth Dilke (1789-1864) zugesprochen. Dilke war ein britischer Literaturkritiker und Herausgeber der Literaturzeitschrift Athenaeum - nicht zu verwechseln mit der von den Schlegels einige Jahre früher unter dem gleichen Titel herausgegebenen Zeitschrift. ${ }^{16}$

14 Hierbei ist zuerst an Aristoteles' Ausführungen zum bios theōrētikos in der Nikomachischen Ethik zu denken, der von den „drei vorherrschenden Lebensformen“- bios apolaustikos, bios politikos und bios theōrētikos - die beste sei, und damit unmittelbar mit dem Gelingen des guten Lebens zusammenhänge. Aristoteles, Nikomachische Ethik, übers. v. Ursula Wolf, Reinbek bei Hamburg 2006, 1095 b 15-20 u. X 7-9.

15 Karl Marx, Theorien über den Mehrwert, Marx-Engels Werke (=MEW), Bd. 26.3, hg. v. Institut für Marxismus-Leninismus beim ZK der SED, Berlin 1968. Es handelt sich hierbei um einen Auszug aus dem 21. Kapitel aus Marx' Theorien über den Mehrwert, einem Kapitel, in dem es insbesondere um David Ricardos (1772-1823) Nationalökonomie geht und das den Titel trägt: „Gegensatz gegen die Ökonomien (auf der Basis der Ricardoschen Theorien)“.

16 Dilke gab die wöchentlich erscheinende Zeitschrift im Zeitraum von 1830-1846 heraus. Sie gilt als eine der bedeutenden literaturhistorischen Dokumente viktorianischer Zeit. Vgl. Leslie A. Marchand, The Athenaeum. A Mirror of Victorian Culture, Chapel Hill 1941. Ausführlicher mit dem Viktorianismus bavarischer Natur und dessen Transformationen bis hin zu Teju Cole's Erzählung über den durch New York flanierenden Protagonisten Julius in Open City (New York 2011) beschäftigt sich Heidi Liedke in ihrem Beitrag zu 
Interessant an diesem Pamphlet ist der Aspekt der Zeit oder besser der Verfügbarkeit von Zeit, der hier zu einem Dreh- und Angelpunkt der Begriffe ,Faulheit' und ,Muße' wird und an dem sich einige der Paradoxien des modernen Kapitalismus entschlüsseln lassen. ${ }^{17}$ Wenden wir uns also dem von Marx zitierten Pamphlet von Dilke zu, um dessen philosophische und philologische Implikationen genauer zu beleuchten.

Zunächst einmal merkt Marx an, dass jenes Pamphlet von Dilke einen „wesentlichen Fortschritt“ gegenüber den Theorien von Ricardo und Adam Smith enthält. ${ }^{18}$ Denn obgleich auch bei Ricardo die verfügbare Zeit als Quelle wahren Reichtums ausgemacht wird, ist diese hier auf die Eigentümer der Produktionsmittel beschränkt. Dagegen setzt Dilke den durch die kapitalistische Produktionsweise erzeugten Mehrwert in unmittelbare Beziehung zu der durch die Arbeiter aufgewendeten Mehrarbeit, für die diese keinen Lohn erhalten. Marx zitiert aus Dilkes Pamphlet: „Was auch immer dem Kapitalisten zukommen möge, er kann immer nur die Mehrarbeit des Arbeiters aneignen, denn der Arbeiter muß leben. (1.c. p. 23)“. ${ }^{19}$ Und ein paar Zeilen später fasst er weiter zusammen: „Es wird zugegeben, daß der den Kapitalisten gezahlte Zins, sei es in der Gestalt von Rente, Geldzins oder Geschäftsprofit, bezahlt wird aus der Arbeit anderer. (p. 23)“.20

Um diesen Zirkel ,Arbeit - Mehrarbeit - Mehrwert`zu unterbrechen, sei eine Verringerung oder gar Abschaffung der Mehrarbeit durch die Arbeiter notwendig, denn erst dadurch würde ,wahrer' Reichtum entstehen. ,Wahrer ' Reichtum ist jedoch nichts, was in materiellen Gütern aufgewogen werden kann, sondern bezieht sich unmittelbar auf die Möglichkeit, diejenige Menge der Zeit zu akkumulieren, in der zwar nicht gearbeitet werden muss, das Verhältnis zur Arbeit jedoch grundsätzlich bestehen bleibt. Dieses Im-Verhältnis-Stehen zur Arbeit ist nun weder zirkulär im Sinne einer im Durchgang durch die arbeitsfreie Zeit auf die Arbeit zurückfallenden Bewegung zu verstehen - dies entspräche im Kern derselben Tautologie, wie die der passiven Trägheit. Auch kann die für das Verständnis von Faulheit und Muße grundlegende Relation zur Arbeit oder aktiven Tätigkeit nicht in einen Dualismus von Faulheit versus Arbeit aufgelöst werden.

diesem Band. Ein ebenso bedeutendes literaturhistorisches Dokument, allerdings für die Jenaer Frühromantik, ist die von den Schlegels zwischen 1798 und 1800 herausgegebene Zeitschrift Athenaeum. Vgl. den Nachdruck: August Wilhelm Schlegel/Friedrich Schlegel (Hg.), Athenaeum. Eine Zeitschrift, Darmstadt 1983.

${ }_{17}$ Zum Verhältnis von Arbeit und Muße vgl. auch den Artikel von Tobias Keiling im vorliegenden Band.

18 Marx, Theorien über den Mehrwert, MEW 26.3, 234. Auch schon Ricardo habe die Verfügbarkeit von Zeit als wahre Quelle des Reichtums ausgemacht, allerdings als exklusives Gut für den Kapitalisten, so Marx. Vgl. Marx, Theorien über den Mehrwert, MEW 26.3, 253 .

19 Marx, Theorien über den Mehrwert, MEW 26.3, 235.

20 Marx, Theorien über den Mehrwert, MEW 26.3, 235. 
Vielmehr wäre der Charakter der Relationalität selbst in den Mittelpunkt zu rücken; denn nur auf diese Weise ist es möglich, die Arbeitszeit mit der verfügbaren Zeit und mit der objektiven Zeit des Marktes so in Verbindung zu setzen, dass ersichtlich wird, worin der Mehrwert der verfügbaren Zeit eigentlich besteht.

In Dilkes Ausführungen kulminiert diese intrinsische Verbindung zwischen Zeit, verfügbarer Zeit und Mehrwert in der von Marx wiederum vielfach zitierten programmatischen Formel: „Reichtum ist verfügbare Zeit und sonst nichts - wealth is disposable time and nothing more. "21 Sehen wir uns also nun die kleine Textpassage genauer an, in der dieser programmatische Satz vorkommt. Zunächst zitiert Marx aus Dilkes Text:

Eine Nation ist dann wirklich reich, wenn 6 statt 12 Stunden gearbeitet wird. Wealth is disposable time, and nothing more.

„Es kann dies nur heißen“, so folgert Marx daraufhin:

Wenn alle arbeiten müssen, der Gegensatz von Überarbeiteten und Müßiggängern wegfällt - und dies wäre jedenfalls die Konsequenz davon, daß das Kapital aufhörte zu existieren, daß Produkt nicht mehr Titel auf fremde surplus labour gäbe - und außerdem die Entwicklung der Produktivkräfte, wie das Kapital sie hervorgebracht hat, in Betracht gezogen wird, so wird die Gesellschaft die nötige abundance [den nötigen Überfluß] in 6 Stunden produzieren, mehr als jetzt in 12, und zugleich werden alle 6 Stunden, disposable time', den wahren Reichtum haben; [...]

Oder es kann auch heißen: Die Arbeiter arbeiten jetzt 6 Stunden Zeit hinaus über das, was sie zu ihrer eignen Produktion (jetzt) brauchen. [...] Hört das Kapital auf, so arbeiten sie nur mehr 6 Stunden, und die Müßiggänger müssen ebensoviel arbeiten. Der materielle Reichtum für alle würde dadurch auf das Niveau der Arbeiter herabgedrückt. Aber alle hätten disposable time, freie Zeit zu ihrer Entwicklung. [... $]^{22}$

Demnach gelangt eine Nation erst dann zu Reichtum - zu ,wahrem' Reichtum -, wenn sie die Kapitalakkumulation, welche auf der Mehrarbeit der Arbeiter besteht, zu unterbrechen weiß. So zitiert Marx abermals aus Dilkes Pamphlet: „Wahrhaft reich ist eine Nation erst, wenn kein Zins [d.h. kein Profit] für Kapital gezahlt wird: wenn statt 12 Stunden nur 6 gearbeitet wird. Reichtum ist verfügbare Zeit, und sonst nichts. (p. 6)“23

Die „verfügbare Zeit“ scheint also das zu sein, worum es sich hierbei dreht, denn erst derjenige, der über seine Zeit zu verfügen vermag und diese nicht allein den Prozessen der Produktion unterwerfen muss, ist dazu in der Lage, sich frei zu entfalten. Damit dies geschieht, damit also der „Gegensatz von Überarbeiteten und Müßiggängern wegfällt" ${ }^{24}$, solle die Kapitalakkumulation gestoppt werden.

${ }^{21}$ Marx, Theorien über den Mehrwert, MEW 26.3, 252.

22 Marx, Theorien über den Mehrwert, MEW 26.3, 252.

23 Marx, Theorien über den Mehrwert, MEW 26.3, 251.

24 Marx, Theorien über den Mehrwert, MEW 26.3, 252. 
Die romantisierende Vorstellung Dilkes, wie es zu diesem Anhalten der kapitalistischen Dynamiken kommen soll, wird von Marx in leicht ironischem Ton einem kritischen Blick unterzogen: Ersterer meinte nämlich einerseits, dass sich gesellschaftlicher Wohlstand für alle gleichermaßen einstellte, wenn alle sechs Stunden arbeiteten, dass also, anders gesagt, alle gleichermaßen zu Arbeitern wie Müßiggänger würden. Andererseits meinte Dilke aber, dass jeder für sich selbst sechs Stunden mehr arbeitete als für seinen unmittelbaren Lebenserhalt notwendig. So hätten zwar alle gleich viel Zeit für den Müßiggang, jedoch auch gleich wenig materiellen Wohlstand. Darüber, welcher der beiden Vorschläge denn nun besser sei, ist sich Dilke, so Marx, offenbar selbst unschlüssig.

Summa summarum gelte es jedoch den Gegensatz zwischen „master and men“ 25 - zwischen „Herr und Knecht“ also, wie Marx im Anschluss an das berühmte Kapitel aus Hegels Phänomenologie des Geistes formuliert ${ }^{26}$ - aufzuheben. Ziel- und Endpunkt dieser Aufhebung sei, allen Menschen „freie Zeit zu ihrer Entwicklung " 27 zu ermöglichen. Allein wenn diese freie Zeit zur Verfügung steht, bestehe überhaupt die Möglichkeit, seine Fähigkeiten und Vermögen zu entwickeln. Oder anders herum formuliert: Die freie Entwicklung der Fähigkeiten werde dadurch verhindert, dass die potentiell verfügbare Zeit zusätzlich in den Produktionsprozess einfließt. Kurzum: die freie Entwicklung der Fähigkeiten hängt also davon ab, ob es uns möglich ist, uns jene disposable time, jene verfügbare Zeit, wieder anzueignen. Daher ergänzt Marx jenen eben zitierten Passus:

[U]nd zugleich werden alle 6 Stunden ,disposable time‘, den wahren Reichtum haben; Zeit, die nicht durch unmittelbar produktive Arbeit absorbiert wird, sondern zum enjoyment [Vergnügen], zur Muße, [so] daß sie zur freien Tätigkeit und Entwicklung Raum gibt. Die Zeit ist der Raum für die Entwicklung der faculties [also der Vermögen und Fähigkeiten] etc. Man weiß, daß sie die Muße, freie Zeit für andre, einen andren Teil der Gesellschaft - und damit für die Gesellschaft der wages-labourer schafft. ${ }^{28}$

Darüber, wie dies im Einzelnen aussehen mag, kann man sich streiten. Man kann sich auch darüber streiten, wie dieser Raum, in der sich die Fähigkeiten ausbilden können, gestaltet werden kann. Darüber, so Marx, ist sich „[d]er Verfasser [...] offenbar selbst nicht klar. Nevertheless bleibt immer noch der schöne Satz: ,Eine Nation ist wirklich reich, wenn 6 statt 12 Stunden gearbeitet wird. Wealth is disposable time, and nothing more. ${ }^{29}$ Mit diesem Leitmotiv im Sinn kommen wir nun zur dritten und letzten Bemerkung.

25 Marx, Theorien über den Mehrwert, MEW 26.3, 253.

26 G.W.F. Hegel, Phänomenologie des Geistes, Werke (=W), Bd.3, hg. v. Eva Moldenhauer/Karl Markus Michel, Frankfurt a. M. 1996.

27 Marx, Theorien über den Mehrwert, MEW 26.3, 252.

28 Marx, Theorien über den Mehrwert, MEW 26.3, 252.

29 Marx, Theorien über den Mehrwert, MEW 26.3, 252. 


\section{Bemerkung: Die Entsetzung der Zeit}

Paul Lafargue, Marx' Schwiegersohn, weist in seinem berühmten Manifest Das Recht auf Faulheit. Widerlegung des, Rechtes auf Arbeit' von $1848^{30}$ - verfasst im nicht weniger berühmten Pariser Gefängnis Saint-Pélagie, dem zeitweiligen Aufenthaltsort einer beachtlichen Anzahl von Anhängern sowohl der Französischen Revolution als auch der Pariser Kommune - darauf hin, dass bereits die antiken Philosophen über den Vorteil von Faulheit und Müßiggang Bescheid wussten und dass sie ein Wissen besaßen, das uns mit dem fortschreitenden Kapitalismus abhandengekommen sei:

In der kapitalistischen Gesellschaft ist die Arbeit die Ursache des geistigen Verkommens und körperlicher Verunstaltung. [...] Die Philosophen des Altertums lehrten die Verachtung der Arbeit dieser Herabwürdigung des freien Mannes: die Dichter besangen die Faulheit, dieses Geschenk der Götter: [und dann zitiert Lafargue Vergil:] O Melibäus, ein Gott schenkte uns diesen Müßiggang. ${ }^{31}$

Karl Kautsky, der nach Engels' Tod 1895 der Erste war, der sich ernsthaft damit befasste, die Theorien des Mehrwerts herauszugeben - in denen, wie wir gesehen haben, auch Marx' Auseinandersetzung mit Dilkes Pamphlet stattfand -, bezog sich in einem ebenfalls 1884 erschienenen kritischen Artikel Das Recht auf Arbeit ${ }^{32}$ unmittelbar auf Lafargues Recht auf Faulheit. Gegen den, wie er schreibt, „kleinbürgerlichen Sozialismus", der sich für das Recht auf Arbeit einsetzte, wendet er ein:

Der moderne wissenschaftliche Sozialismus hat denn auch die Forderung des Rechtes auf Arbeit längst fallen gelassen. [...] Bei diesem bloß kritischen, negativen Ergebnis wollen wir es indes nicht bewenden lassen. Man will positive Vorschläge. Nun, wir wollen auf einen solchen hinweisen, den man in neuester Zeit gemacht, indem man dem Rechte auf Arbeit das ,Recht auf Faulheit' (Müßiggang, Muße) entgegensetze.

In dieser Forderung liegt ein sehr gesunder Kern, trotz aller Witze, die dagegen losgelassen worden. Das ,Recht auf Faulheit' besagt nichts anderes, als das Recht des Arbeiters, sich als Mensch zu fühlen, und nicht bloß als Lasttier; es besagt, daß der Mensch arbeitet, um zu leben und nicht lebt, um zu arbeiten. ${ }^{33}$

Kautsky fordert daraufhin die Beschränkung der täglichen Arbeitszeit auf acht Stunden. Er fährt fort:

30 Paul Lafargue, Das Recht auf Faulheit. Widerlegung des Rechts auf Arbeit von 1848, mod. übers. v. Eduard Bernstein, hg. v. Michael Wilk, Frankfurt a. M. 2010.

31 Lafargue, Recht auf Faulheit, $34 \mathrm{f}$. Im Original steht das Zitat auf Lateinisch: „O Melibae, Deus nobis haec otia fecti."

${ }^{32}$ Karl Kautsky, „Das Recht auf Arbeit“, in: Die neue Zeit. Revue des geistigen und öffentlichen Lebens 7 (1884), 299-303.

${ }^{33}$ Kautsky, Recht auf Arbeit, $302 \mathrm{f}$. 
Der Normalarbeitstag ist nichts, als eine Anerkennung dessen, daß der Arbeiter nicht bloß zur Arbeit da ist, sondern auch zum Lebensgenusse, und daß dies Recht auf Genuß, auf freie Betätigung der körperlichen und geistigen Kräfte in Spiel und Übung, in Kunst und Wissenschaft, ihm nicht verkümmert werden darf. ${ }^{34}$

Die Verkürzung der Arbeitszeit oder andersherum formuliert: die Akkumulation der Zeit, in der nicht gearbeitet wird, schafft demnach erst den Raum, um die, wie Kautsky schreibt, körperlichen und geistigen Kräfte zu betätigen. Oder um es ein weiteres Mal umzuformulieren: Die Möglichkeit, dieses Intervall, in dem sich der Mensch nicht dem Produktionsprozess unterwerfen muss, sondern von diesem für einen Moment zurücktreten kann, diese Möglichkeit zur Verfügung zu haben, ist gleichzusetzen mit der Generierung eines anderen Mehrwerts als dem rein ökonomischen. Hiermit ist ein Mehrwert gemeint, der sich aus der entsetzenden Zeitlichkeitsstruktur jener Momente von Muße oder auch Faulheit heraus begründet. Diese erfordern einerseits eine andere zeitliche Taktung, andererseits schaffen sie damit zugleich den Raum zum Vollzug von Faulheit und Muße - und damit letztlich für die Herausbildung von Fähigkeiten und Vermögen. In anderen Worten: Erst die entsetzende Zeit öffnet den Raum zur Entfaltung der Vermögen und Fähigkeiten.

Dass es einen intrinsischen Zusammenhang zwischen der Entwicklung von Vermögen und Fähigkeiten und der generellen Möglichkeit gibt, sich aus dem gesellschaftlichen Arbeitsprozess für einen Moment zu enthalten, zeigt sich, wenn wir den Bogen zurück zur Antike, und insbesondere zu Aristoteles, spannen. Bei Aristoteles erhielt die Muße bekanntlich einen höheren Stellenwert als die Arbeit. In einer Passage seiner Politik, in der es um die richtige Form der Erziehung in einer politischen Gemeinschaft geht, führt er aus:

Denn die Muße, um noch einmal von ihr zu reden, ist das Prinzip [archē] von allem. Denn wenn auch beides sein muß, so ist doch das Leben in Muße dem Leben der Arbeit vorzuziehen, und das ist das Ziel, mit welcher Art Tätigkeit man die Muße auszufüllen hat. ${ }^{35}$

Einmal abgesehen von seinem expliziten erzieherischen Auftrag verdeutlicht dieses Zitat, dass es sich bei der so verstandenen Muße nicht etwa um eine Form der Passivität handelt. Vielmehr kann auch das inwendige Zurücknehmen von den ökonomischen Notwendigkeiten des Alltags wiederum als eine Form der Tätigkeit in Untätigkeit, als aktives Moment im Inaktiven gelesen werden. Die Muße als inaktive Aktivität unterscheidet sich von der Arbeit als reine Aktivität nun dadurch, dass die Muße um ihrer selbst willen ausgeübt wird. Dabei befindet sich das die Muße ausübende Subjekt immer in einer Art doppeltem Beziehungsgeflecht sowohl nach innen als auch nach außen. Dagegen handelt es sich bei der Arbeit per se um ein Moment der Veräußerlichung, welches diese nach

${ }^{34}$ Kautsky, Recht auf Arbeit, 303.

35 Aristoteles, Politik, übers. u. hg. v. Franz F. Schwarz, Stuttgart 1983, 1337 b 30-35. 
innen gerichtete Bewegung verhindert. Der aristotelischen Teleologie gemäß, ist denn auch jede Arbeit auf ein äußeres Telos gerichtet und dient der Erfüllung dieses oder jenes Zwecks: „Wer nämlich arbeitet, arbeitet für ein Ziel, das er noch nicht erreicht hat" ${ }^{36}$

Aristoteles' Vorstellung ist selbstverständlich zu unterkomplex, um die Dynamiken und Paradoxien der Moderne ausreichend greifen zu können. Was wir dem jedoch entnehmen können ist, dass Muße und auch Faulheit - zumindest in ihrem aktiv gedachten Teil - als inwendige Tätigkeiten nun keinesfalls mehr im Sinne jener tautologischen Selbstreferentialität einer passiven Trägheit à la Oblomow gedacht werden können. Vielmehr sind sie als Tätigkeit qua Nicht-Tätigkeit von Arbeit, als Tätigkeit mittels jenes Widerstehens gegen die durch die Ökonomie vorgegebene teleologische Taktung zu verstehen.

Vor dem Hintergrund unserer Marx-Dilke-Lektüre können Muße und Faulheit somit im Sinne einer doppelten Relationalität - d.h. als Widerstehen gegen die ökonomische Zeit und gleichzeitig als inwendige Zurücknahme in eine andere Taktung - verstanden werden. Die Bewegungen in beide Richtungen erweisen sich als zwingende Voraussetzung dafür, dass gerade nicht sämtliche freie Zeit von der Arbeitszeit absorbiert wird.

Wie auch schon Marx in seinen Theorien des Mehrwerts andeutet, ist die Akkumulation der frei zur Verfügung stehenden Zeit die notwendige Bedingung dafür, dass sich Fähigkeiten und Vermögen überhaupt erst herausbilden können. Diese frei zur Verfügung stehende Zeit ist es, die jene Momente der Muße und der Faulheit ausmacht.

Schließen wir zum Schluss an jenen programmatischen Passus aus Marx' Theorien über den Mehrwert an:

[U]nd zugleich werden alle 6 Stunden, disposable time', den wahren Reichtum haben; Zeit, die nicht durch unmittelbar produktive Arbeit absorbiert wird, sondern zum enjoyment [Vergnügen], zur Muße, [so] daß sie zur freien Tätigkeit und Entwicklung Raum gibt. Die Zeit ist der Raum für die Entwicklung der faculties [also der Vermögen und Fähigkeiten] etc. ${ }^{37}$

Die Zeit ist also der Raum für die Entwicklung der Vermögen und Fähigkeiten - nach dem Dargelegten meint diese Zeit nun nichts anderes als die frei zur Verfügung stehende Zeit. Diese Verfügbarkeit der Zeit, die mit der Entwicklung der Fähigkeiten und Vermögen zusammenfällt, ist nun - wie wir anhand der Marx'schen Auslegung der kleinen Dilke-Passage gesehen haben - potentiell als das Moment zu begreifen, in dem es durch die ihr immanente doppelte Verwiesenheit zu einer Entsetzung oder Verrückung sowohl der Zeit selbst als auch des

36 Aristoteles, Politik, 1338 a 4-6. Der Satz geht dann folgendermaßen weiter: „[D]och die Glückseligkeit aber ist selber schon ein Ziel, sie ist, wie alle meinen, nicht mit Schmerz, sondern mit Lust verbunden."

37 Marx, Theorien über den Mehrwert, MEW 26.3, 252. 
Raumes kommt. Muße und Faulheit dehnen die Zeit und schaffen dadurch erst den Raum, in dem ein Stück Freiheit für uns erfahrbar wird. ${ }^{38}$ Weder die ökonomische Zeit noch der Raum sind damit als festgefügte Anordnung, als teleologische oder theologische Verfügung zu verstehen. Vielmehr ist die Zeit, wie Shakespeares Hamlet sagt, den Derrida in Marx' Gespenster zitiert, out of joint, „aus den Fugen geraten“, wie wiederum Schlegel übersetzt; sie ist durch diese entsetzenden, widerständigen Momente ganz und gar unverfugt. ${ }^{39}$ Spätestens jetzt betreten wir jedoch den Raum der Spekulation ...

38 Vgl. David Dilmaghani/Nassima Sahraoui (Hg.), Kleine Philosophie der Faulheit, Frankfurt a. M. 2012, 246.

39 Jacques Derrida liest in seinem Marx' Gespenster Marx mit Shakespeares Hamlet quer. Hierbei handelt es sich um eine dekonstruktive Lesart, die sich insofern förmlich aufdrängt, als Marx und Engels die literarischen Hinweise selbst evozierten, indem sie das Kommunistische Manifest mit dem Satz: „Ein Gespenst geht um in Europa“ beginnen. Vgl. William Shakespeare, „Hamlet, Prince of Denmark“, in: The Complete Works of William Shakespeare, hg. v. W. J. Craig, London 1978, 941-983; Karl Marx/Friedrich Engels, Manifest der Kommunistischen Partei. Grundsätze des Kommunismus, mit einem Nachwort v. Iring Fetscher, Nachdr., Stuttgart 1997 (auch in: MEW 4, Berlin 1972, 459-493); Jacques Derrida, Marx' Gespenster. Der Staat der Schuld, die Trauerarbeit und die neue Internationale, übers. v. Susanne Lüdemann, Frankfurt a. M. 2004. Das nächtliche Erscheinen des Geistes des Königsvaters deutet bereits auf eine verschobene oder entrückte Zeitlichkeit hin, die einem Einholen des Vergangenen in die Gegenwart gleicht. Im seinem 1852 veröffentlichten Text zum 18. Brumaire beschreibt Marx dies als Beschwörung des Vergangenen: „Die Menschen machen ihre eigene Geschichte, aber sie machen sie nicht aus freien Stücken unter selbstgewählten, sondern unter unmittelbar vorhandenen, gegebenen und überlieferten Umständen. Die Tradition aller toten Geschlechter lastet wie ein Alp auf dem Gehirne der Lebenden. Und wenn sie eben damit beschäftigt scheinen, sich und die Dinge umzuwälzen, noch nicht Dagewesenes zu schaffen, gerade in solchen Epochen revolutionärer Krise beschwören sie ängstlich die Geister der Vergangenheit zu ihrem Dienste herauf, entlehnen ihnen Namen, Schlachtparole, Kostüme, um in dieser altehrwürdigen Verkleidung und mit dieser erborgten Sprache die neue Weltgeschichtsszene aufzuführen." (Karl Marx, „Der achtzehnte Brumaire des Louis Bonaparte“, in: MEW 8, Berlin 1980, 111-207, 115) Diese ängstliche Beschwörung der Geister wird bei Derrida zu einer notwendigen Anrufung der Gespenster. Vgl. Nassima Sahraoui, „Die messianische Kraft der Demokratie. Zur Politik, Geschichte und Zeitlichkeit bei Jacques Derrida“, in: Oliver Flügel-Martinsen/ Franziska Martinsen (Hg.), Demokratiekritik und Staatskritik aus Frankreich. Neuere Diskurse und Perspektiven, Stuttgart 2015, 205-222. 



\title{
Muße und Einfachheit
}

\section{Henry David Thoreaus literarisches Lebensexperiment}

\author{
Günter Figal
}

For A.M.E.S., October 2nd 2008

Ein junger Mann, angehender Autor, baut sich im Wald, am Ufer eines Sees ein kleines Haus, eher eine Hütte, die mit Bett und Tisch, einem Schreibpult, drei Stühlen und etwas an kleinem Hausrat eingerichtet ist. Er lebt in dieser Hütte zwei Jahre, zwei Monate und zwei Tage - wie er schreibt, um das Leben zu entdecken. Er habe ganz bewusst leben wollen, den wesentlichen Dingen des Lebens begegnen und lernen, was das Leben zu lehren habe, statt am Ende entdecken zu müssen, dass er nicht gelebt habe. Die Zeit des Aufenthalts, sie beginnt am 4. Juli 1845, sollte begrenzt sein, und die gewählte Begrenzung zeigt dann, dass sie legendentauglich sein sollte. Die Zeit ist der Erfahrung gewidmet - welcher Erfahrung wird noch zu zeigen sein - vor allem jedoch dem Vorhaben, über die Erfahrung zu schreiben und sie dabei, gleichsam im Echtzeitprotokoll, schreibend verständlich zu machen: Erfahrung mit dem Stift oder der Feder in der Hand. Das Ergebnis wird erst nach etlichen Jahren der Arbeit am Text veröffentlicht, im Jahr 1854, genauer am 9. August dieses Jahres. Am Ende des Jahres sind 1.744 Exemplare verkauft, einige sogar in Übersee, genauer in England, wo das Buch von einer späterhin berühmten Autorin, George Eliot, enthusiastisch rezensiert wird. Das Literatur gewordene Lebensexperiment, das Henry David Thoreau in seinem Buch Walden; or, Life in the Woods beschrieben hat und das, wie gesagt, von vornherein zum Beschreiben und Reflektieren gemacht war, hat offenbar großes Interesse gefunden und findet es immer noch. Walden, betitelt nach Walden Pond, dem im Wald gelegenen See, an dessen Ufer Thoreau seine Hütte baute, wird gelesen, nach wie vor. Allein ins Deutsche gibt es mehrere Übersetzungen, die erste übrigens aus dem Jahr 1897; die jüngste deutsche Neuausgabe von Walden stammt aus diesem Jahr.

Thoreaus Hüttenleben war weniger eskapistisch als man es sich vielleicht denken möchte. Gleich mit dem ersten Satz seines Buches erfährt man, dass der Autor keineswegs in die Einöde gezogen war: When I wrote the following pages, or rather the bulk of them, I lived alone, in the woods, a mile from any neighbor, in a house which I had built myself, on the shore of Walden Pond, in Concord, Mas- 
sachusetts, and earned my living by the labor of my hands only. ${ }^{1}$ Eine Meile entfernt von Nachbarn, das ist eine Entfernung, die man leicht zu Fuß zurücklegen kann. Das Haus steht nicht in der Wildnis, sondern gehört zu einem Städtchen, Concord, und Thoreau dürfte seine Freunde, die dort lebten, nicht selten besucht haben. Weniger als eine Meile entfernt waren die Eisenbahnarbeiter, die hinter Thoreaus Hütte eine Bahnlinie gebaut hatten. Amerika, allein schon Massachusetts wäre groß und wild genug für ein Leben in der Einöde gewesen, doch offenbar war das Lebensexperiment, auf das es dem Autor ankam, durch die Nähe der Zivilisation nicht gestört. So ist Walden durchaus anders, als es die Träumereien des einsamen Spaziergängers Rousseau sind, in deren Nähe man das Buch vielleicht sehen möchte. Rousseau beschreibt sich gleich mit den ersten Sätzen als ausgestoßen, verlassen, allein auf Erden, ohne Bruder, ohne Nächsten, ohne Freund, so dass ihm nichts bleibt als sich zu fragen, wer er sei, losgelöst von allen und allem. ${ }^{2}$ Auch Thoreau preist die Einsamkeit: I find it wholesome to be alone the greater part of the time. To be in company, even the best, is soon wearisome and dissipating. I love to be alone. I never found a companion that was so companionable as solitude. ${ }^{3}$ Aber so kann Thoreau nur schreiben, weil er, anders als der träumende Spaziergänger, Vergleichsmöglichkeiten hat. Gleich zu Beginn seiner Überlegungen zur Einsamkeit berichtet er von Besuchern, die Spuren ihrer Anwesenheit an seiner Hütte hinterließen, während er unterwegs war. Die Einsamkeit, die der Autor von Walden beschreibt, ist keine Verlassenheit. Sie ist Entlastung, wie ein Atemholen. Sie ist einsame Muße. Anders als Rousseaus Selbsterkundung ist sie unangestrengte Selbstvergessenheit, die Möglichkeit, in einen Raum eingelassen zu sein, den Thoreau, darin seinem Freund und Mentor Emerson verpflichtet, ,Natur' nennt, Nature, und groß schreibt:

This is a delicious evening, when the whole body is one sense, and imbibes delight through every pore. I go and come with a strange liberty in Nature, a part of herself. As I walk along the stony shore of the pond in my shirt sleeves, though it is cool as well as cloudy and windy, and I see nothing special to attract me, all the elements are unusually congenial to me. [...] Sympathy with the fluttering alder and poplar leaves almost takes away my breath; yet, like the lake, my serenity is rippled but not ruffled. ${ }^{4}$

Die hier beschriebene Eingelassenheit ins große Ganze, Elementare, dessen Erfahrung möglich ist, wo nichts Besonderes die Aufmerksamkeit in Anspruch nimmt, ist keine Überwältigung; in ihr spielt Freiheit, a strange liberty, Freiheit, die befremden mag, weil sie so anders ist als das, was man sonst meist unter Freiheit versteht. Nicht der Wille ist frei oder der Mensch durch sein Wollen und

\footnotetext{
1 Henry D. Thoreau, Walden. A fully annotated edition, hg. v. Jeffrey S. Cramer, New Haven/London 2004, 1.

2 Jean-Jacques Rousseau, Euvres completes I: Les Confessions, Autres Textes, Autobiographiques, Les rêveries du promeneur solitaire, hg. v. Marcel Raymond, Paris 1959, 997.

3 Thoreau, Walden, 131.

4 Thoreau, Walden, 125.
} 
Tun, sondern die Natur ist Freiheit. Sie ist Freiheit, weil sie freilässt, und sie lässt frei, obwohl der Spaziergänger am Seeufer ein Teil von ihr ist. Sie nimmt nicht so auf, dass man in einer Art dionysischem Rausch in sie ein- und in ihr unterginge, sondern sie weckt Korrespondenzen - zwischen dem See und der Heiterkeit, die beide gekräuselt, aber nicht zerzaust sind. Diese Freiheit ist möglich, weil die Natur, es wurde angedeutet, nicht nur elementar ist, sondern Raum, der ein weiter Bereich und Bezirk ist, a vast range and circuit, some square miles of unfrequented forest, umgebender und freigebender Horizont: I have my horizon bounded by woods all to myself. Dass in weniger als einer Meile Entfernung die Eisenbahn und eine Straße zu sehen sind, kann diesen offenen Horizont nicht stören: a distant view of the railroad where it touches the pond on the one hand, and of the fence which skirts the woodland road on the other. But for the most part it is as solitary where I live as on the prairies. Wo Freiraum ist, Freiraum für Korrespondenzen, tun sich Kontinente auf, und sogar der Kosmos ist offen für den einen, der seine räumliche Freiheit gefunden hat: It is as much Asia or Africa as New England. I have, as it were, my own sun and moon and stars, and a little world all to myself. ${ }^{5}$

Was die Freiheit des Freiraums, wie Thoreau ihn als ,Natur' erfährt, ausmacht, ist, dass dieser Raum einfach Raum ist. Er ist kein Zeitraum, weil die Zeit, als Ordnung des Nacheinander in ihm belanglos wird:

My days were not days of a week, bearing the name of any heathen deity, nor were they minced into hours and fretted by the ticking of a clock; for I lived like the Puri Indians, of whom it is said that for yesterday, to-day, and to-morrow they have only one word, and they express the variety of meaning by pointing backward for yesterday, forward for to-morrow, and overhead for the passing day. ${ }^{6}$

So wird die Zeitordnung in Raumordnung übersetzt; der Lauf der Zeit wird zur räumlichen Richtung.

Der Raum, der Freiraum und darin einfach nur Raum ist, ist unbegrenzt, das heißt: nicht durch Abgrenzungen beeinträchtigt, anders als der Raum, in dem man sonst lebt, der auch Freiraum ist, doch eben begrenzter, in Anspruch genommener und so ein Raum, der sich gegen die Natur, der er abgewonnen ist, bestimmt: There is commonly sufficient space about us. Our horizon is never quite at our elbows. The thick wood is not just at our door, nor the pond, but somewhat is always clearing, familiar and worn by us, appropriated and fenced in some way, and reclaimed from Nature. ${ }^{7}$

Der Freiraum, den die unbegrenzte Natur bietet, schließt Geselligkeit nicht aus. Auch wenn Thoreau die Einsamkeit lobt, betont er, dass er kein Eremit sei und, wenn es darauf ankäme, den strapazierfähigsten Stammgast einer Bar aus-

5 Thoreau, Walden, 126.
6 Thoreau, Walden, 109.
7 Thoreau, Walden, 126. 
sitzen könnte. ${ }^{8}$ Auch die Geselligkeit braucht jedoch Raum, wenn sie sich frei entfalten und ein Gespräch sich frei entwickeln soll. So gibt es in Thoreaus Hütte zwar drei Stühle, einen für die Einsamkeit, zwei für die Freundschaft und drei für Gesellschaft. ${ }^{9}$ Aber die freie Natur sei dem Gespräch günstiger, so der Pinienwald hinter der Hütte. ${ }^{10}$ Und immer braucht es Abstand voneinander, damit man sich frei aufeinander beziehen und einander zuhören kann, was nur möglich sei, wenn man sich auch überhören könnte, statt den Stimmen der anderen ausgeliefert zu sein:

I have found it a singular luxury to talk across the pond to a companion on the opposite side. In my house we were so near that we could not begin to hear, - we could not speak low enough to be heard; as when you throw two stones into calm water so near that they break each others undulations. ${ }^{11}$

Abgrenzungen, Enge, die Schwierigkeit, einander aus dem Weg zu gehen - das sind Hindernisse der räumlichen Freiheit, die Thoreau zu erkennen und zu beschreiben versucht. Das größte Hindernis freilich ist die alltägliche Mühe und Tätigkeit, die die meisten schon gar nicht mehr als Hindernis wahrnehmen, weil sie so selbstverständlich geworden ist. Was ihnen derart fehlt, ist die Fähigkeit zur Muße:

Most men, even in this comparatively free country, through mere ignorance and mistake, are so occupied with the factitious cares and superfluously coarse labors of life that its finer fruits cannot be plucked by them. Their fingers, from excessive toil, are too clumsy and tremble too much for that. Actually the laboring man has not leisure for a true integrity day by day. ${ }^{12}$

Eben dies, dass die meisten Sorgen künstlich sind und die meisten Mühen des Lebens überflüssig grob, will Thoreau mit seinem Lebensexperiment zeigen. Wenn das Leben ist wie in diesem Experiment erfahren wird, ist es, was es sein soll, nämlich ein Leben in Muße, in unversehrter Ganzheit, und der Autor nimmt es gelassen hin, dass diese seinen Mitbürgern als sheer idleness erscheinen mag. ${ }^{13}$ Und, das darf wiederholt werden, dieses Leben ist, trotz allem, was darauf hinzudeuten scheint, kein ,Zurück zur Natur', kein Eskapismus und keine eremitenhafte Misanthropie. Vielmehr ist es ein Test auf die Künstlichkeit und Überflüssigkeit des meisten, was alltäglich, im städtischen Leben oder auch ländlichen Leben getan wird; und es ist der Versuch herauszufinden, was übrigbleibt, wenn all das Künstliche und Überflüssige wegfällt.

\footnotetext{
8 Thoreau, Walden, 135.

9 Thoreau, Walden, 135.

10 Thoreau, Walden, 137.

11 Thoreau, Walden, 136.

12 Thoreau, Walden, 5.

13 Thoreau, Walden, 109.
} 
Der Test ist durch eine Frage geleitet, auf die der Bau der Hütte am Walden Pond eine Antwort ist: Was brauchen wir wirklich? Die Antwort, sie wurde bereits erwähnt heißt: ein Bett, einen Tisch, ein Schreibpult, drei Stühle, etwas an kleinem Hausrat. Aber das ist nur die am Wohnraum veranschaulichte Exemplifikation eines allgemeinen Programms - des Programms der Vereinfachung. Simplify, das ist die programmatische Empfehlung, und der Bau der Hütte, das Leben in ihr sollen zeigen: es geht; Einfachheit ist möglich, und sie ist besser als Kompliziertheit. Einem Brief, den Thoreau nach seiner Mußezeit am Walden Pond geschrieben hat, lässt sich pointierter entnehmen als dem Buch, was er unter Einfachheit versteht:

I do believe in simplicity. It is astonishing as well as sad, how many trivial affairs even the wisest man thinks he must attend to in a day; how singular an affair he thinks he must omit. When the mathematician would solve a difficult problem, he first frees the equation of all incumbrances, and reduces it to its simplest terms. So simplify the problem of life, distinguish the necessary and the real. ${ }^{14}$

Aber wie ist das Vereinfachen möglich? Wie soll man seine Tätigkeiten und Dinge sinnvoll reduzieren? Was ist überflüssig, so dass man es weglassen kann? Thoreau scheut sich nicht vor konkreten Antworten: zu viel Kleidung, die Eisenbahn, Sparkonten, das Postamt, zu viele Mahlzeiten, der Staat und seine Steuern, überhaupt alles, was sich nicht an zehn Fingern und notfalls zehn Fingern und zehn Zehen abzählen lässt, und, wichtiger noch, alles, was nicht der Betrachtung in wachen und kritischen Stunden standhält. ${ }^{15}$ Das mag zu bestreiten sein, aber es ist schließlich auch nur Illustration und kein Punkt für Punkt abzuarbeitendes Programm. Worauf es ankommt, hat Thoreau ebenso lakonisch wie klar in einer Tagebuchnotiz formuliert: The question is whether you can bear freedom. ${ }^{16}$ Alles, was unfrei macht, wie zum Beispiel die Eisenbahn - We do not ride on the railroad; it rides upon us $^{17}$ - sollte man lassen; alles demnach, was den Freiraum, in dem Korrespondenzen mit dem, was umgeben kann und umgibt, verstellt, was Gespräche, die wahrhaft Gespräche sind, unmöglich macht und was die wache Aufmerksamkeit für das Leben in der Welt, wie sie in Muße ermöglicht ist, nimmt. Für diese Unfreiheit des Tuns und die Freiheit des Lassens will Thoreau die Aufmerksamkeit wecken; deshalb macht er eine Probe darauf, wie Freiheit möglich sein kann, und schreibt über sie.

Was für ein Schreiben ist das, und welche Erfahrung spricht sich in diesem so planvoll im Lebensexperiment ermöglichten Schreiben aus? Dass das Leben und Schreiben am See für nötig gehalten werden konnte, sagt viel über die Frei-

${ }_{14}$ Henry David Thoreau, „Letter to H.G.O. Blake“, datiert 27. März 1848. Zitiert nach Thoreau, Walden, 89-90, Anm. 69.

15 Thoreau, Walden, 88-89.

16 Henry David Thoreau, „Journal entry 1 September 1853 “. Zitiert nach Thoreau, Walden, 90, Anm. 69.

17 Thoreau, Walden, 90. 
heit, also über den Freiraum der Muße, die das Hauptmotiv von Walden ist. Offenbar ist diese Freiheit so fremd geworden, dass man an sie erinnern, sie neu entdecken und zurückgewinnen muss. Der Welt, in der Thoreau schreibt, man darf sie auch ohne großen epochentheoretischen Aufwand ,die Moderne' nennen, fehlt, wie es scheint, die Möglichkeit der Muße; diese hat in der Welt, in der und für die Thoreau schreibt, buchstäblich keinen Platz, und deshalb muss dieser Platz anderswo, außerhalb, gefunden werden, dort, wo Freiraum ist und nichts davon ablenkt, diesen Freiraum als solchen zu erfahren. Sonst, im Zusammenhang des alltäglichen Lebens, ist die Möglichkeit der Muße vergessen oder sie gilt nichts, wenn man überhaupt noch an sie denkt. Meist wird sie für sheer idleness gehalten.

Was bei Thoreau gleichsam den Hintergrund seines Lebens am See und seines Schreibens bildet, hat ein anderer, Nietzsche, deutlich gesehen und formuliert - paradoxerweise, wie man als Thoreau-Leser sagen müsste, indem er Amerika, dem comparatively free country, die Schuld am Mußeverlust seiner Zeit gibt. Die „indianerhafte, dem Indianer-Bluthe eigenthümliche Wildheit, in der Art, wie die Amerikaner nach Gold trachten“ habe begonnen, „durch Ansteckung das alte Europa wild zu machen" - als ob das Trachten nach dem Gold eine transatlantische Erfindung wäre. Doch was Nietzsche, über seine Vorurteile hinausblickend, sieht, ist dem, was bei Thoreau als Motiv wirkt, durchaus ähnlich: Mußeverlust durch Arbeitsüberschätzung. Dabei schreibt Nietzsche als ein Philosoph, der für sein Denken die Muße braucht und sich nicht mehr recht traut, sie offen zu leben. Es sind schlechte Zeiten für Philosophie; man schäme „sich jetzt schon der Ruhe“, und „das lange Nachsinnen“ mache „beinah Gewissensbisse“. Man denke „mit der Uhr in der Hand“ und lebe „wie Einer, der fortwährend Etwas ,versäumen könnte ““. Man folge dem Grundsatz „Lieber irgend Etwas thun, als Nichts“ und so einer Richtschnur, die geeignet sei, „,aller Bildung und allem höheren Geschmack den Garaus zu machen“. So gehe auch der „Esprit der Unterhaltung“ verloren „und überhaupt für alles Otium“.18

Nietzsches Kritik seiner Gegenwart, der Moderne also, lebt, wie man leicht sieht, aus dem Kontrast, der seit der Querelle des Anciens et des Modernes geläufig war; „ehedem“, als „die Arbeit das schlechte Gewissen auf sich“ hatte, galt auch, dass „Vornehmheit und Ehre [...] allein bei otium und bellum“ lagen; so, fügt Nietzsche hinzu, „klang die Stimme des antiken Vorurtheils“. ${ }^{19}$ Offenbar muss ein Philosoph dieses Vorurteil irgendwie teilen, auch wenn er es als Vorurteil durchschaut; ein Philosoph, wie Nietzsche ihn versteht, ragt gleichsam aus der Antike in die Moderne hinein, ein prähistorisches Lebewesen, das mit seinen das eigene Tun ermöglichenden Vorurteilen in der Moderne nicht mehr

18 Friedrich Nietzsche, „Die fröhliche Wissenschaft“, $\$ 329$, in: Sämtliche Werke. Kritische Studienausgabe (=KSA), Bd.3, hg. v. Giorgio Colli/Mazzino Montinari, München 1988, 343-664, 556.

19 Nietzsche, „Die fröhliche Wissenschaft“, KSA 3, 557. 
zurecht kommt, ein „Mensch von guter Abkunft“ unter den plumpen, nach der Uhr lebenden Barbaren. ${ }^{20}$

Thoreau, auch er übrigens ein in antiker Literatur gut belesener Autor, hat Nietzsches Problem nicht; er kommt ohne aristokratische Selbststilisierung und ohne klassischen Faltenwurf aus und baut eine Hütte. Das wird Schule machen. Thoreau ist der erste prominente Hüttenbewohner auf Zeit in der Moderne, dem andere anderswo folgen werden: Gustav Mahler in den Dolomiten, Wittgenstein in Norwegen, Heidegger in Todtnauberg. Doch keiner von den Genannten kam dem Lebensexperimentator Thoreau so nahe wie ein Architekt, CharlesÉdouard Jeanneret, der sich Le Corbusier nannte. Zwischen 1951 und 1952 baute er für sich in Roquebrune-Cap Martin an der Côte d'Azur ein sehr schlichtes Blockhaus, Le Cabanon, in dem er sich nicht nur in den Ferien gern aufhielt. Aber Le Cabanon ist mehr als ein kleines Domizil für die Ferien und für das Arbeiten in Muße; das Haus ist ein Raumexperiment, derart, dass Le Corbusier bei seiner Konstruktion herausfinden wollte, wie effektiv, wie beschränkt, ohne beengend zu sein, ein Wohnraum gestaltet sein kann. Einbauten, auf ein Minimum beschränktes Mobiliar, zu dem Holzkästen gehören, die auch als Hocker verwendbar sind, lassen den Raum, im Grundriss ein Quadrat von nur 3,66 Meter Kantenlänge und an der höchsten Stelle des Pultdachs 2,26 Meter hoch, überraschend großzügig erscheinen. Es ist ein Raum, der, so klein er auch ist, Raum gibt, der umschließt und zugleich Weite hat; ein Raum, der in die Wärme seiner Holztöne aufnimmt und durch kräftige Farbakzente, vor allem an der Decke, weiß, rot und grün, sehr frisch wirkt; ein sehr einfacher Raum, der, an traditionelle japanische Häuser erinnernd, in seiner Einfachheit einfach Raum ist.

Im Vergleich mit Le Corbusiers Cabanon ist Thoreaus Hütte am Walden Pond sehr schlicht; sie ist gewiss kein Referenzbau der modernen Architektur, aber als Lebensexperiment, das ein Wohn- und damit ein Raumexperiment ist, ist sie der Initialpunkt einer modernen Entwicklung. Die Frage nach der Vereinfachung von Lebensverhältnissen - simplify the problem of life - hat die Moderne seit der Wende vom 19. zum 20. Jahrhundert bestimmt; man denke an das Bauhaus, an Gerrit van Rietfelds Schröder-Haus in Utrecht und eben an Le Corbusier sowie an alle Jüngeren, die von ihm und seinen Generationsgenossen Gropius und Mies van der Rohe geprägt wurden. Einer von ihnen, John Pawson, hat übrigens nicht nur sehr einfache und darin wunderschöne Bauten gestaltet - sein bisheriges Meisterwerk dürfte die Zisterzienserabtei Novy Dvur in Tschechien, in der Nähe von Marienbad sein - sondern unter dem Titel Minimum auch eine photographische Enzyklopädie des Einfachen herausgegeben; das Spektrum der Beispiele reicht vom griechischen Tempel über den Zen-Garten, von Shaker-Häusern und Bauten der klassischen Moderne wie Mies van der Rohes Farnsworth House bis

20 Nietzsche, „Die fröhliche Wissenschaft“, KSA 3, 557. 
zu Bauten von Tadao Ando und von Pawson selbst; es umfasst japanische Teeschalen, Bilder von Rothko, Skulpturen von Donald Judd und Richard Serra. ${ }^{21}$

Die Vereinfachung des Wohnens und damit eines gesammelten, sich frei entfaltenden und sich nicht an die Vielzahl der zu besorgenden Dinge verlierenden Lebens, wie die Architekten und Gestalter der Moderne sie erforschten und betrieben, geht wohl kaum direkt auf Thoreau zurück, wenngleich ihn mancher der Genannten gelesen haben wird. Die wichtigste Prägung des an der Einfachheit orientierten Bauens und Wohnens kam von Frank Lloyd Wright, der mit den Entwürfen seiner Prairie Houses - Häuser, für die offene Weite des Landes gedacht -das Vorbild der japanischen Architektur auch nach Europa brachte. Und Wright hat Thoreau gelesen; er stellt sich ausdrücklich in seine Nachfolge, wenn er betont, dass es die Architektur sei, in der die Seele menschlicher Kultur zu finden sei und dieses Verständnis der Architektur an die Vorbilder Thoreau, Emerson und Whitman bindet: The true architect is a poet who will someday discover in himself the presence of the tomorrow in our today. ${ }^{22}$,Poetisch ' soll die Architektur darin sein, dass sie das menschliche Leben zu seinen originären Möglichkeiten - und das heißt für Wright wie für Thoreau (und Emerson): zur Natur zurückbringt; zur Natur in dem Sinne, wie sie in Walden beschrieben ist, als das große Ganze, aus dem man sich nicht ausschließt, indem man sich in einem vermeintlich Eigenen einschließt, sondern das Freiraum des Lebens ist und sich als solcher erschließt, wenn man nicht auf etwas Besonderes achtet und erst recht nicht durch etwas Besonderes abgelenkt ist, sondern einfach räumlich im Raum ist, Korrespondenzen erfahrend, Bezüge, vor allem jedoch die Freiheit und Weite, in die jede Wahrnehmung und jede Aktivität gehört. Wright hat das, was Thoreau beschreibt, zu bauen versucht - einfache, offene Räume, offen im Ineinander von Innen und Außen, Räume, in denen man sein kann. Wenn die Architektur das erreicht, wird sie, wie Wright sagt, integral, ganzheitlich, Ausdruck einer neuen alten Realität. Der gebaute Raum (room) erweist sich als Raum (space) und damit als die Freiheit und Weite, ohne die kein Leben möglich ist. Das Haus wird natürlich, natural house. Was die moderne Architektur mit dem natürlichen Haus entdeckt, ist, wie Wright sagt, the livable interior space of the room itself. ${ }^{23}$

Darf man dieses räumliche Sein als Sein in Muße verstehen? Zumindest wird man sagen können, das sich im freien, durch keine Sorge und keinen Tätigkeitszwang dominierten Aufenthalt, der sich mit dem Wort ,Muße'verbindet, das, was Thoreau als Wohnen im freien Raum der Natur beschreibt, in besonderer Weise einstellt. Gewiss darf man Muße als die Möglichkeit verstehen, dieses

21 John Pawson, Minimum, London/New York 1996.

22 Frank Lloyd Wright, „A Testament“, in: Bruce Brooks Pfeiffer (Hg.), The Essential Frank Lloyd Wright. Critical Writings on Architecture, Princeton 2008, 365-439, 381.

23 Frank Lloyd Wright, „The Natural House“, in: Pfeiffer (Hg.), The Essential Frank Lloyd Wright. Critical Writings on Architecture, 319-364, 332. 
Wohnen, herausgehoben aus den Bindungen des Alltags, eigens zur Geltung zu bringen. Das wäre jedoch nicht möglich, wenn das Wohnen nicht als solches den Grundzug der Muße hätte. Wohnen ist kein Tun; es ist auch nichts, das einem widerfährt. Es ist eher ein Lassen - kein Unterlassen, sondern ein Lassen jenseits von Tun und Nichttun, ein Lassen, in dem sich etwas ergeben kann, und eines, das jede Tätigkeit trägt, am besten und leichtesten dann, wenn es einfach ist, einfaches räumliches Hiersein. So verstanden ist es, um noch einmal Thoreau das Wort zu geben, leisure for a true integrity day by day. 



\title{
Ein „edel Ding um Musse und Müssiggehen“ und Nietzsches Metaphorologie der Arbeit
}

\author{
Martin Jörg Schäfer
}

Die folgenden Ausführungen beschreiben, inwieweit nach dem in den Schriften Friedrich Nietzsches entworfenen Modell Praktiken der Muße und des Müßiggehens nicht einfach ein Gegenmodell zu einer kulturellen Hegemonie der Arbeit darstellen. Vielmehr müssen sie aus der Vorherrschaft der Arbeit heraus gegen die Arbeit erstritten werden. Das Lob der Muße findet wie eine Praxis der Muße als Kritik der Arbeit statt und ist von dieser Kritik der Arbeit nicht zu trennen. Sie steht im Zeichen einer Kritik der Moderne insgesamt, wie sie Nietzsche als ,Umwertung aller Werte vorschwebt, erschöpft sich aber nicht in einer bloßen Umkehrung. ${ }^{1}$

Die Rekonstruktion dieses Zusammenhangs erfolgt in drei Schritten: Ein erster stellt Nietzsches Kritik an der Arbeit thematisch dar; ein zweiter problematisiert die Selbstanwendung dieser Kritik auf das eigene Schreiben; ein dritter verortet in diesem Zusammenhang Nietzsches explizites Lob von Muße und Müßiggehen.

1.

Randständig und verstreut, aber immer wieder tauchen in Friedrich Nietzsches publizierten (und unpublizierten) Schriften Polemiken gegen das auf, was in der 1889 publizierten Götzen-Dämmerung das „Zeitalter der Arbeit“2 genannt wird. So hat etwa Nietzsches amerikakritische Rede von der Arbeit als dem „Laster der neuen Welt" ${ }^{\text {“3 }}$ aus der Fröhlichen Wissenschaft von 1882 große Bekanntheit erlangt. In Menschliches, Allzumenschliches ${ }^{4}$ gibt es einige viel beachtete Teilstücke,

1 So die einschlägige Nietzsche-Kritik in: Martin Heidegger, Nietzsche I, Gesamtausgabe, Bd. 6.1., hg. v. Brigitte Schillbach, Frankfurt a. M. 1996, 66-91.

${ }^{2}$ Friedrich Nietzsche, „Götzendämmerung“, in: Sämtliche Werke. Kritische Studienausgabe in 15 Bänden (= KSA), hg. v. Giorgio Colli/Mazzino Montinari, Bd. 6, München 1988, $55-161,130$.

${ }^{3}$ Friedrich Nietzsche, „Die fröhliche Wissenschaft“, in: KSA 3, 343-651, 557.

${ }^{4}$ Friedrich Nietzsche, „Menschliches, Allzumenschliches. Ein Buch für freie Geister. Teil I“, in: KSA 2, 9-366. 
die die antike Muße als alternative Praktik zur Hegemonie der Arbeitsethik in der bürgerlichen Gesellschaft feiern. Nietzsches verstreute Kurzpolemiken gegen die Arbeiterbewegungen des 19. Jahrhunderts, gepaart mit einem scheinbaren Lob der Sklaverei sind ebenfalls notorisch. ${ }^{5}$ All diese Äußerungen sind nicht unbedingt originell ${ }^{6}$ und schon gar nicht auf einen gemeinsamen Nenner zu bringen, haben aber doch von den frühen Vorarbeiten zur Geburt der Tragödie um 1870 bis zur späten Selbststilisierung etwa in Ecce homo am Ende der 1880er einiges gemeinsam: Zunächst werden diese Äußerungen — vor allem vom späten Nietzsche - mit sehr großer Emphase vorgetragen, als ginge es um alles oder nichts. Stets wenn die Texte auf dieses Zeitalter zu sprechen kommen, scheint nicht nur von ganz Selbstverständlichem die Rede zu sein. Worum es sich beim ,Zeitalter der Arbeit' handelt wird keiner näheren Erklärung für nötig oder würdig befunden. Kaum einmal bedienen sich Nietzsches Texte hier jener gleichzeitig so scharfzüngigen wie subtilen und spielerischen Schreibweise, für die sie so berühmt wie berüchtigt geworden sind. Außerdem sind Nietzsches Texte hier wenig innovativ; sie rezitieren und überspitzen eine traditionelle semantische Ordnung, die zwischen guter und schlechter Arbeit unterscheidet: Arbeit als mit Pein beladene des biblischen Fluchs, die nie aufhört und sich beständig abmüht (labor) - eine, schlechte Arbeit, die letztlich unproduktiv bleibt. Ihr gegenüber steht die gottgleiche Arbeit als Werke produzierende, als schöpfende (opus). Seit dem 17. Jahrhundert wird diese Weise der Arbeit in den entsprechenden Diskursen und Praktiken immer mehr zum Ideal erhoben. ${ }^{7}$

Dieses Ideal bricht sich aber an einer Wirklichkeit, in der sie nur selten eingelöst werden kann. Der Mensch ist nicht Gott; die Arbeit findet kein Ende. Das Schöpferische wandert in andere Sphären aus: besonders prominent seit Ende des 18. Jahrhunderts in die neu entstehende autonome Sphäre der Kunst. In der schöpferischen Produktion der Genieästhetik kann eine Arbeit behauptet werden, die von den Fremdbestimmungen der alltäglichen Arbeit befreit ist. In der Eigenständigkeit des Kunstwerks als ,Werk' kann eine ideale Arbeit behauptet werden, die zu einem Ende gekommen ist - und gerade dadurch nie aufhört im positiven Sinne zu wirken. Damit ergibt sich aber die Frage, die vor allem von der deutschsprachigen Romantik gestellt wird, ob es sich bei Kunstproduktion und Kunstwerken überhaupt um eine Arbeit handelt oder ob diese höhere und bessere Form der Arbeit nicht vielmehr eine Nichtarbeit ist: produktive Muße, spielerischer Müßiggang. Einer solchen guten Nichtarbeit lässt sich auch immer

${ }^{5}$ Vgl. Roberto Barros, Kunst und Wissenschaft bei Nietzsche von „Menschliches, Allzumenschliches“ bis „Also sprach Zarathustra“, Berlin 2007, $28 \mathrm{ff}$.

6 Vgl. Jochen Schmidt, Kommentar zu Nietzsches „Die Geburt der Tragödie“, Berlin/ Boston 2012, 336-341.

7 Vgl. Jacques Le Goff/Nicolas Truong, Die Geschichte des Körpers im Mittelalter, übers. v. Renate Warttmann, Stuttgart 2007, 71; Verena Postel, Arbeit und Willensfreiheit im Mittelalter, Stuttgart 2009, 171-177. 
eine schlechte Nichtarbeit entgegensetzten: Die, die da endlos arbeiten und nicht zur Ruhe kommen, sind eigentlich faul, pointieren die Erzählinstanzen in Friedrich Schlegels Lucinde wie in Eichendorffs Taugenichts: Sie produzieren nichts im eigentlichen Sinne. ${ }^{8}$

Diese Spannung zieht sich durch die gesamte Diskursgeschichte. Bei Karl Marx kehrt der nie enden wollende labor der biblischen Arbeit als kapitalistische Lohnarbeit bzw. als ihrer eigentlichen Bestimmung beraubte abstrakte Arbeit wieder. Die befreite Arbeit wird nach dem Prinzip der Kunst gedacht: Eigentliche Arbeit ist schöpferisch. Konstitutiv bleibt hier unklar, ob die Arbeit zu sich befreit werden soll oder von sich. ${ }^{9}$ Im ersten Fall wäre Kunst die eigentliche und bessere Arbeit; im zweiten Fall wäre Kunst eben keine Arbeit mehr.

Ende des 19. Jahrhunderts radikalisiert Nietzsche diese Verzahnung und bringt sie polemisch auf den Punkt. Historische Bezugspunkte sind für Nietzsche zum einen die Fabrikarbeit und zum anderen die „ungeheure[] Beschleunigung des Lebens" ${ }^{10}$, in deren Zeichen er die Arbeit der industrialisierten Welt in Menschliches, Allzumenschliches als allgegenwärtige „Hast"11 von „Ruhelosen“ beschreibt. Bei dieser „neuen Barbarei“, auf die Nietzsche den konstatierten „Mangel an Ruhe"12 hinauslaufen sieht, handelt es sich nicht nur um eine pessimistische Zeitdiagnose. Nietzsche geht es am Ende des 19. Jahrhunderts auch nicht bereits um jene „Proletarisierung der Angestellten“13, wie sie Kracauer 1930 als die Zerstörung des Bürgertums durch die fortschreitende Rationalisierung der Arbeitsprozesse bestimmen wird. Es geht Nietzsche vielmehr um die traditionelle Differenz zwischen der schlechten, nie zu Ende kommenden Arbeit als Mühsal und labor und einer guten, produktiven Tätigkeit. Dies steht im Hintergrund, wenn Nietzsche den in Berufen ,Tätigen' seiner Zeit nicht nur Individualität abspricht, sondern auch (im Stile Schlegels) Arbeitsamkeit im eigentlichen Sinne: „Den Thätigen fehlt gewöhnlich die höhere Thätigkeit: ich meine die individuelle. Sie sind [...] thätig [...] nicht als ganz bestimmte einzelne und einzige Menschen; in dieser Hinsicht sind sie faul."14 In einer einzigen Gleichsetzung: „Der Thätige ist faul“15, denn er produziert letztlich nichts, sondern wiederholt nur die von seiner Spezialisierung vorgegebenen Arbeitsvorgänge. Fabrikarbeit wird daher ebenso zu einer metaphorischen Form der Sklaverei wie

8 Vgl. Friedrich Schlegel, „Lucinde. Ein Roman“, in: Dichtungen, Kritische FriedrichSchlegel-Ausgabe, Bd. 5, hg. v. Hans Eichner, München 1962, 1-92, 29; Joseph von Eichendorff, Aus dem Leben eines Taugenichts. Frankfurt a. M. 1976, 288.

9 Vgl. Hannah Arendt, Vita activa oder Vom tätigen Leben, München 2002, $125 \mathrm{ff}$.

10 Nietzsche, „Menschliches, Allzumenschliches“, in: KSA 2, 231.

11 Nietzsche, „Menschliches, Allzumenschliches“, in: KSA 2, 232.

12 Nietzsche, „Menschliches, Allzumenschliches“, in: KSA 2, 232.

13 Siegfried Kracauer, „Die Angestellten. Aus dem neuesten Deutschland“, in: Schriften, Bd. I, hg. v. Inka Mülder-Bach, Frankfurt a. M. 1971, 205-304, 216.

14 Nietzsche, „Menschliches, Allzumenschliches“, in: KSA 2, 231.

15 Nietzsche, „Menschliches, Allzumenschliches“, in: KSA 2, 232. 
sämtliche anderen Berufe auch: „Alle Menschen zerfallen, wie zu allen Zeiten so auch jetzt noch, in Sclaven und Freie; denn wer von seinem Tage nicht zwei Drittel für sich hat, ist ein Sclave, er sei übrigens wer er wolle: Staatsmann, Beamter, Kaufmann, Gelehrter." ${ }^{16}$ Die Sklaverei liegt hiernach nicht in der Versklavung als solcher (welche einige Texte Nietzsches, ob ernst oder provokant, als Errungenschaft ,starker' Kulturen zu affirmieren scheinen), sondern in den Strukturen und Dynamiken einer allgegenwärtig gewordenen kulturellen Formation, die jenseits der Fabrik auch z.B. auf das vorindustrielle Handwerk und die nach der Industrialisierung entstehende Angestelltenkultur übergegriffen hat, ebenso auf die Arbeit der Wissenssucher wie auf die Subjektkonstitution überhaupt: Vorgeprägt findet sich hier die, wie sie in den späteren Schriften genannt wird, zu bekämpfende „Sklaven-Moral“17, die sich im Inneren ihrer Subjekte verankert hat. Statt für sich selbst zu arbeiten, geschieht dies für Geld, den Fabrikbesitzer oder Gott. Unter dem Begriff Arbeit versammeln sich Praktiken der Fremd- statt solche der Selbstbestimmung.

Nietzsche findet seinen Gegenentwurf zur Arbeit ganz im Sinne der Tradition zum einen in der Nichtarbeit der freien Bürger (bzw. Sklavenhalter) Athens wie auch in der Nichtarbeit der romantischen Aussteiger. Das „edel Ding um Musse und Müssiggehen“, von dem in Menschliches, Allzumenschliches die Rede ist, muss daher von einer Faulheit im regressiven und fremdbestimmten Sinne abgegrenzt werden: „Ihr meint doch nicht, dass ich mit Musse und Müssiggehen auf euch ziele, ihr Faulthiere?"18 Zum anderen wird die Kunst zu einem Modell für Nietzsche, allerdings nicht mehr die früher so bewunderte Kunst Wagners, die jetzt auf Seiten der Trägheit und Faulheit und Unproduktivität verortet wird: einlullend, die Stumpfheit der nicht enden wollenden Arbeit durch narkotisierende Wirkung überspielend. So heißt es auch in einer der späteren Polemiken gegen Wagner: „Der ermüdete und langsam athmende Arbeiter, der gutmüthig blickt, der die Dinge gehen läßt, wie sie gehen: diese typische Figur, der man jetzt, im Zeitalter der Arbeit [...] in allen Klassen der Gesellschaft begegnet, nimmt heute gerade die Kunst für sich in Anspruch, [...] Das verstand Wagner"19. Dagegen setzt Nietzsche in der Fröhlichen Wissenschaft eine „andere Kunst“, nämlich eine Lebenskunst, die sich nicht auf Kunstwerke, sondern auf das eigene Leben als Kunstwerk bezieht: „Wir aber wollen Die werden, die wir sind, - die Neuen, die Einmaligen, die Unvergleichbaren, die Sich-selber-Gesetzgebenden, die Sich-selber-Schaffenden“. „Nur als Schaffende“20, und nicht nur als, sondern

16 Nietzsche, „Menschliches, Allzumenschliches“, in: KSA 2, $231 \mathrm{f}$.

17 Friedrich Nietzsche, „Zur Genealogie der Moral“, in: KSA 5, hg. v. Giorgio Colli/ Mazzino Montinari, München 1988, 245-412, 270.

18 Nietzsche, „Menschliches, Allzumenschliches“, in: KSA 2, 232.

19 Nietzsche, „Götzendämmerung“, in: KSA 6, 130.

20 Nietzsche, „Die fröhliche Wissenschaft“, in: KSA 3, 422. 
auch „nur für Künstler“21, lässt sich folgerichtig die Arbeit von sich selbst befreien und als Kunst verwirklichen. Eine solche Verwirklichung bezieht sich nicht mehr auf die Produktion von Kunstwerken, sondern auf die Mikropolitiken der eigenen Subjektbildung: „[W]ir aber wollen die Dichter unseres Lebens sein, und im Kleinsten und Alltäglichsten zuerst." ${ }^{\text {"22 }}$

\section{2.}

Nietzsches Texte gehen nicht völlig in der von ihnen aufgerufenen Tradition auf. Vielmehr treten sie zu ihr in Differenz, indem sie diese Tradition ernst nehmen: Nietzsches Texte versuchen, die Arbeit tatsächlich in eine ,andere Kunst' zu verwandeln, nicht zuletzt die eigene Arbeit an der Sprache und mit der Sprache: Während die eigenen Texte sich selbst auf der Seite des schöpferischen Spiels statt der repetitiven Arbeit verorten, versucht ihre Praxis doch, die Vorherrschaft der Arbeit durch die eigene Arbeit zu verwinden. Auch wenn Nietzsche immer wieder die Muße der antiken Sklavenhalter polemisch aufruft, hat er doch keine konkrete Praxis und Lebensform abseits der Arbeit im Blick. Gefordert ist vielmehr die Anstrengung der Arbeit der Kritik. Erst diese Arbeit kann dann in eine andere Praxis umschlagen, die vielleicht eine ,andere Kunst' zu nennen wäre und eine Verwandtschaft zu den historisch vergangenen Lebensformen ,Muße und ,Müßiggang' hat.

Unter diesem Gesichtspunkt lässt sich die in Also sprach Zarathustra von Mitte der 1880er erzählte Fabel von den drei Verwandlungen wörtlich lesen: Verwandelt als Kamel muss der Denker in die Wüste; das Arbeitstier trägt die tradierten Werte auf eine ganz asketische Art und Weise; und nur so kann es sich in den Löwen verwandeln, der die Werte zerschlägt, und dieses Zerschlagen macht ihn zum Kind, welches so müßiggängerisch wie souverän mit diesen Werten wie sich selber spielt. ${ }^{23}$ Arbeit muss zunächst angenommen und auf sich selbst angewendet werden; sie muss selbst (mit dem Begriff Freuds in der Verwendung Werner Hamachers) durchgearbeitet werden. ${ }^{24}$ Überall, wo Nietzsches Projekt die allgemeinen Proklamationen bezüglich der Heroik, mit welcher der Löwe destruiert, oder der Leichtigkeit, mit welcher das Kind spielt, an der Auseinandersetzung mit konkreten kulturellen Formationen festmacht, findet sich „die grösste Mühe “ 25 betont, mit der Destruktion und Spiel erst möglich werden: als mühevolles Abarbeiten an den verordneten Arbeitsmühen, die so aber gegen sich

${ }^{21}$ Nietzsche, „Die fröhliche Wissenschaft“, in: KSA 3, 351.

22 Nietzsche, „Die fröhliche Wissenschaft", in: KSA 3, 538.

23 Vgl. Friedrich Nietzsche, „Also sprach Zarathustra“, in: KSA 4, 9-408, 30.

24 Vgl. Werner Hamacher, „Arbeit Durcharbeiten“, in: Dirk Baecker (Hg.), Archäologie der Arbeit, Berlin 2002, 155-200.

25 Nietzsche, „Die fröhliche Wissenschaft“, in: KSA 3, 422. 
gewendet und letztlich von sich befreit werden sollen. Nietzsches ganzes Projekt ist „[e]twas für Arbeitsame“ 26 : Für die ersten Schritte zum Miteinander der freien ,anderen Künstler' sollte „man kluger Weise nur mit Arbeitsamen Freundschaft schliessen“27.

Die entsprechenden Bemerkungen bei Nietzsche sind stets mit emphatischen Wertungen und Stilisierungen verbunden. Besonders markant geschieht dies in der größten Selbststilisierung Nietzsches in seiner philosophischen Autobiographie von 1888/1889 Ecce homo: Hier heißt es rückblickend, bereits in dem frühen Text aus den Unzeitgemäßen Betrachtungen: Vom Nutzen und Nachtheil der Historie für das Leben von 1874 habe Nietzsches Projekt sich, am Beispiel des Wissenschaftsbetriebs, zum ersten Mal über die moderne Strukturierung der Arbeit in der zeitgenössischen europäischen Kultur geäußert und damit auch erstmals deren „Krankheit“ und „Zeichen[] des Verfalls“ benannt. Die elliptische Erläuterung lautet: „Das Leben krank an diesem entmenschten Räderwerk und Mechanismus, an der Unpersönlichkeit des Arbeiters, an der falschen Ökonomie der ,Theilung der Arbeit'. Der Zweck geht verloren, die Cultur.“28

Nicht nur überrascht, dass Nietzsche die neuzeitliche ,Arbeitsteilung' rückblickend als das sein ganzes Schreiben beherrschende Problem stilisiert - in seinem Projekt taucht sie zwar in der Tat schon früh auf, wird aber sonst wenig behandelt. Auch wiederholt Ecce homo die Doppelung aus Emphase und Stillschweigen. Hier wird in der Einführung zum Abschnitt über die Unzeitgemäßen Betrachtungen die ,Arbeitsteilung' zwar als die Problemstellung der zweiten Unzeitgemäßen, Vom Nutzen und Nachtheil der Historie für das Leben, genannt. In der anschließend folgenden ausführlicheren Besprechung der Unzeitgemäßen Betrachtungen in Ecce homo findet dann aber ausgerechnet diese Abhandlung keine Erwähnung mehr. Eine Analyse der vorher so emphatisch behaupteten Krankheit der westlichen Kultur in ihrer Gänze wird einfach beiseite geschoben. Es mag sich dabei um ein Versehen handeln oder der Unabgeschlossenheit des Texts geschuldet sein. Die gleichzeitige Überbetonung und Marginalisierung der Kritik der Arbeit scheint aber auch in Nietzsches Kritik der Arbeit begründet: In der Sphäre der Arbeit sind Schreiben, Leben und Wissen bereits fest verortet. Um zu etwas zu gelangen, das nicht der Arbeit zugehörig wäre, muss die Arbeit von innen aus sich herausgewunden werden. Es gibt keine Position, von der aus man sie von außen befreien könnte.

In Vom Nutzen und Nachtheil der Historie für das Leben selbst wird die zeitgenössische Geschichtsschreibung mit ihrer jeglichen Sinns entleerten Faktenanhäufung als paradigmatisch für das Problem der Arbeit beschrieben: „Glaubt es mir: wenn die Menschen in der wissenschaftlichen Fabrik arbeiten und nutzbar

26 Nietzsche, „Die fröhliche Wissenschaft“, in: KSA 3, 378.

27 Nietzsche, „Menschliches, Allzumenschliches“, in: KSA 2, 491.

28 Friedrich Nietzsche, „Ecce Homo“, in: KSA 6, 255-374, 316. 
werden sollen, bevor sie reif sind, so ist in Kurzem die Wissenschaft ebenso ruiniert, wie die allzuzeitig in dieser Fabrik verwendeten Sclaven..${ }^{\prime 29}$ Die Arbeit, um die es in dem frühen Text geht, stellt also zunächst eine Ähnlichkeitsbeziehung dar: Die Erlangung von Wissen verläuft vergleichbar einer Produktherstellung durch Arbeit an den Maschinen der Fabriken. Nietzsches Text spricht sekundär von Arbeit, wo er theoretische Tätigkeit, primär die des Historikers (der Nietzsche als Kulturkritiker selbst auch ist) vom Problem der Arbeit befallen und überformt sieht. Wissen mit Fabrikarbeit zu vergleichen, lässt sich in diesem Sinne als ein geradezu notwendiger metaphorischer Akt stilisieren, den das Ich der Polemik nur zu gerne vermieden hätte: „Ich bedaure, dass man schon nöthig hat, sich den sprachlichen Jargons der Sclavenhalter und Arbeitgeber zur Bezeichnung solcher Verhältnisse zu bedienen, die an sich frei von Utilitäten, enthoben der Lebensnoth gedacht werden sollten. ${ }^{30}$ Doch ,frei von Utilitäten, enthoben der Lebensnoth ' wäre nur die befreite und eigentliche Arbeit, die der Kunst als kulturschöpferischer Tätigkeit. Nietzsches Text scheint sich durch die ,Noth' seiner Wortwahl in den arbeitsanthropologischen Diskurs zu verstricken: Das Wissen des Texts müsste sich eigentlich auf Seiten der Kunst platzieren, gehört aber doch in seiner Zeitgenossenschaft bereits der ,Arbeit ${ }^{`}$ an. D.h. das Wissen des Texts ist ebenfalls von Teilung, Nachträglichkeit, mangelndem Schöpfertum usw. bedroht.

Die hier beklagte Notwendigkeit der Metapher besteht nicht zuletzt darin, dass ,Arbeit 'im schlechten Sinne selbst schon metaphorisch in einer heteronomen Ersetzungsbeziehung operiert. Sie ist nicht für ein schöpferisches Selbst da, sondern immer bloß für anderes und andere - für das Geld, für die Fabrik, für den Besitzer, für seine Maschinen. Daher kann ,Arbeit' zu derjenigen Metapher werden, die es zu benutzen gilt, wo ein eigenständiges ,Schöpfertum 'verloren gegangen ist. In den Texten des jungen Nietzsche aus den frühen 1870ern geschieht dies, z.B. in „Ueber Wahrheit und Lüge“ oder im Lob der antiken Sklaverei in „Der griechische Staat“ ${ }^{\text {“11 }}$, seinerseits recht stereotyp: im Niedergang einer antiken griechischen Welt, deren Kultur sich in ihrer entfesselten und zu keinem Ende kommenden Sprachschöpfung Selbstzweck war. Hierbei handelt es sich zunächst bloß um das konservative, vergangenheitshörige Gegennarrativ zur marxistischen Erzählung von einer zukünftigen Kultur, in welche sich die befreite Arbeit als Selbstzweck verwirklichen wird. In Nietzsches Narrativ liegt diese Selbstzweckhaftigkeit in einem verlorenen Altertum. Doch interessant an Nietzsches Variante ist nicht der konservative Gestus, sondern die sprachliche und figurative Spannung, die dieser Gestus in einem Projekt bewirkt, welches sich voll und ganz in der eigenen Gegenwart verortet.

${ }^{29}$ Friedrich Nietzsche, „Unzeitgemäße Betrachtungen. Zweites Stück. Vom Nutzen und Nachteil der Historie für das Leben“, in: KSA 1, 243-334, 300.

${ }^{30}$ Nietzsche, „Vom Nutzen und Nachteil der Historie für das Leben“, in: KSA 1, 300.

31 Friedrich Nietzsche, „Der griechische Staat“, in: KSA 1, 764-777, 764. 
Wo sich die Metapher der Arbeit aufdrängt, wo die ,Arbeit' ,Noth' produziert und wo sie die Möglichkeit zur Bildung einer ,harmonischen Persönlichkeit' verstellt hat, da befindet sich auch der Diskurs Nietzsches nicht außerhalb der ,Arbeit'. Vielmehr ist er mit dieser uneinholbaren Metapher „in den Netzen der Sprache eingefangen “32, ihrer eigenen Sprache. ,Arbeit" wird somit zu einer - mit einem Wort von Hans Blumenbergs Interpretation von Nietzsches „Ueber Wahrheit und Lüge“ - „absoluten Metapher"33 erklärt. Nietzsches Behandlung der ,Arbeit' will gar nicht primär auf die real existierende Arbeit eingehen, sondern sich zuallererst mit der, ebenfalls mit einem Wort Hans Blumenbergs, „Metaphorologie“ 34 der Arbeit auseinandersetzen. Allerdings nicht als Begriffsgeschichtler oder distanzierter Zuschauer, sondern eingedenk der Organisation des Lebens, die von diesem sprachlichen Horizont (aus) organisiert wird, die auch Nietzsches Projekt betrifft. Diesen Horizont gilt es zu unterminieren: Es gilt eine Strategie zu entwickeln, den eigenen Diskurs der metaphorischen Fabrikarbeit zu entziehen, und das heißt meistens eben nicht, die ,Noth ' dieser absoluten Metapher offen zu benennen.

,Arbeit' gehört im Sinne von Nietzsches früher Sprachtheorie zu jenen vergessenen „Metaphern, die abgenutzt und sinnlos kraftlos geworden sind“35. Aber

32 Friedrich Nietzsche, „Nachgelassene Fragmente Herbst 1869 bis Ende 1874“, in: KSA 7, 9-838, 463.

33 Hans Blumenberg, Paradigmen zu einer Metaphorologie, Frankfurt a. M. 1998, 10. Allerdings ist dieser Begriff hier nur sinnvoll, wenn man Blumenbergs , absolute Metaphern nicht so sehr (in sehr großer Nähe zu Nietzsches „Ueber Wahrheit und Lüge“) als anthropologische Notwendigkeiten fasst, sondern eher mit einer von Rüdiger Campe ins Spiel gebrachten, von Blumenberg benutzten technischen Metapher als „Halbzeug“ (Rüdiger Campe, „Von der Theorie der Technik zur Technik der Metapher. Blumenbergs systematische Eröffnung", in: Anselm Haverkamp/Dirk Mende [Hg.], Metaphorologie. Zur Praxis von Theorie, Frankfurt a. M. 2009, 283-315, 283): als kulturelle, nicht zuletzt kulturtechnologische Gemengelage, die mit den metaphorischen Weltzugängen in ein Wechselverhältnis tritt. Die letzte Nietzscheanische Konsequenz zieht Blumenberg aus seiner Pointe, einen hermeneutischen Zugriff durch Metaphernanalyse zu ersetzen, allerdings nicht. Nietzsches „Ueber Wahrheit und Lüge" legt es nah, auch die darin formulierte anthropologische Mängelwesenhypothese, nach welcher die menschliche Metaphernschöpfung die menschliche Schwäche kompensiert, zumindest mit Vorsicht zu betrachten, leitet der Text doch andererseits dazu an, den jeweiligen menschlichen Weltzugriff über die dabei verwendeten,Metaphern' zu analysieren, auch die jeweiligen anthropologischen Voraussetzungen. In Blumenbergs metaphorologischem Projekt hält sich Nietzsches Mängelwesenhypothese jedoch am beständigsten. Zu Blumenbergs eigener, absoluter Metapher wird dabei markanterweise die ,Arbeit', durchaus im arbeitsanthropologischen Sinne: Die von Blumenberg ideologiekritisch analysierte „Arbeit am Mythos“ (die für Blumenberg eigentlich eine Arbeit des Mythos selbst ist und gegen den menschlichen Mangel antritt) transformiert durch, Arbeit ' die von der ursprünglichen Angst vor der Welt gegebenen Namen, idealerweise bis der Mythos sich selbst durchsichtig wird. Vgl. Hans Blumenberg, Arbeit am Mythos, Frankfurt a.M. 1979, 40-67, 127-162.

34 Blumenberg, Paradigmen zu einer Metaphorologie, 9.

35 Friedrich Nietzsche, „Über Wahrheit und Lüge im außermoralischen Sinne“, in: KSA $1,873-890,881$. 
eben, wo Nietzsche ihre angebliche sprachliche Gestaltungskraft verloren sieht, beschreibt er immer wieder, wie mit „langem Gebrauche“36 die Metaphern einem kulturellen Prozess der „Einverleibung ${ }^{\text {“37 }}$ unterliegen, von der aus sie Subjekte und ihre Weltverhältnisse bis ins Mikrodetail organisieren werden - ohne selbst dabei noch greifbar zu sein. Als abgegriffene Metapher wäre ,Arbeit' ein in die Kulturtechnologien des Weltzugangs eingesickertes Wahrheitsregime wie eine in die Sprachen eingesickerte Protowahrheit, die sich in ihren Wirkungen beobachten aber nicht mehr als solche, oder eben bloß noch metaphorisch, benennen lässt und bloß nebenbei, so grell wie undifferenziert, angegriffen werden kann. Die als notwendig stilisierte Metaphorisierung von Wissen als Arbeit versteht sich in eben diesem Sinne als das Gegenteil einer „schöpferisch[en]“ „Herrschaft der Kunst über das Leben " ${ }^{38}$ : Sie ist ein Ausbuchstabieren der unkreativen ja fast antimetaphorischen Effekte der Arbeitsmetapher. Dies gilt in Nietzsches Menschheits- und Metapherngeschichte nicht nur für die Metapher der ,Arbeit', sondern für das Vergessen der schöpferischen Metaphernbildung generell. Mit diesem Vergessen sieht das Subjekt sich einer objektiven Wahrheit gegenüber, zu der es sich nachträglich verhalten muss. Bereits mit dieser anfänglichen „Vergesslichkeit ${ }^{\text {"39 }}$ der schöpferischen Metaphernbildung setzt die Fremdbestimmung ein: als eine ,Sklaverei', die später den Namen ,Arbeit trägt. In der ,Arbeit' als einer Metapher für das Vergessen der schöpferischen Metaphernbildung wird anstelle der schöpferischen Metaphernbildung die gebildete Metapher für Wahrheit genommen. Als "Zeichen der Dienstbarkeit" ${ }^{40}$ gilt es demnach, der tradierten Sprache mit dem in ihr tradierten und sedimentierten Weltzugang anzuhängen. Unschöpferisch arbeitend im Sinne von ,sklavisch 'ist somit bereits jedes Welt- und Sprachverhältnis, das die Metaphern für Wahrheit nimmt. Noch nicht dieser Weltzugang ist sklavisch (wie dies Nietzsches spätere Kritik der christlichen Moral als einer Sklavenmoral suggeriert). Sklavisch ist es, ihm ,dienstbar' zu folgen. Deshalb kann die ,Arbeit' bei Nietzsche in erster Linie immer schon eine Zweitrangigkeit, d.h. eine Metapher, darstellen, die uneinholbar bleibt: als Metapher für das Vergessen der eigenen ,Schöpfung in einer Fremdbestimmung durch eben diese, Schöpfung. ${ }^{41}$

Voll von konstruktivistischem Optimismus behauptet der Künder einer Fröhlichen Wissenschaft zwar bekanntlich, dass „,es genügt, neue Namen zu schaffen, um auf Länge hin neue ,Dinge' zu schaffen". Aber dieser Optimismus bricht sich

36 Nietzsche, „Über Wahrheit und Lüge im außermoralischen Sinne“, in: KSA 1, 880.

37 Nietzsche, „Die fröhliche Wissenschaft“, in: KSA 3, 471.

38 Nietzsche, „Über Wahrheit und Lüge im außermoralischen Sinne“, in: KSA 1, 889.

39 Nietzsche, „Über Wahrheit und Lüge im außermoralischen Sinne“, in: KSA 1, 881.

40 Nietzsche, „Über Wahrheit und Lüge im außermoralischen Sinne“, in: KSA 1, 888.

${ }^{41}$ Dies stellt das Schema bereit für die „Tragödie der Kultur" nach Simmel: Diese Tragödie besteht darin, dass der Mensch seine Produktivität in der selbstgeschaffenen, aber verhärteten Kultur nicht wiedererkennt. Vgl. Georg Simmel, „Der Begriff und die Tragödie der Kultur", in: Simmel, Philosophische Kultur. Gesammelte Essais, Potsdam 1923, 236-267. 
durchgängig an der Anstrengung der ,Arbeit': „Dies hat mir die grösste Mühe gemacht und macht mir noch immerfort die grösste Mühe". Denn der berühmte Satz „Nur als Schaffende können wir vernichten!" 42 heißt auch, dass nur in einer Beendigung der Mühen der ,Arbeit' ein befreites ,Schaffen' möglich wäre. Aber das Abtragen der Mühen wird seinerseits mühevolle Arbeit sein. Das schreibende ,Ich' und das rhetorische,Wir' wird sich voll und ganz jene Metapher einverleibt haben und von jener Metapher her schreiben, gegen die es anzugehen gilt. Arbeit heißt hier, in der alten Sprache zu schreiben und sie anders zu wiederholen. Und diese Veränderung ist es, die Arbeit in eine Kunst, aber eine , andere Kunst' transformiert. Sie wäre dann keine Arbeit mehr und daher anschlussfähig an Praktiken wie Muße und Müßiggang.

Eine entsprechende textuelle Strategie findet sich in den bekannten Passagen über Muße und Müßiggang Betrachtung im ersten Band von Menschliches, Allzumenschliches von 1878 angedeutet. Kurz nach der zweiten Unzeitgemäßen sind Nietzsches Kritik an der Arbeitsgesellschaft und ein entsprechendes Lob der (antiken und romantischen) Nichtarbeit hier besonders prominent. Bereits hier heißt es, dass „Arbeit und Fleiß - sonst in Gefolge der grossen Göttin Gesundheit - mitunter wie eine Krankheit zu wüthen scheinen "43. Das Problem liegt also nicht in der Produktivität an sich, sondern in ihrer Organisation, nicht zuletzt ihrer zeitlichen: ,Arbeit und Fleiß` sind bereits selbst, wie eine Krankheit', wo sie doch ,sonst' der, Gesundheit 'bloß nachfolgen. Das Problem liegt in ihrer Verselbständigung. Diese wird als ,Krankheit' zuerst das Wissen befallen, womit der Text das frühere Argument aus den Unzeitgemäßen Betrachtungen aufgreift: „Der Freigeist ist in Verruf gebracht, namentlich durch Gelehrte, welche an seiner Kunst, die Dinge zu betrachten, ihre Gründlichkeit und ihren Ameisenfleiss vermissen. " ${ }^{44}$ Das Problem des modernen Wissens wird mit einer Abwesenheit der Passivität im antiken Sinne zusammengebracht: „Die Gelehrten schämen sich des otium", also der Ruhe der aristotelischen Muße. Sie versuchen stattdessen, jene höhere Wirkungskraft des Maschinellen zu imitieren, welche auf der repetitiven Stupidität des Immergleichen beruht: „Die Thätigen rollen wie der Stein rollt, gemäss der Dummheit der Mechanik. “" ${ }^{45}$

Die Suche nach einer anderen Hervorbringung von Wissen hätte sich daher „, $[z]$ u Gunsten der Müssigen“ 46 umzuorientieren, d.h. zugunsten derjenigen,

42 Nietzsche, „Die fröhliche Wissenschaft", in: KSA 3, 422.

${ }^{43}$ Nietzsche, "Menschliches, Allzumenschliches“, in: KSA 2, 230.

44 Nietzsche, „Menschliches, Allzumenschliches“, in: KSA 2, 231.

45 Nietzsche, „Menschliches, Allzumenschliches“, in: KSA 2, 232.

46 Nietzsche, „Menschliches, Allzumenschliches“, in: KSA 2, 232. 
welche der Passivität im befreiten Sinn einer ,anderen Kunst' frönen. Diese Passivität umfasst hier beide Konnotationen, welche die Rede vom Müßigen aufruft. Sowohl die ,Muße als direkte Nachfolge der aristotelischen schole und scholastischen vita contemplativa als auch der romantische ,Müßiggang', der eher mit dem ungezwungenen und ziellosen Ausprobieren verschiedener Tätigkeiten assoziiert ist, finden Platz, wo Nietzsche vom ,edel Ding um Muße und Müßiggehen' spricht. Allerdings werden sie gerade nicht zum positiven Gegenstück der Arbeit erklärt: „Wenn der Müssiggang wirklich der Anfang aller Laster ist, so befindet er sich also wenigstens in nächster Nähe aller Tugenden, der müssige Mensch ist immer noch der bessere Mensch als der thätige. " ${ }^{47}$ Betont ist statt des positiven Gegenentwurfs ein zeitlicher Index: Eine Lasterhaftigkeit des müßigen Menschen wird kaum bestritten, sie ist aber noch nicht eingetreten. Der müßige Mensch steht bloß insofern am Anfang des Lasters, als dass er noch nicht angefangen hat, tätig zu werden, also für Nietzsche: ,faul' und ,dumm' ist.

,Anfang' ist vom Text hervorgehoben. Wiederholt findet sich so zwar das mittelalterliche, vom Bürgertum angeeignete Sprichwort (das seinerseits Aquins Bestimmung der acedia als Einfallstor für die anderen Todsünden wiederholt). Aber der Akzent wird doch deutlich verschoben, indem es nicht mehr um den Müßiggang, sondern um den Modus des ,Anfangens' geht. ,In nächster Nähe aller Tugenden' kann der Müßiggang sich befinden, weil er mit dem Laster noch gar nicht angefangen hat und sich noch ganz nahe bei allen (bürgerlichen) Tugenden aufhält. Gleichzeitig findet sich aber der ,Anfang' durch die Hervorhebung selbst zu einer Tugend erklärt, da er dem Müßiggang im Sprichwort eben am nächsten steht. Impliziert ist so, dass , alle Tugenden' daraus ihre Tugendhaftigkeit beziehen, dass sie einen ,Anfang' in sich tragen - und nicht die heteronomen Wiederholungen. D.h. in dieser Akzentverschiebung steht plötzlich nicht mehr die Alternative zwischen Arbeit und Nichtarbeit, zwischen heteronomer Arbeit und Kunst, zwischen regressiver Faulheit und produktiver Muße auf dem Spiel. Die Unterscheidungen und Umwertungen weichen an einer der Stellen, in denen Nietzsche Unterscheidung und Umwertung am lautesten proklamiert, einer Unentscheidbarkeit. Und diese Unentscheidbarkeit wird ihrerseits der einen Seite der Unterscheidung, nämlich der Muße, zugeschlagen.

Der hier gelobte ,Anfang' kann bloß ein Innehalten sein, denn der Satz fängt mit nichts an. Er wiederholt seinerseits eine Wiederholung: ein Sprichwort, ohne dass sich das Sprichwort wiederholte. Und sei es als seine eigene Umkehrung. Auch Muße und Müßiggang finden sich nicht positiv aufgefüllt. Ihr Vorteil liegt einzig in ihrem sprichwörtlichen Anfang, der hier selbst mit nichts anfängt, aber die Wiederholung aussetzt. Er mag unentschieden zwischen Arbeit und Nichtarbeit, zwischen Mühsal und Befreiung verharren. In der Umorientierung der Wiederholung auf den ,Anfang' ist aber doch Nietzsches Unterwanderung der

47 Nietzsche, „Menschliches, Allzumenschliches“, in: KSA 2, 232. 
Vorherrschaft der Arbeit auf den Punkt gebracht: ihr als unumgänglich gefasstes heteronomes Wiederholungsschema seinerseits zu wiederholen und auf eine andere mögliche Zukunft zu öffnen. Mit dem Aussetzen der Wiederholung, das nichts anderes an ihre Stelle setzt, käme einer zukünftigen Wiederholung tatsächlich die Möglichkeit zu, anders zu sein - und somit für Zukünftiges tatsächlich offen: für etwas anderes als die Arbeit.

Alles Ausgeführte gilt zuallererst eben für das, wie Nietzsche es nennt, „Kla-

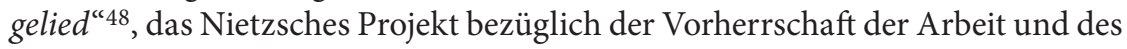
Verlusts der Muße anstimmt. Menschliches, Allzumenschliches kennzeichnet die eigene Kulturkritik seinerseits als erstens stereotyp: also in dem Wiederholungsmuster befangen, das auch die Repetitivität der Arbeit ausmacht; aber zweitens auch als vergänglich: als im Unterschied zur Arbeit nicht darauf aus, sich endlos zu reproduzieren. „- Eine solche Klage, wie die eben abgesungene, wird wahrscheinlich ihre Zeit haben und von selber einmal [...] verstummen“. ${ }^{49}$ Im günstigsten Falle geschieht dies, wenn ein Schreibprojekt wie dasjenige Nietzsches die Arbeit durchgearbeitet und sich zu dem befreit hat, was es als schöpferisches Spiel der antiken Muße und dem romantischen Müßiggang assoziiert.

4.

Nietzsche konnte kaum ahnen, dass das ,Zeitalter der Arbeit ${ }^{`}$ am Ende des 20. Jahrhunderts seinerseits Begriffe wie Schöpfertum, Kreativität oder produktive Muße der Heteronomie der Arbeit einverleiben würde: Nietzsche-Zitate zu Arbeit und Nichtarbeit erleben Anfang des 21. Jahrhunderts eine neue Konjunktur. Ihr aphoristischer Charakter verleiht ihnen eine Zitierfähigkeit, aufgrund derer sie in kaum einer der einschlägigen Publikationen fehlen dürfen. Anleitung zum Müßiggang, Wörterbuch des Müßiggängers, Die Entdeckung der Faulheit, Enzyklopädie der Faulheit ${ }^{50}$ : So lauten die ernsthafteren Titel, die meist einen ähnlichen Einsatzpunkt haben: In den Arbeitsgesellschaften der industrialisierten und postindustrialisierten Welt kann auch noch der privateste Affekt zur Arbeit umgedeutet und nach ihren Maßstäben strukturiert werden. Durchorganisation und Leistung gelten dann auch für Trauerarbeit, Beziehungsarbeit oder Entspannungsarbeit. ${ }^{51}$ Oft geht es den Müßiggang-Ratgebern nicht um eine

48 Nietzsche, „Menschliches, Allzumenschliches“, in: KSA 2, 230.

49 Nietzsche, "Menschliches, Allzumenschliches“, in: KSA 2, 231.

50 Aufgezählt bei Leonhard Fuest, Poetik des Nicht(s)tuns, München 2008, 11. Vgl. auch Karlheinz A. Geißler, Alles hat seine Zeit, nur ich hab keine. Wege in eine neue Zeitkultur, München 2011; Mario Früh (Hg.), Zeit für Muße. Soll/Haben, zwei Bände, Frankfurt a.M. 2011; Ulrich Schnabel, Muße. Vom Glück des Nichtstuns, München 2010; Gisela Dischner, Wörterbuch des Müßiggängers, Berlin 2009; Fritz Reheis, Die Kreativität der Langsamkeit. Wohlstand durch Entschleunigung, Darmstadt 2008.

51 Vgl. Rudolf Helmstetter, „When everything is work it's hard to know what's not (Wir 
konkrete Kritik der Arbeitsgesellschaft, sondern darum, Burnout und Langeweile vorzubeugen und stattdessen ein erfülltes Leben (inklusive einer erfüllenden und wohlvergüteten Lohnarbeit) leben zu können. Muße und Müßiggang lassen demnach in einer von Arbeit befreiten Zeit die eigentlichen Bedürfnisse erkunden und verwirklichen - und so vielleicht hinterher anders und selbstbestimmter wieder in der Arbeitsgesellschaft Fuß fassen. Ganz im Sinne Nietzsches und seiner Vorgänger stellen Muße, Müßiggang etc. zwar keine Arbeit im eigentlichen Sinne dar; sehr wohl sollen sie aber die bessere Arbeit sein, in der das Individuum durch eine höhere Produktivität dasjenige findet, was seinem individuellen Lebensentwurf entspricht. Manchmal geht es schlicht auch bloß um die Erlangung der nötigen Auszeiten, die davor bewahren, ganz den Zwängen der Arbeitsgesellschaft zu verfallen: Mit ein wenig Muße und Müßiggang lässt sich die Arbeit viel besser bewältigen, lässt sich der Job finden, der mehr den eigenen Bedürfnissen entspricht usw.

Diese Muße- und Müßiggang-Ratgeber arbeiten ihrerseits einer Tendenz zu, die in den 1990er und 2000er Jahren auf dem Arbeitsmarkt der sogenannten westlichen Welt häufig beobachtet worden ist. Besonders prominent weisen die soziologischen Studien von Luc Boltanski und Ève Chiapello, Der neue Geist des Kapitalismus (1999) und Ulrich Bröckling, Das unternehmerische Selbst (2007) darauf hin, dass statt der Festangestellten, die ihre Aufgaben zuverlässig erledigen, nun vom Arbeitsmarkt der Typ Künstler gefordert wird. ${ }^{52}$ Der Arbeiter soll in der imaginierten schönen neuen Arbeitswelt nicht mehr auf sein Fachgebiet spezialisiert sein und zuverlässig in einem festen vorgegebenen Rahmen seine Aufgaben ausführen, um dann am Feierabend heimgehen zu dürfen. Gefragt auf einem zunehmend flexibilisierten und deregulierten Arbeitsmarkt sind stattdessen Attribute, die das 19. Jahrhundert dem Kunstdiskurs zuschreibt und welche sich in der populärkulturellen Wahrnehmung des Kunstbetriebs seitdem hartnäckig halten: Kreativität, Eigeninitiative, flexibler Umgang mit wechselnden Bedingungen und unterschiedlichen Kontexten, eine Vermischung von Leben und Arbeit.

Auf entstellte Art und Weise wird Nietzsches Ideal eines Umschlags von der Sklavenmoral des fremdbestimmten Arbeiters in die je singuläre Selbstschöpfung des Individuums am Ende des 20. Jahrhunderts von diesen Diskursen aufgenommen: Die fremdbestimmten Arbeitenden, die eben für Geld arbeiten und nicht für sich, sollen sich nicht als Spezialisten, sondern als ganze Individuen in ihre Arbeit einbringen. Der Lebenslauf stellt, so hört man es schon lange auf den von der Agentur für Arbeit angebotenen Fortbildungen, samt Hobbies und

arbeiten dran)“, in: Jörn Etzold/Martin Jörg Schäfer (Hg.), Nicht-Arbeit. Politiken, Konzepte, Ästhetiken, Weimar 2011, 40-79.

52 Vgl. Luc Boltanski/Ève Chiapello, Der neue Geist des Kapitalismus, Konstanz 2003; Ulrich Bröckling, Das unternehmerische Selbst. Soziologie einer Subjektivierungsform, Frankfurt a.M. 2007. 
Auszeiten das kleine Kunstwerk dar, das die eigene Individualität dem Markt anpreisen soll. Nietzsches,Wir aber wollen die Dichter unseres Lebens sein' wird auf dem Arbeitsmarkt der 1990er und 2000er Jahre jedoch ein ,Wir sollen die Dichter unseres Lebens sein'. Hundert Jahre nach Nietzsche kehrt sein auf individuelles Glück und gegen eine heteronome Gesellschaft gerichteter Diskurs als ökonomischer Zwang wieder: als Anforderung an die beständig aktualisierte Selbstpräsentation eines mit dem Wort Ulrich Bröcklings , unternehmerischen Selbst'. Aus ,Wer von seinem Tage nicht zwei Drittel für sich hat, ist ein Sclave, er sei übrigens wer er wolle' wird oft der flexibel und frei eingeteilte Tag, der trotzdem ganz im Zeichen der Lohnarbeit steht: sei es der Weiterbildung als Arbeit am Lebenslauf, sei es der Lohnarbeit, die ,Spaß bringt', sei es dem Neuentwurf des eigenen Selbst, um mit Haut und Haaren für die neue Stelle qualifiziert zu sein. Angeblich gewinnt, wer sein eigenes Leben am besten erdichten kann. Und wer verliert, muss besser das Dichten lernen: Muße und Müßiggang, die mit einem Wort Michel Foucaults seit dem Aufkommen von Arbeitsgesellschaft, Ökonomisierung und Produktivitätszwang im 18. Jahrhundert letzte mögliche Form von Protest gegen diese darstellen ${ }^{53}$, dienen nunmehr (ihrer) der Aufrechterhaltung der Arbeitsgesellschaft und der Produktivitätssteigerung. - Vielleicht bedarf es dafür heute neuer Nietzscheanischer Strategien des Durcharbeitens, Verschiebens und Unterbrechens.

53 Vgl. Michel Foucault, Wahnsinn und Gesellschaft. Eine Geschichte des Wahns im Zeitalter der Vernunft, Frankfurt a. M. 1996, 91. 


\title{
Kein Raum für Muße? Georg Simmel und die ,ruhelose Rhythmik der Moderne
}

\author{
Annika Schlitte
}

\section{Einleitung: Muße unter den Bedingungen spätmoderner Beschleunigung}

„Geschwindigkeit bringt Hertzenleid“ - was in einem Lexikon der Sprichwörter von 1605 als Volksweisheit aufgeführt wird und auch im 19. Jahrhundert in einschlägigen Sammlungen zu finden ist ${ }^{1}$, scheinen zu Beginn des 21. Jahrhunderts eine Reihe von Soziologen und Medientheoretikern der späten Moderne ins Poesiealbum schreiben zu wollen. Die Kritik an der allgegenwärtigen Zeitknappheit und Schnelllebigkeit bevölkert seit der differenzierten Beschleunigungstheorie von Hartmut Rosa die Feuilletons. Auf rasenden Stillstand (Virilio) und Beschleunigung (Rosa) folgen Das erschöpfte Selbst (Ehrenberg) und die Müdigkeitsgesellschaft (Han) ${ }^{2}$, und auf kulturphilosophischer Seite analysiert Ralf Konersmann jüngst die Unruhe der Welt. ${ }^{3}$

Dass in dieser Gemengelage auch ein gesteigertes Bedürfnis nach Erfahrungen von Muße geäußert wird, ist wenig überraschend ${ }^{4}$, verbindet man mit diesem Begriff doch gemeinhin ein zeitliches Moment - wie der Duden es formuliert, bezeichnet Muße die „freie Zeit und [innere] Ruhe, um etwas zu tun, was den eigenen Interessen entspricht ${ }^{\text {“5 }}$. Ausgehend von Georg Simmels Analyse der Moderne soll im Folgenden plausibel gemacht werden, dass die spätmoderne Sehnsucht nach Muße sich (auch) als Gegenkonzept zu den spezifisch modernen

${ }^{1}$ Friedrich Karl Wilhelm Petri, Der Teutschen Weissheit, Hamburg 1605, 492.

2 Vgl. Hartmut Rosa, Beschleunigung. Die Veränderungen der Zeitstrukturen in der Moderne, Frankfurt a. M. 2005; Paul Virilio, Rasender Stillstand, München/Wien 1992, Alain Ehrenberg, Das erschöpfte Selbst. Depression und Gesellschaft in der Gegenwart, Frankfurt a. M. 2008; Byung-Chul Han, Müdigkeitsgesellschaft, Berlin 2010.

3 Ralf Konersmann, Die Unruhe der Welt, Frankfurt a. M. 2015.

4 Vgl. zu diesem Thema bespielhaft das Interview, das Ulrich Schnabel unter der Überschrift „Muße braucht Zeit“ in der Wochenzeitung DIE ZEIT vom 30.12.2009 mit Harmut Rosa geführt hat.

5 Dudenredaktion (o. J.), „Muße“ auf Duden online, http://www.duden.de/rechtschrei bung/Musze (Abrufdatum 14.02.2017). 
Bedingungen der Raum- und Zeiterfahrung verstehen lässt, die als Entfremdung erlebt werden. Wenn Georg Simmel die räumlichen und zeitlichen Dimensionen des modernen Lebens explizit thematisiert und bereits zu ähnlichen Ergebnissen kommt wie aktuelle Analysen der Beschleunigung, setzt er der räumlichen und zeitlichen Entfremdungserfahrung zwar kein ausgearbeitetes Konzept von Muße entgegen. Gleichwohl kann die Verwendung des Begriffs als Analysekategorie hilfreich sein, um verschiedene Ansätze zur Überwindung der Pathologien der Moderne, die sich bei Simmel finden lassen, zusammenzuführen.

Bei „Muße" handelt es sich um ein Phänomen, das sich mit den kulturellen und gesellschaftlichen Rahmenbedingungen wandelt und insbesondere mit der herrschenden Vorstellung von Arbeit eng verbunden ist. ${ }^{6}$ Ohne eine genaue begriffliche Abgrenzung von Muße leisten zu können, seien zur besseren Einordnung daher einige Differenzierungen vorangeschickt, mit deren Hilfe jüngst versucht worden ist, Muße zu konzeptualisieren. ${ }^{7}$

Zunächst einmal ist zwischen Muße und Freizeit zu unterscheiden. ${ }^{8}$ Während differenzierte Formen der Freizeitgestaltung sich in der modernen westlichen Industriegesellschaft gleichsam als Kehrseite der Erwerbsarbeit herausgebildet haben und Freizeit so von der Arbeit abhängig bleibt (ganz konkret etwa in der Funktion, die Arbeitskraft zu reproduzieren oder die produzierten Güter zu kaufen und zu verbrauchen), geht die Muße auf ältere Wurzeln zurück, die in der antiken Verbindung von theoria und scholé zu suchen sind, über die Aristoteles in der Nikomachischen Ethik spricht. Hier und in der Politik unterscheidet er deshalb die Muße als selbstzweckhafte Tätigkeit von der Erholung von der Arbeit, dem Spiel. ${ }^{9}$ Muße ist hier also nicht Untätigkeit, sondern freie Tätigkeit (praxis), die wiederum von den herstellenden Tätigkeiten, die ihren Zweck außer sich haben, unterschieden wird (poiesis). ${ }^{10}$ Paradigmatisch für selbstzweckhaftes Tun ist jedoch nicht das politische Leben (praxis), sondern die Kontemplation (theoria), auf die in Spätantike und Mittelalter immer wieder als Glücksquelle Bezug genommen wird. ${ }^{11}$ Mit der Aufwertung der Arbeit in der Moderne ändert sich der Bezugsrahmen, bis sich Freizeit im 20. Jahrhundert als üblicher Gegenbegriff

${ }^{6} \mathrm{Zu}$ der problematischen Alternative Arbeit vs. Muße vgl. den Beitrag von Tobias Keiling in diesem Band.

7 Vgl. Joachim Gimmel/Tobias Keiling u. a., Konzepte der Muße, Tübingen 2016; Christoph Henning, „Glück in Arbeit und Muße. Das Spektrum der Tätigkeiten vom Denken zum Feiern“, in: Dieter Thomä/Christoph Henning/Olivia Mitscherlich-Schönherr (Hg.), Glück. Ein interdisziplinäres Handbuch, Stuttgart 2011, 32-42.

8 Vgl. zum Verhältnis von Arbeit, Freizeit und Muße Joachim Gimmel/Tobias Keiling u. a., Konzepte der Muße, Tübingen 2016, Kapitel 2.1, 11-23.

9 Aristoteles, Politik, übers. von Olof Gigon, München 1973, 1338 a 1.

10 Vgl. Aristoteles, Die Nikomachische Ethik, übers. von Olof Gigon, München 1967, 1094 a $1-26$.

11 Vgl. Gimmel/Keiling, Konzepte der Muße, 12 sowie 24-31. 
zu Arbeit etabliert und die aus der Antike überlieferte Konzeption von Muße frag-würdig oder als Müßiggang negativ besetzt wird. ${ }^{12}$

Wenn sich heute ein Unbehagen an der Reduktion des Lebens auf Arbeit und Erholung von der Arbeit artikuliert, gerät das einstige Glücksversprechen von Muße wieder in den Blick. Die von vielen konstatierte Beschleunigung des Alltags scheint der Verwirklichung von Muße jedoch eindeutig im Wege zu stehen, weshalb also verstärkt nach den Möglichkeiten, in unserer Gesellschaft Freiräume für die spezifische Erfahrung von Muße zu schaffen, gefragt wird. Mit dem Begriff „Freiraum“ ist neben dem bereits angesprochenen zeitlichen auch ein räumliches Moment der Muße angesprochen - beide Aspekte scheinen von gesellschaftlichen Entwicklungen bedroht zu werden, die mit der Moderne insgesamt assoziiert werden können. Wie im Folgenden beispielhaft an Georg Simmels Analyse der modernen Gesellschaft gezeigt werden soll, sind Raum- und Zeiterfahrungen selbst historisch variabel, und Veränderungen in diesem Bereich wirken sich daher auch auf die Rahmenbedingungen von Muße aus.

Der Beginn der Beschleunigungstendenz, die uns den Zugang zu Erfahrungen von Muße heute erschwert, wird häufig in der Moderne gesehen, wobei Veränderungen in der Raum- und Zeiterfahrung zusammenkommen. Schließlich gehört zu den genuinen Kennzeichen des modernen Lebensgefühls auch eine veränderte Zeiterfahrung, wie beispielsweise Baudelaires prominente Definition des Modernen als des Transitorischen, Flüchtigen nahelegt. Die Vorliebe für Geschwindigkeit einerseits und die Klage über das beschleunigte Lebenstempo andererseits wurden spätestens mit dem Siegeszug neuer Verkehrsmittel und Kommunikationstechniken Anfang des 20. Jahrhunderts zu einer Art kollektiver Obsession. ${ }^{13}$ Der Eindruck, dass die Gesellschaft sich immer schneller verändert, wurde schon früh formuliert ${ }^{14}$ und entwickelte sich mit der zunehmenden Industrialisierung spätestens seit dem anbrechenden 19. Jahrhundert zu einer vorherrschenden Erfahrung. ${ }^{15}$

Mit der Erfahrung der Moderne als einer beschleunigten Zeit geht - ebenfalls seit dem 19. Jahrhundert - die These einer zunehmenden Ablösung vom Raum einher, die schließlich im Verschwinden des Raumes gipfeln soll. ${ }^{16}$ Die Vorstel-

12 Vgl. Henning, „Glück in Arbeit und Muße“, 34-37.

13 Klassisch zu den Auswirkungen des beschleunigten Verkehrs: Wolfgang Schivelbusch, Geschichte der Eisenbahnreise. Zur Industrialisierung von Raum und Zeit im 19. Jahrhundert, Frankfurt a.M. 2000.

14 Vgl. Reinhart Koselleck, „Gibt es eine Beschleunigung in der Geschichte?“, in: Koselleck, Zeitschichten. Studien zur Historik, Frankfurt a. M. 2000, 150-176, 153.

15 In seinem Buch über die Unruhe betont Konersmann dagegen, nicht die Unruhe selbst sei ein modernes Phänomen, sondern unsere positive Einstellung zu ihr. Vgl. Konersmann, Die Unruhe der Welt, $42 \mathrm{f}$.

16 Vgl. Markus Schroer, „Bringing space back in. Zur Relevanz des Raums als soziologischer Kategorie“, in: Jörg Döring/Tristan Thielmann, (Hg.), Das Raumparadigma. Zur Standortbestimmung des Spatial turn. Bielefeld 2008, 125-148. 
lung, dass durch die schnellere Überbrückung weiter Distanzen, wie sie zuerst mit der Eisenbahn möglich war, die Bedeutung des Raumes insgesamt abnimmt, dass der Raum "getödtet" wird, wie Heine angesichts des neuen Verkehrsmittels schrieb $^{17}$, ist eine Vorstellung, die mit der Einführung des Internets und der globalisierten Wirtschaft heute wieder Konjunktur hat. ${ }^{18}$ So hat David Harvey für die Erfahrung der Mobilität in einer global vernetzten Welt den wirkmächtigen Begriff der „Space-Time-Compression“ geprägt, wobei auch er auf die Beschleunigung des Reisetempos rekurriert. ${ }^{19}$ Paul Virilio konstatiert ein Verschwinden des Raumes ${ }^{20}$, und auch Hartmut Rosa hält die „Emanzipation der Zeit vom Raum“ für die „Geburtsstunde der Moderne“21.

Bemerkenswert ist jedoch, dass gleichzeitig mit der Klage über das Verschwinden des Raumes allerorten in den Kultur- und Sozialwissenschaften von einer Wiederkehr des Raumes die Rede ist, die im Rückblick zeitlich mit dem Anbruch einer Epoche zusammentrifft, die gemeinhin als Postmoderne bezeichnet wird. So hat nicht nur Foucault schon Ende der 1960er-Jahre das Zeitalter des Raumes ausgerufen, auch Fredric Jameson hat davon gesprochen, „daß unser Alltag, daß unsere psychischen Erfahrungen und die Sprachen unserer Kultur heute - im Gegensatz zur vorangegangenen Epoche der ,Hochmoderne - eher von den Kategorien des Raumes als von denen der Zeit beherrscht werden“22.

Dieser widersprüchliche Befund - einerseits Vernichtung, andererseits Wiederkehr des Raumes - lässt auf eine unklare Begriffsbestimmung schließen, wie Markus Schroer richtig bemerkt. ${ }^{23}$ So wird in den entsprechenden kultur- und medienwissenschaftlichen Diagnosen oft nur unzureichend reflektiert, von welcher Art von Raum eigentlich die Rede ist. Es bleibt also zu prüfen, ob man tatsächlich von einem Verschwinden des Raumes sprechen kann oder ob man es nicht vielmehr mit einer Transformation der Raumerfahrung zu tun hat, die sich mit der zeitlichen Beschleunigungstendenz paart. Wenn es jedoch für Muße charakteristisch ist, dass „,sich mit dem Zustand der Muße die Erfahrungen von

17 Heinrich Heine, Lutezia, Teil 2, LVII (05.05.1843), Historisch-kritische Gesamtausgabe der Werke (=Düsseldorfer Ausgabe), hg. v. Manfred Windfuhr, Bd. 14/1, bearb. v. Volker Hansen, Hamburg 1990, 58.

18 Hierzu vgl. Peter A. Berger, „Anwesenheit und Abwesenheit. Raumbezüge sozialen Handelns", in: Berliner Journal für Soziologie 1 (1995), 99-111.

19 Vgl. David Harvey, The Condition of Postmodernity. An Enquiry into the Origins of Cultural Change, Malden, MA/Oxford 1990, 201-323.

20 Vgl. Paul Virilio, „Das dritte Intervall, Ein kritischer Übergang“, in: Edith Decker/ Peter Weibel (Hg.), Vom Verschwinden der Ferne. Telekommunikation und Kunst, Köln 1990, 335-346, 346: „Der Raum zieht sich zusammen und verschwindet in der weltweiten Vernetzung der Teletechnologien.“

21 Rosa, Beschleunigung, 61.

22 Fredric Jameson, „Postmoderne. Zur Logik der Kultur im Spätkapitalismus“, in: Andreas Huyssen/Klaus R. Scherpe (Hg.), Postmoderne. Zeichen eines kulturellen Wandels, Reinbek bei Hamburg: Rowohlt 1986, 45-102, $60 \mathrm{f}$.

23 Vgl. Schroer, „Bringing space back in“, 132. 
Raum und Zeit verändern“24, wenn Muße als Phänomen durch ihre spezifische Raumzeitlichkeit charakterisiert werden kann, dann haben die historischen Veränderungen in der Raum- und Zeiterfahrung auch Auswirkungen auf die Möglichkeit der Muße. ${ }^{25}$

Es kann daher lohnend sein, noch einmal auf die Klassiker der soziologischen Theorien der Moderne zurückzugehen - wie Rosa es selbst vorschlägt ${ }^{26}$ - und dort nach Reflexionen über eine veränderte Raum- und Zeiterfahrung zu suchen. Georg Simmel bietet sich aus mehreren Gründen für ein solches Vorhaben an: Zum einen hat er Ansätze zu einer Soziologie des Raumes entwickelt, die ihm einen Platz als Vorläufer der modernen Raumsoziologie gesichert haben. Zudem ist in Bezug auf seine Gesellschaftsdiagnose bemerkenswert, dass er der Alltagserfahrung des modernen Menschen große Aufmerksamkeit widmet, so dass die Moderne bei ihm insgesamt durch eine besondere Art der Erfahrung charakterisiert wird. ${ }^{27}$ In diesem Punkt ist sein Ansatz von der Stoßrichtung der Zeitdiagnose Hartmut Rosas nicht allzu weit entfernt. In der 1900 erschienenen Philosophie des Geldes, die von vielen als eine Theorie der modernen Kultur interpretiert wird, behandelt Simmel nicht nur Prinzip und Funktion der Geldwirtschaft, sondern auch die Auswirkungen der modernen, von der Geldwirtschaft geprägten Kultur auf das Lebensgefühl der Einzelnen. ${ }^{28}$ Bei diesem Lebensgefühl spielen aber raumzeitliche Begriffe eine zentrale Rolle, insofern Simmel den modernen Lebensstil besonders durch Distanz, Tempo und Rhythmus gekennzeichnet sieht.

Im Folgenden soll daher zunächst herausgearbeitet werden, wie Simmel die Veränderungen der Raum- und Zeitwahrnehmung in der Moderne beschreibt (2), um seine Thesen anschließend mit aktuellen Beschleunigungstheorien in Beziehung zu setzen (3.1). Danach erfolgt ein Ausblick auf sich der Entfremdung widersetzende Erfahrungen (3.2), die als Ansatzpunkte für eine Reflexion über Muße in der Moderne dienen könnten.

${ }^{24}$ Günter Figal/Hans W. Hubert/Thomas Klinkert, „Einleitung“, in: Günter Figal/Hans W. Hubert/Thomas Klinkert (Hg.), Die Raumzeitlichkeit der Muße, Tübingen 2016, 1-6, hier 1.

${ }_{25} \mathrm{Zu}$ einer Ausdifferenzierung verschiedener Aspekte von Raum im Hinblick auf Muße vgl. Günter Figal/Tobias Keiling, „Das raumtheoretische Dreieck“, in: Die Raumzeitlichkeit $\operatorname{der}$ Muße, 9-28.

26 Vgl. Rosa, Beschleunigung, 89-105.

27 Vgl. David Frisby, Fragmente der Moderne. Georg Simmel - Siegfried Kracauer - Walter Benjamin, Rheda-Wiedenbrück 1989, 68: „Simmels Theorie der Moderne nimmt nicht die Form einer historischen Analyse an, sondern sie stellt einen Bericht der Erfahrungsweisen der gesellschaftlichen Wirklichkeit in der Moderne dar."

28 Zur philosophischen Bedeutung der Philosophie des Geldes vgl. Annika Schlitte, Die Macht des Geldes und die Symbolik der Kultur, München 2012. 


\section{Georg Simmel und die Raumzeitlichkeit des modernen Lebensstils}

Im letzten Kapitel der Philosophie des Geldes, das sich mit dem Stil des Lebens befasst, liefert Simmel eine Zeitdiagnose der modernen Kultur, hinter der als Triebfeder und Symbol das Geld steht.

Auffällig ist, dass Simmel in der Beschreibung des modernen Lebensgefühls immer wieder auf räumliche und zeitliche Charakterisierungen zurückgreift. Von den drei Differenzierungstendenzen, die er beschreibt, sind zwei direkt mit Raum und Zeit assoziiert, indem sie als Differenzierung im „Nebeneinander“ und im „Nacheinander“ tituliert werden. Der „räumlichen“ Differenzierung im Nebeneinander entspricht die quantitative Zunahme der Kulturobjekte, während mit der „zeitlichen“ Differenzierung im Nacheinander der schnellere Wandel der Objektwelt, z.B. in der Mode, gemeint ist. Als drittes kommt schließlich die Stilisierung hinzu, die Ausbildung einer einheitlichen Form der Objekte, welche den Einzelnen von einer individuellen Bewertung des jeweiligen Gegenstandes entlastet. Doch auch der Stil des modernen Lebens selbst entfaltet sich in drei Aspekten, die von Simmel mit raumzeitlichen Begriffen belegt werden, nämlich Distanz, Rhythmus und Tempo.

\subsection{Räumliche Aspekte}

Wenden wir uns zunächst den räumlichen Ausdrücken zu, die Simmel verwendet. Distanz ist ein Begriff, der für Simmels Verständnis von kulturellen Prozessen insgesamt von großer Bedeutung ist. Für die Bildung des ökonomischen wie z.B. des ästhetischen Wertes ist die Distanzierung von den Objekten eine Voraussetzung, denn damit man sich überhaupt begehrend auf etwas beziehen kann, muss eine gewisse Distanz vorausgesetzt werden. ${ }^{29}$

Neben einer allgemeinen Dialektik von Nähe und Distanz, die für die Wertbildung im Kulturprozess prinzipiell eine wichtige Rolle spielt, stellt Simmel auch eine historische Veränderung der Distanz zwischen Subjekt und Objekt fest, die er auf die Wirkung des Geldes zurückführt, welche er wie folgt charakterisiert:

Der Abstand, der das Subjektive und das Objektive aus ihrer ursprünglichen Einheit voneinandergetrieben hat, ist im Geld sozusagen körperhaft geworden - während andrerseits sein Sinn ist, getreu der oben behandelten Korrelation von Distanz und Nähe, uns das sonst Unerreichbare nahe zu bringen. ${ }^{30}$

29 Vgl. Georg Simmel, Philosophie des Geldes, Gesamtausgabe (= GA), Bd. 6, hg. v. David P. Frisby/Klaus Christian Köhnke, Frankfurt a. M. 1989, 49: „Distanzierung und Annäherung sind auch im Praktischen Wechselbegriffe, jedes das andere voraussetzend und beide die Seiten der Beziehung zu den Dingen bildend, die wir, subjektiv, unser Begehren, objektiv, ihren Wert nennen."

30 Simmel, Philosophie des Geldes, GA 6, 136. 
Mit der Zunahme der Geldwirtschaft kommt es so einerseits zu einer Vergrößerung der Distanz zwischen den Subjekten und den Objekten, andererseits erleichtert die Geldwirtschaft den Handel und erschließt dem Subjekt viel mehr Objekte als zuvor - was früher unerreichbar schien, wird über die zunehmend global agierende Geldwirtschaft erreichbar gemacht. Typisch für die moderne Gesellschaft sei daher die paradoxe Situation, dass dem Individuum einerseits immer mehr und immer leichter zugängliche Produkte zur Verfügung stehen, es aber andererseits keine wirkliche Beziehung mehr zu den einzelnen Objekten aufbauen kann, weil es alles durch die Brille des Geldes sieht. Denn dieses kann seine Funktion, verschiedenste Gegenstände miteinander vergleichbar zu machen, nur dadurch erfüllen, dass es von allen qualitativen Unterschieden zwischen ihnen absieht und das Verhältnis der Gegenstände zueinander rein quantitativ ausdrückt. Wenn der moderne Mensch sich aber einmal daran gewöhnt hat, alles mit den Augen des Käufers zu betrachten und nur mit quantitativen Unterscheidungen zu operieren, verliert er den Blick für die individuellen Eigenheiten und Besonderheiten der Objekte, die im Preis gerade nicht ausgedrückt werden können. Auf diese Weise scheinen die Gegenstände sich immer weiter von den Subjekten zu entfernen. Simmel sieht diese Entwicklung durchaus nicht nur negativ; zwischen Besitzendem und Besitz werden so schließlich ganz andere Beziehungen möglich, die nicht mehr auf räumlicher Nähe beruhen. Diese wird vielmehr durch das Dazwischentreten des Geldes für bestimmte Beziehungsformen überflüssig:

Der Aktieninhaber, der mit der Geschäftsführung der Gesellschaft absolut nichts zu tun hat; der Staatsgläubiger, der das ihm verschuldete Land nie betreten hat; der Großgrundbesitzer, der seine Ländereien in Pacht ausgetan hat - sie alle überlassen ihre Besitzquanten einem rein technischen Betriebe, dessen Früchte sie allerdings ernten, mit dem an und für sich sie aber garnichts zu schaffen haben. Und das eben ist ausschließlich durch das Geld möglich. ${ }^{31}$

Eine Ambivalenz zeigt sich auch bei den Auswirkungen, welche das Geld auf die interpersonale Distanz hat. ${ }^{32}$ Durch das Geld wird es dem modernen Menschen nämlich möglich, sich mit vielen anderen in reinen Geschäftsbeziehungen $\mathrm{zu}$ verbinden, wo in früheren Gesellschaften persönliche Bindungen vorherrschten. Die Unpersönlichkeit der Geschäftsbeziehung, die eine größere Distanz zwischen den beteiligten Individuen bewirkt, hat aber für den modernen Menschen nicht nur negative Folgen, denn sie bedeutet einen Zuwachs an Wahlfreiheit:

31 Simmel, Philosophie des Geldes, GA 6, 448.

32 Vgl. Simmel, Philosophie des Geldes, GA 6, 465: „Die sachliche Zusammenhangslosigkeit des Subjekts mit dem Objekt, an dem es ein bloßes Geldinteresse hat, spiegelt sich in seiner personalen Zusammenhangslosigkeit mit den anderen Subjekten, mit denen ihn ein ausschließliches Geldinteresse verbindet." 
Während der Mensch der früheren Stufe die geringere Anzahl seiner Abhängigkeiten mit der Enge persönlicher Beziehung, oft persönlicher Unersetzbarkeit derselben bezahlen mußte, werden wir für die Vielheit unserer Abhängigkeiten durch die Gleichgültigkeit gegen die dahinter stehenden Personen und durch die Freiheit des Wechsels mit ihnen entschädigt. ${ }^{33}$

Besonders auffällig wird diese Auswirkung der Geldwirtschaft auf das moderne Lebensgefühl nun in der Großstadt. Die beiden Distanzierungstendenzen, die Entfernung der Menschen von den Dingen und die Entfernung der Menschen voneinander finden ihren Niederschlag auf der individualpsychologischen Ebene in den Phänomenen der Blasiertheit und Reserviertheit.

Als seelische Auswirkung des unruhigen Großstadtlebens stellt die Blasiertheit zunächst eine Reaktion auf zu viele Eindrücke dar, doch hängt sie auch mit der zunehmend dominanten Geldrelation zusammen. Simmel beschreibt diese Erscheinung als „Abstumpfung gegen die Unterschiede der Dinge, nicht in dem Sinne, dass sie nicht wahrgenommen würden, wie von dem Stumpfsinnigen, sondern so, dass die Bedeutung und der Wert der Unterschiede der Dinge und damit der Dinge selbst als nichtig empfunden wird“34. Was hier vernachlässigt wird, sind die qualitativen Differenzen der Einzeldinge, und damit genau das, was bei durch Geld vermittelten Beziehungen gegenüber quantitativen Differenzen in den Hintergrund tritt. Darum kann die Blasiertheit als subjektiver Reflex der Geldfunktion verstanden werden.

Der Blasiertheit als Haltung gegenüber den Dingen entspricht die Reserviertheit als Haltung gegenüber den Mitmenschen, die bis hin zu Fremdheits- und Abstoßungsgefühlen reicht. Diese latente Antipathie, die Simmel Reserviertheit nennt, „bewirkt die Distanzen und Abwendungen, ohne die diese Art Leben

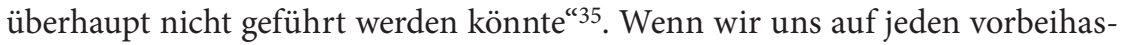
tenden Fremden emotional wirklich einlassen wollten, wären wir in der Großstadt hoffnungslos überfordert, während wir in der Dorfgemeinschaft den Vorbeigehenden durchaus auf ein Schwätzchen anhalten können.

$\mathrm{Daß}$ man sich mit einer so ungeheuren Zahl von Menschen so nahe auf den Leib rückt wie die jetzige Stadtkultur mit ihrem kommerziellen, fachlichen, geselligen Verkehr es bewirkt, würde den modernen, sensibeln und nervösen Menschen völlig verzweifeln lassen, wenn nicht jene Objektivierung des Verkehrscharakters eine innere Grenze und Reserve mit sich brächte. Die entweder offenbare oder in tausend Gestalten verkleidete Geldhaftigkeit der Beziehungen schiebt eine unsichtbare, funktionelle Distanz zwischen die Menschen, die ein innerer Schutz und Ausgleichung gegen die allzu gedrängte Nähe und Reibung unseres Kulturlebens ist. ${ }^{36}$

33 Simmel, Philosophie des Geldes, GA 6, 396.

34 Georg Simmel, „Die Großstädte und das Geistesleben“, in: GA 7, hg. v. Rüdiger Kramme/Angela Rammstedt/Otthein Rammstedt, Frankfurt a. M. 1995, 116-131, 121.

35 Simmel, „Die Großstädte und das Geistesleben“, in: GA 7, 123.

36 Simmel, Philosophie des Geldes, GA 6, 665. 
Diese Distanz zu den Mitmenschen hat also eine wichtige Funktion: Sie schützt den Einzelnen und ermöglicht ihm ein größeres Maß an persönlicher Freiheit, das sich dann wiederum in den Extravaganzen der Großstädter ausdrückt. Derart von seinen Nächsten distanziert, entwickelt der moderne Mensch paradoxerweise auch ein größeres Interesse für ferne Länder und Kulturen. Zu Simmels Zeit waren Telekommunikation und globale Vernetzung noch in den Kinderschuhen, und doch stellt er über seine Zeitgenossen bereits fest, dass bei ihnen die Nahbeziehungen hinter den Fernbeziehungen zurücktreten - eine Entwicklung, die auch heute vielfach beobachtet wird ${ }^{37}$ : „Die Verhältnisse des modernen Menschen zu seinen Umgebungen entwickeln sich im ganzen so, daß er seinen nächsten Kreisen ferner rückt, um sich den ferneren mehr zu nähern." 38

Das Geld hat in diesem ganzen Prozess eine ambivalente Position: Zum einen dient es der „Überwindung der Distanz“, weil „allein die Übersetzung der Werte in die Geldform jene Interessenverknüpfungen ermöglicht, die nach dem räumlichen Abstand der Interessenten überhaupt nicht mehr fragen ". ${ }^{39}$ Doch bedeutender ist nach Simmel die entgegengesetzte Wirkung, die das Geld dadurch ausübt, dass es die von ihm dominierten Beziehungen - seien es ökonomische oder interpersonale - ent-persönlicht und objektiviert. Der Preis, der für die Vorteile der Geldwirtschaft zu entrichten ist, besteht in einer zunehmenden Entfernung und Entfremdung von Dingen wie Menschen. Distanz wird auf diese Weise zu einem wesentlichen Zug des modernen Lebensgefühls. Entscheidend für dieses Gefühl ist das Geld - ,jene Instanz [...], die nur verbindet, indem sie zugleich trennt" 40 .

Neben den Auswirkungen auf die individuellen Beziehungen spricht Simmel aber auch von Veränderungen in der gesamtgesellschaftlichen Raumordnung und ordnet dazu ökonomische Institutionen in eine Skala der „lokale[n] Diffusion“41 ein. Als eine Auswirkung des Geldverkehrs betrachtet Simmel seine Eigenschaft, „daß er zur Konzentration an verhältnismäßig wenigen Plätzen

37 So geht etwa Peter Berger davon aus, dass ,in modernen Gesellschaften und im Zuge der ,Enträumlichung von Kommunikation nicht nur die Bezüge auf konkrete (Nah-)Räume oder ,Orte' an Bedeutung verlieren [...], sondern zugleich die vielfältigen Fernbezüge und Fernwirkungen unserer Handlungen an Gewicht gewinnen“ (Berger, „Anwesenheit und Abwesenheit“, 100). Auch Virilio beschreibt ein „Nahebringen des ,Fernsten“", das mit einer Entfernung des Nächsten einhergeht, als Paradoxie moderner Beschleunigungstechnologien, vgl. Virilio, „Das dritte Intervall“, 344.

38 Simmel, Philosophie des Geldes, GA 6, 663. Eine Tendenz zur Distanz zeigt sich schließlich auch in Kunst und Wissenschaft. Nicht nur sieht Simmel in dem typisch modernen Phänomen des Stilpluralismus selbst schon ein Moment der Distanz, sondern auch die seinerzeit aktuellen Stilrichtungen wie der Symbolismus scheinen ihm auf eine Vergrößerung der Distanz zur Wirklichkeit abzuzielen. Vgl. Simmel, Philosophie des Geldes, GA 6, 661 .

39 Simmel, Philosophie des Geldes, GA 6, 663.

40 Simmel, Philosophie des Geldes, GA 6, 667.

${ }^{41}$ Simmel, Philosophie des Geldes, GA 6, 704. 
drängt “42. Während der Ackerbau auf eine weite Erstreckung im Raum angewiesen ist, brauchen Handwerksbetriebe und Fabriken zunehmend weniger Platz, um ihre Produkte herzustellen. Am wenigsten Raum beanspruche aber die Geldwirtschaft, weil sie die wirtschaftlichen Bewegungen in einer abstrakten und vom Standort losgelösten Form bündelt.

Das Geld steht vermöge der Abstraktheit seiner Form jenseits aller bestimmten Beziehungen zum Raum: es kann seine Wirkungen in die weitesten Fernen erstrecken, ja es ist gewissermaßen in jedem Augenblick der Mittelpunkt eines Kreises potenzieller Wirkungen; aber es gestattet auch umgekehrt, die größte Wertsumme in die kleinste Form zusammenzudrängen - bis zu dem 10 Millionen-Dollar-Check, den Jay Could einmal ausstellte. $^{43}$

Es handelt sich bei dieser Bewegung hin zur Bildung einzelner Finanzzentren, den „Knotenpunkten des Geldverkehrs“44, für welche die Großstädte prädestiniert sind, um eine Abkehr von extensiven Wirtschaftsformen, die mit großen Flächen von Land verbunden sind, doch bewirkt das, was Simmel in dem oben angeführten Zitat als Ablösung vom Raum beschreibt, auf der anderen Seite eben auch eine sichtbare Änderung der räumlichen Ordnung. Schließlich bildet sich mit der Großstadt als Finanzzentrum eine neue räumliche Konstellation heraus, die selbst wieder Einfluss auf das soziale Verhalten nimmt, wie Simmels Überlegungen zur Distanzierung gezeigt haben, die als eine Reaktion auf das „Aneinander-Gedrängtsein und das bunte Durcheinander des großstädtischen Verkehrs"45 gekennzeichnet wurde.

Was aber für viele soziale Phänomene an Bedeutung zu verlieren scheint, ist die Verankerung an einem bestimmten, qualitativ ausgezeichneten Ort. Wie einige Bemerkungen Simmels an verschiedenen Stellen seines Werkes zeigen, vollzieht sich in der Moderne insgesamt eine Neutralisierung und Homogenisierung des Raumes. So beschreibt er in einem kleinen Nebenexkurs im Raumkapitel der Soziologie, wie der Raum selbst zu einer entindividualisierten, quantitativen Größe wird. Zu diesem Ergebnis kommt er, nachdem er den Brauch, mittelalterliche Stadthäuser nach dem Namen ihrer Eigentümer zu benennen, mit der modernen Straßen- und Hausnummernbezeichnung vergleicht, die eine andere Einstellung zur räumlichen Umgebung insgesamt ausdrückt. ${ }^{46}$ Die individuelle und qualitative Auszeichnung geht hier jedoch mit dem Verzicht auf die exakte Positionsbestimmung einher, so dass das moderne Individuum in dem weniger individuellen, nach Hausnummer und Straße geordneten Haus leichter auffindbar ist als in dem Haus, das eine eigene Qualität hat, die sich in seinem Namen

\footnotetext{
42 Simmel, Philosophie des Geldes, GA 6, 704.

43 Simmel, Philosophie des Geldes, GA 6, 704.

44 Simmel, Philosophie des Geldes, GA 6, 704.

45 Simmel, Philosophie des Geldes, GA 6, 665.

46 Vgl. Georg Simmel, Soziologie. Untersuchungen über die Formen der Vergesellschaftung, GA 11, hg. von Otthein Rammstedt, Frankfurt a. M. 2006, 712 f.
} 
ausdrückt. Wie schon bei den Distanzphänomenen geht hier also die Nivellierung individueller Unterschiede mit einer stärkeren Berücksichtigung des Individuums einher - eine Dialektik, die den von Simmel geschilderten Wirkungen der Geldwirtschaft insgesamt zukommt, und die sowohl mit dem modernen Intellektualismus, dem ökonomischen Denken und dadurch auch mit der Großstadt verbunden ist.

Der Raum wird quantifiziert und rationalisiert - es liegt nahe, dass Simmel angesichts dieser Diagnose auch auf den Verkehr zu sprechen kommt und den Umgang mit dem Raum, der im modernen Straßenbau gepflegt wird, mit einer Tendenz nicht nur zur Bezähmung des Raumes, sondern auch mit dem Bedürfnis der Zeitersparnis in Verbindung bringt:

„Die Streckung krummer Straßen, die Anlage neuer Diagonalwege, das ganze moderne System der rechtwinkligen Symmetrie und Systematik ist zwar unmittelbar Raumersparnis, für den Verkehr aber vor allem Zeitersparnis, wie sie vom Rationalismus des Lebens gefordert wird. “47

Zeitersparnis erscheint also schon hier als ein Imperativ, an dem sich die Gestaltung des Zusammenlebens auszurichten hat.

\subsection{Zeitliche Aspekte}

Damit kommen wir zu den Aspekten des modernen Lebensstils, „die nicht, wie die Distanzierung durch eine räumliche, sondern durch eine zeitliche Analogie bezeichnet" ${ }^{48}$ werden, nämlich Rhythmus und Tempo.

An die Stelle einer regelmäßigen Wellenbewegung, die viele natürliche Prozesse bestimmt wie den Ablauf der Jahreszeiten und die Paarungszeiten bei Tieren, tritt schon in frühen menschlichen Kulturen eine Gleichförmigkeit des Zeitablaufs, die sich bei Tieren nicht findet und die sich in der modernen Welt verschärft. Die Auflösung der natürlichen Folge von Anspannung und Entspannung zeigt sich mit fortschreitender kulturellen Entwicklung auch beim Arbeitsablauf. Die Maschinen mit ihren festgelegten Abläufen drücken dem modernen Arbeiter ihren Rhythmus auf, der sich aber nicht nach dessen physiologischen Bedürfnissen richtet. Das moderne kulturelle Leben, das unter dem Einfluss der Geldwirtschaft steht, ist schließlich

von einer durchgängigen Vergleichmäßigung ergriffen, seit man für Geld alles zu jeder Zeit kaufen kann und deshalb die Regungen und Reizungen des Individuums sich an keinen Rhythmus mehr zu halten brauchen, der, von der Möglichkeit ihrer Befriedigung aus, sie einer transindividuellen Periodizität unterwürfe. ${ }^{49}$

\footnotetext{
47 Simmel, Soziologie, GA 11, 713.

48 Simmel, Philosophie des Geldes, GA 6, 676.

49 Simmel, Philosophie des Geldes, GA 6, 680.
} 
Allerdings konstatiert Simmel im Hinblick auf den Rhythmus ebenfalls eine gegenläufige Entwicklung, die zu einer Loslösung von aller Gleichmäßigkeit führt und die er mit dem modernen Individualismus in Verbindung bringt. Auch in diesem Kontext wirkt das Geld gleichsam als Katalysator dieser Entwicklungen. Einerseits ist es selbst „das durchgreifendste, weil für sich völlig indifferente Mittel für die Überführung eines uns überindividuell zwingenden Rhythmus von Lebensbedingungen in eine Ausgeglichenheit und Schwankungslosigkeit derselben ${ }^{\text {"50 }}$. Das Geld ist selbst gegenüber der Person indifferent und keinem natürlichen Zyklus unterworfen, daher wirkt es tendenziell gleichmachend und nivellierend, wenn es intersubjektive Beziehungen dominiert. Andererseits setzt es den Einzelnen frei von persönlichen und sachlichen Bindungen und erleichtert es ihm somit, seine Persönlichkeit zu entwickeln und eigene Akzente zu setzen, die sich auch in einer freieren Gestaltung des eigenen Lebensrhythmus zeigen können.

Nicht nur für Distanz und Rhythmus ist das Geld verantwortlich, es hat auch Auswirkungen auf das Tempo des Lebens, das Simmel so beschreibt: „Was wir als das Tempo des Lebens empfinden, ist das Produkt aus der Summe und der Tiefe seiner Veränderungen. " ${ }^{51}$ Wesentliche soziale Veränderungen werden nun aber durch den Siegeszug der Geldwirtschaft hervorgerufen, deren psychologischen Auswirkungen Simmel sehr großes Gewicht beimisst. So bewirke allein die Zunahme des verfügbaren Geldes eine Beschleunigung der ökonomischen Prozesse - eine These, die der in der Nationalökonomie lange vorherrschenden Grundannahme von der Neutralität des Geldes gegenüber der Realwirtschaft widerspricht. ${ }^{52}$ Simmel betont insbesondere die psychologischen Konsequenzen, die sich aus einer Zunahme der Geldmenge ergeben. Auch wenn die Preissteigerung einen Geldzuwachs bald ausgleichen würde, bliebe ein psychologischer Effekt bestehen, denn:

Solange die neue Anpassung nicht vollzogen ist, wird die gleichmäßige Vermehrung des Geldes zu fortwährenden Differenzgefühlen und psychischen Chocs Veranlassung geben, so die Unterschiede, das Sich-Gegeneinander-Absetzen innerhalb der ablaufenden Vorstellungen vertiefen und damit das Tempo des Lebens beschleunigen. ${ }^{53}$

Steigerungen der Produktivität eines Landes und damit verbundene Lohnerhöhungen führen zu erhöhter sozialer Mobilität, was ebenfalls als Temposteigerung des Lebens empfunden wird.

50 Simmel, Philosophie des Geldes, GA 6, 691.

51 Simmel, Philosophie des Geldes, GA 6, 696.

52 Vgl. Paschen von Flotow/Johannes Schmidt, „Die ,Doppelrolle des Geldes‘ bei Georg Simmel und ihre Bedeutung für Ökonomie und Soziologie“, in: Jürgen G. Backhaus/ Hans-Joachim Stadermann (Hg.), Georg Simmels Philosophie des Geldes. Einhundert Jahre danach, Marburg 2000, 61-94, 69.

53 von Flotow/Schmidt, „Die ,Doppelrolle des Geldes“ bei Georg Simmel“, 697. 
Während die Blasiertheit als psychologisches Pendant der modernen Distanzierung fungierte, bewirkt das veränderte Lebenstempo auf der psychologischen Ebene eine „Steigerung des Nervenlebens, die aus dem raschen und ununterbrochenen Wechsel äußerer und innerer Eindrücke hervorgeht. " 54 Im raschen Wechsel der Mode sieht Simmel ein Kennzeichen der Moderne, die er damit als ein nervöses Zeitalter einstuft:

Der Wechsel der Mode zeigt das Maß der Abstumpfbarkeit der Nervenreize an, je nervöser ein Zeitalter ist, desto rascher werden seine Moden wechseln, weil das Bedürfnis nach Unterschiedsreizen, einer der wesentlichen Träger aller Mode, mit der Erschlaffung der Nervenenergien Hand in Hand geht. ${ }^{55}$

Simmel erwähnt das „spezifisch ,ungeduldige 'Tempo des modernen Lebens“56, welches zu einer Betonung der Gegenwart führe. Durch den Zerfall alter Traditionen würden die „flüchtigen und veränderlichen Elemente des Lebens“ ${ }^{\text {57 }}$ begünstigt.

Die von Simmel beschriebene Nervenspannung, die als Krankheitsbild der Neurasthenie zu seinen Lebzeiten einige Prominenz erlangt hat, hat ihren Ort wiederum in der modernen Großstadt. Durch den schnellen Wechsel der Eindrücke unterscheidet sich das Großstadtleben vom Leben auf dem Land und in der Kleinstadt. Weil das Gemüt laut Simmel von einem gleichmäßigen Lebensrhythmus profitiert und angesichts des enormen Lebenstempos in den Metropolen verunsichert werden würde, spricht das großstädtische Leben eher den Verstand an. Wenn Simmel für das moderne Leben insgesamt eine Intellektualisierung und Versachlichung beobachtet, so handelt es sich dabei erneut um Tendenzen, die eng mit der Geldwirtschaft in Verbindung stehen, denn „Geldwirtschaft [...] und Verstandesherrschaft stehen im tiefsten Zusammenhange “58. Beide bewirken in den von ihnen bestimmten Beziehungen eine Nivellierung von individuellen Unterschieden und eine Konzentration auf objektivierbare Verhältnisse. ${ }^{59}$ Dabei spielt Quantifizierbarkeit eine wichtige Rolle, die aber wiederum durch die zunehmende Geldwirtschaft verstärkt ins Bewusstsein tritt: „Der moderne Geist ist mehr und mehr ein rechnender geworden." 60

54 Simmel, „Die Großstädte und das Geistesleben“, in: GA 7, 116.

55 Georg Simmel, „Die Mode“, in: GA 14, hg. v. Rüdiger Kramme/Otthein Rammstedt, Frankfurt a. M. 1996, 186-218, 194.

56 Simmel, „Die Mode“, in: GA 14, 197.

57 Simmel, „Die Mode“, in: GA 14, 198.

58 Simmel, „Die Großstädte und das Geistesleben“, in: GA 7, 118.

59 Vgl. Simmel, „Die Großstädte und das Geistesleben“, in: GA 7, 118: „Alle Gemütsbeziehungen zwischen Personen gründen sich auf deren Individualität, während die verstandesmäßigen mit den Menschen wie mit Zahlen rechnen, wie mit an sich gleichgültigen Elementen, die nur nach ihrer objektiv abwägbaren Leistung ein Interesse haben."

60 Simmel, „Die Großstädte und das Geistesleben“, in: GA 7, 119. 
Im Großstadt-Aufsatz wie in der Philosophie des Geldes bringt Simmel hinsichtlich der Dominanz der Quantität gegenüber der Qualität das Geld auch mit der Erfindung der Taschenuhr in Verbindung, welche dem Einzelnen die objektiv messbare, „,versachlichte “ Zeit jederzeit zur Verfügung stellt. ${ }^{61}$ Besonders das Großstadtleben wird von diesem neuen, auf Exaktheit ausgerichteten Zeitverständnis bestimmt, da die Akteure auf so vielfältige Weise in Beziehung stehen, dass ihre Aktivitäten anders nicht koordiniert werden können:

Wenn alle Uhren in Berlin plötzlich in verschiedene Richtung falschgehen würden, auch nur um den Spielraum einer Stunde, so wäre sein ganzes wirtschaftliches und sonstiges Verkehrsleben auf lange hinaus zerrüttet. Dazu kommt, scheinbar noch äußerlicher, die Größe der Entfernungen, die alles Warten und Vergebenskommen zu einem gar nicht aufzubringenden Zeitaufwand machen. So ist die Technik des großstädtischen Lebens überhaupt nicht denkbar, ohne dass alle Tätigkeiten und Wechselbeziehungen aufs pünktlichste in ein festes, übersubjektives Zeitschema eingeordnet würden. ${ }^{62}$

In der Philosophie des Geldes bezieht sich Simmel explizit auf den Zusammenhang zwischen dieser neuen, standardisierten Zeit und der Entstehung des Kapitalismus. So sei mit der Entstehung des Welthandels und erster Finanzzentren auch „der moderne Begriff der Zeit [...] als eines durch Brauchbarkeit und Knappheit bestimmten Wertes" 63 entstanden. Das Konzept einer objektiven Zeit wird von Simmel also explizit als historisch und kulturell gewachsenes betrachtet, welches mit der ökonomischen Entwicklung Hand in Hand geht.

Schließlich beschreibt Simmel noch einen allgemeinen Zug des modernen Lebensgefühls, der ebenfalls auf eine Erfahrung der Zeit zurückgeht und in einer besonderen Form der Erwartung besteht. Hier kommt also auch das Verhältnis des modernen Menschen zur Geschichte und insbesondere Zukunft in den Blick:

Durch die moderne Zeit, insbesondere, wie es scheint, durch die neueste, geht ein Gefühl von Spannung, Erwartung, ungelöstem Drängen - als sollte die Hauptsache erst kommen, das Definitive, der eigentliche Zentralpunkt des Lebens und der Dinge. ${ }^{64}$

Außerdem bemerkt er eine „heimliche Unruhe“ und eine „wirre Halt- und Rastlosigkeit"65, die das moderne Leben bestimmen soll und die er wie die Distanzproblematik mit den Auswirkungen der Geldwirtschaft in Verbindung bringt. Das Gefühl der Erwartung und des Aufschubs, das Simmel auf der Ebene der Individuen beschreibt, passt genau zu der Eigenart des Geldes, dass es als uni-

61 Vgl. Simmel, „Die Großstädte und das Geistesleben“, in: GA 7, 119: „Durch das rechnerische Wesen des Geldes ist in das Verhältnis der Lebenselemente eine Präzision, eine Sicherheit in der Bestimmung von Gleichheiten und Ungleichheiten, eine Unzweideutigkeit in Verabredungen und Ausmachungen gekommen - wie sie äußerlich durch die allgemeine Verbreitung der Taschenuhren bewirkt wird.“

62 Simmel, „Die Großstädte und das Geistesleben“, in: GA 7, 120.

63 Simmel, Philosophie des Geldes, GA 6, 707.

64 Simmel, Philosophie des Geldes, GA 6, $669 \mathrm{f}$.

65 Simmel, Philosophie des Geldes, GA 6, 675. 
versales Mittel die Orientierung auf einen Endzweck zu ersetzen scheint. Indem wir Geld anhäufen und nicht ausgeben, schieben wir die Konsumentscheidung immer weiter auf und halten uns so alle Möglichkeiten offen. Das Geld baut auf der Erwartung auf, dass wir auch in Zukunft noch etwas dafür bekommen werden. Diese Ausrichtung des Geldes auf Zukunft - und nicht auf die Stillung gegenwärtiger Bedürfnisse - zeigt sich im Kredit und in den Instrumenten des Finanzkapitalismus, mit denen wir es heute zu tun haben, noch viel deutlicher. ${ }^{66}$

\section{Simmels kritische Diagnose der Geldwirtschaft und die Möglichkeit der Muße in der Moderne}

Zusammenfassend lässt sich festhalten, dass in Simmels Diagnose der modernen Kultur Raum und Zeit wichtige Analysekategorien darstellen. Insbesondere seine Überlegungen zum Raum sind in der Raumsoziologie bereits vielfach aufgegriffen worden ${ }^{67}$, wobei es aber interessant zu sehen ist, dass Simmel nicht nur als Vorläufer der Raumsoziologie gewertet wird, sondern auch als jemand, „der als einer der ersten Soziologen zu der Schlußfolgerung gelangt, daß mit der Entfaltung der Geldwirtschaft der Raum zunehmend an Bedeutung verliert" 68 . Diese These, die Elisabeth Konau bereits 1977 vertreten hat ${ }^{69}$ und die in der Soziologie immer noch kontrovers diskutiert wird, scheint jedoch bei einem genaueren Blick auf Simmels Behandlung der modernen Raumerfahrung insgesamt nicht haltbar. Zwar verändert sich die Beziehung zum Raum bei vielen sozialen Phänomenen, aber doch nicht so, dass der Raum überhaupt keine Rolle mehr spielen würde.

Bei der Zeit zeigen sich die Auswirkungen der Moderne auf der Ebene der subjektiven Zeiterfahrung, die von einer Beschleunigungstendenz geprägt ist. Die Objektivierung und Quantifizierung der Zeit, die mit den modernen Messtechniken einhergeht, steht in Diskrepanz zu der individuellen Zeiterfahrung, weswegen es nicht verwunderlich ist, dass Bergson und auch Simmel an der Schwelle zum 20. Jahrhundert so stark auf sie abheben. Mit der Beschleunigungserfahrung wie mit der Quantifizierung und Objektivierung von Zeit und Raum ist das Geld für Simmel eng verbunden, das als Symbol und gleichzeitig als Ursache dieser Entwicklung betrachtet wird: „Erst die Geldwirtschaft hat in das

66 Vgl. Birger Priddat, „Wozu Geld?“, in: Annika Schlitte/Alexander Denzler/Franziska Huditz (Hg.), Geld. Werte und Werte, Würzburg 2017, 199-209.

67 Vgl. Markus Schroer, Räume, Orte, Grenzen, Frankfurt a.M. 2006, 60-81; Martina Löw, Raumsoziologie, Frankfurt a. M. 2000, 58-68.

68 Löw, Raumsoziologie, 62.

69 Elisabeth Konau, Raum und soziales Handeln. Studien zu einer vernachlässigten Dimension soziologischer Theoriebildung, Stuttgart 1977. Löw, Raumsoziologie, teilt diese pauschale Diagnose von Konau jedoch nicht vollständig. 
praktische Leben - und wer weiß, ob nicht auch in das theoretische - das Ideal zahlenmäßiger Berechenbarkeit gebracht ${ }^{\text {"70 }}$, schreibt er dazu in der Philosophie des Geldes.

Simmels Analyse zeigt deutliche Züge einer Kritik der modernen Gesellschaft. Nicht erst in seinem berühmten Tragödienaufsatz, sondern bereits in der Philosophie des Geldes benennt er Entwicklungen der modernen Kultur, die als Entfremdungserfahrungen betrachtet werden können. Dazu tragen nach Simmel die arbeitsteilige Produktion und die Geldwirtschaft wesentlich bei. In der Diskrepanz zwischen subjektiver und objektiver Kultur, die das moderne Leben nach Simmel wesentlich prägt, werden sowohl die räumlichen als auch die zeitlichen Aspekte des modernen Lebensgefühls als krisenhaft erfahren. Die Entfernung von den Objekten geht einher mit dem Gefühl, nicht mehr mit der Entwicklung der Sachkultur mithalten zu können. Das folgende Zitat macht diesen Zusammenhang, in dem sich räumliche und zeitliche Aspekte treffen, explizit:

Täglich und von allen Seiten her wird der Schatz der Sachkultur vermehrt, aber nur wie aus weiter Entfernung ihr folgend und in einer nur wenig zu steigernden Beschleunigung kann der individuelle Geist die Formen und Inhalte seiner Bildung erweitern. ${ }^{71}$

Bei allen Wesenszügen, die Simmel der modernen Kultur zuschreibt, hat das Geld eine besondere Rolle, die darin besteht, die genannten Entwicklungen nicht nur voranzutreiben, sondern symbolisch zu verkörpern. So ist das Geld sowohl Motor der Beschleunigung des modernen Lebens als auch deren Sinnbild:

Endlich muß die Geschwindigkeit, die der Zirkulation des Geldes gegenüber der aller anderen Objekte eigen ist, das allgemeine Lebenstempo unmittelbar und in demselben Maße steigern, in dem das Geld das allgemeine Interessenzentrum wird. Die Rundheit der Münzen, infolge deren sie >rollen müssen`, symbolisiert den Rhythmus der Bewegung, die das Geld dem Verkehr mitteilt: selbst wo die Münze ursprünglich eckig war, muß der Gebrauch zunächst die Ecken abgeschliffen und sie der Rundung angenähert haben; physikalische Notwendigkeiten haben so der Intensität des Verkehrs die ihm dienlichste Werkzeugsform verschafft. ${ }^{72}$

\subsection{Zeitdiagnose damals und heute}

Bevor mögliche Gegenkonzepte zu Krisen- und Entfremdungserfahrungen zur Sprache kommen, soll am Schluss noch einmal geprüft werden, wie sich Simmels Beobachtungen um $1900 \mathrm{zu}$ den aktuellen Zeitdiagnosen verhalten, welche zur Bestimmung des Übergangs von der Moderne zur Postmoderne auf ähnliche Veränderungen der Raum- und Zeitwahrnehmung rekurrieren. Was sich in der Spätzeit der Moderne laut Hartmut Rosa geändert haben soll, sind ja nicht nur

70 Konau, Raum und soziales Handeln, 614.

${ }^{71}$ Konau, Raum und soziales Handeln, $621 \mathrm{f}$.

${ }^{72}$ Konau, Raum und soziales Handeln, 708. 
die Erfahrungen der Geschwindigkeit bestimmter gesellschaftlicher Veränderungsprozesse, sondern die Erfahrung der Zeit - und, wenn es um Geschwindigkeit geht, notwendigerweise auch des Raumes - selbst. Wie der Untertitel von Rosas Buch sagt, geht es ihm um eine Untersuchung der „Veränderung der Zeitstrukturen in der Moderne“. Simmel wird als Kronzeuge für diese Gesellschaftsdiagnose vielfach zitiert, schließlich stellt er für Rosa „von allen Klassikern der Soziologie den Beschleunigungsaspekt am stärksten in das Zentrum seiner Modernebestimmung, allerdings ohne ihm eine eigenständige theoretische Ausarbeitung zu widmen"73. Schon vom Frageinteresse her lässt sich eine große Nähe erkennen, denn Rosa wie Simmel interessieren die Auswirkungen, welche die moderne Gesellschaft auf das Lebensgefühl der Individuen ausübt.

Auf der phänomenologischen Erfahrungsebene geht für Rosa mit der technischen Beschleunigung eine „Revolutionierung des Raum-Zeit-Regimes"74 einher, die sich als „Loslösung der Raumwahrnehmung vom Ort und der Zeitwahrnehmung vom Raum“75 äußert. Obwohl hier eher die Bindung an einen konkreten Ort gemeint ist, spricht Rosa an anderer Stelle auch von einer „Entfremdung vom Raum“. ${ }^{76}$ Bei Simmel dagegen lässt sich, was die Rolle des Raumes betrifft, kein eindeutiges Votum für eine insgesamt nachlassende Bedeutung des Raumes finden, vielmehr werden Raumkonzepte unter den Bedingungen der modernen Gesellschaft transformiert und umgestaltet.

Hinsichtlich des Lebenstempos zeigt sich für Rosa eine „Steigerung der Handlungs- und/oder Erlebnisepisoden pro Zeiteinheit infolge einer Verknappung von Zeitressourcen"77. Er knüpft hier an Simmels Begriff des Lebenstempos an und teilt viele seiner Diagnosen. So benennen beide soziale Pathologien wie die Neurasthenie Anfang des 20. Jahrhunderts oder die Depression Anfang des 21. Jahrhunderts ${ }^{78}$, auch die Technik spielt bei beiden eine prominente Rolle.

Während Simmel sich jedoch ganz auf die Rolle des Geldes als Ursache der Steigerung des Lebenstempos konzentriert, bietet Rosa insgesamt drei Ursachenkomplexe an, nämlich 1. ökonomische, 2. kulturelle und 3. sozialstrukturelle Faktoren. Allerdings lässt sich feststellen, dass der zweite, nämlich der kulturelle Ursachenkomplex, den Rosa als Umstellung des Lebensstrebens auf das Diesseits fasst, bei Simmel schon erwähnt wird, wenn er das Geld als Ersatz für einen verlorengegangenen Endzweck des Lebens anspricht. ${ }^{79}$

73 Rosa, Beschleunigung, $100 \mathrm{f}$.

74 Rosa, Beschleunigung, 161.

75 Rosa, Beschleunigung, 162.

76 Hartmut Rosa, Beschleunigung und Entfremdung, Frankfurt a. M. 2013, 123-125.

77 Rosa, Beschleunigung, 198.

78 Vgl. Rosa, Beschleunigung, 437.

79 Rosa weist selbst auf die „religiöse Ersatzfunktion“ des Geldes hin (Rosa, Beschleunigung, 285). 
Wie bei Simmel mündet der veränderte Umgang mit Zeit und Raum bei Rosa in eine Krise und wird als Entfremdung beschrieben - als Zustand, in dem Subjekte freiwillig Ziele verfolgen, die sie eigentlich nicht wollen. Bei seiner Analyse dieser Entfremdungserscheinungen (u.a. in Bezug auf den Raum, die Zeit und die Dingwelt) klingen viele Aspekte an, die auch in Simmels Überlegungen zur Distanzierung und zur Quantifizierung des Raumes eine Rolle spielen - wie das von Rosa beschriebene Moment einer Distanzierung und Entfremdung von den Dingen. ${ }^{80}$ Es ist jedoch auffällig, dass Simmel in vielen Wertungen der modernen Kultur ambivalent bleibt.

So ist die Versachlichung der menschlichen Beziehungen mit einem Freiheitsgewinn für das Individuum verbunden, das sich aus persönlichen Abhängigkeiten lösen kann und seine Individualität gerade dadurch entfaltet, dass es in Geschäftsbeziehungen nicht mit seiner ganzen Persönlichkeit eintritt. Die Distanzierung ist auf der zwischenmenschlichen Ebene von großem Nutzen, auf der sachlichen ohnehin, denn ohne Objektivierung und damit Distanzierung wäre kein Kulturprozess denkbar. In der Kunst etwa ist ein neuer, intensiverer Zugang zur Welt erst auf der Basis der ästhetischen Distanz möglich, so dass man mit Simmel sagen kann, die Kunst bringe uns die Dinge gerade dadurch näher, dass sie sich zunächst von ihnen distanziert. Es scheint also, als würde die Selbstentfaltung des Individuums unter den Bedingungen der modernen Geldwirtschaft nicht zwangsläufig eingeschränkt, sondern als eröffneten sich ihm auch neue Möglichkeiten, die aus dem Zuwachs an individueller Freiheit resultieren.

Die Beschleunigungstendenz ist laut Rosa nun für die ganze Moderne kennzeichnend, doch unterscheidet sich die Spätmoderne dadurch von der ,klassischen' Moderne, dass nun die Zielgerichtetheit dieses Prozesses nicht mehr gewährleistet ist. Die Erwartung einer besseren Zukunft, die es vor dem Einbruch der sogenannten Postmoderne in den 1960er-/1970er-Jahren noch gegeben habe, sei danach weggebrochen, so dass aus der Erfahrung eines linearen Fortschritts die Erfahrung einer sinnlosen Hast, eines „rasenden Stillstandes“ werden konnte: „In individueller wie kollektiver Hinsicht, so der Befund, ist es der Übergang von einer als gerichtet erfahrenen Bewegung in eine richtungslose Dynamisierung, der den Eindruck des Stillstandes trotz oder gerade aufgrund einer hohen Ereignisdynamik hervorruft." ${ }^{81}$ Doch ist es mit Blick auf Simmel keineswegs klar, ob die Beschleunigung des Lebenstempos in ihrer modernen Form wirklich noch eine Richtung hatte oder ob sich die Frage des ,Fortschritt - wohin?' nicht auch in der Zeit vor dem Ersten Weltkrieg schon stellte.

Interessant ist gleichwohl die Frage, ob ein Austreten aus diesem Beschleunigungsprozess möglich ist. Während Rosa mit der Theorie der Resonanz einen umfassenden Vorschlag als Antwort auf die Entfremdungsproblematik vorgelegt

80 Rosa, Beschleunigung und Entfremdung, 125-128.

81 Rosa, Beschleunigung, 437. 
hat $^{82}$, finden sich bei Simmel allenfalls Ansätze zu einem Entgegenwirken auf der Ebene der individuellen Lebensführung, die auch Tätigkeitsformen einschließt, welche sich vielleicht treffend als Muße beschreiben ließen. Diese Perspektiven sollen im Folgenden zumindest kurz angedeutet werden.

\subsection{Mögliche Gegenkonzepte}

Damit kommen wir zu der Frage, ob sich bei Simmel auch Überlegungen zu den Möglichkeiten der Erfahrung von Muße in der Moderne finden lassen, die als Gegengewicht zu den von ihm beobachteten Entfremdungstendenzen betrachtet werden können. Bezeichnenderweise ist Muße bei Simmel kein zentraler Begriff, auch wenn seine Diagnose der Moderne einen Bedarf an Mußeerfahrungen nahezulegen scheint. So stellt er in einer Nebenbemerkung zur Mode „Ruhe und Muße“ der „wirtschaftlichen Arbeit“ gegenüber, ohne daraus ein positives Gegenbild zu entwickeln. ${ }^{83}$ Hier wie andernorts bleibt „Muße“ negativ definiert als absoluter Gegensatz zur Arbeit. ${ }^{84}$

Dennoch finden sich in seinem Werk durchaus Spuren von Erfahrungen, die ein Gegengewicht zu Beschleunigung und Entfremdung bilden. Wenngleich hier Muße nicht als zentraler Begriff fungiert, so steht sie der Sache nach doch im Hintergrund. Bei der folgenden Darstellung orientiere ich mich daher an den oben eingeführten Unterscheidungen und suche nach selbstzweckhaften Tätigkeiten bei Simmel, die in das Feld der Muße fallen, auch wenn sie von Simmel nicht explizit als Fälle von „Muße“ bezeichnet werden. ${ }^{85}$

Die verschiedenen Freizeitaktivitäten des Großstadtmenschen finden bei Simmel vielfach Erwähnung. ${ }^{86}$ Dabei hat Simmel in Bezug auf die Freizeit klar im Blick, dass diese mit der Entwicklung der Arbeit einhergeht und von der Geldwirtschaft stark beeinflusst wird:

Wie man gesagt hat, die Geschichte der Frauen habe das Eigenthümliche, daß sie nicht die Geschichte der Frauen, sondern die der Männer sei, so kann man sagen, die Geschichte der Erholungen, des Spieles, der Vergnügungen sei, näher betrachtet, die Geschichte der Arbeit und des Ernstes. ${ }^{87}$

82 Hartmut Rosa, Resonanz. Eine Soziologie der Weltbeziehung, Frankfurt a. M. 2016.

83 Vgl. Simmel, „Die Mode“, in: GA 14, 196.

${ }^{84}$ Vgl. Simmel, Philosophie des Geldes, GA 6, 65: „Insoweit der Wunsch nach Muße oder einem bloß sich selbst genügenden Spiel der Kräfte oder der Vermeidung der lästigen Anstrengung besteht, ist jede Arbeit unbestreitbar eine Aufopferung."

85 Vgl. oben, Abschnitt 1.

86 Vgl. David Frisby, „Simmel and Leisure“, in: Chris Rojek (Hg.), Leisure for leisure, Basingstoke u. a. 1989, 75-91.

87 Georg Simmel, „Infelices possidentes!“, in: GA 17, hg. v. Klaus Christian Köhnke, Frankfurt a. M. 2005, 293-297, 295. 
Nun haben sich laut Simmel aber die Arbeitsbedingungen unter dem Einfluss der Geldwirtschaft und der Arbeitsteilung so verschärft, dass für die Zeit jenseits der Arbeit kaum noch Energie für anspruchsvolle Freizeitgestaltung übrigbleibe. „Sieht der Tag so aus, welches Gesicht kann der Abend tragen?" 88 , ist daher eine Frage, die Simmel in dem polemischen Text Infelices possidentes von 1893 stellt. Seine Antwort fällt deutlich genug aus: Die veränderten Zeiterfahrungen der Moderne, die Unruhe, die Schockerfahrungen sowie die allgemeine „Hyperästhesie " 89 führen insgesamt zu einer Verflachung der Freizeitaktivitäten, bei denen „man ssich nur amüsiren will < - >nur amüsiren < - darin liegt das ganze Elend unseres Vergnügungswesens ${ }^{\text {“90 }}$. So spiegeln einige Freizeitaktivitäten das veränderte Zeitempfinden deutlich wider, wie der schnelle Wechsel der Moden, das Interesse an komprimierten Konsumformen wie der Kunstausstellung etc. Auch die räumlichen Veränderungen des modernen Lebens zeigen sich im Bereich der Freizeit: Die „Tendenz auf Distanzirung ${ }^{\text {“91 }}$, die Simmel für die moderne Kultur beschreibt, führt zu einer gewissen „Berührungsangst“92 mit den Dingen, die sich auch bei Freizeitaktivitäten wie der Kunstbetrachtung in der Vorliebe für bestimmte Stile niederschlägt, die zum Beispiel durch die Betonung des Fremden die Distanz zu den Dingen erhöhen. ${ }^{93}$ Simmel sieht also durchaus, dass Arbeit und Freizeit in der Moderne ein ,Gesamtpaket' bilden, dass sich die Probleme der vom Geld dominierten, beschleunigten Arbeitswelt in den Freizeitaktivitäten fortsetzen. Die Freizeit ist nur die Kehrseite der Arbeitszeit und kein Gegenmittel gegen die moderne Entfremdung, so scheint es.

Wenn man Muße bestimmt als Tätigsein, das seinen Zweck in sich selbst hat, muss man also von Simmels Beschreibungen der alltäglichen Vergnügungen absehen und nach Spuren eines solchen selbstzweckhaften Tätigseins suchen. Die Zweck-Mittel-Unterscheidung ist für Simmels Kulturphilosophie nun insgesamt zentral. Während die Welt der Lohnarbeit durch Zweck-Mittel-Relationen gekennzeichnet ist, findet in den verschiedenen Sphären der Kultur irgendwann eine „Achsendrehung " ${ }^{\text {“94 }}$ statt, wodurch die kulturellen Objektivationen zu autonomen Formen werden, die sich nicht mehr als Mittel zu einem Zweck verstehen lassen. Dieser Prozess birgt nun beide Möglichkeiten: dass damit eine eigengesetzliche Welt geschaffen wird, welche sich als positives Gegenbild von einem entfremdeten Alltag löst, oder dass damit eine eigengesetzliche Welt geschaffen wird, die dem Individuum als fremd und lebensfeindlich erscheint und sich ge-

88 Simmel, „Infelices possidentes!“, in: GA 17, 295.

89 Simmel, „Soziologische Aesthetik“, in: GA 5, hg. v. Heinz-Jürgen Dahme/David P. Frisby, Frankfurt a. M. 1992, 197-214, 211.

90 Simmel, „Infelices possidentes!“, in: GA 17, 295.

91 Simmel, „Soziologische Aesthetik“, in: GA 5, 212.

92 Simmel, „Soziologische Aesthetik“, in: GA 5, 211 u. 213.

93 Vgl. Simmel, „Soziologische Aesthetik“, in: GA 5, $210 \mathrm{f}$.

94 Georg Simmel, „Lebensanschauung, vier metaphysische Kapitel“, in: GA 16, hg. v. Gregor Fitzi/Otthein Rammstedt, Frankfurt a. M. 1999, 209-425, 245. 
gen dieses zurückwendet wie in der Tragödie der Kultur beschrieben. Während eine fortschreitende Autonomisierung von Wirtschaft und Technik für Simmel eher letzteres bewirkt, sieht er die fortschreitende Autonomisierung der Kunst z.B. vielfach positiv, obgleich er auch hier vor Extremformen des l'art pour l'art warnt.

Denn obwohl sie in veränderten Rezeptionspraktiken wie der Kunstausstellung mit ihrer kurzen Halbwertszeit selbst auch von der Logik des Geldes beeinflusst wird ${ }^{95}$, hat die Kunst für Simmel doch noch ein echtes Befreiungspotenzial, indem sie eine fruchtbare Distanz zu den Dingen ermöglicht. Hierin könnte man - eher noch als in seinem Philosophiebegriff - eine Nähe zur Kontemplation finden, wenn er davon schreibt, Kunst „veränder[e] die Blickweite, in die wir uns ursprünglich und natürlich zu der Wirklichkeit stellen "96. Simmels Überlegungen zu großen Künstlerpersönlichkeiten wie Goethe und Rembrandt zeigen ferner, dass in der künstlerischen Produktion von Werken ein Verhältnis von Individuellem und Allgemeinem möglich ist, welches das Werk dem Produzenten nicht entfremdet, wie es bei dem arbeitsteilig entstandenen Industrieprodukt passiert. Dies wäre möglicherweise eine als nicht-entfremdet zu beschreibende Tätigkeit, die jedoch auf dem persönlichen Talent und der Neigung des Einzelnen aufruht und am Werk orientiert bleibt, sodass hier eher der Bereich der poiesis betroffen ist.

Eine besondere Zeiterfahrung, die den Alltag durchbricht, von der objektiven Zeitordnung der Arbeit befreit und nicht auf die Herstellung eines Werkes ausgerichtet ist, stellt das Abenteuer dar. Das formale Kennzeichen des Abenteuers ist, „daß es aus dem Zusammenhange des Lebens herausfällt“ “97 Gleichzeitig weist es eine innere Geschlossenheit auf, die es von anderen Episoden des Lebens unterscheidet und es in die Nähe des Kunstwerks rücken lässt. Das Abenteuer bietet eine Freiheit, die weder die Arbeit noch die alltäglichen Vergnügungen bieten, und als derartige Unterbrechung des Alltäglichen kann man es in die Nähe des Festes rücken, welches immer wieder als Kandidat für Mußeerfahrungen herangezogen wird. ${ }^{98}$ Allerdings teilt das Abenteuer mit der modernen Zeiterfahrung die Unruhe und die Sensationslust.

Näher an einer Mußeerfahrung ist daher vielleicht eher das, was Simmel unter dem Stichwort der Geselligkeit zusammenfasst. Die Geselligkeit ist laut Simmel die "Spielform der Vergesellschaftung“"99, bei der sich Formen des Zusam-

95 Georg Simmel, „Ueber Kunstausstellungen“, in: GA 17, hg. v. Klaus Christian Köhnke, Frankfurt a.M. 2005, 242-250.

96 Simmel, „Soziologische Aesthetik“, in: GA 5, 209.

97 Georg Simmel, „Das Abenteuer“, in: GA 14, hg. v. Rüdiger Kramme/Otthein Rammstedt, Frankfurt a. M. Suhrkamp 1996, 168-185, 168.

98 Vgl. Josef Pieper, Muße und Kult, München 1952; Henning, „Glück in Arbeit und Muße“, 37-40.

99 Georg Simmel, „Soziologie der Geselligkeit“, in: GA 12, hg. v. Rüdiger Kramme/Angela Rammstedt, Frankfurt a. M. 2001, 177-193. 
menlebens einüben lassen, ohne dass die Beteiligten direkte Interessen verfolgen. Dies zeige sich am deutlichsten an den Gepflogenheiten des Gesprächs. Das gesellige Gespräch zeichne sich nämlich dadurch gegenüber dem alltäglichen Gespräch aus, „daß im Ernst des Lebens die Menschen um eines Inhaltes willen reden, den sie mitteilen oder über den sie sich verständigen wollen - in der Geselligkeit aber das Reden zum Selbstzweck wird"100. Wenn der Bereich des Politischen in Simmels Denken insgesamt keinen eigens ausgezeichneten Platz hat, so finden sich bei der Schilderung der Geselligkeit im Sinne der praxis doch Momente, die nahelegen, dass die Geselligkeit als Beispiel einer Mußeerfahrung in der Moderne dienen kann. ${ }^{101}$

\subsection{Nachspiel: Muße und Müßiggang}

Eine nicht ganz ernst gemeinte Möglichkeit, die Rastlosigkeit des modernen Lebens zu überwinden, schildert Simmel schließlich in seiner satirischen Metaphysik der Faulheit. Diese anonyme Veröffentlichung in der Zeitschrift Jugend von 1900 ist dem Autor rückblickend wohl eher etwas peinlich, wie eine Äußerung gegenüber William Stern zeigt, in welcher er schreibt, er sei „offen gestanden, nicht sehr entzückt davon, dass dieser flüchtige Scherz in irgend einem bewusstsein fortlebt "102. Simmel nimmt hier das auch von ihm im Kontext der Kulturentwicklung häufig vorgebrachte Prinzip der Kraftersparnis aufs Korn, indem er suggeriert, dass dieses nur als Euphemismus für das Streben der Kultur nach Untätigkeit fungiere. Die allgegenwärtige Tätigkeit sei bloßer Schein, denn in Wahrheit strebt der Mensch danach, sich auszuruhen:

Nichts anderes ist jede Thätigkeit, als die Brücke zwischen zwei Faulheiten, und alle Cultur arbeitet, daß sie immer kürzer und kürzer werde. Denn welchen Sinn und Zweck hätte das ungeheure Mühen und Schaffen des modernen Menschen, als daß er damit ein umso tieferes, umfassenderes, heiligeres Faulsein erringe? ${ }^{103}$

Da die Faulheit in der kapitalistischen Gesellschaft jedoch nur auf wenige verteilt sei, müsse eine gerechte Umverteilung stattfinden. Am Ende schließlich stehe eine völlige Bewegungslosigkeit, der auch die Philosophie nur noch durch Schweigen gerecht werden könne: „Dann ist das Säculum der Bewegung zu Ende

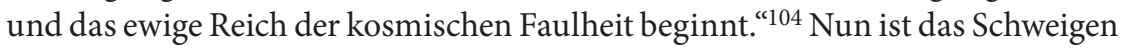

100 Simmel, „Soziologie der Geselligkeit“, in: GA 12, 187.

101 Zur Geselligkeit im Kontext des Spiels vgl. Annika Schlitte, „Das symbolische Spiel bei Georg Simmel“, in: Michel Henri Kowalewicz (Hg.), Spiel. Facetten seiner Ideengeschichte, Münster 2013, 55-71.

102 Georg Simmel an William Stern (Postkarte vom 05.10.1902), in: GA 22, hg. v. Klaus Christian Köhnke, Frankfurt a. M. 2008, 426 f., hier 426.

103 Georg Simmel, „Metaphysik der Faulheit. Ein Satyrspiel zur Tragödie der Philosophie“, in: GA 17, hg. v. Klaus Christian Köhnke, Frankfurt a. M. 2005, 392-397.

104 Simmel, „Metaphysik der Faulheit“, in: GA 17, 397. 
über aktuelle gesellschaftliche Entwicklungen Simmels Sache nicht, wie die bisherigen Ausführungen hinlänglich deutlich gemacht haben sollten; und es sieht auch sonst alles danach aus, als ob wir auf das Reich der kosmischen Faulheit noch ein wenig warten müssten. 



\title{
Die Muße des Flaneurs
}

\section{Raum und Zeit in Franz Hessels Spazieren in Berlin (1929)}

\author{
Peter Philipp Riedl
}

Die idealtypische Form urbaner Muße ist die Flanerie. Hektik und Dynamik großer Städte stehen indes in einem offenkundigen Spannungsverhältnis zu einem betont langsamen, ziellosen Schlendern. Diese Ambivalenz zeigt sich auch in jenem Prosawerk, dem die folgenden Überlegungen gewidmet sind: Spazieren in Berlin (1929) des Schriftstellers Franz Hessel (1880-1941) reflektiert implizit wie explizit Bedingungen, Möglichkeiten und Grenzen der Erfahrung urbaner Muße. Dieser Ausgangsbefund soll nun in drei Schritten näher beleuchtet werden. Zunächst werden der innere Zusammenhang von Muße und Flanieren sowie die Bedingungen des Flanierens im Berlin der Roaring Twenties erläutert. In einem zweiten Schritt wird das Konzept des Flanierens, das Hessel in seinem Text expressis verbis entwickelt, analysiert und anschließend, drittens, wird untersucht, wie dieses Konzept erzählerisch umgesetzt wird.

Harald Neumeyer definiert das Flanieren als

ein vom Zufall bestimmtes Gehen, ein Gehen, das, was das Erreichen eines bestimmten Ortes oder das Durchschreiten eines festgelegten Raumes angeht, als richtungs- und ziellos zu verstehen ist, ein Gehen, das dabei zugleich frei über die Zeit verfügt, Zeit mithin keiner Zweckrationalität unterwirft. ${ }^{1}$

Ziellosigkeit, frei verfügbare Zeit, Unabhängigkeit von Zweckrationalität - die zentralen Attribute dieser definitorischen Zuschreibung weisen das Flanieren als eine Form von Muße aus, wie sie im Sonderforschungsbereich (SFB) 1015 $\mathrm{Mu} ß e$ verstanden wird. ${ }^{2}$ Dementsprechend liegt den folgenden Überlegungen, wie die genannten Attribute bereits signalisieren, eine formale Bestimmung von Muße zugrunde und keine essentialistische, einen exklusiven inhaltlichen Traditionsstrang privilegierende Zuschreibung. In diesem Sinne lassen sich Phänomen und Vorstellung von Muße über paradoxale Wendungen wie ,bestimmte Unbestimmtheit', ,tätige Untätigkeit und ,produktive Unproduktivität' genauer

\footnotetext{
${ }^{1}$ Harald Neumeyer, Der Flaneur. Konzeptionen der Moderne, Würzburg 1999, 11.

2 Grundzüge des gemeinsamen Forschungsprogramms des SFB finden sich in der Einleitung des Bandes: Burkhard Hasebrink/Peter Philipp Riedl (Hg.), Muße im kulturellen Wandel. Semantisierungen, Ähnlichkeiten, Umbesetzungen, Berlin/Boston 2014, 1-11.
} 
erschließen. Bestimmt ist Muße durch ein negatives Freiheitsverständnis: ihre Freiheit von temporalen Zwängen, unmittelbaren Zielen, Zwecken und Leistungserwartungen. Unbestimmt ist die Muße durch ein positives Freiheitsverständnis: Das Freiheitsmoment der Muße liegt darin, dass offen ist, wie im Einzelnen eine solche Ausgestaltung geschieht. ${ }^{3}$ Die Unbestimmtheit meint also die spezifische Ausfüllung der freien Zeit, die aber nicht rein wertneutral aufzufassen ist. Die Unabhängigkeit der Muße vom Diktat der Zeit geht mit der Erwartung einer qualitativ wertvollen Ausgestaltung - welcher konkreten Art auch immer - der freien Zeit einher. Diese Einschränkung ist notwendig, um Muße von Freizeit sowie von prekären Zuständen wie Langeweile oder Burnout abzugrenzen. Das an sich Untätige der Muße kann dahingehend auch eine Form selbstbestimmter Tätigkeit hervorbringen; die Negation einer funktionalistischen, utilitaristischen Produktivitätslogik kann in den Freiräumen, die eine Abwesenheit von unmittelbaren Leistungserwartungen ermöglicht, überaus produktiv werden. Bezogen auf den Typus des Flaneurs, der nicht zielgerichtet von einem Ort zum anderen eilt, bedeutet das: Der offene, nicht zweckrational geprägte Wahrnehmungsmodus, also die Freiheit von einer die eigene Zeit beschränkenden Tätigkeitsform, lässt sich als tätige Untätigkeit beschreiben, die sich literarisch etwa als kreative und damit produktive „Oszillation von Narration und Reflexion“4 niederschlagen kann.

Die skizzierten Zusammenhänge verdeutlichen die enge Korrelation von Muße und Flanieren, die in der Forschung gleichwohl noch nicht systematisch erforscht worden ist. ${ }^{5}$ Zumeist wird eine Verwandtschaft von Flanieren und Müßiggang erwogen, sei es zustimmend ${ }^{6}$, sei es ablehnend. ${ }^{7}$ Als Mußeform im engeren Sinn muss das Flanieren dagegen noch gründlicher als bisher geschehen beschrieben werden. Das gilt insbesondere für das Raum-Zeit-Verhältnis, bei dem in der Forschung zum Flaneur ebenso wie zur Muße hauptsächlich die fraglos essentielle Emergenz von Räumlichkeit betont wird, wohingegen Temporalstrukturen nicht jene Aufmerksamkeit erhalten haben, jedenfalls nicht in angemessener Differenziertheit, die der Gegenstand gebietet. Beides, das Flanieren

${ }^{3}$ Mit der auf Isaiah Berlin rekurrierenden Unterscheidung von negativer und positiver Freiheit kann auch der Zusammenhang von Muße und Freiheit fruchtbar diskutiert werden, wie Jochen Gimmel/Tobias Keiling u. a., Konzepte der Muße, Tübingen 2016, 61-66, darlegen.

4 So Wolfgang G. Müller, „Der Flaneur: Begriff und kultureller Kontext“, in: Literaturwissenschaftliches Jahrbuch 54 (2013), 205-225, 215. Band.

Zum Flanieren als einer Mußepraxis vgl. auch den Beitrag von Heidi Liedke in diesem

${ }^{6}$ Vgl. Leonhard Fuest, Poetik des Nicht(s)tuns. Verweigerungsstrategien in der Literatur seit 1800, München 2008, 101; außerdem Robert Krause, ",dem müßigen Flaneur den angenehmsten Zeitvertreib gewähren'. Figurationen des Müßiggangs in Heines ,Briefen aus Berlin' und ,Lutezia“", in: Thorsten Unger/Claudia Lillge/Björn Weyand (Hg.), Arbeit und Müßiggang in der Romantik, München 2017, 171-182.

7 Müller, „Der Flaneur: Begriff und kultureller Kontext“, 214. 
als Mußeform sowie dessen spezifische Raumzeitlichkeit, steht im Mittelpunkt der folgenden Betrachtungen.

Der Flaneur ist ein Spaziergänger in der Großstadt. Gerade in der modernen Großstadt kontrastiert er deren von Beschleunigung und Hektik geprägte Lebensform mit seiner betonten Langsamkeit, Ziellosigkeit und Offenheit für Wahrnehmungen, die er mit einer von Kontingenz bestimmten gelassenen Haltung jenseits strenger Intentionalität zulässt. Das Flanieren lässt sich daher ohne Abstriche als urbane Ausformung von Muße charakterisieren: Es impliziert einen ästhetischen Wahrnehmungsmodus des Verweilens jenseits der von Beschleunigung und Utilitarismus geprägten Funktionszusammenhänge der Großstadt. Der Flaneur bewegt sich nicht zielgerichtet von einem Ausgangspunkt zu einem Endpunkt, er lässt sich vielmehr treiben, ohne Eile, ohne festes Ziel, ohne unmittelbaren Zweck, ohne direkt in funktionale Abläufe involviert zu sein, welche die Möglichkeiten, über die eigene Zeit frei verfügen zu können, entscheidend einschränken. Er verkörpert die Bereitschaft, sich unerwarteten Eindrücken mit Offenheit und Gelassenheit hinzugeben.

Historisiert man nun diese abstrahierende Definition des Flanierens, stellt sich zunächst einmal die Frage nach den spezifischen Bedingungen des Spazierengehens im Raum der rasant wachsenden Metropole Berlin in den späten zwanziger Jahren des 20. Jahrhunderts. ${ }^{8}$ In den ersten Jahrzehnten nach 1900 wuchs Berlin zu einer Viermillionen-Metropole. In den sprichwörtlich gewordenen ,Goldenen Zwanziger Jahren' avancierte die Hauptstadt nicht nur zum politischen und ökonomischen, sondern auch zum kulturellen Zentrum der Weimarer Republik mit internationaler Strahl- und Anziehungskraft. Eine Metropole in ständiger Bewegung wuchs heran, eine Stadt, die nicht zur Ruhe zu kommen schien. Die Elektrifizierung der Stadt sowie der rasche Ausbau der Verkehrs- und Kommunikationstechnik prägten diesen tiefgreifenden Umgestaltungsprozess entscheidend. All diese Faktoren dynamisierten auch die Wahrnehmung von Zeit und Raum. Die Beschleunigung des Verkehrs und die Fülle heterogener Reize beförderten eine gewisse Oberflächlichkeit und Flüchtigkeit der Wahrnehmung in der Großstadt. So jedenfalls wurde das im Diskurs der Zeit wiederholt festgestellt. Georg Simmel konstatierte eine Reizüberflutung im urbanen Raum ${ }^{9}$, die andere wiederum als eine wesentliche Ursache für die entsprechend dia-

8 Die Entwicklung Berlins in den ersten Jahrzehnten des 20. Jahrhunderts skizziert Sabina Becker, Urbanität und Moderne. Studien zur Großstadtwahrnehmung in der deutschen Literatur 1900-1933, St. Ingbert 1993, 24-72. Vgl. auch Matthias Bauer, „Berlin ist eine ausführliche Stadt'. Einleitende Bemerkungen zur Berliner Stadt-, Kultur- und Mediengeschichte“, in: Matthias Bauer (Hg.), Berlin. Medien- und Kulturgeschichte einer Hauptstadt im 20. Jahrhundert, Tübingen/Basel 2007, 13-72.

9 Diese Beobachtungen finden sich in Simmels Aufsatz Die Großstädte und das Geistesleben (1903), in: Simmel, Das Individuum und die Freiheit. Essais, Berlin 1984, 192-204. 
gnostizierte wachsende Nervosität und Neurasthenie des modernen Menschen ausmachten. ${ }^{10}$

War nun aber das Berlin der Moderne ein Ort des Flanierens? Insbesondere die ältere Forschung hat den Flaneur nicht selten auf einen ganz spezifischen $\mathrm{Pa}-$ riser Künstlertypus des 19. Jahrhunderts festgelegt. Sein paradigmatischer Ort sind die Passagen in Paris, sein geradezu idealtypischer Protagonist ist Charles Baudelaire. Demgegenüber ließ allein die heterogene Struktur und städtische Entwicklung Berlin zu einem urbanen Raum werden, der für die Flanerie alles andere als geeignet schien - im Unterschied zu dem von Baron Haussmann im 19. Jahrhundert massiv und markant umgestalteten Paris. Der Gründerboom veränderte das Stadtbild Berlins umfassend. Neu- und Umbauten von Straßen, breite Ausfallstraßen, Bahnhöfe, große Warenhäuser, Industrieanlagen und Mietskasernen prägten das Stadtbild und schufen Bedingungen, die das Flanieren prima facie eher erschwerten, jedenfalls im Vergleich zu den Pariser Boulevards und Passagen - und immer unter der Voraussetzung literarischer Konstruktionen, die gleichsam um einen bestimmten kulturellen Idealtypus kreisten und diesen sehr oft auch normativ verstanden: den Pariser Flaneur des 19. Jahrhunderts, dem insbesondere Charles Baudelaire seine prägende Gestalt und Walter Benjamin eine wirkmächtige kulturelle Physiognomie verliehen hat. In den ersten Jahrzehnten des 20. Jahrhunderts veränderte sich die preußische Residenzstadt Berlin in einem Ausmaß, dass das ,alte Berlin' regelrecht zu verschwinden drohte. In beispielloser Geschwindigkeit entstanden große Teile der Stadt neu. So verfestigte sich das Bild Berlins als einer betriebsamen Stadt in permanenter Bewegung, einer Stadt, der es an Zeit ebenso fehlte wie an Räumen des Verweilens.

Eine ausgesprochen folgenreiche, in sich jedoch alles andere als konsistente Theorie des Flaneurs entwickelte, wie angedeutet, Walter Benjamin. ${ }^{11}$ Benjamin erklärte die Flanerie aus den Bedingungen des Warenmarktes und setzte dem-

10 Vgl. dazu Joachim Radkau, Das Zeitalter der Nervosität. Deutschland zwischen Bismarck und Hitler, München/Wien 1998.

11 Einschlägig ist insbesondere der Abschnitt zum „Flaneur“ in Benjamins Studie „Das Paris des Second Empire bei Baudelaire“, in: Benjamin, Gesammelte Schriften, Bd. I/2, hg. v. Rolf Tiedemann/Hermann Schweppenhäuser, Frankfurt a. M. 1974, 537-569. Hinzu kommen v. a. noch das Passagenwerk sowie die Rezension zu Hessels Spazieren in Berlin. Die Herausforderung, daraus ein konturiertes Bild zu gewinnen, umreißt Fuest, Poetik des Nicht(s)tuns, 109: „Walter Benjamins Flaneurkonzeption nachzuzeichnen, führt in ein philologisches Labyrinth. Denn der Flaneur geistert nicht nur durch einige seiner bedeutendsten Texte, er trägt auch Eigenschaften, die mit weitverzweigten Begrifflichkeiten des gesamten Werkes korrespondieren." Zu Benjamins Konzeptionen des Flaneurs vgl. auch Neumeyer, Flaneur, 14-25; Anke Gleber, The Art of Taking a Walk. Flanerie, Literature, and Film in Weimar Culture, Princeton University Press 1999, 43-60. Der verwandten Frage nach dem Verhältnis von Muße und Müßiggang in den Schriften Benjamins geht Robert Krause in diesem Band nach. 
entsprechend den Flaneur in Analogie zur Ware. ${ }^{12}$ Darüber hinaus variieren Benjamins eher assoziative und bruchstückhafte Vorstellungen zum Flaneur in seinen Texten erheblich. Eine Grundüberzeugung hat Benjamin indes, wenigstens weitgehend, bei allen Unterschieden in der Zuschreibung einzelner Attribute beibehalten: Die Stadt des Flaneurs ist Paris, und hier sind es wiederum die Passagen, die seinen eigentlichen Aktionsraum bilden. Daraus folgt, dass in der Logik dieser Argumentation mit den Passagen auch der Flaneur verschwunden ist. Gleichwohl ließ derselbe Walter Benjamin den Flaneur auf den Straßen und in den Warenhäusern Berlins der Roaring Twenties seine Wiedergeburt feiern. Die Wiederkehr des Flaneurs ist ein kurzer Text überschrieben, der am 4. Oktober 1929 in der Zeitschrift Die literarische Welt erschienen ist. Es handelt sich um eine Rezension von Franz Hessels Spazieren in Berlin. Die Prosaskizzen Hessels, mit dem Benjamin befreundet war, seien, so seine vielzitierte Wendung, „ein Memorieren im Schlendern“. ${ }^{13}$ Für sein Buch sei die „Erinnerung nicht die Quelle, sondern die Muse“ .14 Die Stadt fungiere dabei „als mnemotechnischer Behelf des einsam Spazierenden “ ${ }^{15}$ Hessels Stadtbild nötigt Benjamin dazu, seine eigene frühere Position zur Flanerie zu revidieren, wie er unumwunden eingesteht: Was die Stadt Berlin in Hessels Schilderungen „eröffnet, ist das unabsehbare Schauspiel der Flanerie, das wir endgültig abgesetzt glaubten“. ${ }^{16}$ Damit geht freilich auch die Veränderung des Typus einher. Nicht in Paris, sondern in Berlin „versteht man, wie der Flaneur vom philosophischen Spaziergänger sich entfernen und die Züge des unstet in der sozialen Wildnis schweifenden Werwolfs bekommen konnte". 17

Im Folgenden soll aber nicht die Frage im Fokus des Interesses stehen, wie ein philosophischer Spaziergänger, bei dem man eher an Rousseau als an Baudelaire denkt, zum schweifenden Werwolf mutiert - bei diesem Bild schimmert Benjamins Lektüre von Edgar Allan Poes The Man of the Crowd (1840) durch. Diese Formulierungen zählen zu den bereits erwähnten eher assoziativen Attributen, die Benjamin dem Flaneur ohne erkennbaren Anspruch auf Kohärenz zuschreibt. Hessels Stadtbild vergegenwärtigt auch keine soziale Wildnis; die soziale Problematik Berlins in den zwanziger Jahren des 20. Jahrhunderts wird allenfalls angedeutet, insgesamt betrachtet aber eher auffallend ausgeblendet.

12 Vgl. Benjamin, „Das Paris des Second Empire“, in: GS I/2, $557 \mathrm{f}$.

13 Walter Benjamin, „Die Wiederkehr des Flaneurs“, in: GS III, hg. v. Hella Tiedemann-Bartels, Frankfurt a. M. 1972, 194-199, 194. Vgl. dazu Markus Svoboda, „Die Straße als Wohnung. Walter Benjamins Rezension von Franz Hessels ,Spazieren in Berlin“", in: Peter Sprengel (Hg.), Berlin-Flaneure. Stadt-Lektüren in Roman und Feuilleton 1910-1930, Berlin 1998, 137-160.

14 Benjamin, „Die Wiederkehr des Flaneurs“, in: GS III, 194.

15 Benjamin, „Die Wiederkehr des Flaneurs“, in: GS III, 194.

16 Benjamin, „Die Wiederkehr des Flaneurs“, in: GS III, 194.

17 Benjamin, „Die Wiederkehr des Flaneurs“, in: GS III, 198. 
Doch wie präsentiert sich der Ich-Erzähler? Und handelt es sich bei den Erzählungen tatsächlich um ein „Memorieren im Schlendern“?

Hessels Spazieren in Berlin besteht aus 23 Abschnitten oder Kapiteln sowie einem Nachwort an die Berliner. Es handelt sich dabei um Prosaskizzen unterschiedlicher Länge. Die meisten sind eher kurz und umfassen nur wenige Seiten. Nur eine Prosaskizze fällt mit gut 80 Seiten in der diesen Ausführungen zugrunde liegenden Ausgabe aus diesem Rahmen. ${ }^{18}$ Sie macht ein knappes Drittel des Gesamttextes aus. Auf dem Schutzumschlag der Erstausgabe von 1929 findet sich eine programmatische Charakterisierung der Prosaskizzen: „Ein Lehrbuch der Kunst | in Berlin spazieren zu gehen | ganz nah dem Zauber der Stadt | von dem sie selbst kaum weiß | Ein Bilderbuch in Worten“" (S, 21). Die Bestimmung als „Lehrbuch“ verspricht eine Anleitung, die das Spazierengehen im urbanen Raum, also das Flanieren, als eine Kunstform ausweist, in welche die Leserinnen und Leser eingeführt werden, und darüber hinaus in der erzählerischen Vergegenwärtigung dieser Kunst womöglich sogar eine Poetik des Flanierens. Das angekündigte „Bilderbuch in Worten“ erhebt den Selbstanspruch, dass der Text Bilder der Stadt in einer Weise generiert oder in Erinnerung ruft, dass die Rezipienten gedanklich selbst zu Flaneuren werden, jedenfalls die erzählte Flanerie anschaulich nachvollziehen, nachempfinden können. Diese Ankündigung verbindet die Kunstform des Flanierens mit einer ästhetischen Wahrnehmung, die das Optische privilegiert und im Akt des Sehens dasjenige offenbart, das zwar an der Oberfläche grundsätzlich sichtbar ist, aber sich nur demjenigen zeigt, der sich dem hektischen Getriebe der Metropole entzieht und im Modus des Verweilens mit einem schweifenden Blick sich den städtischen Raum visuell anzueignen vermag. Wer dagegen dem Geschwindigkeitsrausch der Stadt erliegt, dem bleibt ihr "Zauber" verborgen.

Dieser paratextuell erhobene Anspruch wird in den Prosaskizzen an drei Stellen explizit aufgegriffen und ausformuliert: zu Beginn, nach gut der Hälfte des Werks sowie an dessen Ende. Die entsprechenden Ausführungen akzentuieren zudem implizit die innere Affinität, ja die Korrelation von Flanieren und Muße. Die erste Prosaskizze ist mit dem Titel Der Verdächtige überschrieben. Die ersten Sätze des Werks schreiben sich bereits dahingehend in die literarische Tradition des Flaneurs ein, dass sie intertextuell auf Baudelaires Prosagedicht Les Foules anspielen:

Langsam durch belebte Straßen zu gehen, ist ein besonderes Vergnügen. Man wird überspült von der Eile der andern, es ist ein Bad in der Brandung. Aber meine lieben Berliner Mitbürger machen einem das nicht leicht, wenn man ihnen auch noch so geschickt aus-

18 Zitiert wird nach der Ausgabe: Franz Hessel, Spazieren in Berlin. Mit einem Geleitwort v. Stéphane Hessel, München/Berlin 2012. Die Textnachweise erfolgen im fortlaufenden Text unter Angabe der Sigle S und der jeweiligen Seitenzahl. 
biegt. Ich bekomme immer mißtrauische Blicke ab, wenn ich versuche, zwischen den Geschäftigen zu flanieren. Ich glaube, man hält mich für einen Taschendieb. (S, 23)

Das langsame Schlendern fällt im hektischen Getriebe der Großstadt nicht nur aus dem Rahmen beschleunigter Fortbewegung; es wirkt in diesem Kontext wie eine Provokation. Der Flaneur macht sich, wie bereits die Überschrift des Eingangskapitels unmissverständlich darlegt, verdächtig: ${ }^{19}$

Die hurtigen, straffen Großstadtmädchen mit den unersättlich offnen Mündern werden ungehalten, wenn meine Blicke sich des längeren auf ihren segelnden Schultern und schwebenden Wangen niederlassen. Nicht als ob sie überhaupt etwas dagegen hätten, angesehn zu werden. Aber dieser Zeitlupenblick des harmlosen Zuschauers enerviert sie. Sie merken, daß bei mir nichts ,dahinter!'steckt. (S, 23)

Die Entschleunigung des Gehens korrespondiert mit einer Verlangsamung des Sehens. ${ }^{20}$ Die Blicke fokussieren sich auf Oberflächenphänomene. Der Betrachter belässt es bei der Erzählung dessen, was er sieht, ohne Wertung, ohne Urteil, ohne tiefergehende Interpretation. Der Flaneur beschränkt sich auf eine visuell wahrgenommene und narrativ vermittelte Phänomenologie der Oberfläche. Zur Bestätigung, dass er seine Wahrnehmung ausschließlich als - vermeintlich naiven Blick konzeptionalisiert, fügt er noch bestärkend hinzu: „Nein, es steckt nichts dahinter. Ich möchte beim Ersten Blick verweilen. Ich möchte den Ersten Blick auf die Stadt, in der ich lebe, gewinnen oder wiederfinden“ (S, 23).

Mit der Ästhetik und Poetik des Ersten Blicks ${ }^{21}$, der dezidiert kein analytischer Blick sein soll, schließt Hessel an einschlägige literarische Traditionen an: Adalbert Stifter, dann insbesondere die Literatur der Jahrhundertwende, Hugo von Hofmannsthal und Peter Altenberg, dessen Werke Hessel in frühen Jahren enthusiastisch rezipierte, fand er hier doch „den kindlichen Blick auf die Dingwelt bewahrt“ ${ }^{22}$,Kindlich` darf dabei aber nicht vorschnell mit ,naiv` oder

19 Zur kritischen Auseinandersetzung mit der „Marginalisierung und vor allem Kriminalisierung des Flaneurs" im 19. Jahrhundert vgl. Rüdiger Severin, Spuren des Flaneurs in deutschsprachiger Prosa, Frankfurt a. M. 1988, 7-13, 8.

20 Die Verwendung des Begriffs ,Zeitlupenblick“ „zeigt auch, dass Hessel terminologisch auf dem neuesten Stand ist, denn der Begriff ,Zeitlupe kommt erst Mitte der 1920er Jahre auf", erläutert Sebastian Marx, Betriebsamkeit als Literatur. Prosa der Weimarer Republik zwischen Massenpresse und Buch, Bielefeld 2009, 130-172, 136.

${ }^{21}$ Zum ,Ersten Blick'vgl. z.B. Matthias Keidel, Die Wiederkehr der Flaneure. Literarische Flanerie und flanierendes Denken zwischen Wahrnehmung und Reflexion, Würzburg 2006, 30; Neumeyer, Flaneur, 295-327, 311-318.

22 So Eckhardt Köhn, Straßenrausch. Flanerie und kleine Form. Versuch zur Literaturgeschichte des Flaneurs bis 1933, Berlin 1989, 155. Auf Hessels Rezeption von Stifter, Hofmannsthal und Altenberg weist Eva Banchelli hin: „Zwischen Erinnerung und Entdeckung. Strategien der Großstadterfahrung bei Franz Hessel“, in: Michael Opitz/Jörg Plath (Hg.), „Genieße froh, was du nicht hast“. Der Flaneur Franz Hessel, Würzburg 1997, 105116, 112. Eine Nähe von „Altenbergs Abbreviatur-Verfahren“ zur „Wahrnehmungsweise des Flaneurs" konstatiert auch Severin, Spuren des Flaneurs in deutschsprachiger Prosa, $155-160,158$. 
,unreflektiert' gleichgesetzt werden, sondern ist, dem eigenen Anspruch gemäß, im Sinne von offener, unvoreingenommener Neugier zu verstehen. Der nur vermeintlich ,kindliche' Blick schließt ästhetisch vielmehr an die avancierte Poesie und Poetik um 1900 an. Die Forschung hat es indes bei dem bloßen Hinweis auf die Tradition der Ästhetik der Dinge bei Stifter, Hofmannsthal und Altenberg belassen. Gerade Peter Altenbergs impressionistische Ästhetik des Blicks drängt sich indes als eine grundlegende Bezugsgröße für Hessels, Ersten Blick ' geradezu auf. Altenberg, der prototypisch den sogenannten Wiener Kaffeehausliteraten verkörperte, bevorzugte die kleine Form der Prosaskizzen, aus denen sich grosso modo auch Hessels Spazieren in Berlin zusammensetzt. Altenberg beschränkt seine impressionistischen Skizzen auf das, was er - so seine Suggestion - aus dem Kaffeehaus heraus sieht: ein bewusst unvoreingenommener Blick, der einer wie auch immer gearteten subjektiv interpretierenden Aneignung vorgelagert ist. Altenbergs schriftstellerisches Debüt aus dem Jahr 1896 trägt den programmatischen Titel: Wie ich es sehe. Wie der Titel auszusprechen sei, hat Altenberg ausdrücklich erläutert. Die Betonung liege auf dem Sehen:, Wie ich es sehe - und nicht: ,Wie ich es sehe. ${ }^{23}$ Die visuelle Wahrnehmung bestimmt die Poetik der Prosaskizzen, in Altenbergs Kaffeehausliteratur ebenso wie bei Hessels Flaneur, zumindest der eigenen Theorie, dem eigenen Anspruch nach.

Hessels Flaneur führt sich selbst als Außenseiter ein. Er ist Außenseiter, weil er der hektischen Betriebsamkeit der Metropole seine geradezu provokative Haltung der Entschleunigung, des freien Verweilens entgegensetzt. Die Ziellosigkeit seines schlendernden Gehens kontrastiert mit dem schnellen Schritt, mit dem der Großstädter Distanzen so rasch wie möglich überwinden will: „Hierzulande muß man müssen, sonst darf man nicht. Hier geht man nicht wo, sondern wohin. Es ist nicht leicht für unsereinen." (S, 25 f.) Dieses Eingeständnis ist Ausdruck einer Fremdheitserfahrung in der eigenen Stadt.

In der achten Prosaskizze, die den Titel Berlins Boulevard trägt, wird nun das Flanieren näher bestimmt. Flanieren, so heißt es hier, sei eine „urbane Betätigung" $(\mathrm{S}, 156)$, für die sich in Berlin die Tauentzienstraße und der Kurfürstendamm besonders eigneten. Der Boulevard ist Lehrpfad und Aktionsraum für Flaneure, die hier noch halbwegs günstige Bedingungen für die Kunst des Verweilens finden können. Es folgt nun eine der bekanntesten und meistzitierten Definitionen des Flaneurs in deutscher Sprache überhaupt:

Flanieren ist eine Art Lektüre der Straße, wobei Menschengesichter, Auslagen, Schaufenster, Caféterrassen, Bahnen, Autos, Bäume zu lauter gleichberechtigten Buchstaben werden, die zusammen Worte, Sätze und Seiten eines immer neuen Buches ergeben. Um richtig zu flanieren, darf man nichts allzu Bestimmtes vorhaben. (S, 156)

23 So Altenberg im Jahr 1906. Vgl. dazu das entsprechende Zitat in: Gotthart Wunberg (Hg.), Die Wiener Moderne. Literatur, Kunst und Musik zwischen 1890 und 1910, Stuttgart 1981, $424 \mathrm{f}$. 
Man könne dabei, so der Ich-Erzähler weiter, „die Promenade ohne festes Ziel riskieren und auf die ungeahnten Abenteuer des Auges ausgehn“ (S, 156). Mit diesen definitorischen Zuschreibungen wird das Flanieren implizit als genuine Mußeform ausgewiesen. Das freie Verweilen in der Zeit jenseits von Zweckrationalismus und einer die Zeit beschränkenden Leistungserwartung akzentuiert den Mußecharakter des Flanierens. Darüber hinaus lässt sich die eingangs erläuterte formale Bestimmung von Muße mit der zitierten Definition des Flanierens inhaltlich ausfüllen und konkretisieren. Ihre eigentliche Spannung gewinnt Muße, wie erwähnt, durch ihren Schwellencharakter zwischen Bestimmtheit und Unbestimmtheit. Davon leiten sich weitere paradoxale Bestimmungen der Muße ab, die gleichermaßen auf die Flanerie als Ausprägung einer genuin urbanen Muße zutreffen: Der offene, verweilende Blick, der die disparaten Zeichen der Stadt wahrnimmt und - aktiv - liest, kann als tätige Untätigkeit, als produktive Unproduktivität begriffen werden. Der von Kontingenz bestimmte Rezeptionsvorgang wird produktionsästhetisch übersetzt und findet in den Prosaskizzen seine angemessene literarische Gestalt.

Im Falle des Flanierens in Hessels Spazieren in Berlin wird die wertvolle Ausfüllung der freien Zeit mit der Metapher der „Lektüre der Straße“ (S, 156) zum Ausdruck gebracht. Dieses Bild ist keine Erfindung Hessels. Bereits Ludwig Börne hat in seinen Schilderungen aus Paris (1822-24) die Hauptstadt Frankreichs als ein „aufgeschlagenes Buch“ bezeichnet und weiter ausgeführt: durch die Straßen von Paris „wandern heißt lesen“. ${ }^{24}$ Bei Hessel setzt die „Lektüre der Straße“ eine Haltung der Gelassenheit voraus, das heißt den Verzicht auf zielgerichtetes Handeln oder, in den Worten des Ich-Erzählers, die Bereitschaft, dass „man nichts allzu Bestimmtes“ (S, 156) vorhat. Diese Offenheit, etwas zuzulassen, was man nicht intentional herbeiführen will, ermöglicht es, dass sich ästhetische Erfahrungen einstellen, auf die man es nicht bewusst abgesehen hat. Die Muße des Flaneurs entsteht so einerseits aus der negativen Freiheit, „nichts allzu Bestimmtes“ (S, 156) vorzuhaben, und führt andererseits zu der Erfahrung positiver Freiheit einer ganz spezifischen ästhetischen Erfahrung, die in dieser Prosaskizze als Lektüreerlebnis metaphorisiert wird. Die unterschiedlichen Wahrnehmungen und Eindrücke des ,Ersten Blicks' werden als grundsätzlich gleichberechtigte Buchstaben verstanden, die in einem gleichsam poststrukturalistischen Bricolage-Verfahren stets aufs Neue und in unterschiedlichen Abfolgen zusammengesetzt werden können, so dass sie „zusammen Worte, Sätze und Seiten eines immer neuen Buches ergeben“ (S, 156). Die Offenheit des Blicks ermöglicht eine Rezeptionshaltung, durch die sich die Textur des urbanen Raumes in unterschiedlichen Formen stets neu zu konstituieren vermag. Das Buch der Stadt entsteht immer wieder neu im Akt des augenblicklichen Lesens, das

${ }^{24}$ Ludwig Börne, Sämtliche Schriften, Bd. 2, neu bearb. u. hg. v. Inge Rippmann/Peter Rippmann, Düsseldorf 1964, 34. 
im Zustand des freien Verweilens und in einer Haltung der Gelassenheit erfolgt, das heißt mit einer ästhetischen Offenheit für das, was einem ohne aktives Zutun begegnet. Die strukturelle Analogie von Muße und Flanerie wird hier besonders evident.

In seinem abschließenden Nachwort an die Berliner fasst der Ich-Erzähler sein Konzept des Flanierens noch einmal pointiert zusammen, und zwar mit einer für das Werk insgesamt alles andere als singulären Apostrophe:

Das waren ein paar schüchterne Versuche, in Berlin spazieren zu gehen, rund herum und mitten durch, und nun, liebe Mitbürger, haltet mir nicht vor, was ich alles Wichtiges und Bemerkenswertes übersehen habe, sondern geht selbst so wie ich ohne Ziel auf die kleinen Entdeckungsreisen des Zufalls. Ihr habt keine Zeit? Dahinter steckt ein falscher Ehrgeiz, ihr Fleißigen. (S, 283)

Das absichtslose Flanieren steht im Widerspruch zum allmächtigen Postulat der Zeiteffizienz. Die Kunst des Flanierens ist unter diesen Bedingungen alles andere als selbstverständlich, im Gegenteil, es muss wieder erlernt werden. Hessel versteht ja, wie erwähnt, sein Werk programmatisch als „Lehrbuch“ (S, 21) und schließt seine Erzählungen auch mit dem Hinweis: „[...] wir wollen ein wenig Müßiggang und Genuß lernen [...]“ (S, 285).

Doch wie sieht es nun mit der Umsetzung dieses Programms aus, das zugleich ja ein Lehrprogramm sein soll? Folgen die Erzählungen der Prosaskizzen dem postulierten Konzept des Flanierens? Lösen die Prosaskizzen diesen explizit vorgetragenen Anspruch ein?

Eine erste Beobachtung, die das Konzept des Flanierens in der vorgetragenen Form etwas modifiziert, ist noch weitgehend unproblematisch. Das sehr forciert formulierte Kriterium der Ziellosigkeit des Flanierens, der schlendernden Raumerschließung jenseits von Zeitbeschränkung und Funktionalismus, ist in der konkreten Umsetzung nicht gleichbedeutend mit reiner Absichtslosigkeit. Die Frage ist nur, auf welcher Ebene die Intention beim Flanieren angesiedelt ist. Die meisten Kapitel sind mit topographischen Angaben oder Himmelsrichtungen betitelt: Berlins Boulevard, Alter Westen, Tiergarten, Der Landwehrkanal, Der Kreuzberg, Tempelhof, Hasenheide, Über Neukölln nach Britz, Nach Osten, Norden, Nordwesten, Friedrichstadt, Dönhoffplatz, Zeitungsviertel, Südwesten. Diese Anordnung zeigt v. a. eines: Das Flanieren erfolgt nicht im eigentlichen Sinn intentions- und ziellos; innerhalb eines vorgegebenen Musters kann sich der Flaneur aber der Laune des Augenblicks frei hingeben. Hessels Flaneur erschließt die Stadt achsenförmig. ${ }^{25}$ Innerhalb dieses topographischen Ordnungsrahmens lässt der Erzähler indes intentionslos Erfahrungen ganz unterschiedlicher Art zu. Das artikuliert sich in der Wiedergabe betont zufälliger bzw. kon-

25 Vgl. dazu Sabina Becker, „Flanerie und Architekturbeschreibung. Die Stadtlektüren Franz Hessels", in: Robert Krause/Evi Zemanek (Hg.), Text-Architekturen. Die Baukunst der Literatur, Berlin/Boston 2014, 187-205, 199. 
tingenter Beobachtungen und gedanklicher Abschweifungen. Der ,Erste Blick“ $(S, 23)$ und die „Lektüre der Straße“ (S, 156) ermöglichen narrative Verfahren, Schreibweisen, die in besonderem Maß als mußeaffin bezeichnet werden können: Essayistische Einschübe und Digressionen sind poetischer Ausdruck eines textuellen Flanierens, das Abschweifungen, Umwege und Verweilen privilegiert, Randerscheinungen und Nebensächlichkeiten aufnimmt und damit die Kunst des Spazierengehens im urbanen Raum literarisch übersetzt.

Die postulierte Ziellosigkeit ist aber keine Orientierungslosigkeit. Zweckfreiheit meint auch nicht Zwecklosigkeit. Auf der Ebene der unmittelbaren Wahrnehmung herrscht zwar Intentionslosigkeit vor sowie die Bereitschaft, sich zufälligen Eindrücken vorbehaltlos hinzugeben. Auf der übergeordneten Ebene des Ordnungsrahmens, der die Kontingenz ästhetischer Erfahrungen organisiert, ist jedoch eine intentionale Struktur unverkennbar. Hier lässt sich auch eine strukturelle Gemeinsamkeit zwischen Hessels Konzept des Flanierens und dem eingangs entwickelten formalen Begriff von Muße konstatieren. Die Vorstellung vom Schwellencharakter der Muße impliziert auch deren Grenzen in Form einer Rahmung.

Schränkt also die vorhandene rahmende Ordnungsstruktur des topographischen Rasters Hessels theoretischen Anspruch des ,offenen' Flanierens nicht ein, jedenfalls nicht signifikant und erst recht nicht substantiell, so sieht das bei der zweiten Auffälligkeit der Prosaskizzen schon etwas anders aus. Über weite Strecken geht der vermeintliche Spaziergänger gar nicht zu Fuß, sondern benutzt technische Verkehrsmittel: Auto, Bus, Straßenbahn, Schiff. Gleich in der zweiten Prosaskizze, die Ich lerne überschrieben ist und unmittelbar auf die programmatischen Überlegungen des Auftaktkapitels folgt, setzt sich der selbsternannte Spaziergänger ins Auto und lässt sich von einem Architekten - es handelt sich um den Stadtbaurat und Stadtplaner Martin Wagner ${ }^{26}$ - auf einer Rundfahrt moderne, vorwiegend neusachliche Architektur zeigen, die der Ich-Erzähler im krassen Unterschied zum pompösen Baustil und eklektizistischen Historismus des Wilhelminismus wertzuschätzen weiß. ${ }^{27}$ Weitere Autofahrten folgen, auch eine Fahrt mit der Trambahn sowie ein Ausflug auf einem „Vergnügungsdampfer mit Musik“ (S, 205).

${ }^{26}$ Vgl. z.B. die Einleitung von Moritz Reininghaus in der hier zitierten Ausgabe: Franz Hessel, Spazieren in Berlin, 11-20, 19.

27 Den „Spuren der Neuen Sachlichkeit“ in Hessels Stadtspaziergängen folgt Christiane Zauner-Schneider, Die Kunst zu balancieren. Berlin-Paris. Victor Auburtins und Franz Hessels deutsch-französische Wahrnehmungen, Heidelberg 2006, 340-355, 340. Ästhetische Konzeptionen Hessels im Kontext der Neuen Sachlichkeit diskutiert Arndt Potdevin, „Franz Hessel und die Neue Sachlichkeit“, in: Sprengel (Hg.), Berlin-Flaneure, Berlin 1998, 101-135. Dass Hessel an der neusachlichen Architektur in erster Linie ihren Funktionalismus würdigt, betont demgegenüber, einseitig argumentierend, Jan T. Schlosser, „Berlin als Ort und Nicht-Ort. Franz Hessels Spazieren in Berlin im Kontext der Modernekritik“, in: Philologie im Netz 66 (2013), 21-54, 43. 
Das, wie erwähnt, mit weitem Abstand längste Kapitel trägt den Titel Rundfahrt. Es umfasst nahezu ein Drittel des gesamten Textes (S, 67-149). Diese Prosaskizze handelt von einer Sightseeing-Tour im offenen Autobus für Touristen. Von einem freien Verweilen in der Zeit, einem offenen Blick, dem sich die einzelnen Zeichen, die im Modus der Gelassenheit wahrgenommen werden, zu stets neuen Texturen zusammenfügen, kann hier nicht die Rede sein. Der Touristenführer im Bus lenkt vielmehr die Blicke der Fahrgäste mit vielen abrupten Wechseln in unterschiedliche Richtungen. Die Rundfahrt ist von Rastlosigkeit geprägt, alles wird nur „beim Namen genannt“ (S, 71). Widerwillig lässt der Ich-Erzähler die Fahrt über sich ergehen, wendet seine Blicke indes nicht immer in jene Richtung, in die sie der Touristenführer lenken möchte, schweift gedanklich ab und gibt sich seinen subjektiven Erinnerungen hin, bis er zuletzt doch genug hat, in ein Café flieht und sich so endgültig vom Typus des eiligen Touristen abgrenzt: „Fahrt ohne mich weiter, ihr richtigen Fremden!“ (S, 149)

Allenfalls die gedanklichen Abschweifungen und Erinnerungen inmitten der Fülle und Vielfalt heterogener Signale deuten an, dass urbane Muße gerade auch in der Dynamik der Großstadt transgressiv, im Sinne einer rastlosen Rast, erfahren werden kann. Das Subjekt kann in der Hektik der Metropole durch innere Distanzierung zum äußeren Trubel zu sich selbst finden. In Spazieren in Berlin konterkarieren diese erzählerischen Einschübe indes eher die Bevormundung und Fremdbestimmung durch die guided tour. Diese Rundfahrt steht in einem augenfälligen Widerspruch zu jener Haltung des Flaneurs, die im Einleitungskapitel als „Zeitlupenblick des harmlosen Zuschauers“ (S, 23) beschrieben worden ist. Dem Tempo der modernen Metropole gemäß wird der Betrachter in rascher Folge mit unterschiedlichsten Eindrücken konfrontiert. Dem Ich-Erzähler bleibt unter diesen Bedingungen nur, seinen Sitznachbarn imaginär anzusprechen und zu einer anderen Art der Stadterkundung zu ermuntern: „Ich aber rate dir, lieber Fremdling und Rundfahrtnachbar, wenn du noch einmal in diese Gegend kommst und Zeit hast, dich hier ein wenig zu verirren." (S, 79 f.) Aber nicht nur die technischen Fortbewegungsmittel beschleunigen den Lebensrhythmus in der Großstadt, sondern auch die Lebenslust, der Hessel eine eigene Prosaskizze widmet (S, 52-66). Anders als in Paris oder Wien herrschen, so der Ich-Erzähler, selbst in den Vergnügungstempeln Berlins nicht Genuss, sondern vielmehr „Betrieb“ (S, 52) und „Tempo“ (S, 54) vor. Eine vibrierende Stadt kommt nicht zur Ruhe, auch der Flaneur sucht sie vergebens, kann er sich doch der urbanen Geschwindigkeit nur schwer entziehen.

Und die Flanerie? Kann der Flaneur dem rasenden Rhythmus der Stadt, ihrer Rast- und Ruhelosigkeit, die Arbeit und Freizeit gleichermaßen prägen, doch nicht entkommen? Ganz so einfach ist es nun auch wieder nicht. Die Prosaskizze über den Tiergarten beginnt folgendermaßen: 
Herbstsonntag. Dämmerung. Die Erde dampft ein wenig, nicht so feucht wie Feld, mehr wie Kartoffelacker. Auf den vielen, vielen ins Halb- und Ganzdunkel verstreuten Bänken an den schlängelnden Pfaden sitzen Liebespaare. Manche scheinen mir noch ein bißchen ungeschickt in der Liebkosung, sie könnten von einem Pariser Arbeiter, der sein Liebchen streichelt, lernen. Manche haben für ihre Zweisamkeit eine ganze Bank erwischt, aber auch die, welche mit andern Pärchen teilen müssen, lassen sich nicht stören. (S, 172)

Diese wie zeitentrückt geschilderte Impression kommt dem nahe, was Peter Altenberg in seinen Prosaskizzen um die Jahrhundertwende als „Extracte des Lebens" bezeichnet hat. ${ }^{28}$ Der verweilende Blick des Flaneurs tastet optisch einen Raum ab und gibt das wieder, was er zufällig und unmittelbar wahrnimmt. Aber selbst in Schilderungen wie diesen, die Hessels Ästhetik und Poetik des ,Ersten Blicks' am Nächsten kommen, versagt er sich Einschätzungen und Wertungen nicht gänzlich, setzt also seine Programmatik auch hier nicht buchstabengetreu um. Gleichwohl findet der Flaneur in Beschreibungen wie dieser zumindest temporär zu jener Haltung, die der Ich-Erzähler theoretisch postuliert hat. Er kann sich ziel- und richtungslos treiben lassen: „Ich gehe weiter ohne bestimmte Richtung, weiß nicht, ob ich zur Rousseau- oder zur Luiseninsel kommen werde." (S, 173) Bezeichnenderweise sind es tendenziell mußeaffine Räume wie hier der Tiergarten oder Parks, die der Offenheit und Unbestimmtheit des Flanierens entgegenkommen. Dazu zählt auch der Friedhof. Den Besuch auf dem Invalidenfriedhof erlebt der Ich-Erzähler, wie auch den Tiergarten und manch andere Orte Berlins, als eine Heterotopie der Zeit, das heißt als einen Ort „potentiell unendlicher Zeitakkumulation“, wie Rainer Warning die Zeitheterotopie definiert: ${ }^{29}$ „Auf diesen schönen kleinen Friedhof war ich geraten, statt mich, wie beabsichtigt, ans andre Ende der Invalidenstraße zum Kriminalgericht zu begeben, um zu meiner Belehrung einer Gerichtsverhandlung beizuwohnen“ (S, 235). Die Passivkonstruktion „war ich geraten“verdeutlicht das nichtintentionale Moment des ziellosen Spazierens, dem die an sich vorgesehene funktionale Absicht, der aktive Gang zum Kriminalgericht, entgegengesetzt wird. Der Flaneur entzieht sich dem Drängen der Zeit, lässt in Muße etwas zu, was er nicht geplant hat, und erschließt sich so den Ort, den Friedhof, wenigstens vorübergehend als Möglichkeitsraum potentiell unbegrenzter Erfahrungen.

Doch auch diese zeitliche und räumliche Entrückung findet ein jähes Ende: „Die Trambahn brachte mich rasch vorbei an dem ehemaligen Hamburger Bahnhof, der so hübsch ungebraucht aussieht (es ist aber ein Verkehrsmuseum darin), am Humboldtshafen, Lehrter Bahnhof und Ausstellungspark “ (S, 235). Das Modaladverb „rasch“ kontrastiert das vorangegangene Sich-Verlieren in Muße aufs Schärfste. Die Heterotopie der Zeit im Mußeraum des Friedhofs weicht sogleich

28 So Peter Altenberg in seiner Selbstbiographie aus dem Band Was der Tag mir zuträgt. Fünfundfünzig neue Studien, Berlin 1901, 1-8, 2.

29 Rainer Warning, Heterotopien als Räume ästhetischer Erfahrung, München 2009, 13. 
wieder dem Tempo der Großstadt. Die einzelnen Stationen, die auf der Strecke der Trambahn liegen, werden nun, der Geschwindigkeit des Verkehrsmittels gemäß, atemlos aneinandergereiht. Und wenn, wie im Falle des ehemaligen Hamburger Bahnhofs, dem Hinweis, er sehe „so hübsch ungebraucht“ aus, noch eine weitere Bemerkung hinzugefügt wird, wie in diesem Fall seine jetzige Bestimmung, dann bleibt dazu, angesichts der knappen Zeit, nur eine Parenthese in Klammern. Die Trambahn hat ja schließlich, so suggeriert es der gedrängte Stil, diesen Ort bereits wieder passiert.

Diese auffällige Vielgestaltigkeit dessen, was Hessels Flaneur über seine Beobachtungen auf den Straßen, in den Gärten, Parks, Vergnügungstempeln, Warenhäusern und Hinterhöfen Berlins erzählt, sowie die Diversität seiner Erfahrungen von Raum und Zeit verdeutlichen bereits, dass der Protagonist das eigene, an sich ja sehr scharf profilierte Konzept des Flanierens keineswegs bruchlos narrativ umsetzt. In Hessels Spazieren in Berlin rückt zudem noch etwas Anderes, ja sogar Entscheidendes, ins Zentrum. Dieses Andere findet sich bereits in der zweiten Prosaskizze, die den Titel Ich lerne trägt. Diese zweite Skizze schränkt den erzählerischen Auftakt, der ja, in der ersten Prosaskizze, das Flanieren als freies Verweilen in Zeit und Raum zum eigentlichen Programm erhoben hat, in zweifacher Hinsicht ein. Neben der Autofahrt, die, wie erwähnt, hier bereits stattfindet und den Spaziergang ersetzt, wird auch das eigentliche Ansinnen des Werks benannt, ein Ansinnen, das nicht gerade mit dem Verständnis von Flanieren und seiner offenen Wahrnehmungsstruktur, wie sie in der ersten Prosaskizze postuliert worden ist, in bruchlosem Einklang steht:

[...] ich muß etwas für meine Bildung tun. Mit dem Herumlaufen allein ist es nicht getan. Ich muß eine Art Heimatskunde treiben, mich um die Vergangenheit und Zukunft dieser Stadt kümmern, dieser Stadt, die immer unterwegs, immer im Begriff, anders zu werden, ist. (S, 28)

Unter „Heimatskunde“ versteht der Ich-Erzähler, „im Gegenwärtigen das Vergangene zu erleben“ (S, 130). Die historische Spurensuche soll im kulturellen Gedächtnis dasjenige bewahren, was im Stadtbild selbst durch den radikalen Umund Ausbau Berlins verloren zu gehen droht. Seine „Heimatskunde“ betreibt der Ich-Erzähler freilich nicht in erster Linie als Flaneur auf der Straße, sondern als Leser in der Bibliothek. ${ }^{30}$ Hessels Spazieren in Berlin ist auch ein Buch über Bücher; es ist geprägt durch angeeignetes Wissen, das die Beobachtungen des Flaneurs nicht ersetzt, aber organisiert und strukturiert, ihnen insbesondere eine kulturgeschichtliche Tiefe verleiht, die im auffallenden Kontrast zur bekennt-

30 Die Bibliothek ist „als imaginärer Raum einer Sammlung von Berlin-Literatur in Hessels Buch stets präsent", betont Lothar Müller, „Peripatetische Stadtlektüre. Franz Hessels Spazieren in Berlin“, in: Opitz/Plath (Hg.), „Genieße froh, was du nicht hast“. Der Flaneur Franz Hessel, 75-104, 97. Neumeyer, Flaneur, 295-327, wertet die „Heimatskunde“ von Hessels Flaneur einseitig als kulturkonservative Haltung. 
nishaft vorgetragenen Apologie des ,Ersten Blicks` und seiner Phänomenologie der Oberfläche steht.

Folgende Bücher werden in Spazieren in Berlin ausdrücklich genannt, zum Teil auch mehrfach. Sie sind hier in der Reihenfolge ihrer Erwähnung mit entsprechenden Textnachweisen zusammengestellt:

Felix Eberty, Jugenderinnerungen eines alten Berliners (1878): S, 33 f.; 150; 245; 260.

Jules Laforgue, Berlin. Der Hof und die Stadt (1887); frz. Original: Berlin, le cour et la ville (1887): S, 70; 119-121; 126; 253.

E.T.A. Hoffmann, Des Vetters Eckfenster (1822): S, 78.

Wilhelm Raabe, Die Chronik der Sperlingsgasse (1856): S, 80.

Lili Parthey, Tagebücher aus der Berliner Biedermeierzeit 1814-1829, hg. von Bernhard Lepsius, Berlin/Leipzig 1926: S, 81.

Baedeker Reiseführer Berlin und Umgebungen, 20. Aufl., 1927: S, 105; 108; 136; 172; 180; $205 ; 271$.

Karl August Varnhagen von Ense, Tagebücher. Aus dem Nachlaß Varnhagen's von Ense, hg. von Ludmilla Assing-Grimelli, 15 Bde., 1861-1870: S, 106; 115; 131; 139.

Hans Mackowsky, Häuser und Menschen im alten Berlin, Berlin 1923: S, 109; 125.

Carl Friedrich Zelter, Carl Friedrich Christian Fasch. Biographie, Berlin 1801: S, 121 f.

Friedrich Nicolai, Beschreibung der Königlichen Residenzstädte Berlin und Potsdam und aller daselbst befindlicher Merkwürdigkeiten: Nebst Anzeige der jetztlebenden Gelehrten, Künstler und Musiker, und einer historischen Nachricht von allen Künstlern, welche vom dreyzehnten Jahrhunderte an, bis jetzt, in Berlin gelebt haben, oder deren Kunstwerke daselbst befindlich sind, Berlin 1769; neue völlig umgearbeitete Aufl. mit genauen Grundrissen der Städte Berlin und Potsdam, und einer Charte der Gegend um Berlin und Potsdam, Berlin 1779: S, 130; $249 \mathrm{f}$.

Heinrich Heine, Nachgelassene Gedichte 1812 - 1827: S, 131.

F.H. Bothe, Berliniade/Lindenlied, in: Adolf Heilborn, Berliner Kalender: S, $131 \mathrm{f}$.

Karl Müchler, Scherzhafte Lieder (1820): S, 132 f.

Eugen Szatmari, Das Buch von Berlin, München 1927 (Was nicht im Baedeker steht, Bd. I): S, 138 .

Theodor Fontane, Wanderungen durch die Mark Brandenburg (1862-1889): S, 144; 146; 284.

Wilhelm Speyer, Charlott etwas verrückt. Roman, Berlin 1927: S, 157 f.; 280.

Ernst Consentius, Alt-Berlin. Anno 1740, Berlin 1911. Dritte vermehrte Aufl. Berlin 1925: $\mathrm{S}, 159 \mathrm{f}$. 
E.T.A. Hoffmann, Lebens-Ansichten des Katers Murr nebst fragmentarischer Biographie des Kapellmeisters Johannes Kreisler in zufälligen Makulaturblättern (1819/21): S, 175.

Stefan George, Das Jahr der Seele (1897), hier das Gedicht Nun säume nicht, die Gaben zu erhaschen: S, 176.

Die Chronik der Cölner Stadtschreiber von 1542-1605, hg. von Ernst Fidicin, Berlin 1865 (Schriften des Vereins für die Geschichte Berlins, Bd. 1): S, 188.

Peter Hafftitz, Microchronologikon [entstanden in den letzten Jahrzehnten des 16. Jahrhunderts, erstmals gedruckt: 1731]: S, 189.

Gustav Langenscheidt, Naturgeschichte des Berliners. Zugleich ein Spaziergang durch das Berlin von 1789. Für Einheimische und Fremde, Berlin 1878: S, 258-260.

Ludwig Pietsch, Aus jungen und alten Tagen. Erinnerungen, Berlin 1904: S, 260.

Georg Hermann, Spaziergang in Potsdam (1926): S, $283 \mathrm{f.}$

Carl Burney's der Musik Doctors Tagebuch einer musikalischen Reise durch Frankreich und Italien. Deutsch von Christoph Daniel Ebeling, Hamburg 1772: S, 285.

Karl Scheffler, Berlin. Ein Stadtschicksal, Berlin 1910: S, 285.

Wohlgemerkt: Es handelt sich ausschließlich um markierte Hinweise. Allein die Fülle und Vielfalt der Werke verdeutlichen den bildungsbürgerlichen Charakter der „Heimatskunde“ (S, 28), die den drohenden Geschichtsverlust im Stadtbild Berlins mit einem umfänglichen Konzept historischen Erinnerns konfrontiert. Der Ich-Erzähler flaniert gewissermaßen durch ganz unterschiedliche Texte, die er nicht systematisch auswertet, sondern vielmehr essayistisch und digressiv adaptiert.

Die Funktion dieses Verfahrens soll nun an einem Beispiel kurz erläutert werden. Es handelt sich um Hans Mackowskys Häuser und Menschen im alten Berlin (1923). Mackowsky war Kunsthistoriker und leitete seit 1916 die Gemäldegalerie der Berliner Museen. Zu seinen wissenschaftlichen Schwerpunkten zählte u.a. das Werk von Johann Gottfried Schadow. Zu Mackowsky äußert sich der IchErzähler folgendermaßen:

Berliner Romantik wirst du in den Landschaftsbildern des großen Schinkel, der ja eigentlich kein Maler, sondern ein Baumeister war, finden. Er hat sie für eines der alten Patrizierhäuser in der Brüderstraße gemalt und wenn du Muße dafür hast, so lies, was Hans Mackowsky in seinen ,Häusern und Menschen im alten Berlin' darüber schreibt, und lies weiter, was er von diesem Haus und andern berichtet, das wird dir eine vergangene Stadt mitten in der gegenwärtigen aufbauen. (S, 109)

Das rhetorische Mittel der Apostrophe, das auch hier eingesetzt wird, ist, wie erwähnt, durchaus symptomatisch für Spazieren in Berlin und erzeugt eine appellative Erzählstruktur im Sinne des annoncierten Lehrbuchs. Abgesehen davon, dass das Wort ,Muße' nur an dieser Stelle explizit genannt und dabei ein direkter Konnex von Muße und Lesen hergestellt wird, spricht der Ich-Erzähler die ei- 
gentliche Funktion seiner bildungsbürgerlichen „Heimatskunde“ (S, 28) inmitten des Berliner Baubooms unmissverständlich an. Es geht darum, dass in der Erinnerung sowie an ganz bestimmten Orten, die man aufsucht, „eine vergangene Stadt mitten in der gegenwärtigen“" wiederersteht. Diese ,vergangene 'Stadt ist insbesondere jene des Klassizismus im späten 18. und frühen 19. Jahrhundert. Dieses Berlin um 1800 betrachtet der Ich-Erzähler als ästhetisches Leitbild, das insbesondere dem bombastisch-aufgeblähten Historismus des Wilhelminismus entgegengesetzt wird. Seine Berliner Erinnerungsorte sind keine Manifestationen eines nationalen Heldenkults, im Gegenteil. Der Ich-Erzähler beschwört vielmehr „den Reiz der unbeachteten Dinge“ (S, 165). Gleichwohl schreibt auch Hessel mit seinem regional ausgerichteten Konzept von Erinnerungsorten bis zu einem gewissen Grad Bildungsgeschichte als Gedächtnisgeschichte. ${ }^{31}$

Die weiteren Werke, die aufgeführt werden, spielen, zumindest expressis verbis, eine unterschiedliche Rolle. Das Spektrum reicht von einer bloßen Nennung bis zum seitenlangen Zitat (z.B. aus Gustav Langenscheidts Naturgeschichte des Berliners: (S, 258-260). In meiner Argumentation geht es mir indes nicht um die je spezifische Verwendung der aufgeführten Texte, sondern um das Muster, das dieser Aneignung zugrunde liegt. Dabei fällt erneut eine signifikante Differenz zwischen dem theoretischen Konzept des Flanierens und der spezifischen Form seiner Realisierung ins Auge. „Flanieren ist eine Art Lektüre der Straße" (S, 156), stellt, wie erwähnt, der Ich-Erzähler in eingängiger Weise fest. Die metaphorische Lektüre der Stadt, genauer gesagt: ihrer Oberfläche, wird durch die tatsächliche Lektüre von Büchern über die Stadt ergänzt und vertieft. ${ }^{32}$ Dem ,Ersten Blick', der in der Tradition der Literatur der Jahrhundertwende ausschließlich auf die Phänomene selbst gerichtet ist, folgt nicht selten ein vertiefender zweiter Blick, der durch die Oberfläche der sichtbaren Phänomene zur Geschichte der aufgesuchten Orte vordringt und ihnen so jene kulturhistorische Tiefe zurückgibt, die im sich rasant verändernden Stadtbild verloren zu gehen droht.

Abschließend, in seinem Nachwort an die Berliner, spitzt der Ich-Erzähler seinen historisierenden Ansatz noch einmal zu:

Einer der großen Kenner der Geschichte, Kultur- und Kunstgeschichte Berlins (ihre Namen finden sich im Baedeker unter dem Abschnitt Literatur) sollte einmal eine Beschreibung der Stadt aus lauter alten Beschreibungen zusammenstellen und alle Denkmäler von den näheren Zeitgenossen ihres Entstehens darstellen lassen [...]. Das gäbe einen hübschen bibliographischen Spaziergang durch Berlin und würde uns immer neue Ver-

31 Vgl. dazu Maren Jäger, „Franz Hessel - Spazieren in Berlin“, in: Bauer (Hg.), Berlin, $107-128,115$.

32 Vgl. auch Lothar Müller, „Franz Hessel und Georg Hermann. Zwei Spaziergänger im Berlin der Neuen Sachlichkeit“, in: Aber ihr Ruf verhallt ins Leere hinein. Der Schriftsteller Georg Hermann (1871 Berlin-1943 Auschwitz). Aufsätze und Materialien, hg. u. eingeleitet v. Kerstin Schoor, Berlin 1999, 119-133, 124. 
gangenheiten der Stadt bildhaft nahebringen und im noch Sichtbaren Verschwundenes genießen lehren. (S, $284 \mathrm{f.})$

Die spezifische Wahrnehmungsstruktur des Flanierens bei Hessel - das hat Walter Benjamin in seiner eingangs zitierten Rezension zutreffend herausgestellt - ist mnemotechnisch ausgerichtet. Diese Hinwendung zum Vergangenen, die Historisierung des Gegenwärtigen, das intensive Interesse am Verschwundenen oder vom Verschwinden Bedrohten, schafft ein Gegengewicht zur Beschleunigung und zum rasanten Wandel des modernen Großstadtlebens. Historisierung und Erinnerung werden in Hessels Spazieren in Berlin damit zu einer überaus wichtigen Form von Muße, widersetzen sie sich doch der scheinbar unausweichlichen Beschleunigungserfahrung weitaus wirkungsvoller als das Flanieren selbst, das ständig durch unterschiedlich motivierte Tempowechsel eingeschränkt wird. Die Kunst des Verweilens erlernt man am besten beim „bibliographischen Spaziergang“.

In ihrem radikalen Umbau droht der Stadt ein Gedächtnisverlust, dem der Flaneur entgegenwirkt, aber weniger auf der Straße, erst recht nicht als schweifender Werwolf, als den ihn Benjamin charakterisiert, sondern vielmehr in der Bibliothek, als schweifender Leser, der selbst wiederum assoziativ historische Mosaiksteine in essayistisch freier Form zusammenfügt, ohne jeden Anspruch auf wissenschaftliche Stringenz. In seinem Nachwort an die Berliner verdeutlicht der Ich-Erzähler noch einmal Zweck und Ausprägung seines Aneignungsverfahrens:

Zum Schluß müßte ich nun eigentlich auch einige ,Bildungserlebnisse beichten und gestehn, aus welchen Büchern ich lerne, was nicht einfach mit Augen zu sehen ist, und manches, was ich sah, besser zu sehen lerne. So eine saubere kleine Bibliographie am Ende, das gäbe meinem Buch ein wenig von der Würde, die ihm mangelt. Ach, aber auch in den Bibliotheken und Sammlungen bin ich mehr auf Abenteuer des Zufalls ausgegangen als auf rechtschaffne Wissenschaft, und zu solchem Kreuz und Quer durch die Welt der Bücher möchte ich auch die andern verführen. (S, 284)

Hessels Flaneur ist weder ein philosophischer Spaziergänger wie Rousseau noch ein Baudelairescher Künstlertyp. Er durchmisst vielmehr in ganz unterschiedlichen Formen einen urbanen Raum, der ihm aufgrund seines rasanten Wandels fremd zu werden droht. In diesem dynamisierten Raum fällt es auch dem bekennenden Flaneur schwer, sich dem Drängen der Zeit zu entziehen. Es gelingt ihm auch nur in eingeschränkter Form. Die eigentliche Entschleunigung äußert sich in Spazieren in Berlin nicht primär im Schlendern des urbanen Spaziergängers, sondern vielmehr im Lektüreverhalten und in den Reflexionen eines Heimatkundlers, der seine Erinnerungsarbeit nicht auf den Straßen der Großstadt, sondern in einer Bibliothek oder in seinem Arbeitszimmer leistet. Der kulturelle Gedächtnisraum, der in den Prosaskizzen reich bestückt wird, speist sich zwar auch aus vielen persönlichen, emotional aufgeladenen Erinnerungen, aber 
nicht aus jenen von Marcel Proust herrührenden unwillkürlichen Erinnerungen, mémoires involontaires, wie Walter Benjamin in seiner Rezension nahelegt ${ }^{33}$; er setzt sich vielmehr zu großen Teilen aus einer Fülle von Leseeindrücken zusammen, die nicht wissenschaftlich systematisch zusammengefügt werden, aber allein aufgrund der schieren Anzahl und Dichte eben auch nicht einem „Abenteuer des Zufalls“ (S, 284) entspringen, wie der nicht immer ganz zuverlässige Ich-Erzähler behauptet.

Diese Form von Entschleunigung durch Erinnerung verleiht auch der Muße dieses spezifischen Flaneurs ein besonderes Gepräge. Die Historisierung der Stadt verräumlicht nicht die Zeit, sondern umgekehrt: Sie verzeitlicht zwar nicht den Raum, aber die aufgesuchten Orte, die zu Erinnerungsorten transformiert werden. Hessels Flaneur erfährt Muße daher nicht in erster Linie als ein sich wechselseitig bedingendes Zusammenwirken von Verräumlichung und Entzeitlichung. Vielmehr beschreibt er, zumindest teilweise, ein gegenläufiges Verfahren: Im urbanen Raum werden die aufgesuchten Orte im Mußeakt des Lesens verzeitlicht. Die Muße des lesenden Flaneurs artikuliert sich in dieser Verzeitlichung, die der Stadt ihre geschichtliche Physiognomie zu bewahren und damit dem rasanten Wandel einer Metropole in permanenter Bewegung sowie dem dadurch hervorgerufenen Furor des Verschwindens zu trotzen versucht. Der massive Traditionsverlust verunsichert den Einheimischen, der Fremdheitsgefühle nicht ganz zu unterdrücken vermag: „Der Zukunft zittert die Stadt entgegen.“ (S, 285)

Hessel hat sein theoretisches Programm des Flanierens drei Jahre nach Spazieren in Berlin erneut aufgegriffen. In dem Essay Von der schwierigen Kunst spazieren zu gehen, der 1932 in der Zeitschrift Die literarische Welt erschienen ist, definiert Hessel das Flanieren noch einmal als eine Kunstform, die „zu einem besonders reinen zweckentbundenen Genuß werden “ könne. ${ }^{34}$ Erfolge das Flanieren „um seiner selbst willen“35, dann könne es analog zur Dichtkunst begriffen werden. In diesem Zusammenhang wiederholt Hessel auch sein Bild der Lektüre der Straße: Der Spaziergänger „liest die Straße wie ein Buch, er blättert in Schicksalen, wenn er an Hauswänden entlang schaut.“36 Mit der Wendung, die Straße sei „eine Art Lektüre“"37, greift er seine eingängige Formulierung aus Spazieren in Berlin (S, 156) wörtlich auf. Auch ein weiteres Moment, das in dieser Analyse eine wichtige Rolle gespielt hat, spricht Hessel hier, wieder in Form

33 Dies betonen zu Recht: Jörg Plath, Liebhaber der Großstadt. Ästhetische Konzeptionen im Werk Franz Hessels, mit Abdruck eines unbekannten Textes von Franz Hessel, Paderborn 1994, 92-129, 114; Marx, Betriebsamkeit als Literatur, 158.

34 Franz Hessel, „Von der schwierigen Kunst spazieren zu gehen“, in: Hessel, Ermunterung zum Genuß. Kleine Prosa, hg. v. Karin Grund/Bernd Witte, Berlin 1981, 53-61, 53.

35 Hessel, „Von der schwierigen Kunst spazieren zu gehen“, 53.

36 Hessel, „Von der schwierigen Kunst spazieren zu gehen“, 57.

37 Hessel, „Von der schwierigen Kunst spazieren zu gehen“, 59. 
einer Apostrophe, noch einmal explizit an: „Wenn du spazierst, beabsichtige, irgendwohin zu gelangen. Vielleicht kommst du dann in angenehmer Weise vom Wege ab. Aber der Abweg setzt immer einen Weg voraus. " ${ }^{\text {"38 }}$ Offenheit und Unbestimmtheit des Flanierens, das freie Verweilen in Zeit und Raum, erfolgt innerhalb eines Ordnungsrahmens, der Intentionalität und Intentionslosigkeit des Gehens nicht in einem paradoxen Wechselspiel zusammenfügt, sondern gerade durch die deutliche Unterscheidung der verschiedenen Ebenen Freiräume der Muße zu generieren vermag. Der Ordnungsrahmen ermöglicht es, dass das flanierende Ich diese Freiräume ohne Orientierungsverlust oder gar Selbstverlust ausfüllen kann. Analog dazu lässt sich auch das Lektüreverhalten in Spazieren in Berlin interpretieren. Innerhalb des strukturierenden Ordnungsrahmens, der vorgibt, die historischen Spuren Berlins im kulturellen Gedächtnis zu bewahren, herrscht digressive Freiheit, die in essayistischer Form genutzt wird. Stadtgeschichte setzt sich über heterogene Stadtgeschichten, die lose aneinandergereiht werden können, zusammen. Diese Einzelbilder fügen sich allenfalls schemenhaft zu einem Gesamtmosaik. Auch bei den Lektüren herrscht also eine gerichtete Richtungslosigkeit, eine zielführende Ziellosigkeit vor. Lesen und Flanieren, zumindest in seiner theoretischen Fundierung, erfolgen gleichermaßen im Modus der Muße, die innerhalb eines vorgegebenen Ordnungsrahmens offen ist für Zufälliges und Kontingentes, für Abschweifungen und Nebensächliches. Die Muße des Spaziergängers und des Lesers, die Muße des Flaneurs, der sich in den urbanen Räumen ebenso verliert wie in Büchern über diese Räume, changiert so zwischen Aktivität und Passivität. In diesen Erfahrungen von Muße verblasst zudem ein bedrohliches Gefühl, das der Flaneur angesichts des rasanten Gestaltwandels Berlins ansonsten nicht ganz zu unterdrücken vermag: das Gefühl, fremd in der eigenen Stadt zu werden.

Der Aspekt der Fremdheit gewinnt hier noch eine weitere, allerdings beklemmende Dimension. Hessel veröffentlichte seinen Essay Über die Kunst spazieren $z u$ gehen zu einer Zeit, als eher andere Formen der Fortbewegung zu Fuß das Straßenbild Berlins prägten. Von politischen Aufmärschen ist in Hessels Essay indes nicht und in Spazieren in Berlin nur am Rande die Rede. ${ }^{39}$ Symptomatisch für die unpolitische Betrachtung tagespolitischer Vorgänge ist die Erwähnung einer Veranstaltung der Nationalsozialisten in der letzten Prosaskizze von Spazieren in Berlin. In diesem Kapitel, Südwesten, schildert der Ich-Erzähler zunächst Eindrücke vom Sechstagerennen im Sportpalast. Nahezu unvermittelt wechselt er dann vom Sport zur Politik: „Sport ist international und kennt keine politischen Parteien. Aber sein Palast hier steht auch der politischen Lei-

38 Hessel, „Von der schwierigen Kunst spazieren zu gehen“, $60 \mathrm{f}$.

39 Spazieren in Berlin „scheint im toten Winkel des politischen Geschehens verfaßt", resümiert Martin Meyer, „Bewegte Stadt. Franz Hessel: ,Ein Flaneur in Berlin' (Neue Zürcher Zeitung, 23.5.1985)“, in: Gregor Ackermann/Hartmut Vollmer (Hg.), Über Franz Hessel. Erinnerungen - Porträts - Rezensionen, Oldenburg 2001, 182-185, 183. 
denschaft offen. Große Kundgebung der Nationalsozialisten wird angekündigt. Die Hallen füllen sich" (S, 273). Vor dem Palast findet eine Gegendemonstration der Kommunisten statt. Es kommt zu Ausschreitungen, die Polizei greift gewaltsam ein. All das gibt der Ich-Erzähler sachlich, im Stile eines Chronisten, ohne eine eigene wertende Einschätzung der politischen Gemengelage wieder - ganz im Sinne seiner Flaneurs-Programmatik des ,Ersten Blicks. Eine urteilende Bemerkung bezieht sich auf rein Äußerliches und präsentiert sich gerade dadurch betont unpolitisch: „Wenn sie nicht ihre Abzeichen trügen, Orden der Reaktion oder Revolution, sie wären kaum zu unterscheiden, die kecken Berliner Jungen aus beiden Lagern" (S, 274). Mit mokantem Tonfall wird die politische Radikalisierung in der Weimarer Republik banalisiert. In der Diktion des Ich-Erzählers handelt es sich bei der Konfrontation von Nationalsozialisten und Kommunisten um ein (sportliches) Spektakel, das auf jeweils wechselnden Bühnen aufgeführt wird: „Mitunter lauern auch draußen die vom Stahlhelm, während drinnen die Roten tagen" (S, 274). Der unaufhaltsame Aufstieg des Nationalsozialismus, der ja bereits Ende der zwanziger Jahre die Weimarer Republik und mit ihr die parlamentarische Demokratie in Deutschland in ihrer Existenz bedrohte, und die kommunistische Bewegung, die das bestehende politische System auch beseitigen wollte, werden als Aufbruch einer Jugendbewegung und Ausdruck einer sportlichen Begeisterung bagatellisiert:

All das nimmt der Sportpalast mit einer Art riesenhafter Gutmütigkeit in seine runden Weiten. Mit unparteiischem Echo dröhnen seine Wände ,Hakenkreuz am Stahlhelm und ,Auf zum letzten Gefechte` wieder wie die Zurufe der Sportfreunde. Es ja alles Überschwang derselben ungebrochnen Lebenslust (S, 274).

Der politische Extremismus wird so zu einer von vielen Artikulationsformen der Roaring Twenties und ihrer ungebremsten „Lebenslust" verharmlost. Zwischen ,Stahlhelm'-Gebrüll und Anfeuerungsrufen bei Sportveranstaltungen sieht der Ich-Erzähler keine nennenswerten Unterschiede. Kritische Reflexionen über Politik und Gesellschaft, über Radikalisierungstendenzen, die Realität der Arbeitswelt und die prekäre soziale Lage vieler Menschen in der Großstadt Berlin, sucht man in Spazieren in Berlin und in Über die Kunst spazieren zu gehen vergebens. Hessels Essay über die Kunst des ungezwungenen und freien Flanierens, des ziellosen Schlenderns im urbanen Frei-Raum, erschien nur wenige Monate vor jenem Fackelzug, bei dem, am 30. Januar 1933, 15.000 Angehörige von SA und SS durch das Brandenburger Tor marschierten. Den Aufmärschen in seiner Stadt schenkte Hessel in seiner Apologie des Flanierens keine Beachtung. Dem IchErzähler in Spazieren in Berlin bereiten sie keine Sorgen. Ihren Folgen fiel Franz Hessel, der nach der Invasion Frankreichs durch die deutsche Wehrmacht im Sommer 1940 für einige Wochen in Les Milles bei Aix-en-Provence interniert wurde und an den Folgen der Lagerhaft am 6. Januar 1941 starb, aber zum Opfer. 



\title{
Walter Benjamins Suche nach der „Schwelle [...], die den Müßiggang von der Muße trennt"
}

\author{
Robert Krause
}

Wenn es in Walter Benjamins facettenreichem Euvre, das wie nur wenige vor und nach ihm literarische Praxis mit theoretischer Reflexion verbindet ${ }^{1}$, eine Konstante gibt, so ist das sicherlich sein stetiger Versuch, die Moderne und die Möglichkeit von Erfahrung in der Moderne zu reflektieren. ${ }^{2}$ Besonders in den Fokus rücken modernetypische Phänomene und Erfahrungen im 19. und frühen 20. Jahrhundert. Diesen nähert sich Benjamin zuweilen autobiographisch an, wie in der Berliner Kindheit um 1900 (1932 ff.), oder in Form einer alternativen Geschichtsschreibung, wie in seiner Berliner Chronik (1932 ff.) und in den Passagen-Arbeiten (1928-40), seinem Fragment gebliebenen Spätwerk über Paris als „Hauptstadt des XIX. Jahrhunderts“. ${ }^{3}$ Doch auch an Benjamins frühere Untersuchungen ist hier zu erinnern, an die Dissertation zum Begriff der Kunstkritik in der deutschen Romantik (1920) und an die abgelehnte Habilitationsschrift zum Ursprung des deutschen Trauerspiels (1928); tragen sie doch bereits implizit oder explizit dazu bei, die Vorgeschichte der Moderne zu erkunden. Diese und weitere Entsprechungen zwischen seinen Schriften hat Benjamin selbst vielfach akzentuiert, ohne dabei deren perspektivische Verschiebungen, von Deutschland im 17. Jahrhundert hin zu Frankreich im 19. Jahrhundert, zu verhehlen. ${ }^{4}$

\footnotetext{
${ }^{1}$ Benjamins umfangreiches Werk speist sich aus verschiedenen Traditionen, Kulturen, Sprachen, Wissensbereichen und Disziplinen; es wird in der Literatur-, Kultur- und Medienwissenschaft ebenso rezipiert wie in der Philosophie und Soziologie.

${ }^{2}$ Vgl. Willem van Reijen/Herman van Doorn, Aufenthalte und Passagen. Leben und Werk Walter Benjamins. Eine Chronik, Frankfurt a. M. 2001, bes. 194-197 (Kap. „Die neue Theorie der Moderne und die früheren Arbeiten“); Thomas Weber, „Erfahrung“, in: Michael Opitz/Erdmut Wizisla (Hg.), Benjamins Begriffe, Bd.1. Frankfurt a. M. 2000, 230-259; außerdem die Beiträge in: Burkhardt Lindner (Hg.), unter Mitarb. v. Thomas Küpper und Timo Skrandies, Benjamin-Handbuch: Leben - Werk - Wirkung, Stuttgart/Weimar 2006.

3 So lautet der sprichwörtlich gewordene Titel des Exposés von Walter Benjamin in: Das Passagen-Werk, Gesammelte Schriften, Bd. V/I, hg. v. Rolf Tiedemann/Hermann Schweppenhäuser, Frankfurt a.M. 1982, 45-59. Zitiert wird im Folgenden nach der genannten, 1980 gebunden im Suhrkamp Verlag erschienenen Werkausgabe (abgekürzt als GS) und nach der ab 1995 erschienenen Ausgabe der Gesammelten Briefe (= GB), und zwar jeweils unter Angabe der Bandnummer in römischen sowie der Teilbandnummer und der Seitenzahl in arabischen Ziffern.

${ }^{4}$ So im Brief an Gershom Scholem, 20.05.1935, in dem Benjamin von der Entwicklung
} 
Mit Blick auf Benjamins geschichtsphilosophische Überlegungen und kulturhistorische Befunde ist die, Moderne mithin als Makroepoche zu verstehen ${ }^{5}$ : als eine Epoche, die um 1800 mit eminenten Neuerungen in Literatur und Philosophie, Wissenschaft und Gesellschaft einsetzt und die mit dem Erstarken des Faschismus und dem ausbrechenden zweiten Weltkrieg an ihr Ende gelangt. Dieses Ende der Moderne koinzidiert auf verstörende Weise mit Benjamins Lebensende, mit seinem Suizid im September 1940. All das ist bereits hinlänglich dokumentiert und kann nunmehr als wohl bekannt vorausgesetzt werden.

Weniger bekannt ist hingegen die Bedeutung von Muße und Müßiggang für Benjamins Geschichte und Theorie der Moderne. ${ }^{6}$ Nahezu unbemerkt blieb bisher sein ambitionierter Versuch, historisch und systematisch zwischen Muße und Müßiggang zu unterscheiden. ${ }^{7}$ Genau davon handelt mein hier vorliegender Beitrag. Ausgangspunkt ist die Beobachtung, dass eine derartige Differenzierung zwischen Muße und Müßiggang nach wie vor ein Forschungsdesiderat darstellt. ${ }^{8}$

seiner Passagen-Arbeiten berichtet: „Endlich ist der Titel Pariser Passagen verschwunden und der Entwurf heißt „Paris die Hauptstadt des neunzehnten Jahrhunderts" und im stillen nenne ich ihn Paris capitale du XIXe siècle. Damit ist eine weitere Analogie angedeutet: wie das Trauerspielbuch das siebzehnte Jahrhundert von Deutschland aus, so würde dieses das neunzehnte von Frankreich aus aufrollen." (GBV,83f.)

5 Zur Periodisierung der Moderne und ihrem Verständnis als Mikro- oder Makroepoche vgl. Hans Ulrich Gumbrecht, „Modern, Modernität, Moderne“, in: Geschichtliche Grundbegriffe. Historisches Lexikon zur politisch-sozialen Sprache in Deutschland, hg. v. Otto Brunner/Werner Conze/Reinhart Koselleck, Bd.4, Stuttgart 1978, 93-131; außerdem Silvio Vietta, Die literarische Moderne. Eine problemgeschichtliche Darstellung der deutschsprachigen Literatur von Hölderlin bis Thomas Bernhard, Stuttgart 1992, 33-37, und Sabina Becker/Helmuth Kiesel (Hg.), unter Mitarb. v. Robert Krause, Literarische Moderne. Begriff und Phänomen, Berlin/New York 2007.

6 Vgl. den instruktiven Aufsatz von Walter Fähnders, „Benjamins Müßiggang-Studien“, in: Klaus Garber/Ludger Rehm (Hg.), global benjamin. Internationaler Walter-Benjamin-Kongress 1992, Bd. 3, München 1999, 1554-1568; außerdem die Studien von Martin Jörg Schäfer, „Eingefrorene Zeit. Zur Schreibweise der Muße bei Walter Benjamin“, in: Ulrich Kinzel (Hg.), An den Rändern der Moral. Studien zur literarischen Ethik, Würzburg 2008, 37-49; Martin Jörg Schäfer, Die Gewalt der Muße. Wechselverhältnisse von Arbeit, Nichtarbeit, Ästhetik, Zürich/Berlin 2013, 249-323.

7 Dieses Vorhaben dokumentiert wohl am explizitesten die (hier als Titelzitat gewählte) Bemerkung Benjamins, die auf einem Manuskriptblatt überliefert (Benjamin-Archiv, Ms 1055r) und aufgrund ihres thematischen Zusammenhangs mit dem Baudelaire-Essay im Anhang abgedruckt ist: „Die sichtbare Schwelle aber, die den Müßiggang von der Muße trennt, ist die Sammlung." (GS I/3, 1180) - Zu Benjamins Denkfigur der Schwelle vgl. die Abhandlung von Winfried Menninghaus, Schwellenkunde. Walter Benjamins Passage des Mythos, Frankfurt a.M. 1986. Menninghaus stellt darin "Schwellenkunde“ und „Passage“ als Themen und Denkmodelle Benjamins heraus und geht dabei auch auf Benjamins Verständnis von „Schwellenerfahrungen“ ein (8), nicht aber auf die in Benjamins Briefen und Aufzeichnungen erwähnte Schwelle zwischen Muße und Müßiggang.

8 Zur Begriffsgeschichte von „Muße“ vgl. Norbert Martin, „Muße“, in: Historisches Wörterbuch der Philosophie, hg. v. Joachim Ritter/Karlfried Gründer, Bd. 6, Basel 1984, $257-$ 260; Hans-Joachim Gehrke/Martin Heimgartner, „Muße“, in: Der Neue Pauly. Enzyklopädie der Antike, hg. v. Hubert Cancik/Helmuth Schneider, Bd. 8, Stuttgart/Weimar 2000, 
Das gilt auch für deren Verhältnis zur Arbeit. ${ }^{9}$ Daran hat selbst der Freiburger Sonderforschungsbereich $\mathrm{Muße}$, dessen erste Förderphase nunmehr abgeschlossen ist, wenig geändert. Im Gegenteil: Das intrikate Verhältnis von ,Muße und ,Müßiggang` bleibt selbst nach mehrjähriger interdisziplinärer Arbeit in Freiburg und natürlich ebenfalls andernorts im besten Sinne diskutabel. Zudem sind die benannten Phänomene immer noch, ja vielleicht mehr denn je, von hohem gesellschaftlichem Interesse. Das belegen verschiedenste, kaum mehr vollständig zu überblickende Debatten der deutschen und europäischen Öffentlichkeit, die sich beispielsweise um die Themen bedingungsloses Grundeinkommen, Burnout und Rente drehen und dabei implizit oder gar explizit auch die Zukunft der Arbeit und ihre Alternativen betreffen. ${ }^{10}$

\section{Die Muße des Modernetheoretikers: biographisch-werkgeschichtliche Bemerkungen}

Die Sehnsucht nach Muße in der Moderne war Benjamin wohl vertraut, wahrscheinlich war sie sogar ein Grundzug seines unsteten Lebens und facettenreichen Denkens. Benjamin reiste gern und viel, bevorzugte Hotelzimmer und kleine Appartements und war „immer auf der Suche nach einem Ort, an dem er möglichst ungestört schreiben, denken und so billig wie irgend möglich leben konnte. "11 Bis zum gescheiterten Habilitationsversuch im Sommer 1925 größtenteils von seinen Eltern finanziert, war Benjamin in der Endphase der Weimarer Republik plötzlich genötigt, sein Geld als freier Schriftsteller, Kritiker und Übersetzer selbst zu verdienen. Zusätzlich erschwert wurde dies ab 1933 durch die Machtübertragung auf die Nationalsozialisten, vor denen Benjamin

554-557; Albert Schirrmeister, „Muße“, in: Enzyklopädie der Neuzeit, hg. v. Friedrich Jaeger, Bd. 8, Darmstadt 2008, 977-979; Tobias Keiling, „Glossar: Muße“, in: Muße. Ein Magazin, 1 (2015), DOI: 10.6094/musse-magazin/1.2015.48. Zur begriffsgeschichtlichen Abgrenzung der Muße vom Müßiggang vgl. Robert Krause, „Glossar: Müßiggang“, in: Muße. Ein Magazin, 2 (2015) DOI: 10.6094/musse-magazin/2.2015.47.

9 Einen historischen Überblick zur ,Arbeit' bieten: Werner Conze, „Arbeit“, in: Geschichtliche Grundbegriffe, Bd. 1, 154-215, bes. 193-205; Marie-Dominique Chenu, „Arbeit I“, in: Historisches Wörterbuch der Philosophie, Bd. 1, 1971, Sp. 480-482, und Hans Joachim Krüger, „Arbeit II“, in: Historisches Wörterbuch der Philosophie, Bd. 1, 1971, Sp. 482-487. Vgl. außerdem den Band Arbeit und Müßiggang 1789-1914. Dokumente und Analysen, hg. v. Wolfgang Asholt/Walter Fähnders. Frankfurt a. M. 1991.

10 Zur Aktualität und soziopolitischen Relevanz der Frage nach Muße und Müßiggang vgl. meine einleitenden Bemerkungen zu ,Muße und Moderne' im vorliegenden Band. Zu den Problemen von Überproduktion, Unterbeschäftigung und postmarkwirtschaftlich bedingter neuer Freizeit vgl. Jeremy Rifkin, The End of Work: The Decline of the Global Labor Force and the Dawn of the Post-Market Era, New York 1995.

11 Van Reijen/van Doorn, Aufenthalte und Passagen. Leben und Werk Walter Benjamins, 7. 
nach Paris flüchtete. Als exilierter Autor in seinen Publikationsmöglichkeiten eingeschränkt, erhielt er ideelle und materielle Unterstützung vom Institut für Sozialforschung, das, in den USA wiederaufgebaut, von Max Horkheimer geleitet und von Theodor W. Adorno maßgeblich mitbestimmt wurde. Diese durch Briefwechsel gut dokumentierte Verbindung bot Benjamin einerseits wichtige Freiräume und kann durchaus als produktive intellektuelle Freundschaft mit Adorno gelesen werden. Andererseits brachte die Institutsanbindung auch neue Hierarchien und diverse Abhängigkeiten - formal und inhaltlich, monetär und persönlich - und dementsprechende Enttäuschungen auf beiden Seiten mit sich.

Diese biographisch-institutionelle Gemengelage ist durchaus von thematischer Bedeutsamkeit: Denn auf Benjamins langjährige und zuletzt fieberhafte Arbeit an seinen Projekten zu den Pariser Passagen und zum französischen Lyriker, Kunstkritiker und Essayisten Charles Baudelaire folgten Ernüchterung und erzwungener Müßiggang. Als sein erster Baudelaire-Essay ${ }^{12}$, den Benjamin mit großer Anstrengung im Sommer und Herbst 1938 fertiggestellt hatte, von der Institutszeitschrift, namentlich von Adorno, abgelehnt wurde, verfiel Benjamin in Depressionen. Es dauerte Monate, bis er den Aufsatz, der doch zugleich als Mittelteil seiner Baudelaire-Monographie und als „Miniaturmodell“ der Passagen-Arbeit gedacht war ${ }^{13}$, umarbeitete und neuerlich zur Publikation einreichte. ${ }^{14}$ Eine merkwürdige Koinzidenz: Im Ausgang aus dieser Schaffenskrise, im Frühjahr 1939, legte Benjamin ein neues Konvolut an, das just den Müßiggang thematisiert. Es handelt sich um das 10-seitige Konvolut „m“, das 45 Einträge enthält und neben dem Müßiggang explizit auch die Muße behandelt. ${ }^{15}$ Neben den für Benjamins Arbeitsweise üblichen Zitatsammlungen samt Kommentaren sind hier auffallend viele Bemerkungen bereits ausformuliert. Demnach war die Ausarbeitung des Konvoluts vergleichsweise weit fortgeschritten. Über zahlreiche interne Zusammenhänge hinaus sind auch intertextuelle Beziehungen zu Benjamins beiden Hauptprojekten der späten 1930er-Jahre erkennbar: Die Einträge zu Muße und Müßiggang „stehen allesamt im Kontext der Baudelaire- und der Passagen-Arbeiten" 16 , sie streifen oder bündeln viele der prominenten Aspekte und Motive, etwa Flanerie, Spiel, Rausch, Kapitalismus, Marxismus u.a.m. Das Konvolut bildet also das Zentrum von Benjamins weit verzweigten Müßiggang-Studien und dokumentiert dessen historische und systematische Ausrichtung. Zum einen liefert es zahlreiche Beobachtungen und Hinweise zur Geschichte der ,Arbeit', der

12 Benjamin, „Das Paris des Second Empire bei Baudelaire“, in: GS I/2, 511-604.

13 Vgl. GB VI, $64 \mathrm{f}$.

14 Vgl. van Reijen/van Doorn, Aufenthalte und Passagen. Leben und Werk Walter Benjamins, 178-184, bes. 183 f. - Ende Februar 1939 beginnt Benjamin eine revidierte Fassung, die Anfang 1940 unter dem Titel Über einige Motive bei Baudelaire in der Zeitschrift für Sozialforschung erscheint (nun in GS I/2, 605-653, vgl. dazu den Kommentar in GS I/3, 1125).

15 In GS V/2, 961-970. Zur Datierung vgl. den Kommentar des Herausgebers Tiedemann, GS V/2, 1145.

16 Fähnders, „Benjamins Müßiggang-Studien“, 1554. 
,Muße und des ,Müßiggangs' von der griechischen Antike über das Mittelalter und die frühe Neuzeit bis in die industrielle und kapitalistische Moderne des 19. und 20. Jahrhunderts. ${ }^{17}$ Zum anderen skizziert Benjamin in systematischer Absicht das Verhältnis von ,Arbeit', ,Muße' und ,Müßiggang' und deutet dabei auch komplementäre Begriffe und Phänomene aus.

Im Folgenden soll dieses doppelte, historisch-systematische Anliegen erstmals umfassend rekonstruiert werden, um somit das Konvolut „m“ als methodische Grundlage für Müßiggang-Studien mit und nach Benjamin zu etablieren. Dabei werden textnah die m. E. wichtigsten Exzerpte präsentiert und kommentiert, etwaige Abweichungen von der Chronologie des überlieferten Textbestands dienen der synoptischen Darstellung. ${ }^{18}$

\section{Kulturgeschichte der Arbeit: zum Ort der Muße in der antiken und mittelalterlichen Wirtschafts- und Gesellschaftsordnung}

Benjamins Konvolut „m“ beginnt mit der Kulturgeschichte der Arbeit, nämlich mit einer Beobachtung zur antiken Wirtschafts- und Gesellschaftsordnung. Hingewiesen wird auf eine

[b]emerkenswerte Verschränkung: im Griechentum wird die praktische Arbeit in Acht und Bann getan; obwohl sie im wesentlichen in den Händen von Sklaven liegt, verurteilt man sie nicht zum wenigsten, weil sie ein niedres Streben nach irdischen Gütern (Reichtum) verrät; diese Anschauung dient dann weiterhin der Diffamierung des Kaufmanns als Mammonsknecht. („m I, 1“, in: GS V/2, 961)

Benjamin benennt hier einen vermeintlichen Widerspruch bzw. ein sozioökonomisches Missverhältnis in der griechischen Antike: Zwar wurde die praktische Arbeit hauptsächlich von Sklaven verrichtet, aber dennoch als Form materiellen Gewinnstrebens verstanden, mithin auf eine Motivation zurückgeführt, die als niederer Beweggrund galt und einer Diffamierung dieser praktischen Arbeit Vorschub leistete. Dass hier vom klassischen Griechenland, wohl von der sogenannten Blütezeit Athens im 3. und 4. Jahrhundert v. Chr., die Rede ist, zeigen die erwähnten Quellen. Referenzautoren sind Platon und Aristoteles. Doch nicht aus deren Schriften zur politischen Philosophie zitiert Benjamin, sondern aus der Studie Machinisme et philosophie (1938) des französischen Philosophen

17 Diesen historischen Ansatz hat bereits Fähnders bemerkt: „So beginnen die Notizen mit Hinweisen auf die Geschichte.“ (Fähnders, „Benjamins Müßiggang-Studien“, 1554)

18 Für instruktive Anregungen und hilfreiche Rückfragen danke ich den Teilnehmern der Lesegruppe, namentlich Rebekka Becker, Heidi Liedke und Tobias Keiling, die mit mir im Sommersemester 2015 über Benjamins Konvolut „m“ diskutiert und als Mitherausgeber auch meinen daran anschließenden Beitrag aufmerksam gelesen haben. 
Pierre-Maxime Schuhl (1902-1984) ${ }^{19}$ - aus einem kleinen Büchlein mit weitgespanntem historischen Horizont, das Vorlesungen versammelt, die von der klassischen Antike bis ins 19. Jahrhundert reichen und die laut Auskunft des Verfassers zwischen 1935 und 1937 gehalten wurden. ${ }^{20}$ Schuhl, der damals als maître de conférences in Montpellier und sodann in Toulouse lehrte und sich mit der Entstehung des griechisch-antiken Denkens, insbesondere mit Platon beschäftigte, referiert dessen Arbeitsauffassung folgendermaßen:

Platon prescrit dans les Lois (VIII, 846) qu'aucun citoyen n'exerce une profession mécanique [...] tout ce qui est artisanal ou manœuvrier porte honte, et déforme l'âme en même temps que le corps. En général, ceux qui exercent ces métiers [...] n’ont d'industrie que pour satisfaire $[\ldots]$ ce , désir de richesse, qui prive tout notre temps de loisirs $[\ldots]^{c}{ }^{21}$

Laut dem achten Buch der Nomoi, welche die Gesetze behandeln und neben der Politeia Platons politisches Hauptwerk sind, darf kein Bürger Athens eine mechanische Tätigkeit ausüben, da jede handwerkliche Betätigung einem freien Mann Schande bringe und den Geist sowie Körper schädige. Ein athenischer Staatsbürger müsse sich auf seinen eigentlichen Beruf konzentrieren, so Platon:

Erstens gehöre kein Einheimischer zu denen, welche handwerkmäßigen Beschäftigungen sich widmen [...]. Denn ein Staatsbürger eignet sich, um das Ansehen eines Staates zu erhalten und zu erhöhen, eine anständige Kunst an, die sowohl Übung wie vielfache Kenntnisse erheischt, als einen nicht als Nebenbeschäftigung zu betreibenden Beruf.. ${ }^{22}$

Diejenigen, die einem mechanischen Gewerbe nachgingen, nutzten die Produktion nur, so Platon, um ihr Verlangen nach Reichtum zu befriedigen, welches sie indes von der Muße abhalte. ${ }^{23}$ Der exzessiv ausgeübten Kunst, Reichtümer zu erwerben, hält Aristoteles sodann die Weisheit der häuslichen Ökonomie entgegen, wie Schuhls eingängige Darstellung verdeutlicht:

Aristote à son tour oppose aux excès de la chrématistique [...] la sagesse de l'économie domestique [...]. Ainsi, le mépris que l'on a pour l'artisan s'étend au commerçant: par rapport à la vie libérale, qu’occupent de studieux loisir [otium] [...], le négoce [neg-otium] $[\ldots]$, , les affaires' n'ont, le plus souvent, qu'une valeur negative. ${ }^{24}$

Die Verachtung, die man für den Handwerker habe, betreffe somit auch den Händler, erklärt Benjamins Gewährsmann Schuhl. Im Gegensatz zum selbst be-

19 Pierre-Maxime Schuhl, Machinisme et philosophie, Paris 1938.

20 Zur Entstehung der Studien und der Frage ihrer Aktualität vgl. Schuhls Vorwort („Préface“, VII-XV) zur zweiten Auflage (1947), auf die ich mich im Folgenden stütze.

${ }^{21}$ Das exzerpierte Zitat findet sich in Pierre-Maxime Schuhl, Machinisme et philosophie, 2. Aufl., Paris 1947.

22 Platon, Nomoi, 846d. Zitiert nach: Sämtliche Werke (=SW), Bd.3, neu hg. v. Ursula Wolf, übers. v. Friedrich Schleiermacher/Hieronymus u. Friedrich Müller (Briefe), Reinbek bei Hamburg 1994, 424.

23 Vgl. dazu Platon, Theaitetos, 172c-177b. Zitiert nach: SW 3, 195-201.

24 Schuhl, Machinisme et philosophie, 14. 
stimmten Leben, das dem Studium der Muße (gr. scholê; lat. otium) gewidmet sei oder sein sollte, habe das Geschäft (neg-otium) zumeist nur eine negative Bedeutung. Diese Sichtweise geht tatsächlich auf Aristoteles zurück, der in seiner Politik-Schrift über das richtige Verhältnis von Tätigkeit und Muße reflektiert und die Ansicht vertritt, dass

die Natur selber nicht nur richtig tätig zu sein, sondern sich auch in würdiger Weise der Muße zu erfreuen sucht - dies ist das eine Grundprinzip von allen, und wir wollen das hier wiederholen. Nun sind zwar beide unerlässlich, Muße ist aber dem Tätigsein vorzuziehen und ist ihr Zweck, daher muss man untersuchen, womit man sich während der Muße beschäftigen soll. Bestimmt nicht mit Amüsement [...]. Muße dagegen enthält, wie man glaubt, Vergnügen, Glück und glückseliges Leben in sich selber; dieser (Segnungen) erfreut sich aber (nur), wer in Muße lebt, nicht dagegen diejenigen, die arbeiten müssen. ${ }^{25}$

Laut Aristoteles ist Muße demnach der Dreh- und Angelpunkt des gelingenden Lebens und eng mit Freiheit verbunden. Muße ist generell erstrebenswert, aber nicht allen zugänglich: Sie bleibt ein Elitenphänomen ${ }^{26}$, bedarf sie doch des Studiums bzw. der Erziehung, mithin der freien Zeit und materiellen Unabhängigkeit. Wer der Muße nachgeht, frönt bewusst einer selbstgewählten Tätigkeit, kümmert sich um sich selbst und beweist damit die eigene Autonomie. ${ }^{27}$

Bis hierher thematisieren Benjamins Exzerpte die antike Arbeitsauffassung und die Muße. Diese Befunde werden in historischer und systematischer Hinsicht ergänzt durch die folgenden Exzerpte Benjamins, die das Mittelalter fokussieren und neue, epochentypische Leit- und Komplementärbegriffe einführen. Dabei stützt sich Benjamin wiederum auf Schuhls bereits erwähnte Monographie. Zitiert wird daraus ein Passus zur Fortuna-Darstellung in mittelalterlichen Bilderbüchern: „Les imagiers du Moyen Age représentent les hommes qui s'adonnent à la vie active liés à la roue de la Fortune, s'élevant ou s'abaissant se-

25 Aristoteles, Politik, 1337b30-1338a. Zitiert nach: Werke in deutscher Übersetzung, begr. v. Ernst Grumach, hg. v. Hellmut Flashar, Bd. 9, übers. u. erl. v. Eckart Schütrumpf, Darmstadt 2005, 49. - In der Nikomachischen Ethik (X, 7) behauptet Aristoteles die Überlegenheit der Kontemplation über die höchsten Formen des Tätigseins. Vgl. dazu und zu Plotins Auffassung der Kontemplation Schuhl, Machinisme et philosophie, 14.

${ }^{26}$ Diesen Aspekt akzentuiert Ada Neschke-Hentschke, „Die uneingeschränkt beste Polisordnung", in: Otfried Höffe (Hg.), Aristoteles. Politik (= Klassiker auslegen 23), Berlin 2001, 169-186, 175: „In der historischen Wirklichkeit handelt es sich um den Gegensatz von Reichen und Armen (III 8), in der Wunschpolis um den Unterschied der ,arbeitenden Klasse und der Mußeklasse (VIII 9, 1328b33-1329a2).“

27 Zur Bedeutung der Muße in der Politik des Aristoteles vgl. Simon Varga, Vom erstrebenswertesten Leben: Aristoteles' Philosophie der Muße, Boston/Berlin 2014, insbes. 107139; außerdem Neschke-Hentschke, „Die uneingeschränkt beste Polisordnung“, 172 f., 175 und 178-180, insbes. 172: „,Muße ist ein Zentralbegriff: Er beinhaltet negativ die Freiheit vom Erwerb des Lebensnotwendigen [...], positiv die Freiheit zur Realisierung des Glücks.“ Zur Glücksauffassung des Aristoteles s. Philipp Brüllmann, „Glück“, in: Christoph Rapp/ Klaus Coralius (Hg.), Aristoteles Handbuch, Leben - Werk - Wirkung, Stuttgart/Weimar 2011, 232-238. 
lon le sens dans lequel elle tourne, alors que le contemplatif reste immobile au centre. ${ }^{28}$ Mit der genannten ,Fortuna' ist hier „das ,Glück' oder der ,Zufall'““ gemeint. ${ }^{29}$ Demnach sind Menschen, die sich der, vita activa' widmen, auf den Zufall oder das Glück angewiesen und metaphorisch an das Rad der Fortuna geknüpft, sie steigen oder fallen je nach Richtung, in der sich das Rad dreht. In dessen Zentrum sitzt hingegen der Kontemplative, der unbeweglich und von der Kontingenz unberührt bleibt.

Den Zusammenhang zwischen Fortuna und ,vita activa' thematisiert Benjamin auch in eigenen Worten, wobei er Fortuna weiterhin im römisch-antiken Sinne als Göttin personifiziert ${ }^{30}$, anstatt diese, nach dem eben beschriebenen mittelalterlichen Vorbild, als Rad zu repräsentieren. Zudem führt Benjamin nun den Begriff des Müßiggangs ein. Sein bereits erwähntes Exzerpt („m I, 2“) beginnt wie ein Aphorismus:

Wer Muße genießt, der entrinnt der fortuna, wer sich dem Müßiggang ergibt, der fällt ihr anheim. Die fortuna, die ihn im Müßiggang erwartet, ist aber eine mindere Göttin als jene war, die der der Muße ergebene floh. Diese fortuna ist nicht mehr in der vita activa zuhause; ihr Hauptquartier ist die Lebenswelt. (GS V/2, 961)

Behauptet wird hier dreierlei: Erstens bestehe ein unterschiedliches Verhältnis der Muße und des Müßiggangs zu Fortuna, von letzterer sei nur derjenige betroffen, der müßig gehe. Bereits die Wortwahl (,genießen'vs. ,sich ergeben', ,entrinnen' vs. , anheimfallen') indiziert, dass die Muße den Primat vor dem Müßiggang besitzt; denn die Muße ist hier positiv konnotiert, wird aktiv ausgeübt und verschafft Autonomie, während der Müßiggang passiv wirkt und in Abhängigkeit von Fortuna bringt. Zweitens unterscheidet Benjamin diese Göttin Fortuna qualitativ von der zuvor genannten, und analog dazu wird auch der Müßiggang von der Muße unterschieden. Durch die Duplizität und hierarchische Ordnung der beiden Gottheiten, zu denen sich die Muße oder der Müßiggang je unterschiedlich verhalten, erscheint letzterer allenfalls als Schwundstufe der Muße. Begründet oder eher veranschaulicht wird diese Differenz drittens durch das jeweilige Habitat der Göttinnen: Residierte die erste, höhere noch in der ,vita activa', so

28 Schuhl, Machinisme et philosophie, 32 (von Benjamin zitiert in „m I, 2“). Als Quelle verweist Schuhl hier auf: V. E. Mâle, L'art religieux du XIIIe en France, Paris 1898, 128-132, und Alfred Doren, Fortuna im Mittelalter und in der Renaissance, Warburg Vorträge, 192223, $86 \mathrm{f}$.

29 Vgl. Art. „Fortuna“, in: Lexikon der alten Welt, hg. v. Carl Andresen/Hartmut Erbse/ Olof Gigon/Karl Schefold/Karl Friedrich Strohecker/Ernst Zinn, Bd. 1 A-6, Düsseldorf 2001, Sp. 990.

30 Vgl. zu dieser Darstellungstradition den Artikel im Wörterbuch der Antike. Mit Berücksichtigung ihres Fortwirkens, begr. v. Hans Lamer, fortgeführt v. Paul Kroh, neunte, verb. u. erg. Aufl., Stuttgart 1989, 216: „F. war eine Funktion des Iuppiter; sie repräsentierte das glückliche Gelingen“" und „wurde mit Tyche identifiziert." 
hat die zweite, niedere ihre Basis nur noch in der „Lebenswelt“, so Benjamin, der weder den einen noch den anderen Begriff näher erklärt.

\section{Von der Muße zum Müßiggang: Transformationsprozesse zwischen feudaler und bürgerlicher Gesellschaft}

Im Hinblick auf die Geschichte der Muße und des Müßiggangs, die Benjamin im Konvolut „m“ skizziert, bietet es sich nun an, zum Exzerpt „m 2 a, 5“ (GS $V / 2,964)$ überzugehen. Dort kontrastiert Benjamin die feudale und die bürgerliche Gesellschaft und erklärt aus beiden Gesellschaftsordnungen heraus, was die Muße einst ausmachte, mit welchen anderen sozialen Praktiken sie interagierte und wem sie wann und wie zugebilligt wurde. ${ }^{31}$ „In der feudalen Gesellschaft“ sei Muße „das Entbundensein von Arbeit“ und „ein anerkanntes Privileg“ gewesen, heißt es zu Anfang des längeren Exzerpts, dessen Ende den „Dichter“ als denjenigen Privilegierten ausweist (GS V/2, 964) ${ }^{32}$ Des Weiteren kannte und gestattete der Feudalismus „die Muße des Grandseigneurs, des Prälaten, des Kriegers“, die in zwei wesentliche soziale Praktiken, in die „religiöse Kontemplation und das Hofleben“, eingebettet bzw. „gegossen“ waren, wie Benjamin es ausdrückt. Damit verwendet er eine bemerkenswerte Metapher: Die Muße brauche „gleichsam die Hohlformen“ des erwähnten religiösen und höfischen Lebens, um ihren Platz in der Gesellschaft zu haben. ${ }^{33}$ Diese zwei „Attitüden“, die Benjamin sodann als „Pietät“ und „Repräsentation“ reformuliert, sind „den Wechselfällen des Lebens, der Fortuna, enthoben und damit auch den Lastern des Müßigganges, die das Mittelalter ja durchaus auch kennt“, wie Walter Fähnders anmerkt. ${ }^{34}$ Beide, die „Pietät“ und die „Repräsentation“, kamen laut Benjamin auch „dem Dichter zu

31 Zur Begriffs- und Bedeutungsgeschichte des Feudalismus, der sich ursprünglich auf das seit dem 12. und 13. Jahrhundert aufgezeichnete Lehnsrecht und auf den Lehensstaat bezieht und „im 18. Jahrhundert vom Rechtsterminus zum Verfassungsbegriff mit geschichtsphilosophischer Wertung geworden war“, s. Otto Brunner, „Feudalismus, feudal“, in: Geschichtliche Grundbegriffe, Bd.2, 337-350, 337. Thematisch einschlägig für meine Fragestellung ist Brunners Hinweis auf Saint-Simons und Hegels geschichtsphilosophische Deutungen des Feudalismus und auf dessen „Bezug zur Arbeit“, über den „die verbreitete Vorstellung von der Ablösung einer auf Krieg und Gewalt gegründeten Feudalherrschaft durch eine auf Frieden gerichtete bürgerliche Arbeitsverfassung impliziert ist" (Brunner, Art. „Feudalismus“, 345). Ebenso sind es Brunners Einlassungen zu Marx, in dessen „Geschichtsbild [...] ,Feudalismus' eine Stufe der progressiven ökonomischen Gesellschaftsformen, eine der Produktionsweisen [war]" (Brunner, Art. „Feudalismus“, 346).

32 Vgl. Fähnders, „Benjamins Müßiggang-Studien“, 1554, der in diesem Zusammenhang auf das „Spannungspaar der ,vita activa“ und der ,vita contemplativa“" hinweist.

33 Auf diese Metaphorik wird noch in Zusammenhang mit dem Müßiggang zurückzukommen sein (vgl. „m 3 a, I“).

34 Fähnders, „Benjamins Müßiggang-Studien“, 1559. 
gute“: „Sein Werk begünstigte sie zumindest mittelbar, indem es den Kontakt mit der Religion und dem Hofstaat wahrte", eine Allianz, die Voltaire partiell aufkündigte, da er „als erster der großen Literaten mit der Kirche [brach]“, sich aber dennoch „am Hofe Friedrichs des Großen einen Platz zu sichern“ trachtete (GS V/2, 964). Im 19. Jahrhundert, nach dem Ende des Absolutismus, entsteht Literatur unter veränderten soziopolitischen Bedingungen, in der bürgerlichen Gesellschaft, in welcher „der Dichter“ laut Benjamin „zum Müßiggänger [wird]“

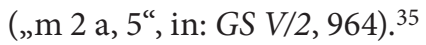

Das Thema der religiösen Kontemplation ${ }^{36}$, die als „Hohlform“ der „gegossenen" Muße verstanden und damit metaphorisiert wurde, nimmt ein späterer Eintrag wieder auf. Dort vermutet Benjamin: „Die strenge Arbeits- und Werkmoral des Calvinismus dürfte im engsten Zusammenhang mit der Entwicklung der vita contemplativa stehen. Sie suchte dem Abströmen der in der Kontemplation gefrornen Zeit in den Müßiggang einen Damm entgegenzusetzen“ („,m 3 a, I“, in: GS V/2, 965 f.). An diesem Eintrag fällt auf, dass er aus zwei Teilen besteht, die nicht nur grammatikalisch getrennt, sondern auch stilistisch und rhetorisch deutlich unterschieden sind. Im ersten Satz wird sachlich eine Hypothese formuliert, der zweite hingegen ist enigmatisch, da das Subjekt unklar ist und eine metaphorische Ausdrucksweise das Verständnis zusätzlich erschwert. Der Eintrag bedarf also einer eingehenden Analyse und Explikation. Klar ist, dass Benjamin eine Verbindung zwischen der reformierten Theologie nach Calvin (1509-1564) und der Lebensform der, vita contemplativa' annimmt. Worin deren Beziehung genau besteht, bleibt uneindeutig. Doch dürfte Benjamin kein reziprokes Verhältnis zwischen beiden, sondern ein unilaterales, meinen: Denn der im zweiten Satz benannte Akteur („Sie“) ist niemand anders als die calvinistische Arbeitsund Werkmoral, sie reagiert auf eine vorgängige oder akute Veränderung der ,vita contemplativa ${ }^{37}$ Diese Transformation betrifft die Temporalstruktur, ja die Beschaffenheit der Zeit selbst. In der Kontemplation war sie "gefroren“, so Benjamins metaphorischer Ausdruck, der eine Stillstellung und Konservierung der Zeit nahelegt. ${ }^{38}$ In und bei der Kontemplation wäre demnach ein spezifisches, statisches Zeitverhältnis gegeben. Doch Benjamins Bemerkung lässt noch wei-

35 Vgl. auch die „Notes sur les Tableaux parisiens de Baudelaire“ in GS I/2, 746.

${ }^{36}$ Dazu ausführlich: Carolin Duttlinger, „Studium, Aufmerksamkeit, Gebet: Walter Benjamin und die Kontemplation", in: Daniel Weidner (Hg.), Profanes Leben. Walter Benjamins Poetik der Säkularisierung, Frankfurt a. M. 2010, 95-119.

37 Vgl. Schäfer, „Eingefrorene Zeit“, 42: „Das Subjekt des zweiten Satzes der Benjaminnotiz bezieht sich in diesem Sinne auf die ,Arbeitsmoral', die den Umschlag von Kontemplation in Müßiggang verhindern soll.“

38 „Bemerkenswert an dieser Formulierung ist“, so Schäfer („Eingefrorene Zeit“, 42), „daß in ihr die vita contemplativa an sich keiner eigenen Bestimmung unterworfen wird.“ Schäfer folgert weiter: „Daß die Zeit als Muße ,eingefroren' wird [,] besagt [...] zum ersten ihren völligen Stillstand und zum zweiten die Konservierung dessen, was, abseits aller inhaltlichen Bestimmung, im Moment der Muße zum ,Einfrieren' gebracht worden ist.“ 
tere Schlüsse zu. Hingedeutet wird auf eine grundsätzliche Transformation der Zeit, die ihren Aggregatszustand verändert hat, gleichsam getaut und am Abfließen bzw. „Abströmen“ ist („m 3 a, I“, in: GS V/2, 966).

Wann und wodurch genau es zu dieser Dynamisierung der Zeit kam, erklärt Benjamin wiederum nicht. In einer späteren Fassung des Exzerpts findet sich allerdings ein Hinweis auf „Max Weber: Religionssoziologie“ (GS I/3, 1176). Vor dem Hintergrund von Webers religionssoziologischer Studie Die protestantische Ethik und der „Geist“ des Kapitalismus (1920) vermutet Martin Jörg Schäfer eine Anspielung auf den neuzeitlichen „Geltungsverlust des Religiösen“, den bereits das Melancholie-Kapitel von Benjamins Trauerspiel-Buch thematisiert ${ }^{39}$, und schlussfolgert, dass die angesprochene „Entwicklung der vita contemplativa“ deren „Entwertung“ meint. ${ }^{40}$ Bildlich dargestellt wäre diese Verfalls- bzw. Verlaufsgeschichte durch das zitierte „Abströmen“ der Zeit, die, nicht mehr durch religiöse Andacht und Besinnung gebunden, ,schmilzt' und in den Müßiggang abfließt. Dem ein Hindernis entgegenzusetzen und damit auch das Zunehmen des Müßiggangs selbst aufzuhalten, wäre Benjamins Bemerkung zufolge das Anliegen der protestantischen Arbeitsethik gewesen. Die maßgebliche Differenz zwischen der Kontemplation, die im Sinne des zuvor erläuterten Exzerpts auch die Muße einschließt, und dem Müßiggang bestünde also in den jeweiligen Temporalstrukturen. Diese beschreibt bzw. umschreibt Benjamin als zwei distinkte Aggregatszustände (fest/flüssig). Seine gewählte Metaphorik ist kein rhetorischer Schmuck, sondern eine spezifische Ausdrucksweise und ein Beispiel dafür, dass Benjamin „dichterisch dachte“, so Hannah Arendts berühmte Formulierung. ${ }^{41}$

Deutlich sachlicher ist Benjamin hingegen im Brief an Bernard von Brentano, 22. April 1939, in dem er berichtet:

Ich bin bei einem Abschnitt meines Buchs über Baudelaire, der es mit dem Spektrum des Müßiggangs in der bürgerlichen Gesellschaft zu tun hat. Er unterscheidet sich sehr markant von der ,Muße in der feudalen, die den Vorzug hat, von der vita contemplativa auf der einen, von der Repräsentation auf der andern Seite flankiert zu sein. (GB VI, 271)

Analog zu den behandelten Exzerpten ordnet Benjamin auch im zitierten Brief die Muße der feudalen und den Müßiggang der bürgerlichen Gesellschaft zu und nennt wiederum die „vita contemplativa“ und die „Repräsentation“ als Begleitphänomene der Muße.

„Zur Charakteristik der Muße“ zitiert Benjamin im Konvolut „m“ außerdem einen Essay des Literaturkritikers Charles-Augustin Sainte-Beuve (1804-1869) über den Moralisten Joseph Joubert (1754-1824), in dem es heißt: „,Converser et connaître, c'était en cela surtout que consistait, selon Platon, le bonheur de la vie privée.' Cette classe de connaisseurs et d'amateurs [...] a presque disparu en

39 Vgl. GS I/1, 317-320.

40 Schäfer, „Eingefrorene Zeit“, 41.

${ }^{41}$ Hannah Arendt, Menschen in dunklen Zeiten, München/Zürich 1989, 187. 
France depuis que chacun y fait un métier.“42 („m I, 3“, in: GS V/2, 961 f.) Joubert selbst, der mit den Enzyklopädisten d'Alembert und Diderot und mit Chateaubriand befreundet und für seine soziale und freundschaftliche Umgangsweise bekannt war, der zahlreiche Briefe und Aphorismen schrieb und umfassende Notizen anfertigte, aber nie etwas publizierte ${ }^{43}$, verfügte noch über die Konversationskunst und das Wissen, die laut Plato das private Lebensglück ausmachen. Doch solche kundigen Menschen seien mittlerweile in Frankreich, wo jeder einem Metier nachgehe, beinahe verschwunden, moniert Sainte-Beuve im Zitat.

Eine Professionalisierung lehnte auch Saint-Beuves Bekannter Baudelaire entschieden ab, das zeigen seine Aufzeichnungen zum Dandy, auf die eigens und sicherlich mit Gewinn einzugehen wäre, denn: „In der Figur des Dandy sucht Baudelaire für den Müßiggang einen Nutzen zu gewinnen, wie die Muße, vordem, solchen besessen hat. Die vita contemplativa wird durch etwas vertreten, was man die vita contemptiva nennen könnte." So heißt es in einem der folgenden Einträge Benjamins („m I a, 2“, in: GS V/2, 962; Herv. R.K.). Dass die Muße einst einen Nutzen besaß, weil sie der antiken Selbstsorge diente ${ }^{44}$ und gemäß mittelalterlicher Vorstellungen half, Fortuna zu entrinnen, geht aus den bereits behandelten Einträgen hervor. Nun wird mit Baudelaire ein, wenn nicht gar der Dichter der Moderne genannt. Auf Beobachtungen zu Baudelaire und zur Moderne, nämlich auf Teil III (Abschnitt: „Die Moderne“) seines Manuskripts Das Paris des Second Empire bei Baudelaire (1938), verweist Benjamin selbst im Anschluss an den zitierten Eintrag („m I a, 2“, in: GS V/2, 962). Auch diesen Hinweis aufgreifend, wäre Baudelaires Dandytum mit Blick auf Muße und Müßiggang eigens zu untersuchen. Vordringlicher erscheint jedoch eine kurze Erläuterung der enigmatischen „vita contemptiva“. Dieser Neologismus Benjamins bezeichnet den charakteristischen, elitär-verächtlichen Habitus des Dandys, der als moderne Lebensform in der Nachfolge der ,vita contemplativa' begriffen wird. ${ }^{45} \mathrm{Im}$ Hintergrund steht wiederum die Frage, inwieweit sich Muße und Müßiggang unterscheiden oder einander doch ähneln. Dabei findet, analog zur epochalen Ausrichtung von Benjamins Passagen-Arbeiten insgesamt, das 19. Jahrhundert im Konvolut „m“ besondere Beachtung. „In der bürgerlichen Gesellschaft hatte die Faulheit“, so Benjamin, „aufgehört ,heroisch“ zu sein.“ Dabei bezieht er sich explizit auf Marx, der, die preußische Revolution bilanzierend, vom „Sieg [...]

42 Joseph Joubert, Correspondance de Joubert, Paris 1924, XCIX.

43 Thematisch einschlägig ist hier das Kapitel 5, „Philosopher sur l'oreiller: Joubert“, in: Pierre Saint-Amand, Paresse des Lumières, Rom 2014, 139-162.

44 Solche Muße wäre als Selbstsorge im Sinne Michel Foucaults zu untersuchen. Vgl. Michel Foucault, Histoire de la sexualité 3: Le souci de soi, Euvres, Bd.2, hg. v. Frédéric Gros, Paris 2015.

${ }^{45}$ Vgl. dazu auch „m 5, 4“: „In dem Flaneur, den sein Müßiggang durch eine imaginäre Stadt von Passagen trägt, tritt dem Dichter der dandy entgegen (der dandy, welcher sich durch die Menge hinbewegt, ohne auf die Stöße zu achten, denen er ausgesetzt ist)." (GS $V / 2,969)$ 
der Industrie über die heroische Faulheit“ sprach („m I a, I“, in: GS V/2, 962). ${ }^{46}$ Doch übrig bleibt keineswegs nur die Arbeit, auch der Müßiggang wird nun öffentlich praktiziert. Zwar hat der Müßiggang „wenig Repräsentatives, wird aber weit mehr als die Muße ausgestellt", behauptet Benjamin und fügt als Erklärung hinzu: „Der Bürger hat begonnen, sich der Arbeit zu schämen. Er, für den sich die Muße nicht mehr von selbst versteht, stellt seinen Müßiggang gern zur Schau“ („m 2, 2“, in: GS V/2, 963). Angesprochen sind damit die Sozialgeschichte und Sozialpsychologie des Bürgertums: Es verdankte seinen Aufstieg hin zur führenden gesellschaftlichen Klasse im 19. Jahrhundert auch und gerade der eigenen Arbeit, die zu ökonomischem, sozialem und kulturellem Kapital führte. Die Arbeit war nach altprotestantischem Worte „,des Bürgers Zierde““ („m 4, 6“, in: GS V/2, 967), der Adel galt dagegen als faul. Doch mit der fortschreitenden Etablierung des Bürgertums änderten sich auch die Statussymbole und sozialen Codes. Arrivierte und saturierte Bürger zeigen nun gerne, dass sie ebenfalls zu Reichtum und Macht gekommen sind und es längst nicht mehr nötig haben, selbst zu arbeiten. War noch in der Feudalgesellschaft die Muße ein adliges und klerikales Privileg und damit ein unübersehbarer sozialer Marker, wird im bürgerlichen Zeitalter ausgerechnet der Müßiggang für Teile des Bürgertums identitätskonkret und zum neuen Distinktionsmerkmal. Dabei markiert er, anders als die vormals zur Schau gestellte Muße, nun klasseninterne Differenzen, also Unterschiede, die zwischen Angehörigen derselben Klasse, zwischen Bürgern, bestehen.

\section{Arbeit, Muße, Müßiggang: Benjamins Typologien}

Weitere Differenzen zwischen Muße und Müßiggang erkennt Benjamin im jeweiligen Verhältnis zur Arbeit: „Der Müßiggang sucht jedweder Beziehung zur Arbeit des Müßiggängers, schließlich zum Arbeitsprozeß überhaupt aus dem Wege zu gehen. Das unterscheidet ihn von der Muße“ („m 3, I“, in: GS V/2, 964 f.). Demnach sind Arbeit und Muße sehr wohl kompatibel, nicht aber Arbeit und Müßiggang. „Die verschiednen Spielformen zwischen Arbeit und Müßiggang dürften sich in einem System bestimmen lassen, dessen eine Koordinate die Zielvorstellung, dessen andere der Kraftaufwand darstellt", notiert Benjamin im Kontext seiner Baudelaire-Studien (GS I/3, 1177). ${ }^{47}$ Eine Skizze aus seinem Nachlass dokumentiert, wie er sich das erwähnte Koordinatensystem bildlich vorstellte:

46 Vgl. Karl Marx/Friedrich Engels, „Die Bourgeoisie und die Kontrerevolution“ [1848], in: Marx-Engels Werke (=MEW), Bd. 6, hg. v. Institut für Marxismus-Leninismus beim ZK der SED, Berlin 1961, 102-124, 107.

47 Vgl. GS I/3, 1177-1180. 


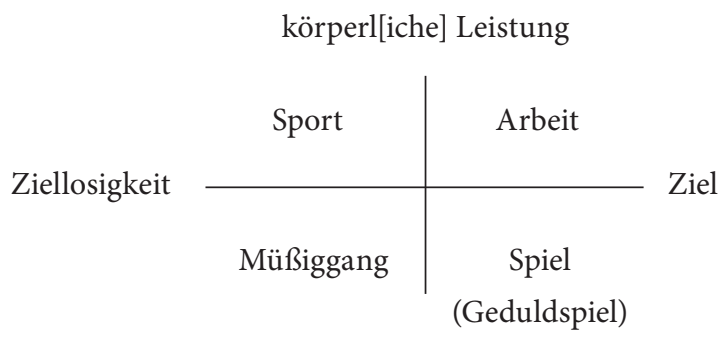

körperliche Ruhe

Die vertikale Achse reicht von „körperlicher Leistung“ bis zu „körperlicher Ruhe“, die horizontale Achse verzeichnet die Spanne zwischen „Ziel“ und „Ziellosigkeit“. „Sport“ und „Arbeit“ stehen dabei oben, „Müßiggang“ und „Spiel“ unten $(G S I / 3,1177)$. Auf die „besondere Position des Geduldspiels“ (GS I/3, 1177) wird noch eigens, nämlich im „Spiel“-Kapitel der vorliegenden Studie, einzugehen sein. Priorität hat jedoch, das basale Verhältnis von Arbeit und Müßiggang möglichst präzise zu bestimmen.

Benjamins Konvolut „m“ ist äußerst instruktiv, weil es historische Befunde und systematische Ansätze bietet. Von besonderem systematischen Interesse ist die folgende Bemerkung: „Die Erfahrung ist der Ertrag von Arbeit, das Erlebnis ist die Phantasmagorie des Müßiggängers“ („m I a, 3“, in: GS V/2, 962). ${ }^{48}$ Benjamin kontrastiert hier Arbeit und Müßiggang und charakterisiert beide in ästhetischer und ökonomischer Hinsicht. Syntagmatisch ordnet er im ersten Satzteil die Erfahrung und den Ertrag der Arbeit zu und im zweiten Satzteil das Erlebnis und die Phantasmagorie dem Müßiggang. Jeder Satzteil beinhaltet also eine Begriffstrias. Die bezeichneten Phänomene sind aufeinander bezogen und kausal verknüpft: Aus der Arbeit resultiert die Erfahrung, aus dem Müßiggang das Erlebnis. ${ }^{49}$ Gleichzeitig beinhaltet Benjamins Bemerkung auch eine paradigmatische Ebene. Hier stehen Erfahrung und Erlebnis, Ertrag und Phantasmagorie und schließlich Arbeit und Müßiggang einander gegenüber.

Die Dichotomie von ,Erfahrung und ,Erlebnis' erläutert Benjamin im Exzerpt „m 2 a, 4“ genauer. Dort heißt es: „Was die Erfahrung vor dem Erlebnis auszeichnet, ist, daß sie von der Vorstellung einer Kontinuität, einer Folge nicht abzulösen ist" (GS V/2, 964). Demnach besteht ein hierarchisches Verhältnis zwischen ,Erfahrung und ,Erlebnis‘. Qualitativ hat die Erfahrung Vorrang vor dem Erlebnis, schließlich sind Erfahrungen kontinuierlich, Erlebnisse hingegen unzusam-

48 Vgl. identisch in GS I/3, 1179. Zu dieser Unterscheidung und ihrem Zusammenhang mit den „sozialhistorische[n] und -psychologische[n] Bedingungen“, insbesondere den „Arbeits-, Kommunikations- und Erinnerungsverhältnisse[n]“s. Weber, „Erfahrung“, $236 \mathrm{f}$.

49 Vgl. Webers Ausführungen (in, „Erfahrung“, 243-247) zum Verhältnis von „Erfahrung und Arbeit" im Ausgang von Marxens Kapital. 
menhängend. Gewohnheiten werden daher von Erlebnissen in Frage gestellt und von Erfahrungen vertieft: „Gewohnheiten sind die Armatur der Erfahrungen. Von Erlebnissen wird diese Armatur angegriffen", so Benjamins technisches Vokabular („m 4,5“, in: GS V/2, 967). Seine Bemerkungen umkreisen die Frage nach "Erfahrung und Erfahrungsverlust" in der Moderne, ein Thema, das Benjamin seit den 1920er Jahren zunehmend beschäftigt und das insbesondere sein Kunstwerkaufsatz (1935) systematisch behandelt. ${ }^{50}$

Erschienen Arbeit und Müßiggang bislang inkompatibel, kennt Benjamin doch zwei Ausnahmen von dieser Regel: „Es gibt zwei soziale Institutionen, in denen der Müßiggang integrierend auftritt: der Nachrichtendienst und das Nachtleben. Sie verlangen eine spezifische Form der Arbeitsbereitschaft. Diese spezifische Form ist der Müßiggang.“ („,m 2 a, 2“, in: GS V/2, 964) Der Müßiggang wird hier also nicht, wie in der Begriffs- und Bedeutungsgeschichte allzu üblich, einfach als Arbeitsversäumnis oder Arbeitsverweigerung diffamiert. ${ }^{51}$ Stattdessen begreift Benjamin die Potenzialität des Müßiggangs, der auch eine abwartende Haltung, eine Art ,Bereitschaftsdienst' sein kann. Das gilt zumindest für die zwei genannten Fälle: Denn der Journalist oder Reporter wartet häufig darauf, dass etwas Neues und Berichtenswertes geschieht; und im Nachtleben, ob Gastronomie, Entertainment oder Prostitution, wechseln sich Arbeitsphasen und Leerzeiten ebenfalls beständig ab. Das thematisieren Benjamins Aufzeichnungen zum Feuilleton-Autor, der umher flaniert oder mit griffbereitem Notizblock auf Café-Terrassen und an Zeitungskiosks ausharrt, und die Fragmente zur Prostituierten als Ware und Verkäuferin in Personalunion. ${ }^{52}$ Anschaulich wird ein solches müßiges Warten auch in Federico Fellinis Filmklassiker $L a$ dolce vita (1960), in dem die neu kreierte Figur des Paparazzo auf der Via Veneto in Cafés und Nachtclubs solange dem Müßiggang frönt, bis sich eine möglichst sensationelle Story zeigt. Benjamin reflektiert diesen charakteristischen Zusammenhang von „Nachrichtendienst und Müßiggang" und hält in einer gleichnamigen Bemerkung („m 2 a, 3“) im Konvolut fest: „Feuilletonist, Reporter, Bildberichterstatter stellen eine Klimax dar, in der das Warten, das: ,parat sein' mit anschließendem ,losschießen' gegenüber der sonstigen Leistung immer wichtiger wird.“ (GS V/2, 964) Benjamins zitierte Beobachtung zur Technik des Wartens, das gerade im journalistischen Bereich zunehmend relevant, ja entscheidend wird, wäre für eine überfällige Kulturgeschichte des Wartens ${ }^{53}$ sicherlich von

50 Also Walter Benjamin, „Das Kunstwerk im Zeitalter seiner technischen Reproduzierbarkeit“, in: GS I/2, 431-508; dazu van Reijen/van Doorn, Aufenthalte und Passagen. Leben und Werk Walter Benjamins, 182.

51 Vgl. Anm. 8.

52 Vgl. Benjamin, „Der Flaneur“, in: GS I/2, 537-569; Benjamin, „Zentralpark“, in: GS $I / 2,671$ u. $686 \mathrm{f}$.

53 Eine solche hätte auch „Die Wartenden“von Siegfried Kracauer, der mit Benjamin gut bekannt war, zu berücksichtigen (in: Werke, Bd. 5.1, hg. v. Inka Mülder-Bach unter Mitarb. v. Sabine Biebl, Frankfurt a. M. 2011, 383-394). 
ähnlichem Belang wie sie es für die hier zumindest skizzierte Geschichte und Phänomenologie des Müßiggangs ist. Noch hinzuzuziehen sind weitere themenverwandte Bemerkungen aus dem Konvolut „D“ („, die Langweile, ewige Wiederkehr") der Passagen-Arbeit (GS V/1, 156-178), wo es u.a. heißt: „Langeweile haben wir, wenn wir nicht wissen, worauf wir warten.“ („D 2, 7“, in: GS V/1, 161) ${ }^{54}$

\section{Figurationen des Müßiggangs: Studenten, Spieler und Flaneure}

Das Warten zeigt: Der Müßiggang ist nicht kategorisch von der Arbeit geschieden, sondern geht zuweilen in diese über. Warten ist ein Schwellen- und Übergangsphänomen zwischen Müßiggang und Arbeit, kann doch die Passivität von Wartenden abrupt in Aktivität umschlagen. Dies exemplifiziert Benjamin anhand unterschiedlicher Figuren, die alle etwas Verbindendes aufweisen: „Die dem Studenten, dem Spieler, dem Flaneur gemeinsame Spontaneität ist vielleicht die des Jägers, will sagen, der ältesten Art von Arbeit, die von allen mit dem Müßiggang am engsten verflochten sein dürfte.“ („m 5,2“, in: GS V/2, 969) Hier werden wiederum mehrere Vorannahmen und Vermutungen artikuliert, die in historischer und systematischer Hinsicht zu explizieren sind. Historisch betrachtet nimmt Benjamin erstens an, dass die Jagd die ,älteste[.] Art von Arbeit" sei, zweitens mutmaßt er, sie sei „mit dem Müßiggang am engsten verflochten“. Drittens schreibt Benjamin dem Studenten, dem Spieler und dem Flaneur eine „Spontaneität“ $z u$ und vermutet viertens, sie eigne auch dem Jäger. Mit dem Studenten, dem Spieler und dem Flaneur sind die maßgeblichen Figurationen des Müßiggängers angesprochen. ${ }^{55}$

$\mathrm{Zu}$ ihnen finden sich drei weitere Bemerkungen im Konvolut „m“. Benjamin spricht dort von der „imitatio dei“ bzw. „Gottähnlichkeit des Müßiggängers“ (GS V/2, 967) und sinniert über „die ,schlechte Unendlichkeit', die im Müßiggang vorwaltet" (GS V/2, 969). Dabei erwähnt er sowohl Baudelaires Satanismus (vgl. GS V/2, 967) als auch Hegels Theorie der bürgerlichen Gesellschaft (vgl. GS V/2, 969). Die erste dieser ebenso instruktiven wie enigmatischen Bemerkungen bezieht sich auf die soeben genannte ,imitatio dei des Müßiggängers: er verfügt als Flaneur über die Allgegenwart, als Spieler über die Allmacht und

54 Vgl. außerdem Benjamins Bemerkung zum Wartenden und seinem Umgang mit Zeit: „D 3,4“, in: GS V/1, 164.

$55 \mathrm{Zu}$ ergänzen wäre dieses Figurenpanorama durch den Haschisch- bzw. Drogenkonsumenten. Vgl. dazu Benjamins, Drogen'-Protokolle (GS VI, 558-618) und seine MarseilleStädtebilder: „Haschisch in Marseille“, in: GS IV/1, 409-416, und „Myslowitz - Braunschweig - Marseille“, in: GS IV/2, 729-737; dazu Robert Krause, „Des situations de repos et de suspens artificiels. Otium et écriture dans 'la nouvelle d'une ivresse de haschich' de Walter Benjamin“, in: Recherches \& Travaux 88 (2016), 131-140. 
als Student über die Allwissenheit“ („m 4,3“, in: GS V/2, 967). Hier geht Benjamin davon aus, dass der Müßiggänger im Sinne des Alten Testaments (Deuteronomium 13,5) Gott nacheifere. Das Vorbild des Bürgers ist dabei der „Gott des siebenten Tages“, der „die Schöpfung hinter sich [hat]“, so ergänzt die überübernächste Bemerkung („m 4,6“, in: GS V/2, 967). ${ }^{56}$ Flanerie, Spiel und Studium wären demnach religiöse oder quasireligöse Handlungen, die dem Müßiggänger zu den göttlichen Attributen „Allgegenwart“, „Allmacht“ und „Allwissenheit“ verhelfen würden. „Diese Trinität ist im Ursprung des Satanismus bei Baudelaire", schreibt Benjamin anschließend (GS V/2, 967). Er legt also nahe, dass ein genealogischer Zusammenhang zwischen Müßiggang, imitatio dei und Satanismus bei Baudelaire besteht. ${ }^{57}$ Diesem Hinweis, der eine Neuinterpretation von Baudelaires berühmt-berüchtigten Satanismus verspricht, wurde bereits andernorts nachgegangen. ${ }^{58}$ Daher ist hier Benjamins Befund anzuführen, die imitatio dei des Müßiggängers bleibe unvollendet. Keines der drei erwähnten göttlichen Vermögen (Allwissenheit, Allmacht, Allgegenwart) sei für den Müßiggänger erreichbar: „Der Student ,lernt nie aus'; der Spieler ,hat nie genug; dem Flaneur ,gibt es immer etwas zu sehen'. Der Müßiggang hat die Anweisung auf unbegrenzte Dauer, die dem bloßen Sinnengenuß, von welcher Art er auch sei, grundsätzlich abgeht.“ („m 5, I“, in: GS V/2, 969) Die müßige Ewigkeit bleibt unverfügbar, der Genuss temporär. Im Müßiggang waltet ein perennierendes Sollen, das als Mechanismus bereits von Fichte und Hegel benannt wurde. ${ }^{59}$ Dem weiter nachzugehen und mit Blick auf Muße und Müßiggang auch Benjamins Rezeption des Deutschen Idealismus einzubeziehen, erscheint geboten. Zumal Benjamin selbst im zitierten Exzerpt in Klammern die Frage notiert, ob „es richtig“ sei, „daß die ,schlechte Unendlichkeit', die im Müßiggang vorwaltet, als Signatur der bürgerlichen Gesellschaft bei Hegel vorkommt“ („m 5, I“, in: GS V/2, 969). ${ }^{60}$

56 Vgl. GS V/2, 967: „Dieser Gott des siebenten Tages ist es, den der Bürger sich zum Vorbild seines Müßigganges genommen hat. In der flanerie verfügt er über dessen Allgegenwart; beim Spiel über dessen Allmacht und im Studium über seine Allwissenheit.“

57 „Zum Müßiggang“ ist dann auch eine französischsprachige Bemerkung Benjamins im Baudelaire gewidmeten Konvolut „)“ („J 87,9“) der Passagen-Arbeit überschrieben, die an seine Satanismus-Deutung anschließt: „le satanisme de Baudelaire - dont on a fait si grand cas - n'est autre chose que sa façon à lui de relever le défi que la société bourgeoise jette au poète oisif. Ce satanisme n'est qu'une reprise raisonée des velleités destructrices et cyniques, illusoires surtout, qui partent des bas-fonds sociaux." $(G S V / 1,479)$

58 Dazu Robert Krause, „Baudelaires Devianz. ,Die Blumen des Bösen` vor Gericht und in Benjamins Deutungsperspektive“, in: Sergej Taškenov (Hg.), Produktivität der Abweichung. Projektion, Konstruktion, Vermessung, München 2016, 137-153.

59 Vgl. Georg Wilhelm Friedrich Hegel, Wissenschaft der Logik, Werke, Bd. 5, hg. v. Eva Moldenhauer/Karl Markus Michel, Frankfurt a. M. 1979, 151-156.

60 Zur Denkfigur der ,schlechten Unendlichkeit' im epochalen Kontext vgl. Daniel Unger, Schlechte Unendlichkeit. Zu einer Schlüsselfigur und ihrer Kritik in der Philosophie des Deutschen Idealismus, Freiburg 2015. 
Überhaupt gelangen durch das Konvolut „m“neue, in der Benjamin-Forschung bislang kaum berücksichtigte Referenzautoren in den Blick. Etwa Jean-Jacques Rousseau, bei dem Benjamin „[d]ie klassische Beschreibung des Müßiggangs“ findet; komme doch „da ebenso zum Vorschein, daß das Dasein des Müßiggängers etwas göttergleiches hat wie die Einsamkeit als ein wesentlicher Zustand des Müßiggängers zu ihrem Rechte kommt“ („m 4 a, I“, in: GS V/2, 968). Als Beleg wird aus Rousseaus autobiographischen Bekenntnissen, den Confessions (1782/88), zitiert, wo es im letzten Buch (Livre douzième, 1762-1765) heißt:

L'âge des projets romanesques étant passé, et la fumée de la gloriole m’ayant plus étourdi que flatté, il ne me restait, pour dernière espérance, que celle de vivre sans gêne dans un loisir éternel. C'est la vie des bienheureux dans l'autre monde, et j'en faisais désormais mon bonheur suprême dans celui-ci.

Ceux qui me reprochent tant de contradictions ne manqueront pas ici de m'en reprocher encore une. J'ai dit que l'oisiveté des cercles me les rendait insupportables, et me voilà recherchant la solitude uniquement pour m'y livrer à l'oisiveté [...] L'oisiveté des cercles est tuante, parce qu'elle est de nécessité. Celle de la solitude est charmante, parce qu'elle est libre et de volonté. ${ }^{61}$

Nach dem Ende der Romanprojekte hofft auch Rousseau auf ewige Muße („loisir“), das Leben der Glücklichen in einer anderen Welt. ${ }^{62}$ Der Müßiggang („oisivieté") gesellschaftlicher Zirkel sei ihm indes unerträglich geworden, er habe daher die Einsamkeit gesucht, um sich ganz allein dem Müßiggang zu widmen. Letzterer sei frei gewählt, ergo charmant, der gesellige Müßiggang hingegen sei aufgezwungen. Aus Rousseaus zitierter Lebensbeschreibung schlussfolgert Benjamin in der nächsten Bemerkung („m 4 a, 2“):

Unter den Bedingungen des Müßigganges kommt der Einsamkeit ganz besondere Bedeutung zu. Erst die Einsamkeit emanzipiert nämlich das Erlebnis virtuell von jedem, wie auch immer geringen oder dürftigen Ereignis: sie stellt ihm, auf dem Wege der Einfühlung, jeden beliebigen Passanten als sein Substrat bei. Einfühlung ist nur dem Einsamen möglich; darum ist die Einsamkeit eine Bedingung des echten Müßigganges. (GS $V / 2,968)$

Im Anschluss an Rousseaus Unterscheidung zwischen geselligem und alleinigem Müßiggang akzentuiert Benjamin letzteren. Nur der in Einsamkeit erfahrene Müßiggang sei „echter Müßiggang“; denn die Einsamkeit verabsolutiere das Erlebnis, das zu Anfang des Konvoluts als „die Phantasmagorie des Müßiggängers“ definiert wurde („m I a, 3“, in: GS V/2, 962). Neu hinzu tritt hier die Kategorie der Einfühlung, die „nur dem Einsamen möglich“ sei, ihm einen beliebigen Be-

61 Jean-Jacques Rousseau, Les Confessions, texte établi par Bernard Gagnebin/Marcel Raymond, Paris 1973, 756.

62 Auf die Muße in Rousseaus Rêveries du promeneur solitaire geht Thomas Klinkert ein in Muße und Erzählen: ein poetologischer Zusammenhang. Vom „Roman de la Rose“ bis zu Jorge Semprún, Tübingen 2016, 105-114. 
gleiter verschaffe und ihn damit von den „dürftigen“ äußerlichen Ereignissen unabhängig mache $(G S V / 2,968)$. Die Einfühlung erscheint als Rettungsanker in der Not des Lebensüberdrusses: „Wenn alle Stricke reißen, wenn am verödeten Horizont kein Segel, kein Wellenkamm des Erlebens auftaucht, dann bleibt dem vereinsamten, vom taedium vitae ergriffenen Subjekt ein letztes übrig: das ist die Einfühlung.“ („m 4 a, 3“, in: GS V/2, 968) Angesprochen ist damit die Gefahr des Müßiggangs, der zu Ereignislosigkeit und Vereinsamung führen und in Lebensüberdruss umschlagen kann. Als ultima ratio gilt Benjamin die Einfühlung in andere und anderes, denn eine solitäre Beschäftigung wie das Studium befördert die Melancholie. ${ }^{63}$

Mit der Melancholie-Problematik, ebenso wie mit der Figur des Flaneurs und des Sammlers, hat sich Benjamin auch andernorts intensiv beschäftigt. Erinnert sei an das Melancholie-Kapitel aus seinem Trauerspiel-Buch ${ }^{64}$, an den autobiographischen Text über den Umgang mit den Beständen seiner Bibliothek ${ }^{65}$, an seinen 1937 erschienenen Essay Eduard Fuchs, der Sammler und der Historiker (GS II/2, 465-505) und an die Zeugnisse seiner Zusammenarbeit mit Franz Hessel, in dessen Berlin-Texten Benjamin die „Wiederkehr des Flaneurs“ erkannte. ${ }^{66}$ Diese und weitere Texte wären hinsichtlich der Leitfrage nach dem Verhältnis von Muße und Müßiggang neu zu lesen. Doch das kann hier nicht geleistet werden. Stattdessen bleibt ein letzter Teil seines Konvoluts „m“ $\mathrm{zu}$ erwähnen, wo sich aufschlussreiche Äußerungen zum Verhältnis von Ästhetik und Ökonomie finden.

\section{Müßiggang in der Moderne: von Benjamin zu Arendt und Gorz}

Benjamin zufolge basiert der Müßiggang auf der Bereitschaft zum ästhetischen Erlebnis, das nicht mit anderen geteilt, sondern allein genossen wird. Der Müßiggang erscheint ihm in historisch-systematischer Perspektive „als eine Vorform der Zerstreuung oder des Amusements“, er beruhe „auf der Bereitwilligkeit, eine

${ }^{63}$ Das dokumentieren verschiedene Zitate Goethes, Flauberts, Baudelaires und Mallarmés: „Flauberts ,peu de gens devineront combien il a fallu être triste pour entreprendre de ressusciter Carthage 'macht den Zusammenhang des Studiums mit der melencolia transparent. (Diese droht wohl nicht minder als dieser Form der Muße aller des Müßiggangs.) Vgl. ,mon âme est triste et j'ai lu tous les livres' (Mallarmé) Spleen 11, La voix (Baudelaire) „Habe nun ach“ (Goethe).“ („m 5, 3“, in: GS V/2, 969). - Flaubert bezieht sich hier auf die Arbeit an seinem Roman Salombô. Bei dem zitierten Mallarmé-Gedicht handelt es sich um Brise marine, wo es allerdings heißt: „La chair est triste, hélas! et j’ai lu tous les livres.“

64 Vgl. GS I/1, 317-323.

65 „Ich packe meine Bibliothek aus“, in: GS IV/1, 388-396.

66 So lautet der Titel von Benjamins Rezension (GS III, 194-199) von Franz Hessels Buch Spazieren in Berlin (1929). Vgl. dazu den Beitrag Peter Philipp Riedls im vorliegenden Band. 
beliebige Abfolge von Sensationen allein auszukosten“ („m 4, I“, in: GS V/2, 967). Benjamin bestimmt zwar, was auf den Müßiggang folgt („Zerstreuung“, „Amusement"), nicht aber, inwiefern dieser dazu „eine Vorform“ darstellt. Anzunehmen ist, dass Benjamin hier weniger eine Stufe des individuellen ästhetischen Erlebens meint, sondern vielmehr die historische Stellung des Müßiggangs in der Unterhaltungskultur bezeichnet. Darauf deutet zumindest der Fortgang der Bemerkung hin, die eine Zäsur samt Paradigmenwechsel im hochindustriellen Zeitalter konstatiert. Benjamin beschreibt, wie „der Produktionsprozeß große Massen ins Feld zu führen begann" und daraufhin ,,in denen, die ,frei hatten', das Bedürfnis [entstand], sich massenweise gegen die Arbeitenden abzusetzen“. Diesem „Bedürfnis" nach Massenunterhaltung entspreche in der kapitalistischen Moderne "die Vergnügungsindustrie“, die jedoch „alsbald auf ihre spezifischen Probleme“ gestoßen sei. Als besonders problematisch erweisen sich die zunehmend schnellere Taktung und die abnehmende Halbwertszeit von Reizen und Beschäftigungen. Bereits im 19. Jahrhundert bemerkt der Politiker und Kritiker Saint-Marc Girardin (1801-1873) dazu in seiner Vorlesung an der Académie Française: „combien peu de temps l'homme est amusable ${ }^{\text {". }}{ }^{67}$ Benjamin zitiert dessen Befund ohne bibliographische Angabe, kommentiert allerdings in Klammern: „(Der Müßiggänger ermüdet nicht so schnell, wie der Mann, der sich amüsiert.)“ („m 4, I“, in: GS V/2, 967). ${ }^{68} \mathrm{Kraftraubender}$ als der schiere Müßiggang ist demnach das Amüsement, das in der modernen Vergnügungsindustrie auf ihn folgt.

Durch Benjamins zuletzt rekapitulierte Äußerungen kommt die Wirtschaftsund Gesellschaftsordnung, mit der sein Konvolut einsetzte, wieder nachdrücklich in den Blick. „Dahingestellt mag bleiben, ob und in welchem Sinn die Muße von der Produktionsordnung, durch die sie ermöglicht wird, auch bestimmt werde“, so Benjamins Selbstbeschränkung. Verdeutlichen möchte er durch seine Arbeiten hingegen, „wie tief dem Müßiggang die Züge der kapitalistischen Wirtschaftsordnung, in welcher er gedeiht, eingegraben sind “ (,m 4 a, 4“, in: GS V/2, 968). Hier formuliert Benjamin in wünschenswerter Klarheit sein Erkenntnisinteresse: Es geht ihm um den Zusammenhang von Produktionsordnung und Müßiggang. Kurz angesprochen, aber gleich wieder zurückgestellt, wird indes derjenige der Muße. Insofern ist an dieser Stelle nicht zu klären, welche Produktionsordnung zur Zeit der Muße überhaupt bestand. Zu denken ist wohl an das ständisch organisierte Agrar- und Lehnswesen. Fokussiert wird jedoch die „kapitalistische Wirtschaftsordnung", von ihr künde der Müßiggang. Näheren Auf-

67 Charles Labitte, „Historiens littéraires de la France - M. Saint Marc Girardin“, in: Revue des Deux Mondes, Période Initiale, Bd. 9, 1845, 477-515. https://fr.wikisource.org/wiki/ Historiens_litt\%C3\%A9raires_de_la_France_-_M._Saint_Marc_Girardin (abgerufen am 30.07.2015).

68 Vgl. Benjamins Forderung im Konvolut zu Baudelaire: „Der Müßiggänger muß mit Sensationen versorgt werden, der Kaufmann mit Kunden und der kleine Mann mit einem Weltbild.“(„J 90, 3“, in: GS V/1, 484). 
schluss darüber versprechen Benjamins zeitgleiche Studien zu Baudelaire, dem "profundesten Praktiker des Müßiggangs" (GB VI, 271) und dem exemplarischen Lyriker im Zeitalter des Hochkapitalismus, so der Titel von Benjamins begonnenem Baudelaire-Buch.

In den vorliegenden Teilen des Baudelaire-Buchs, aber auch in den Vorarbeiten und natürlich in Baudelaires CEuvre selbst wäre weiter nach der ,Schwelle zwischen Muße und Müßiggang zu suchen. Doch all dies muss einer zukünftigen Studie vorbehalten bleiben, die bestenfalls Benjamins thematisch und epochal ähnlich gelagerte Bemerkungen zu den Pariser Passagen ebenfalls einbezöge; denn auch dieser charakteristische Bautyp des 19. Jahrhunderts ist sozioökonomisch und soziokulturell als Passage zwischen Muße und Müßiggang zu begreifen. In Paris, kurz vor Ausbruch des Zweiten Weltkriegs, trafen sich Benjamin und Hannah Arendt regelmäßig. Ob es bei ihren Gesprächen um Benjamins zeitgenössische Studien zu Arbeit, Muße und Müßiggang ging, ist ungewiss. Doch wird dieses Themenfeld fortan auch Arendt beschäftigen, die 20 Jahre später ihre bekannte Monographie zur Vita activa (engl. 1958) publiziert. ${ }^{69}$ An diese wird wiederum André Gorz' „Kritik der ökonomischen Vernunft“ anschließen..$^{70}$ In der 1980er Jahren entwickelt, bleibt sie in gegenwartsdiagnostischer Absicht ebenso hinzuzuziehen wie seine, in der Auseinandersetzung mit den Studien von Jeremy Rifkin gewonnene Beobachtung, dass im heutigen Hyperkapitalismus „Nicht-Arbeitszeit nicht mehr Zeit für Muße, Besinnung, Genuß und freie Selbsttätigkeit“ ist, sondern „selbst unter Zeit- und Verwertungsdruck" steht. ${ }^{71}$

69 Hannah Arendt, Vita activa oder Vom tätigen Leben, München/Zürich, 2. Aufl. 2003, bes. 98-160 (Kap. 3: „Die Arbeit“) und 318-415 (Kap. 3: „Die Vita activa und die Neuzeit“).

70 André Gorz, Métamorphoses du travail. Quête du sens. Critique de la raison économique, Paris 1988.

71 André Gorz, Vom totalitären Vorhaben des Kapitals, 2001, https://www.freitag.de/ autoren/der-freitag/vom-totalitaren-vorhaben-des-kapitals (abgerufen am 10.09.2015). 



\title{
Mußemöglichkeiten des Lesens und die frühen Gedichte von Samuel Beckett
}

\author{
Jan Wilm
}

In einem Gedicht des polnischen Lyrikers Adam Zagajewski heißt es: „Wenn wir Gedichte ebenso aufmerksam lesen könnten, wie wir die//Speisekarte in einem teuren Restaurant studieren ...". Was genau geschähe, wenn ein Lesen auf diese Weise möglich wäre, bleibt in Zagajewskis Gedicht eine Leerstelle. Der Satz über das aufmerksame Lesen endet mit drei Auslassungspunkten - oder endet deshalb nicht. So mag man geneigt sein, diesen Punkten zu folgen, als wären sie vom Dichter ausgestreute Brotkrumen. Doch sie führen weniger zur Aue der auktorialen Intention, als in die verwilderte Ungewissheit der leserlichen Vorstellung über die Arbeit des Lesens. So gerät der Leser in eine Vorstellung über langsames, aufmerksames Lesen, während er aufmerksam, langsam liest.

Die Aufmerksamkeit und Langsamkeit, von denen Zagajewskis Sprecher beim Lyriklesen träumt, ist im Bild verbunden mit dem Ort des Restaurants, mit Hunger, Worthunger, gewiss einem kulinarischen Antrieb, der den Weg zu Köstlichkeiten verkürzen soll. Die Dynamik hinter diesem Lesen ist eine getriebene und sucht, den Hunger zu stillen. Aber sie ist gewürzt mit einem Paradox, denn sie führt zu Aufmerksamkeit, ist sie doch verbunden mit der Preisklasse des „teuren Restaurant[s]“ in Zagajewskis Gedicht. Die Höhe der Speisepreise bedingt ein gewisses Zögern, ein Zaudern vor der Wahl, die schließlich zu einem Lustgewinn führen soll, ob in der Menükarte oder im Gedichttext. Der Lustgewinn, der am Ende der Auswahl, am Ende des Lesens, steht, ist hier allerdings mit noch etwas weiterem verquickt. Denn es scheint, dass in der Chronologie dieses Satzes, den Zagajewski durch ein hartes Enjambement über zwei Strophen verteilt und somit ästhetisch schon ein minimales Element der Verzögerung einbaut - in der Chronologie des Satzes mündet diese besondere Form der Aufmerksamkeit beim Lesen nicht explizit in der Erfahrung von Sinnlichkeit. Denn am Ende des Satzes erfahren wir, ein Gedicht wird auf diese Weise eben nicht nur gelesen, nein es wird studiert. Oder auch nicht - schließlich endet der Satz nicht in einer Auflösung oder einer Anweisung, sondern läuft aus in die Ellipse. Vielleicht liegt in dieser Ellipse sogar etwas Melancholie, etwas Bedauern,

1 Adam Zagajewski, „Antennen im Regen“, in: Unsichtbare Hand, übers. v. Renate Schmidgall, München 2012, 57. 
dass diese Form des Lesens eben nicht für die Literatur, sondern nur für die Speisekarte reserviert ist.

Lesen als Studieren: aufmerksam, zaudernd, lustvoll. Das hier aufgerufene Moment des langsamen Lesens ist gespeist aus einer Lust, die ihren Ursprung nimmt in einem Gefühl der Hast, und die so verstandene Leselust ist konnotiert mit Eile, befriedigt zu werden, also mit Lektüre gestillt zu werden. Gleichzeitig ist sie in ihrer Auslebung, im Akt des Lesens, paradoxerweise eine mußevolle Lust: Eine nicht sezierende, sondern schwelgende Leselust, nicht unähnlich der von Susan Sontag skizzierten „Erotik der Kunst“" , anstelle einer sterilen Hermeneutik oder der von Vladimir Jankélévitch beschriebenen Lust, in der man ein „Element der Ewigkeit wiederfinde[t]“3, ein Element der Ewigkeit, das hier nicht (nur) transzendent, sondern (zunächst) zeitlich gedacht werden soll. Das Lesen als ein lustvoller, langsamer, studierender Moment, der in den Wirkraum des Wortes „Muße“ vorstößt, betrachtet man es im Kontext seiner etymologischen Wurzeln in der deutschen Sprache als "gelegenheit, freie zeit etwas zu thun“4. Das Restaurantbild Zagajewskis betrachtend, könnte man sagen, das Gedicht erschafft sowohl in der Welt des Textes als auch in der Welt seiner Rezeption ein Moment der Muße, einen Mußeraum, in dem sich Gelegenheit und Freiheit bieten, einen Text langsam zu lesen und lustvoll zu studieren.

Was an diesem Bild reizvoll ist, ist nicht nur die Gelegenheit auf freie Zeit, etwas zu tun, sondern wie sich diese Gelegenheit, diese freie Zeit ergeben, nämlich indem eine Form des Zwangs besteht, etwas zu tun: das Lesen der Speisekarte. Liest man das Gedicht im Kontext moderner oder postmoderner Gehetztheiten, mag sogar die Frage gestellt werden, ob ein Zwang auf Muße besteht, der das Gedicht und die Lektüre antreibt. Das Gedicht entwirft, wörtlich und metaphorisch, einen Raum, der Gelegenheit zur Muße nicht nur eröffnet, sondern scheinbar oktroyiert. Es entsteht, unter der antreibenden Kraft eines Mußezwangs, eine konkrete Mußemöglichkeit, die es erlaubt, lustvoll und langsam zu lesen, wie es der Lyrik im Verständnis von Zagajewskis Gedicht gebührt.

Wie führt die tiefe Aufmerksamkeit, wie bei Zagajewskis Sprecher, zu einem Zögern oder Zaudern, das wiederrum zum lustvollen Studieren eines Textes führen kann? Das oben erwähnte Bedauern aufmerksam ernst nehmend, könnte man auch fragen: Warum wird nicht jeder Text auf diese Weise gelesen? Gewiss, die beschworene beschleunigte Gesellschaft ${ }^{5}$ erschwert das Verweilen in einer

2 Susan Sontag, „Gegen Interpretation“, in: Sontag, Kunst und Antikunst, übers. v. Mark W. Rien, München 1980, 9-18, 18.

3 Vladimir Jankélévitch, Die Ironie, übers. v. Jürgen Brankel, Berlin 2012, 30.

${ }^{4}$ Jacob Grimm/Wilhelm Grimm, „musze“, in: Deutsches Wörterbuch, http://woerterbuchnetz.de (abgerufen am 10.05.2016).

${ }^{5}$ Exemplarisch seien hier die Arbeiten des Soziologen Hartmut Rosa genannt, besonders Beschleunigung. Die Veränderung der Temporalstrukturen in der Moderne (Frankfurt a. M. 2005). Während Rosa eine gesellschaftliche Veränderung der gelebten Zeit diagnostiziert, reflektiert der Philosoph Byung-Chul Han in Der Duft der Zeit. Ein philosophischer 
mittelalterlichen accedie, auf Steinen sitzend darüber nachzusinnen, wie man auf der Welt zu leben habe, oder bei einsamen Spaziergängen in romantische Träumereien zu versinken. Die Akzeleration des privaten und beruflichen Lebens führt aber vielleicht nicht nur zum Verlust von nachdenklicher Mußezeit, sondern auch zum Verlust einer Muße des Lesens, eines langsamen, gelassenen, meditativen Nachdenkens über den literarischen Text. ${ }^{6}$ Vielleicht aber ist gerade die moderne, akzelerierte Gesellschaft jene, die am meisten Mußeräume und Mußemöglichkeiten bietet, da die Muße auf zwanghafte Weise erlösend wirkt, da Zeiten der Beschleunigung und Entzeitlichung die Empfindung von Dauer ${ }^{7}$ erschweren, sie aber gerade deshalb nicht nur möglich, sondern lebensnotwendig machen. Während die Welt zu rasen scheint oder entleert wirkt, bedarf es der „Sammlung des Geistes“, wie Tobias Keiling mit Verweis auf eine Enzyklopädie des 19. Jahrhunderts die Muße zu fassen versucht. ${ }^{8}$

Versteht man das Denken während des Lesens als einen meditativen Zustand, so wird die meditative Dimension des Lesens dann unmöglich, wenn das Lesen zum reinen Zweck zerfällt, oder deutlicher zu einem Zweckmittel, indem man den Akt, die Techniken und sogar die Methoden des Lesen nur als zu überwindende Trittsteine auf dem Weg zur Bewältigung, auf dem Weg zum Ende des Lesens, betrachtet. Die Dauer mit dem Text wird vernachlässigt, der Text wird entzeitlicht, wird durchrast, bis man an sein Ende gelangt. Konzentrierte man sich auf das Lesen in einem philologischen Kontext, könnte man kulturpessimistisch diagnostizieren, man lese heute vermehrt mit Kalkül, man lese instrumentell, auf den Artikel schielend, der seit Wochen abgeschlossen sein sollte, ein Lesen hingeordnet auf die Anforderungen des Lehrdeputats, schlimmstenfalls ein Lesen für den Drittmittelantrag, der mit lebhaften Beispielen aufgefüttert werden muss. Kurzum und mit Zagajewski im Sinn, als läse man einen literarischen Text nicht wie die Speisekarte eines teuren Restaurants, sondern wie das Tagesmenü in der zu kurzen Mittagspause; als läse man ein Kochbuch und die Gäste sind schon auf dem Weg. Das Lesen, das immer zu spät liest.

Essay zur Kunst des Verweilens (Bielefeld 2009) - explizit gegen Rosa - über eine Veränderung der Wahrnehmungsparameter von Zeit in der Moderne, die ein Empfinden von beschleunigtem Leben akut spürbar macht.

${ }^{6}$ In meiner Studie zum Werk J. M. Coetzees, The Slow Philosophy of J. M. Coetzee (London/New York 2016) ist es das meditative, gelassene Moment, das sich im langsamen Lesen gegen eine instrumentelle Hermeneutik richtet und im dauerhaften Verweilen im Text über neue Denkmöglichkeiten über die jeweilige Lektüre und über das Lesen zu eröffnen versucht.

7 Nach Han wurde die Empfindung von Dauer in der modernen Gesellschaft erschwert und führte gar zu einem Gefühl der Entzeitlichung. Am Beispiel von Prousts Marcel der Recherche ist es der kurze Moment des Kostens vom Madeleine der Erinnerung, das ein unmittelbares Gefühl von Zeitlichkeit zurückgibt: „Prousts Strategie der Dauer lässt die Zeit duften" (Han, Der Duft der Zeit, 49).

8 Vgl. Tobias Keiling, „Glossar: Muße“, in: Muße. Ein Magazin, 1 (2015), DOI: 10.6094/ musse-magazin/1.2015.48. 
Für einen Moment noch den beschleunigten gesellschaftlichen Kontext auf die akademische Welt verengt, könnte man fragen, ob überhaupt noch Gelegenheit und Freiheit bestehen, einen literarischen Text langsam, mußevoll und nicht instrumentell zu lesen? Ob es vielleicht mehr und mehr unmöglich wird, den Leseprozess für den beruflich behandelten Text so zu verlangsamen, dass man den Text intensiv studiert? Ob es vielleicht sogar unmöglich wird, ein versunkenes Lesen durchzuführen, weil es keinen Raum mehr hat und der Text in verknappten Zeiträumen auf diese Weise nicht erfahren werden kann? Wäre die These der Unmöglichkeit des nicht-instrumentellen Lesens in den heutigen Geisteswissenschaften dann nichts als das ironische Paradox im überraschenden Ende einer O. Henry-Kurzgeschichte, da die berufliche Auseinandersetzung mit Literatur einen Arbeitsraum erzeugt, der es verhindert, sich beruflich mit Literatur auseinanderzusetzen auf eine Weise, die Friedrich Nietzsche das "gute“ Lesen genannt hat?9 Sollte man also allen angehenden Literaturnarren und Textliebhabern raten, bloß keine Philologen zu werden, weil die berufliche Beschäftigung mit Literatur in einem Kontext geschieht, der sich immer lesefeindlicher, immer unphilologischer, weil beschleunigter darstellt? Und war es für alle bereits gewesenen Philologen umsonst gewesen, Philologe geworden zu sein?

Nietzsche sagt Nein: „Man ist nicht umsonst Philologe gewesen, man ist es vielleicht noch, das will sagen, ein Lehrer des langsamen Lesens. "10 Welche weiteren Qualitäten und Techniken Nietzsche den Philologen zuschreiben möchte, bleibt in seiner Vorrede zu Morgenröte verhüllt und erlaubt es, darüber zu reflektieren, was das langsame Lesen als Ideal mußevoller, lustvoller, meditativer ${ }^{11}$ Versenkung bedeuten könnte. Das langsame Lesen, von dem hier die Rede ist, ist ein Lesen, das sich dem Text auf eine ethische Weise unterwirft, den Text nicht mit den Messern der Hermeneutik des Verdachts zu sezieren versucht, ihn überwinden oder unterlaufen möchte, kein Lesen, das den Text meistern, sondern ein Lesen, das mit dem Text gemeinsam zu arbeiten sucht. Die langsame, achtsame Lesehaltung ist nicht unähnlich der unterwürfigen Einstellung von Rilkes Malte, wenn er resigniert konstatiert: „So ist mir klar geworden, daß ich

9 Friedrich Nietzsche, „Morgenröte“, in: Sämtliche Werke. Kritische Studienausgabe (=KSA), Bd.3, hg. v. Giorgio Colli/Massimo Montinari, München 1999, 9-332, 17.

10 Nietzsche, „Morgenröte“, in: KSA 3, 17.

11 Die Trias aus mußevoll - lustvoll - meditativ, die eine langsame Lektüreerfahrung durchwirkt, wurde in meiner Arbeit zu Coetzees Euvre mit Hilfe von phänomenologischen Zugängen zum literarischen Werk entworfen. Besonders das Moment des Meditativen wurde, in seiner begrifflichen und philosophischen Anlehnung an Martin Heideggers Unterscheidung zwischen einem rechnenden (instrumentellen) und besinnenden (meditativen) Denken in Gelassenheit (Pfullingen 1960), als ein tiefes, besinnliches, langsames und philosophisches Nachdenken über den Text und die Erfahrung des Textes während des Leseprozesses beschrieben. Vgl. Wilm, The Slow Philosophy of J.M. Coetzee, 10-13. 
nie ein richtiger Leser war"12, während sein empfindsamer Umgang mit Büchern und Literatur seine Aussage widerlegt. Das langsame Lesen ist ein Lesen des Hingebens und Hinnehmens, was nicht bedeutet: ein naives oder blindes Lesen. Im Gegenteil, das langsame, mußevolle Lesen ist ein Lesen, das sich dem Text ausliefert, bestückt mit den Werkzeugen der phänomenologischen Genauigkeit und durch diese eine tiefe Verinnerlichung des Textes bewirkend, eine „Erotik der Kunst“ ${ }^{13}$ Gleichzeitig ist es ein Lesen, das wach ist, das sich nicht passiv ergibt, sondern kritisch folgt, immer bedacht auf Entdeckung und Überraschung. Ein Lesen, das einlädt abzudriften, Assoziationen und intertextuellen Verzweigungen gelassen nachzuspüren, wie den Brotkrumen in der zuvor bemühten intertextuellen Abzweigung in den Märchenwald - und, es ist zu wünschen, mit besserem Ausgang.

Vielleicht gibt es dieses alles in sich aufsaugende Lesen, wie Nietzsche es sich vorstellte, jene von ihm geforderten „vollkommene[n] Leser"14, nur als Ideal. Aber vielleicht genügt die Ideal-Bewegung als gemächlicher Antrieb, darüber nachzusinnen, wie man eigentlich liest, zu welchem Zweck, mit welchem Ziel, oder ob als Reaktion gegen Ziel und Zweck. In der Vorrede zu seinem 1886 verfassten Buch lobt Nietzsche die Philologie als ,jene ehrwürdige Kunst, welche von ihrem Verehrer vor Allem Eins heischt, bei Seite gehen, sich Zeit lassen, still werden, langsam werden. "15 Die Grundzüge der Philologie sind aber nicht nur das sorgsame und langsame Umgehen mit Schriften und Texten, die „Goldschmiedekunst und -kennerschaft des Wortes"16, sondern auch die Reflexion über diesen Umgang mit Text und Schrift, ob langsam oder ganz anders. Man wird also kein schlechterer Philologe, wenn man presto liest und nicht sofort ein besserer, wenn man lento liest, wie Nietzsche empfiehlt. Man könnte sogar sagen, dass die veränderten Kontexte und Verfahren der Literaturwissenschaft in einem hastigeren Zeitalter vielleicht produktive Brandbeschleuniger für die Reflexion über die philologischen Grundbedingungen und Verfahren darstellen könnten. Wie Carlos Spoerhase darlegt, gehörte das schnelle Lesen, das selektive Lesen, das Auslassen, das rasche Durchblättern eben auch (und immer schon) zur Arbeit und Technik der Philologie, wie auch die Idee eines Durchkauens von Texten, was bereits mittelalterliche Mönche als stilles, versunkenes Lesen beschrieben haben. ${ }^{17}$ So könnte man also die reale oder empfundene Beschleunigung der Räume der Philologie betrachten als einen willkommenen Umstand

12 Rainer Maria Rilke, Die Aufzeichnungen des Malte Laurids Brigge, Frankfurt a. M. 2000, 158 .

13 Sontag, „Gegen Interpretation“, 18.

14 Nietzsche, „Morgenröte“, in: KSA 3, 17.

15 Nietzsche, „Morgenröte“, in: KSA 3, 17.

16 Nietzsche, „Morgenröte“, in: KSA 3, 17.

17 Carlos Spoerhase, „Lese lieber ungewöhnlich“, in: Frankfurter Allgemeine Zeitung, 03.11.2015, N4. 
für eine notwendige Reflexion über und eine produktive Reaktion durch das "gute Lesen“.

Für Nietzsche ist das gute Lesen ausschließlich „langsam, tief, rück- und vorsichtig, mit Hintergedanken, mit offen gelassenen Thüren“, ein Lesen „mit zarten Fingern und Augen " ${ }^{18}$ Aus heutiger Perspektive und durchaus reduktiv betrachtet, klingt Nietzsches essentialistische Beschreibung des guten Lesens wie bloß einen Schritt weit entfernt von romantischen, einseitigen und reaktionären Diskursen, in denen Achtsamkeit, Sorgsamkeit und Langsamkeit um jeden Preis und in allen Lebenssparten zelebriert werden.

Jedoch ist das soziologisch Interessante an den realen Ausformungen des so genannten slow movements gerade die darin enthaltene Reaktion. Langsamkeit wird hier nicht als etwas Inhärentes verstanden, sondern meist als etwas Verlerntes, das es zu reanimieren gilt in Zeiten, die als schnell wahrgenommen und beschrieben werden. Das Ironische ist, dass sich die reaktionäre Huldigung von Langsamkeit gegen eine Welt richtet, die als ausschließlich beschleunigt verstanden wird, und es scheint, sie wird ausschließlich so verstanden, weil sie nur selektiv betrachtet, nicht sorgsam analysiert, nicht genau - oder eben nicht langsam gelesen wird.

Ein langsames Lesen sollte nicht primär zeitlich verstanden werden, sondern im Sinne eines philosophischen Verständnisses von Gelassenheit, philologischer Genauigkeit und einer mußevollen Haltung der Reflexion gegenüber dem Text. Diese Vorstellung des langsamen Lesens ist durchaus verwandt mit Nietzsches gutem Lesen. Langsam ist in diesem Verständnis - und vielleicht in Nietzsches Verständnis - nicht zu betrachten als eine direkte, gerichtete Reaktion - gegen eine schnelle Zeit, gegen ein rasches Überfliegen des Textes -, nein, langsam ist zu verstehen als eine reflexive, meditative Rezeptionshaltung auf etwas zu, nämlich auf den Text. Mit diesem Verständnis verändern sich die etymologischen Wurzeln von Rezeption nur auf den ersten Blick, denn das lateinische recipere, aufnehmen, das zunächst eine Bewegung vom Text auf den Rezipienten impliziert, bedeutet in einem Verständnis des Annehmens eben auch ein (ethisches) Zugehen auf den Text. ${ }^{19}$

Doch es ist durchaus nützlich, allgemeiner zu fragen, ob die Vorstellung eines guten Lesens als langsames Lesen nur von soziokulturellen Kontexten des Rezipienten geprägt sein muss, ob ein langsames Lesen überhaupt in Verbindung gebracht werden muss mit akzelerierten Bedingungen des Lebens des Lesers? So wie Muße vielleicht nicht nur von äußerlichen, zeitlichen Bedingungen des Reflektierenden abhängig gemacht werden muss, sondern, wie Burkhard Hasebrink und Peter Philipp Riedl formulieren, als eine „Freiheit von den Zwängen

18 Nietzsche, „Morgenröte“, in: KSA 3, 17.

19 Lat. receptio, Aufnahme; lat. recipere, aufnehmen, annehmen. 


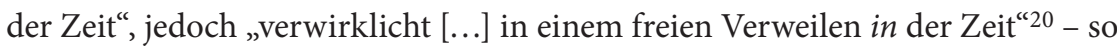
ist langsames Lesen vielleicht nicht ausschließlich bedingt durch langsame Lesebedingungen, langsame Leseräume; so ist, nach dem hier skizzierten Verständnis, langsames Lesen auch nicht als eine rückwärtsgewandte Reaktion gegen eine beschleunigte Philologie anzusehen, sondern als eine Facette des philologischen Spektrums, eine Technik und ein Modus unter vielen, aus denen man à la carte wählen kann, als wähle man aus der „Speisekarte in einem teuren Restaurant“. ${ }^{21}$

Unter den Vorzeichen dieser skizzierten Beschreibungen und geprägt durch Nietzsches Bemerkungen über ein gutes Lesen, ist es produktiv etwas weiter zu spazieren und über ein langsames Lesen zu träumen, wenn man diese Träumereien in aktuellen Diskursen von Lektüremodellen und Lesemethoden in der Literaturwissenschaft ausreflektiert. Vor allem im angloamerikanischen Bereich sind derzeitige Reflexionen über das Lesen hier von Bedeutung, von Franco Morettis distant reading ${ }^{22}$, über Derek Attridges Vorschlag des literal reading ${ }^{23}$ hin zu Stephen Best und Sharon Marcus' Idee eines surface reading 24 .

Während die geläufige Lektüremethode des close reading eine präzise und analytische Nähe zu Text oder Textteilen impliziert, und mit dieser Nähe möglicherweise eine notwendige Langsamkeit der Auseinandersetzung, wirkt Franco Morettis distant reading nicht nur terminologisch wie ein Gegenentwurf zur habituellen Nähe des close reading. In seinen quantitativen Untersuchungen konzentriert sich Moretti nicht auf eine einzelne Passage oder auch nur einen einzelnen Text, nicht einmal auf ein einzelnes Euvre, sondern bisweilen in einer einzelnen Analyse auf bis zu 7000 verschiedene Romane, genauer Romantitel. Moretti wählt statt der myopischen Sicht auf Texte eher eine weite Vogelperspektive, die es erlaubt, weniger mikroskopisch die Gemachtheit eines Textes zu betrachten als landkartenartig Verbindungen zwischen gewaltigen Textmengen $\mathrm{zu}$ erkennen und zu analysieren. Man könnte fragen, ob das distant reading im Vergleich zum close reading „schneller“ genannt werden könnte, wenn „schneller" hier bedeutete, dass größere Textmengen verarbeitet werden, als sie es bei gleicher Analysezeit in einem close reading getan werden könnten. Man könnte den Begriff der Schnelligkeit aber auch von seiner rein zeitlichen Bedeutung lösen und Schnelligkeit metaphorisch verstehen, als etwas, das kursorisch, unaufmerksam oder ungenau vorgeht. Hier merkt man allerdings, wie schnell ein derartig segregierter und also hierarchischer Vergleich zwischen close und distant

20 Burkhard Hasebrink/Peter Philipp Riedl, „Einleitung“, in: Hasebrink/Riedl (Hg.), Muße im kulturellen Wandel. Semantisierungen, Ähnlichkeiten, Umbesetzungen, Berlin/ Boston 2014, 11; Herv. i. O.

21 Zagajewski, „Antennen im Regen“, 57.

22 Franco Moretti, Distant Reading, London/New York 2013.

${ }^{23}$ Derek Attridge, J. M. Coetzee and the Ethics of Reading. Literature in the Event, Chicago 2004.

${ }^{24}$ Stephen Best/Sharon Marcus, „Surface Reading. An Introduction“, in: Representations 108/1 (2009), 1-21. 
reading an seine Grenzen gerät, obschon sicherlich anzumerken ist, dass Moretti durch seine polemische Begriffswahl diesen Vergleich natürlich provoziert. Man sollte aber nicht vergessen, dass Morettis distant reading ein deutlich anderes Erkenntnisinteresse verfolgt als das close reading, da es versucht, feststehende Kanongrenzen zu erodieren, indem ein einzelner Text nicht isoliert von seinen materiellen und soziokulturellen Nachbartexten betrachtet wird. Das distant reading stellt unter anderem die interessante Frage, ob der mikroskopische Blick der bessere Blick ist und gutes Lesen bewirken kann, obwohl er durch seine Nähe ein myopischer Blick sein muss.

So ist der Impetus hinter dem distant reading ein sorgsamer, sogar ein ethischer, denn er verengt seine Konzentration nicht auf den Kanon, sondern öffnet ihn dezidiert über diese Grenzen hinaus. Und selbst wenn man Morettis Methode als schnell betrachten möchte, ließe sich fragen, ob diese Schnelligkeit nicht auch eine tiefere Aufmerksamkeit generieren könnte, gerade weil weniger Zeit für einen individuellen Text bleibt, so wie man versucht, genauer hinzusehen, wenn man auf Reisen an einem Ort ist, den man bald wieder verlassen muss, vielleicht für lange Zeit, vielleicht für immer.

Dennoch wirkt eine Reihe aktueller Lektüremethoden intuitiv aufmerksamer, langsamer, ethischer als Morettis Methode, zum Beispiel das literal reading oder das surface reading. Ethisches Lesen ist in diesen Kontexten kein Modus, der aus den literarischen Texten ethischen Gehalt herausfiltert, sich mit ethischen Fragen auf der Ebene des Plots beschäftigt oder literarische Texte als moralischen Kompass gebraucht. Im Gegenteil, ein ethisches Lesen ist in diesem Sinne das Lesen, was einen Text nicht derart unterlaufen oder ausplündern will. Der Text ist kein Steinbruch, aus dem Material für ein zu bauendes Argument gehoben wird, und der Text ist kein Pferd, auf das man eine Theorie heraufsattelt, um es an einen Ort zu reiten, an dem es vielleicht nicht sein will. Die Lesemethoden, die hier als ethisch und langsam beschrieben werden, sind jene, die nicht „symptomatisch“ "lesen ${ }^{25}$, die nicht versuchen, sich instrumentell auf ein Ziel hinzuordnen, die nicht „lesen-mit" und nicht „lesen-für", sondern lediglich lesen als Verweilen im Lesen, mit Fokus nur auf den Text und auf alles, was sich im meditativen Dialog zwischen Text und Leser langsam entfaltet, vielleicht etwa wie die japanischen Papierblumen von Prousts Marcel in ihrem Wasser.

Alles, was ein Text beinhaltet, ist zugegeben eine komplexe Kategorie, und eine, der sich Attridge sowie Best und Marcus in verschiedenen Arbeiten theoretisch stellen, wenn sie sich gegen symptomatisches Lesen positionieren: in Attridges Fall gegen allegorische Lesarten, die den Leser vom Text wegführen zu etwas Anderem, etwas Ungesagtem, etwas auf der Textoberfläche nicht Erkennbarem. Attridges literal reading, also das wörtliche Lesen, entfaltet sich unter anderem am Beispiel von Tieren in J. M. Coetzees Romanen, besonders den Hun-

25 Best/Marcus, „Surface Reading“, 2. 
den des Romans Disgrace von 1999 (Schande). Attridge konstatiert, wir bewegen uns nicht auf den Text zu, sondern entfernen uns auf unproduktive Weise vom Text, wenn wir beispielsweise argumentieren, die Hunde des Romans stünden allegorisch für ausgegrenzte Akteure in der Diegese, etwa Schwarze und Farbige in den sozial noch fortwirkenden Rassengrenzen des post-Apartheid Südafrika. Wir sollten beachten, dass die hier verwendete Rhetorik von Nähe und Ferne auf einer anderen Ebene angesiedelt ist, als jene von Moretti. Moretti argumentiert ebenfalls nicht für ein Lesen, das den Text unterläuft oder derartig dekonstruiert, bis bald alles für alles andere stehen kann. Seine Distanz ist eine Distanz, die ein unverstelltes, genaues Beobachten ermöglichen soll. Es ist auch zu beachten, dass Morettis Ansatz in seiner Hinwendung zum soziologischen Beschreiben von Textkonstellationen bisweilen eher nicht-interpretativ ist, während Attridges Position sich eher hermeneutisch ausgestaltet.

Attridges wörtliches Lesen plädiert für ein Verweilen mit dem Text auf der wörtlichen Oberfläche des Textes, on the surface, ein Lesen also, das dem surface reading von Best und Marcus ähnlich ist, denn die beiden Methoden verbindet, dass sie sich entschieden gegen eine Hermeneutik des Verdachts und somit gegen eine Oberflächen- und Tiefenmetaphorik richten, nach der die „wahren“ Aussagen eines Textes, die „eigentlichen“ Interpretationen, in der Tiefe gesucht und gehoben werden müssen. Bei einem solchen symptomatischen Lesen wäre die Oberfläche des Textes eben lediglich als Symptom anzusehen für die verborgenen Schätze (oder da man von Symptom spricht, für die verborgenen Krankheiten), die mit triumphaler Geste enthüllt werden, wenn man den Vorhang wegzerrt, wie jenen, der den Zauberer von Oz verdeckt, dann allerdings nicht nur Enthüllung, sondern auch Enttäuschung bringt.

Vielleicht ist gerade die Literatur der Moderne, mit ihren formalen und inhaltlichen Experimenten sowie ihrer gleichzeitigen Inwendung und Infragestellung des Subjekts, jene Literatur, die allzu raschen oder abschließenden hermeneutischen Enthüllungen und Enttäuschungen vorbeugt; vielleicht ist es die Literatur der Moderne, die sich, in einen verzierten Vorhang der Ambiguitäten gekleidet, vor einem instrumentellen Lesen, einem Wegzerren der verhüllenden Form, bewahrt. Dies ist besonders in den Arbeiten der großen europäischen high modernists - James Joyce, Virginia Woolf und Samuel Beckett - zu erkennen, deren Werke von radikalen Versprachlichungen der inneren, gedanklichen Vorgänge rasche Verkürzungen durch Paraphrase sowie auflösende Interpretationen mit den literarischen Techniken der Moderne komplizieren oder gar unmöglich machen.

Gerade weil Joyces Ulysses (1922), Woolfs To the Lighthouse (1927) oder Becketts Watt (abgeschlossen 1948; publiziert 1953) ihre Komplexität von Assoziation, Fragmentierung, und Wiederholung offen am Revers tragen - in Joyces Finnegans Wake (1939) sind sie auf die Spitze getrieben -, stellt die Lektüre solcher Texte explizite Mußemöglichkeiten dar, indem sie ein langsames Lesen 
provozieren oder sogar erzwingen. Paradoxerweise scheint der Antrieb während der Lektüre dieser Romane ein hermeneutischer zu sein, man möchte verstehen, interpretieren, während die Texte sich kontinuierlich gegen dieses Verstehen sperren und einen anderen Zugang erfordern. In einem mußevollen, langsamen Lektürezugang ermöglichen die Texte durch ihre Komplexität, ihre Assoziations- und Deutungsvielfalt eine Überwindung des hermeneutischen Drangs nach Verstehen. So meint Seamus Deane in einer Einführung zu Finnegans Wake gleich zu Beginn:

The first thing to say about Finnegans Wake is that it is, in an important sense, unreadable. In order to pay it the attention it so impertinently and endlessly demands, the reader must forego most of the conventions about reading $[\ldots] .{ }^{26}$

Es ist speziell das Komplexe, das Ambige, gar das Obskurantistische an Joyces Werken, was parallel zu ihm sowie im Nachgang dieses Riesen der Moderne auch in vielen weiteren Werken des Modernismus erkennbar ist. So sind besonders die frühen Texte Samuel Becketts noch stark den Joyces'schen Werken nachgebildet. Der bisweilen undurchdringliche Frühstil Becketts ist am deutlichsten in seinen frühen Gedichten erkennbar. Die lyrische Hochphase des Zeitgenossen und Bekannten von Joyce ist anzusiedeln in den späten 1920er und besonders den frühen 1930er Jahren, bevor Beckett 1936 seinen ersten (publizierten, aber zweiten verfassten) Roman Murphy veröffentlicht. Obschon Murphy durchaus stark von Joyce geprägt ist, besonders vom Joyce der Dubliners (1914) und des Ulysses, setzt mit Murphy eine Phase der Befreiung von Joyces Über-Einfluss auf Beckett ein, die nach dem Abschluss des letzten Romans in englischer Sprache, Watt, und mit dem ersten Roman auf französisch, Molloy (1951), ihren Abschluss findet. ${ }^{27}$

Wie Joyces Ulysses und Finnegans Wake, aber ganz anders als Joyces eher realistisch geprägte Gedichte, zum Beispiel in Pomes Penyeach (1927), so ist Becketts frühes Gedichtwerk ein manischer Assoziationsapparat, sein erstes Gedicht Whoroscope (1930) beinhaltet gar ein Kommentarverzeichnis, das im Umfang an T. S. Eliots Notizen zu The Waste Land (1922) erinnert, doch häufig weniger Schlaglichter der Erläuterung als weitere Nebelkerzen darstellt. Wie die Ästhetik von Finnegans Wake bietet Becketts frühe Lyrik eine Form der Literatur, die auf den ersten Blick unlesbar erscheint, auf den zweiten - also schon langsameren - Blick allerdings eine ähnliche Überwindung oder Infragestellung habitueller Lektüremodi möglich macht.

26 Seamus Deane, „Introduction“, in: James Joyce, Finnegans Wake, London 1992. vii-xlvii, vii.

27 Unter der Forschungsflut zu den Einflüssen von Joyce auf Beckett seien hier exemplarisch nur zwei genannt, die frühe Monographie von Barbara Reich Gluck Beckett and Joyce. Friendship and Fiction (Lewisburg/London 1979) sowie der kritische Sammelband In Principle, Beckett is Joyce (Edinburgh 1994), herausgegeben von Friedhelm Rathjen. 
Es soll im Folgenden versucht werden, nicht der Versuchung zu verfallen, die oben skizzierten Ideen, Fragen und Thesen dem Dichter auf den Rücken zu schnallen und ihn, wie in dem zuvor erwähnten Bild des Pferdes, mit der Peitsche der Argumentation, an textfremde Orte zu jagen. Im Gegenteil, die Ideen eines langsamen, mußevollen Lesens sollen nicht als Anwendung auf Beckett verstanden werden, sondern ein Zugehen-auf, ein Verweilen-mit einigen von Becketts Gedichten darstellen. Nicht Beckett-mit-Attridge, oder Beckett-mit-Bestund-Marcus, sondern Beckett-mit-Beckett. Die Ideen von Langsamkeit und Verweilen in Becketts Lyrik sollen aufgenommen werden und so gelesen werden, wie die Texte es selbst andeuten.

Zunächst erwächst diese Andeutung aus der inhaltlichen Ebene. Wie Becketts gesamtes Werk aus Theaterstücken, Romanen und Erzählungen, so sind auch seine Gedichte geprägt von Momenten der Langsamkeit und Behäbigkeit, die oft aus Einsamkeiten und Verletzungen des Subjekts entstehen. So heißt es in dem Gedicht „Cascando“ von 1936: „die Stunden da du fort bist sind so bleiern/ zu früh fangen sie immer an zu schleppen“. ${ }^{28}$ Aber Becketts Lyrik ist ebenso gesättigt mit schwelgendem Spazieren und mußevollem Träumen. Die Figuren, die Becketts Welten bevölkern, sind geprägt von dynamic stillness, dynamisiertem Stillstand, in Mary Brydens treffendem Begriff ${ }^{29}$, ein paradoxes Treiben des Geistes bei körperlicher Ruhe, nicht unverwandt mit Rousseaus Schweifzügen des Denkens, während er sich in seinem Boot „vom Willen des Wassers treiben“"30 lässt über den Bieler See in der fünften Träumerei.

Es finden sich in Becketts Euvre zwei Gedichte mit dem Titel „Enueg“. Enueg ist eine poetische Form der Troubadourlyrik und weist eine etymologische Verbindung zu ennui auf. ${ }^{31}$ Und ennui, auf eine beschwerende aber auch schwelgende Weise, ist Teil des Inhalts der Gedichte. In dem Gedicht „Enueg II“ von 1931 finden wir eine Figur nach einem langen Spaziergang erschöpft auf der O'Connell-Brücke in Dublin herumliegend und auf beinahe romantische Weise einige Tulpen betrachtend, die „Tulpen des Abends [...]/die grünen Tulpen“.32 Wie in „Enueg II“ hat man häufig das Gefühl, Becketts Figuren begäben sich auf lange Wanderschaften und Fahrradtouren - das Fahrrad ist ebenfalls ein beliebtes Bild für das bewegte Stillsitzen bei Beckett -, mit dem Ziel, körperliche

28 Samuel Beckett, Gedichte, übers. v. Eva Hesse/Elmar Tophoven, München 1977, 49. Einige, aber bei weitem nicht alle, Gedichte Becketts haben eine deutsche Übertragung erfahren. Die Auswahl des englischen Originals oder der deutschen Übersetzung erfolgt hier, aus rezeptionsästhetischer Sicht, mit Blick auf ihre Dienlichkeit für die Argumentation.

29 Mary Bryden, „Beckett and the Dynamic Still“, in: Samuel Beckett Today/Aujourd'hui 14/1 (2004), 179-92, 182.

30 Jean-Jacques Rousseau, Träumereien eines einsam Schweifenden, übers. v. Stefan Zweifel, Berlin 2012, 135.

31 Chris Ackerley/S. E. Gontarski, The Grove Companion to Samuel Beckett: A Reader's Guide to his Works, Life, and Thought, New York 2004, 179.

32 Beckett, Gedichte, 19. 
Erschöpfung zu suchen, um den Geist zu erwecken. Ein häufiges Motiv Becketts ist die von Aristoteles stammende, in Dantes Inferno auftauchende Trope des stillsitzenden Körpers, der sitzend und ruhend, sedendo et quiescendo - wie eine Kurzgeschichte Becketts betitelt ist - Klugheit und Weisheit erlangt. ${ }^{33}$ Beckett, der zu Beginn seines Romans Murphy seinen gleichnamigen Helden an einen Schaukelstuhl fesselt - wieder stillsitzende Bewegtheit -, um das geistige Leben zu dynamisieren, sich zum Schwelgen, zur Muße zu zwingen, versuchte in verschiedensten Werken eine Überwindung des cartesischen Dualismus zu inszenieren und den Geist durch Ausschaltung der körperlichen Bewegung zu aktivieren. Deshalb finden wir so häufig Sitzende, Liegende, langsam Schlurfende und erschöpft Stillstehende in Becketts Kosmos vor.

Besonders in seinen frühen Gedichten - die frühe Phase ist nach dem zweiten Weltkrieg und mit Beginn der großen Trilogie der Romane Molloy, Malone Dies, Der Namenlose (1951-1953) als beendet anzusehen - findet diese Inszenierung der Dualismusthematik Niederschlag, und vielleicht erscheint durch die Problematisierung der Bewegung des Körpers eine Inszenierung derselben häufig gerade auf inhaltlicher Ebene. In dem Gedicht „Enueg I“ (1931?) heißt es beispielsweise: „Ich trudle dahin, rasch nun auf meinen kaputten Füßen“. ${ }^{34}$ Die körperliche Zerbrechlichkeit und das apodiktische Bewusstwerden des begrenzten Körpers erzeugen oft das Spannungsfeld zwischen Stillstehen und Bewegen, zwischen nicht weiter können und weiter müssen, und die körperliche Eingeschränktheit, die Beckett schon früh mit ausgestoßenen Vagabundenfiguren assoziiert, wird sich über Warten auf Godot (1952) bis in sein Spätwerk hin fortsetzen. Die Figuren in Becketts frühen Gedichten sind einerseits geprägt von einem Goethe'schen, wie Beckett es nannte, „on and up“35, einem Bewegungsimpetus à la „Wer immer strebend sich bemüht,/Den können wir erlösen“, wie die Engel in Faust II rufen ${ }^{36}$; anderseits sind Becketts Figuren geprägt von Einflüssen der Mystik und sehr zugeneigt einer Hinwendung zur vollkommenen Passivität und Rezeptivität, so dass es gelingt, sich nur nach innen wenden zu können.

Die langsamen Bewegungen bei meditativem Denken und Schwelgen der frühen Gedichte werden in späteren Texten transformiert in ein stillgelegteres Sein, ein enttäuschtes, aber auch gelassenes Existieren. Doch schon in den frühen Gedichten findet auf inhaltlicher Ebene eine Inszenierung von Langsamkeit statt in der von Becketts Figuren empfundenen Erdenschwere, die vom existenziellen Makel des Daseins ausgeht. Becketts Figuren stimmen sehr der Diagnose von Sophokles in Die Trachinierinnen (vor 442 v. Chr.) zu, dass es besser wäre, nie geboren worden zu sein, aber sie stimmen auch überein mit Woody Allens Schlussfolgerung, dass es für diesen Wunsch nun schon reichlich spät ist.

33 Ackerley/Gontarski, Grove Companion, 517.

${ }^{34}$ Beckett, Gedichte, 11.

35 Zit. n. Ackerley/Gontarski, Grove Companion, 232.

${ }^{36}$ Johann Wolfgang Goethe, Faust II, Köln 2005, 378. 
So ist in den frühen Texten die ganze Erde, vielleicht das ganze Universum schon sehr ermüdet und verlangsamt von all der Zeit, die sich darin abgelagert hat. Wie die alte Sonne am Anfang des Romans Murphy keine Wahl hat als auf das „Nichts des Neuen“37 zu scheinen, so erschöpft ist auch die „Erden-//wippe“ in dem 1933 geschriebenen Gedicht „Serena II“, die sich nur noch im „Leerlauf“ befindet. ${ }^{38}$ Im Vergleich der Erde mit einer Wippe (und die ästhetisch durch das harte Enjambement nachvollzogene, lange Schwungbewegung) ist schon das müßige Hin-und-Her enthalten, das zur wichtigsten Bewegung eines dynamischen Stillstands von Becketts späterem Werk werden wird, wenn beispielsweise in dem Stück Tritte (1976) eine Frau mittleren Alters eine scheinbar endlose Zeit in einem Zimmer auf und ab gehen wird; oder wenn es in dem Gedicht „neither“, aus dem selben Jahr, heißt: „to and fro in shadow from inner to outershadow// from impenetrable self to impenetrable unself by way of neither", oder wenn es darin lautet: „beckoned back and forth and turned away“. ${ }^{39}$ Das Hinwenden und Abgewiesenwerden ist bereits in dem Gedicht „Dieppe“ von 1937 umzirkelt: „und wieder das letzte Verebben/das tote Geschiebe/die Umkehr und dann die Schritte/nach den alten Lichtern" ${ }^{40}$ Das Bild und die Bewegung des Hin-undHer erzeugen hier bereits eine müde Monotonie und rufen einen Moment auf, der sich scheinbar kurz vor dem Ende befindet: Das Verebben ist zwar das Letzte, aber das Tote ist noch befähigt zu schieben.

Becketts Gedichte erzeugen oft eine Spannung zwischen dem Wunsch stillzustehen, reglos zu sein und der Unfähigkeit auszuharren, Stillstand zu erfahren. Es korreliert dieses Spannungsverhältnis mit einem Konzept der Muße als einem Empfinden von Dauer, während die Zeit weiter verstreicht. Während das Beckett'sche Subjekt sich in die Lage bringt, durch Hinwendung zum Inneren, zum Einkehren in sich selbst, ein mußevolles Versinken zu erreichen, treibt die Welt um dieses Subjekt herum weiter, die Erdenwippe bleibt in ständiger Bewegung, während das Ego reglos auf ihr sitzen kann oder muss.

Erfordert oder bewirkt diese inhaltliche Langsamkeit auch eine langsamere Auseinandersetzung mit dem Text als Leser, lässt der Text die Leser langsamer lesen, weil Langsamkeit inhaltlich verhandelt wird? Diesem Gedanken auf anderer Ebene folgend gefragt: Ist ein Text nur dann philosophisch, wenn darin der Name Kant oder Kierkegaard fällt, ist ein Text nur dann politisch, wenn er von Revolution oder Regierung handelt? Während es natürlich möglich ist, von Ivan Gontscharows horizontalem Helden Oblomow in seiner Lebenslangsamkeit beim Lesen angesteckt zu werden, ist es fraglich, ob eine Lesemethode auf eine so einfache Weise das spiegeln kann, was ein Text inhaltlich inszeniert. Be-

37 Samuel Beckett, Murphy, übers. v. Elmar Tophoven, Hamburg 1959, 5.

38 Beckett, Gedichte, 37.

39 Samuel Beckett, The Complete Short Prose: 1929-1989, hg. v. S. E. Gontarski, New York 1995, 258.

40 Beckett, Gedichte, 71. 
stünde eine solch einfache Korrelation, könnte man umgekehrt Allan Sillitoes Einsamkeit des Langstreckenläufers (1959) am besten rennend lesen, oder indem man sich durch den Text hetzt.

Mit Bezug auf Beckett soll hier lediglich argumentiert werden, dass das langsame Lesen nicht primär vom inhaltlichen Gehalt eines Textes abhängig ist und dass es stattdessen genau dann produktiv möglich wird, wenn die Ästhetik des Textes den poetischen Gehalt der Sprache so maximiert und verdichtet, dass eine meditativere Form des Denkens fruchtbar wird. Becketts Texte nutzen modernistische Techniken, die ein solches langsameres Lesen und ein meditativeres Denken bewirken können, zum Beispiel durch die bereits erwähnte beinahe obsessive Intertextualität des frühen Euvres und die häufig damit verbundene Verfremdung.

Unter Becketts frühen Gedichten findet sich eine Reihe von Texten, die ihr Arkanwissen über andere Texte auf eine Weise plakatieren, die ablehnend wirkt; man ist an die hermetische Lyrik erinnert und geneigt, nicht zu versuchen, den Text zu entschlüsseln, ihn zu verstehen oder zu durchdringen, sondern ihn zu erfahren, vielleicht als ein der Musik angenähertes Phänomen, auf dessen zeitliche Entfaltung man sich einlassen muss, so wie Joyce es im singenden und polternden "Sirens“-Kapitel seines Ulysses erprobte. Als Demonstration soll nur das Beispiel Becketts „Text 1“ (1932) herausgegriffen werden, das auf der Oberfläche so verschlossen und fremd wirkt, dass man als Leser oder Hörer vielleicht versteht, auch beim Lesen hat die Kategorie des Verstehens nicht die alleinige Übermacht:

oh and I dreamed he would come and come come come and cull me bonny bony double-bed cony swiftly my springal and my thin Wicklow twingle-twangler comfort my days of roses days of beauty week of redness with mad shame to my lips of shame to my shamehill for the newest of news the shemost of shenews is I'm lust-be-lepered and unwell oh I'd liefer be a sparrow for my puckfisted coxcomb bird to bird and branch or a cave of coal with veins of gold for my wicked doty's potystick and trimly to besom gone the hartshorn and the cowslip wine gone and the lettuce nibbled up nibbled up and gone for the last day of beauty the red time opened its rose struck with its thorn oh I'm all of a gallimaufry and a salady salmagundi singly and single to bed she said I'll have no toadspit about this house and whose quab was I'd like to know that from my cheerfully cornuted Dublin landloper and whose foal hackney mare toeing the line like a Viennese Täubchen take my tip and clap a lock on your Greek galligaskins ere I'm quick and living in hope and glad to go snacks with my twingle-twangler and grow grow into the earth mother of whom clapdish and foreshop ${ }^{41}$

In einer Radiosendung traf William H. Gass einmal eine Aussage über Henry James, die auf einen Text wie „Text 1“ ebenso zutrifft. Gass meinte, man müsse diese Texte langsam im Kopf abspielen, subvokalisieren, auch im Stillen mit imaginierter Zunge, nicht bloß mit schweifenden Augen, vorlesen. James schneller

41 Samuel Beckett, The Collected Poems of Samuel Beckett, hg. v. Seán Lawlor/John Pilling, London 2012, 36. 
zu lesen, meinte Gass, sei so, als würde man ein Konzert von Mozart schneller abspielen, man käme zwar rascher zum Ende, aber man höre nie die Musik. ${ }^{42}$ Ein Text wie jener Becketts treibt vielleicht nur auf die Spitze, was für viele Texte der Moderne gilt: Ein Text ist etwas Fremdes, ein Text ist ein Fremder. Nicht etwas, das aus meinem Subjekt, sondern etwas, das in mein Ich kommt, das völlig fremde Kontexte in mein Innenleben spült und sie dort ausfaltet. Der moderne Text ist immer ein anderer.

Einen Text symptomatisch zu lesen, bedeutet den Text auszuglätten oder $\mathrm{zu}$ durchbohren, in jedem Fall nicht bei dem Text zu verweilen auf eine phänomenologisch aufmerksame Weise. Den Text symptomatisch zu lesen, bedeutet, den Text schnell zu lesen, weil er fortinterpretiert wird von dem, was er ist. Die Fremdheit, die Komplexität eines Textes auf eine ethische Weise annehmen, bedeutet hingegen, die Fremdheit des Textes nicht reduzieren zu wollen, sondern sie im Gegenteil so lange wie möglich aufrechtzuerhalten, mit der Fremdheit eines Text zu arbeiten, sie als Dauer zu erfahren, auf eine meditative Weise über sie zu reflektieren und im Warten mit dem Text möglicherweise ein gutes Lesen zu erfahren.

Becketts Werk ist ein Beispiel unter vielen in der Moderne, wie produktiv es sein kann, in einem Text und mit einem Text Dauer zu erkennen und zu erfahren. Die Langsamkeit und die angedeutete verlangsamte Rezeption, ein meditativeres Reflektieren, ein mußevolleres Nachdenken über Text (und Welt), können eine Rezeption des singulären Zusammenspiels von Inhalt und Form bedeuten, das die Literatur der Moderne möglich macht. In Becketts Gedichten ist vielmals Inhalt wie Form bis in kleinste Details so mit Langsamkeit und Langsamkeit evozierenden Techniken durchwoben, dass eine langsame Rezeption möglich wird, und dass es vielleicht erst diese Langsamkeit im Lesen ist, die anschließend weitere verlangsamende Phänomene im Text erkennbar werden lässt - eine Kreisbewegung im Textraum. Selbst Becketts Syntax und seine Grammatik können als Zeitdämpfer betrachtet werden. So ist in Becketts lyrischem Werk eine häufige Partizipialtendenz der Verben erkennbar. Das eindeutigste Beispiel ist eines der schönsten und konzisesten Gedichte Becketts, publiziert im Jahr 1934, mit dem Titel „Gnome“:

Spend the years of learning squandering

Courage for the years of wandering

Through the world politely turning

From the loutishness of learning. ${ }^{43}$

42 William H. Gass/Don Swaim, „Interview with William H. Gass“, in: Wired for Books, Ohio University, 1985, http://www.wiredforbooks.org/mp3/WilliamGass1985.mp3 (abgerufen am 10.05.2016).

43 Samuel Beckett, Collected Poems, 55. 
Das Gedicht basiert formell auf den Verb- und Zeilenendungen in „-ing“. Diese ermöglichen dem Gedicht den gleichzeitig innehaltenden und fortlaufenden Einsatz der Enjambements, und durch die partizipialen Strukturen wird ein anhaltendes Geschehen ausgedrückt, das schließlich noch inhaltlich potenziert wird durch die Anspielung auf die andauernden Lehr- und Wanderjahre. Die Erfahrung, die das Gedicht somit inszeniert, ist eine Erfahrung von Unabgeschlossenheit, von Dauer, so wie auch die Verben in ihrer Partizipialgestaltung ein Gefühl des Schwebens, des treibenden Verweilens, verdeutlichen, was durch Vergangenheitsformen nicht möglich wäre.

So entsteht im Zusammenspiel von wiegendem Rhythmus (Pentameter und Tetrameter), Enjambement und Partizip die Bewegung eines sachten Pendelns, eines Hin-und-Her. Das zyklische und vielleicht ohne Ende andauernde Schwingen zwischen Innehalten und Fortlaufen, antizipiert (drei Jahre vor „Dieppe“) eines der Kernthemen von Becketts CEuvre, die schwebende Bewegung von einem Ende zum andern. Das Selbst wird zum pendelnden Subjekt, gefangen in einem Raum, einem Kubus, einer Zelle, einem Kreis, sich befindend in einer Welt, einem Dasein, ohne bewusst wahrgenommenen Anfang, ohne bewusst wahrnehmbares Ende. Der Beckett-Mensch, der in einem vorrationalen Stadium geboren wird und also nie bewusst geboren wird und der unbewusst, weil unerinnerbar, seinen Tod „erleben“ muss, scheint auf ewig in einem Limbus gefangen, aus dem es keinen Ausweg gibt, der aber gerade deshalb eine Mußemöglichkeit, ja einen Mußezwang darstellt. Der Beckett-Mensch erfährt gezwungenermaßen ein gelassenes Hinnehmen, ein erschöpftes Akzeptieren des Seinskäfigs, aus dem er in die Welt blickt. Dies muss sich allerdings bei Weitem nicht so karg und pessimistisch gestalten, wie Beckett häufig gedeutet wird, denn bisweilen fällt Sonne in den Käfig, wie es in dem Gedicht „Casket of Pralinen for a Daughter of a Dissipated Mandarin“"(1931) heißt. ${ }^{44}$ Allerdings kann diese Sonne nur auf ein langes Warten folgen, und da nutzt es nichts, auf das Ende des Wartens zu warten, denn vielleicht kommt das Ende des Wartens nicht. Eher muss man partizipial warten, nicht Warten auf Godot, sondern Wartend auf Godot.

Schon in seinen deutschen Tagebüchern von 1936-37, während Beckett Walter Bauers Roman Die notwendige Reise (1932) liest, notiert er die programmatisch werdenden Worte: „Das notwendige Bleiben“ ${ }^{4}{ }^{45}$ Die Erfahrung des Eingesperrt-seins, ob räumlich oder existenziell, erzeugt einen Wartezwang, wie in der späten Erzählung „Der Verwaiser“ (1965), wo sich Menschen unerklärt im Innern eines Zylinders befinden. Wie üblich im Beckett-Kosmos gibt es ein kontinuierliches und ewig wiederkehrendes Hinstreben zum Unerreichbaren, und es ist hier an einem entscheidenden Moment, dass die Figuren im Innern dieses

44 Beckett, Collected Poems, 33.

45 James Knowlson, Damned to Fame. The Life of Samuel Beckett, London 1996, 247; Herv. i. O. 
Zylinders durch ihre Umgebung genötigt sind, sich auf eine beinahe gleichgültige Weise etwas Muße zu gestatten, sich der „beliebige[n] Erkundung des sagenhaften Bereichs" zu widmen, „der unzugänglich genannt wird und es demnach [theoretisch] gar nicht ist“". ${ }^{46}$ So kristallisiert sich eine Dynamik gerade aus der Ausweglosigkeit, aus dem vielleicht endlosen Warten. Weil es keinen Ausweg gibt, beginnt eine Pendelbewegung innerhalb der Grenzen der Ausweglosigkeit; ein teleologisches oder theologisches Ende existiert nicht, lediglich das Hin-undHer-Schweifen innerhalb der Wände eines Raumes.

Am Ende des Romans Watt (1953) warnt Becketts Erzähler: „Weh dem, der Symbole sieht! “47 Vielleicht macht man sich eines symbolischen, allegorischen Lesens schuldig, wenn man sagt, die Empfindung des Wartens, ohne aufs mögliche Ende des Wartens zu schielen, mag fruchtbar auch fürs Lesen sein, ein Lesen, das nicht liest, um ans Ende des Lesens zu gelangen, sondern ein Lesen, das im ungeheuren Privileg schwelgt, literarisch leben zu können, zu lesen. Um es pathetischer zu sagen: Das hier dargelegte Verständnis eines langsamen Lesens baut auf einer Liebe zum Lesen auf, keine Idealisierung, eine Liebe, ein Annehmen, statt eines Verändernwollens. Lieben nicht auf ein Ziel hin, sondern um ein Bleiben im Lieben.

Ist die Kategorie des Ziels aufgebrochen, bröckelt auch die Kategorie der einen Interpretation, der einen Erkenntnis, und damit fiele auch die Gefahr, einen Leseprozess irgendwann wirklich abzuschließen. Ausgehend von den Wartezwängen von Becketts Figuren könnte sich im Text, im langsamen Leseprozess, ein paradoxer Mußezwang ausbilden, ein zur Muße Gedrängt-sein, weil es kein Ziel der Reflexion geben kann und muss. Aber aus dieser Vertiefung, aus diesem Verweilen, dynamisiert sich möglicherweise eine produktive Bewegung, die den Limbus, in dem man sich befindet, gelassen annimmt und innerhalb seines Käfigs auf das Einscheinen der Sonnenstrahlen durch die Gitterstäbe wartend verweilt - auch wenn es nie dazu kommt.

46 Samuel Beckett, Erzählungen, übers. v. Elmar Tophoven, Frankfurt a. M., 1995, 219.

47 Samuel Beckett, Watt, übers. v. Elmar Tophoven, Frankfurt a. M. 1970, 271. 



\title{
Oberland und Bloomsbury: Städtische und ländliche Muße in Dorothy Richardsons Pilgrimage
}

\author{
Kerstin Fest
}

Dorothy Richardsons Lebenswerk, das dreizehnbändige Pilgrimage (1915-1967), ist ein Text der klassischen Moderne. Erzählt wird die Entwicklung von Miriam Henderson, einer jungen berufstätigen Frau, die sich in Londons künstlerischen und intellektuellen Kreisen bewegt. Formal betrachtet ist Pilgrimage ein roman fleuve oder Zyklenroman, wie ihn zum Beispiel Lynette Felber definiert: sehr lang, mit inhaltlichen und zeitlichen Sprüngen zwischen den einzelnen Romanen und einem offenen Ende. ${ }^{1}$ Aber es ist Richardsons Erzählweise, die am meisten ins Auge sticht. Alle 13 Bände hindurch liegt die figurale Erzählerinstanz auf Miriam Henderson, und Richardson verwendet früher noch als Virginia Woolf die Technik des stream of consciousness. ${ }^{2}$

Pilgrimage ist mit seinem strengen Fokus auf die Subjektivität seiner Hauptfigur und den langen ausführlichen Beschreibungen von alltäglichen Vorgängen und Dingen also ein typisch modernistischer Roman. Auch thematisch ist dies der Fall: Die Protagonistin entwickelt sich vom spätviktorianischen Typus

1 Vgl. Lynette Felber, Gender and Genre in Novels Without End. The British RomanFleuve, Gainesville 1995. Für Finn ist Pilgrimage ein Vorläufer des nouveau romans (Howard Finn, „Oberland. ,A Charming Interlude“", in: Pilgrimages. The Journal of Dorothy Richardson Studies 1 [2008], 118-144). Er zitiert u. a. die Schriftstellerinnen Bryher (Annie Winifred Ellerman) und H.D. (Hilda Dolittle), die Pilgrimage auch in diese Kategorie einordnen. Llantada Díaz interpretiert Pilgrimage in der Tradition des europäischen Bildungs- bzw. Künstlerromans (Maria Francisca Llantada Diaz, „An Analysis of Poetic and Cinematic Features in Dorothy M. Richardson's Pilgrimage", in: English Studies 90,1 [2009], 57-77). Pilgrimage ist auch deutlich autobiographisch; zum Verhältnis von Text und Biographie vgl. Gloria G. Fromm, Dorothy Richardson. A Biography, Urbana 1977.

2 Es ist im Zusammenhang mit Dorothy Richardson, dass May Sinclair den Ausdruck stream of consciousness prägt: „In this series there is no drama, no situation, no set scene. Nothing happens. It is just life going on and on. It is Miriam Henderson's stream of consciousness going on and on." (May Sinclair, „The Novels of Dorothy Richardson“, in: The Egoist 5,4 [1908], 57-59, 58) Dies erinnert sehr an Hélène Cixous' Konzept der écriture féminine. Für Analysen von Richardsons Werk in diesem Zusammenhang siehe u.a. Kristin Bluemel, Experimenting on the Borders of Modernism. Dorothy Richardson's Pilgrimage, Atlanta 1997; Felber, Gender and Genre in Novels Without End. 
der new woman ${ }^{3}$ zu einer unabhängigen erwerbstätigen intellektuellen Frau, die am politischen und kulturellen Leben ihrer Zeit mehr oder weniger aktiv teilnimmt. London ist der Haupthandlungsort des Romanzyklus und spielt eine ebenso wichtige Rolle wie Miriam selbst. Es ist der Inbegriff der modernen Stadt und Miriam nutzt diesen auch dementsprechend. Sie frequentiert Museen und die British Library, besucht politische Veranstaltungen und neue soziale Räume, wie zum Beispiel die aus dem Boden schießenden billigen coffee houses. ${ }^{4}$

In diesem Aufsatz soll argumentiert werden, dass es, vielleicht konterintuitiv, dieser Kontext der Moderne ist, der Miriam mußeähnliche Zustände, die sich oft durch Ziel- und Zwecklosigkeit auszeichnen, erlaubt. In den früheren chapter novels, die Miriams erste Jahre im Londoner Intellektuellenviertel Bloomsbury zum Thema haben, ist dies das anonymisierte, schnelle Stadtleben; in Oberland - dem neunten Band der Serie, in dem ein Aufenthalt in der Schweiz geschildert wird - die Erfahrung des modernen Tourismus. Bloomsbury und Oberland werden also zu Mußeorten, die nicht den Erwartungen entsprechen. Die Stadt ist laut und anstrengend, die Schweizer Berge sind kommerzialisiert. Miriams Muße geschieht an öffentlichen, demokratischen' Plätzen, nicht abgeschiedenen exklusiven Örtlichkeiten. Doch nicht nur die Lokalisierung von Miriams Muße in der Öffentlichkeit macht diese Muße zu einer modernen. Auch Miriams Geschlechtsidentität spielt eine Rolle. Für sie als Frau (und insbesondere als new woman, die sich in der Arbeitswelt und im intellektuellen und politischen Leben Londons bewegt) ergibt sich zwangsläufig eine Mußepraxis, die sich vom ,klassischen' Mußekonzept absetzen muss: Miriams Muße ist urban und weiblich. Auch auf formaler Ebene ist Pilgrimage ein Text, in dem die Spannung aber auch das Zusammenspiel von Muße und Moderne deutlich hervortritt, erlaubt doch der stream of consciousness, ein modernistisches Stilmittel par excellence, eine

\footnotetext{
3 Vgl. Jessica Gray, „Typewriter Girls in Turn-of-the-Century Fiction. Feminism, Labor and Modernity", in: English Literature in Transition 1880-1920 58,4 (2015), 486-502; Ann Heilmann, New Woman Fiction. Women Writing First-Wave Feminism, Basingstoke, England/New York 2000; Lyn Pykett, „Sensation and New Woman Fiction“, in: Linda H. Peterson (Hg.), The Cambridge Companion to Victorian Women's Writing, Cambridge 2015, 133-143.

${ }^{4}$ Für Scott McCracken sind die coffee houses zentral für Miriams Leben in der modernen Großstadt: „Her wage and situation give her access to a public life and the ABC [Aerated Bread Company] provides the stage upon which she can perform her new identity. [...] The role of the London café in Richardson's text makes it possible to suggest that the new chains like the $\mathrm{ABC}$ and J. Lyons coffeehouses did provide the kinds of public space in which a new gendered identity could be performed“ (McCracken, „Embodying the New Woman. Dorothy Richardson, Work and the London Café", in: Avril Horner/Angela Keane [Hg.], Body Matters. Feminism, Textuality, Corporeality, Manchester 2000, 58-71, 67). Zur Bedeutung der coffee shops im Stadtbild Londons siehe McCracken, „Voyages by Teashop. An Urban Geography of Modernism“, in: Peter Brooker/Andrew Thacker (Hg.), Geographies of Modernism. Literatures, Cultures, Spaces, New York 2005, 86-98.
} 
ebenso eindringliche Darstellung hektischer Moderne wie eine radikale Entschleunigung des Erzählstroms.

Miriams Gehen in der Großstadt lässt sich leicht mit der Figur des Flaneurs in Verbindung bringen, einer prototypischen Mußefigur der Moderne, dem Mann, der, „am Asphalt botanisieren“5 geht und schon 1840 von Edgar Allen Poe als

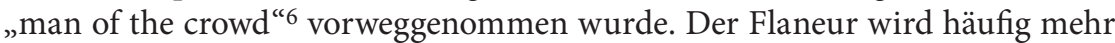
oder weniger bewusst als männlich wahrgenommen. Es ist gerade die Öffentlichkeit des Flaneurs, also seine Zuordnung zu einem maskulinen Raum, die diesen Eindruck verstärkt. Dies wird zum Beispiel von Janet Wolff argumentiert, für die eine weibliche Version schlichtweg unmöglich ist: „There is no question of inventing the flâneuse: the essential point is that such a character was rendered impossible by the sexual divisions of the nineteenth century “ 7 Deborah Parsons andererseits argumentiert überzeugend, dass die Diskussion über die Möglichkeit einer Flaneuse über einen simplen Vergleich mit dem Benjaminschen Vorbild hinausgehen muss, da das Erleben der Stadt aus weiblicher Sicht Alternativen zum männlichen Erleben darstellt:

[Female authors] created an urban consciousness modelled on alternative values to those of their male counterparts, and urban narratives that present much more organic cities than the utopian/dystopian representations by hegemonic male modernism; cities that follow natural, temporal, and social rhythms. ${ }^{8}$

Gerade Pilgrimage ist für Parsons ein Text, der diesem Gedanken entspricht, denn Miriams Flanieren ist nicht in erster Linie ein mehr oder weniger teilnehmendes Beobachten der Großstadt. Für sie ist das Gehen, und im Grunde auch einfach das Existieren in der Großstadt, eine Erfahrung der Entgrenzung, die sie aus dem Alltagsleben enthebt und sie immer wieder in einen mußeartigen Zustand versetzt.

Die Großstadt London rückt in Miriams Erfahrungswelt, nachdem sie erst als Lehrerin an einem deutschen Internat und an einer Mädchenschule in einem Londoner Vorort (in den Bänden Pointed Roofs und Backwater) und dann als Gouvernante bei einer wohlhabenden Familie auf dem Land (in Honeycomb)

5 Walter Benjamin, Charles Baudelaire. Ein Lyriker im Zeitalter des Hochkapitalismus, hg. v. Rolf Tiedemann, Frankfurt a. M. 1974, 34. Siehe auch die Beiträge von Robert Krause und Peter Philipp Riedl in diesem Band.

${ }^{6}$ Edgar Allan Poe/Stuart Levine/Susan Levine, Thirty-Two Stories, London Publishing $2000,120$.

7 Janet Wolff, „The Invisible Flâneuse. Women and the Literature of Modernity“, in: Andrew Benjamin (Hg.), The Problems of Modernity. Adorno and Benjamin, London 1989, 141-156, 47. Ähnlich vehement äußert sich Griselda Pollock: „There is no female equivalent of the quintessential masculine figure, the flaneur: there is not and could not be a female flaneuse." (Griselda Pollock, Vision and Difference. Feminism, Femininity and Histories of Art, London 1998, 71)

8 Deborah L. Parsons, Streetwalking the Metropolis. Women, the City and Modernity, Oxford 2000, 16. Siehe auch den Beitrag von Heidi Liedke in diesem Band. 
gearbeitet hat. In keiner dieser Tätigkeiten fühlt sich Miriam wirklich wohl und es gelingt ihr nur schwer, Momente der Einkehr zu finden. In der pseudo-häuslichen Tätigkeit als Lehrerin und Erzieherin empfindet sie den ständigen Kontakt mit anderen als anstrengend und einengend. ${ }^{9}$ Auch die ländliche Idylle Newlands, dem Besitz der neureichen Familie Corrie, taugt nicht zum Mußeort. Damit wendet sich Pilgrimage gegen einen der prototypischsten Mußeorte der englischen Literatur, dem Landhaus. Newlands kann Miriam keine grüne und distinguierte Gegenwelt zum spießigen Hannover und dem langweiligen Londoner Vorort bieten. Im Gegenteil, Miriam erscheint das Leben in Newlands als oberflächliches Spektakel und Festumzug. Hier ist für sie kein authentisches Raum- und Mußeerlebnis möglich.

Dies ändert sich, als sie Mrs. Corrie zum Einkaufen nach London begleitet. Als sie Zeit zur freien Verfügung hat (Mrs. Corrie möchte sich ungestört mit einer Freundin unterhalten), wird der bis dahin mehr oder weniger geordnete Erzählstrom in Kapitel VI zum assoziativen Bewusstseinsstrom:

The West End street ... grey buildings rising on either side, angles sharp against the sky ... softened angles of buildings against other buildings ... high moulded angles soft as crumb, with deep undershadows ... creepers fraying from balconies ... strips of window blossoms across the buildings, scarlet, yellow, high up, a confusion of lavender and white pouching out along the dipping sill ... a wash of green creeper up a painted house front ... patches of shadow and bright light. (Honeycomb, I, 416) ${ }^{10}$

Die Stadt ist überwältigend, aber nicht furchteinflößend. Interessanterweise wird hier einer der geschäftigsten Teile Londons als ,natürlicher', gleichsam organischer Ort geschildert. Es gibt hier nicht nur Blumen, auch das Pflaster ist belebt:

I am part of the dense smooth clean paving stone ... sunlit; gleaming under dark winter rain; shining under warm sunlit rain, sending up a fresh stony smell. [...] Life streamed up from the close dense stone. [...] The pavement of heaven. (Honeycomb, I, 416)

Diese Schilderung ist besonders bemerkenswert, da Miriam ja gerade aus der ländlichen Idylle in die Großstadt gekommen ist. Im Vergleich zu London ist Newlands aber ein künstlicher Ort. Miriam, die sich ansonsten ihrer selbst ständig und beinahe schmerzlich bewusst ist, verliert sich in der Stadt. Ihr Flanieren wird zum Flow. Die Allgegenwart moderner Luxusgüter (die sie sich natürlich nicht leisten kann) steht dazu nicht im Gegensatz, sondern wird zum Teil dieser paradox natürlichen und beseelten Stadt:

9 Kerstin Fest, And All Women Mere Players? Performance and Identity in Dorothy Richardson, Jean Rhys and Radclyffe Hall, Wien 2009, 165.

10 Zitiert wird aus der vierbändigen Virago-Ausgabe von Pilgrimage (hg. v. Gillian E. Hanscombe, London 1974). Im Text angegeben sind Romantitel, Bandnummer und Seitenzahlen. 
The bright teeth of a grand piano running along the edge of a darkness, a cataract of light pouring down its raised lid; forests of hats; dresses shining against darkness, bright headless crumpling stalks; sly, silky, ominous furs; metals, cold and clanging; brandishing the light; close prickling fire of jewels. (Honeycomb, I, 417)

Die Modernität der Konsumwelt und ihrer Güter ist ein Grundbestandteil des Flaniererlebnisses und der Moderne im Allgemeinen. Aber Miriams Erleben unterscheidet sich vom Flanieren als Lesen und Beobachten der Stadt als Zeichensystem. Eine „Konzentration auf die Oberfläche "11 findet nicht statt. Miriams Muße in der Großstadt ist ganzheitlicher, da die Stadt ihr nicht bloß als Beobachtungsobjekt gegenübersteht. Vielmehr verräumlicht sich Miriams Muße hier: Die Protagonistin ,verweilt' in einem Zustand, der Sukzession und Zielgerichtetheit enthoben ist und der eng an den Raum in dem er stattfindet gebunden ist. Gleichzeitig steht aber auch der Raum still, ,intensiviert' sich quasi und wird so zum ,Freiraum'.

Als Miriam endgültig nach London zieht, kommt es zu einer ähnlichen Erfahrung. In ihrem ersten eigenen Zimmer in einer billigen Pension angekommen öffnet sie ihr Fenster und erlebt London nicht als einen Ort von Geschäftigkeit, sondern als einen Raum der in der Zeit liegt (vor Miriams Fenster vergehen Tag und Nacht), ihr aber trotzdem enthoben ist:

No need to trouble about the blind. London could come freely in day and night through the unscreened happy little panes; light and darkness and darkness and light. London, just outside all the time, coming in with the light, coming in with the darkness, always present in the depths of the air in the room. (The Tunnel, II, 16)

Wenig später erlebt sie einen Moment beinahe ekstatischer Einheit mit der Stadt, der aber auch als mußeähnlicher, beinahe meditativer, Zustand gelesen werden kann:

The bells played [the melody] out, without the semitone, with a perfect, satisfying falsity. Miriam sat hunched against the table listening for the ascending stages of the last line. The bells climbed gently up, made a faint flat dab at the last top note, left it in the air askew above the decorous little tune and rushed away down their scale as if to cover the impropriety. They clamoured recklessly mingling with Miriam's shout of joy as they banged against the wooden walls of the window space. (23)

Elisabeth Bronfen bezeichnet das, was Miriam in der Großstadt erlebt, treffend als „shared solitude [...] an alone with London"12 und Parsons spricht davon,

11 Sabina Becker, „Flanerie und Architekturbeschreibung. Die Stadtlektüren Franz Hessels“, in: Robert Krause/Evi Zemanek (Hg.), Text-Architekturen. Die Baukunst der Literatur, Berlin 2014, 187-205, 190. Siehe auch den Beitrag von Peter Philipp Riedl in diesem Band.

12 Elisabeth Bronfen, Dorothy Richardson's Art of Memory. Space, Identity, Text, Manchester 1999, 85. 
dass Miriam geradezu eifersüchtig über ihr Individualität wacht ${ }^{13}$. Genau dafür bietet ihr die moderne Stadt die perfekte Möglichkeit und dies führt zu Miriams ganz individuellem Erleben von Muße.

Ihre Reise in die Schweiz konfrontiert Miriam mit anderen aber ebenso modernen Situationen und Kontexten: Sie wird zum ersten Mal zur Touristin. ${ }^{14}$ Diese neue Identität und die mit ihr einhergehenden Raum- und Mußeerfahrungen sind eindeutig anders als die, die sie als berufstätige Frau in London oder auch als überforderte Gouvernante in Deutschland und in Newlands macht. Als Touristin erkauft sich Miriam das Erlebnis von Muße und auch den Mußeraum. Konsum und Muße erscheinen auf den ersten Blick hin widersprüchlich, auch kommerzialisierter Tourismus ist nicht unbedingt sofort mit mußevollem Reisen gleichzusetzen. Dies wird am Anfang von Oberland deutlich: Miriam befindet sich auf der Anreise in die Schweiz und durchlebt die typischen Probleme des modernen Reisens. Diese Unannehmlichkeiten sind oft mit zeitlich mehr oder weniger effizienten Abläufen, denen sich der/die Reisende unterwerfen muss, verbunden. So beginnt Oberland in medias res mit einer Szene von Hektik und leichter Panik, als Miriam versucht einen Anschlusszug rechtzeitig zu finden, ohne dabei ihr Gepäck zu verlieren:

The sight of a third porter, this time a gentle-looking man carrying a pile of pillows and coming slowly, filled her with hope. But he passed on his way heedless like the others. [...] She wasted a precious moment seeing again the three brutishly preoccupied forms as figures moving in an evil dream. If only she were without the miserable handbags she might run alongside one of these villains, with a tip in an outreached hand and buy a simple yes or no that was all she needed. But she could not bring herself to abandon her belongings to the mercy of this ill-mannered wilderness where not a soul would care if she wandered helpless until the undiscovered train had moved off into the night. (Oberland, IV, 11)

Miriam ist hier nicht einfach nur gestresst, sondern findet sich in einer zum Alptraum verzerrten Situation moderner Arbeit wieder. Die Gepäcksträger sind wie Zahnräder in einem System, das auf einem reibungslosen und schnellen Ablauf basiert. Zu Miriams Unglück verlassen sie ihre ,Rollen' in diesem System nicht, um ihre spezifische Frage zu beantworten. Sie bleiben Teile einer Maschinerie und verweigern jeglichen ,menschlichen' individualisierten Kontakt mit Miriam.

Ihre bisherige Reise durch Frankreich erinnert Miriam ähnlich unangenehm und vergleicht sich mit einer abgefeuerten Patrone, die keinerlei Kontrolle über ihre Laufbahn hat: „a state of being a helpless projectile that had spoiled Dieppe and made Paris a nightmare" (Oberland, IV, 13). Modernes Reisen wird also zum

13 Parsons, Streetwalking the Metropolis, 226.

14 Richardson veröffentlichte auch mehrere Zeitschriftenartikel zum Thema Alpintourismus. Vgl. Finn, „Oberland. ,A Charming Interlude““. 
Alptraum, wenn es zum reinen, Absolvieren 'von Stationen wird und keine Möglichkeit zum Wahrnehmen der vorbeirauschenden Städte bietet. Wieder ist es die aufgezwungene Effizienz des modernen Bahnbetriebs, der Muße unmöglich macht, und sie, in Miriams Erleben, sogar absichtlich zerstören will. Miriam ist ein „hurrying traveller robbed right and left of things passing too swiftly“ (13). Mußevoll für Miriam sind nur vignettenhafte Eindrücke von Frankreich, die der Zeit enthoben scheinen und sich im Gegensatz zur Bahn elegant und ruhig bewegen: „the way the frontage of the town met the sky and blended with the air", „slender trees along the high bank of a river, the way they had of sailing by, mannered, coquettish " und eine Pariserin, deren elegante Erscheinung sogar den Bahnhof verschwinden lässt: „she swept by, suddenly beautiful; from head to foot all gracefully moving rhythm" (13).

Bezeichnenderweise ist es dann auch eine für sie typisch kontinentaleuropäische Gepflogenheit, die sie schlussendlich am Bahnhof in Bern zur Ruhe kommen lässt: „And upon a table beyond the counter stood rows and rows of steaming cups. Coffee. Café, mon Dieu! Offered casually, the normal beverage of these happy continentals" (18). Das Erleben der Reise tritt zurück und wird zu einem Moment des sinnlichen Genießens kondensiert. Hier geht das Konsumieren des Getränks über das reine Stillen des Durstes hinaus und wird zum Ankerpunkt in einer ansonsten von Bewegung geprägten Zeit. Ein ausgewiesenes Mußegetränk ist es, das Miriam in einen wenigstens vorübergehenden Zustand der Muße versetzt. Und wie im Fall der Stadtschilderungen, ist es auch hier wieder ein eigentlich höchst betriebsamer Ort, der diesen Moment der Muße beinhaltet und ermöglicht und so auch selbst intensiviert wird.

Eine materielle Verankerung in Muße geschieht auch nachdem Miriam ihr Hotel in Oberland bezogen hat. An ihrem ersten Morgen wird sie während ihres Frühstücks (zu dem sie mit Absicht spät erschienen ist, um Gesellschaft zu vermeiden) von dem Amerikaner Vereker in ein Gespräch verwickelt, welches Miriam nicht erlaubt, sich in sich selbst zurückzuziehen. Es ist aber nicht nur das konkrete Gespräch, das in diesem Moment Muße verhindert, sondern auch die Themen, die angeschnitten werden. Das Gespräch mit Vereker zieht sie geradewegs in die moderne Öffentlichkeit; so geht es zum Beispiel um die unterschiedlichen Stromtarife in England und der Schweiz und um die moralisch-politische Frage, ob Landbesitz und Profit durch Verpachtung desselben vertretbar sind. Die Abwesenheit von Muße wird dann durch das Erscheinen anderer Gäste verstärkt. Das vom Erzähler unkommentierte Gespräch zwischen Vereker und Daphne, einem lebhaften Urlauberkind, in das keinerlei Gedanken und Gefühle Miriams einfließen, wird auch erzählerisch zu einer stakkatohaften Darstellung von Geschäftigkeit. Dies ändert sich, als Miriam sich aus dem Frühstücksraum zurückzieht und sich in einem leeren kleinen Salon wiederfindet. Der Ton der Erzählung expandiert gleichsam. Details des Raumes werden ausführlich be- 
schrieben, das Zur-Ruhe-Kommen Miriams vollzieht sich auch auf textueller Ebene:

Filled with morning light it seemed larger, a little important and quite self-sufficient, giving out its secret strangeness of a Swiss room, old; pre-existing English visitors, proof, with its way of being, set long ago and unaltered, against their travel hilarity. The little parlour piano, precious in chosen wood, highly polished, with faded yellow keys and faded silk behind its trellis, was full of old music, seemed to brood over the carrolings of an ancient simplicity unknown to the modern piano whose brilliant black-and-white makes it sound in a room all the time, a ringing accompaniment to the life of today. (56)

Muße wird hier auch visuell festgemacht, die Einzelheiten des alten Pianos laden zum Verweilen ein, die optische Brillanz eines neuen Klaviers wäre hingegen nur ein Bestandteil des schnelllebigen modernen Lebens.

Wenig später ist es wieder ein konkretes Objekt, welches Miriam in der Muße verankert, nämlich eine Schweizer Zeitung:

On a near table was a folded newspaper, thin, heavily printed continental. Switzerland radiant all about her and the Swiss world within her hand - a reprieve from further seeing [...].

The simple text was enthralling. For years she had not so delighted in any reading. In the mere fact of the written word, in the building of the sentences, the movement of phrases linking part with part. (58)

In dieser Passage ,rettet' also die Zeitung Miriam davor, sich im Betrachten ihrer Umgebung zu verlieren. Dies scheint auf den ersten Blick absurd, da sich ja auch das Betrachten oft als Mußepraxis verstehen lässt. Miriam betrachtet hier jedoch ihr Hotel und denkt über dessen Standort nach, der die Aussicht und die das Hotel umgebende Natur wie eine Ware präsentiert (für die man bezahlen muss), sie aber nicht konkret erlebbar macht. ${ }^{15}$ Das Zeitunglesen enthebt sie aber diesen Gedanken. Auch dass die hochintellektuelle Miriam sich nicht auf den Inhalt eines Artikels konzentriert, sondern auf den Aufbau von Sätzen fokussiert, ist bezeichnend.

Ein anderer absolut banaler Alltagsgegenstand, der Miriam in einen Zustand der Kontemplation und Achtsamkeit führt, ist ein Stück Seife, das sie während eines Einkaufsbummels im Dorf ersteht. Auch hier empfindet Miriam zuerst hektische und moderne Betriebsamkeit. Ihre Suche nach möglichst authentischen Schweizer Souvenirs führt sie in einen Laden, in dem sie mit einer verwirrenden Menge englischer Artikel konfrontiert wird, darunter Kekse, Nachtlichter und Seife, die gleichsam als Zeichen moderner, globaler Beschleunigung gesehen werden können. Etwas überfordert kauft Miriam schließlich ein Stück Seife, das schlussendlich wieder zu einem Ankerpunkt in all der Hektik wird:

15 Zur englischen Reiseliteratur und der Rolle des Sehens darin siehe Barbara Korte, English Travel Writing. From Pilgrimages to Postcolonial Explorations, Basingstoke 2000. 
The secret of its power was in the way it pervaded one's best realizations of everyday life. No wonder Beethoven worked at his themes washing and re-washing his hands. And even in merely washing with an empty mind there is a charm [...]. (62)

Und wie die oben beschriebenen Kaffeetassen, das alte Klavier und die Zeitung wird der Anblick der Seife zum Auslöser von Muße: „Its little weight, treasure, minutely heavy in the hand, is life, past, present, and future, compactly welded“ (63).

In Oberland sind es also Momente des Innehaltens, welche Epiphanien ${ }^{16}$ gleichen, die Miriams Mußeerfahrungen prägen und die in einem paradox komplementären Gegensatz zu der positiven Überwältigung und Entgrenzung der frühen Londoner Jahre stehen. Aber auch in der Schweiz bleibt Miriams Verlangen nach „shared solitude“ bestehen. Wenn sie sich auch in Gesellschaft besser bewegen kann, sind ihr Gemeinschaftserlebnisse noch immer fremd. An einem Skikurs teilzunehmen lehnt sie zum Beispiel kategorisch ab; sie entschließt sich aber Rodeln zu gehen, da sie der Meinung ist, dies könne man alleine einüben. Auch hier gelingt es Miriam, aus in einem Alltags- und kommerzialisierten Gegenstand - die Rodel muss ausgeliehen werden - einen Quell der Achtsamkeit und Muße zu machen. Schon das Ziehen der Rodel wird Gehmeditation. Als sie sich auf den Weg in die Berge macht, bemerkt sie, dass sie es nicht eilig hat zum Rodelhang zu gelangen:

[T]he invisible distant slopes seemed lonely, and her plan for getting immediately away to them postponed itself in favour of enjoying for a while the thrilled equilibrium with everything about her that was the gift of the slight pull on the cord [...]. (69)

Ihre erste Abfahrt mit der Rodel gleicht dem Erlebnis des ersten Fahrradfahrens, in dem sich Angst zu einem Gefühl der Ekstase und Schnelligkeit wandelt:

Ramming her heels into the snow she recovered too late, with a jolting pang in both ankles and a headlong dive into this morning's drift, a memory of what she should have done and stood up tingling with joy in the midst of the joyous landscape, stilled again, that had flown with her and swooped up as she plunged and was now receiving her exciting news. (71)

Aus der Kontemplation wird wieder Entgrenzung, die sich am Gegenteil der Muße festmachen lässt. Hier zeigt sich vielleicht das typisch Moderne an $\mathrm{Mi}$ riams Muße bzw. vielmehr an den Momenten, die Miriam dem Alltag entheben: Sie lassen sich nicht ausschließlich an nur einem Phänomen festlegen. Miriam erlebt stille Kontemplation, welche nahe an der Achtsamkeit ist, Entgrenzung des Selbst im Strom der Großstadt, aber eben auch (Geschwindigkeits)rausch, der durchaus orgastische Züge in sich trägt. ${ }^{17}$ Wie im oben diskutierten Zitat zum

16 Vgl. Eveline Kilian, „,Gliding as if Forever. Speed and Movement in Richardson's Pilgrimage", in: Pilgrimages. The Journal of Dorothy Richardson Studies 1 (2008), 28-49.

$17 \mathrm{Zu}$ Moderne und Beschleunigung in Pilgrimage siehe Kilian, „,Gliding as if Forever“". 
,Eindringen 'Londons in Miriams Zimmer erlebt Miriam eine quasi körperliche Vereinigung mit ihrer Umgebung. Und wie auch in London, ist dies nicht Furcht einflößend, sondern resultiert in einem Zustand des Friedens und der Muße. Die Abfahrt führt Miriam nämlich tiefer in den Wald und damit weiter weg vom Tourismusbetrieb: „She had tobogganed herself away from Oberland into the wilderness, the unknown valley waiting now to be explored, with the conquered steed trailing once more meek and unprotesting in the background." (71) Was sie nun, zum ersten Mal während ihres Aufenthalts, sieht, ist unberührte Natur:

The high bridge that in the distance looked so small, a single sturdy arch; but beneath it dropped a gorge whose spines led down to a torrent, frozen; strange shapes of leaping water arrested, strange coloured: grey in shadow, black in deep shadow, and here and there, caught by the light, a half transparent green. (71)

Hier steht die Zeit (und die Erzählung) nach der rauschhaften Fahrt wieder still. Der Effekt wird noch verstärkt durch die Vereisung des Wasserfalls. Es ist beinahe absolute Versenkung in die Kontemplation der Natur möglich, sogar die Schattierungen des Eises können detailliert beschrieben werden. Teil dieses Stillstands ist auch eine totale Abwendung vom Ort Oberland:

There was a great fellowship of pines clustered on either bank and spreading, beyond the bridge, to a wood that sent out a rising arm blocking the view of the valley and the pass. They made a solitude down here above the silenced waters. The backward view was closed by the perilous slope whose top was now the sky-line, leaving Oberland far away out of sight in another world. (71-2)

Interessant ist hier die Anthropomorphisierung der Zirben, die sich zu einer Gemeinschaft zusammengefunden haben. Wenig später „marschieren“ diese sogar durch den Wald. Dieses vielleicht seltsame Bild löst sich in Miriams Idealvorstellung von Gesellschaft auf:

The track through the wood, wide and level for a while, with spired pines marching symmetrically by, narrowed to a winding path that took her in amongst them, into their strange fellowship that left each one a perfect thing apart. (72)

Eine Gemeinschaft, in der jedes Mitglied trotz der Zusammengehörigkeit „a perfect thing apart" ist, ist genau die „shared solitude“, die Bronfen für Miriams Leben in der Großstadt postuliert. Miriam kommt zu der Erkenntnis, die wohl Muße fast perfekt zusammenfasst: „And very secret; here thought was sheltered as in a quiet room" (72). Aus den kurzen Augenblicken des Innehaltens im regen touristischen Betrieb Oberlands wird nun ein längerer Moment der Erkenntnis und Transzendenz:

Out in the immense landscape, in the down-pouring brilliance of pure light, thought was visible. Transparent to the mountains who took its measure and judged, yet without wounding, and even while they made it seem of no account, a small intricate buzzing in the presence of mighty, simple thoughtless submission to their influence as to final in- 
finite good that would remain when they were no more seen, there was pathos in their magnificence [...]. And to walk and walk on and on amongst, along their sunlit corridors with thought shut off and being changed, coming back refreshed and changed and indifferent, was what most deeply she wanted now. (72)

Ganz am Ende von Pilgrimage, im posthum veröffentlichten und fragmentarischen Roman March Moonlight, gelingt es Miriam in London zu einem ähnlichen Zustand zurückzufinden, indem sich Natur und Stadt vereinen:

No one in the other room of this top floor. The garden, its washing lines, ash-heap and dustbins invisible, the lime tree and the tops of those poplars pointing up in the next garden. Solitude. Secure. Filled each morning with treasure undamaged by compulsory exchange. (March Moonlight, IV, 656)

Was sich in Oberland nur temporär und in oft überraschenden Situationen einstellte, hat sich nun zu einer produktiv-unproduktiven, länger währenden Zeit gewandelt. Auch das Überwältigt-Werden von Sinneseindrücken und die damit verbundene Auflösung einer zielgerichteten vom Subjekt initiierten Tätigkeit, welche so typisch für Miriams frühe Bloomsbury Jahre ist, sind verschwunden. Miriam ist gleichsam achtsam geworden, ihr ist ihr Mußeerlebnis bewusst geworden und sie hat auch erkannt, dass dies mit einem positiv konnotierten Alleinsein einhergeht:

Fully to recognize, one must be alone. Away in the farthest reaches of one's being. As one can richly be, even with others, provided they have no claims. Provided one is neither guest nor host. With others on neutral territory, where one can forget one is there, and be everywhere. (657)

Wie schon oben angedeutet, vollzieht sich dies aber nicht an typischen Mußeorten, die von prototypischem Naturerlebnis, oft klassen- oder geschlechtsspezifischer Exklusivität und Abgeschiedenheit geprägt sind. Es ist vielmehr die anonyme Großstadt und hier nicht einmal die glitzernden Einkaufspassagen oder stilvollen Cafés. Miriam ist zu den coffee shops der unteren Mittelschicht zurückgekehrt und es sind genau diese, die ihr die für Muße zur schriftstellerischen Tätigkeit notwendige Anonymität bieten:

Hence, for me, the charm of that Eustace Miles place. [...] All day the place awaits me. Gives me the long ramble from suburb to centre, sure of the welcome of a spacious interior well filled but never crowded. [...] I can sit within the differently nourishing variations of the assembled company, reading as receptively as if I were alone [...]. (657)

Ausgesöhnt mit der Omnipräsenz anderer Menschen, erkennt Miriam diese sogar als Gleichgesinnte an, die wie sie Muße oder vergleichbare Zustände suchen: „feeling one with even that woman who sat at my table last night eye [sic] downcast in meditation, breathing out now and again her Buddhistic O-m" (657). ${ }^{18}$

${ }^{18}$ Es ist bezeichnend, dass Miriam das anscheinend offensichtliche ,Bekenntnis' der 
Diese Situation erlaubt es ihr auch eines der meistpostulierten Ziele der Muße zu erreichen: Sie schreibt. Während Miriam den ganzen Romanzyklus hindurch als Schriftstellerin angelegt ist (und hier spielt sicher auch die mehr oder weniger bewusste Lesart von Pilgrimage als wenigstens partiell autobiographisches Werk Richardsons mit), wird sie erst gegen Ende des Zyklus, in March Moonlight, als solche dargestellt: „While I write, everything vanishes, but what I contemplate. The whole of what is called, the past' I see anew. [...] Contemplation is adventure into discovery; reality." (665) Am Ende von Pilgrimage stellt sich also dann doch eine fast prototypische Mußesituation ein und das Schreiben wird zum Weg als auch zum Ziel eines dem Alltag enthobenen Zustands.

Frau zu einer bestimmten Gruppe oder Religion mit milder Ironie wahrnimmt. Ein Leitmotiv des Romans sind Miriams wiederholte Kontakte mit unterschiedlichen Gruppen (Sozialisten, Fenians, Suffragetten), in denen sie sich trotz klarer Sympathien nur halbherzig engagiert und von denen sie sich stets zugunsten der "shared solitude“ wieder zurückzieht. 


\title{
Arbeit oder Muße
}

\section{Über eine moderne, aber falsche Alternative}

\author{
Tobias Keiling
}

Versteht sich jemand als modern, so kann das heißen, sich von einem alternativen Selbstverständnis absetzen zu wollen, das als überholt erscheint. Ob es sich dabei um jenen Fortschritt handelt, der in der Gegenüberstellung von Moderne und Vormoderne gern in Anspruch genommen wird, ist eine andere Frage. Die moderne Philosophie der Muße zeichnet sich jedoch, und das ist auffällig, nicht durch den Anspruch aus, eine programmatisch moderne Form der Muße zu beschreiben. Wenn man sich die wenigen Autoren anschaut, die zu einem Zeitpunkt zu einer Philosophie der Muße beitragen, der problemlos der Moderne zuzuordnen ist, dann erscheint es fraglich, ob sich Epochenbrüche feststellen lassen. Die prägenden Thesen und Argumentationsmuster der antiken Philosophie werden ergänzt und modifiziert, aber im Grundsatz beibehalten.

Was sich jedoch verändert, ist die Motivation des philosophischen Nachdenkens über Muße. Muße wird als Gegenbegriff und -phänomen zur Arbeit als Grundform menschlichen Lebens und sozialer Organisation verstanden. Diese veränderte Motivation ist jedoch eher eine Reaktion auf Phänomene der Moderne, als dass versucht würde, programmatisch die bisherige Philosophie der Muße zu überwinden. Erst in der Reaktion auf sie umgebende historische und gesellschaftliche Bedingungen gehört die Philosophie der Muße in die querelle des anciens et des modernes hinein. Sucht man ihren Beitrag für das Nachdenken über Muße, dann haben diese Philosophien der Muße vor allem einen kritischen Effekt: Unter den Bedingungen der Moderne treten systematische Probleme deutlicher hervor, welche in der klassischen Muße-Konzeption antiken Ursprungs angelegt sind. Der Versuch, aus der Gegenüberstellung von Muße und Arbeit eine positive Bestimmung von Muße zu entwickeln, erzeugt weniger eine eigene, spezifisch moderne oder sogar in der Sache fortschrittlichere Philosophie der Muße, als dass sie in verschiedene Formen eines klassischen Dilemmas führt. Damit, das zu zeigen, kann die Philosophie einen Beitrag zur Aufklärung über Muße als etwas leisten, das integraler Bestandteil eines guten Lebens ist.

Diese These möchte ich im Folgenden anhand von zwei Autoren untersuchen, die verschiedenen ideengeschichtlichen Strömungen zuzuordnen sind und sich 
daher eignen, Grundoptionen des philosophischen Nachdenkens über Muße (oder idleness oder leisure) in der Moderne zu erörtern. Dabei ziehe ich mit Bertrand Russell (1872-1970) und Josef Pieper (1904-1997) zwei Autoren heran, die auch dem eigenen Anspruch nach zu einer Philosophie der Muße beitragen. Diese Herangehensweise hat den Vorzug, dass sich leicht begründen lässt, warum diese philosophischen Positionen einen Beitrag zu einer Philosophie der Muße leisten. Nietzsche und Heidegger etwa erscheinen in dieser Hinsicht als Grenzfälle, da es bereits einer systematisch anspruchsvollen Argumentation bedarf, um zu zeigen, dass beide zu einer Philosophie der Muße beitragen. Zweifellos sind beide Schlüsselautoren für das Verständnis der Moderne und machen es möglich, eine Philosophie der Muße zu entwickeln. Aber während bei Heidegger eher die Frage im Vordergrund steht, ob Gelassenheit als Beschreibung und Maßstab menschlichen Lebens tragfähig ist, erscheinen mir Nietzsches Bemerkungen zur Muße in erster Linie als zeitkritische Kommentare und stark auf die eigene literarische Produktion bezogen. In beiden Fällen ist keineswegs offensichtlich ist, dass die philosophischen Bemerkungen eine eigene systematische Position im Diskurs der Philosophie der Muße skizzieren. ${ }^{1}$

Das ist bei den beiden Autoren anders, die als offensichtliche Vertreter einer modernen Philosophie der Muße gelten können: Russell und Pieper haben beide Texte verfasst, welche die Muße bereits im Titel tragen und offenbar als programmatische Beiträge mit gesellschaftspolitischem Anspruch zu verstehen sind. Diese beiden Positionen möchte ich diskutieren, indem ich zuerst auf ein Grundmuster des Nachdenkens über Muße aufmerksam mache, das seinen Ursprung in der Antike hat. (1.) Zwar lässt dasselbe argumentative Schema sich bereits bei Platon finden und hat eine komplexe Wirkungsgeschichte entfaltet, die bis in die Gegenwart reicht. ${ }^{2}$ Aber in der Philosophie des Aristoteles ist dieses Argument am klarsten entwickelt. Deshalb nenne ich es das , aristotelische Paradigma' bzw. das , aristotelische Argument. Pieper und Russell arbeiten beide, so die These, noch innerhalb dieses Paradigmas, wenn sie es auch in Reaktion auf ihre Zeit modifizieren. Da Pieper sich explizit an Aristoteles orientiert, kann

${ }^{1} \mathrm{Zu}$ Heidegger, vgl. Bret W. Davis, Heidegger and the Will. On the Way to Gelassenheit, Evanston 2007; Tobias Keiling, „Letting things for themselves: Gelassenheit as enabling thinking", in: Aaron Wendland/Christos Hadjioannou/Christopher Merwin (Hg.), Heidegger on Technology, London, im Erscheinen; zu Nietzsche, vgl. Volker Gerhardt, „Der freie Geist und die Muße. Zur Anthropologie der Theorie bei Nietzsche“, in: Thomas Jürgasch/ Tobias Keiling (Hg.), Anthropologie der Theorie, Tübingen 2017, 225-246; Martin Jörg Schäfer, Die Gewalt der Muße. Wechselverhältnisse von Arbeit, Nichtarbeit, Ästhetik, Zürich/ Berlin 2013; Schäfer, „Müssiggang eines Gottes. Schreibarbeit nach Nietzsche“, in: Alexander Karschnia/Oliver Kohns/Stefanie Kreuzer/Christian Spies (Hg.), Zum Zeitvertreib. Strategien - Institutionen - Lektüren - Bilder, Bielefeld 2005, 175-186, sowie den Beitrag von Schäfer in diesem Band.

2 Zu Platon, vgl. Hélder Telo, „The freedom of theoría and scholé in Plato“, in: Jürgasch/ Keiling (Hg.), Anthropologie der Theorie, 11-28. Zur Wirkungsgeschichte, siehe die Beiträge in jenem Band. 
seine Philosophie der Muße als exemplarischer Fall einer Aktualisierung des ,aristotelischen Paradigmas' in der Moderne gelten (2.). Während Russell in einem Punkt die Position Aristoteles' ergänzt, folgt er jedoch wie Pieper dem argumentativen Schema des aristotelischen Paradigmas. (3.) Bei beiden wird, so möchte ich zeigen, das Verständnis dessen, was Menschen in Muße tun, jedoch unplausibel: Piepers Verständnis des Tuns in Muße ist zu restriktiv, Russells zu unspezifisch. Aus dieser kritischen Beobachtung resümiere ich (4.) die Problemlage einer (modernen) Philosophie der Muße und formuliere zwei vorläufige Ergebnisse der Diskussion.

\section{Das aristotelische Paradigma}

Das Thema der Muße (scholé) durchzieht Aristoteles' Philosophie. Das macht eine systematische Rekonstruktion schwierig, da diese sich auf ganz verschiedene Aspekte seines Werks beziehen muss. Allerdings gibt es einige entscheidende Anhaltspunkte, die sich als eine spezifische Form des Nachdenkens über und als Argument für den ethischen Wert der Muße beschreiben lassen. Die verschiedenen, oft operativen Bestimmungen der Muße lassen sich am besten durch ihre Funktion für dieses Argument beschreiben. Aristoteles' Philosophie der Muße nicht über die Diskussion verschiedener Passagen, sondern über ein leitendes Argument zu erfassen, bereitet die Frage vor, wie plausibel dieses Argument in seinen antiken und modernen Variationen ist. ${ }^{3}$

Als Ziel des aristotelischen Arguments lässt sich formulieren, was Aristoteles knapp definiert: dass die Glückseligkeit (eudaimonía) des Menschen, in der Muße' sei (en te schole einai). ${ }^{4} \mathrm{Da}$ Glückseligkeit erstrebenswert ist, definiert den damit der Muße zugesprochenen Wert einsichtig zu machen, das normative Ziel des aristotelischen Arguments. Auf diese im zehnten Buch der Nikomachischen Ethik formulierten These folgt unmittelbar ein Vergleich, demzufolge sich der Wert der Muße darin erweise, dass wir sie aufgäben, um sie zu erlangen, so wie wir Krieg führten, um in Frieden zu leben. Diese Analogie verdeutlicht den Wert der Muße in emphatischer Weise. Sie ist gewissermaßen das kürzest mögliche Argument für die Muße. Allerdings gibt Aristoteles keine expliziten Hinweise darauf, worin genau Muße und Frieden übereinkommen. Der Vergleich setzt

${ }^{3}$ Einschlägig sind vor allem das erste und das zehnte Buch der Nikomachischen Ethik sowie das achte Buch der Politik. Als alternative Rekonstruktionsversuche zu Aristoteles, vgl. Simon Varga, Vom erstrebenswertesten Leben. Aristoteles' Philosophie der Muße, Boston/Berlin 2014; Varga, „Antike politische Anthropologie. Lebensform, Muße und Theorie bei Aristoteles", in: Jürgasch/Keiling, Anthropologie der Theorie, 29-48; Gabriel Richardson Lear, Happy lives and the highest good. An essay on Aristotle's „Nicomachean Ethics“, Princeton 2004; Kostas Kalimtzis, An inquiry into the philosophical concept of Scholê. Leisure as a political end, London 2017.

${ }^{4}$ Aristoteles, Nikomachische Ethik, 1177b. 
zudem einen Kontrast von Muße und Nichtmuße (ascholía) voraus, der in der Analogie jenem von Krieg und Frieden entspricht. Diesen Kontrast und über diesen die Muße genauer zu fassen, ist das deskriptive Ziel des aristotelischen Arguments.

Das aristotelische Argument hat damit ein deskriptiv-normatives Doppelziel. Es geht nicht von Definitionen aus, sondern die in diesem verwendeten Begriffe klären sich im Zusammenspiel der Prämissen und der Konklusion. Seine Struktur lässt sich schematisch folgendermaßen rekonstruieren:

(i) Muße ermöglicht die qualifizierte Tätigkeit der Theorie (theorein, theoría).

(ii) Die Tätigkeit der Theorie definiert eine eigene kontemplative Lebensform (bios theoretikós).

(iii) Die Tätigkeit der Theorie stellt die Verwirklichung (érgon) des menschlichen Lebens dar.

(iv) Diese Verwirklichung ist das Gute (agathón) für menschliches Leben.

Diese vier Prämissen führen nicht nur zu der Konsequenz, dass, in der Muße Glückseligkeit sei, sie spezifizieren diesen Gedanken auch. Dies betrifft insbesondere die Überlegung, dass Muße sich durch eine Tätigkeit oder Wirklichkeit (enérgeia) auszeichnet, als deren Ermöglichung Muße in den Blick kommt. ${ }^{5}$ Es ist diese Tätigkeit, die sich in der aristotelischen Anthropologie als Verwirklichung der menschlichen Naturanlagen beschreiben lässt und unter den verschiedenen Lebensformen die theoretische oder kontemplative auszeichnet. Daher kommt für die verschiedenen Schritte dieses Arguments alles darauf an, was Theorie als Tätigkeit definiert. Die Beschreibung dieser Klasse von Handlungen konkretisiert, worin Muße und menschliche Glückseligkeit bestehen. Unabhängig davon, wie diese verschiedenen Thesen genauer zu verstehen und ob sie richtig sind, ist diese Engführung von Muße und Theorie das erste strukturelle Merkmal des aristotelischen Paradigmas. Was ,Theorie ist, kann in verschiedenen Diskursen und zu verschiedenen Zeiten unterschiedlich bestimmt werden. ${ }^{6}$ Für den Typus des aristotelischen Arguments bleibt es aber kennzeichnend, Muße von einer bestimmten Klasse von Tätigkeiten her zu bestimmen, die sich nur in Muße realisieren lassen und so indirekt den Wert der Muße ausmachen.

Das zweite Merkmal ergibt sich daraus, wie Aristoteles für die einzelnen Thesen argumentiert. Denn es ist kennzeichnend, dass Aristoteles dihairetisch verfährt, jeweils mehrere Alternativen diskutiert, von denen sich eine als vorzugswürdig erweist. Das gilt bereits für den Kontrast von Muße und ,Unmuße', aber

5 Vgl. auch Jochen Gimmel/Tobias Keiling u.a., Konzepte der Muße, Tübingen 2016, 53-55.

6 Als Überblick über Variationen dieses Gedankens einer Anthropologie der Theorie, vgl. die Beiträge in Jürgasch/Keiling (Hg.), Anthropologie der Theorie; Kalimtzis, An Inquiry, 51-82. Zur Bedeutungsgeschichte von theoría, vgl. Hannelore Rausch, Theoria. Von ihrer sakralen zur philosophischen Bedeutung, München 1982. 
es gilt ebenso bei jedem der verschiedenen Schritte des Arguments. Besonders offensichtlich ist das im Hinblick auf die Beschreibung von Theorie und einer dieser Tätigkeit entsprechenden Lebensform: Handlungen der Klasse der ,Theorie‘ werden denjenigen gegenübergestellt, die als Formen von praxis sich wesentlich darüber bestimmen, dass sie durch das diesen Tätigkeiten inhärente Ziel (télos) beschrieben und normativer Bewertung zugänglich werden (i). Das gilt auch für Tätigkeiten der Theorie, allerdings haben diese Selbstzweckcharakter. Sie sind autotelisch, tragen ihr Ziel also in sich selbst. Theorie ist deshalb die ,höchste Form des Tätigseins. ${ }^{7}$ Dies führt zum entscheidenden Merkmal der kontemplativen Lebensform gegenüber der politischen Lebensform (bios politikós) als zweitbester Lebensform (ii): Das Leben der Theorie wahrt ihre Autarkie gegenüber Zielen, die über das hinausgehen, was in dieser Lebensform selbst enthalten ist. Diese Beschreibungen von Handlungsklassen und Lebensformen konkretisieren die abstraktere Unterscheidung eines erfüllten von einem unerfüllten Leben (iii) als eines guten und eines schlechten Lebens (iv). Auch hier ist jedoch die Opposition verschiedener Alternativen entscheidend, wie sie in den Kontrasten theoretisch/praktisch, erfüllt/unerfüllt, gut/schlecht zum Ausdruck kommt. Erst aus diesen Oppositionen ergibt sich, welche Weise zu handeln und zu leben in besonderer Weise ,muße-affin' ist und Glückseligkeit verspricht.

Ein Denken in solchen binären und hierarchischen Oppositionen könnte grundsätzlich problematisch sein. ${ }^{8}$ Aber unabhängig von dieser Frage belastet es das aristotelische Paradigma mit einem spezifischen Problem. Denn es besteht die Gefahr, aus falschen Alternativen heraus zu argumentieren. Die Überzeugungskraft des Paradigmas hat viel damit zu tun, dass zum Beleg der Triftigkeit einer Opposition auf die analoge Gegenüberstellung auf einer anderen Ebene des Paradigmas verwiesen werden kann, so dass sich die verschiedenen Schritte oder Ebenen des Arguments gegenseitig verstärken. Wenn etwa die Unterscheidung der Lebensformen problematisch erscheint, weil man Mischformen entdeckt,

7 Zur Unterscheidung von Theorie und Praxis bei Aristoteles, vgl. Thomas Jürgasch, Theoria versus Praxis? Zur Entwicklung eines Prinzipienwissens im Bereich der Praxis in Antike und Spätantike, Boston/Berlin 2013, 189-199.

8 Als Exposition dieses poststrukturalistischen Allgemeinplatzes, vgl. etwa Jacques Derrida, „Die différance“, in: Randgänge der Philosophie, Wien 1988, 31-56. Ein ähnlicher Fall dafür, wie problematisch hierarchische Oppositionen für die Beschreibung von phänomenalen und epistemischen Strukturen sein können, ist die Unterscheidung von Mythos und Logos. Es ist jedoch keineswegs klar, ob diese ,mythologische Differenz' dekonstruiert werden muss oder nicht vielmehr selbst Gegenstand kulturwissenschaftlicher Beobachtung sein kann. Vgl. Tobias Keiling, „Dekonstruktion und Phänomenologie mythologischer Differenzen“, in: Christoph Jamme/Stefan Matuschek (Hg.), Die mythologische Differenz. Studien zur Mythostheorie, Heidelberg 2009, 127-150. Gerade Aristoteles vermeidet in der Beschreibung von mythoi übrigens strikte Oppositionen. Vgl. Tobias Keiling, „Mimesis und Mythostheorie bei Aristoteles und Gadamer: Hermeneutische Überlegungen“, in: Bent Gebert/Uwe Mayer (Hg.), Zwischen Präsenz und Repräsentation: Mythos in theoretischen und literarischen Diskursen, Berlin/Boston 2014, 48-70. 
dann lässt sich darauf verweisen, dass dies nicht grundsätzlich in Frage stellt, dass es einen Unterschied zwischen zweckgebundenem und autotelischem Handeln oder zwischen einem guten und einem schlechten Leben gibt. Nimmt man dieses Merkmal mit dem ersten, der Bestimmung von Theorie als dem Handeln in Muße zusammen, dann wird deutlich, dass für die Stimmigkeit des aristotelischen Paradigmas im Ganzen alles darauf ankommt, wie ,Theorie in den verschiedenen Schritten des Arguments zu verstehen ist. Die Beschreibung dessen, was in Muße getan wird, muss plausibel werden, um von hier aus zu bestimmen, worin Muße sich auch als Lebensform, menschliche Natur und Erfahrung von Glückseligkeit verwirklicht.

Pieper und Russell versuchen jedoch, Muße-Handeln von seinem Gegenteil - dem Arbeiten - her zu begreifen. Deshalb scheint es zunächst, als ob sie die Engführung von Muße und Theorie unterlaufen. Der Kontrast von Muße und „Unmuße' (ascholía) in der modernen Variante Muße und ,Arbeit' ersetzt die Beschreibung dessen, was man in Muße tut, jedoch bei genauerem Hinsehen nicht. Die Beobachtung, dass antike Sprachen, Arbeit' in Ausdrücken wie ascholía oder negotium als Negation von Muße (scholé, otium) fassen, während in der Moderne Muße als Negation der Arbeit konzipiert wird, ist zwar zutreffend. Aber diese Beobachtung rechtfertigt nicht die Konsequenz, die Bestimmung eines maßgeblichen Muße-Handelns sei in der Logik moderner Beschreibungen und Rechtfertigungen von Muße irrelevant und durch die Gegenüberstellung zur Arbeit ersetzt worden. Zwar ist auffällig, dass der Versuch gemacht wird, aus einer Vorstellung von Arbeit, die als problematisch bewertet wird, durch deren Umkehrung eine positive Bestimmung von Muße zu generieren. Bei genauerem Hinsehen ist der Gedanke, sie sei das Andere der Arbeit, jedoch weder für Pieper noch für Russell hinreichend zur Bestimmung der Muße.

\section{Josef Pieper: Muße und Kult (1948)}

Pieper beginnt seinen Essay mit dem Einwand, die unmittelbare Nachkriegszeit sei „nicht die rechte Zeit ... von der Muße zu reden“. Dieser Einwand werde jedoch durch die Überlegung widerlegt, ,just die neue Grundlegung [mache] eine Verteidigung der Muße notwendig“. Ob der „Neubau“ der deutschen Kultur „in abendländischem Geiste geplant“ werde, stehe „heute zur Entscheidung“. Und diese Frage entscheide sich eben daran, ob Muße als ,eines der Fundamente der abendländischen Kultur" anerkannt werde. ${ }^{9}$

Es ist für seinen Essay kennzeichnend, dass Pieper nach dieser kurzen Situierung im ,Heute' unvermittelt zur aristotelischen Philosophie springt, welche

9 Josef Pieper, „Muße und Kult“, in: Werke in acht Bänden $(=W), B d .6$, hg. v. Berthold Wald, Hamburg 1999, 1-44, 2. 
eben den in Rede stehenden Gedanken artikuliert, dass Muße alle kulturellen Leistungen bedinge. Der wortgeschichtliche Ursprung von ,Schule im griechischen scholé könne als erstes Indiz für die Allgemeingültigkeit dieser Überlegung gelten. ${ }^{10}$ Für Pieper gibt diese Überlegung jedoch nicht nur eine erste Orientierung, sondern sie bildet auch den Anspruch seines eigenen Nachdenkens. Entsprechend schließt Pieper mit der Wiederholung dieses Gedankens. ${ }^{11}$ Wirkungsgeschichtlich wird dies darin deutlich, dass die englische Übersetzung von $\mathrm{Muße}$ und Kult bereits 1952 unter dem Titel Leisure, the basis of culture erschien. ${ }^{12}$ Die Verbindung dieser systematischen, kulturtheoretischen Überlegung mit einer Krisendiagnose definiert die sehr spezifische Perspektive Piepers auf seine Gegenwart: Den gerade geschehenen Zivilisationsbruch thematisiert Pieper lediglich als Moment des Gegenphänomens der Muße - der Arbeit. ${ }^{13}$

Damit setzt Pieper diesem Bruch keine alternative Erzählung geschichtlicher Kontinuität, sondern ursprüngliche und unverändert gültige Einsichten entgegen, für die vor allem Aristoteles, im Verlauf des Textes auch Augustinus und Thomas einstehen. ${ }^{14}$ Die geschichtliche Situation hat zwar die Kontingenz kulturellen Lebens aufgezeigt. Dieser Kontingenz begegnet Pieper aber mit einer Gegenüberstellung von Muße und Arbeit, die nicht auf die jüngere Geschichte festgelegt ist, sondern die Moderne als Ganze in den Blick nimmt, in der sich die hierarchische Opposition beider verkehrt habe. Ohne auf den drei Jahre zuvor zu Ende gegangenen Weltkrieg einzugehen, schreibt Pieper, der „ursprüngliche Begriff ,Muße“ „, sei „in der programmatischen Mußelosigkeit der totalen Arbeitswelt ganz und gar unkenntlich geworden“. Dieser Diagnose folgt ein Therapievorschlag, der zwar eine Gemeinschaft adressiert, aber auch individuelles

10 Pieper, „Muße und Kult“, in: W 6, 3. Ob die Bemerkung Aristoteles' über den historischen Ursprung der Mathematik im antiken Ägypten wirklich diesen Grad der Allgemeinheit beansprucht, ist jedoch keineswegs klar. Vgl. Aristoteles, Metaphysik, $981 \mathrm{~b}$.

11 Vgl. Pieper, „Muße und Kult“, in: W 6, 41-44.

12 Josef Pieper, Leisure, the basis of culture, übersetzt v. Alexander Dru, London 1952. Der Band enthält auch eine Übersetzung von Piepers Vorlesungen Was heißt Philosophieren? (W 3, hg. v. Berthold Wald, Hamburg 1995, 15-69) Initiiert wurde diese Übersetzung von T. S. Eliot, der eine Einleitung verfasste und den Titel in das Verlagsprogramm von Faber \& Faber aufnahm. Die Einleitung ist auf Deutsch in der Werkausgabe enthalten (W 3, 70-75). Eliot sieht Piepers Philosophie als Antwort auf das lebensferne Philosophieverständnis des Logischen Positivismus. Anders als dieser verbinde Pieper Philosophie und Theologie wieder, was Eliot für ein plausibles Verständnis von Philosophie für unumgänglich hält. Pieper stelle sich zudem gegen die „illusion of a progress of philosophy“ (Pieper, Leisure, 14; W 3, 72)

13 Diese Analyse hat jedoch Vorläufer in Piepers frühen sozialphilosophischen Schriften. Vgl. Frank Töpfer, „Josef Pieper on the Intellectual Foundations of Totalitarianism“, in: Bernard N. Schumacher (Hg.), The Cosmopolitan Hermit, Washington 2009, 63-87.

${ }^{14}$ Diese Kontinuitätsannahme entspricht Piepers Geschichtsphilosophie. Vgl. Josef Pieper, Hoffnung und Geschichte (W 6, 375-440) sowie Joseph J. Godfrey, „The Future of Pieper's Hope and History", in: Bernard N. Schumacher (Hg.), The Cosmopolitan Hermit, 141-170. 
Umdenken fordert. Es gelte, ,unseren eigenen Widerstand zu überwinden, der aus der Überbewertung der Arbeitswelt stammt". ${ }^{15}$

Die „Überbewertung“ der Arbeit sieht Pieper in den kulturtheoretischen Schriften seiner Zeit durchaus thematisiert. Pieper verweist auf Max Webers Geist des Kapitalismus, Ernst Niekischs Die dritte imperiale Figur und Ernst Jüngers Der Arbeiter. ${ }^{16}$ Aus diesen übernimmt Pieper den Gedanken, entscheidend für das moderne Nachdenken sei das Selbstverständnis, das die Arbeitswelt Menschen anbiete. Dieses Selbstverständnis werde eben im Begriff des ,Arbeiters' deutlich, der keine soziale Stellung, kein Milieu oder eine Schichtzugehörigkeit meine, sondern als „allgemein menschliches Richtbild“ einen „, anthropologischen Sinn" gewonnen habe. Die Krise der modernen Gesellschaft ist damit eine anthropologische Krise: „eine gewandelte Meinung vom Wesen des Menschen überhaupt und eine gewandelte Deutung des menschlichen Daseins überhaupt, die sich kundtun in dem neuen Anspruch des Begriffs der Arbeit und des Arbeiters". Piepers Ziel ist jedoch nicht historiographischer, sondern therapeutischer Art: nicht den "geschichtlichen Weg" dieser Veränderung im menschlichen Selbstverständnis nachzuzeichnen, sondern „den Wurzelgrund einer philosophisch-theologischen Lehre vom Menschen "zu untersuchen. ${ }^{17}$ Dazu geht Pieper auf Muße als deskriptiven und normativen Gegenbegriff zur Arbeit ein und darin über die genannten Theoretiker hinaus.

Mit der Bestimmung des ,Arbeiters' als Symptom einer anthropologischen Krise setzt Piepers Modernediagnose im Bereich der dritten These des aristotelischen Paradigmas an, der Frage, worin sich menschliches Leben verwirklicht. Auch wenn Pieper im ersten Kapitel des Essays nur die kritische These präsentiert, dass ,Arbeit' diese Verwirklichung offenbar nicht bezeichnet, wird im zweiten Kapitel klar, dass es Pieper um eine Rehabilitierung von Theorie als anthropologisch privilegierter Tätigkeit geht. Denn Pieper diskutiert kritisch die Vorstellung, Philosophie sei als „,geistige Arbeit “ ${ }^{\prime 18}$ selbst nichts anderes als eine Form von Arbeit. Diese Zuspitzung ist aber nur dann sinnvoll, wenn man davon ausgeht, mit dem theoretischen Tun gehe etwas besonders Wertvolles verloren, das geeignet ist, als anthropologische Konstante wiederentdeckt zu werden.

Wie eng sich Pieper dabei am aristotelischen Paradigma orientiert, kann man sich im Kontrast deutlich machen. Denn es wären auch alternative Möglichkeiten denkbar, den Gedanken zu kritisieren, Arbeit sei Inbegriff menschlichen Tä-

15 Pieper, „Muße und Kult“, in: $W 6,3$.

16 Vgl. Pieper, „Muße und Kult“, in: W 6, 3-5. Chad Lakies hat vorgeschlagen, diese Diagnose mit Charles Taylor zu aktualisieren und von Arbeit als social imaginary zu sprechen. Vgl. Chad Lakies, „Challenging the Cultural Imaginary. Pieper on How Life might live", in: New Blackfriars 91 (2010), 499-510.

17 Pieper, „Muße und Kult“, in: W 6, 5. Zu Piepers philosophischem Projekt vgl. Bernard N. Schumacher, Rechenschaft über die Hoffnung. Josef Pieper und die zeitgenössische Philosophie, Mainz 2000.

18 Pieper, „Muße und Kult“, in: W 6, 6. 
tigseins, etwa eine Reflexion auf Freiheit oder Selbstbestimmung als Leitkategorien des menschlichen Selbstverständnisses in der Moderne. Diese von Pieper nicht ergriffene Alternative wäre attraktiv, weil sie die Beschreibung von Philosophie als Arbeit aus ihren eigenen Prämissen heraus widerlegen könnte. Denn Pieper macht als Schuldigen dieses philosophischen Selbstmissverständnisses Kant aus. In seinem Aufsatz über den „neuerdings erhobenen vornehmen Ton in der Philosophie“ beschreibt Kant es als ein „Gesetz der Vernunft, durch Arbeit sich einen Besitz zu erwerben“. ${ }^{19}$ Pieper weist zwar auf die historischen Bedingungen dieses gegen die Romantik gerichteten Kommentars hin, wertet ihn jedoch als Teil einer wirkmächtigen, aber durchaus zu durchschauenden Selbsttäuschung. Diese bestehe insbesondere darin, das Bemühen um Erkenntnis als hinreichende Bedingung für deren Erreichen zu beschreiben. Solches Bemühen ist für Pieper aber Kennzeichen von Arbeit. Sobald „Erkenntnismühe“ zum „Kriterium der Wahrheit“ erhoben wird, erscheint deshalb Arbeit als maßgebliche Vollzugsform von Philosophie. ${ }^{20}$ Damit geht zum einen einher, dass philosophische Erkenntnis als diskursiv, nicht intuitiv begriffen wird, was Pieper als erstes Merkmal "geistiger Arbeit“ identifiziert. Dieses begrenzte Verständnis geistigen Erkennens führt dazu, dass die eigentlich „höchste Form des Erkennens - der blitzhafte Einfall, die echte Kontemplation“ als Erkenntnismöglichkeit ausgeschlossen wird, und zwar nicht deshalb, weil sie leer, sondern weil sie „mühelos und ohne Beschwer“ sei. ${ }^{21}$ Die Ablehnung eines Verständnisses von Erkenntnis als passivem Geschehen statt aktivem Tun ist das zweite Merkmal „geistiger Arbeit“. ${ }^{22}$ Die Vorstellung, Philosophie sei Arbeit, hat drittens Konsequenzen für die soziale Organisation. Denn aus dieser scheint zu folgen, dass sich die sozialen Formen, in denen sich solche Erkenntnis vollzieht, als Formen von Arbeit starker sozialer Kontrolle und Rationalisierung unterwerfen müssen. Das Verständnis von Philosophie als einer freien Kunst (ars libera) ist davon bedroht, sich dem „,Soll' der dienenden Funktionserfüllung“ zu unterstellen, so dass Erkennen zur „sozialen Dienstleistung“ wird. ${ }^{23}$ Auch hier sollte man sich klar machen, welche Alternative Pieper damit ausschließt: Wenn die kritische Erkenntnisleistung der Philosophie etwas mit Freiheit zu tun hat, dann ließe sich argumentieren, Kants Festlegung der Philosophie auf Arbeit stehe in Konflikt mit seiner eigenen emphatischen Betonung des Werts menschlicher Freiheit, laufe also dem

19 Zitiert bei Pieper, „Muße und Kult“, in: $W$ 6, 7 .

20 Pieper, „Muße und Kult", in: W 6, 15.

${ }^{21}$ Pieper, „Muße und Kult", in: W 6, 14.

22 Pieper führt in diesem Zusammenhang sogar ein Zitat Hitlers an, welches sich zwar nicht auf die Tätigkeit des Erkennens bezieht, aber für Pieper „in extremer Radikalität“ jenes Selbstverständnis beschreibt, das Pieper ablehnt: „Jede Tat ist sinnvoll, selbst das Verbrechen; jede Passivität ... ist dagegen sinnnlos.“ (Pieper, „Muße und Kult“, in: $W 6,11$ ) Pieper bewertet diese Äußerung als einen „furchtbaren Satz“. (Pieper, „Muße und Kult“, in: $W 6,11)$.

${ }^{23}$ Pieper, „Muße und Kult“, in: W 6, 16. 
Anspruch autonomer Subjekte entgegen, selbstbestimmt zu handeln. Pieper verwendet jedoch ein anderes Kriterium, das exakt dem aristotelischen Paradigma entspricht, nämlich die Selbstzweckhaftigkeit einer Erkenntnis aus Freiheit: „Die ,Freiheit' der ,freien Künste ' liegt ... darin, dass sie sich nicht zu legitimieren brauchen aus der sozialen Funktion". ${ }^{24}$

Das vierte Kapitel macht deutlich, dass Pieper die Sozialstruktur und die Verteilung von Muße auf soziale Gruppen letztlich nicht beschäftigen. Vielmehr unterläuft Piepers Diskussion die Frage nach einer zur Arbeit alternativen sozialen Organisation dadurch, auf die anthropologischen Konsequenzen abzustellen, welche die „totale Arbeitswelt“ erzeugt. Der Exkurs über Proletarität und Entproletarisierung, der den Großteil des vierten Kapitels ausmacht, ist in dieser Hinsicht vielsagend. Denn der Exkurs zielt darauf, den Begriff des Proletariats von einer Beschreibung sozialer Differenzierung zu einer Beschreibung des unter dem Stichwort ,Arbeiter ' bereits analysierten anthropologischen Selbstmissverständnisses zu machen. „Proletarität“ bedeute, so Piepers These, „im Grunde nichts anderes als die Fesselung an den Arbeitsprozeß“. Eine „echte Entproletarisierung “ könne entsprechend dadurch erreicht werden, „daß dem arbeitenden Menschen ein Bereich sinnvollen Wirkens zugänglich gemacht werde, der nicht ,Arbeit' ist - mit anderem Wort, darin, dass ihm der Bezirk wahrer Muße erschlossen werde“. 25

Damit modifiziert Pieper die Unterscheidung von Arbeit und Muße gegenüber seinen vorherigen Bemerkungen. Von einer Beschreibung und Bewertung sozialer Organisation wird diese Unterscheidung zu einem Kontrast von Lebensformen, zwischen denen Individuen offenbar wechseln. Zwar bezeichnet Pieper es als etwas „Unumgängliches“, „durch politische Maßnahmen eine wirtschaftliche Ausweitung“ jenes „Lebensraums herbeizuführen“, der für Muße zur Verfügung steht. Damit ist eine „äußere Ermöglichung der Muße“ gemeint, eine Veränderung der sozialen Organisation. ${ }^{26}$ Für Pieper ist diese Veränderung zwar notwendig, jedoch nicht hinreichend. Das „Entscheidende“ betreffe nicht die soziale Organisation, sondern das Individuum als Repräsentanten des Menschlichen: „Eine rein äußere Ermöglichung von Muße genügt nicht; sie kann erst dann zur Frucht gedeihen, wenn es dem Menschen von sich aus möglich geworden ist ,Muße zu wirken' (so lautet die griechische Ausdrucksweise - scholèn ágein...)“. 27

24 Pieper, „Muße und Kult“, in: $W$ 6, 17.

25 Pieper, „Muße und Kult“, in: $W$ 6, 35-36.

26 Pieper, „Muße und Kult“, in: $W$ 6, 36. Zu Piepers Sozialphilosophie, vgl. Berthold Wald, „Der ,linke Pieper" und das Dritte Reich“, in: Hermann Fechtrup/Friedbert Schulze/Thomas Sternberg (Hg.), Wissen und Weisheit. Zwei Symposien zu Ehren von Josef Pieper, Münster 2005, 199-218.

27 Pieper, „Muße und Kult“, in: W 6, 36. 
Damit wird die Beschreibung und Bewertung von Muße von einer Frage der politischen Philosophie oder Sozialphilosophie zurückverwiesen auf die Bestimmung jenes Handelns, das in Muße geschieht oder selbst Muße ist, wie Pieper hier mit Verweis auf Aristoteles meint. Diese Überlegung impliziert allerdings, dass die Gegenüberstellung von Arbeit und Muße, so wichtig sie ist, um Piepers Nachdenken zu motivieren und auf die soziale Situation seiner Gegenwart zu beziehen, letztlich zu kurz greift, um eine positive Bestimmung von Muße zu entwickeln. Pieper verbleibt innerhalb der Vorgaben des aristotelischen Paradigmas, wenn er die Frage nach der sozialen Organisation von Arbeit und Muße auf die Anthropologie und zuletzt auf die Handlungstheorie zurückverweist, in der sich erst eine positive Bestimmung dessen geben lässt, was es heißt, in Muße zu handeln. Aus der modernekritischen Diagnose und ihrem gesellschaftspolitischen Anspruch wird eine Frage individuellen Handelns.

Dies wird besonders deutlich darin, dass Pieper im dritten Abschnitt seines Essays Muße im Gegensatz nicht zur Arbeit, sondern im Gegensatz zur Trägheit (acedia) bestimmt. Jemand, der faul oder träge ist, arbeitet ebenso wenig wie derjenige, der ,Muße wirkt'. Dieses Phänomen bietet sich daher an, um innerhalb der Nicht-Arbeit noch einmal zu differenzieren. Der Gegensatz von Muße und Arbeit spezifiziert sich zum Kontrast von Muße und Trägheit. Im Rückgriff auf Thomas von Aquin schreibt Pieper, den „Gegenbegriff zur acedia“ stelle „nicht der Arbeitsgeist des alltäglichen Erwerbslebens“ dar, sondern „die hochgemute Bejahung und Zustimmung des Menschen zu seinem eigenen Wesen, zur Welt insgesamt, zu Gott - also die Liebe“ ${ }^{28}$ Es ist überdeutlich, wie Pieper hier den anthropologischen Maßstab des aristotelischen Paradigmas unter christlichen Vorzeichen reaktualisiert, um zu einer positiven Bestimmung von Muße zu gelangen: „Muße kann es nur geben, wenn der Mensch eins ist mit sich selbst, wenn er seinem eigentlichen Sein zustimmt. “29 Dieses Kriterium macht deutlich, warum Muße nicht auf ihre „äußere Ermöglichung“ in sozialen Formen zu reduzieren ist: Übereinstimmung mit sich selbst ist, wie die Überwindung der Sünde der acedia, eine individuelle und innere Angelegenheit. Die soziale Einbettung kann sie lediglich erschweren oder begünstigen, aber nicht garantieren. Auch seine Analyse der Moderne entwickelt Pieper deshalb im Verlauf des Essays immer stärker auf diese Beschreibung von Spiritualität hin, welche dadurch zum Zentrum seiner Argumentation wird. Emphatisch heißt es: „Muße ist, als seelische Haltung (dieses Selbstverständliche muß festgehalten werden: Muße ist mit den äußeren Fakten von Arbeitspause, Freizeit, Wochenend, Urlaub nicht schon gegeben. Muße ist ein Zustand der Seele!) - die Muße ist präzis der Kontrapost des Richtbilds vom ,Arbeiter" 30

28 Pieper, „Muße und Kult“, in: W 6, 21-22.

29 Pieper, „Muße und Kult", in: W 6, 22.

30 Pieper, „Muße und Kult“, in: W 6, 23. 
Diese Beschreibung von Muße als einer „seelischen Haltung“ weicht einerseits vom aristotelischen Paradigma ab, da dieser Haltung, zumindest in der aristotelischen Philosophie, nichts direkt entspricht. ${ }^{31}$ Andererseits folgt Pieper dem aristotelischen Argument doch, da diese „seelische Haltung“ sich nur in spezifischen Weisen des Tätigseins konkretisiert, die sich in der ,Innenperspektive des Handelnden durch diese Motivation auszeichnen. So beschreibt Pieper in Inversion des ,Arbeiters' Muße als „Haltung der Nicht-Aktivität, der inneren Ungeschäftigkeit, der Ruhe, des Geschehen-Lassens, des Schweigens“. Als Haltung solchen „empfangenden Vernehmens“ sei Muße aber zugleich die Haltung „der anschauenden, kontemplativen Versenkung in das Seiende“. ${ }^{32} \mathrm{Muße}$ als so verstandene Disposition definiert sich also über ihre Erfüllung in einem spezifisch theoretischen Tätigsein, das nicht diskursiv und reflexiv, sondern intuitiv und damit objekt- oder weltbezogen ist. Eine Form des Erkennens, die sich nicht als ,Arbeit' missversteht, überschreitet konstitutiv das Subjekt auf die Gegenstände seiner Betrachtung hin und findet in diesen seine Erfüllung. Die „seelische Haltung" kann dies mehr noch als die soziale Organisation von Muße begünstigen, wenn sie es letztlich nicht garantieren kann.

Aus dieser Überlegung ergibt sich das zweite Charakteristikum der Muße, die Inversion des Gedankens, erkennendes Tätigsein müsse mühsam sein: Muße ist die „Haltung feiernder Betrachtung“. Erst in dieser nach ,außen“ und auf bestimmte Tätigkeiten gerichteten Haltung liegt die Erfahrung, nicht nur „dem wahren Wesen seiner selbst“ zuzustimmen, sondern „auch mit dem Sinn der Welt in Übereinstimmung zu sein“ “ ${ }^{33}$ Aus dieser Überlegung beschreibt Pieper als das exemplarische Phänomen, als „höchste Form der Bejahung“, das Feiern eines Festes. Denn hier werde eine intensive Übereinstimmung von Selbst- und Weltverhältnis erfahren. Das Fest ist die exemplarische Muße-Zeit, „der innere und innebleibende Ursprung von Muße. Es ist der Feier-Charakter, durch den es der Muße zukommt, nicht allein mühelos zu sein, sondern das Gegenteil von Mühe. "34 Erst im Fest erlangt das Nicht-Arbeiten einen Sinn, den Pieper als „Übereinstimmung“ und „Zustimmung zur Welt“ fasst, welche dem Arbeiten ebenso wie der Trägheit fehlen. ${ }^{35}$

Anhand dieses Kriteriums einer intensiven Erfüllung und am Beispiel des Fests ergibt sich dann auch Piepers konkretes Verständnis von Muße-Handeln. Während im zweiten Kapitel Piepers Kritik der „geistigen Arbeit“ das Selbstver-

31 Das betrifft vor allem die Qualifikation dieser Haltung als „seelisch“. Denn Aristoteles geht durchaus davon aus, dass es eine Haltung oder Disposition (héxis) zum tugendhaften Verhalten gibt, und das schließt die Theorie nicht aus, welche die Tugend oder Bestheit (areté) des geistigen Vermögens (nous) des Menschen bezeichnet. Vgl. Aristoteles, Nikomachische Ethik, 1177a.

32 Pieper, „Muße und Kult“, in: $W$ 6, 23.

33 Pieper, „Muße und Kult", in: $W$ 6, 24.

34 Pieper, „Muße und Kult“, in: W 6, 25.

35 Pieper, „Muße und Kult“, in: $W$ 6, 36. 
ständnis der Philosophie betraf, so dass die Philosophie und die anderen freien Künste als exemplarische Fälle von Theorie galten, wird im letzten Kapitel der (deutsche) Titel von Piepers Essay eingeholt: Der exemplarische Fall eines Tuns in Muße ist jetzt nicht mehr das Philosophieren, sondern das kultische Handeln. Der Gedanke, dass Feste exemplarische Muße-Zeiten sind, zielt jedoch auf eine sehr spezifische Konsequenz, die sich in der Umdeutung der sozialen zur anthropologischen und zuletzt zu einer spirituellen Frage bereits angedeutet hatte: „Wenn aber Feiern der Kern von Muße ist, dann empfängt die Muße ihre innere Ermöglichung und Legitimierung von eben dort her, von woher das Fest und die Feier ihren Sinn und ihre innere Ermöglichung empfangen. Dies aber ist der Kult!"36

Kultisches Handeln ist damit das paradigmatische Muße-Handeln. Pieper bekräftigt dies durch den Gedanken einer hierarchischen Opposition verschiedener Handlungsklassen. Da „keine intensivere Zustimmung zur Welt" vorstellbar sei „als das ,Gottes-Lob', die Preisung des Schöpfers eben dieser Welt", ist der Kultus die höchste Verwirklichung dessen, was Menschen tun können. Der Kultus ist die Vervollkommnung des Feierns als desjenigen „unalltäglichen“ Tuns, dem bereits vor dem Arbeiten Vorrang gebührt. Der Kult wiederum ist „,das festlichste Fest“. Aus diesem Ideal ergibt sich auch ein Kriterium für richtige und falsche Formen des Feierns. „Echte Festlichkeit“ stelle sich nur dort ein, „wo die Beziehung zum Kult noch lebendig ist" ${ }^{37}$ Pieper legt Wert darauf, dass dies nicht nur als „Forderung“, sondern auch als „Feststellung“ gemeint sei, das durchaus normative Kriterium der ,Echtheit' im Phänomen des Fests selbst also deskriptiv festzumachen sei. Mit der Verwirklichung des spezifischen theoretischen und des menschlichen Handelns allgemein im Kult ist dann auch der dritte Bereich des aristotelischen Paradigmas berührt. „Abgetrennt vom Kult“ werde Muße zur acedia, nämlich „müßig“, und ohne Widerhalt im Kult werde Arbeit „unmenschlich “. ${ }^{38}$ Allein im kultischen Handeln findet sich demnach jene Verwirklichung menschlicher Natur, die Trägheit und Arbeit beide nicht bieten, welche aber als einzige Glückseligkeit verspricht.

\section{Bertrand Russell: In Praise of Idleness (1932)}

Russells Kritik der Moderne zielt ebenfalls auf ein durch Arbeit geprägtes Selbstverständnis und entwickelt unter dem Titel leisure eine Alternative. Dabei differenziert Russell nicht zwischen leisure und dem titelgebenden idleness, sondern sieht beide durch die spezifische Ambivalenz geprägt, dass menschliches Glück

\footnotetext{
36 Pieper, „Muße und Kult“, in: W 6, 36.

37 Pieper, „Muße und Kult", in: W 6, 37.

38 Pieper, „Muße und Kult", in: W 6, 39.
} 
gerade hier entweder zu erreichen oder zu verfehlen sei. Aufgrund dieses Versprechens ist Muße für Russell „essential to civilisation“.39 Darin ähnelt Russells Anliegen demjenigen Piepers, auch wenn Russell dieses im Rückblick auf den gewonnenen ersten Weltkrieg in weniger drastischer Form als Pieper in der Zeit unmittelbar nach dem Zweiten Weltkrieg formuliert. Ohne explizit auf Aristoteles oder dessen Wirkungsgeschichte zu verweisen, orientiert sich auch Russell dabei an der Grundform des aristotelischen Arguments.

Das wird bereits darin deutlich, wie Russell das Ziel seines Essays beschreibt: „I want to say, in all seriousness, that a great deal of harm is being done in the modern world by belief in the virtuousness of wORK [sic!], and that the road to happiness and prosperity lies in an organised diminuation of work. " ${ }^{40}$ Das deskpritiv-normative Ziel seiner Überlegungen ist also die Beschreibung von leisure als mögliche Erfahrung von Glück, dem Arbeit entgegensteht. Zur Abgrenzung beider Formen menschlichen Tätigseins stellt Russell dabei, ganz dem aristotelischen Paradigma entsprechend, auf das Kriterium der Selbstzweckhaftigkeit ab. Zwar gibt Russell zuerst eine vulgär physikalische Definition von Arbeit. Arbeit sei ,altering the position of matter at or near the earth's surface relatively to other such matter [or] telling other people to do so ". ${ }^{41}$ Diese Beschreibung dient jedoch nicht der Abgrenzung zur Muße. Das entscheidende Kriterium liegt vielmehr in der Selbstzweckhaftigkeit, welche in der Moderne fälschlicherweise der Arbeit zugeordnet werde. Arbeit werde als „end in itself“ angesehen, „rather than as a means to a state of affairs in which it is no longer needed " ${ }^{42}$ Erst aus ihrer jeweils spezifischen teleologischen Struktur ergibt sich mithin der Kontrast von Arbeiten und Muße-Handeln.

Allerdings ist es vielsagend, dass Russell als Bedingung für ein Handeln in Muße eine Verringerung der Arbeitszeit ansieht. Konkret geht es ihm um eine Begrenzung der Arbeitszeit auf vier Stunden pro Tag. Die Beibehaltung der "scientific organisation of production“ ${ }^{43}$, die im ersten Weltkrieg etabliert worden sei, habe es möglich gemacht, eine soziale Organisation zu erreichen, in der Arbeit gleich verteilt ist und strukturelle Arbeitslosigkeit vermieden werden kann. Anstatt die während des ersten Weltkriegs eingeführte Organisation beizubehalten, sei man jedoch zum „old chaos“ der kapitalistischen Produktionsweise zurückgekehrt. Dies habe zur strukturellen Arbeitslosigkeit geführt, die Russell als Anzeichen für die falsche Organisation von Arbeit während der great depression ansieht. Diese Arbeitslosigkeit identifiziert Russell als den spezi-

39 Bertrand Russell, „In Praise of Idleness“, in: Russell, In Praise of Idleness, Abingdon 1996, 1-15, 5. Der Text erschien 1932 in Harper's Magazine und bereits 1935 als erstes Kapitel einer Aufsatzsammlung gleichen Titels, die bis heute wiederaufgelegt wird.

40 Russell, „In Praise of Idleness“, 3.

41 Russell, „In Praise of Idleness", 3.

42 Russell, „In Praise of Idleness“, 10.

43 Russell, „In Praise of Idleness“, 6. 
fischeren Kontrast von Muße, der auf eine paradoxe Beziehung zwischen Arbeit und Muße aufmerksam macht. Während die eine Hälfte der Gesellschaft „totally idle“ ist, ist die andere „overworked“. Durch die falsche Verteilung von Arbeit und Muße verkehrt sich die Erfahrung von Muße in das für sie spezifische Gegenteil: „The unavoidable leisure shall cause misery all around instead of being a universal source of happiness" ${ }^{44}$

Auch wenn beide in verschiedenen kulturellen und historischen Kontexten ihren Ursprung haben, erfüllt die strukturelle Arbeitslosigkeit damit eine ähnliche Funktion für die Bestimmung und Bewertung von Muße wie die acedia. Die Diskussion der Unterbeschäftigung macht deutlich, dass leisure als Gegenbegriff zur Arbeit für Russell Muße und Müßiggang gleichermaßen umfasst. ${ }^{45}$ Aber dieser semantischen Ambivalenz des Ausdrucks steht eine systematische Differenzierung zwischen freier und erzwungener Muße gegenüber: Russell orientiert sich offenbar am aristotelischen Paradigma, denn beide Formen von Muße sind dadurch zu unterscheiden, dass Unterbeschäftigung jenes Glück nicht verwirklicht, das Muße verspricht. Aus diesem Glücksversprechen ergibt sich die Motivation dafür, der sozialen Organisation von Arbeit und Muße größte Aufmerksamkeit zu schenken.

Offensichtlich beeinflusst von Keynes' enthusiastischen Prognosen zur Verringerung der Arbeitszeit bei gleichbleibender Produktion beurteilt Russell die Verbindung von Arbeit und Moderne deshalb anders als Pieper. ${ }^{46}$ Erscheint bei Pieper das Bild des ,Arbeiters' als anthropologisches und spirituelles Verlustund Entfremdungsphänomen, ist für Russell das moderne Verhältnis zur Arbeit konstitutiv widersprüchlich. Die Paradoxie besteht darin, in immer größerem Maße Erfüllung in Arbeit zu suchen und zugleich in immer geringerem Maße arbeiten zu müssen. Die Überzeugung, dass sich menschliches Leben in Arbeit verwirkliche, entstamme dem vorindustriellen Zeitalter und sei daher „not adapted to the modern world“. Gerade die industrielle Organisation von Arbeit mache es möglich, weniger Zeit mit Arbeit zu verbringen und räumt so die Freiheit ein, sich von der normativen Überschätzung der Arbeit zu befreien: „Modern technology has made it possible for leisure, within limits, to be not the prerogative of small privileged classes, but a right evenly distributed throughout

44 Russell, „In Praise of Idleness“, 7.

45 Eine ähnliche Ambivalenz lässt sich für den Ausdruck idleness feststellen. Zu Semantik und Kulturgeschichte beider, vgl. die Beiträge in Monika Fludernik/Miriam Nandi (Hg.), Idleness, indolence and leisure in English literature, Basingstoke 2014. Zur Interdependenz von leisure, work und idleness im England des 19. Jahrhunderts vgl. Heidi Liedke, The Experience of Idling in Victorian Travel Texts, 1850-1901, Basingstoke 2018.

46 Zur gegenwärtigen Bewertung von Keynes' (unzutreffenden) Prognosen, vgl. Lorenzo Pecchi, Revisiting Keynes. Economic possibilities for our grandchildren, Cambridge 2008; Alexander Lenger, „Economic possibilities for our grandchildren“, Muße. Ein Magazin 4 (2016), 48-52, DOI: 10.6094/musse-magazin/2.2016.48. 
the community. The morality of work is the morality of slaves and the modern world has no need of slavery. "47 Anstatt die Sklavenmoral durch eine alternative Ideologie zu bekämpfen, möchte Russell Muße anders verteilen. Diese andere Verteilung von Muße kann dadurch gelingen, weniger arbeiten zu müssen und mehr Freizeit zu haben. Der qualitative Kontrast von Arbeit und Muße wird so zum quantitativen Kontrast von Arbeitszeit und Freizeit. ${ }^{48}$

Das Bild der von Arbeit geprägten Moderne als paradoxer kultureller Ordnung geht damit einher, dass Russell den Gedanken, Muße sei Bedingung kultureller Leistung, in spezifischer Weise konzipiert. Auch Russell geht davon aus, dass Muße die Bedingung jeglicher Kulturleistung sei. Allerdings führt dieser Gedanke nicht allein zur Diagnose eines fortschreitenden Verlusts von Muße, sondern auch zu der Forderung, die technischen Möglichkeiten einer gerechten Verteilung von Muße zu nutzen. Die Moderne ermöglicht so auch die Überwindung der durch sie selbst verursachten Entfremdung. Allerdings bleibt das Kriterium für eine solche alternative Moderne, dass es möglich werde „to distribute leisure justly without injury to civilisation". 49 Dieser Optimismus unterscheidet Russells Analyse zwar deutlich von Piepers Modernediagnose. Allerdings basiert dieser Optimismus auf einer Voraussetzung, die dem aristotelischen Paradigma entspricht. Denn Russell akzeptiert durchaus, dass der Wert der Muße als Bedingung von Kultur sich durch die kulturellen Errungenschaften rechtfertigt, in denen die Muße ihre Erfüllung findet.

So ist in der Formulierung zur gerechten Verteilung von Muße die Qualifikation wichtig, diese solle „without injury to civilisation“ geschehen. Russell spielt offenkundig auf die klassische griechische Kultur und den Ursprung der Philosophie an, wenn er bemerkt, „Athenian slave-owners, for instance, employed part of their leisure in making a permanent contribution to civilisation which would have been impossible under a just economic system" “. ${ }^{50}$ Der Widerspruch zwischen menschlicher Vervollkommnung und Gerechtigkeit ist mithin zwar historisches Faktum, aber auch historisch kontingent. Es besteht kein prinzipieller Konflikt zwischen einer gerechten Verteilung und der kulturstiftenden Funktion von Muße. Dass sich diese Verteilung noch nicht durchgesetzt hat, erklärt Russell durch eine ideologische Manipulation der Arbeiterklasse durch die leisure class: „The rich and their sycophants ... have tried to make manual workers believe that there is some special nobility about alternating the position of matter in space, just as men tried to make women believe that they derived

47 Russell, „In Praise of Idleness“, 4-5. Dass die Moral des Arbeiters eine Sklavenmoral sei, gibt Nietzsches Kritik wieder. Vgl. etwa die Darstellung im Beitrag von Schäfer in diesem Band.

${ }_{48} \mathrm{Zu}$ dieser Unterscheidung vgl. Gimmel/Keiling u. a., Konzepte der Muße, 11-23.

49 Russell, „In Praise of Idleness“, 5.

50 Russell, „In Praise of Idleness“, 5. 
some special nobility from their sexual enslavement. ${ }^{\text {“51 }}$ Dieser Ideologie steht die naive, aber letztlich aufgeklärtere Selbstbeschreibung der Arbeiterklasse gegenüber: „They consider work, as it should be considered, a necessary means to a livelihood, and it is from their leisure hours that they derive whatever happiness they may enjoy. ${ }^{\text {"52 }}$

Diese Bemerkungen machen nicht nur deutlich, wie nahe Russell sozialistischen Diskursen seiner Zeit steht. Sie zeigen auch, wie schwach Russells positive Bestimmung von Muße jenseits ihres Gegensatzes zur Arbeit ist. Zwar macht seine Diskussion der Unterbeschäftigung deutlich, dass Russell einen qualitativen Unterschied zwischen dem Nicht-Arbeiten und einer Erfahrung von Muße sieht. Allerdings bietet Russell zur Unterscheidung von Muße und Arbeit letztlich nur die Erfahrung von Glück an, die lediglich unter bestimmten Bedingungen im Nicht-Arbeiten gefunden werden könne. Nicht zu arbeiten ist die erste notwendige Bedingung für Muße, aber nicht die einzige. Neben dem Selbstzweckcharakter des Handelns in Muße nennt Russell ein drittes Kriterium, das ebenfalls dem aristotelischen Paradigma entspricht: Handeln in Muße ist erfülltes Handeln und verwirklicht die menschliche Natur. So betont Russell, Muße-Tätigkeiten seien nicht „mainly of the sort of things that would be considered ,high-brow. Peasant dances have died out except in rural areas, but the impulses which caused them to be cultivated must still exist in human nature." Damit eine Tätigkeit jedoch die menschlichen Naturanlagen erfüllen kann, muss sie aktiv sein. Die „pleasures of the urban population“ seien dagegen „mainly passive: seeing cinemas, watching football matches, listening to the radio, and so on". 53 Obwohl Arbeit also Aktivität ist, ist jene Aktivität, die in der Muße geschieht, prinzipiell höher zu bewerten.

Es ist überdeutlich, wie stark sich Russell mit diesen humorig vorgetragenen Beschreibungen am aristotelischen Argument orientiert. Zwar vermeidet Russell es, eine einzelne Tätigkeit oder eine Klasse von Handlungen zu benennen, die innerhalb des Spektrums dessen, was man in der arbeitsfreien Zeit tun kann, privilegiert sind. Die Überlegung, dass die neben den vier Arbeitsstunden pro Tag verbleibende Zeit eines Arbeiters ,should be his to use as he might see fit“ legt zudem nahe, dass Russell gerade vermeiden möchte, Muße genauer denn als Freizeit zu bestimmen und jene Tätigkeiten zu bewerten, mit denen der Arbeiter seine freie Zeit füllt. ${ }^{54}$ Diese Überzeugung entspricht auch der emotivistischen Metaethik, die Russell zu dieser Zeit vertrat. ${ }^{55}$ Doch führt gerade diese

51 Russell, „In Praise of Idleness“, 9.

52 Russell, „In Praise of Idleness", 11.

53 Russell, „In Praise of Idleness“, 12-13.

54 Russell, „In Praise of Idleness“, 12.

55 Eine emotivistische Metaethik führt die Bedeutung des Prädikats ,gut' auf einen emotionalen Zustand zurück, durch welchen ein Sachverhalt bewertet wird. Zu den Phasen Russells metaethischer Theoriebildung, vgl. Charles R. Pigden, „Bertrand Russell: Moral 
liberale Überzeugung zu einem Widerspruch in seiner Beschreibung von Muße. Denn wenn ,Arbeiter ' aus freien Stücken keine Tätigkeit beginnen, die sich nach den genannten Kriterien als Muße-Handeln bestimmen lässt, dann liegt dies für Russell daran, dass ,their active energies are fully taken up with work; if they had more leisure, they would again enjoy pleasures in which they took an ac-

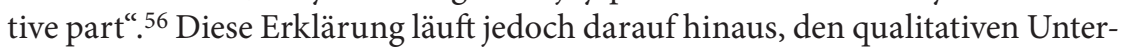
schied zwischen Muße und Arbeit wieder rein quantitativ als Unterschied zwischen Arbeits- und Freizeit zu fassen. Denn nur unter dieser Prämisse ist der Gedanke plausibel, ein bloß passives Verbringen der eigenen Freizeit sei allein durch noch mehr Freizeit zu überwinden.

Diese Widersprüchlichkeiten in Russells Essay lösen sich nicht auf. Die Schlusspassagen zeichnen vielmehr ein im Grunde utopisches, wenn auch in der Darstellung ironisch gebrochenes Bild jener Gesellschaft, in der Arbeit und Muße gerecht verteilt werden: „Above all, there will be happiness and joy of life, instead of frayed nerves, weariness, and dyspepsia." Auch in diesem Idealzustand löst sich der Gegensatz von Muße und Arbeit allerdings nicht auf: „The work exacted will be enough to make leisure delightful, but not enough to produce exhaustion. ... Ordinary men and women, having the opportunity of a happy life, will become more kindly and less persecuting and less inclined to view others with suspicion. The taste for war will die out ${ }^{\text {" }}{ }^{57}$ Russells utopisches Bild modifiziert so die aristotelische Analogie zwischen Krieg und Arbeit.

\section{Aporien einer modernen Philosophie der Muße}

Piepers und Russells Varianten des aristotelischen Paradigmas kommen darin überein, dieses durch die Bestimmung von, Arbeit' als Gegenbegriff zur Muße in der Moderne zu verorten. Beide gehen davon aus, dass, Arbeit' als Kategorie zur Beschreibung und Bewertung menschlichen Handelns, der Erfüllung menschlichen Lebens und als Merkmal gerechter sozialer Organisation ungeeignet ist. Verschiedene Probleme moderner Gesellschaften bündeln sich für sie in einem Verlust von Muße, der ein emphatisches praise of idleness motiviert. Muße wird dabei als Möglichkeit individueller und gesellschaftlicher Verwirklichung beschrieben. Sie erscheint insbesondere als Voraussetzung kultureller Leistungen.

Dennoch gibt es entscheidende Unterschiede darin, wie Pieper und Russell das aristotelische Paradigma ,modernisieren'. Das betrifft nicht nur die historischen und kulturellen Umstände, die beide Autoren und die Entstehung ihre Schlüsseltexte voneinander trennen. Auffällig ist vielmehr, wie unterschiedlich

Philosopher or Unphilosophical Moralist“, in: Nicholas Griffin (Hg.), The Cambridge Companion to Bertrand Russell, Cambridge 2006, 475-506.

56 Russell, „In Praise of Idleness“, 13.

57 Russell, „In Praise of Idleness“, 15. 
Pieper und Russell das Handeln in Muße als Alternative zum Arbeiten auch in systematischer Hinsicht bestimmen. Neben notwendigen Bedingungen wie dem Kriterium der Selbstzweckhaftigkeit, die beide Autoren aus dem aristotelischen Paradigma übernehmen, formuliert Pieper ein offenbar hinreichendes Kriterium, wenn kultisches Handeln als ursprüngliches Muße-Handeln beschrieben wird. Russell sucht dagegen Anschluss an die Tradition des Liberalismus, wenn neben die aristotelischen Kriterien das Kriterium tritt, alles, was in Freizeit aus freien Stücken getan werde, könne Muße sein.

Die beiden modernen Philosophien der Muße verbindet, dass sie ,Arbeit' als stärksten Kontrast zu einem Handeln in Muße konzipieren und von hier aus Kriterien für ein Handeln in Muße gewinnen: Während Russell den Unterschied zwischen Arbeit und leisure als Unterschied von Arbeitszeit und arbeitsfreier Zeit zu fassen sucht, generiert bei Pieper die Inversion der drei Merkmale des ,Arbeiters' positive Kriterien für Muße. In beiden Fällen reicht die Gegenüberstellung von Muße und Arbeit jedoch nicht hin, um eine Bestimmung dessen zu geben, was Menschen in Muße tun (sollten). Die Alternative von Arbeit und Muße erweist sich zwar als eine zentrale Motivation, Muße zu suchen und über Muße nachzudenken, aber letztlich als für eine positive Bestimmung von Muße unzulänglich. Insoweit ist die Alternative von Arbeit und Muße eine moderne, aber systematisch falsche Alternative.

Doch reagieren beide durch die Berücksichtigung des Arbeitsbegriffs auf ein Problem des aristotelischen Paradigmas, das sich in diesem grundsätzlich stellt: Die Bestimmung einer maßgeblichen Form von Muße-Handeln, wie sie in der aristotelischen Philosophie mit der theoría benannt ist, muss plausibel sein, damit das aristotelische Argument überzeugt. Sind die Kriterien des aristotelischen Paradigmas für die Bestimmung eines maßgeblichen Muße-Handelns nicht hinreichend oder nicht klar genug, und kann auch der Kontrastbegriff der Arbeit dieses Problem nicht vermeiden, dann ist die Frage danach, was eine solche Handlungsklasse auszeichnet, wieder offen. Beide Konzeptionen sind im Ergebnis deshalb kaum überzeugend, weil das Verständnis von Muße-Handeln, das sie generieren, extensional und intensional unplausibel ist. Das ist der Grund, warum sie zwar das aristotelische Paradigma jeweils verschieden fortschreiben, aber das für dieses Paradigma spezifische Problem, Muße-Handeln plausibel zu beschreiben, nicht lösen:

- Piepers Verständnis von Muße ist zu restriktiv. Denn es hat zur Konsequenz, dass nur kultisches Handeln originäre Muße-Praxis ist. Alle anderen Tätigkeiten sind in ihrem Muße-Charakter entsprechend daran zu messen, wie nahe sie diesem exemplarischen Fall kommen. ${ }^{58}$ Das ist jedoch nicht nur extensional unplausibel, da andere Tätigkeiten, die ein Handeln in Muße dar-

58 Diese Position vertritt gegenwärtig Hayden Ramsay im Anschluss an Pieper. Vgl. Ramsay, Reclaiming leisure. Art, sport, and philosophy, Basingstoke 2005. 
stellen können, ausgeschlossen werden - etwa das Briefeschreiben, das bereits in der Antike als Muße-Praxis reflektiert worden ist. ${ }^{59}$ Die Intension führt außerdem dazu, dass Pieper alle Tätigkeiten, die intuitiv als Muße-Handlungen qualifiziert werden, auf den Kultus beziehen muss - etwa die Philosophie. Selbst wenn die These des kultischen Ursprungs von Philosophie kulturgeschichtlich zutrifft, folgt daraus nicht, dass Philosophieren eigentlich kultisches Handeln ist. ${ }^{60}$ Ähnliche Einwände ließen sich für andere Muße-Praktiken formulieren.

- Russells Verständnis von Muße ist unterbestimmt. Denn Russell führt Fälle einer Verwirklichung menschlicher Freiheit in arbeitsfreier Zeit an, welche die notwendigen Bedingungen für eine Muße-Tätigkeit nicht erfüllen - das freiwillige overworking oder der bloß passive Gebrauch der Freizeit. Damit ist jedoch unklar, wie das Freiheits-Kriterium die klassischen Kriterien des aristotelischen Paradigmas ergänzen soll, da beide in diesen Konfliktfällen zu unterschiedlichen Bewertungen führen. Da keine qualitative Abgrenzung von Arbeiten und einem Tun in Muße gelingt, fällt Russell auf den rein quantitativen Unterschied von Arbeit und Freizeit zurück. Damit bleibt seine Beschreibung von Muße nicht nur negativ, sondern auch auf eine rein quantitative Angabe beschränkt.

Die beiden modernen Varianten des aristotelischen Paradigmas zeigen mithin eines: ,Muße' kann als programmatischer Gegenbegriff zu einer durch Arbeit ausgezeichneten Lebenswelt gebraucht werden, ohne dass diese Wertung durch eine kohärente oder plausible Philosophie der Muße gestützt würde. Mit den hier untersuchten modernen Philosophien der Muße werden zwei Möglichkeiten durchgespielt, ein im aristotelischen Paradigma angelegtes Problem zu lösen, ohne dass die überzeugend gelänge. Vielmehr laufen beide auf neue, aber wiederum jeweils problematische Alternativen hinaus: Pieper rechtfertigt seine Engführung von Muße und Kult dadurch, dass es ,in dieser Zeit sinnlos geworden [sei], den Bereich der Muße von vorletzten Positionen aus verteidigen $\mathrm{zu}$ wollen“. ${ }^{61}$ Aber die damit angesprochene Alternative, entweder das Selbstverständnis des ,Arbeiters' oder das des Gläubigen anzunehmen, ist offenbar nicht zwingend. Und Russells Essay setzt zwar dazu an, das aristotelische Paradigma

59 Vgl. Franziska C. Eickhoff (Hg.), Muße und Rekursivität in der antiken Briefliteratur. Mit einem Ausblick in andere Gattungen, Tübingen 2016; Eickhoff, Muße und Poetik in der römischen Briefliteratur (Diss. Freiburg), im Erscheinen.

60 Vgl. Pieper, „Muße und Kult“, in: W 6, 41.

61 Pieper, „Muße und Kult“, in: W 6, 41. In der kurzen Einführung zur englischen Übersetzung betont Pieper, dass die Verteidigung des Kultus eine Verteidigung der Freiheit sei: „Suppress that last sphere of freedom, and freedom itself, and all our liberties, will in the end vanish into thin air." (Pieper, Leisure, 20) Auch die Freiheitserfahrung der Muße ist deshalb bedingt durch die Freiheit des Kultus: „leisure, in its turn, is free because of its relation to worship, to the cultus." (Pieper, Leisure, 21). 
dadurch zu ergänzen, das Verhältnis von selbstzweckhaftem Tun und autonomer Selbstbestimmung zu klären. Doch gelingt dies Russell aus dem genannten Grund keineswegs. Eher benannt denn gelöst wird so ein Problem, das sich aus der Spannung eines modernen, liberalen Selbstverständnisses und dem aristotelischen Paradigma ergibt. ${ }^{62}$ Damit bleibt das aristotelische Paradigma auch ohne den hypostasierten Kontrast von Muße und Arbeit die beste verfügbare philosophische Beschreibung von Muße. Wenn dieses Paradigma jedoch Muße-Handeln nicht plausibel bestimmt, dann beschreibt genau das das weiterhin entscheidende Problem auch für die Gegenwartsphilosophie.

Wenn man sich jedoch mit „Vorletzen“ Ergebnissen begnügen möchte, so fällt auf, dass Pieper und Russell aus der Gegenüberstellung von Arbeit und Muße eine ,Umwertung' des Werts der Arbeit initiieren möchten, die auch dann bedenkenswert erscheint, wenn sie kein kohärentes und plausibles Verständnis von Muße erzeugt. Zwei solcher vorläufigen Ergebnisse sind augenfällig: Russell macht darauf aufmerksam, dass es ein Problem der gerechten Verteilung von Muße gibt, von dem her sich eine gerechtere Organisation von Arbeit beschreiben lassen soll. Selbst Pieper gesteht zu, dass trotz seines letztlich spirituellen Verständnisses des Handelns in Muße auch die „äußere Ermöglichung“ von Muße einen Wert darstellt. Trotz der unterschiedlichen Akzentsetzungen stellt sich für moderne Gesellschaften die Frage nach einer gerechten Verteilung von Muße, die im aristotelischen Paradigma nicht berücksichtigt ist. ${ }^{63}$

Pieper und Russell beschreiben zudem beide einen Prozess des Erlernens von Muße-Handeln ${ }^{64}$, und beide verorten diesen Prozess insbesondere in Bildungsinstitutionen. Nicht die freie Zeit als solche, sondern "the wise use of leisure“ beschreibt Russell als „a product of civilisation and education“ ${ }^{65}$ Lässt man außer acht, dass Pieper auch eine erneute „Eingründung der schola im Kult" ${ }^{“ 66}$ fordert, dann könnten diese Bemerkungen als Hinweis darauf verstanden werden, dass es Formen der Institutionalisierung von Muße gibt, die von der gerechten Ver-

62 Ein weiterer Autor, der sich mit diesem Problem konfrontiert sieht, ist Hans Blumenberg. Denn Blumenberg stellt sich das Problem, die antike Anthropologie und ihre Identifizierung von Eudämonie und Theorie mit der kantischen Beschreibung menschlicher Vernunft zu verbinden. Vgl. Tobias Keiling, „The pleasure of the non-conceptual. Theory, leisure, and happiness in Blumenberg's anthropology", in: SATS. Northern European Journal of Philosophy 17 (2016), 81-113.

${ }^{63}$ Vgl. dazu, im Rückgriff auf andere Autoren, den Beitrag von Christoph Henning in diesem Band.

${ }^{64}$ Annette Holba hat eine Theorie der transformative leisure vorgelegt, die auf die Bedeutung von Muße in individuellen und gesellschaftlichen Selbstverständigungsprozessen abstellt. Holba schließt zwar an Pieper an, kritisiert aber, Pieper „does not make explicitly clear the relationship between leisure and the communicative structure that organizes and propels our lives“. (Annette Holba, Transformative Leisure. A Philosophy of Communication, Milwaukee 2013, 14)

65 Russell, „In Praise of Idleness“, 8.

66 Pieper, „Muße und Kult“, in: W 6, 41. 
teilung von Arbeitszeit und Freizeit auf unterschiedliche gesellschaftliche Gruppen relativ unabhängig ist. Formen der Institutionalisierung von Muße lassen sich deshalb als soziale Verstetigungen von Muße-Handeln untersuchen, die verschiedene Muße-Lebensformen repräsentieren. Wenn Muße einen gesellschaftlichen Wert darstellt, dann liegt es nahe, nicht nur die Verteilung von Arbeits- und Muße-Zeit zu problematisieren, sondern ebenso den Zugang zu Muße-Institutionen. Trotz ihres systematischen Ungenügens führen die modernen Philosophien der Muße damit auf zwei sozialphilosophisch interessante und gesellschaftspolitisch relevante Konsequenzen und tragen so zu einer Aufklärung über Muße bei. 


\title{
Muße zur Selbstreflexion
}

\section{Autobiographisches Erzählen in der Moderne}

\author{
Georg Feitscher
}

\section{Selbstkonstitution in Muße}

$\mathrm{Zu}$ den wesentlichen Prämissen des modernen Diskurses über die Muße gehört die Vorstellung, die Muße bilde einen privilegierten Zustand für die Selbstkonstitution des Subjekts. In diesem Sinne gilt: Muße ermöglicht es uns nicht nur, endlich einmal das zu tun, was wir selbst tun wollen, sondern uns - indem wir es tun - selbst zu verwirklichen. Auf welche Weise die Muße zu einem bevorzugten Modus der Selbstreflexion avancierte und wie sich dieser Zusammenhang in literarischen Autobiographien manifestiert, ist das Thema des folgenden Beitrags.

Besonders deutlich hat Arthur Schopenhauer in der Mitte des 19. Jahrhunderts die Muße in dieser Weise bestimmt. Er behauptete, dass „die errungene freie Muße eines jeden, indem sie ihm den freien Genuß seines Bewußtseins und seiner Individualität gibt, die Frucht und der Ertrag seines gesamten Daseins

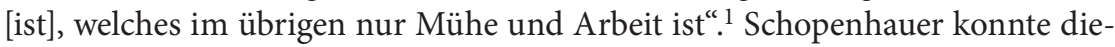
sen Kausalzusammenhang so emphatisch formulieren, weil der fundamentale Strukturwandel der europäischen Gesellschaften im 18. und 19. Jahrhundert auch die ,Geschichte der Subjektivierung' in eine neue, kritische Phase geführt hatte. ${ }^{2}$ Die modernen Konzeptionen von Individualität und Subjektivität, die sich in dieser Zeit herausbildeten, veränderten unmittelbar auch das Nachdenken über die Muße.

An seine oben zitierte Definition der Muße knüpft Schopenhauer mit einer bemerkenswerten Überlegung an:

Was nun aber wirft die freie Muße der meisten Menschen ab? Langeweile und Dumpfheit, so oft nicht sinnlicher Genüsse, oder Albernheiten da sind, sie auszufüllen. Wie völlig wertlos sie ist, zeigt die Art, wie sie solche zubringen; sie ist eben: die langweilige

${ }^{1}$ Arthur Schopenhauer, Aphorismen zur Lebensweisheit. Vollst. Ausg. mit Erl. u. Übers. d. fremdsprachigen Zitate, Frankfurt a. M. 1976 [1851], 29 f. Herv. i. O.

2 Vgl. Michel Foucault, Le gouvernement de soi et des autres. Cours aus Collège de France (1982-1983), Paris 2008. 
Muße der Toren. Die gewöhnlichen Leute sind bloß darauf bedacht, die Zeit zuzubringen; wer irgend ein Talent hat, - sie $z$ u benutzen. ${ }^{3}$

Schopenhauer differenziert normativ zwischen der gewöhnlichen und „langweilige[n] Muße der Toren“ einerseits und der ,wertvollen' Muße der talentierten Individuen andererseits. Diese elitäre Unterscheidung mag aus heutiger Sicht provozierend wirken, sie steht aber in einer weit zurückreichenden Tradition. Schon die theoría, d.h. das Ideal einer theoretischen Lebensweise in der griechischen Antike, stellte ein Privileg der Philosophen dar, die wiederum freie männliche Bürger der Polis waren. ${ }^{4}$

Innovativ im Vergleich zu einem antiken oder mittelalterlichen Verständnis des otium ist vielmehr, auf welche Weise Schopenhauer den besonderen Status der Muße begründet. Als entscheidendes Kriterium, ob eine Person zur Muße befähigt ist, nennt er nicht die Zugehörigkeit zu einer bestimmten gesellschaftlichen Gruppe, einer Klasse oder einer Schicht. Muße ist im 19. Jahrhundert längst nicht mehr ein Privileg des Adels oder Klerus. Statt der sozialen Position ist für Schopenhauer allein die persönliche Disposition entscheidend: Der individuelle Mensch muss sich für die Muße eignen. Damit hebt sich der Einzelne aus dem Feld der ,Toren' heraus, die mit der Muße nichts anzufangen wissen. Schopenhauers Begriff der Muße setzt daher ein modernes Verständnis von Subjektivität voraus. Er basiert auf der Vorstellung von Subjekten, die nicht länger - in der ursprünglichen Bedeutung des Wortes - der Herrschaft einer ständischen Ordnung unterworfen (subiectus) sind. An ihre Stelle sind vielmehr bürgerliche Individuen getreten, die ,sich selbst gehören', die sich selbst entwerfen und entfalten können, und die daher auch persönlich die Verantwortung dafür tragen, ob sie ihre Muße produktiv nutzen. Damit ist nicht gesagt, dass im 19. Jahrhundert keine sozialen Privilegien im Hinblick auf die Muße bestanden hätten. Bemerkenswert ist allein, dass sie in Schopenhauers Argumentation keine Rolle mehr spielen.

Doch die Neubestimmung des Muße-Begriffs betrifft einen zweiten Aspekt: Schopenhauer erhebt den aus der Muße gezogenen Nutzen zum Kriterium ihres Gelingens. Er stellt damit die Muße in einen utilitaristischen Funktionszusammenhang, der über sie hinausweist. So verabschiedet er die historisch wirkmächtige Vorstellung, die Muße sei vor allem durch ihre Selbstbezogenheit und Selbstgenügsamkeit charakterisiert - schon Aristoteles fasste die theoría als eine Lebensweise auf, die „keinen anderen Zweck hat, als sich selbst [...] Sie ist ja keines anderen Dinges bedürftig, sondern sich selbst genug “ .5 Die Idee der Autono-

${ }^{3}$ Schopenhauer, Aphorismen zur Lebensweisheit, 30.

4 Vgl. Hannah Arendt, Vita activa oder Vom tätigen Leben, München/Zürich 2008, 24; Hans-Georg Soeffner, „Muße - Absichtsvolle Absichtslosigkeit“, in: Burkhard Hasebrink/ Peter Philipp Riedl (Hg.), Muße im kulturellen Wandel. Semantisierungen, Ähnlichkeiten, Umbesetzungen, Berlin 2014, 34-53, 38.

5 Aristoteles, Nikomachische Ethik, auf d. Grundl. d. Übers. v. Eugen Rolfes hg. v. Günther Bien, Hamburg 1972, X, 6, 1176b (246). 
mie ist in Schopenhauers Formulierung der ,freien Muße durchaus noch präsent. Doch nimmt sie nun eine neue Bedeutung an: Schopenhauer begreift die Autonomie weniger als eine Eigenschaft der Muße, als vielmehr der Individuen, die Muße erleben und darin zu freier Selbstverwirklichung gelangen. Denn der primäre Nutzen und die Funktion der Muße bestehe eben darin, dass sie einen Menschen ,in den Besitz seines eignen Selbst einsetzt“, ihn also von aller Fremdbestimmung befreit. Daher, so stellt Schopenhauer nun wieder distinktionsbewusst fest, „sind die glücklich zu preisen, welche dann auch etwas rechtes an sich selber erhalten; während den allermeisten die freie Muße nichts abwirft, als einen Kerl, mit dem nichts anzufangen ist, der sich schrecklich langweilt, sich selber zur Last" .6

Schopenhauer denkt den Zusammenhang von Muße und Subjektkonstitution folglich als einen zirkulären Prozess: Einerseits muss der individuelle Mensch bereits über eine grundsätzliche Disposition zur Muße verfügen, um diese überhaupt produktiv erfahren zu können. Hat die Person Muße erlangt, kann sie darin ihre Talente verwirklichen und jene individuellen Qualitäten weiterentwickeln, die sie zu einem noch intensiveren Erleben von Muße disponieren. Die moderne Konzeption der Muße ist auf doppelte Weise an die Subjektivität gebunden: Sie setzt ein souveränes Subjekt voraus und trägt zugleich zu seiner Konstituierung bei. So wird die Muße zum Katalysator von Individualität.

\section{Autobiographisches Erzählen}

Wie aber manifestiert sich die moderne Konzeption der Muße konkret in Texten und Erzählungen? Diese Frage liegt nah, bildet doch das Erzählen eine der entscheidenden Techniken der menschlichen Selbstkonstitution: Im Medium der Narration kann der Mensch seinem Leben Bedeutung verleihen, sich selbst eine identité narrative konstruieren. ${ }^{7}$ Mit der Autobiographie hat die europäische Kulturgeschichte eine Textsorte hervorgebracht, die vollständig auf die Konstruktion narrativer Identitäten ausgerichtet ist und die für den Leser den Prozess der Selbstkonstitution eines Subjektes transparent macht. Die bis in die Gegenwart anhaltende Konjunktur autobiographischer Narrative beginnt etwa in jener Zeit, in welcher der moderne Subjektbegriff Kontur gewinnt und die Selbstkonstitution zu einer Funktion der Muße avanciert, nämlich im ausgehenden 18. Jahrhundert. ${ }^{8}$ Es leuchtet intuitiv ein, dass zugleich mit der Idee menschlicher Individualität auch die literarische Lebenserzählung an Bedeutung gewinnt. Wenn

${ }^{6}$ Schopenhauer, Aphorismen zur Lebensweisheit, 31.

7 Vgl. Paul Ricœur, „L'identité narrative“, in: Esprit 12 (1988), 295-304.

8 Vgl. Oliver Sill, Zerbrochene Spiegel. Studien zur Theorie und Praxis modernen autobiographischen Erzählens, Berlin/New York 1991, 53 f.; Kerstin Stüssel, „Autorschaft und Autobiographik im kultur- und mediengeschichtlichen Wandel“, in: Ulrich Breuer/Beatrice 
aber das autobiographische Erzählen eine Form der Selbstkonstitution darstellt, und wenn die Idee der Selbstkonstitution konzeptuell an die Muße gekoppelt ist, so liegt die Vermutung nahe, dass in modernen Autobiographien häufig Situationen der Muße inszeniert werden.

Tatsächlich eröffnet schon ein Blick auf eines der einflussreichsten autobiographischen Werke des ausgehenden 18. Jahrhunderts, mit welcher Emphase die Muße als wichtigste Voraussetzung der Selbstreflexion bestimmt wird. In der fünften Promenade der Rêveries du promeneur solitaire von Jean-Jacques Rousseau hebt das erzählende Ich zu einer Eloge des ,kostbaren Nichtstuns' an:

Le précieux far niente fut la première et la principale de ces jouissances que je voulus savourer dans toute sa douceur, et tout ce que je fis [...] ne fut en effet que l'occupation délicieuse et nécessaire d'un homme qui s'est dévoué à l'oisiveté. ${ }^{9}$

[Das kostbare far niente war der vordringlichste und wichtigste Genuss, den ich in seiner ganzen Süße aufzusaugen suchte, und all mein Tun (...) beschränkte sich in der Tat auf die allernotwendigsten und lustvollen Beschäftigungen eines Menschen, der sich dem Müßigen verschrieben hat. $\left.{ }^{10}\right]$

Rousseau stilisiert die Muße zu einem idealen Modus des Daseins, der seinem autobiographischen Erzähler eine glückliche Selbsterfahrung ermöglicht. Solange die Muße anhält, treten die äußeren Zwänge und Notwendigkeiten in den Hintergrund. Rousseaus Subjekt kann sich selbst in den Mittelpunkt seiner Kontemplation rücken und erlebt einen Zustand, göttlicher' Selbstgenügsamkeit:

De quoi jouit-on dans une pareille situation ? De rien d'extérieur à soi, de rien sinon de soi-même et de sa propre existence, tant que cet état dure on se suffit à soi-même comme Dieu. $(O C, 1047)$

[Woran ergötzt man sich in solchen Situationen? An nichts, was uns äußerlich ist, an nichts außer an uns selbst und an unserem eigenen Dasein, denn solange dieser Zustand währt, genügt man sich selbst wie Gott. (Tr, 136)]

Ein Phänomen der Rêveries ist für das moderne autobiographische Erzählen in besonderer Weise symptomatisch: Die mußevolle Selbstreflexion ist an bestimmte Orte geknüpft. ${ }^{11}$ In der fünften Promenade ist es die St. Petersin-

Sandberg (Hg.), Grenzen der Identität und der Fiktionalität (= Autobiographisches Schreiben in der deutschsprachigen Gegenwartsliteratur, Bd. 1), München 2006, 19-33.

9 Jean-Jacques Rousseau, Les rêveries du promeneur solitaire, CEuvres complètes, Bd. 1, hg. v. Bernard Gagnebin, Paris 1959 [1776-1778], 993-1097, 1042. Im Folgenden im Fließtext zitiert mit der Sigle OC.

10 Jean-Jacques Rousseau, Träumereien eines einsam Schweifenden. Nach dem Manuskript und den Spielkarten neu übersetzt, kommentiert und mit einem Nachwort versehen von Stefan Zweifel, Berlin 2012, 128. Im Folgenden im Fließtext zitiert mit der Sigle Tr.

11 Zum räumlichen Charakter der Muße im Allgemeinen vgl. Günter Figal, „Die Räumlichkeit der Muße“, in: Burkhard Hasebrink/Peter Philipp Riedl (Hg.), Muße im kulturellen Wandel. Semantisierungen, Ähnlichkeiten, Umbesetzungen, Berlin 2014, 26-33. 
sel im Bielersee, auf die sich Rousseau vor seinen Verfolgern flüchtet. In diesem Exil verbringt er sechs Wochen, die er mit Spaziergängen über die Insel füllt. In Rousseaus anderem großen autobiographischen Werk, den Confessions, ist es der Wald von Montmorency nördlich von Paris, in den sich der Autor zurückzieht, um allein zu spazieren und zu schreiben. ${ }^{12}$ Ein derart starker Ortsbezug der Selbstreflexion ist allerdings keine Innovation Rousseaus, sondern zeigt sich schon in den Anfängen der Autobiographie. Berühmt ist etwa die Schlüsselszene in den Confessiones des Augustinus: In einem abgelegenen Mailänder Garten erreichen Augustins Zweifel am eigenen Leben ihren Höhepunkt und münden, angeregt durch die Lektüre der Paulusbriefe, in seiner Bekehrung zum Christentum. ${ }^{13}$ Die klassischen und wirkmächtigen Autobiographien führen vor, wie entscheidend die räumliche Position des autobiographischen Ich für dessen Selbsterkundung und - in einem darauf aufbauenden Schritt - für die Selbsterzählung ist. Nur unter bestimmten äußeren Rahmenbedingungen erscheint die Reflexion des eigenen Lebens möglich, legitim und erfolgversprechend. ${ }^{14}$

Die literarische Praxis, das erinnernde und erzählende Ich in einer Situation der Muße und an einem zumeist abgeschiedenen und naturnahen Ort zu zeigen, findet im Laufe der Moderne Eingang in den gattungstheoretischen Diskurs über die Autobiographie. Nicht zuletzt die wissenschaftliche Forschung zur Autobiographik hat entscheidend dazu beigetragen, dass aus der literarischen Praxis eine Gattungsnorm wurde. So argumentiert Roy Pascal in seiner einflussreichen Monographie Design and Truth in Autobiography (1960), die gelungene Konstruktion einer kohärenten Autobiographie sei an bestimmte Voraussetzungen gebunden, die er mit einer räumlichen Metapher zu fassen versucht: „This coherence implies that the writer takes a particular standpoint, the standpoint of the moment at which he reviews his life, and interprets his life from it."15 Der autobiographische Erzähler bedürfe einer interpretatorischen Grundhaltung, eines standpoint, von der seine Entscheidungen ausgehen, ob und wie er die Ereignisse seines Lebens darstellt. Über seine metaphorische Bedeutung hinaus lässt sich der standpoint jedoch auch als ein konkreter Ort verstehen: Der Autobiograph müsse am Ende seines Lebens einen ruhigen, sicheren Platz erreicht haben, der ihm gleichermaßen den Rückblick auf das eigene Leben sowie den Überblick über die historischen Zusammenhänge gestattet. Vom Standort des Erzählers hänge der Erfolg oder Misserfolg der Autobiographie ab. Aus diesem Grund sei, so Pascal, die Fähigkeit zur konsistenten Selbstdeutung das exklusive Vorrecht

12 Vgl. Jean-Jacques Rousseau, Les confessions, Euvres complètes, Bd. 1, hg. v. Bernard Gagnebin, Paris 1959 [1782-1789], 5-656, 404.

13 Aurelius Augustinus, Confessiones/Bekenntnisse. Lateinisch und Deutsch, übers., hg. u. komm. v. Kurt Flasch u. Burkhart Mojsisch, Stuttgart 2009 [397-401 n. Chr.], 386 f.

${ }^{14}$ Von den ,Rahmungen der Muße' als sozio-historischen, räumlichen und zeitlichen Reglements spricht daher Soeffner, „Muße - Absichtsvolle Absichtslosigkeit“, 43-45.

15 Roy Pascal, Design and Truth in Autobiography, London 1960, 9. 
einiger weniger herausragender Individuen. Nur die „men and women of outstanding achievement in life" hätten sich eine herausgehobene Position im Laufe ihres Werdegangs verdient, ihr standpoint sei ,the indubitable result of their life's work “. ${ }^{16}$ Um ihn zu erreichen, hätten die Autobiographen häufig schmerzvolle Brüche in Kauf nehmen und sich gegen erhebliche äußere Widerstände behaupten müssen, wie es der Fall Rousseaus demonstriert. Nun aber, am Ende ihres Lebens, könnten sie die Früchte ihrer Anstrengungen ernten, indem sie aus der Ruhe des Alters auf das Erreichte zurückblicken und es erzählen.

Die jüngere Autobiographieforschung hat sich von den normativen und exklusiven Thesen, die nicht nur Pascal seinerzeit formulierte, zu Recht distanziert. Nichtsdestoweniger kann die Theorie des standpoint einige interessante Einsichten in die Subjektkonzeptionen und Erzählschemata der konventionellen Autobiographik eröffnen. Erstens geht Pascal von der aus seiner Sicht evidenten Prämisse aus, dass nur ein festes, stabiles Identitätsmodell die Grundlage für eine Selbsterzählung bietet. Das erinnernde Ich müsse sich demzufolge als identisch mit seinem vergangenen Selbst begreifen und durch eine kohärente Geschichte diese Identität literarisch darstellen. Zweitens lässt sich die Metapher des standpoint narratologisch fruchtbar machen, um zwei Erzählebenen der traditionellen Autobiographie gegeneinander zu profilieren, die von einer jeweils eigenen Dynamik geprägt sind. Während nämlich die erzählte Lebensgeschichte der ereignisreichen und bewegten Entwicklung des Protagonisten folgt, steht der gealterte Erzähler an einem festen Punkt und befindet sich in einem ruhigen Zustand der Muße. So steht der zeitlichen und räumlichen Dynamik der erzählten Geschichte die raumzeitliche Stabilität der Erzählsituation gegenüber.

Besonders deutlich hat Wayne Shumaker in seiner Studie über die English Autobiography (1954) die Position des Erzählers in dieser Weise charakterisiert: "As a rule, $[. .$.$] autobiographical composition is undertaken at some moment$ of apparently permanent elevation above passion and ambition. ${ }^{\text {"17 }}$ Ähnlich wie Pascal erkennt auch Shumaker in der erhöhten, außeralltäglichen Position des erinnernden Ich die Voraussetzung für den autobiographischen Rückblick. Zudem grenzt Shumaker explizit die Welt des autobiographischen Erzählers von der Welt der Arbeit ab: „The career is over; no further advancement is hoped for, no further retrogression feared. Life has been lived, and is now to be recorded in tranquility, with a serenity and honesty that would have been impossible in the thick of the struggle. "18 Was ihm in den anstrengenden Kämpfen des Lebens verwehrt geblieben sei, erreiche der ideale Autobiograph nun in der Gegenwart

16 Pascal, Design and Truth in Autobiography, 10.

17 Wayne Shumaker, English Autobiography. Its Emergence, Materials and Form, Berkeley 1954, 128.

18 Shumaker, English Autobiography, 128. 
seines Erzählens, nämlich „a stability appropriate to the subject“. Shumaker findet dafür ein recht klischiertes Bild der Muße: „Autobiography [...] closes with the chair tilted against a sunny wall“ ${ }^{19}$ Ein sonniger, mußevoller Sonntagnachmittag - so imaginiert Shumaker den Endpunkt großer Autobiographien, von dem aus sich die Erzählung entfalten lässt.

In der traditionellen Autobiographik, so lässt sich als Zwischenfazit formulieren, korrespondiert der stabile Selbstentwurf des Autobiographen mit dem mußevollen, verdienten Altersort des erzählenden Ich. Im Rückblick auf die Goethezeit wurde diese Vorstellung von der Autobiographieforschung zur kaum noch hinterfragten Grundannahme des autobiographischen Schreibens erklärt, und dies ungeachtet der Tatsache, dass sich schon in den Klassikern der Autobiographik - nicht zuletzt in den Confessions und erst recht den Rêveries Rousseaus - die Umstände der Selbstfindung durchaus als prekär und die resultierenden Identitätsentwürfe häufig als instabil erweisen. Gleichwohl proliferierte die Idee des stabilen, mußevollen Lebensrückblicks in den theoretischen Gattungsdiskurs der Autobiographie und wurde dort zur wirkmächtigen Norm. Insbesondere abgeschiedene, naturnahe, idyllische Szenerien bilden demnach einen idealen Rahmen für den Erzähler, der in Ruhe auf sein Leben zurückblicken will. Die Koppelung von autobiographischer Reflexion und Muße erlangt auf diese Weise topischen Charakter: Die Muße des Autobiographen ist an bestimmte Orte der Selbstreflexion gebunden, die sich im Laufe der Literatur- und Kulturgeschichte in dieser Funktion etablierten und über Epochengrenzen hinweg ihren Einfluss entfalten. So stellt sich die Frage, auf welche Weise die poetologischen Prämissen des ,klassischen' autobiographischen Erzählens noch in gegenwärtige Texte hineinwirken. In den folgenden Textanalysen soll der Fokus auf zwei ausgewählte Räume bzw. räumliche Praktiken der Muße gelegt werden, welche die autobiographische Kontemplation in besonderer Weise zu begünstigen scheinen: erstens auf die Bewegung durch die Landschaft und zweitens auf den privaten Rückzug in die Häuslichkeit. ${ }^{20}$

19 Shumaker, English Autobiography, 128.

20 Damit sind zwei durch ihre Räumlichkeit charakterisierte Varianten der Muße in der Moderne benannt, die auch in anderen Beiträgen dieses Bandes eine Rolle spielen: Die zurückgezogene Muße untersucht Günter Figal am Fall von Henry David Thoreau. Zum Topos des mußevollen Spazierens durch ländliche bzw. urbane Landschaften hingegen vgl. die jeweiligen Beiträge von Peter Philipp Riedl, Kerstin Fest und Heidi Liedke. 


\section{In der Landschaft - Max Frischs Montauk ${ }^{21}$}

Vor Jean-Jacques Rousseau war die Landschaft nur selten Gegenstand ästhetischer Anschauung, vielmehr wurde sie von Reisenden „als der zeitraubende Zwischenraum erachtet, der lohnende Ziele voneinander trennt“. ${ }^{22}$ Das autobiographische Erzählen kann diesbezüglich jedoch als Ausnahme gelten. Michail Bachtin hat darauf hingewiesen, dass die, Entdeckung der Landschaft' schon die (Auto-)Biographien der Antike prägte, weil sie die Möglichkeit einer Relationierung von äußerer Natur und innerer Subjektivität eröffnete:

Es entsteht die ,Landschaft', d.h. die Natur als Blickfeld (als Gegenstand des Sehens) und Umgebung (als Hintergrund, Rahmen) des gänzlich privaten und einsam-untätigen Menschen. [...] In Form malerischer Ausschnitte findet die Natur in der Zeit der Spaziergänge, der Mußestunden oder in Momenten, da der Blick zufällig auf eine sich eröffnende Ansicht fällt, in die intime Welt des privaten Menschen Eingang. ${ }^{23}$

Das Spazierengehen als langsame, äußerlich zweckfreie Bewegung stellt eine spezifisch moderne Form der Begegnung von Mensch und Landschaft dar. Spätestens seit dem Ende des 18. Jahrhunderts zählt der Spaziergang zu jenen besonders populären und verfügbaren Praktiken der Muße, die den Angehörigen beinahe aller sozialen Gruppen eine Möglichkeit eröffnen, nicht nur die Natur außerhalb der schnell wachsenden Großstädte zu betrachten, sondern auch ,in sich selbst hineinzuschauen'. Wiederum ist es Rousseau, der das einflussreiche Bild des einsamen Spaziergängers etablierte, der seinen Blick nach innen wendet ${ }^{24}$ : „Jamais je n'ai tant pensé, tant existé, tant vécu, tant été moi, si j’ose ainsi dire, que dans [les voyages] que j’ai faits seul et à pied." $(O C, 162)$ [Nie habe ich so viel nachgedacht, nie war ich mir meines Daseins, meines Lebens so bewußt, nie war ich sozusagen mehr ich selbst als auf den Reisen, die ich allein und zu Fuß gemacht habe. $\left.{ }^{25}\right]$

In der 1975 erschienenen autobiographischen Erzählung Montauk von Max Frisch spielt die Landschaft als Ort der Introspektion und Erinnerung eine entscheidende Rolle. ${ }^{26}$ Auslöser der autobiographischen Reflexion ist eine Lesereise

21 Teile des Kapitels erschienen bereits in französischer Übersetzung in Georg Feitscher, „Les postfigurations du loisir. Vers une typologie des réflexions autobiographiques“, in: Recherches e Travaux 88 (2016), 157-176.

22 Petra Raymond, Von der Landschaft im Kopf zur Landschaft aus Sprache. Die Romantisierung der Alpen in den Reiseschilderungen und die Literarisierung des Gebirges in der Erzählprosa der Goethezeit, Berlin 1993, 61. 71.

23 Michail Bachtin, Chronotopos, aus d. Russ. v. Michael Dewey, Frankfurt a. M. 2008,

24 Vgl. Jacques Plessen, Promenade et poésie. L'expérience de la marche et du mouvement dans l'Euvre de Rimbaud, Paris 1967, 67-70.

25 Jean-Jacques Rousseau, Die Bekenntnisse, übers. v. Alfred Semerau, durchges. v. Dietrich Leube, Einf. v. Jean Starobinski u. Anm. v. Christoph Kunze, München 1978, 162.

${ }_{26}$ Max Frisch, Montauk. Eine Erzählung, Frankfurt a. M. 1975. Im Folgenden im Fließtext zitiert mit der Sigle $M O$. 
Frischs durch die USA, die ihn abschließend nach New York City führt. Dort beginnt der Autor - zu diesem Zeitpunkt 63 Jahre alt - ein Verhältnis mit einer mehrere Jahrzehnte jüngeren Verlagsangestellten namens Lynn. In dem fragmentarisch gestalteten Text zeigt sich der in der Regel schlicht „Max“ genannte Ich-Erzähler als Flaneur in New York, vor allem aber als Spaziergänger auf der östlich davon liegenden Halbinsel Long Island. Denn dorthin unternimmt ,Max am Wochenende des 11. und 12. Mai 1974 einen Ausflug mit seiner jungen Geliebten.

Die Opposition Stadt/Land strukturiert den Raum der Erzählung. Den von einer melancholischen Ruhe geprägten Wochenendausflug inszeniert Frisch als folgenreichen Bruch mit den eigenen Alltagsroutinen. Anfangs noch mit dem Auto unterwegs, folgen Max und Lynn einem Schild „OVERLOOK“, das ihnen einen Punkt mit guter Aussicht über die Insel verspricht. Doch bald müssen sie den Wagen stehen lassen und sich zu Fuß einen Weg durch die Natur bahnen: „Büsche und Gestrüpp um den leeren Parkplatz; keine Aussicht also, aber es gibt einen Pfad, der durch das Gestrüpp führt, und sie haben nicht lang beraten: der Pfad wird sie zur großen Aussicht führen." $(M O, 7)$ Natürlich ist der Erzähler nicht einfach auf der Suche nach einem schönen Aussichtpunkt, der ihm einen weiten Blick über die Landschaft gestattet. Die Konstruktion ist höchst symbolisch: Der Lebenspfad führt erst durch undurchsichtiges Gestrüpp, bevor Max schließlich einen Punkt findet, der ihm den Rück- und Überblick auf das eigene Leben ermöglicht. Long Island wird für ihn zum Ort der biographischen Kontemplation, denn die Affäre mit der jungen Lynn lässt Frisch sein eigenes Alter empfinden und weckt in ihm das Bedürfnis, Bilanz zu ziehen.

Die Erzählung des Montauk-Wochenendes wird daher immer wieder von Episoden der Lebenserinnerung durchbrochen. Es ergibt sich eine Struktur aus Rahmung und Binnenerzählungen: Die Erlebnisse auf Long Island schildert der Erzähler im Präsens, spricht allerdings vorwiegend (wenn auch nicht durchgehend) in der distanzierenden dritten Person von sich, als würde er sich selbst von außen beobachten. Dazwischen schaltet er Erinnerungen an bedeutende Ereignisse seines Lebens, die zumeist in der ersten Person Präteritum stehen - der klassischen Grammatik der Autobiographie. ${ }^{27}$ Die Rahmenerzählung des Montauk-Wochenendes ist im Hinblick auf die Topik der Muße besonders instruktiv, denn Frisch artikuliert darin, an welche raumzeitlichen und praktischen Bedingungen seine Reflexion geknüpft ist.

Es ist „ein langer leichter Nachmittag“, als Max und Lynn den Ort Montauk am äußersten Ende von Long Island erreichen:

27 Einen ganz „unsystematisch[en]“ Gebrauch der Personalpronomen, die allenfalls „verschiedene Grade von Rollenhaftigkeit“ ausdrücken, erkennt dagegen Anton Krättli, „Leben im Zitat‘. Max Frischs Montauk“, in: Walter Schmitz (Hg.), Über Max Frisch, Frankfurt a. M. 1976, 428-434, 431 f. 
Ein meilenlanger Strand, ein Ende des Strandes nicht zu sehen, er verliert sich nach beiden Seiten im milchigen Lila-Licht der Verdampfung. Trotz Wind ist es fast heiß. Zwei Liegesessel mit verblichenen Kissen stehen im Sand, keine andern weit und breit; wem gehören sie? Kein Mensch weit und breit. $(M O, 95)$

Nur hundert Meilen von der geschäftigen Weltstadt entfernt, finden Max und Lynn sich in einer menschenleeren Einsamkeit wieder. Im Erzähler wächst das Bedürfnis, vollständig in dieser Gegenwart aufzugehen. Er versucht sich an verschiedenen ritualisierten Praktiken, um eine Erfahrung der Präsenz und des Verweilens herzustellen. So stopft er z.B. seine Pfeife:

Er hat die Pfeife ausgeklopft, er denkt: [...] stopfe die Pfeife mit dem rechten Daumen und mit Bedacht, der Augenblicke ausfüllt, Augenblicke ohne Gedächtnis, [...] ziehe mit Bedacht den ersten Zug, einen kurzen, dann einen zweiten, einen langen, bis du da bist ganz und gar. Im Augenblick gibt es nur sie beide in den beiden Sesseln [...]. (MO, 98)

Vom Liegesessel am Strand aus ergibt sich endlich der ersehnte Blick in die Weite, jener „Overlook“, den das erzählende Ich sucht. Max will ,jetzt ins Weite schauen [...] damit er sich dabei vergißt: ein zu schwerer Mann, [...] das Haar grau bis weiß“. $(M O, 55)$ Doch erweist sich die Präsenzerfahrung als brüchig und der Zustand der mußevollen Entkoppelung von Zeit und Alltag als vergänglich: „Er vergißt nicht seine Rolle, nicht die nächsten Verpflichtungen, die sich ergeben aus dieser Rolle; Termine, er vergißt nicht einmal die Weltlage. Es ist allerlei, was er nicht vergißt in dieser dünnen Gegenwart." $(M O, 103)$ Sein Selbstverständnis als politisch engagierter Autor kann Frisch nicht einfach abstreifen. Zu sehr ist ihm die ,Rolle des gesellschaftlichen Beobachters und Kommentators zur zweiten Haut geworden. Idiosynkratische Reflexionen, wie Frisch sie in Montauk anstellt, entsprechen im Grunde nicht seiner Auffassung von Literatur: „Die Literatur hat die andere Zeit, ferner ein Thema, das alle angeht oder viele - was man von ihren zwei Schuhen im Sand nicht sagen kann." $(M O, 103)$ Und so ist es gerade die Literatur, die Frisch aus der, dünnen Gegenwart ' des Augenblicks herauszureißen und sein Nachdenken wieder auf eine politische Ebene zu lenken droht: „Literatur hebt den Augenblick auf, dazu gibt es sie.“ (MO, 103)

Dieses hier beinahe schon zum ironischen Selbstzitat geronnene Bekenntnis zur politischen Literatur steht in einem performativen Widerspruch zur Erzählung Montauk, die fraglos zu Frischs persönlichsten Werken zählt. In der Tat kann man Montauk als eine poetologische Wende innerhalb von Frischs Spätwerk betrachten. Der Möglichkeit eines autobiographischen Erzählens war Frisch in seinen früheren Werken wie Stiller (1954) und Mein Name sei Gantenbein (1964) mit großer Skepsis begegnet ${ }^{28}$, hatte dagegen die „Öffentlichkeit als

28 Vgl. Max Schiendorfer, „Dichtung und Wahrheit. Zur Literarisierung biographischer Wendepunkte: Max Frisch - Felix Fabri - Heinrich Seuse - Augustinus“, in: Brigitte Boothe/Pierre Bühler/Paul Michel/Philipp Stoellger (Hg.), Textwelt - Lebenswelt, Würzburg 2012, 303-320, 304-307. 
Partner" des Autors beschworen. ${ }^{29}$ In Montauk rückt er nun die Beziehung von Schriftsteller und Gesellschaft in ein problematischeres Licht. Frisch klagt, er „habe irgendeine Öffentlichkeit bedient mit Geschichten. Ich habe mich in diesen Geschichten entblößt, ich weiß, bis zur Unkenntlichkeit“. Grundlage seiner Werke sei zwar sein eigenes Erleben gewesen, doch interessierten ihn nur jene „Teile davon, die ich habe literarisieren können“ $(M O, 156)$. Der Erzähler Frisch erkennt darin nun einen Verrat an sich selbst, den er zu kompensieren versucht, indem er sich auf Innerlichkeit und Selbsterforschung besinnt. Er erklärt, er wolle „nichts erfinden“, sondern „wissen, was ich wahrnehme und denke, wenn ich nicht an mögliche Leser denke. Schreibe ich denn, um Leser zu befriedigen, um Kritiker zu beliefern!“ (MO, 137 f.) Das Wochenende auf Long Island bietet Frisch einen willkommenen Anlass zur Selbstreflexion, aber auch zur Erkundung eines für ihn neuen, subjektiven Schreibens. So nimmt er sich vor, die Erzählung „autobiographisch, ja, autobiographisch“ zu gestalten, „ohne Ereignisse zu erfinden, die exemplarischer sind als seine Wirklichkeit [...]. Ohne seine Schriftstellerei zu rechtfertigen durch Verantwortung gegenüber der Gesellschaft; ohne Botschaft. [...] Er möchte bloß erzählen [...]: sein Leben“ (MO, 155).

Dem Impuls, nun einmal ,für sich selbst' und ,über sich selbst‘ zu schreiben, kann der Autor unverzüglich nachgeben, denn noch in New York hatte er sich das nötige Material besorgt - eine „OLIVETTI LETTERA“: „ich kann’s nicht lassen, ich habe eine kleine Schreibmaschine gekauft ohne literarische Absicht. [...] Diese Obsession, Sätze zu tippen." $(M O, 21)$ Frisch beginnt, das Wochenende zu beschreiben, und das Resultat dieses autobiographischen Vorhabens ist die Erzählung Montauk selbst. Das Bekenntnis zur Introspektion, das Interesse an der eigenen Geschichte mag für Frisch eine Neuorientierung seines Schreibens darstellen, doch ist es zugleich eine Rückkehr zur mußevollen Topik der Autobiographie. Frisch aktualisiert rousseausche Muster wie den Rückzug aus der Stadt in die Natur, den Spaziergang und das kontemplative Betrachten des Wassers.

Eine bloße imitatio der rousseauschen Spaziergänge stellt Frischs Erzählung indes nicht dar, finden sich die klassischen Topoi hier doch in modernisierter und modifizierter Form. Der autobiographische Erzähler Max ist nur zeitweise ein einsamer Spaziergänger, vielmehr genießt er während der Strandspaziergänge die Begleitung Lynns. Der bedeutendste Unterschied zum traditionellen Modell des autobiographischen Erzählens besteht aber darin, dass der gealterte Frisch nicht aus einem selbstbewussten Zustand der Stabilität heraus auf sein Leben zurückblickt, sondern aus einer Situation der Verunsicherung. Die Diskrepanz zur jungen Lynn führt ihm sein eigenes Alter vor Augen, zudem kommen ihm poetologische Zweifel an der literarischen Verwertung seines Lebens.

29 So das Thema der Rede, die Frisch zur Eröffnung der Frankfurter Buchmesse 1958 hielt. Veröffentlicht als Max Frisch, Öffentlichkeit als Partner, Frankfurt a. M. 1967, 56-67. 
In eher augustinischer Tradition betont Frisch das krisenhafte Moment, das seiner Selbstreflexion innewohnt. Gleichwohl entfalten die Praktiken der Muße auch bei Frisch ihre Wirkung und setzen seine literarische Produktivität frei. Spazierend am Strand von Montauk kann sich der gealterte Autor zumindest vorübergehend aus den Alltagszusammenhängen lösen, in der Gegenwart aufgehen und schließlich den Blick zurück auf das eigene Leben wagen.

\section{Rückzug - Marcel Reich-Ranickis Mein Leben}

Alles andere als verunsichert, sondern ausgestattet mit einem erheblichen Selbstbewusstsein, präsentiert sich Marcel Reich-Ranicki in seiner 1999 erschienenen Autobiographie Mein Leben. ${ }^{30}$ Wie kaum ein anderer Lebensbericht der letzten Jahrzehnte bezeugt das Buch, dass die ,klassische' Konzeption des autobiographischen Erzählens in vielen Fällen noch immer die Textproduktion und - wie die verkaufte Auflage von über eineinhalb Millionen Exemplaren bezeugt ${ }^{31}$ auch die Rezeptionserwartungen des Publikums bestimmt. Bereits in den ersten Zeilen des Buches skizziert Reich-Ranicki den dramatischen Verlauf seines Lebens, der von zwei bedeutenden Daten markiert wird:

Es war Ende Oktober 1958 auf einer Tagung der „Gruppe 47“ in der Ortschaft Großholzleute im Allgäu. Von den hier versammelten Schriftstellern kannte ich nur wenige - kein Wunder, denn ich lebte erst seit drei Monaten wieder in dem Land, aus dem mich die deutschen Behörden im Herbst 1938 deportiert hatten. $(M L, 11)$

Wie eine Klammer umschließen die beiden einschneidenden Erlebnisse den zentralen Entwicklungsbogen der Autobiographie, der von Reich-Ranickis Deportation aus der deutschen Vorkriegsgesellschaft (1938) bis zu seiner Reintegration in die deutsche Nachkriegsgesellschaft (1958) reicht. Zudem spannt Reich-Ranicki einen roten Faden entlang der prägenden Themen und Motive seines Lebenslaufs, nämlich der Verfolgung als Jude durch die Nationalsozialisten, die jedoch seiner Hingabe an die deutsche Literatur nichts anhaben konnte. Der Erzähler präsentiert in einem einzigen Satz seine Autobiographie in nuce, die dann auf den folgenden 550 Seiten ausführlich entfaltet wird. So steht von Beginn an außer Frage, dass Reich-Ranickis Vita die Relevanzkriterien der traditionellen Autobiographik auf außerordentliche Weise erfüllt - es ist ein bewegtes, bedeutendes, von enormen Brüchen gekennzeichnetes Leben, musste Reich-Ranicki seinen Erfolg als Literaturkritiker doch gegen alle Wahrscheinlichkeiten und Gefahren erkämpfen.

30 Marcel Reich-Ranicki, Mein Leben, Stuttgart 1999. Im Folgenden im Fließtext zitiert mit der Sigle $M L$.

31 Vgl. Uwe Wittstock, Marcel Reich-Ranicki. Geschichte eines Lebens, München 2005, 235. 
Zudem signalisiert Reich-Ranicki in diesen ersten Zeilen des Buches, dass er sich als ein souveräner Autobiograph begreift, der mühelos seine Erinnerungen wachrufen kann und dem es keine Schwierigkeiten bereitet, auch über weite Zeiträume hinweg die Zusammenhänge in seiner Biographie herauszustellen. Seiner Autobiographie legt er eine weitgehend ungebrochene, stabile Subjektkonzeption und ein Modell souveräner Autorschaft zugrunde, die im literarischen Umfeld der letzten Jahrzehnte merkwürdig deplatziert wirken können, weil sie häufig ein Merkmal, trivialer ' Autobiographien bilden. Doch wäre es ein Fehlschluss, Reich-Ranickis Identitätsmodell als anachronistisch oder gar naiv abzutun. Denn wie Reich-Ranicki deutlich macht, reflektiert das Erzählmodell schlicht eines der bestimmenden Motive seines Lebens: die Behauptung seines Selbstentwurfes gegen einen antisemitischen Wahn, der ihm die Identität zu nehmen versuchte.

Dem stabilen Identitätsentwurf ist es auch geschuldet, dass Reich-Ranicki in Mein Leben kaum die genauen Umstände seines Erzählens erwähnt. Weder geht er auf Aufzeichnungen oder Dokumente ein, die seinen Erinnerungen zugrunde liegen, noch thematisiert er den räumlichen und zeitlichen Kontext, aus dem heraus er seine Autobiographie verfasst. Die Erzählsituation bleibt weitestgehend abstrakt, sodass der Eindruck entsteht, die Retrospektion funktioniere völlig unproblematisch und das Erzählen gelänge dem Autor wie von selbst. Erst im Anschluss an seine Lebenserzählung, nämlich im kurzen Schlusskapitel, geht Reich-Ranicki explizit auf die Erzählsituation ein, verlässt also den Bereich der retrospektiven Darstellung und springt in die Gegenwart des erzählenden Ich. Am „12. März 1999“, dem 79. Geburtstag seiner Frau Tosia, befindet sich Reich-Ranicki mit ihr im gemeinsamen Haus. „Wir sind allein, es ist sehr still, ein später Nachmittag“, umreißt der Erzähler die Situation. $(M L, 552)$ Die Privatheit und Ruhe des Moments stehen im starken Kontrast zur bewegten Karriere Reich-Ranickis im Scheinwerferlicht der Öffentlichkeit - noch im vorherigen Kapitel hatte er seine Begegnungen mit Willy Brandt geschildert. Doch Reich-Ranicki ist, wie sich zeigt, nicht völlig allein mit seiner Frau; denn diese sitzt, „wie immer, auf dem schwarzen Sofa vor einer unserer Bilderwände, hinter ihr die Porträts von Goethe, Kleist, Heine und Fontane, von Thomas Mann, Kafka und Brecht" $(M L, 552)$. Die literarische Tradition ist in der Szene durch Abbildungen ihrer kanonischen Vertreter anwesend. Die berühmten Autoren erscheinen jedoch nicht als Repräsentanten einer deutschen Literatur und Kultur, die es öffentlich zu bewahren und zu verteidigen gelte. Reich-Ranicki behandelt sie, denen er im Laufe seiner Autobiographie mehrfach seine bedingungslose „Liebe“ attestiert hatte, auch am Lebensende noch wie Angehörige seines engsten Bekannten- und Familienkreises. Das räumliche Arrangement verstärkt den Eindruck der Intimität, denn der Erzähler nennt die Bildergalerie der Autoren im gleichen Atemzug mit „einige[n] Fotos“ seines Sohnes und seiner Enkelin, die „[a]uf dem Schränkchen neben dem Sofa stehen“. Auch Reich-Ranickis eigene 
Position in der Szene ist herausgehoben: Er sitzt „Tosia gegenüber“ und damit auch den Familien- und Autorenporträts, die er gut im Blick hat. $(M L, 552)$

Der ruhige Rückzug ins Private, die familiäre Stabilität und die kulturelle Selbstvergewisserung erscheinen bei Reich-Ranicki als ideale Voraussetzungen, um seine autobiographische Erzählung abschließen zu können. Der Erzähler tritt auf den Balkon, auf dem der Sonnenuntergang „ein etwas zu schönes, ein gar zu feierliches Schauspiel“ veranstaltet. $(M L, 552)$ Der kokette Exzessiv kann nicht darüber hinwegtäuschen, dass Reich-Ranicki gezielt die harmonische Übereinstimmung zwischen der Innenwelt des erzählenden Ich und seiner Umgebung exponiert. Tatsächlich kommt dem Erzähler in diesem Moment die ersehnte Idee, die ihm zur Vollendung seines Lebensberichts noch fehlte. Zurück im Zimmer - „Es ist immer noch ganz still, man hört kaum einen Hauch“ erklärt er seiner Frau: „,Weißt du, jetzt, auf unserem Balkon, als die Sonne unterging, da ist mir eingefallen, womit ich das Buch abschließen werde.' ,Ja', sagt sie erfreut und will wissen: ,Womit?' ,Mit einem Zitat.“" $(M L, 553)$ Es ist ein Vers aus Hugo von Hofmannsthals Libretto zum Rosenkavalier, das Reich-Ranicki nun ans Ende seiner Autobiographie setzt: „Ist ein Traum, kann nicht wirklich sein,/daß wir zwei beieinander sein.“32 $(M L, 553)$ Im Schlussduett des Rosenkavaliers besingen Sophie und Octavian mit diesen Worten ihre Liebe, die sie erst ausleben dürfen, nachdem der Baron Ochs, der um Sophies Hand angehalten hatte, als Heiratsschwindler überführt und davongejagt ist. Im Glück der beiden Figuren findet Reich-Ranicki ein Vorbild für seine eigene Ehe, zugleich hebt er mit dem Zitat die Unwahrscheinlichkeit und schicksalhafte Notwendigkeit seiner Liebe zu Tosia hervor.

Doch ist der Umstand bedeutend, dass Reich-Ranicki den Vers aus dem Rosenkavalier eben nicht einfach ans Ende des Textes seiner Autobiographie setzt, sondern explizit darstellt, wie es zu der Entscheidung für das Zitat kam. Mithilfe dieses narrativen Kniffs löst Reich-Ranicki im letzten Kapitel in geradezu prototypischer Weise das gattungstypische Erzählmodell ein: Die autobiographische Retrospektive konvergiert mit der Gegenwart des Erzählens, bis die Ebenen der erzählten Geschichte und der Erzählsituation am Ende in eins fallen. Dieser Endpunkt der Konvergenz von Leben und Erzählen - und damit die Gegenwart des gealterten Reich-Ranicki - entspricht dem von Stabilität und Harmonie, von Rückzug, Ruhe und Muße gekennzeichneten standpoint, den einst die Gattungstheoretiker zur Voraussetzung gelungener Autobiographien erklärten. Reich-Ranicki präsentiert sich an einem gleichermaßen zurückgezogenen wie herausgehobenen Altersort, den er sich im Laufe seines ereignisreichen Lebens erarbeitet hat. Unter diesen Bedingungen verfasst er einen scheinbar mühelosen Lebensbericht.

32 Hugo von Hofmannsthal, Der Rosenkavalier. Komödie für Musik, Sämtliche Werke, Bd. 23, hg. v. Dirk O. Hoffmann/Willi Schuh, Frankfurt a. M. 1986, 1-101, 101. 
So demonstriert Reich-Ranickis Mein Leben ebenso wie Max Frischs Montauk eindrücklich, dass die Topoi der autobiographischen Reflexion auch in der Gegenwart nichts von ihrer Wirkmacht eingebüßt haben. In der Moderne avanciert die Muße zu einem idealisierten und privilegierten Zustand, in dem der Mensch sich als Subjekt konstituieren kann, indem er seine eigene Geschichte reflektiert und erzählt. Die Muße manifestiert sich dabei an konkreten Orten und in Form kontemplativer Praktiken, die zum Teil schon in den kanonischen Autobiographien als Bedingungen der Selbsterkundung aufgerufen werden und von dort bis in jüngste Texte proliferieren. ${ }^{33}$

${ }^{33} \mathrm{Zu}$ vermuten ist allerdings, dass die Destabilisierung und Dezentrierung von Identitätsmodellen im Laufe der Postmoderne nicht nur die autobiographische Praxis beeinflusste, sondern auch die Vorstellungen veränderte, unter welchen Bedingungen ein Lebensbericht noch möglich ist. Dies wird an anderer Stelle zu besprechen sein. 



\title{
Muße und Ungleichheit
}

\section{Zur Dialektik eines modernen Problems}

\author{
Christoph Henning
}

\begin{abstract}
„Damit der Boden für eine größere Kunstentwicklung vorhanden ist, muss die ungeheure Mehrzahl im Dienste einer Minderzahl über das Maß ihrer individuellen Notwendigkeit hinaus der Lebensnot sklavisch unterworfen sein. Auf ihre Unkosten, durch ihre Mehrarbeit soll jene bevorzugte Klasse dem Existenzkampfe entrückt werden, um nun eine neue Welt des Bedürfnisses zu erzeugen." (Nietzsche) ${ }^{1}$
\end{abstract}

\section{Künstlerkritik: Warum fehlende Muße als Resultat der Ungleichheit begreifen?}

Die Muße, die für die Selbstreproduktion, aber auch für das akademische Arbeiten notwendig ist, ist für viele in den letzten Jahren zu einem immer kostbareren, weil stets knapperen Gut geworden. Das ist eine verbreitete Erscheinung nicht nur, aber auch unter Akademikern, gerade sofern sie einen höheren Gestaltungsraum über ihre Arbeit haben (vergleichbar den „Kreativ“-Arbeitenden, bei denen Selbstausbeutung und Burnout prominent untersucht werden). ${ }^{2}$ Sie nehmen sich zu viel vor (angefeuert nicht zuletzt durch befristete Verträge, Deadlines für Bewerbungen oder anstehende Evaluierungen), überfordern sich damit selbst, und sind am Ende stets abgehetzt und ausgebrannt, fangen an sich zu wiederholen - und über fehlende Muße zu klagen. „Wie war zu Köln es doch vordem, mit Heinzelmännchen so bequem. ${ }^{\text {"3 }}$ Es gab Zeiten, so meinen sich viele zu erinnern, als man noch einfach so ein Buch zur Hand genommen hat, um daran zu lesen - ohne unmittelbaren Verwertungsdruck, also nicht, weil man selbst etwas schreiben oder durcharbeiten muss. Gerade für etablierte Akademiker erscheint die Vergangenheit daher häufig als goldenes Zeitalter des zeitlichen Reichtums. ${ }^{4}$

${ }^{1}$ Friedrich Nietzsche, Nachgelassene Fragmente 1869-1874, Kritische Studienausgabe (= KSA), Bd. 7, hg. v. Giorgio Colli/Mazzino Montinari, Berlin/New York 1980, 339.

2 Siehe Andrea Manske, Kapitalistische Geister in der Kultur- und Kreativwirtschaft. Kreative zwischen wirtschaftlichem Zwang und kreativem Drang, Bielefeld 2015.

3 August Kopisch, Gedichte, ausgew. u. eingel. v. Franz Brümmer, Leipzig 1887, 249.

4 Karl Marx/Friedrich Engels, Ökonomische Manuskripte 1857/1858, Werke (=MEW), 
So wie ich es jetzt geschildert habe, sieht es aus, als sei diese spätmoderne Beschleunigung zum großen Teil selbstverschuldet. Es gibt zwar äußere Zwänge, die sie befördern (etwa formelle Leistungsvorgaben oder informelle Erwartungen), doch sie beruht weitgehend auf freien Entscheidungen. Vielleicht ist die Zeitarmut daher gar nicht länger mit der Ungleichheitssemantik gekoppelt, die frühere Formen der Sozialkritik noch angetrieben hat? ${ }^{5}$ Wir hätten es dann, im Sinne von Boltanski und Chiapello nicht mit Sozialkritik, sondern mit einer reflexiven Form von Künstlerkritik zu tun: ${ }^{6}$ Dem Klagen darüber, dass die Verwirklichung dieser eher von Intellektuellen und Künstlern formulierten Kritik (etwa Forderungen nach mehr Selbstbestimmung, mehr Freiraum sowie mehr Selbstverantwortung und Kreativität in der Arbeit) paradoxerweise zu mehr Leistungsdruck, zu höheren emotionalen Belastungen und so zu einer tiefsitzenden Erschöpfung geführt hat. ${ }^{7}$

Man könnte nun einschränken, dass die Klage über fehlende Muße, wenn sie von einer beamteten Vollzeitstelle aus erfolgt, eine reichlich zynische Angelegenheit ist - denn im Vergleich etwa zur Supermarkt-Verkäuferin, die nach ihrer Arbeitszeit noch die Abrechnung machen und den Laden reinigen muss, z. T. sogar unbezahlt, gibt es zur Klage wenig Anlass. Aber die Frage bleibt: spielt die Ungleichheit für die Selbstausbeutung und die Zeitarmut wirklich keine Rolle mehr? Das lässt sich mit guten Gründen anzweifeln. Zunächst gibt es selbst bei etablierten Jobs eine Erosion: auch Stellen im Hochschuldienst sind zunehmend befristet, innerhalb dieser Fristen gibt es Evaluationen - und die Kriterien für eine Evaluation können recht diffus sein. Die Betroffene - allem voran der sogenannte wissenschaftliche „Nachwuchs“ - steht damit unter deutlich höherem Leistungsdruck als jemand, der eine unbefristete Stelle hat. (Aber natürlich zugleich deutlich weniger als jemand, der gar keine Stelle hat und Anträge schreibt, oder im „blue-collar“-Bereich tätig ist). Die Milieu-interne Ungleichheit durch befristete Verträge, von Leiharbeit in anderen Sektoren ganz zu schweigen ${ }^{8}$, heizt die Selbstüberforderung an und ist insofern für den Muße-Schwund mitverantwortlich. Ein Lob also auf den „alten“ Beamten, der sich in seiner Arbeit noch ausruhen konnte? Dostojewski- oder Flaubert-Leser werden wissen, wie genüsslich sich dieser Typus schildern ließ: Schreibtisch, Bauchansatz und Langeweile

Bd. 42, hg. v. Institut für Marxismus-Leninismus beim ZK der SED, Berlin 1983, 192: „Ökonomie der Zeit, darin löst sich schließlich alle Ökonomie auf."

5 Diese Lesart, die Hartmut Rosa (Beschleunigung. Die Veränderung der Zeitstrukturen in der Moderne, Frankfurt a. M. 2005) erwägt, hat ihm viel Kritik eingebracht. Dabei ist es durchaus erwägenswert, ob soziale Ungleichheit und Zeitarmut nicht zumindest auch je eigene soziale Quellen haben können, selbst wenn sie eng zusammenhängen.

6 Siehe Luc Boltanski/Eve Chiapello, Der neue Geist des Kapitalismus, Konstanz 2005.

$7 \mathrm{Zu}$ einer Kritik insbesondere an Alain Ehrenberg siehe Christoph Henning, Theorien der Entfremdung zur Einführung, Hamburg 2015, 176 ff.

8 Siehe Klaus Dörre/Hajo Holst (Hg.), Fragmentierte Belegschaften. Leiharbeit, Informalität und Soloselbstständigkeit in globaler Perspektive, Frankfurt a. M. 2017. 
(nicht zuletzt für an sie gekettete Gattinnen) gehen in der Imagination bruchlos ineinander über. Was am Typus des Beamten zum Teil bis heute kritisiert wird, ist allerdings weniger sein Arbeitsethos selbst als vielmehr die Ungerechtigkeit, die darin liegt, dass nicht alle Arbeitenden in den Genuss eines solch geruhsamen und gesicherten Arbeits-Lebens kamen, wie man es sich vom Beamten vorstellt. Ich erinnere mich noch an den einen Ortsbeamten im Dorf, der für allerlei Verwaltungsangelegenheiten zuständig war, der uns Kinder aber vor allem durch seine Kunst des Pausemachens beeindruckt hat. Kritik an fehlender Muße ist also, wenn auch über Umwege, durchaus als Sozialkritik zu begreifen.

Mit dieser kurzen Eingangsbetrachtung habe ich meine eigentliche These plausibilisiert, die ich in diesem Aufsatz verteidigen möchte. Ich denke nämlich, dass der Mußediskurs auf den zweiten Blick überaus stark in die Ungleichheitsthematik verwoben ist. Im Blick auf die neuere Literatur zur Muße (auch aus Freiburg $)^{9}$ bekommt man das Gefühl, dass das nicht immer so gesehen wird. Ich möchte diese These daher im Folgenden auf zwei Weisen näher ausführen. Erstens meine ich, dass die Theorie der Gerechtigkeit, zumindest ihr egalitärer Zweig, in ihren interessantesten Ausformungen gerade eine Theorie der Verteilung von Muße gewesen ist. Für John Rawls gilt das zwar nur eingeschränkt (aber er ist auf den zweiten Blick auch kein ,echter Egalitarist, da sein Hauptanliegen die Rechtfertigung von Ungleichheit ist), wohl aber für die Tradition der „radikalen Aufklärung“, die stark auf Karl Marx und die frühe kritische Theorie gewirkt hat. ${ }^{10}$ Zweitens möchte ich dann, in einer reflexiven Wendung in das Begriffliche, überlegen, inwiefern der Idee der Muße nicht selbst schon eine gewisse Ungleichheit eingeschrieben ist. Das Nachdenken über die Idee der Muße - und erst recht über ihre Praxis - war lange Zeit ein Elitendiskurs. Je nachdem, wie tief die Spuren dieses begrifflichen Elitismus sind, könnte das zu Problemen führen, wenn man, wie im ersten Teil vorgeschlagen, Muße zur „currency of justice“ machen will. Wie lässt sich diese Spannung auflösen?

\section{Die Idee der Muße und der Egalitarismus}

Zunächst also zur Frage, inwieweit Muße eigentlich Gegenstand einer egalitaristischen Gerechtigkeitstheorie sein könnte. Man muss in der Gerechtigkeitstheorie unter anderem klären, was es eigentlich ist, das man auf eine gerechte Weise - und der Einfachheit halber will ich annehmen: möglichst gleich - verteilen

9 Eine Ausnahme bildet etwa Pia Masurczak in diesem Band.

10 Zeugnis davon ab legen etwa die Habilitationsschrift von Leo Löwenthal zu Helvetius (von 1926) oder die (von Adorno betreute) Doktorarbeit von Günther Mensching: Totalität und Autonomie: Untersuchungen zur philosophischen Gesellschaftstheorie des französischen Materialismus, Frankfurt a.M. 1971. 
sollte („What's the currency of Justice“ fragte bereits Dworkin). ${ }^{11}$ Wir kennen die Kandidaten, wie sie im Lehrbuch stehen: Im Angebot stehen Ressourcen, Wohlergehen, Zugang zu oder Recht auf Wohlergehen oder Ressourcen, oder Rechte ohne Wohlergehen (d.h. ein gleicher moralischer Status, was immer das konkret heißen mag). Neuerdings könnte man hinzufügen: gleich zu verteilen ist der Zugang zu Möglichkeiten der Resonanz (so gibt Rainer Forst Hartmut Rosas neues Buch wieder), oder, was ich selbst bevorzugen würde, ein gleicher Zugang zu Möglichkeiten der Selbstvervollkommnung. ${ }^{12}$

Der wichtigste Kandidat in unserem Zusammenhang, der sonst selten gesehen wird, ist die Muße. Kann man Gerechtigkeit auch so verstehen, dass ihr zufolge $M u ß e$ als Gut gilt, das möglichst gleich zu verteilen ist? ( $\mathrm{Zu}$ fragen wäre dann, was neben der „freien Zeit" noch dafür nötig wäre.) Wenn man genauer hinschaut, ist das keineswegs ein schwacher Kandidat. So fordert etwa J.G. Fichte in seiner späten Rechtslehre, dass der Staat einem Jeden neben Arbeit und Eigentum „freie Muße zu beliebigen Zwecken“ zu garantieren habe. ${ }^{13}$ Das ist keine kleine Forderung. Der Umfang an Muße, den ein Staat seinen Bürgern zu erlauben im Stande ist, ist für Fichte sogar das Maß seines Reichtums: „Fichte thus comes to view leisure as an object of distributive justice and one of the state's main tasks as distributing it equally among its citizens. ${ }^{14}$ Fichte ist bei näherem Hinsehen kein Einzelfall, sowohl was die Berechnung des wahren Reichtums der Nationen in terms of Muße, also auch was Muße als Währung der Gerechtigkeit angeht. Noch Karl Marx definiert den „wahren Reichtum“, um den es im Wirtschaften letztlich geht, als freie Zeit zur freien Entwicklung. „Aber free time, disposable time, ist der Reichtum selbst - teils zum Genuss der Produkte, teils zur free activity, die nicht wie die labour durch den Zwang eines äußeren Zwecks bestimmt ist. ${ }^{\text {"15 }}$ Marx kritisiert den Kapitalismus nicht zuletzt deswegen, weil dieser die Muße zum „Firlefanz“ erkläre. Muße wird dabei verstanden als: „Zeit zu menschlicher Bildung, zu geistiger Entwicklung, zur Erfüllung sozialer Funktionen, zu geselligem Verkehr, zum freien Spiel der physischen und geistigen Lebenskräfte. ${ }^{\text {"16 }}$ Quer zur elitären Unterscheidung zwischen Freizeit und Muße, die uns im zweiten Teil beschäftigen wird, sagt Marx klar: Freizeit ist für solche

11 Siehe Ronald Dworkin, „What Is Equality? Part 1: Equality of Welfare“, in: Philosophy and Public Affairs 10 (1981), 185-236.

12 Siehe Hartmut Rosa, Resonanz: Eine Theorie der Weltbeziehungen, Berlin 2016; Christoph Henning, „Perfektionismus als Kritik“, in: Philip Hogh/Sven Ellmers (Hg.): Warum Kritik? Begründungsformen kritischer Theorien, Weilerswist 2017, 51-72.

${ }^{13}$ Johann Gottlieb Fichte, Wissenschaftslehre und das System der Rechtslehre, Johann Gottlieb Fichtes nachgelassene Werke, Bd. 2, hg. v. I. H. Fichte, Bonn 1834, 542.

14 David James, Fichte's Social and political Philosophy, Cambridge 2013, 73.

15 Karl Marx/Friedrich Engels, Theorien über den Mehrwert. Dritter Teil, MEW 26.3, Berlin 1968, 253.

${ }^{16}$ Karl Marx/Friedrich Engels, Das Kapital. Kritik der politischen Ökonomie. Erster Band, MEW 23, Berlin 1968, 280. 
höherstufigen Entwicklungen die „Grundbedingung“17, und daher nicht von der höheren Muße zu trennen: „Die Ersparung von Arbeitszeit gleich Vermehren der freien Zeit, d.h. Zeit für die volle Entwicklung des Individuums. "18 Muße meint für Marx also kein konsumierendes Dahinvegetieren, sondern die Möglichkeit einer Aneignung und Ausübung von Kultur, als dem „gegenständlich entfalteten Reichtum des menschlichen Wesens" ${ }^{19}$ Auch aus diesem Grund sind - neben Parteien, Gewerkschaften und Genossenschaften - die eigenen Bildungsinstitutionen als eigenständiger Zweig der Arbeiterbewegung zu begreifen. ${ }^{20}$ Sie waren nicht nur ein strategisches Mittel, um die Kampfkraft der Arbeiter zu stärken, sondern erfüllten ganz im Sinne von Aristoteles einen Selbstzweck.

Marxkenner mögen einwenden, dass meine Lesart von Marx ihn mehr zum Egalitaristen macht als er eigentlich ist - in der Tat hat sich Marx in der „Kritik des Gothaer Programms“ gegen die Forderung einer gleichen Verteilung gewandt. ${ }^{21}$ Aber dort argumentiert er eher gegen die Verkürzung auf die Verteilung von Gütern. Hinsichtlich anderer Fragen - einerseits der Mitbestimmung über den wirtschaftlichen Gesamtprozess (einer kollektiven Autonomie), andererseits nach der Beteiligung an ihrem Hauptergebnis, nämlich der Möglichkeit $\mathrm{zu}$ einem guten Leben (und das heißt: einem Leben mit viel freier Zeit zu freier Entwicklung - also der Muße), muss man ihn meines Erachtens als Denker der Gleichheit lesen.

Eine solche Verbindung von gesellschaftlicher Gleichheit und Muße als Währung gibt es aber keineswegs nur im Marxschen Sozialismus. Auch der erzliberale Denker J.S. Mill etwa, ein Zeitgenosse von Marx und ebenfalls Londoner, hat Muße und Gleichheit in einen Zusammenhang gebracht. Sein Gedanke war, dass das Wachstum kapitalistischer Gesellschaften aus ökonomischen und sozialen Gründen irgendwann an ein Ende kommen muss. Die Postwachstums-Gesellschaft muss sich darauf einstellen. Zwei Dinge kann sie dafür tun (und hier verbinden sich die beiden Werte): einerseits muss sie auf mehr materielle Gleichheit hinwirken, um jenseits der Konkurrenz ein Klima des Friedens zu wahren. Denn: „the best state for human nature is that in which, while no one is poor, no one desires to be richer, nor has any reason to fear being thrust back by the efforts of others to push themselves forward. “22

17 Karl Marx/Friedrich Engels, Das Kapital. Kritik der politischen Ökonomie. Dritter Band, MEW 25, Berlin 1964, 828.

18 Marx/Engels, Ökonomische Manuskripte 1857/1858, MEW 42, 607. Siehe den Beitrag von Robert Krause in diesem Band.

19 Karl Marx/Friedrich Engels, Ergänzungsband. Schriften. Manuskripte. Briefe bis 1844. Erster Teil, MEW 40, Berlin 1968, 541.

20 Peter von Rüden/Kurt Koszyk (Hg.), Dokumente und Materialien zur Kulturgeschichte der deutschen Arbeiterbewegung, Bd. 1, Frankfurt a.M. u. a. 1979; Brigitte Emig, Die Veredelung des Arbeiters. Sozialdemokratie als Kulturbewegung, Frankfurt a. M. 1980.

21 Karl Marx/Friedrich Engels, März 1875-Mai 1883, MEW 19, Berlin 1987, $24 \mathrm{f}$.

22 John Stuart Mill, Principles of Political Economy with Some of Their Applications to 
Andererseits geht es um die Ermöglichung von mehr kulturellem Wachstum der Bürger (anstelle des wirtschaftlichen Wachstums), auf „Bildung“ im Sinne Wilhelm von Humboldts also - und dahinter steht das klassische Bild der Muße, das hier von einer Elitenpraxis auf die ganze Gesellschaft übertragen werden soll: society would exhibit these leading features: a well-paid and affluent body of labourers; no enormous fortunes, except what were earned and accumulated during a single lifetime; but a much larger body of persons than at present, not only exempt from the coarser toils, but with sufficient leisure, both physical and mental, from mechanical details, to cultivate freely the graces of life. ${ }^{23}$

Wie bei Marx ist die „Grundbedingung“ für diese Egalisierung der Muße als Ziel der neuen Gesellschaft, dass die technologischen Verbesserungen, die es nach wie vor geben soll, nicht länger in den Profit der Kapitaleigner umgelegt wird, sondern in Arbeits-Ersparnis und damit in reale Arbeitszeitverkürzung.

Even the industrial arts [as opposed to the „art of living“ mentioned earlier, $\mathrm{CH}$ ] might be as earnestly and as successfully cultivated, with this sole difference, that instead of serving no purpose but the increase of wealth, industrial improvements would produce their legitimate effect, that of abridging labour. ${ }^{24}$

Mit Fichte, Marx und Mill gibt es schon drei Philosophen, die Muße als Reichtum definieren und Gerechtigkeit als gleiche Verteilung dieses Reichtums. Das ist beachtlich. Es könnte aber eine historische Kontingenz sein. Als Philosoph muss man an dieser Stelle daher fragen: Gibt es eigentlich einen internen Zusammenhang zwischen diesen beiden Größen (Muße und Gleichheit), oder kommen sie nur zusammen, weil beides wünschenswerte Dinge sind? In diesem Fall könnten je nach Geschmack weitere Dinge zu dieser Liste hinzutreten oder verschwinden.

Doch es gibt einen solchen systematischen Zusammenhang, nämlich in der Idee der möglichst vollständigen Entwicklung der menschlichen Anlagen. Diese Idee war seit der radikalen Aufklärung in der Folge von Rousseau eine Art common sense. Ich spreche daher andernorts von einem Dreiklang von Freiheit, Gleichheit und Entfaltung. ${ }^{25}$ Freiheit und Gleichheit sind wünschenswert, weil sie der Entfaltung der Individuen dienen (und das tun sie u.a. über den gleichen Zugang zur Muße). Zugleich sind sie nur solange wünschenswert, wie sie das tun. Umgekehrt ist Entfaltung der Individuen nur dann wünschenswert, wie sie in Freiheit und Gleichheit geschieht; die drei Werte sind also ineinander verklammert. Nehmen wir als Beleg für ein solches Denken pars pro toto das älteste Sys-

Social Philosophy. Books III-V and Appendices, Collected Works, Bd. 3, hg. v. J. M. Robson, Toronto 1965, 754 .

23 Mill, Principles of Political Economy, Collected Works 3, 755.

24 Mill, Principles of Political Economy, Collected Works 3, 243.

${ }_{25}$ Christoph Henning, Freiheit, Gleichheit, Entfaltung: Die politische Philosophie des Perfektionismus, Frankfurt a.M./New York 2005, $309 \mathrm{ff}$. 
temprogramm des Deutschen Idealismus von 1796. Hier sieht man klar, wie eng diese drei Größen zusammenhängen:

Nimmer der verachtende Blick, nimmer das blinde Zittern des Volks vor seinen Weisen und Priestern. Dann erst erwartet uns gleiche Ausbildung aller Kräfte, des Einzelnen sowohl als aller Individuen. Keine Kraft wird mehr unterdrückt werden. Dann herrscht allgemeine Freiheit und Gleichheit der Geister! ${ }^{26}$

Freiheit und Gleichheit in der Gesellschaft sind also daran gebunden, dass es auch im Bereich der Bildung eine annähernde Gleichheit gibt, denn für die Autoren ist die (korrigierbare) Ungleichheit auf diesem Gebiet ein emotionsgetriebener Verstärker und Stabilisator bestehender sozialer Ungleichheiten. Wie wenig dieser Deutsche Idealismus doch in die Zeit der Exzellenzinitiativen passt!

Der Zusammenhang speziell von Gleichheit und Muße als Wege zur Entfaltung lässt sich noch genauer aufzeigen. Wenn die Entfaltung der Individuen ein Wert ist, und das ist er für die radikale Aufklärung bis hin zu Horkheimer und Adorno, dann ist speziell die ökonomische Ungleichheit dasjenige, was diesem Wert entgegensteht. Trotz eines großen gesellschaftlichen Reichtums kann sich keine Klasse mehr der Selbstentfaltung in Muße hingeben: Die Armen nicht, weil ihnen die nötige Zeit und die nötigen Ressourcen fehlen; die Reichen ebenfalls nicht, weil sie in eine Kultur der Äußerlichkeit, des Zurschaustellens und Sich-Überbietens abgleiten, die der persönlichen Entwicklung ebenfalls entgegensteht (solch Rousseauistische Gedanken gibt es noch von Veblen bis zu Marcuse und Juliet Schoor). Anders gesagt: Ungleichheit der Ressourcen verlängert und verstärkt sich durch die korrelierende Ungleichheit in Sachen Muße - die einen haben $\mathrm{zu}$ wenig davon und verzehren sich, die anderen $\mathrm{zu}$ viel und verlottern. Erst jüngst wurde dieser Zusammenhang empirisch belegt: „more equal societies have more leisure time and higher levels of participation in cultural and sporting activities“. ${ }^{27}$ Doch diese Idee ist nicht neu. Hören wir als älteren Kronzeugen für diese Idee, dass bestehende soziale Ungleichheiten sich über ihre Effekte auf die Muße noch verschlimmern, Claude Adrien Helvétius:

In den meisten Königreichen gibt es nur zwei Klassen von Bürgern; die eine entbehrt des Notwendigsten, die andere schwimmt im Überfluss. Die erstere kann nur durch exzessive Arbeit für ihre Bedürfnisse sorgen. Diese Arbeit ist ein physisches Übel für alle, und für einige ist sie eine Strafe. Die andere Klasse lebt im Überfluss, aber auch in der Furcht vor der Langeweile, denn die Langeweile ist ein fast ebenso schreckliches Übel wie die Armut. ${ }^{28}$

${ }^{26}$ G. W. F. Hegel, Frühe Schriften, Werke, Bd. 1, hg. v. Eva Moldenhauer/Karl Markus Michel, Frankfurt a. M. 1971, 237.

27 A. J. Veal, „Leisure, Income Inequality and the Veblen-Effect: Cross-national analysis of leisure time and sport and cultural activity", in: Leisure studies 35.2 (2016), 215-240.

28 Claude Adrien Helvétius, Vom Menschen, seinen geistigen Fähigkeiten und seiner Erziehung (1772), hg. v. Günther Mensching, Frankfurt/M. 1972, 367. Zur Parallele bei Fried- 
Der Zusammenhang ist wechselseitig. Begreift man die Muße als Selbstwert, dann wird sie durch soziale Ungleichheit verdorben. Es gilt also gerade im Interesse der Muße, die Ungleichheit zu bekämpfen. Geht man hingegen von der Ungleichheit aus und begreift sie als Unwert, dann lässt sich ähnliches für die Muße sagen: Bestehende soziale Ungleichheiten werden durch ihre Effekte auf das Freizeitverhalten verstärkt. Das gilt allein schon im Blick auf die Lebenserwartung bei Reich und Arm: Es lässt sich ein Unterschied in der Lebenserwartung beobachten - und pikanterweise sind die Jahre, die reichere Menschen länger leben als ärmere, im Regelfall Jahre in der Rente, also Jahre in kultivierter Muße, die den Ärmeren damit verloren gehen. Hinzu kommt, dass wirklich arme Menschen, selbst wenn sie Rente bekommen, häufig gar nicht alles bekommen, was ihnen zustünde, etwa weil die Beantragung so aufwendig ist. ${ }^{29}$

Sogar der Meisterdenker der Gerechtigkeit, John Rawls, hat die Muße daher in einer Überarbeitung seiner Theorie unter die zu verteilenden Grundgüter aufgenommen. Das klingt gut, nur leider hat das bei ihm den paradoxen Nebensinn, dass diejenigen, die mehr als die allen zustehende Muße verbrauchen (das sind 24 Stunden minus ein Normalarbeitstag), damit den Anspruch auf soziale Unterstützung verlieren. Denn sie haben ja, nach der Logik von Rawls, schon etwas von der Gesellschaft bekommen - die Freizeit -, und dürfen daher nicht noch etwas fordern, also etwa ein Grundeinkommen oder ähnliches.

Those who are unwilling to work would have a standard working day of extra leisure, and this extra leisure itself would be stipulated as equivalent to the index of primary goods of the least advantaged. So those who surf all day off Malibu must find a way to support themselves and would not be entitled to public funds. ${ }^{30}$

Im Detail argumentiert Rawls aus ökonomisch-liberalen Gerechtigkeitsüberlegungen also gegen eine Ausdehnung der Muße. Er befürchtet, dass die Menschen sonst zu wenig arbeiten würden. Anders gesagt: Er betrachtet weniger riesige Gehälter und Boni, sondern mehr freie Zeit als Luxus. Daher sollte man in diesem Punkt (wie in anderen) besser nicht auf Rawls setzen. ${ }^{31}$

rich Schiller siehe Christoph Henning, Theorien der Entfremdung zur Einführung, Hamburg 2015, $62 \mathrm{ff}$.

29 Siehe Teresa Ghilarducci, „Leisure Inequality: What the Rich-Poor Longevity Gap Will Do to Retirement“, in: The Atlantic Sep. 28 (2015).

30 John Rawls, „The Priority of Right and Ideas of the Good“, in: Philosophy \& Public Affairs 17 (1988), 251-276, 257.

31 Näher Simon Birnbaum (Basic Income reconsidered, Basingstoke 2012) und Karl Widerquist (Independence, Propertylessness, and Basic Income, Basingstoke 2013). Eine grundlegend ansetzende Rawlskritik formuliere ich hinsichtlich ökonomischer Voraussetzungen in Philosophie nach Marx. 100 Jahre Marxrezeption und die normative Sozialphilosophie der Gegenwart in der Kritik, Bielefeld 2005, und hinsichtlich der Theorie des Guten in Die politische Philosophie des Perfektionismus, Frankfurt a. M. 2015, 63 ff. 
Ausgehend von diesen Beobachtungen und Systematisierungsversuchen kann man sozialphilosophisch davon ausgehen, dass ein starker Zusammenhang zwischen der Idee der Muße und dem Egalitarismus besteht. Beide sind nur miteinander zu haben. Der Egalitarismus wurde anfangs häufig in der Währung der Muße ausbuchstabiert, und es gibt gute Gründe dafür, das (nach einer einflussreichen liberalen ,Entkernung' des Gerechtigkeitsdenkens durch Rawls) erneut zu tun. Daher sind die Akteure im Mußediskurs gehalten, sich über ihre Verortung innerhalb der Ungleichheitsdebatte Gedanken zu machen. Damit komme ich nun zu meinem reflexiven zweiten Teil, nämlich der Frage, ob dem Begriff der Muße selbst schon eine gewisse Ungleichheit eingeschrieben ist. Das würde mein Plädoyer für einen gleicheren Zugang zur Muße zumindest verkomplizieren.

\section{Ist der Begriff ,Muße` elitär?}

Was ist das Problem an dieser Stelle? Historisch betrachtet war Muße eine elitäre Praxis: Sie war, kurz gesagt, meist gebunden an Eigentum als Garantie dafür, nicht arbeiten zu müssen. Nur wenige hatten dies. Doch es gibt noch eine weitere Schwelle, die das Aufsteigen zur Muße erschwerte. Begrifflich nämlich ist sie an einen gewissen Bildungsstand gebunden, als Ermöglichung dafür, dass man wirklich die sogenannte „höhere“ Muße betreibt und nicht einfach dumpfer Freizeit-Erholung fröhnt. Sprichwörtlich für letzteres ist das Dosenbier vor dem Fernseher, oder die couch-potato im Trainingsanzug, die sonntags ihr Auto wäscht. ${ }^{32}$ Ein solches Freizeitverhalten sei, wie etwa Schopenhauer sagte, noch nicht die echte Muße: „Muße ohne geistige Ausfüllung ist Tod und lebender Menschen Grab" (frei nach Seneca). ${ }^{33}$

Was genau ist das Problem? Möglicherweise geht es hier nicht nur um unterschiedliche reale Bedingungen (die einen haben viel Ressourcen, die anderen weniger; die einen haben formale Bildungstitel, die anderen weniger), sondern dem voraus bereits um eine Einschreibung dieser Differenzierungen in den Begriff selbst, der damit als eine Selbstbespiegelung der Bildungsbürger erscheinen könnte, die sich damit normativ und begrifflich von allen anderen abgrenzen wollen. Schaut man genauer hin, so beißt sich die Unterscheidung zwischen Muße und Nicht-Muße, als Differenz zwischen anspruchsvollen und niveaulosen Praktiken, mit der zwischen Arbeit und Freizeit. Es meint durchaus nicht dasselbe. Bücher lesen und Kunst betrachten nämlich; Forschung betreiben und

32 Der schon zitierte Ronald Dworkin spricht hier vom „television-watching, beerdrinking citizen" (A Matter of Principle, Cambridge, Mass./London 1985, 191).

33 Arthur Schopenhauer, Parerga und Paralipomena. Kleine philosophische Schriften, Sämtliche Werke, Bd. 4, hg. v. Wolfgang Frhr. von Löhneysen, Darmstadt 1968, 405. 
Dinge ausprobieren, das ist etwas, das Bildungsbürger - wenn sie Glück haben durchaus nicht nur in ihrer Freizeit tun können, sondern auch in ihrer Arbeit. ${ }^{34}$ Im Gegenzug ist die Freizeit hier schwer von der Arbeit zu trennen: Einige erinnern sich vielleicht noch an anstrengende Urlaube mit den Eltern, in denen man Kirchen oder Museen anschauen musste statt baden zu gehen. Ob Arbeit oder Freizeit, im Prinzip werden solche Schichten dem (selbstgesteckten) Ideal der Muße fast immer gerecht - außer eben, sie überfordern sich selbst durch zu viele Verpflichtungen. Dann fehlt irgendwann die Ruhe dabei, so dass das Ganze zur Massenfertigung und zur Routine verkommt. Hier wäre der Punkt gekommen, mehr Aufgaben zu delegieren oder abzugeben, oder mehr Leute einzustellen.

Bei Nicht-Bildungsbürgern hingegen, oder sagen wir besser: bei Normalarbeitenden (ob in der Produktion, der Dienstleistung oder im mittleren Management) soll dagegen weder die Arbeit noch die Freizeit als „höhere“ Muße gelten. Arbeitet man aus Geldnot etwa in zwei Jobs, die eher manuell angelegt sind und körperlich anstrengen, dann fehlt einem schlicht Zeit und Energie dazu. Hat man hingegen eine geregelte Arbeit, sagen wir, in der Produktion, und verbringt seine Freizeit bei Fußballspielen des Lokalvereins oder mit der Modelleisenbahn, dann ist das der hochgesteckten Theorie nicht tätig, nicht, geistig genug und gilt ebenfalls nur als Freizeitverhalten, nicht aber als edle oder höhere Muße, wie sie von Aristoteles bis Adorno in der Philosophie kolportiert wird. Was könnte den Verdacht ausräumen, dass es sich dabei lediglich um ein petrifiziertes Klassenvorurteil handelt, das eine bestimmte soziale Schicht glorifiziert und das den anderen Menschen vorschreiben will, wie sie ihre Zeit eigentlich verbringen sollen? Tun sie das nicht, wie man insgeheim hofft, kann man sie vor Gleichgesinnten rasch abwerten; tun sie es doch, dann vielleicht nur, weil wir sie dazu gezwungen haben; wie es bei Mill deutlich ist (,until the better minds succeed in educating the others into better things"), ${ }^{35}$ und wie es noch in manchen Elementen der Hartz-Gesetze angedacht war (etwa mit den Bildungsgutscheinen oder dem Zwang zur Aufnahme einer Arbeit). Richtig zufrieden können Oberschichten damit aber auch nicht sein, denn sie verlören dann ihren Distinktionsgewinn und verfallen, sofern sich keine subtileren Abgrenzungskriterien einspielen, ${ }^{36}$ den Ängsten vor einer Abstiegsgesellschaft ${ }^{37}$.

Das also ist das Problem: Wenn man das Problem der Gerechtigkeit in modernen Gesellschaften als gleichen Zugang zur Muße formuliert, wie es der erste Teil angedacht hat, Muße dabei aber qualitativ auflädt; dann mag das in der Theorie richtig sein, taugt aber nicht für die Praxis, weil damit intellektueller Snobismus

\footnotetext{
34 Siehe den Beitrag von Tobias Keiling in diesem Band.

35 Mill, Principles of Political Economy, Collected Works 3, 754.

36 Michael Hartmann, Der Mythos von den Leistungseliten. Spitzenkarrieren und soziale Herkunft in Wirtschaft, Politik, Justiz und Wissenschaft, Frankfurt a. M. 2002.

37 Oliver Nachtwey, Die Abstiegsgesellschaft. Über das Aufbegehren in der regressiven Moderne, Berlin 2015.
} 
und im Ernstfall sogar ein harter Paternalismus einhergehen können. Anders gesagt: Die Umstellung der Gleichheitssemantik auf Muße könnte ein Vorurteil zugunsten "gebildeter“ Klassen sein, das auf Volkserziehung hinauslaufen würde. Sie wäre problematisch, weil sie diese Klassenvorurteile zwangsweise überstülpt, und würde vermutlich gar nicht ernsthaft betrieben, weil damit ja die feinen Unterschiede, die die Bildungsbürger zugleich zu ihrer Distinktion benötigen, erodieren würden. Das sind keine guten Aussichten für den Egalitarismus.

Wie ist damit umzugehen? Sollte die egalitäre Gerechtigkeitsintuition von einer qualitativ bestimmten Idee von Muße doch wieder umstellen auf einen formalen Begriff von „Freizeit“, auf die Gefahr hin, dass diese dann in shopping malls, an Tankstellen und Kraftstudios oder vor der Spielkonsole verbracht wird? Hier geht die politische ,Liberalität' des Nichteingreifens bruchlos mit einer umsatzsteigernden Reduktion auf eine nur ökonomische Wahlfreiheit einher. Es gibt gute perfektionistische Gründe gegen diese Reduktion. ${ }^{38}$ Ceteris paribus ist es für ein gutes Leben besser, freie Zeit etwa für das Erlernen einer Sprache zu nutzen, als alle Folgen von „Germany's next Topmodel“ zu schauen; ist ein Ausflug mit Freunden besser als ein Kaufrausch im Supermarkt. ${ }^{39}$ Zugleich ist allerdings klar, dass ein Muße-Paternalismus politisch ein Problem wäre. Wie kommt man hier weiter?

Wenn Philosophen in eine Zwickmühle geraten, behelfen sie sich gern mit Unterscheidungen; in der Hoffnung, damit das Problem aufzulösen. Vielleicht hilft das auch hier. Zwei Unterscheidungen scheinen hier aussichtsreich: die zwischen Zwang und Bereitstellung (oder Verordnung und Ermöglichung) einerseits; und die zwischen privat und öffentlich andererseits. Sehen wir zu, wie weit wir damit kommen.

Bereitstellung statt Zwang meint, dass es wenig helfen würde, eine „höhere“ Muße per Dekret zu verordnen, wenn doch (wie eingangs festgestellt) die realen Bedingungen dafür - Einkommen, freie Zeit und Bildungsstand - so ungleich verteilt sind. Politisch sinnvoller wäre es, diese Mittel bereitzustellen, als direkt und unvermittelt das Ziel erzwingen zu wollen. Das hieße in unserem Fall: Mehr soziale Gleichheit in terms of Einkommen und freier Zeit sowie real gleichere Zugangsbedingungen zu Bildungseinrichtungen zu schaffen (das betrifft auch Dinge wie Studiengebühren, Stipendien, Schul- und Unterrichtsformen, Schüler-Lehrer-Schlüssel etc.). Sind wir hier erfolgreich, dann wären wir einer gerechteren Verteilung der Muße vermutlich schon einen Schritt näher - gerade wenn

38 J.S. Mill widersprach daher Benthams Aussage: „push-pin is as good as poetry“, siehe John Stuart Mill, „Bentham“, in: Essays on Ethics, Religion and Society, Collected Works 10, hg. v. J. M. Robson, Toronto 1969, 75-115, 113.

39 Begründungsstrategien dafür gibt es verschiedene - das soll uns hier nicht aufhalten. Man könnte von intrinsischen Werten reden, von stärkeren und nachhaltigeren Glücksgefühlen, oder einer höheren Komplexität der dabei in Gang gebrachten menschlichen Kräfte. 
das im ersten Teil Gesagte stimmt, dass es einen Zusammenhang gibt zwischen sozialer Gleichheit und der Summe und Qualität von Muße in einer Gesellschaft.

Aber vielleicht ist es nicht genug damit, wenn diese „Muße“ privat gepflegt wird - wenn also neben den Videos nun ein Brockhaus steht, der nie gelesen wird. Von Veblen und Bourdieu haben wir gelernt, dass privat ausgeübte Muße auch zur elitistischen Status-Abgrenzung dienen kann. Aus Gerechtigkeitserwägungen her wünschenswertere Praktiken der Muße wären daher solche, die öffentlich ausgeübt werden, die darum auch öffentlichkeitswirksam sind. Mit diesem Punkt lassen sich die Ideen des ersten Teils gegen die Zweifel des zweiten Teils verteidigen. Jemandem, der öfter mit Kindern in Städten unterwegs ist, fällt so etwas im Stadtbild deutlich auf. In shopping malls, Bahnhöfen und Fußgängerzonen etwa gibt es kaum noch Bänke. Man soll nicht verweilen oder trödeln, man soll kaufen - oder verschwinden. Und wenn es Bänke gibt, wovor hat man Angst? (So wie die Bänke abgenommen haben, hat die security zugenommen, die eigentlich eher Ausdruck von Unsicherheit ist.) Man hat Angst, dass sie von Leuten „bewohnt“"werden, die Berge von Müll hinterlassen (im besten Fall nur das). Diese Verlagerung hat etwas mit unserer öffentlichen Kultur zu tun: Wenn sich Arbeit und Muße nur noch hinter verschlossenen Türen vollziehen, verkommt der öffentliche Raum zur reinen Transport-Sphäre und wird zudem sozial segregiert. ${ }^{40}$ "Wir“ (die Normalarbeitenden aus verschiedenen Schichten) durcheilen ihn auf dem Weg zur Arbeit oder zum Einkaufen, doch wir bewohnen ihn nicht mehr. Das einzige, was man dort noch tut, und das wäre dann unsere öffentliche Kultur, ist beispielsweise, sich gemeinsam zu betrinken (flash mobs zum Zwecke des kollektiven binge drinking sind ein Beispiel dafür, aber das können auch digitale Analphabeten, wie das Oktoberfest zeigt).

Daher denke ich, dass die aus Gerechtigkeitserwägungen zu fordernde stärkere Ermöglichung und gleichere Verteilung des Zugangs zur Muße nicht zuletzt auch eine öffentliche sein sollte. „Reclaim the streets“ war dafür ein schönes Motto. Der Unterschied zwischen einer shopping mall und einem gelungenen Spielplatz ist, dass auf dem letzteren im doppelten Sinne „Raum“ ist für öffentliche Muße. ${ }^{41}$ Mein Lieblings-Spielplatz in Zürich etwa hat Raum für ganz verschiedene Menschen: für Familien, die dort ganze Tage verbringen, für Stadtbewohner, die dort stundenlang Zeitung lesen (mit oder ohne das Café in Anspruch zu nehmen); aber auch für die sogenannten „Randständigen“, die dort mit Hunden ihr Dosenbier oder ihr Koks konsumieren. Letztere kommen so zugleich in Kontakt mit den anderen Gruppen - nicht immer ohne Konflikte na-

40 Eine schöne Veranschaulichung dessen ist der öffentliche Raum in dem Film The Fifth Element (1997), in dem es nur noch und überall privaten Verkehr gibt - und zwar in allen in drei Dimensionen. Diese Optik gibt es über mehrere Filme hinweg, schon Metropolis (1927) oder Blade Runner (1982) sahen im Stadtbild ähnlich aus.

41 Sharon Zukin, Naked Cities. The Death and Life of Authentic Urban Places, Oxford 2010. 
türlich, selbst im Paradies kann es Streit geben - und erlangen auf diese Weise im Wortsinne einen „Zugang“ zur öffentlichen Kultur der anderen. Im besten Fall wird daraus ein wechselseitiges Lernen. Diese hervorzuhebende Gemeinsamkeit des Müßiggangs tritt besonders deutlich dann zutage, wenn der geteilte Raum auch gemeinsam zelebriert wird: etwa bei Sommerkonzerten oder Festen. ${ }^{42}$ Das mag etwas kitschig klingen, aber hier geht es mir darum, Perspektiven aufzuzeigen. Ich denke, davon brauchen wir mehr - mehr Zeit, mehr Gelegenheit und mehr öffentlichen Raum für geteilte Praktiken der Muße. ${ }^{43}$ Das wird die soziale Ungleichheit nicht aufheben, aber es könnte helfen, ihre schädlichen Folgen zu mindern oder abzufangen.

42 Dazu siehe Christoph Henning, „Formen der Muße zwischen Faulheit und Fest“, in: Muße: Ein Magazin, 1/2016, DOI: 10.6094/musse-magazin/1.2016.12; erneut in: Glanzlichter der Wissenschaft - ein Almanach 2016, hg. v. Deutschen Hochschulverband, Heidelberg 2016, 89-96.

43 Siehe dazu auch den Beitrag von Heidi Liedke in diesem Band. 



\title{
Walking the (Open) City
}

\section{Vom viktorianischen München ins postmoderne New York}

\author{
Heidi Liedke
}

\begin{abstract}
"After a time I left the church, and not being inclined to return home, and finding that all the music from the public-houses [...] w[as] very inharmonious to my then state of mind, I wandered on towards the plain, and feasted my eyes on a view of the Alps [...]"1

"[My] walks [...] steadily lengthened, taking me farther and farther afield each time, so that I often found myself at quite a distance from home late at night, and was compelled to return home by subway." 2
\end{abstract}

Gehen bedeutet, den Ort zu verfehlen. Um dieser Behauptung Michel de Certeaus nachzugehen, und zu überlegen, ob diesem Verfehlen nicht auch ein Gewinn anhaftet, beschäftigen sich die folgenden Ausführungen mit dem Zusammenhang von Mobilität und Muße und vor allem dem Gehen durch die Großstadt, das zentrale Symbol der Moderne. Der oder die Gehende befindet sich oft, und so auch in den beiden Fallstudien, am Rande der Gesellschaft. Marginalität ist sowohl kennzeichnend für den Status Anna Mary Howitts, von der das erste Einstiegszitat stammt, als alleine auf der Straße spazierende Frau; als auch für den Afro-Amerikaner Teju Cole bzw. seinen Protagonisten Julius, der aufgrund seiner Ethnizität marginalisiert wird, wenn auch durch seine eigene Absicht.

Die folgenden Ausführungen beharren auf idling als Mußepraxis, durch die heterotopische Blasen geschaffen werden. ${ }^{3}$ Der Titel „Walking the (Open) City“ ist sowohl eine Anspielung auf Michel de Certeaus Aufsatz „Gehen in der Stadt“ in seinem Buch Kunst des Handelns, auf den ich in meiner Analyse zurückgreifen werde, als auch auf Teju Coles Romantitel Open City (2011). Im Kern geht es darum, die vorgestellten Texte von einem zentralen Phänomen, von einer sie verbindenden Praxis ausgehend zu lesen, nämlich dem Fortbewegen durch eine Großstadt mit einer mußevollen Haltung und der Umsetzung dessen im Text.

\footnotetext{
1 Anna Mary Howitt, An Art-Student in Munich, London 1853. Im Folgenden im Fließtext zitiert mit der Sigle ASM.

2 Teju Cole, Open City, New York 2011. Im Folgenden im Fließtext zitiert mit der Sigle $O C$.

${ }^{3}$ Das Verb „to idle“ wird im Englischen gebraucht, um eine langsame Bewegung auszudrücken, ein nicht zielgerichtetes Umherstreifen, oft auch in Verbindung mit einem Vertreiben der Zeit. Vgl. den Eintrag im Oxford English Dictionary (http://www.OED.com).
} 
De Certeaus strukturalistischer Ansatz, der eine Parallele zwischen Gehen und Sprechen herstellt (Gehen als Realisierung des Raumes, wie auch parole die Umsetzung von langue ist), sowie das mit dem psychogeographischen Terminus dérive gefasste ziellose Umherschweifen durch die Stadt und Michel Foucaults Heterotopie-Begriff werden im Folgenden miteinander verwoben. Der Kontext der beiden Primärtexte wird nicht gänzlich ausgeklammert, allerdings ist mein Ansatz in erster Linie textimmanent. Es lässt sich eine Verbindung herstellen zwischen einer Flaneuse im München des 19. Jahrhunderts - auf Anna Mary Howitts An Art-Student in Munich von 1853 liegt der Schwerpunkt der Ausführungen - und einem Flaneur im New York des 21. Jahrhunderts. Durch ihre Muße-Praktiken lassen sie den durchquerten Raum überhaupt erst (für sich) entstehen und machen ihn erfahrbar. Die Texte stehen an zwei Enden des Spektrums dessen, was für einen Effekt praktizierte Muße auf ein Individuum haben kann. Grundsätzlich verstehe ich Muße also nicht als statisches Konzept, sondern als idling, als ständig neu zu initiierenden Prozess, durch den das ihn realisierende Individuum für sich selbst heterotopisch aufgeladene Blasen schafft.

Ein Nebeneffekt davon, und das werde ich kurz skizzieren, ist, dass das größte Vergnügen für den Erzähler (nicht den Autor) die größte Langeweile für die (generische) Leserin mit sich bringt. Die Erzähler schaffen sich für sie (selbst) stimmige imaginäre Räume der Muße, an denen die Leserschaft nie ganz teilhaben kann. Mit Rückgriff auf Thesen der Reader-Response-Theory werde ich Stellen in beiden Texten identifizieren, die entweder aufgrund ihres extremen Grads an Subjektivität oder der in ihnen vorkommenden spezifischen Verweise zwar dem Erzähler Muße bereiten, aber die Leserin nur gleichsam marginalisieren und langweilen und somit eine Rezeption erschweren.

\section{Der Flaneur, die Flaneuse: Gehende}

Im Paris Review bezeichnete Bijan Stephen die Figur des Flaneurs als die des „leidenschaftlichen Wanderers", die emblematisch für die literarische Kultur Frankreichs im 19. Jahrhundert stehe. Sie sei „essentiell zeitlos“; Walter Benjamin habe sie in den akademischen Diskurs eingeführt, und die Figur als „essentiellen Teil unserer Vorstellungen von Modernismus und Urbanismus" identifiziert. In den Jahrzehnten nach Benjamin sei das Konzept der Flanerie als eines begehrenswerten Lebensstils jedoch in Ungunst gefallen, verursacht durch eine Kombination von steigender Produktivität und der immer noch (bzw. wieder) existenten Angst davor, absolut nichts zu tun. ${ }^{4}$

${ }^{4}$ Bijan Stephen, „In Praise of the Flâneur“, in: Paris Review, 17. Oktober 2013, o. S. 
Auch wenn die Figur des Flaneurs „essentiell zeitlos“ ist, ist sie nicht essentiell genderlos, sondern essentiell männlich. Daher sei zu Beginn die Frage gestellt, ob es denn so etwas wie die ,Flaneuse' gibt. Wie Deborah Epstein Nord in Walking the Victorian Streets: Women, Representation, and the City (1995) ausführt, fällt die literarische Darstellung des Phänomens des urbanen Lebens um 1900 mit der Darstellung des einsamen Mannes, der ungestraft und gelassen mit einem penetrierenden Blick durch die Straßen schritt, zusammen. Dieser Beobachter war „the rambler, the stroller, the spectator, the flaneur"5. Die urbane Skizze und die Kultur der Bohème wurden von dem mit einer Hochstimmung aufgenommenen Zusammenhang von Ausgeschlossensein und Anonymität befeuert - wie Benjamin es in seinen Überlegungen über Charles Baudelaire ${ }^{6}$ formulierte: von der Existenz am Rand, sowohl der großen Stadt als auch der Mittelschicht. Die Distanziertheit des marginalen Mannes, des Künstlers, verlieh ihm den Status des Fremden und stärkte seine Identifizierung mit (aber nicht zwangsläufig Sympathie für) die Ausgestoßenen und Außenseiter. Im Zentrum dieses Diskurses stand ebenfalls die Figur der gefallenen Frau, der Frau der Straße, doch wie Epstein Nord zeigt, war die Rolle der Frau auf dieser „rambler's stage“ keineswegs monolithisch entweder die des beschauten Spektakels oder Spielers; sie konnte auch als Projektion des entfremdeten Selbst des männlichen Spaziergängers fungieren oder ein Partner auf urbanen Erkundungstouren sein. Aber was war mit der weiblichen Beobachterin, die selbst Akteurin und Schauende und nicht in irgendeiner Form Counterpart zum männlichen Beobachter war? Vor allem geht es um die offen weibliche Beobachterin, also nicht wie in den berühmten Fällen von George Sand und Vita Sackville-West Frauen, die in Männerkleidung die Stadt erkundeten. In Bezug auf die Mitte des 19. Jahrhunderts stellt sich der überwiegende Eindruck ein, dass Frauen, die alleine auf Straßen spazierten, gefährdet oder gefährlich waren. Einzige Ausnahme stellte gegen Ende des 19. Jahrhunderts das Shopping und Schaufensterbummeln dar. Eine Frau kam also nie in den Genuss einer der Voraussetzungen fürs Flanieren - der Anonymität - da sie automatisch aus der Menge herausstach. Einige Kritikerinnen und Kritiker haben deshalb auf die Unmöglichkeit des Konzeptes der Flaneuse hingewiesen. Was passiert also, wenn ein Text trotzdem die Subjektivität der immer objektivierten weiblichen Persona darstellt? Was passiert mit der urbanen Landschaft, wenn die gejagte Frau zur Dechiffriererin der Menge, selbst der Jäger, der Detektiv wird?

In seinem Essay „Clues: Roots of an Evidential Paradigm“ argumentiert Carlo Ginzburg, dass um die Wende zum 20. Jahrhundert ein neues Paradigma darüber, wie Wissen innerhalb eines spezifischen Kontextes produziert wird, ent-

5 Deborah Epstein Nord, Walking the Victorian Streets: Women, Representation, and the City, Ithaca 1995, 1.

6 Vgl. Walter Benjamin, „Konvolut J“, in: Gesammelte Schriften, Bd. V/I, hg. v. Rolf Tiedemann/Hermann Schweppenhäuser, Frankfurt a. M. 1982, 301-489. Siehe auch den Beitrag von Robert Krause in diesem Band. 
stand. In den Vordergrund rückte eine Methode, die darauf beruhte zu raten, Eindrücke zu sammeln, die aber auch die Sinne des Hörens, Riechens und Fühlens aufwertete, was auch mit der Popularität der Symptomatologie zusammenfiel. Man ließ sich stärker von der Intuition statt der männlich kodierten Rationalität leiten. Ginzburg schreibt:

Man has been a hunter for thousands of years. In the course of countless chases he learned to reconstruct the shapes and movements of his invisible prey from tracks on the ground, broken branches, excrement, tufts of hair, entangled feathers, stagnating odors. [...] He learned how to execute complex mental operations with lightning speed, in the depth of a forest or in a prairie with its hidden dangers. ${ }^{7}$

Der Aspekt des Gelerntseins fällt um die Jahrhundertwende weg, es geht um intuitives Sammeln, ein Charakteristikum des Flaneurs, aber auch eher mit dem Weiblichen assoziiert - die griechische Göttin Metis war mit dieser Gabe ausgestattet; diese Art des Wissens war bestimmten Gruppen von Menschen vorbehalten, nämlich Seglern, Jägern und Frauen. Die jagende, sammelnde Frau ist somit in doppelter Hinsicht eine machtvolle Figur, ihr wohnt eine destabilisierende Kraft inne.

Im Hinblick auf die von mir untersuchten Texte wird der Blick der beiden Protagonisten wesentlich durch den Blick des nach Bildern Suchenden geprägt: im Falle Howitts ist es die Kunststudentin, in deren Augen eine Szene erst dann an Wert gewinnt bzw. erst dann überhaupt existiert, wenn sie an ein Bild erinnert oder zur Schaffung eines solchen inspiriert. Außerdem ist sie von dem dauerhaften Willen angetrieben, ihrem Status als Spektakel zu entkommen und selbst Betrachterin zu sein. Im Falle Coles bzw. seines Erzählers Julius ist es der etwas unstetere Blick des street photographers, der nach lohnenswerten ,shots' sucht. Beide Blicke erschließen ihren Trägern mehr, schließen aber auch vieles aus. Mit diesem wörtlich exklusiven Blick geht auch ein sich veränderndes Maß an Subjektivierung einher; ich schreibe bewusst „sich veränderndes“ und nicht wachsendes, auch wenn beispielsweise Manfred Pfister zufolge die Geschichte des Reisebuchs als eine der sich steigernden Subjektivität zu beschreiben ist. ${ }^{8}$ Ich stimme mit Ralph Pordzik überein, der eine solche Interpretation als Simplifizierung bezeichnet, da sie auf der Annahme beruht, Reiseliteratur hätte sich in einer direkten Linie von der frühen Neuzeit bis zur Postmoderne entwickelt. ${ }^{9}$ Es gibt in jedem Jahrhundert Autorinnen und Autoren von Reiseberichten, die sig-

7 Carlo Ginzburg, „Clues: Roots of an Evidential Paradigm“, in: Clues, Myths, and the Historical Method, übers. v. John Tedeschi/Anne C. Tedeschi, Baltimore 1992, 96-125, 102.

8 Vgl. Manfred Pfister, „Bruce Chatwin and the Postmodernization of the Travelogue“, in: LIT 7 (1996), 253-67, 263.

9 Vgl. Ralph Pordzik, „Travel Writing and Its Discontents: Culture, Tourism and the Dynamics of Narration in Bruce Chatwin's In Patagonia and The Songlines", in: Anglia: Zeitschrift für englische Philologie 121,3 (2003), 373-389, 376. 
nifikant von der Masse abweichen, insbesondere auch im 19. Jahrhundert. ${ }^{10}$ Ein beispielhafter Text dafür aus der Mitte des 19. Jahrhunderts ist die Textgrundlage dieses Aufsatzes, Anna Mary Howitts An Art-Student in Munich von 1853. Auf eine Formel gebracht, präsentiert der Text einen Akt im Wesentlichen ortsunabhängiger Subjektivität, der durch die mußevolle Haltung der Autorin beschleunigt wird.

Michel Foucaults Heterotopiebegriff ist in abgewandelter Form für meine Analyse von Nutzen. Foucault definiert Heterotopien als Orte, die außerhalb aller Orte liegen, obwohl sie sich durchaus lokalisieren lassen, sozusagen realisierte Utopien. Sie stellen einen mythischen und zugleich realen Gegensatz zu dem Raum, in dem wir leben, dar: „Heterotopien besitzen die Fähigkeit, mehrere reale Räume, mehrere Orte, die eigentlich nicht miteinander verträglich sind, an einem einzigen Ort nebeneinander zu stellen. "11 Heterotopien sind auch dadurch gekennzeichnet, dass sie eine Funktion ausüben, die entweder darin besteht, einen gänzlich illusorischen Raum zu schaffen oder einen realen Raum, der eine vollkommene Ordnung aufweist. ${ }^{12}$ Die persönliche Stadtlandschaft (cityscape), die die Kunststudentin Anna Mary Howitt in ihrem Reisebuch kreiert, weist meiner Meinung nach wesentliche heterotopische Merkmale auf. Es handelt sich hierbei um eine besondere Form der Heterotopie: zum einen handelt es sich um ,objektiv' heterotopische Orte wie die traditionellen Gärten, zum anderen werden diese und andere Orte erst durch Howitts Betrachtung in ihrer heterotopischen Qualität verstärkt. Howitts Mußeräume sind nämlich solche heterotopischen Blasen, die sich erst durch ihr Driften durch die Stadt materialisieren. Ich halte den Blasenbegriff für eine passende Beschreibung an dieser Stelle, da er den Charakter einer menschengemachten Ausnahmesituation verstärkt; die Momente sind kurzlebig und können jederzeit vorbei sein; sie sind auch gewissermaßen ,mobil', weil sie erst im Gehen entstehen. Howitts Sich-treiben-lassen bestimmt ihre Erfahrung der Stadt - Gehen ist für sie ein Akt der Appropriation, der sie von einem Mußeraum zum anderen transportiert.

10 Siehe die Forschungsarbeit des Teilprojektes B4 „Prekäre Muße im Schatten des Tourismus: Individualität und Entschleunigung im Spiegel britischer Reiseberichte von 1840 bis zum Ersten Weltkrieg“ (Leitung: Barbara Korte, Laufzeit 01.01.2013-31.12.2016) am SFB 1015 ,Muße und Heidi Liedke, The Experience of Idling in Victorian Travel Texts, 18501901, Basingstoke 2018.

${ }^{11}$ Michel Foucault, „Von anderen Räumen“, in: Jörg Dünne/Stephan Günzel (Hg.), Raumtheorie. Grundlagentexte aus Philosophie und Kulturwissenschaften, Frankfurt a.M. 2012 [1967], 317-329, 324.

12 Foucault, „Von anderen Räumen“, 326. 


\section{Anna Mary Howitt ergeht sich München}

Bereits am Anfang ihres Reiseberichts, der zuerst in Auszügen in den Zeitschriften The Athenaeum und Household Words erschien, also dezidiert literarischen, im Fall von Household Words reformerischen Publikationen, beschreibt sie den ersten Besuch im Atelier des deutschen Malers und späteren Direktors der Münchner Kunstakademie, Wilhelm von Kaulbach, als Erfüllung eines langersehnten Traums - sie möchte auf die Knie sinken und Gott danken (vgl. ASM, 4-5). Von Anfang an ist München für Howitt eine Stadt, die sie mit Stolz durchschreitet; entsprechend eignet sie sich das topographische System Münchens an und setzt "das poetischste Kapitel ihres Lebens", wie sie es im Vorwort nennt, um. Im Folgenden werde ich ausgewählte Passagen in Verbindung mit Michel de Certeaus Aufsatz „Gehen in der Stadt“ lesen, um Howitt als idler zu identifizieren, für die Gehen eine Taktik ist, die Stadt/landschaft einzunehmen. Einige Argumente de Certeaus sind für meine Analyse relevant, und auch für Reiseberichte generell. In „Gehen in der Stadt" sind die Fußgänger die gewöhnlichen Benutzer der Stadt; ihre Körper folgen einem urbanen Text. Im Fall von Howitt folgt sie dem Text, den sie aus der Stadt schafft. Nach de Certeau ist „[d]er Akt des Gehens [...] für das urbane System das, was die Äußerung (der Sprechakt) für die Sprache oder für formulierte Aussagen ist ${ }^{\text {"13 }}$. Er besteht aus einem Prozess der Aneignung des topographischen Systems durch den Fußgänger und einem räumlichen Ausleben oder Nachspielen des Ortes. Die Idee von Theatralik und Performativität ist daher zentral. Die Stadt ist eine Bühne, auf der das Individuum eine private, auch imaginierte Stadtlandschaft inszenieren kann. Weitere Merkmale des Fußgänger-Sprechakts, wie de Certeau es nennt, sind das Gegenwärtige, also die Idee, dass Gehen einige der Möglichkeiten der räumlichen Ordnung aktualisiert, und sie auch transformiert und neue hinzufügt (beispielsweise kann ein Stadtplaner nie ganz sicher vorhersagen, an welchen Orten sich Menschen zum Mittagessen versammeln); das Diskontinuierliche: der Fußgänger „verurteilt“ einige Orte dazu „brach zu liegen oder zu verschwinden, und mit anderen bildet er ,seltene', zufällige oder gar unzulässige räumliche ,Wendungen' (wie Redewendungen). Und das führt bereits zu einer Rhetorik des Gehens. ${ }^{\text {"14 }}$ Der Fußgänger geht also hier- und nicht dorthin. Diese Kategorie ist für Reisende im Allgemeinen relevant, da Reiseberichte gerade auf der Idee basieren, auszuwählen und auszulassen, wodurch sie überhaupt erst neu und persönlich werden. Schließlich spricht de Certeau von der phatischen' Funktion, womit er die „,on [Bronislaw] Malinowski und [Roman] Jakobson herausgearbeitete Funktion von Termen versteht, die einen Kontakt herstellen, aufrecht-

13 Michel de Certeau, „Gehen in der Stadt“, in: Kunst des Handelns, übers. v. Ronald Vouillé, Berlin 1988, 179-208, 189.

14 De Certeau, „Gehen in der Stadt“, 191. 


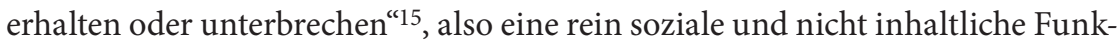
tion erfüllen. Er meint damit konkret, dass „Gehen, das sich Schritt für Schritt fortsetzt oder fortgesetzt wird, [...] aus der Umgebung etwas Organisch-Bewegliches [macht], eine Abfolge von phatischen topoi"16. Im Grunde bezieht sich das „Phatische“ auf den Gedanken, dass die Wege, die ein Fußgänger in der Stadt auswählt, aktualisiert und aktiviert werden, indem auf ihnen gegangen wird, wohingegen andere Pfade davon ausgelassen werden. De Certeau argumentiert auch für eine formal linguistische Struktur räumlicher Praktiken und sagt, dass zum Beispiel die Synekdoche auf den Prozess des Gehens durch die Stadt angewandt werden kann. In diesem Kontext gedacht, kann man eine Synekdocheähnliche Struktur beobachten, wenn Totalitäten (z.B. eine Nachbarschaft) von einem Fußgänger durch Fragmente ersetzt werden (wenn, zum Beispiel ein Fahrrad, das an einer Straßenecke abgestellt wurde, stellvertretend für das ganze Viertel steht). Howitts Umherschweifen ist auf ähnliche Weise Synekdoche-artig: während ihres Aufenthalts in München, und vor allem dann, wenn sie durch die Stadt läuft, erweitert sie kleine räumliche Elemente so, dass sie die Rolle eines ,Mehr' (einer Totalität) spielen; mit anderen Worten schafft sie imaginative Blasen aus scheinbar unscheinbaren Orten. Diese Blasen ersetzen die Totalität der Stadt und machen die Stadt als Ganzes viel dichter. Das bedeutet auch, dass es in Howitts Text zu einer wahrgenommenen Erweiterung des Raums kommt, wenn sie umherschweift; wie Barbara Korte in Bezug auf Robert Louis Stevenson und Jerome K. Jerome zeigt, korrespondiert für den mußevollen Reisenden, für den sich die Landschaft gefühlt ausdehnt, die Erfahrung geistiger ,Tiefe ' mit einer Wahrnehmung von Weite der Umgebung ${ }^{17}$. Die Mußeräume, die Howitt in der Natur kreiert, sind solche Ausdehnungen oder imaginativen Blasen und ich werde ein paar Passagen vorstellen, die die Verbindung zwischen idling und Räumlichkeit in Howitts Text und Gehen als einer Relation zwischen Selbst und Umwelt illustrieren. Spricht Howitt von Richtungen? Schreibt sie, dass sie sich verirrt hat, dass sie abschweift? Rufen diese Momente „kartographische Angst"18 hervor oder sind sie vielmehr Erfahrungen angenehmen präsent-Seins und der Einheit mit dem umgebenden Raum? Robert T. Tally spricht von der beruhigenden Kraft von einem „YYou are here arrow or dot or other marker [which] provides the point of reference from which we can both imagine and navigate the space $^{\text {"19 }}$, aber im Hinblick auf Howitt ist es interessanter herauszufinden, wie sie

15 De Certeau, „Gehen in der Stadt“, 191.

16 De Certeau, „Gehen in der Stadt“, 191.

17 Vgl. Barbara Korte, „Against Busyness: Idling in Victorian and Contemporary Travel Writing", in: Monika Fludernik/Miriam Nandi (Hg.), Idleness, Indolence and Leisure in English Literature, New York 2014, 215-34, 216.

18 Tally verwendet den Ausdruck „cartographic anxiety“, vgl. Robert T. Tally, Jr., Spatiality. The New Critical Idiom, London 2013, 5.

19 Tally, Spatiality, 2. 
Karten des sie umgebenden Raumes schafft und dabei solchen deiktischen Markern nur marginale Aufmerksamkeit schenkt und sie vielmehr auf eher launenhafte Art konsultiert/einsetzt.

Nach dem ersten Treffen mit Kaulbach denken A. M. Howitt und ihre Begleiterin Jane Benham an ihre Überlegungen am Vorabend zurück. Wie viele junge Menschen, die das erste Mal weit weg von Zuhause im Ausland sind, sind die beiden nach ihrem anfänglichen Enthusiasmus etwas geknickt; sie fragen sich, warum sie überhaupt nach Deutschland gekommen sind und denken, dass England vielleicht doch einfach das bessere Land für sie sei. Sie gehen spazieren, um ihre weiteren Pläne zu besprechen:

We talked and talked, and walked into that lovely English Garden, along the banks of the Isar [...] all was silent in the approaching twilight; long gleams of pale flesh-coloured sky gleamed through the clumps of trees in the distance; acres of rich summer grass and flowers stretched away from our feet. Behind us rose a gentle mound surmounted by a white marble pavilion, more like something on the stage than a reality; there was the scent of early mown grass, the distant hum of the city, the towers and spires of which, in the distance, rose abruptly into the evening sky, as if from a sea of wood; there was the near rush of the water, the gentle voice of a bird ever and anon. The peace of Nature sunk into our hearts: never had nature and life and art seemed so holy and beautiful to us, I believe. We talked of a thousand things; a certain cloud, a certain barrier which seemed to have existed between our hearts, melted away; for, after all, our hearts had been strangers to each other until this night. (ASM 4-5, meine Hervorhebungen)

Diese Passage zeigt mehrere Aspekte. Im Hinblick auf den Rest des Reiseberichts beginnt sich an diesem Abend des Gehens und Redens eine tiefe Freundschaft zwischen den beiden Frauen zu entwickeln; die beiden geben ihre Zweifel über München auf und entschließen sich dazu, für längere Zeit als Schülerinnen bei Kaulbach zu bleiben. Der Spaziergang entlang der Isar und durch Münchens Straßen und die Erfahrung der Natur, als solcher hat eine heilende Wirkung und treibt die Handlung nach vorne.

Wenn man sich mit Räumlichkeit in Howitts Text beschäftigt, fällt auf, dass die obige Beschreibung eines Spaziergangs sowohl ortsspezifisch (weil die beiden entlang der Ufer der Isar schlendern) als auch vage ist: sie sehen Bäume in der Ferne (,in the distance"), sie hören das entfernte Rauschen der Stadt, sie sehen ihre Türme in der Ferne; der Hügel hinter ihnen erscheint unwirklich und die einzigen anderen Geräusche sind das ,nahe' Rauschen des Wassers und das Singen der Vögel. Die einzige spezifische Präposition, die Howitt also verwendet - ,hinter - bezieht sich auf etwas, das unwirklich erscheint. Alle anderen Hinweiswörter sind unspezifisch, was darauf hindeutet, dass der sie umgebende Raum eine unscharfe und vage Qualität annimmt, wenn sie idled. Er ist da, er umgibt sie, aber nur in der Entfernung. Nach Edward S. Casey ist eine Möglichkeit, das Verhältnis zwischen ,Raum' und ,Ort' zu erklären und zu bestimmen, was davon primär und sekundär ist, zu sagen, dass „human experience starts 
from a mute and blank ,space to which placial modifiers such as ,near,',over there,' ,along that way, and ,just here' are added, sooner or later: presumably sooner in perception and later in culture ${ }^{\text {"20 }}$. In Howitts Fall hat jedoch die Unbestimmtheit, mit der sie diese Beiwörter benutzt, einen gegensätzlichen Effekt. Sie bringt sie zurück in einen stummen, kahlen und sogar undefinierten Raum, weil sie als mußevolle Spaziergängerin abschweift und den jeweiligen Ort, an dem sie sich aufhält, in Raum diffundieren lässt. Ihr Umherschweifen wandelt das Ortshafte egal welchen Raumes in eine Kategorie von zweitrangiger Bedeutung um, zumindest während des Zeitabschnitts, in dem sie sich bewegt. Im obigen Beispiel mag sie sich zwar an der Isar aufhalten, einem Ort, von dem sie natürlich Kenntnis nimmt, aber sie schreibt nicht über das spezifische ,Hier, sondern über das allgemeinere ,präsent-Sein' (thereness) des Raumes um sie herum, mit dem sie eine Erfahrung der ,Einheit' hat. Ihr idling bewirkt also, dass die Dominanz des Ortes, an dem sie sich befindet, in den Hintergrund tritt.

Das Außerkraftsetzen von Konzepten, die durch die Kultur und moderne Wissenschaft überhaupt erst hinzugefügt wurden, ist, so möchte ich argumentieren, ein Effekt der re-subjektivierenden Kraft von mußevollem Dahintreiben, der zu seiner Prekarität beiträgt. Denn wenn eine Frau innerhalb eines historischen Kontexts, in dem zunehmend der Status moderner Wissenschaft und Wissenschaftlichkeit zunimmt, ein Konzept außer Kraft setzt, das für gegeben angenommen wird, handelt es sich um einen mutigen Akt.

In einer anderen Szene führt Howitt ihr Mäandern an einen Mußeort. Zum wiederholten Mal handelt es sich dabei um eine Kirche. Da es sich aber um eine sehr unscheinbare, schlichte Kirche handelt, veranschaulicht die Szene, was ich meine, wenn ich ihr idling als Synekdoche-artig bezeichne - es ermöglicht ihr, kleinere räumliche Elemente in imaginäre, kurzlebige Blasen umzuwandeln und ihnen eine heterotopische Qualität zu verleihen:

One day lately the streets were gay with people, and the sun shone down in my very heart. I longed to be among trees and fields. And was there not to be a Kirchweih (wakes) in the $\mathrm{Au}$ - the church festival of the beautiful church there? Thither I would go. Through the gay streets accordingly I went; crowds of holiday people moving towards the Isar-gate, and over the bridge, and past the Volk's Theatre. [...] The open space in which the lovely Au church stands was very gay, and under the acacia-trees [...] hundreds of people were congregated. (ASM 74)

Ihr Spaziergang ist spontan; sie sehnt sich danach, auf einem weiten Feld zu sein, sie wird ganz wesentlich von ihren Emotionen gesteuert. Howitt ist auf einem dérive, das nach Guy Debord sowohl auf einem Loslassen als auch auf seinem notwendigen Widerspruch beruht, nämlich der Dominanz der psycho-

20 Edward Casey, „How to Get from Space to Place in a Fairly Short Stretch of Time: Phenomenological Prolegomena", in: Steven Feld/Keith H. Basso (Hg.), Senses of Place, Santa Fe 1996, 13-52, 15. 
geographischen Variationen, die maßgeblich vom Wissen der Berechnung ihrer Möglichkeiten geprägt werden. ${ }^{21}$ Howitt lässt es zu, von den Attraktionen des Terrains und den Begegnungen, die sie dort potenziell erwarten, angezogen zu werden). ${ }^{22}$ Die Wiederholung von ,go (in „Thither I would go [...] accordingly I went"), in diesem Fall auch ein Polyptoton, unterstreicht die Spontanität der Situation und auch ihre Zufälligkeit, man hat den Eindruck, man würde eine Person belauschen, die vor sich hin murmelnd wiederholt, was sie sich zu tun entschlossen hat, damit sie es in der nächsten Sekunde nicht wieder vergisst. Sie bricht auf (oder aus) und findet sich in einem ,offenen Raum '(open space“) wieder - während die Kirche als solche hübsch ist, zieht es sie doch in erster Linie zu der sie umgebenden Gegend und Natur. Nach dem Betreten der Kirche beobachtet Howitt:

The air was heavy with incense; the graceful, slender, white columns rose up like the clustered stems of a palm-grove! The sun shone and glowed through the gloriously painted windows. [...] I knew that these windows were very beautiful, but it was only to-day that their full beauty burst upon me. The exquisite groups stained upon them, with their correct drawing, and rich draperies, are inclosed, as it were, in jewelled shrines; the upper portions of the window being filled with Gothic work of every brilliant colour, like missal pages. Pity only that too much yellow is used. [...] After a time I left the church, and not being inclined to return home, and finding that all the music from the public-houses, and all the eating, and the dancing, were very inharmonious to my then state of mind, I wandered on towards the plain, and feasted my eyes on a view of the Alps, which today appeared fairly to have stalked towards Munich, so near did they seem, - of a tender, quiet, blue-grey, but their forms gigantic, stern, Alpine! (ASM 74-75)

Drei Dinge, die für meine Interpretation relevant sind, stechen aus dieser Passage hervor: in dem Moment, in dem Anna Mary Howitt sich scheinbar geistesabwesend (im Englischen kann man hierfür auch das Adverb ,idly' verwenden) auf der Holzbank in der Kirche hinsetzt, den schweren Duft von Weihrauch und die Schönheit der Farben auf sich wirken lässt, fühlt sie die Schönheit über ihr ,zerbersten', der Moment der Muße an sich macht sich also somatisch und fast schon mit Gewalt bemerkbar. ${ }^{23}$ Im gleichen Moment, und das ist ein Beispiel für die duale Qualität von Howitts Muße, ist da ein Teil von ihr, der sich nicht gänzlich ablenken lässt und der sich eben nicht ganz dem Muße-Anfall hingibt; sie ist deshalb immer noch in der Lage festzustellen, dass die Ornamente auf den

21 Vgl. Guy Debord, „Theory of the Dérive“, in: Ken Knabb (Hg.), Situationist International Anthology, Berkeley 1995 [1958], 50-54, 50.

22 Vgl. Debord, „Theory of the Dérive“, 50.

23 Vgl. William Henry Hudson, Idle Days in Patagonia, London 1893, wo wiederholt, zum Beispiel auf $145 \mathrm{f}$., von „,fits of idleness“, also sog. Muße-Schüben, die Rede ist, die Hudson in den Weiten der patagonischen Landschaft erlebt. Zum Zusammenhang von Muße und Schreiben in Hudsons Reisebericht siehe Heidi Liedke, „Oisiveté et écriture dans Un flâneur en Patagonie de W. H. Hudson (1893)“, übers. v. Anna Pevoski/Clara Schwarze, in: Recherches \& Travaux 88 (2016), hg. v. Thomas Klinkert, 107-127. 
Fenstern ,korrekt' sind und sie kann kritisieren, dass zu viel von der Farbe Gelb verwendet wird. Auch wenn sie das nicht kommentiert, scheint es fast blasphemisch für eine religiöse Person an einem Ort der Andacht den genauen Farben der Fenster so große Aufmerksamkeit zu schenken. Am Ende des Abschnitts steht ein einziger Satz, der ihr zielloses Wegtreiben von der Kirche widerspiegelt; sie zieht weiter und, als ob um zu zeigen, dass es ihr gelungen ist, sich von dieser Szene loszureißen, endet der erste Strang des Satzes mit einem Geviertstrich, auf den eine elliptische Beschreibung des alpinen Blicks auf die Alpen, den es ihr einzufangen gelingt, folgt. Ähnlich wie in der Beschreibung über ihren Ausflug zur Kirchweih, wo sie sich nach den Feldern sehnt, stellt sie das Gehen oft nicht wie eine physische Aktivität dar, sondern wie eine emotionale, plötzliche und manchmal auch überraschende - ein Begehren packt sie. Auch das erinnert an den Ansatz der Psychogeographen, die sich bereitwillig auf ein neues Bewusstsein für die urbane Landschaft einließen. ${ }^{24}$

Am Anfang der meisten ihrer spontanen Streifzüge spricht Howitt explizit von einem Verlangen, das von ihr Besitz ergreift oder dass sie und ihre Begleiterin sich angetrieben fühlen (,feel bound to take a walk“, $A S M, 67$ ) an den Abenden im Sommer noch einmal das Haus zu verlassen. Auf eine Art haben ihre Schritte (zumindest für sie), hat dieses transgressive Durchqueren der Stadt die Funktion von Pinselstrichen, die die sonst schwarz-weiße Umgebung färben. Die Farben, die Howitt sieht, wenn sie den Sonnenuntergang beschreibt, sind deep-blue, pale amber, lovely azure, dark indigo, azure, rose-tinted, blue, lilac (vgl. ASM, 68-9). Spazieren zu gehen, zum Beispiel auf der Ludwigstraße am Abend, verzaubert sie; den Gesang einer Gruppe von Pilgern zu hören, versetzt sie in ein Delirium (vgl. ASM, 67-8).

Es gibt auch andere Passagen im Text, in denen die Erfahrung von Muße zwar auch so dargestellt wird, dass sie die Form eines ziellosen Tastens hat, die dann jedoch von Beobachtungen ausbalanciert wird, die darauf hinweisen, dass hier der Verstand einer Kunststudentin arbeitet. Was nämlich geschieht, ist eine kontrollierte Auflösung von Grenzen: Sie nimmt die durchquerte Umgebung unter dem Aspekt unter die Lupe, inwiefern sie für die Zwecke der Kunst von Nutzen ist. In einer Szene geht sie zwar „[o]n, and still on [...] until the avenue became wilder" (ASM, 151), aber als sie an der Allee ankommt, schwächt sich dieser Eindruck ab, wird zu einer schönen Perspektive und sie blickt nunmehr auf eine Komposition: auf der linken Seite die Allee, rechts ein Flussstück; Männer, die dort arbeiten, werden nicht in erster Linie als menschliche Wesen betrachtet, sondern als Faktoren, die der Szene Leben und äußerst pittoreske Animation verleihen. Als ein Vogelschwarm sich über den Himmel erstreckt und so einen weiteren belebenden Effekt hinzufügt, erstarrt Howitt vor lauter Bewunderung für die künstlerische Kraft der Natur. Für sie ist die Natur also personifiziert und

24 Vgl. Joseph Hart, „A New Way of Walking“, in: Utne Reader, Juli/Aug. 2004, o. S. 
selbst eine Künstlerin. Auf diese Weise werden alle Naturphänomene und Merkmale der Landschaft zu Schritten im künstlerischen Prozess gemacht und Howitt erlaubt es sich selbst nicht, gänzlich vom Driften eingenommen zu werden.

Das Erkunden der Stadt zu Fuß und das Umwandeln von fremden Landschaften in Konzepte, mit denen sie sich auskennt, stärken Howitt in ihrem Selbstbild der aufstrebenden Künstlerin, und ermöglichen es ihr und ihrer Begleiterin ihren eigenen Raum zu schaffen und darzustellen. Für Howitt, die in einem liberalen Umfeld aufwuchs und von ihren Eltern, die beide Schriftsteller waren, unterstützt wurde, mag das keine vollkommen neue Erfahrung gewesen sein, wie sie das für die Mehrheit der viktorianischen Frauen in der Mitte des 19. Jahrhunderts war. Aber dennoch schreibt sie darüber, was für ein beruhigendes Gefühl es sei, sich frei zu bewegen, den Körper frei treiben zu lassen und nicht auf männliche Begleitung angewiesen zu sein - wie eingangs erwähnt, war die Position von Frauen, die alleine in der Stadt unterwegs waren, prekär. In der Tat gab es so etwas wie die Figur des „female bachelor", also der alleinstehenden Frau, die öffentlich alleine auftrat, in England nicht bis in die 1890er. Erst zu diesem Zeitpunkt war es mehr oder weniger akzeptiert, dass eine Frau ihre Heirat zumindest aufschieben konnte; diese Akzeptanz ging einher mit einer Art Bewunderung dieser neuen weiblichen Freiheit im öffentlichen Raum und einiger neuer Publikationen für Frauen, die die ,new woman ' diskutierten. ${ }^{25}$ In Zeitschriftenartikeln aus der Zeit werden moderne Frauen „[who] go to theatres without masculine escort" ${ }^{\text {" } 6}$ entweder in einem fast triumphierenden Ton genannt oder stattdessen beschrieben als Frauen, die in "the old old days" unter besseren Bedingungen in ein Kloster gegangen wären und jetzt die Freiheit eines Mannes für sich beanspruchen und versuchen, alle Unterschiede zwischen den Geschlechtern zu nivellieren, was keine guten Aussichten verspreche. ${ }^{27}$ Howitt und ihre Freundin können auch ihre Rollen der Kunststudentinnen ablegen und sich wie „proper young ladies“ (ASM, 70) anziehen, was deutlich macht, dass sich Howitt auch der Wirkung der Mode und der Performativität ihrer Weiblichkeit im öffentlichen Raum bewusst ist. Es freut sie, dass in München nichts merkwürdig daran ist, dass die beiden ohne Begleitung in Konzerte und ins Theater gehen - „all is silence and poetry" (ASM, 71). Wenn sie in Kaulbachs Garten arbeiten, haben sie das ganze Paradies, wie sie es nennen, für sich und tragen nicht einmal ihre Hauben. $(A S M, 39)$ Die Schriftstellerin Elizabeth Eiloart, die häufig für das proto-feministische Magazin English Woman's Journal schrieb, bringt ähnliche Gedanken zum Ausdruck, als sie einen Spaziergang durch Hamburg unternimmt

25 Emma Liggins, „,The Life of a Bachelor Girl in the Big City؛ Selling the Single Lifestyle to Readers of Woman and the Young Woman in the 1890s", in: Victorian Periodicals Review 40,3 (2007), 216-238, 216.

26 Ella Hepworth Dixon, „Why Women are Ceasing to Marry“, in: Humanitarian 14 (1899), 391-396, 394.

27 „The Female Bachelor“, in: Saturday Review (1894), 582-583. 
und über ihre unsystematischen Erkundungstouren schreibt; wie Korte schlussfolgert, präsentieren ihre Artikel die Figur einer unabhängigen Frau, die eine fremde Stadt in einem selbst gewählten Tempo und von ihren eigenen Interessen geleitet kennenlernt, und dabei von keinem Ehemann und keiner Aufsichtsperson behindert wird; diese Figur funktioniert wie der Gegenpart zum Flaneur. ${ }^{28}$ Es scheint also, dass das Unterfangen des mußevollen Reisens nur dann befriedigend sein kann, wenn man, vor allem als Frau, von niemandem gebremst oder gesteuert wird und wenn man alleine einen ,rohen' Eindruck von dem Raum, den man durchquert, gewinnen kann.

Während Anna Mary Howitt sich München ergeht, verwendet de Certeau in seinem Aufsatz das Beispiel von New York City, das - in seiner Gestalt aus dem 21. Jahrhundert - der Schauplatz von Teju Coles Open City ist, auf das im Folgenden eingegangen wird. De Certeau schreibt, dass diese Stadt von oben betrachtet ein „gewaltiges Lustempfinden“ in ihm auslöse, weil mit diesem Betrachten eine Ekstase einhergehe, die ein großer zu entziffernder Kosmos verspreche. Die Stadt New York stellt „diesen maßlosesten aller menschlichen Texte“ dar ${ }^{29}$, der vom Betrachter totalisiert wird, da er die Stadt zu kennen meint ${ }^{30}$; statt von oben $\mathrm{zu}$ gucken, besteht noch eine zweite Möglichkeit, eine Stadt zu erkunden, nämlich auf Straßen-/Augenhöhe mit dem Spaziergänger, und so die Stadt zu schreiben. Howitt gehört zu der zweiten Gruppe; sie guckt nicht auf München herunter, sondern guckt es an, lässt sich durch die Stadt treiben und konstruiert ihren eigenen menschlichen Text aus den vielen verschiedenen Fragmenten, die sie an unterschiedlichen Tagen sieht. Das bedeutet nicht, dass sie einen konkreten Ort hat. Ihre immer wiederkehrenden Schübe der Muße scheinen sie in die eine und andere Richtung zu stoßen. Auch wenn sie eine Vielzahl von „Blasen“ entlang des Weges für sich findet, ist ihr unruhiges Treiben letzten Endes doch ein Verfehlen. „Gehen bedeutet“ - auch im Fall von Howitt - „den Ort zu verfehlen. Es ist der unendliche Prozess, abwesend zu sein und nach einem Eigenen zu suchen. Das Herumirren, das die Stadt vervielfacht und verstärkt, macht daraus eine ungeheure gesellschaftliche Erfahrung des Fehlens eines Ortes. “31

Nun verfehlt Howitt jedoch nicht gänzlich ihr Tasten in Muße nach - nun, es ist nicht ganz klar, wonach sie tastet - künstlerischer Perfektion? Gottes Stimme? Weiß sie selbst überhaupt, wonach sie sucht? Es kommt zu einem temporären Moment des Gefunden-Habens als sie, gegen Ende ihres ersten Jahres in München, fast schon überrascht feststellt, dass die Erinnerungen an die Natur merkwürdigerweise die Erinnerung an die Schönheit der Kunst übertreffen werden.

28 Barbara Korte, „Travel Writing in The English Woman's Journal (1858-64): An Area of Leisure in the Context of Women's Work“, in: Victorian Periodicals Review 45,2 (2012), 158-174, 164.

29 De Certeau, „Gehen in der Stadt“, 180.

30 Vgl. Tally, Spatiality, 96.

31 De Certeau, „Gehen in der Stadt“, 197. 
Sie schlussfolgert: „Nature seems to pronounce her blessing upon [colour in architecture], by heightening the beauty of man's work ..." (ASM, 148). Howitt, die die Natur immer und immer wieder so beurteilt und kritisiert als würde es sich um Kunst handeln, zeigt hier eine veränderte Haltung, wenn sie anerkennt, dass die Natur sogar noch schöner als Kunst oder andere menschengemachte Werke, zum Beispiel architektonischer Art, sein kann. Noch hervorzuheben ist, dass sie nicht von der Schönheit der Natur und der Kunst als solcher spricht, sondern von den Erinnerungen, die sie von beiden hat. Es ist also wieder ihre Imagination, die arbeitet. Sie ermöglicht es ihr, die Einheiten Raum und Zeit aufzuheben, durch die Stadt zu driften und eingebildete Muße-Blasen zu schaffen, d.h. sich von etwas gedanklich zu entfernen; die Erinnerungen, die sie für sich schafft, ermöglichen es ihr, eine Distanz zu der durch sie erfahrenen Umgebung zu schaffen. Bereits am Ende des ersten Bandes ihres Reiseberichts entsteht also der Eindruck einer Entfremdung; am Ende des zweiten Bandes spricht sie rückblickend von sich in der dritten Person, nämlich der Kunststudentin, was mich auch dazu veranlasst, das „Ich“ in dem Reisebericht nicht mit Howitt gleichzusetzen, sondern mit einer Erzählerin. Der Text ist ihr ultimativer Mußeraum, mit dem sie sich eine Erinnerung und eine Erzählerfigur schafft: das Gefunden-Haben findet seine Gestalt primär im nachträglichen Erinnern und Erzählen und nicht im Moment des (vergangenen) Erlebens.

\section{Zwischenschritt: Langeweile}

$\mathrm{Zu}$ Beginn dieses Beitrags wurde angemerkt, dass in den vorgestellten Fallstudien das größte Vergnügen für den Erzähler zusammenfällt mit der größten Langeweile für die Leserin. Das hängt auch damit zusammen, dass ich betont habe, dass idler die Räume, die sie durchqueren, für sich selbst schaffen. Ich möchte diesen Gedankengang ausführen. Die vorgestellten Texte entsprechen nicht einem Textideal in Barthes' oder Isers Sinn, denn sie bieten der Leserin so gut wie keine Angriffsfläche für eine eigene Rezeption. Wenn es bei der Reader-Response-Theory darum geht, der Leserin ein größtmögliches Maß an Eigenständigkeit im Deutungs- und sogar Entstehungsprozess eines Textes zuzugestehen, wird die Leserin in den beiden ausgewählten Beispielen zwar nicht unmündig gemacht, aber von einem Quell der Freude für die Erzähler ausgeschlossen. Je größer die Muße für die Erzähler, desto kleiner die Muße für die Leserin, desto größer der Unmut, von etwas Entscheidendem ausgeschlossen zu sein. Es sind der den Text formende Erzähler und die durch ihn/sie hergestellten Lücken, die die Leserin zu einem Gefühl der Ausgeschlossenheit verdammen oder zumindest zwingen. Roland Barthes unterschied zwischen „lisible“ (das heißt lesbaren - schlechten) und „scriptible“ (das heißt schreibbaren - guten) Texten; ein lesbarer Text entspreche den Erwartungen der Leserin und sei deshalb von geringerem Wert; ein 
schreibbarer Text lasse die Leserin in einem Zustand der anhaltenden Erwartungshaltung und stelle jouissance (Wollust) her. ${ }^{32}$ In Wolfgang Isers transaktionaler Reader-Response-Theory liegt die Betonung ebenfalls darauf, dass es so etwas wie Bedeutung nicht gebe; sie werde gemacht. Die beiden Pole eines Textes seien der artistische (der Text des Autors) und der ästhetische (die Realisierung/ Aktualisierung des Textes durch die Leserin). ${ }^{33}$

Im gleichen Maße, wie man in allen zwischenmenschlichen Beziehungen und Interaktionen keine vollkommene Erfahrung des Gegenübers haben könne, weil man nie wisse, wie das Gegenüber einen sehe, und so Kontakte auf einem kontinuierlichen Füllen von - wie Iser sie nennt - Unbestimmtheitsstellen in unserer Erfahrungen beruhen, sind Berichte von mußevollen Erfahrungen, so mein Argument, von Lücken gekennzeichnet. Jedoch sind diese Lücken nicht in erster Linie für die Leserin da, sondern für die Erzähler. Diese Lücken werfen sie (sich) selbst auf und füllen diese auf, gleichsam mit Tennisspielern, die gegen eine Wand spielen und sich selbst die Vorlagen liefern. So ist der Erzähler von einem Verlangen angetrieben, beim Schreiben des Textes ein kohärentes Ganzes zu schaffen - die Lücken geben ihm eine Art Feedback, aus dem er ein selbst-referentielles Feld formt und sich so eine Struktur für das zukünftige Schreiben schafft. Die Leserin kann nur zugucken. Die Erzähler schreiben sich aus der Marginalität heraus, und transportieren die Leserin in eine Marginalität des Nicht-Wissens, Nicht-Teilhabens und Ausgeschlossenseins.

\section{Teju Coles Erzähler: Langweiliges Gehen in Muße}

Im Fall von Teju Coles Erzähler Julius in Open City erfolgt dieses Ausschließen auf der Ebene der jouissance der Leseerfahrung, da er über den ganzen Roman hinweg seine Kenntnis verschiedener Bereiche der Hochkultur zelebriert und somit die Erwartungshaltung der Leserin dauerhaft strapaziert. Open City wurde 2011 veröffentlicht, 2012 mit dem PEN/Hemingway Award und anderen Preisen ausgezeichnet. Der Roman erzählt aus der Perspektive des jungen Psychiaters Julius von seinen Spaziergängen durch New York und Brüssel, von unzusammenhängenden Begegnungen mit Menschen, in der Vergangenheit und Gegenwart des Erzählers. Der ganze Roman beruht auf einem Zusammenspiel von der Vorwärts-(und Seitwärts)-Bewegung des Protagonisten und seinem große Teile des Narratives dominierenden inneren Monolog.

In der Forschungsliteratur über Open City gibt es zwei widerstreitende Gruppen, die Julius entweder als Flaneur, und auch als „Afropolitan flaneur" bezeich-

32 Vgl. Roland Barthes, Die Lust am Text, übers. v. Traugott König, Frankfurt a. M. 1974.

33 Vgl. Wolfgang Iser, Die Appellstruktur der Texte. Unbestimmtheit als Wirkungsbedingung literarischer Prosa, Konstanz 1970. 
nen, oder den von Pieter Vermeulen vorgebrachten überzeugenderen Vorschlag, Julius vielmehr als Fuguer zu bezeichnen, da er fundamental egozentrisch sei. ${ }^{34}$ Was die erste Gruppe angeht, so wird beispielsweise von Susanne Gehrmann argumentiert, dass Julius' Denken sich aus einem dichten Netzwerk intertextueller und intermedialer Verweise auf Weltliteratur, Musik und Kunst bezieht, was ihn als Prototypen des elitären, intellektuellen Kosmopoliten auszeichnet. Er sei als distanzierter Beobachter eine Version des Flaneurs im 21. Jahrhundert: eine postmoderne Variante, was seinen kulturellen Eklektizismus und seine Distanziertheit angeht, aber auch eine postkoloniale Variante im Hinblick auf sein politisches Bewusstsein. ${ }^{35}$

Not long before this aimless wandering began, I had fallen into the habit of watching bird migrations from my apartment, and I wonder now if the two are connected. On the days when I was home early enough from the hospital, I used to look out the window like someone taking auspices, hoping to see the miracle of natural immigration. [...] While I waited for the rare squadrons of geese, I would sometimes listen to the radio. I generally avoided American stations, which had too many commercials for my taste - Beethoven followed by ski jackets, Wagner after artisanal cheese - instead turning to Internet stations from Canada, Germany, or the Netherlands. And though I often couldn't understand the announcers, my comprehension of their languages being poor, the programming always met my evening mood with great exactness. Much of the music was familiar, as I had by this point been an avid listener to classical radio for more than fourteen years, but some of it was new. There were also rare moments of astonishment, like the first time I heard, on a station broadcasting from Hamburg, a bewitching piece for orchestra and alto solo by Shchedrin (or perhaps it was Ysaÿe) which, to this day, I have been unable to identify. (OC, 3-4)

New York ist, wie auch in Howitts München, ein fluider Raum, dessen Raumhaftigkeit den konkreten Ort übertönt. Julius wandelt umher, teilt ein paar Weisheiten, Beispiele für guten Geschmack, historische Anekdoten mit; es ist nicht nur die psychogeographische Landschaft des öffentlichen Raumes, den er durchschreitet, und die man als Leserin ggf. nacherleben könnte, die erzählt wird, sondern in erster Linie die psychogeographische Landschaft - und die damit einhergehende Amoralität und der Solipsismus - in Julius' Kopf, die traumhaften Wirrungen und Windungen seines Gehirns. Es ist zwar aufregend, auf diesem Trip hinter seinen Augen zu sitzen, aber der Tonfall, in dem er erzählt, schafft Distanz statt Nähe. ${ }^{36}$ Die Fluidität wird auch dadurch verstärkt, dass es in dem Roman keine Anführungszeichen gibt, und es somit manchmal unklar ist, ob

34 Vgl. Pieter Vermeulen, „Flights of Memory: Teju Cole's Open City and the Limits of Aesthetic Cosmopolitanism“, in: Journal of Modern Literature 73,1 (2014), 40-57, 40.

35 Susanne Gehrmann, „Cosmopolitanism with African Roots. Afropolitanism's Ambivalent Mobilities“, in: Journal of African Cultural Studies 28,1 (2016), 61-72, 68.

36 Vgl. Stephen, „In Praise of the Flâneur“, o.S. 
man den inneren Monolog des Erzählers liest, seine direkte Rede oder die indirekte Rede seiner Begegnungen.

Wie auch bei Howitt, die von einem Begehren ergriffen wird, sich wie ein Blatt durch die Stadt schubsen zu lassen, findet man bei Julius Beschreibungen des Getriebenwerdens, des Zufällig-irgendwo-Seins, womit auch ein hoher Grad an Verantwortungslosigkeit einhergeht:

These walks, a counterpoint to my busy days at the hospital, steadily lengthened, taking me farther and farther afield each time, so that I often found myself at quite a distance from home late at night, and was compelled to return home by subway. In this way, at the beginning of the final year of my psychiatry fellowship, New York City worked itself [walked itself] into my life at walking pace. $(O C, 3)$

Julius scheint nicht einmal der Akteur seines Gehens zu sein, er wird gegangen, seine offene Haltung der Muße lässt ihn die Stadtlandschaft auf intuitive Weise erkunden (die Formulierung „I found myself“ kommt sehr häufig vor). Seine Haltung ist auch von Resignation gekennzeichnet, weil er an seinen Streifzügen besonders genießt, dass es keinerlei Konsequenzen hat, ob er an der nächsten Ecke links abbiegt, oder gedankenverloren vor einem zerfallenden Gebäude stehen bleibt, sich entlang von schattigen Mauern in der East Side die Zeit vertreibt - keine Konsequenzen bedeuten Freiheit. Triumphierend stellt Julius fest, er habe New Yorks Häuserblocks mit seinen Schritten ausgemessen; sein Fortschritt ist ziellos, die Haltestellen der Subway dokumentieren das. (vgl. OC, 7)

Was für Howitt Gärten und Kirchen sind, ist für Coles Erzähler die Musik. In einer Szene besucht Julius einen bald schließenden Plattenladen. Schließlich findet er sich damit ab, dass es in dem Geschäft nicht leise ist:

[...] before long, I was rapt and might have, for all the world, been swaddled in a private darkness. In this trance, I continued to move from one row of compact discs to another, [...]. On hearing Christa Ludwig's voice, in the second movement, a song about the loneliness of autumn, I recognized the recording as the famous one conducted by Otto Klemperer in 1964. With that awareness came another: that all I had to do was bide my time, and wait for the emotional core of the work, which Mahler had put in the final movement of the symphony. I sat on one of the hard benches near the listening stations, and sank into reverie, and followed Mahler through drunkenness, longing, bombast, youth (with its fading), and beauty (with its fading). Then came the final movement, „Der Abschied“, the Farewell, and Mahler, where he would ordinarily indicate the tempo, had marked it schwer, difficult. [...] It simply wasn't possible to enter the music fully, not in that public space. [...] The song followed me home. Mahler's music fell over my activities for the entirety of the following day. There was some new intensity in even the most ordinary things all around the hospital. (OC, 17, meine Hervorhebungen)

Im Musikgeschäft versinkt der Erzähler in der Musik, er ist wie in einer Trance, geleitet von dem Bewusstsein, das Stück einordnen zu können; er findet sich damit ab, nur auf den nächsten Akkord warten zu können, die harten Holzbänke erinnern ironischerweise an Bänke in einer Kirche, er versinkt in eine Träume- 
rei, die sich noch am nächsten Tag auf ihn legt - das sind die Begriffe, die ich in dem Zitat hervorgehoben habe und die das semantische Feld der intensiven Mußeerfahrung aufmachen. Es ist, als würde das Subjekt hier nicht existieren; es wird von einem Gefühl übernommen und aufgelöst in seiner Existenz.

Ich teile nicht die Ansicht von Kritikern wie James Wood, der im New Yorker postulierte, Coles Erzähler erlange durch seine Distanziertheit einen epistemologischen Vorteil; diese kosmopolitische Gleichgültigkeit gegenüber seiner amerikanischen Erfahrung führe zu einer produktiven Entfremdung. ${ }^{37}$ Paradoxerweise ist die Welt des Erzählers, trotz seiner Obsession mit Musik, eine stumme, hermetisch abgeriegelte Welt. Gegen Ende des Romans spricht er davon, dass jede Person sich selbst als Kalibrierungspunkt für Normalität nehmen müsse; was auch immer unsere Exzentrizitäten seien, wir sind nicht die Bösewichte unserer Geschichten, sondern spielen die Helden. (OC, 243) Diese ins Extreme gezogene Selbstgenügsamkeit erklärt auch, warum Julius die Bilder des tauben Malers John Brewster so bewegen: sie fokussieren ein starrendes, zweidimensionales Abbild seines Selbstverständnisses.

Das Bild der Taubheit, und des so erleichterten Abgeschottetseins passt sehr gut auf den Effekt der vom Erzähler praktizierten Mußehaltung. Durch den Konsum von Hochkultur verstärkt erschafft er sich eigene heterotopische Blasen, die aber, mehr noch als im Falle Howitts, von unvollständigen Informationen gefüllt sein können. Sein (Hobby-)literarisches Kosmopolitendasein isoliert ihn, was ihm aber keinen Kummer bereitet. Insofern ist Vermeulens Hinweis darauf, dass Julius Anzeichen eines sog. Fugueurs (vom frz. fuguer, durchbrennen/ ausbüxen) aufweist, zutreffend. Nach dem ICD (International Statistical Classification of Diseases and Related Health Problems) beschreibt die sog. dissoziative Fugue zielgerichtete Ortsveränderungen, an die sich die Betroffenen hinterher oft nicht erinnern können und während derer ihr Verhalten auf unabhängige Beobachter völlig normal wirkt (Code F44.1). ${ }^{38}$

In Frankreich gab es zwischen 1887 und 1909 eine Fugue-Epidemie, die aber nur eine Fußnote der Geschichte der Psychiatrie darstellt. In Open City gibt es viele Szenen, in denen Julius sich nicht genau erinnert, wie er an einen Ort oder nach Hause zurück gelangt ist; in einer erschütternden Szene gegen Ende des Buchs wird er damit konfrontiert, einige Jahre zuvor eine Freundin vergewaltigt zu haben - er erinnert sich nicht daran, und geht auch anschließend nicht darauf ein. Die vorliegenden Ausführungen enden mit einem Verweis auf eine dissoziative Störung, weil ich versuche, von den 1850ern bis heute einen Bogen aufzuspannen, der den Zusammenhang von Muße und Mobilität widerspiegelt, aber auch das Spektrum der Muße-Erfahrungen, von positiv und angenehm bis

37 James Wood, „The Arrival of Enigmas“, NewYorker.com, 28. Februar 2011, o. S.

38 Vgl. auch Ian Hacking's Studie über Fugueure im 19. Jahrhundert: Mad Travellers: Reflections on the Reality of Transient Mental Illnesses, London 1999. 
negativ und auf extreme Art in sich gekehrt. Auch sehr ähnliche Muße-Praktiken können unterschiedliche Effekte auf Individuen haben. Der Fall Howitt zeigt das Beispiel einer jungen, eigensinnigen Frau, die sich in einer Zeit, in der ein die Mobilität und den Tourismus preisender Diskurs aufkommt, bewusst für einen langsamen Reisemodus entscheidet. Auch Coles Erzähler fällt mit seinem ambulatorischen Automatismus ${ }^{39}$ aus dem Raster, nach dem im 21. Jahrhundert schnelle Mobilität selbstverständlich ist, aber nebenher passieren sollte und der Vernetzung mit anderen dient und nicht der Isolation (sowohl äußerlich, weil er sich zu Fuß fortbewegt, und nicht zum Beispiel die Subway nimmt und innerlich, weil seine mußevolle Haltung einen verwirrten Zustand mich sich bringt).

Somit ist ein Howitt und Julius verbindendes Element ihre Marginalität: sie betrifft es wegen ihres Geschlechts, ihn wegen seines Flüchtens in die Hochkultur und seiner Ethnizität (bei einem Besuch von Ellis Island, dem Symbol für europäische Immigration in die USA, spricht er von sich und anderen afrikanischen Immigranten als „we blacks“, andererseits „überrascht“ ihn jedes Mal beim Blick auf seinen Pass, dass er einen zweiten Yoruba-Namen hat); durch ihr mußevolles Treiben, das einem Zeichnen von eigenen Karten (aber keinen abstrakten, sondern praktisch umsetzbaren) gleichkommt, begeben sie sich aus dieser Randrolle in das pulsierende Herz einer Stadt; nur um am Ende doch in einer neuen, selbst geschaffenen Randrolle zu bleiben. Doch dass sie bleiben, steht außer Frage. Vielleicht könnte man hier das Konzept der Präsenz aufgreifen: durch das Umherstreifen (idling) erst entsteht die Erfahrung von präsent-sein (thereness), die Erfahrung ist also nicht statisch, sondern ergibt sich vielmehr aus der vorher erfahrenen Dynamik der Bewegung des Körpers gekoppelt mit dem fokussierten Blick des oder der sich Bewegenden. Wie in dem Wort präsent-sein der Bindestrich kein ,Minus' sondern eine Verbindung darstellt, so lässt sich auch im Falle des idling durch die Stadt keine Trennung zwischen dem Umherstreifen und dem Einstellen des Gefühls von präsent-sein konstruieren, das sich allerdings nicht steuern lässt. An dieser Stelle kommt die mußevolle Haltung ins Spiel, das idle mindset. Im Englischen ist dieser Ausdruck von einer Ambivalenz gekennzeichnet, die entscheidend ist: er kann sowohl für rezeptive Leere als auch spielerische Nonchalance stehen. Auch diese gewährleistet nicht, dass man eine bestimmte herbeigesehnte Erfahrung haben wird; dem idling haftet ein Risiko an, es ist ein Wagnis.

39 Vgl. Vermeulen, „Flights of Memory: Teju Cole's Open City and the Limits of Aesthetic Cosmopolitanism", 52. 



\title{
Freiträumen
}

\author{
Über Peter Handkes Schauspiel \\ Die Unschuldigen, ich und die Unbekannte am Rand \\ der Landstraße mit Abstechern zu Wim Wenders' pina. \\ Ein Film für Pina Bausch
}

Antonia Egel

Für H. G. - am behaupteten Platz

„Ja, geht denn das, daß in einem Traum der Träumer nicht nur das erste, sondern auch das letzte Wort hat? - in einem Wachtraum: Ja! - Ach, ja. Ach, ja! “1

Am Ende von Peter Handkes Schauspiel Die Unschuldigen, ich und die Unbekannte am Rand der Landstraße sprechen die beiden Protagonisten des Stücks „unisono “2 den eben zitierten Satz. Gemeinsam, im Einklang (uni-sono) sprechen die Figuren „Ich-der-Dramatiker" und „Ich, Erzähler“, wie sich über sich selber wundernd diesen Satz, der innerhalb des Textes über den Text Auskunft gibt. Der Text, ein Traum, geträumt und gesprochen von einem besonderen Träumer, einem Wachträumer, der sich, am Ende des Dramas zu einem „Ja!“3 entschlieBen kann und zwar ganz ohne Aufregung, in aller Gelassenheit in der Mittellage zwischen Kopf- und Bruststimme, ein Ja, nur leicht angebrochen durch ein, wie nachträglich hinzugefügtes „,ach“ - „Ach, ja. Ach, ja!“4

Mit diesem Satz lässt Wim Wenders seinen Film pina. Ein Film für Pina Bausch, enden, mit diesen Worten verabschiedet sich die Tänzerin aus dem Leben: Der Abspann läuft schon, das letzte Solo der großen Tänzerin ist schon gezeigt, sie hat schon, müde und kräftig zugleich wie zum Abschied gewinkt, sie hat schon den berühmten Satz: „Tanzt, tanzt, sonst sind wir verloren“ mit ihrer leisen, verrauchten Stimme gesagt, als laut und fröhlich noch einmal „Kontakthof" gespielt wird. Wieder und wieder ist die gleiche musikalische Schleife zu hören, wieder und wieder tanzt die Truppe der mittelalten Menschen mit den

\footnotetext{
1 Peter Handke, Die Unschuldigen, ich und die Unbekannte am Rand der Landstraße. Ein Schauspiel in vier Jahreszeiten, Berlin 2015, 177.

2 Handke, Die Unschuldigen, 177.

3 Handke, Die Unschuldigen, 177.

${ }^{4}$ Handke, Die Unschuldigen, 177.
} 
alltäglichen Figuren an die Rampe und zurück - als wollte Wenders mit dieser Hommage kein Ende finden, der Abspann läuft und es wird weiter und weiter getanzt. Als dann doch einmal das Tanzen aufgehört hat, hört man, der Abspann läuft, sehr leise, noch einmal die Stimme von Pina Bausch mit einem, wie hingehauchten, aber sehr freundlich hingehauchten „Ach, ja“. Der Abspann läuft auch dann noch eine ganze Weile weiter, der Film zögert den Abschied von der großen Tänzerin hinaus, so lange, wie es eben geht. ${ }^{5}$

Am Ende von Peter Handkes Stück ist Winter - die Jahreszeit, die mit dem Tod assoziiert wird, das Wort, mit dem Thomas Bernhards Der Ignorant und der Wahnsinnige, ein Stück über den Abschied einer Künstlerin von ihrer Kunst und zugleich von ihrem Leben, endet. ${ }^{6}$ Bernhard dort und Handke hier spielen beide auf Rilkes Sonette an Orpheus an, die den Topos des Winters als Zeichen für den Tod beispielhaft ausgestaltet haben:

Sei allem Abschied voran, als wäre er hinter dir, wie der Winter, der eben geht.

Denn unter Wintern ist einer so endlos Winter, daß, überwinternd, dein Herz überhaupt übersteht.

Sei immer tot in Eurydike - , singender steige, preisender steige, zurück in den reinen Bezug. Hier, unter Schwindenden, sei, im Reiche der Neige, sei ein klingendes Glas, das sich im Klang schon zerschlug.

Sei - und wisse zugleich des Nicht-Seins Bedingung, den unendlichen Grund deiner innigen Schwingung, daß du sie völlig vollziehst dieses einzige Mal.

Zu dem gebrauchten sowohl, wie zum dumpfen und stummen Vorrat der vollen Natur, den unsäglichen Summen, zähle dich jubelnd hinzu und vernichte die Zahl. ${ }^{7}$

${ }^{5}$ Wim Wenders, pina. tanzt, tanzt, sonst sind wir verloren. Ein Film für Pina Bausch, Berlin 2011, 1:32:29-1:35:50.

${ }^{6}$ Der Name des Kellners („Winter“), der am Schluss dieses Stücks immer wieder gerufen wird, und der durchaus als Todesbote verstanden werden kann, bestimmt den Schluss des Stückes. Der Ruf nach einer Erlösung von der „Erschöpfung“, nach einem Eintauchen in die Dunkelheit, ins Nichts, ist mit dem Ruf nach dem Kellner so ein Ruf nach dem „Winter", nach dem Tod. Vgl. Thomas Bernhard, Der Ignorant und der Wahnsinnige, Thomas Bernhard. Werke, hg. v. Martin Huber/Wendelin Schmidt-Dengler, Bd. 15, Frankfurt a.M. 2004, 223-328, hier 328.

7 Rainer Maria Rilke, Werke. Kommentierte Ausgabe in vier Bänden (=KA), Bd. 2, hg. v. Manfred Engel u. a., Frankfurt a. M./Leipzig 1996, 263-364. 
Die Sonette an Orpheus sind, so sagt ihr Untertitel, „Geschrieben als ein GrabMal für Wera Ouckama Knoop", eine mit Rilke bekannte Tänzerin, die im Alter von 19 Jahren zuerst beschloss, nicht mehr zu tanzen und wenig später starb. ${ }^{8}$ Wim Wenders, wie Handke ein gründlicher Leser Rilkes, kennt diesen Subtext auch, wenn er einen Film für die mit ihm bekannte und zu früh gestorbene Tänzerin, als ein Requiem gleichsam, dreht. „Ach, ja!“ am Schluss des hier zu verhandelnden Stücks von Peter Handke ist eine Antwort auf die letzte, immer offene Frage.

Dass „Ich-der-Dramatiker“ und „Ich-Erzähler “10 am Ende des Stücks vereint sprechen, ist keine Selbstverständlichkeit. Ja, man könnte sagen es sei gerade der Konflikt dieses Dramas, der Konflikt zwischen „Ich, der Dramatische“ und „Ich, Erzähler" ${ }^{\text {"11 }}$, der sich hier am Ende gelassen löst. Wenn das so ist, dann sehen wir dem inneren Konflikt einer Figur zu, die die Modi ihrer Ausdrucksformen verhandelt. Bei der Erkundung dieses inneren Konfliktes - schreibe ich dramatisch oder episch? - spielt die Seinsweise des Schreibenden eine zentrale Rolle. ${ }^{12}$ Diese wird im Folgenden als eine Seinsweise in Muße herausgearbeitet. Muße zeigt sich so als Freiheit nicht von etwas (zum Beispiel von Arbeit), sondern als Freiheit zu etwas (zum Beispiel zum Schreiben). ${ }^{13}$ Das Sein in Muße, das das Schreiben

8 Vgl. Rainer Maria Rilke, Brief an Gräfin Sizzo vom 12. April 1923, in: Rainer Maria Rilke, Die Briefe an Gräfin Sizzo, hg. v. Ingeborg Schnack, Frankfurt a. M. 1977, $60-61$.

9 Am direktesten nachzuvollziehen ist die gemeinsame Rilke-Lektüre beider Künstler in ihrem gemeinsam konzipierten Film Der Himmel über Berlin, der als eine Interpretation von Rilkes Duineser Elegien gelesen werden kann. Auch eines der beiden Motti des Drehbuchentwurfs stammte aus der achten der Duineser Elegien (vgl. https://handkeonline.onb. ac.at/node/1503, abgerufen am 10.10.2016).

${ }^{10}$ Handke, Die Unschuldigen, 177.

${ }^{11}$ Handke, Die Unschuldigen, 6. Im Personenverzeichnis werden die beiden Teile dieser Sprechinstanz als „Ich, Erzähler" und „Ich, der Dramatische“ angegeben. Die Bezeichnungen variieren durch das Stück leicht. Aber erst auf den letzten Seiten, am Ende des Stücks heißen sie „Ich-der-Dramatiker" und „Ich-Erzähler“. Während „Ich, der Dramatische" auch einfach eine Eigenschaft bezeichnen kann, ist der Dramatiker am Ende geradezu eine Berufsbezeichnung. Und die Verwandlung von Ich, Erzähler zum Ich-Erzähler, einer Instanz, über die die Literaturwissenschaft ganze Regalmeter gefüllt hat, ist eine bewusste Selbstverortung der Sprechinstanz. Wahrscheinlich ist es auch kein Zufall, dass diese Selbstverortung nach dem Auftritt der Unbekannten erfolgt.

12 Den inneren Zusammenhang von Muße und Erzählen zeigt eindrücklich Thomas Klinkert, Muße und Erzählen. Ein poetologischer Zusammenhang, Tübingen 2016.

${ }_{13}$ Muße als „Freiheit zur Sache" ist ein Baustein derjenigen Grundüberlegungen, die den SFB 1015 ins Leben gerufen haben. Siehe Günter Figal, „Muße als Forschungsgegenstand“, in: Muße. Ein Magazin 1, 17-25, hier 20, DOI: 10.6094/musse-magazin/1.2015.17, sowie Burkhard Hasebrink/Thomas Klinkert (Hg.), Muße. Konzepte, Räume, Figuren. Der Freiburger Sonderforschungsbereich 1015 im Überblick, Freiburg 2014. Die Überlegungen im hier vorgetragenen Aufsatz ruhen auf dem dort entwickelten Muße-Begriff auf. 
ermöglicht, ist an die Raumerfahrung des Schreibenden gebunden. ${ }^{14}$ Die Erfahrung von Zeitlosigkeit und Ziellosigkeit macht erst die Erfahrung des Raumes als Raum möglich. Die ,Landstraße', der ,Königsfleck' der hier vorgestellten Figur, ist ein Ort der Möglichkeiten zum Schreiben und so ein Muße-Ort. Dieser Ort „bestimmter Unbestimmtheit"15 wird gegen die Welt des modernen, zielgerichteten, am Smartphone hängenden homo digitalis profiliert. Muße und Moderne scheinen so ein Gegensatzpaar zu sein, das sich allerdings gegenseitig bedingt. Der geschriebene Muße-Ort des Schreiben-Könnens gewinnt sein Profil gerade inmitten der und gegen die (hier) technisiert und vor allem digitalisiert verstandenen Moderne. Es ist dieser Bedingungszusammenhang von Muße und Moderne, der die Spannungen, die Uneindeutigkeiten und schließlich die Eindeutigkeiten im hier verhandelten Text ausmacht.

So scheinbar unentschlossen die doppelt konnotierte Sprechinstanz des Stücks sich gibt, so scheinbar verwirrt werden hier die Gattungsbezeichnungen. Für einen Text eines Autors, der wieder und wieder als ein Repräsentant des "postdramatischen Theaters" angesprochen wird, habe ich einfach einmal die Bezeichnung Schauspiel, einmal Stück und einmal Drama verwendet, gar von einem „dramatischen Konflikt" gesprochen. Und das mit Absicht. Man gerät wahrlich auf Glatteis, wenn man sich diesem Handke-Text überlässt und denkt, man läse ein Drama. Es heißt ja auch Schauspiel, könnte man sagen, vergessen wir doch das Drama (das es ja seit ungefähr 1967 ohnehin nicht mehr geben soll). ${ }^{16}$ Allein, so einfach ist es nicht.

Halten wir uns, um das Verwirrspiel zu verstehen, an den Text. Handke hat ihn im Untertitel „Schauspiel in vier Jahreszeiten“ genannt. Ein Schauspiel bezeichnet jedwede öffentliche Aufführung zur Unterhaltung des Publikums oder aber „die aufführung eines „dramatischen gedichts“. ${ }^{17}$ Etwas näher wird Schauspiel als „zusammenfassender ausdruck für die ganze gattung, gleichbedeutend mit drama, und trauerspiel wie lustspiel einschlieszend" gebraucht. ${ }^{18}$ Wie Grimms Wörterbuch im Anschluss an Schiller außerdem festhält, ist Schauspiel auch als ein ausweichender Begriff im Spiel: also dann, wenn nicht klar ist, ob es sich um eine Tragödie oder um eine Komödie handelt, wird Schauspiel zur Bezeichnung einer „mittelgattung“ verwendet. ${ }^{19}$ Ein Schauspiel

14 Günter Figal spricht von „räumliche[m] Sein als Sein in Muße“, siehe seinen Beitrag in diesem Band.

15 Günter Figal, „Muße als räumliche Freiheit“, in: Hasebrink/Klinkert (Hg.), Muße. Konzepte, Räume, Figuren, 13.

16 Vgl. zum Beispiel Hanna Klessinger, Postdramatik. Transformationen des epischen Theaters bei Peter Handke, Heiner Müller, Elfriede Jelinek und Rainald Goetz, Berlin/Boston 2015, 3-4.

17 Jacob und Wilhelm Grimm, Art. „Schauspiel“, in: Deutsches Wörterbuch (=DWB), Bd. 14, Sp. 2375-2376, Sp. 2375.

18 Jacob/Wilhelm Grimm, Art. „Schauspiel“, Sp. 2375.

19 Jacob/Wilhelm Grimm, Art. „Schauspiel“, Sp. 2375. 
bietet sich außerdem den Augen ganz allgemein dar, wenn etwas Bemerkenswertes vor denselben vor sich geht und schließlich ist die Redensart gebräuchlich, dass sich jemand in den Augen der anderen durch ungeziemliches Verhalten „zum Schauspiel“ macht. ${ }^{20}$

Zum Schauspiel macht sich in Die Unschuldigen, ich und die Unbekannte am Rand der Landstraße nicht nur einer: Die Figuren dieses Stückes spielen sich gleichsam gegenseitig etwas vor und werden gegenseitig zu ihren jeweiligen Zuschauern. Am bemerkenswertesten ist in dieser Hinsicht wohl die Gegenüberstellung zweier „Ichs“, eben, „Ich, der dramatische“ und „Ich, Erzähler“, zwei Aspekte einer Instanz, die, im Wandel zwischen Dramatiker und Erzähler, mal Drama und mal Erzählung vorlegt und am Ende nur noch eine Stimme hat. Zwei Seelen in einer Brust, die am Ende als „Brustton (nicht dem der Überzeugung)“21 laut werden. Eine Mittelgattung ist dieses Stück allemal. Und zwar nicht nur im Zwischen zwischen Tragödie und Komödie, sondern im Zwischen eben auch zwischen Drama und Epos. Und eine Aufführung schließlich ist dieses Stück in vielerlei Hinsicht. Die Performanz des Erzählens und Dramatisierens wird im Text selbst performativ vollzogen, so dass, wenn man sie nicht hat, die Bühne auch ohne Bühne da ist, wie oft bei Handke, als eine erzählte Szene. ${ }^{22}$

Ein Schauspiel also ist das Stück, nicht anders als es der Untertitel verspricht. „Ein Schauspiel in vier“ - Akten, könnte man meinen, wenn man beginnt den Untertitel zu lesen, aber nein, es heißt: „Schauspiel in vier Jahreszeiten“. Wir Leser werden schon auf der Titelseite mit Handkes Hakenschlagen, einer von Wolfram abgeschauten poetischen Technik ${ }^{23}$, bekanntgemacht: Das Bekannte wird, einmal mehr, einmal weniger merklich, abgebogen hin zum Unbekannten. Ein Schauspiel in vier Jahreszeiten war bis dato nicht geschrieben worden. Oder vielleicht doch?

Zu Beginn von Wim Wenders Film pina sieht man zuerst die leere Bühne und hört erst eine Stimme, dann sieht man eine Tänzerin sprechend allein auf der Bühne, bekleidet mit Pums und einer windelartigen Unterhose, eine Ziehharmonika umgehängt. Die Tänzerin spricht, und zwar den folgenden Text:

20 Vgl. Jacob/Wilhelm Grimm, Art. „Schauspiel“, $2375 \mathrm{f}$.

${ }^{21}$ Handke, Die Unschuldigen, 175.

22 Vgl. etwa Über die Dörfer oder Immer noch Sturm. Schon mit den stummen Stücken schlug Handke dem Regie-Theater ein Schnippchen, indem er so genau und gut erzählt, was auf der Bühne vor sich geht, dass jede Inszenierung mit dieser Genauigkeit des Erzählten zumindest in Konkurrenz tritt. Vgl. dazu auch Klessinger, Postdramatik, 195-197 und 204-207.

${ }^{23}$ Vgl. Wolfram von Eschenbach, Parzival, vv. I, 15-19. Wolfram von Eschenbach, Parzival, nach der Ausgabe Karl Lachmanns revidiert u. kommentiert v. Eberhard Nellmann, übertragen v. Dieter Kühn, Frankfurt a. M. 1994, 10. 


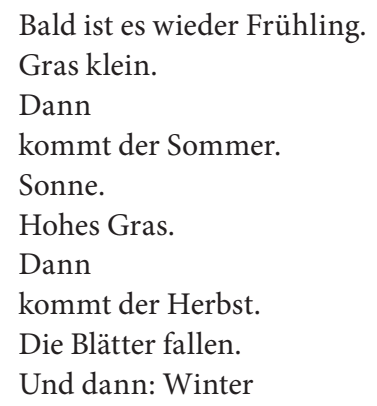

Die Sätze sind jeweils mit sehr einfachen Gesten aus der Sprache zugleich in den Tanz überführt. Das kleine Gras wird mit Daumen und Zeigefinger am so weit wie möglich nach unten gestreckten Arm gezeigt, das hohe Gras mit beiden nach oben gereckten aber abgewinkelten Armen und schalenartig geöffneten Händen, die dazugehörige Sonne durch eine Geste, die Daumen und Zeigefinger zu einer angedeuteten Kugel sich runden lassen. Die fallenden Blätter bilden sich aus dieser Sonnengeste, Daumen und Zeigefinger nähern sich einander an und die dadurch entstehende flache Öffnung deutet die Schmalform von trockenen Blättern an. Der Winter wird durch die mit geschlossenen Fäusten vor der Brust, das heißt, vor der Ziehharmonika, parallelgeführten, zitternden Arme tänzerisch umgesetzt. Während Frühling, Sommer und Herbst jeweils ein Attribut mit sich führen (kleines Gras, hohes Gras und Sonne, fallende Blätter), stehen das Wort und die Geste Winter am Ende dieser Jahreszeitenreihe allein, und die Geste zeigt nichts als winterliche Kälte. Diese Geste wird allerdings von einem strahlenden Lächeln begleitet - als gäbe es nichts Schöneres auf der Welt als Winterkälte, die einen Frieren macht. Kommt das erste Wort „Frühling“ aus dem Off über die scheinbar leere Bühne (der Spot ist auf die Hinterbühne gerichtet, während die Tänzerin vorn im Dunkeln steht), so ist nach dem Wort „Winter" nicht etwa Schluss, sondern der Lauf der Jahreszeiten beginnt von Neuem: Frühling, Sommer, Herbst, Winter, jeweils begleitet durch die oben beschriebenen sparsamen und klaren Gesten, werden von der Tänzerin wiederholt, dazu stellt sich erst leise, dann lauter werdende Musik ein, und das ganze Wuppertaler Tanztheater, Bauschs Truppe, findet sich zur Polonaise auf der Bühne ein. Hintereinander schreitend, immer die Gesten von Frühling, Sommer, Herbst und Winter synchronisiert wiederholend, schreitet die Truppe auf der normalgroßen Bühne einen scheinbar unendlichen Raum aus. Anfang und Ende dieser zyklischen Wiederkehr der Jahreszeiten sind nach einer Weile nicht mehr auszumachen. Auf den Winter folgt der Frühling, auf den Frühling der Sommer, auf den Sommer der Herbst, auf den Herbst der Winter und auf den Winter der Frühling und so weiter. Wie am Ende des Films kein Ende gefunden werden will, so kommt auch der Anfang wie aus dem Nichts, der Vorspann schon zeigt - „neue roadmovies" - eine (Land?)Straße und das nächtliche Wuppertal, die scheinbar leere 
Bühne und dann die schon gestorbene Tänzerin auf einem Portrait, dessen Lider sich plötzlich bewegen, als wäre das Bild lebendig und dann die Tänzerin, die aus der Dunkelheit heraus erst spricht und dann mit den sparsamsten Gesten ein ganzes Schauspiel in vier Jahreszeiten aufführt. ${ }^{24}$

Für Handkes „Schauspiel in vier Jahreszeiten“ mag es wohl dies Vorbild gegeben haben, und es ist nicht ohne Grund, dass er Schauspiel mit seiner weiten Bedeutung als „Gattungsbezeichnung“ gewählt hat. Schon beim Personenverzeichnis aber kommt das Drama ins Spiel. Die hier aufgelisteten Figuren sind „Ich“, „Die Unschuldigen“, „mein Doppelgänger“, „Der Wortführer der Unschuldigen oder: Häuptling/Capo“, „Die Wortführerin der Unschuldigen oder: Häuptlingsfrau/Häuptlingin/Frau“ und „Die Unbekannte von der Landstraße“ ${ }^{25}$ Die Figur „Ich““ ist zwiefach konzipiert, wie es heißt, „im Wechsel zwischen, ,Ich, Erzähler' und ,Ich, der Dramatische', noch dazu „nicht immer unterschieden; zeitweise beide in einem)“. ${ }^{26}$ „Ich, der Dramatische“ und „Ich, Erzähler“ sind die widerstreitenden und am Ende versöhnten zwei Stimmen in diesem Text. Wie diese beiden Figuren, so sind Epos und Drama im Text manchmal klar voneinander zu unterscheiden und manchmal fast untrennbar ineinander verschlungen. Im Text selbst ist mehrfach explizit vom Drama die Rede: Es handele sich hier, so „Ich, der dramatische“, um das „Epos ohne Krieg, das Drama ohne Intrige“.27 Für die „Zeit dieses Dramas“ gelte das „andere Ich“28, über Art und Sinn von Monolog und Dialog wird trefflich gestritten. Schließlich heißt es gar: „Das Drama, es lebe.“ Diesen Satz spricht - naturgemäß, ist man versucht zu sagen - „Ich-der-Dramatiker“ und zwar, „im Zickzacklauf, wie einen Fluchtweg suchend“ und „mit Kopfstimme“: „Um so besser so. Drama und Streit. Entzweiung tut not. Nicht Krieg, sondern Streit ist der Vater aller Dinge. Der epische Schritt versichert: meinetwegen. Der Dramatische Schritt verunsichert: recht so! Das Drama, es lebe. " ${ }^{29}$ Hier spricht die eine Hälfte dieses Ich, mit Kopfstimme und lobt den Streit - die andere Hälfte dieses Ich, die epische Hälfte, wird gleich einfallen, „mit dem eher leisen Brustton der Erzählerstimme“ ${ }^{30}$ Dieser Streit geht noch eine Weile weiter, wird immer sanfter, bekennt sich zur Aporie, zu einem Nichtschluss, um am Ende, eben in der Mittellage, mit einer Stimme zu „singen“31. Das Drama als Gattung des Streites wird hier inszeniert, um den inneren

24 Wenders, pina, 0:00-2:37. Thomas Bernhards Der Ignorant und der Wahnsinnige ist nicht zuletzt durch den so genannten Notlichtskandal berühmt geworden. Die stockdunkle Bühne am Schluss des Stücks, die das Ende der Kunst und des Lebens für die Augen sinnfällig machen soll, wird hier bei Wenders als ein Anfang für neue Kunst umgedeutet.

25 Handke, Die Unschuldigen, 6.

26 Handke, Die Unschuldigen, 6.

27 Handke, Die Unschuldigen, 14.

28 Handke, Die Unschuldigen, 21.

29 Handke, Die Unschuldigen, 173.

30 Handke, Die Unschuldigen, 173.

31 Handke, Die Unschuldigen, 177. 
Streit zwischen Erzähler und Dramatiker in dem sich hier zur Aufführung bringenden Ich auszutragen und, eben, in der „Aporie“32 zu versöhnen - das ist die Voraussetzung für das Buch, das noch keiner je geschrieben hat.

Also, dieses Schauspiel ist auch ein Drama mitten in postdramatischen Zeiten. Was ist ein Drama? Diese, von Handke wieder und wieder gestellte Frage stellt er auch mit diesem Stück wieder. Auf diese Weise macht er Begriffe, zum Beispiel den des Dramas aber auch den des Stücks, des Schauspiels, nicht zuletzt den des postdramatischen Theaters, unsicher. Niemand hat so viele vorher nie dagewesene Formen auf die Bühne gestellt. Das Sprechstück, das Stumme Stück, die Beschimpfung, das Schauspiel in vier Jahreszeiten, alle sie sind Erfindungen Handkes. Mit diesem Projekt steht er nicht allein, sondern in einer Tradition. Schon Lessing und Schiller wichen von allzu klaren Gattungsbezeichnungen ab, indem sie ein Stück zum Beispiel „dramatisches Gedicht" nannten, eine Gattungsbezeichnung, die Handke für Über die Dörfer aufnimmt.

Aber, wie versprochen, wir sind auf dem Glatteis. Denn gibt es überhaupt diese klare Unterscheidung zwischen der dramatischen und der epischen Gattung? Haben wir nicht von Kleist gelernt, wie nah Drama und Erzählung sich sind? ${ }^{33}$ Und reden wir nicht seit Brecht vom epischen Theater, vom Drama also mit all seinen eingebauten Erzählerfiguren? Handke nimmt diese Traditionslinien auf und verhandelt sie neu und zwar unter den Bedingungen seines, aus der Muße kommenden Schreibens, inmitten unserer, gegenwärtigen Moderne. Nur wie?

Ich könnte jetzt versuchen, die „Handlung“ des Stücks kurz „nachzuerzählen": und schon gerät alles wieder ins Rutschen, achten wir einmal auf unseren Sprachgebrauch: wir erzählen für gewöhnlich den Inhalt eines Dramas als Handlung nach. Wenn wir die Verhältnisse umdrehen, haben wir ungefähr, was Handke macht: er erzählt uns nämlich die Handlung eines Dramas oder eines Fast-Dramas vor. So kommt Episches zur Aufführung. Das beginnt in gewissem Sinne schon mit dem Personenverzeichnis, das ausschweifenden Nebentext aufweist und es geht weiter, indem das, was wir normalerweise Nebentext nennen, ein genuiner Bestandteil des Stücks ist, nämlich „Ich, Erzähler" erzählt uns die Szene vor und mehr noch, es erzählt uns vor, wie es zum Vorerzählen der Szene kommt:

Kommen lassen. Anfliegen lassen. Träumen lassen. Hellträumen. Umfassend träumen. Verbindlich! Freiträumen. Wen? Mich? Uns? Traumtanzen lassen. Gestalten lassen. Umgestalten lassen. Aufeinandertreffen lassen. Wen mit wem aufeinandertreffen lassen? Wen gegen wen? Kommen lassen erst einmal die Szenerie: Und da kommt sie, da erscheint, sie, da fliegt sie mich an, da erstreckt sie sich, die Landstraße, vorderhand leer.

32 Handke, Die Unschuldigen, 177.

33 Jochen Schmidt, Heinrich von Kleist. Die Dramen und Erzählungen in ihrer Epoche, Darmstadt 2003, 180-296, 180-182. 
Und indem ich mir das laut vorerzähle, ist die Straße auch schon bevölkert mit mir, der ICH am Rand der Straße daherschlendere mit ausgreifenden, epischen Schritten, vorderhand allein. ${ }^{34}$

Die Situation, in der die erzählte Szenerie „erscheint“, ist durch ein Wort dominiert, nämlich „lassen“. Hier wird suggeriert, dass nicht etwas gemacht, sondern eben etwas gelassen wird. Im Hinterkopf sollte man hier behalten, dass am Ende des Textes, im Winter, eben jene inspiratorische Situation beschrieben wird, mit dem der Text hier, im Frühling, beginnt. ${ }^{35}$ Aus der Offenheit des Träumens - Wachträumens - heraus entsteht die Szene, dann entstehen die Figuren, dann entsteht der Konflikt, das Drama, die Handlung, und das Wiederausklingen des Ganzen in einen unbestimmten Raum der Inspiration, aus dem alles, wie organisch, entwachsen ist und in den alles, wie organisch, wieder eingeht. Das erste und das letzte Wort hat der „Träumer“, in seinem Wachtraum. Dies ernst genommen, erklärt sich auch der Ablauf der erzählten „Handlung“ in „Jahreszeiten“ - wie unversehens und wie seit Urzeiten ist Frühling, Sommer, Herbst und Winter, das performative Kein-Ende-Finden impliziert am Winterende auch schon wieder den neuen Frühling und so immer weiter wird ein Raum des Lebens ausgeschritten - mit epischem Schritt und im dramatischen Traumtanz -, dessen Zeitordnung nicht nach der „Uhr“, sondern nach dem „Ur“ gemessen wird. Ewige Wiederkunft des Vertrauten, nicht des Gleichen, an der immer gleichen Stelle, am „Rand der Landstraße“:

Ja, dem großen Bogen! Aufrauschen der Sommerbäume, Rauschen des Sommers. Anbrausen der Herbstbäume, Brausen des Herbstes, Ansausen der Winterbäume, Sausen des Winters. Die summende Luft über der Straße, wie über Prosperos Insel. - Der Weg ist das Ziel: Blödsinn. Herrliche Weglosigkeit, endlich. ${ }^{36}$

Vor Pina Bauschs letztem Solo in Wenders Film, in dem sie wie zum Abschied winkt, tritt wieder das ganze Ensemble mit der Jahreszeitenparade auf, die am Anfang des Films gezeigt wird. Diesmal nicht auf einer Bühne sondern in einem Steinbruch, am Rand eines großen Kraters, im deutlich zu hörenden Wind. Für nichts und ohne Ziel feiert die Truppe Frühling, Sommer, Herbst und Winter in ihrer ewigen Wiederkehr, mitten in der durch Rohstoffabbau zerstörten Natur, vorbei an aufgestellten Skulpturen, bedeutungslos und schön. ${ }^{37}$ Diese Jahreszeitenpromenade vom Anfang taucht hier am Ende des Films wieder auf und

34 Handke, Die Unschuldigen, 7.

35 Diese zyklische Struktur von inspiratio und ihrem Resultat hat Friedrich Hölderlin im Hyperion angewandt und sie kommt in Rilkes Malte, einem weiteren Subtext für das Handke-Stück, von dem im Folgenden noch die Rede sein wird, wieder vor. Zum Hyperion s. Jochen Schmidt, Hyperion. Konzeption und Struktur, in: Friedrich Hölderlin, Sämtliche Werke und Briefe in drei Bänden, Bd.2, hg. v. Jochen Schmidt, Frankfurt a.M. 1994, 940-965, 941.

36 Handke, Die Unschuldigen, 140.

37 Wenders, pina, 1:31-1:32:25. 
sie wird in der Mitte des Films, auf der Terrasse des Wuppertaler Opernhauses, gezeigt. Diese Jahreszeitenpromenade strukturiert Wenders Film als Leitmotiv und gibt dem Film, gut aristotelisch, Anfang, Mitte und Schluss. ${ }^{38}$

Abgesehen von den das Stück wie den Film strukturierenden Jahreszeiten, mag eine Parallele zwischen Film und Stück in den vielen Anklängen an den Tanz und das Tänzerische in Handkes Stück gesehen werden. Dem Epischen und dem Dramatischen ordnet Handke „Schritte“ zu. So unterscheidet er den „epischen Schritt“ ${ }^{\prime 39}$ und den „dramatischen Schritt" ${ }^{40}$, wobei letzterer auch nicht selten „Tanz “41 heißt und in den für das Stück schon emblematisch gewordenen Veitstanz übergeht. ${ }^{42}$ Diese Gegenüberstellung findet sich auch in Wenders' Film. Denn einige Minuten vor der oben beschriebenen Jahreszeitenschlusspromenade führt ein einzelner Tänzer am Rand des nämlichen Steinbruchs, der in dieser Szene manchmal auch aussieht wie eine Landstraße, einen ekstatischen Tanz auf, der mit der latenten Absturzgefahr in den Abgrund spielt und den Tänzer zugleich an den Rand seiner Drehkräfte bringt. ${ }^{43}$

Bei Handke ist es ist das Epische, das in diesem "Schauspiel“ eine Urzeit vertritt und das in der Erzählung entstehende „Drama“, mit seiner eigenen, nur für es gültigen Zeit, planmäßig stört:

Ich übe den epischen Schritt. Denn das Drama droht. Habe ich was gegen das Drama? Möchte ich es vermeiden? O nein. Das Drama muß sein. Das Drama hat stattzufinden. Ohne Drama kein Blauen des Blau, kein Grünen des Grün, kein Grauen des Grau, kein Schimmern der Nacht. Aber das Drama jetzt, das Drama hier, es droht so rein wie kleinklein nach den Gesetzen der Physik sich abzuspielen, Stoß, Gegenstoß, Schlag, Rückschlag, Wort, Widerwort. Nach den Gesetzen der Physik, und nach denen der Ökonomie [...]. Habe ich was gegen Physik und Wirtschaft? O nein. Oder nur, wenn in das Drama kein anderes Gesetz hineinspielt. Im Epischen sehe ich das andere Gesetz. Oder so: es weht mich an. Herbst und Epos. [...] ein Hauch in dem und dem dramatischen Moment, ein Anhauch. ${ }^{44}$

38 Aristoteles, Poetik, 1450b, 26-27.

39 Handke, Die Unschuldigen, 7, 102 und öfter.

40 Handke, Die Unschuldigen, 173.

41 Vgl. zum Beispiel Handke, Die Unschuldigen, 22.

42 Handke, Die Unschuldigen, 21-23. Anke Dürr hebt in ihrer Kritik der Uraufführung unter dem Titel „Rumpelstilzchens Raserei“ das ,wütende Rumpelstilzchen' hervor (http://www.spiegel.de/kultur/gesellschaft/handke-urauffuehrung-am-wiener-burg theater-a-1079712.html, zuletzt abgerufen am 05.10.2016) und auch Hubert Spiegel untertitelt das seine Kritik begleitende Bild in der FAZ mit „Selbstbewusstes Rumpelstilzchen des Selbsthasses“ (http://www.faz.net/aktuell/feuilleton/buehne-und-konzert/claus-pey mann-inszeniert-handke-am-burgtheater-in-wien-14095725.html, zuletzt abgerufen am 05.10.2016).

43 Wenders, pina, 1:22:09-1:23:30.

44 Handke, Die Unschuldigen, 102. 
Das hier sprechende Ich verwendet ohne alle Umschweife und scheinbar ganz ohne Ironie oder Brechung eine alte Sprache der Inspiration: Zum Traum, der am Beginn des Stücks ausgestaltet ist, kommen hier „Wind“, „Hauch“ und „Anhauch" als Schlagworte der Inspiration, die zugleich in ihrer hier spezifischen Verwendung wieder ein überdeutliches Rilke-Zitat sind. Handke nimmt fast wörtlich zwei der Sonette an Orpheus auf und vermischt sie, wenn er schreibt: „ein Hauch in dem und dem dramatischen Moment“ ${ }^{45}$ „In Wahrheit singen, ist ein andrer Hauch./Ein Hauch um Nichts. Ein Wehn im Gott. Ein Wind“, heißt es in Sonette an Orpheus I, $3^{46}$ und „Denn Orpheus ists. Seine Metamorphose/ in dem und dem“ in Sonette an Orpheus I, 5. ${ }^{47}$ Das Sonett I, 3 macht auch Martin Heidegger in seinem Aufsatz über Rilke für die Interpretation von Rilkes Gedicht Wie die Natur die Wesen überlässt fruchtbar. ${ }^{48}$ Dieses Gedicht wiederum zitiert Handke, durchaus durch die Brille der Heideggerschen Interpretation $^{49}$, im nämlichen Abschnitt, wenn er vom „anderen Gesetz“ das ihn „anweht" spricht.

Wie die Natur die Wesen überläßt
dem Wagnis ihrer dumpfen Lust und keins
besonders schützt in Scholle und Geäst:
so sind auch wir dem Urgrund unseres Seins
nicht weiter lieb; er wagt uns. Nur daß wir,
mehr noch als Pflanze oder Tier,
mit diesem Wagnis gehn; es wollen; manchmal auch
wagender sind (und nicht aus Eigennutz)
als selbst das Leben ist - , um einen Hauch
wagender... Dies schafft uns, außerhalb von Schutz,
ein Sichersein, dort wo die Schwerkraft wirkt
der reinen Kräfte; was uns schließlich birgt
ist unser Schutzlossein und daß wir's so
in's Offne wandten, da wir's drohen sahen,
um es, im weitsten Umkreis, irgendwo,
wo das Gesetz uns anrührt, zu bejahen. ${ }^{50}$

45 Handke, Die Unschuldigen, 102.

46 Rilke, Die Sonette an Orpheus, KA Bd. 2, 242.

47 Rilke, Die Sonette an Orpheus, KA Bd. 2, 243.

48 Martin Heidegger, Wozu Dichter? In: Holzwege, Frankfurt a. M. 1972, 248-295, $292-$ 293.

49 Heidegger macht in seinem Aufsatz darauf aufmerksam, dass Rilke hier nicht von „einem Gesetz“, sondern von „dem Gesetz“ spricht. Daraus wird bei Handke „das andere Gesetz".

${ }^{50}$ Rilke, Wie die Natur, KA Bd. 2, 324. 
Wenn schließlich später im Stück, im Winter, gar noch vom „Diktat“ die Rede ist, so spielt Handke zwar allgemein auf das Diktat als Metapher für die Inspiration an, aber auch speziell auf Rilkes Inspirations-Diktion, die er in zahlreichen Briefen über den Winter 1922, in dem die Sonette an Orpheus und die Duineser Elegien entstanden sind, an den Tag legt. Besonders ausgeprägt ist dabei die Metapher des Sturms als eines gewissermaßen verstärkten „Anhauchs“ künstlerischer Inspiration. ${ }^{51}$

Handke wäre aber nicht Handke, wenn er all dies zitierte und nicht ironisch oder halbironisch, ein wenig wehmütig auch, bräche:

Vor lauter Freiheiten kein Wind, kein Sturm, kein Ansturm einer Freiheit. [...] Was mich betrifft, hier an der Landstraße: nicht frei sein. Nie wieder frei sein. Ewig hier dem Ort und der Stelle verpflichtet bleiben. Zu Diensten sein! Knecht sein, wie meine Vorfahren. Endlos hier eingespannt sein, ins Umreißen, Umrunden, Ornamentieren. Hier, nur hier noch!, wird mir das Buch diktiert, und nicht allein meines, und nicht allein mir. Und hier auch mich pflichtgemäß treiben lassen, streunen, stromern, strawanzen. ${ }^{52}$

Der „Königsfleck“, wie die „Landstraße“ in diesem Zusammenhang auch genannt wird, ist ein Ort der Muße: Das Ich gefällt sich im Betrachten (von Wolken zum Beispiel), im Angehauchtwerden von inspiratorischem Geist, im ziellosen, ja, weglosen Dasein, im ,Streunen' und ,Strawanzen', in müßiger Erwartung des Buchs, das ihm in den Schoß fallen wird, aufgrund müßiger Dienstbarkeit.

„Der Sohn bleibt am Rand der Straße bis in die Äonen“"53, zitiert das Ich das Neue Testament und legitimiert seinen Ort so aus den alten Schriften. Dazu passt auch die Parzival-Figuration, die in mehrfacher Schichtung, mal offensichtlicher, mal mehr versteckt, den Text durchzieht. Die Anspielungen werden aber, getreu der Technik, das Bekannte ins Unbekannte zu lenken, auch hier abgelenkt. So zieht „Parzival [...] über die Landstraße, nicht der Gralsburg entgegen, nicht dem Kampf entgegen, er zieht bloß dahin, und zieht". ${ }^{54}$ Parzival steht für den erfolglos Suchenden, Umherirrenden, für den sein Ziel aufgrund des gezielten Suchens beständig Verfehlenden. Parzival plus Muße nimmt dem Weg sein Ziel und dem Weg noch seinen Wegcharakter und verbleibt so in der reinen Möglichkeit des Schreibenkönnens: „Spiralen von tausend und abertausend gespitzten

51 Rilke, Brief an Gräfin Sizzo vom 12. April 1923, in: Rainer Maria Rilke, Briefe an Gräfin Sizzo. 1921-1926, hg. v. Ingeborg Schnack, Frankfurt a. M. 1977, 56-64, hier 60; Rilke, Brief an Anton Kippenberg vom 9. Februar 1922, in: Rainer Maria Rilke, Briefwechsel mit Anton Kippenberg, hg. v. Ingeborg Schnack/Renate Scharffenberg, Frankfurt a.M./Leipzig $1995,255-256$.

52 Handke, Die Unschuldigen, 134. Es zeigt sich hier die „Freiheit zur Sache“ (Figal, „Muße als Forschungsgegenstand“, 20), die aus der Muße kommt, die gerade nicht willensbestimmt ist, sondern sich, sich selbst vergessend, ganz einer Sache und der aus dieser sich ergebenden Arbeit hingibt.

53 Handke, Die Unschuldigen, 126.

54 Handke, Die Unschuldigen, 102. 
Bleistiften, die im Spätherbstwind über die Landstraße trudeln“ " 55 Ziellosigkeit und Weglosigkeit, einfach da sein im Möglichkeitsmodus, die Zeit vergessend, das ist Muße-Haben:

Es lebe das Unnütze, wenn es nur Ornament wird! Ornament um Ornament, Seitenzweig um Seitenzweig! [...] Und nirgends habe ich mich näher an der Gotteswelt gespürt als bei nutzlosen Tätigkeiten, wie beim Auf- und Abgehen hier am Straßenrand - so wie auch du, Mutter, beim Sticken, nicht wahr? - nie näher an euch, nie näher an der Schöpfung - nie ferner von all der Kreativität, all den Kreativen, all den Kreationen. Schöpfung, Böschung: Was für schöne Wörter. Straßengraben: weniger schön. Und was sehe ich jetzt, ihr Lieben?: Unsere Straße als Meridian, in der Länge und in der Breite. Der Meridian des Abglanzes. Der Schimmer-Meridian. Der Mittagskreis! Ich selber der Meridian. Anmaßung? Recht so: unsere tägliche Schuld gib uns heute. ${ }^{56}$

Wieder wird geradezu provozierend eindeutig eine Sphäre der Inspiration beschworen: die Ganzheit des Mittagskreises assoziiert auch die panische Mittagsstunde, in der die Zeit still zu stehen scheint, der schöpferische Mensch - der hier etwas ganz etwas anderes sein will als „kreativ“ - macht sich selbst zu diesem weltumspannenden, geographischen Zeichen, zum Mittelpunkt auch, seiner Welt. Damit lädt er Schuld auf sich. Und das ist es, was ihn von den Unschuldigen, gegen die er sich positioniert, unterscheidet. Er erfindet, mitten in der Welt, eine eigene Welt. Das ist es, was die Unschuldigen von ihm trennt, das ist es paradoxerweise aber auch, was sie mit ihm verbindet. Um dieses Paradox zu verstehen, stelle ich im Folgenden die Perspektive um. Habe ich bis jetzt den Blick des „Ich“ auf die Welt und auf seine eigene Position in ihr nachvollzogen, so kommt jetzt der Blick der anderen, eben der Unschuldigen, auf dieses Ich zur Sprache.

Die poetische Sphäre der Muße, der Freiraum des Schreibens, vom Schreiber in ihrer Unbedingtheit als Provokation angelegt, verfehlt die Wirkung auf die „anderen“ die „Unschuldigen“ nicht - die Unschuldigen sind die blasse Folie der „echten“ Welt mit Mobiltelefonen und künstlicher Intelligenz, ja, mit Unsterblichkeit ausgestattet, vor der sich die inspiratorische Situation schärft. ${ }^{57}$ Und so müssen diese unschuldigen Figuren auf das kompromisslose Autoren-Ich gereizt reagieren. Was aus der Sicht des (Erzähler)-Ichs als ein Leben in Muße als Bedingung zum Schreiben erscheint, sieht in den Augen der „Unschuldigen“ eher nach

${ }^{55}$ Handke, Die Unschuldigen, 130.

${ }^{56}$ Handke, Die Unschuldigen, 131. Handke ruft hier Topoi des Flaneurs auf, die in den Beiträgen von Kerstin Fest, Robert Krause, Heidi Liedke und Peter Philipp Riedl in diesem Band zitiert und besprochen werden. Zum dort auch besprochenen Zusammenhang von Muße und Gehen siehe außerdem Antonia Egel, „Muße im Gehen. Handke, Stifter, Thomas Mann“, in: Günter Figal/Hans W. Hubert/Thomas Klinkert (Hg.), Die Raumzeitlichkeit der Muße, Tübingen 2016, 109-135.

57 Peter Philipp Riedl beschreibt in seinem Beitrag zu diesem Band ebenfalls die inszenierte Provokation des langsamen Gehens inmitten großstädtischen Getriebes. Siehe auch Günter Figals Beitrag in diesem Band, der diese Struktur an Henry David Thoreaus Walden aufzeigt. 
Nutzlosigkeit und Müßiggang aus. Aber noch in der pejorativ vorgebrachten Abwehr dieser Lebenshaltung kommt, gleichsam in der Parodie, für die Muße Charakteristisches zum Vorschein.

In den Augen der anderen - es ist kein Zufall, dass es „Die Frau“ ist, die die Vorwürfe vorbringt, denn das „Drama“, der Konflikt bahnt sich in Handkes Texten dann doch wieder und wieder als der „klassische“ Konflikt zwischen Mann und Frau an - in den Augen der anderen ist das sich zur Tätigkeit in Muße be-

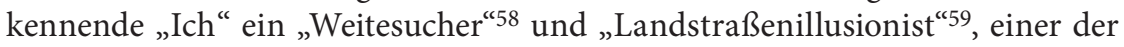
„in den verschwundenen Kornfeldern tapert nach der letzten Kornblume“ 60 (man darf und soll hier natürlich die Anspielung auf den unbelehrbaren Romantiker, der die „blaue Blume“ sucht, erkennen), einer, der der "Sucht nach Stille“61 krankhaft verfallen ist, einer der nervt: „Du mit deiner Urzeit statt unserer Uhrzeit“, einer der stört: „Warum ist so jemand nicht ungeboren und wir Unschuldigen bleiben ungeschoren?" ${ }^{2} 2$ Der Mußehabende steht in das Gleichmaß der Unschuldigen hinein - seine Art, die Welt zu betrachten, ist für die Unschuldigen ganz offensichtlich eine abzuwehrende Gefahr. Er ist der „Idiot“ (Parzival) ${ }^{63}$, der Narr, der den anderen den Spiegel vorhält. Einer mit einer anders eingestellten Aufmerksamkeit:

Er könnte der Idiot sein, den wir hier an der Landstraße zeitweise nötig haben. Einmal hat ihm der Wind ein Hemd von der Wäscheleine in den Dreck geweht, und er hat das Hemd aufgehoben und es lange gestreichelt und gesagt: „Armes Hemd!“. Ein andermal habe ich ihn beobachtet, wie er hier auf der Landstraße einen Stein aufgehoben, ihn an die Lippen gedrückt und ihn angeredet hat mit: „Geliebtes Kind!“ Und wieder ein andermal ist er im Obstgarten nebenan im Zickzack von Apfelbaum zu Apfelbaum gegangen und hat die Äpfel an den untersten Zweigen zum Schaukeln gebracht, nicht mit der Hand, mit der Stirn! - Stirn gegen Apfel, Apfel gegen Stirn. In Betrachtung eines Rotkehlchens bekommt er einen roten Latz, in Betrachtung einer Eule werden seine Augen rund und gelb, zur Blindschleiche sagt er: „Schleich dich sehend!“ [...] Und immer wieder habe ich ihn beobachtet, wie er sich bei einem Ding, wenn ihm daran ein Mißgeschick passiert ist, entschuldigt hat: Er stößt einen Stuhl um: „Entschuldigung, Stuhl!" Eine Türklinke rutscht ihm aus der Hand, und die Tür knallt zu: „Verzeihung! Pardon! Al-Chofu! ${ }^{64}$

58 Handke, Die Unschuldigen, 144.

59 Handke, Die Unschuldigen, 144.

60 Handke, Die Unschuldigen, 94.

61 Handke, Die Unschuldigen, 86.

62 Handke, Die Unschuldigen, 95. In der Muße verliert die Zeit ihre Bedeutung, wie auch Günter Figal in diesem Band erneut zeigt.

${ }_{63}$ Handke, Die Unschuldigen, 94.

64 Handke, Die Unschuldigen, 90. 
Hier erscheint Achtsamkeit, zum Beispiel im Umgang mit den Dingen des alltäglichen Lebens, als Muße-Übung ${ }^{65}$, aber parodiert. Genau wie die Aufmerksamkeit, die der Natur gewidmet ist, die bis zur übermäßigen Einfühlung (ins Rotkehlchen) zum Beispiel reicht.

Und hier wird, mitten in der vehementen Abwehr dieses „Idioten“ auch deutlich, dass er von den Unschuldigen nicht ganz abgeschafft werden soll, sondern auf Abruf, von Zeit zu Zeit ganz gut zu gebrauchen sei.

Wer sind aber eigentlich die „Unschuldigen“, die hier den Blick auf den „Schuldigen“ richten? Sie sind vom erfundenen Schuldigen erfundene Figuren, eine Gegensatzfolie - es ist nämlich „Ich“, der uns diese Figuren erst vorerzählt, um sie dann zu beschimpfen - aus Handkes Publikumsbeschimpfung von anno 1966 ist eine „Unschuldigenbeschimpfung“ anno 2015 geworden:

Ja, der Wächter einer armen Straße bin ich -

Daraufer:

- eines armen Gartens heißt's bei Vergil, nicht „Straße“!

Darauf ICH, stotternd und stammelnd, wobei ich lange brauche für das erste Wort, wie auch für die folgenden:

\section{ICH ins Schreien geratend}

.... Hundsfotte...Kassendiebe...Hirnschrott...Tätowierte Schwimmlehrer... Menschgewordene Fischgrätmuster...Pizzabäcker...Hutschenschleuderer...Sprechblasenkrebse...Oberförster...Holzäpfel...Zwetschgenröster...Mostbirnen...Krauterer.... Staubfänger...Schmudelputze...Rundinformierte...Freiheitsliebende...Ghiauren!...Horizonträuber!...Gotteskrieger...Friedenssoldaten!...Existenzuntergraber!...Pack!Doppelpack!Tetrapack!...Reitknechte!....Ahnungslose!...

Ich bin zunehmend ins Stottern und Stammeln geraten, verschlucke mich usw.

Ihr...ewig Heutigen!..Ihr....halblustigen Unernsten....Ihr Unberührbaren...Ihr...Unbesiegbaren...Ihr...Unbeleckten...Ihr

Unablenkbaren...Ihr...Unguten!...Ihr...unlieben...Bißchen!...Ihr...Unansprechbaren und Unerreichbaren...Ihr...ihr...Unzugänglichen...ihr...ihr...... ihr...Unerreichbaren!...Ihr Unüberraschbaren...ihr...ihr...Unhiesigen!66

Die „Unschuldigen“ werden vom Ich als die anonyme Masse derer, die, ständig mit ihren Mobiltelefonen sprechend, immer woanders sind als gerade da, wo sie leibhaft sind, erzählt, als die beständig abgelenkten, die wie aus Versehen, Leute,

65 Siehe dazu auch den Beitrag von Annika Schlitte in diesem Band.

66 Handke, Die Unschuldigen, $49 \mathrm{f}$. 
wie „ich“, umrennen, wie es im Text heißt immer ohne Absicht, unbewusst. ${ }^{67}$ Diese in mannigfacher Variation erzählte ,Masse Mensch' in ihrer zeitgenössischen, vielleicht auch ein wenig zukunftsfiktionalen Ausprägung ist die „unerreichbare“, immer schon zufriedengestellte, „nicht hiesige“ Kontrastfolie zum tobenden, hyperhiesigen „Ich“. 68

Wir können festhalten, dass diese Gegenüberstellung von „Ich“ und ,Masse funktioniert, weil beide Seiten grandios übertrieben und überzeichnet werden. In dieser Überzeichnung wird aber doch eine Zeitdiagnose sichtbar, die Muße und Moderne in derselben Zeit, in unserer Moderne, als hart gegeneinander gefügte Gegensätze aufzeigt, die sich in der Übertreibung gegenseitig erhellen und sich als gegenseitig voneinander abhängig zeigen. So ist „Ich“ für die Masse soviel Narr, der ihr den Spiegel vorhält, wie die Masse für „Ich“. Und das macht die Geschichte dann wieder interessant. Und daher wenden wir uns ihr jetzt noch einmal, aber anders, zu.

Der erste ,Akt' spielt im Frühling, wie schon erwähnt, erzählt wird zuerst die Szene - eine Landstraße mit einem Holzgestell, das dem beobachtenden und erzählenden Ich als „Nieder-Hoch-Sitz" ${ }^{69}$ dient. „Ich“ " positioniert sich gegenüber der erwähnten Masse der Unschuldigen, gewissermaßen gegen den Strom, wird von diesem Menschenstrom seinerseits aber nicht wahrgenommen. Die „Unschuldigen“ leben in einer anderen, einer digitalen Welt, während „Ich“ auf der ausrangierten Landstraße wie aus einer analogen Urzeit in diese hineinragt. Erst, nachdem „Ich“ sich selbst gegenübergestellt hat, als „Ich, der Dramatische“ und "Ich, Erzähler", also gewissermaßen seine zwei Seiten akzeptiert hat und insbesondere sich selbst gestattet hat, dass das „dramatische Ich“ mit ihm „durchgehen" darf ${ }^{70}$, entsteht ein dramatischer Dialog zwischen den erfunden Figuren und ihrem Erfinder. Im Verlaufe dieses Frühlings- und Eröffnungsaktes entspinnt sich das „Drama“, der Streit zwischen einem unkonventionellen, aus der Muße heraus erzählenden Ich, das bei Bedarf seine dramatische, schimpfende Stimme hören lässt, gegen einen Besserwisser- und Germanistenchor, in den sich die „Unschuldigen“ unversehens verwandelt haben. In formvollendeter Stichomythie wird das zum Erzählen aufgeforderte Ich beständig unterbrochen, weil schon wieder ein Detail nicht stimmt:

67 Handke, Die Unschuldigen, 29-33.

68 Handke, Die Unschuldigen, 29-33.

69 Handke, Die Unschuldigen, 9.

70 Handke, Die Unschuldigen, 21. 
$\mathrm{ICH}$

Und, ah, erst die Landstraßenstille! So nährhaft -

DER ANFÜHRER

Soll es nicht richtiger „nahrhaft“ heißen?

$\mathrm{ICH}$

- die Seele nimmt in dieser Stille Farbe, Verzeihung, Form an -

\section{DER ANFÜHRER}

in den Kreis, wobei er den Zeigefinger hebt Die Seele und die Formen: Georg Lukács! Seele als Form der Formen, alias: Eleganz -

\section{$\mathrm{ICH}$}

- und spuckt, pardon spricht: Es gibt mich, die Seele, noch, hier auf der Landstraße, weit weg von meinem stillen Haus, und nicht nur in der dunklen Nacht dort, sondern am hellichten Tag, hier, hier, nicht nur en una notte obscura -

\section{DER ANFÜHRER}

Noche! Oscura! Johannes vom Kreuz war Spanier. Juan-de-la-Cruz!

$\mathrm{ICH}$

- und in der Landstraßenstille und -sonne von unbestimmter Liebe entflammt zu gehen-

\section{DER ANFÜHRER}

„Con ansias en amores enflamada“ würde ich anders übersetzen

\section{$\mathrm{ICH}$}

- das entspricht meiner heutigen Seele eher als die bestimmte, jemand Bestimmtem bestimmte Liebe -

\section{DER ANFÜHRER}

„Bestimmtem bestimmt?“ Wortwiederholung! 
Dieser "Streit" geht noch eine Weile weiter, immer mehr der Unschuldigen schalten sich ein, wobei die Gewissheiten immer weiter zurück und die „kann-ich-jaschnell-mal-bei-Wikipedia-nachschauen-und-muss-ich-mir-also-nicht-so-genau-merken-Ungewissheiten“ zunehmen bis die Unschuldigen „fast im Sprechchor" verkünden: „Gott liebt die Neuigkeiten“ und das Hohelied der Information singen ${ }^{71}$, worauf „Ich “ in den oben zitierten Beschimpfungsmodus verfällt.

Der zweite ,Akt', „Sommer“, bahnt sich sehr langsam an. Schon mitten im Frühling kündigt er sich an: „Ob dann im Sommer, oder morgen schon, hier an den Rändern - was sage ich? an den Säumen, den lieblichen Säumen! - statt der vereinzelten Linden, wilden Kirschbäume und Mostbirnen die Palmen stehen werden “72 und wenig später: „Teufel der Landstraße [...] Noch ist nicht aller Tage Abend. Das ist noch nicht der letzte Akt. Morgen ist auch noch ein Tag. Morgen ist Sommer. Einen Jahrhundertsommer sollt ihr Unschuldigen steigen sehen." ${ }^{\text {"73 }}$ Bevor dieser, den anderen angedrohte Sommer aber wirklich eintritt, klärt „Ich“ im „dramatischen Selbstgespräch “74, dass der Konflikt, den er verzweifelt sucht, nur in ihm selbst zu finden ist: „Mein einziger Feind, nein, nicht Feind: Widersacher, das bin ich selber, zeitweise, traumweise. Und das ist nicht schön. Das ist keine Art! Frühling meines Mißvergnügens.“75 In einer klassischen und von Handke vielerlorts eingesetzten erzählten Verwandlung der Szene wird aus Frühling Sommer - die Bühne wird dunkel, man hört zuerst noch die Geräusche des Frühlings, dann allmählich die des Sommers, wenn die Bühne wieder hell ist, ,ist es auf der Landstraße Sommer geworden ${ }^{\text {“76 }}$. Wie gezeigt, bahnt sich dieser Sommer langsam an, ist dann fast unmerklich da und wird durch Verräumlichung der Zeit beständig relativiert. Mitten im Sommer wird der Winter in Neuseeland assoziiert; die Wetterliste auf dem i-phone macht es ja möglich, das Weltwetter gleichzeitig zu sehen. Der „Erste“ der „Unschuldigen“, die sich in diesem Sommer-Akt des Textes als unsterblich herausstellen, plant seinen Geburtstag im November minutiös über Jahre hinaus - Überraschungen sind in diesem, vom Tod befreiten Leben, nicht vorgesehen. Das todeslose Leben macht auch die Raum- und Erzählerfahrungen des Ich zunichte. ${ }^{77}$

Der Sommer-Akt ist dominiert vom oben geschilderten Blick der anderen auf den „Idioten“, den unverbesserlichen tumben Tor, der, so der Chor der Unschuldigen, besser nicht geboren wäre. ${ }^{78}$ An dieser, wenn man so will höhepunktartigen Bedrohung des Ich, das, wie erzählt wird, sich, wie im Traum, nicht wehren

71 Handke, Die Unschuldigen, 48.

72 Handke, Die Unschuldigen, 56.

73 Handke, Die Unschuldigen, 57.

74 Handke, Die Unschuldigen, 58.

75 Handke, Die Unschuldigen, 59.

76 Handke, Die Unschuldigen, 61.

77 Vgl. Handke, Die Unschuldigen, 146.

78 Vgl. Handke, Die Unschuldigen, 95. 
$\mathrm{kann}^{79}$, erscheint, endlich, die Unbekannte. Ganz unbekannt ist diese DiotimaFigur, die wie eine dea ex machina auf der Szene erscheint, allerdings nicht. Die Figur kennt man aus anderen Stücken Handkes und auch im vorliegenden Stück wird sie immer wieder durch „Ich“ antizipiert und herbeigesehnt. Die Unbekannte redet die sommerliche Szene in den Herbst hinein und rehabilitiert das Muße-Ich vor der Unschuldigen-Effizienz, allerdings auf eine ungewöhnliche Weise, nämlich so, dass sie beiden, dem Ich und den Unschuldigen wiederum jeweils den Spiegel vorhält. ${ }^{80}$ Sie ist sozusagen ein Meta-Narr. Mit ihrem Auftauchen trennt sie die „Konfliktparteien“ für eine „Bedenkzeit“" 81 und schafft so den Raum für eine Erzählung. Insofern bringt der Herbst, als dritter und vorletzter Akt dieses Textes, eine Art Peripetie mit sich, die in die winterliche Lösung der Nichtlösung (Aporie) mündet, in der Dramatisches und Episches sich versöhnen, und eine Sphäre der Inspiration geschaffen ist, die den Text, der vorliegt, erst möglich macht.

Die Art, wie die „Jahreszeiten“, die „Akte“ ineinander übergehen, durch diese Übergänge, Antizipationen und Rückblenden, entsteht jener zyklische Raum, in dem alles gleichzeitig da zu sein scheint.

Das Verhältnis zur Zeit wird mehrfach angesprochen und je mehr von der Muße-Sphäre der Inspiration die Rede ist, desto fragwürdiger wird die Kategorie der Zeit. Dies fällt zusammen mit dem Raumgewinn der Erzähler-Stimme, der Erzählung: Das Drama zeigt sich als die Zeitkunst, das Epos als die Raumkunst. Deshalb plädiert „Ich“ in diesem Text für ein Drama, das aus dem „andere[n] Gesetz“ des Epos heraus leben soll. Für eine hiesige und heutige Kunst, die ihre Herkunft aus dem Zeitlosen nicht vergisst. „Als ob sie die Uhr einer anderen Zeit aufzieht!? Ich bin nicht aus der Zeit. Ich und die Landstraße, wir verkörpern die Zeit.“" ${ }^{2}$ Und der „epische Schritt“" schließlich verkörpert eine Eigenzeit:

Epischer Schritt: ich skandiere damit, daß ich Zeit habe, mehr: Daß Zeit ist. Nicht: Es ist Zeit, sondern: Zeit ist, noch. Ich habe Zeit, du hast Zeit, wir haben Zeit. Epischer Schritt: Ich grüße, und dieses Grüßen allein ist die Botschaft. Epischer Schritt: Der ganze Mensch bewegt sich als Ganzer. Die Parallelen schneiden sich im Endlichen und ein Fenster tut sich auf im Asphalt. ${ }^{83}$

Angesichts solcher Selbstbeschreibung sagen die anderen kopfschüttelnd: „Nun hat's ihn endgültig erwischt “" 84 : „Es geht darum, daß du so als Barfußwanderer, auf der doch durchweg geteerten, kochheißen Hochsommer-Straße, mitten auf der Fahrbahn, so daß ich im Auto dir habe ausweichen müssen - Augen für nichts auf der Welt gehabt hast“. Der Häuptling versichert, er gehe auch von Zeit

\footnotetext{
79 Vgl. Handke, Die Unschuldigen, 95.

80 Vgl. Handke, Die Unschuldigen, 97-99.

81 Handke, Die Unschuldigen, 99.

82 Handke, Die Unschuldigen, 135.

83 Handke, Die Unschuldigen, 103.

84 Handke, Die Unschuldigen, 120.
} 
zu Zeit barfuß, „weil das angeblich gesund ist“, auch er kenne, was er hier angesichts von „Ich“ „Weltvergessenheit“ nennt: „Eine gewisse Weltvergessenheit von Zeit zu Zeit [...] frischt den Kräftehaushalt auf, strukturiert das Wirtschaften und ist Bestandteil der Ökonomie. Ich weiß, wovon ich rede: Von der Welt entschieden wegschauen, mit einem Ruck, wie ein Tangotänzer, nicht wahr?" 85

Also, „Muße“ als Freizeitvergnügen und Erholungsmodus ist, in diesem Anwurf des Häuptlings an „Ich“, geschenkt. Die Provokation besteht darin, es mit der Muße ernst zu meinen: „Es geht darum, Nachbar, daß du so, im Barfußgehen, Meilen um Meilen auf der Carretera, die Welt nicht zum Schein, nicht im Spiel - was gibt es Schöneres und dazu noch Förderlicheres als den Schein und das Spiel?! - vergessen hast, sondern in Wirklichkeit, im Ernst“ ${ }^{\circ 6}$

„Der außenstehende Betrachter erkennt oft keinen Unterschied zwischen dem Dösenden und dem Müßigen" ${ }^{87}$, mit diesem Bonmot aus einem zugegebenermaßen etwas skurrilen, in Teilen jedoch ertragreichen Werk über Muße (scholé) von Hans Brühweiler, kann man erklären, warum Der Wachträumer „Ich“ und die außenstehenden Unschuldigen einander nur, im Idealfall zum wechselseitigen Gewinn, bestaunen können: Der Träumer, dem die anderen vorwerfen, dass er partout aus seinem „Wachtraum“ nicht aufwachen will, hat von der Wirklichkeit mehr gesehen, als dem Schmähenden ahnt:

Ich habe Augen für den Horizont [gehabt], den [...] weltfernsten. Ich weiß noch, daß dort eine Öffnung in einer der Horizontwolken war, die während, zeit des Gehens, Stunde um Stunde, ein und dieselbe Form bewahrt hat. Nicht die Wolke habe ich im Blick gehabt, nur die Offenheit in ihr. Ja, es war eine Offenheit - ein Durchschuß - und so einen Durchschuß, den habe ich mir gefallen lassen. Ja, und das war alles. Eins noch: dieses Schauen war kein Wegschauen. Jedenfalls habe ich dich im Auto wahrgenommen wie in einem Film: Du hattest einen dreiteiligen Nadelstreif an, mit Uhrkette und Stecktuch. Das Stecktuch war verrutscht, und dein Hosenschlitz war offen. Eine Frau war an deiner Seite. Ihr habt abwechselnd aus einem Flachmann getrunken, und ich könnte den Film noch viel länger erzählen. - Ich wirtschafte immer noch, Meister, vielleicht begeisterter denn je. ${ }^{88}$

Von seinem „Königsfleck“, dem Muße-Ort zum Schauen, Sammeln und Gestalten hat „Ich-Erzähler“ im Verein mit „Ich-der-Dramatiker" einen Textraum geschaffen, der, die Jahreszeiten immerwiederkehrend ausschreitend, Verschiedenheiten gelassen gelten lassen kann - nicht zuletzt die eigene Verschiedenheit und Einsamkeit als Textemacher: Diesen Königsfleck, die selbsterzählte Land-

85 Handke, Die Unschuldigen, 119.

86 Handke, Die Unschuldigen, $119 \mathrm{f}$.

87 Hans Brühweiler, Muße (scholé). Ein Beitrag zur Klärung eines ursprünglich pädagogischen Begriffs, Zürich 1971, 7 .

88 Handke, Die Unschuldigen, 121. 
straße, behauptet „Ich“ als sein kleines großes Königreich: „Diesen Platz werdet ihr mir nicht nehmen". 89

Mitten in Wuppertal, auf einer Verkehrsinsel inmitten einer vielbefahrenen Straßenkreuzung, unter der Schwebebahn und die nächstgelegene Filiale des bekanntesten Schnellrestaurants der Welt im Hintergrund sitzt eine Frau im weißen Kleid mit langen schwarzen, offenen Haaren mit dem Rücken zum Betrachter, einen Ghettoblaster vor sich und davor die Straße mit dem weißen Mittelstreifen im Blick. Auf der Verkehrsinsel wächst trockenes Gras und hier liegen zwei mittelgroße Steine, nebst einem Laternenpfahl rhythmisch arrangiert, so dass sich, mitten in Wuppertal, inmitten einer belebten Straßenkreuzung eine Art Zen-Garten zeigt. Die Tänzerin spielt sich ein Lied vor und träumt von der einen, der wahren und der einzigen Liebe, die vorübergehend auch zu erscheinen scheint, was ein anmutiger pas de deux erlaubt, nur, um die Frau im weißen Kleid mit den langen schwarzen offenen Haaren wieder mit ihrem Traum von der einen, der wahren, der einzigen Liebe allein zu lassen. Diesen Platz, am Rand der Straße, bevölkert mit ihrem Traumpersonal, kann man ihr nicht nehmen. ${ }^{90}$

89 Handke, Die Unschuldigen, 10.

90 Wenders, pina, 52:59-54:10. 



\section{Autorenverzeichnis}

Egel, Antonia, Dr.

Promotion in Neuerer Deutscher Literaturwissenschaft an der Albert-LudwigsUniversität Freiburg (2013). Assistenzen an den Universitäten Freiburg und Salzburg, Gastdozentur an der Kwansei Gakuin University Nishinomiya/Japan. Seit 2018 Lise-Meitner-Stelle an der Universität Salzburg.

Feitscher, Georg, Dr.

Promotion in Neuerer deutscher Literaturwissenschaft an der Albert-LudwigsUniversität Freiburg (2017). 2013-2016 Wissenschaftlicher Mitarbeiter im Freiburger SFB 1015 „Muße“. Seit 2016 ebenda Wissenschaftlicher Mitarbeiter im SFB 948 „Helden“.

Fest, Kerstin, Dr.

Promotion in Englischer Literaturwissenschaft an der Albert-Ludwigs-Universität Freiburg (2006). 2013-2016 Wissenschaftliche Mitarbeiterin im SFB 1015 „Muße“. Seit 2017 Wissenschaftliche Mitarbeiterin am Englischen Seminar der Albert-Ludwigs-Universität Freiburg.

Figal, Günter, Prof. Dr.

Promotion in Philosophie an der Ruprecht-Karls-Universität Heidelberg (1976). Habilitation ebenda (1987). 1989-2002 Professor für Philosophie an der Eberhard-Karls-Universität Tübingen. 2002-2017 Ordinarius für Philosophie an der Albert-Ludwigs-Universität Freiburg.

Gerstner, Jan, Dr.

Promotion in Allgemeiner und Vergleichender Literaturwissenschaft an der Johannes Gutenberg-Universität Mainz (2010). Seit 2010 wissenschaftlicher Mitarbeiter im Bereich Neuere deutsche Literaturwissenschaft und Literaturtheorie an der Universität Bremen.

Henning, Christoph, PD. Dr.

Promotion in Philosophie über Karl Marx an der TU Dresden (2003). 2004-2006 Postdoktorand an der Zeppelin Universität Friedrichshafen. 2006-2014 an der Universität St. Gallen, dort Habilitation 2014. Seit 2014 Fellow für Philosophie am Max-Weber-Kolleg für kultur- und sozialwissenschaftliche Studien, Universität Erfurt. 2015 Vertretungsprofessor an der Zeppelin Universität Friedrichshafen. 
Keiling, Tobias, Dr., PhD.

PhD am Boston College, USA, und Promotion zum Dr. phil. an der AlbertLudwigs-Universität Freiburg (2013). 2013-2016 Wissenschaftlicher Mitarbeiter am Freiburger SFB 1015 „Muße“. Seit 2017 Forschungsstipendiat am Human Dynamics Centre der Julius-Maximilians-Universität Würzburg.

Krause, Robert, Dr.

Promotion in Neuerer Deutscher Literaturwissenschaft an der Albert-LudwigsUniversität Freiburg (2009). 2012-2013 Postdoc-Stipendiat der Fritz Thyssen Stiftung. 2013-2014 Wissenschaftlicher Mitarbeiter am SFB 1015 „Muße“. Seit 2009 akademischer Mitarbeiter am Deutschen Seminar, Abteilung Neuere deutsche Literatur, der Albert-Ludwigs-Universität Freiburg. Assoziiertes Mitglied der Forschungsstelle „Nietzsche-Kommentar“ der Heidelberger Akademie der Wissenschaften.

Riedl, Peter Philipp, Prof. Dr.

Promotion in Neuerer Deutscher Literaturwissenschaft an der Universität Regensburg (1995). 2002 Habilitation. 2013-2016 Projektmanager des Freiburger SFB 1015 „Muße“. Seit 2017 Wissenschaftlicher Mitarbeiter am Deutschen Seminar der Universität Freiburg.

Sahraoui, Nassima, Dr. des.

Promotion in Philosophie an der Goethe-Universität Frankfurt. Lehre in der Allgemeinen und Vergleichenden Literaturwissenschaft der Goethe-Universität Frankfurt sowie Ethik und Politische Theorie an der Dualen Hochschule Baden-Württemberg. Koordinatorin des Promotionsbereichs der Hochschule für Gestaltung Offenbach und Lektorin des S. Fischer Verlages. 2017 Fellow am Forschungsinstitut für Philosophie Hannover.

Schäfer, Martin Jörg, Prof. Dr.

Promotion in Neuerer Deutscher Literaturwissenschaft an der Universität Hamburg (2001), Habilitation an der Universität Erfurt (2010). Seit 2014 Professor für Neuere deutsche Literatur an der Universität Hamburg.

Schlitte, Annika, Dr.

Promotion in Philosophie an der Ruhr-Universität Bochum (2010). 2011-2016 wissenschaftliche Mitarbeiterin und Sprecherin der Graduiertenkollegs „Philosophie des Ortes“ an der Katholischen Universität Eichstätt-Ingolstadt. Seit 2016 Juniorprofessorin für Philosophie an der Johannes Gutenberg-Universität Mainz. 
Liedke, Heidi, Dr.

Promotion im Fach Englische Philologie an der Albert-Ludwigs-Universität Freiburg (2017). 2013-2016 Wissenschaftliche Mitarbeiterin am Freiburger SFB 1015 „Muße“. Seit 2017 Wissenschaftliche Mitarbeiterin im Fach Anglistik an der Universität Koblenz-Landau, Campus Landau. 2018-2020 Feodor Lynen-Stipendiatin der Alexander von Humboldt-Stiftung an der Queen Mary University of London, GB.

Masurczak, Pia Florence, M.A.

Promotion in Englischer Literaturwissenschaft. 2013-2016 Wissenschaftliche Mitarbeiterin am Freiburger SFB 1015 „Muße“ zu Faulheit und Nichtstun im britischen Kolonialdiskurs. Seit 2016 Koordinatorin der EU-Projekte „Respect Words" und „Radio Grenzenlos" bei Radio Dreyeckland Freiburg.

Wilm, Jan, Dr.

Promotion in englischer Literaturwissenschaft an der Goethe-Universität Frankfurt am Main (2014). Fellow am Kulturwissenschaftlichen Institut Essen (KWI), Übersetzer, Literaturkritiker. 



\section{Personenregister}

Adorno, Theodor W. 40, 124

Allen, Woody 154

Altenberg, Peter 105-106, 111

Ando, Tadao 58

Arendt, Hannah 131, 141

Aristoteles 42, 47-48, 76, 125, 127, 154, 175-177, 184, 186, 188, 192-193, 196

Attridge, Derek 149-151

Augustinus 179, 199

Bachtin, Michail 202

Baedeker, Karl 113, 115

Barthes, Roland 238-239

Baudelaire, Charles 102-103, 104, 116, 124, 132-133, 136-137, 139-141, 227

Bauer, Walter 158

Bausch, Pina 249-254

Beckett, Samuel 151-159

Benjamin, Walter 5, 35-36, 102-103, 116117, 121-141, 226

Berlin, Isaiah 100

Bernhard, Thomas 246

Best, Stephen 149-151

Bhabha, Homi 26

Boltanski, Luc 212

Börne, Ludwig 107

Bothe, F.H. 113

Brewster, John 242

Bronfen, Elisabeth 165

Bronner, Franz Xaver 12

Brüllmann, Philipp 127

Brunner, Otto 129

Bryden, Mary 153

Burney, Carl 114

Calvin, Johannes 130

Casey, Edward S. 232-233

Certeau, Michel de 225-226, 230-231, 237

Chateaubriand, François-René de 132

Chiapello, Eve 212
Coetzee, J. M. 145-146, 150

Cole, Teju 225, 237, 239-243

Collingham, Elizabeth 22, 30

Consentius, Ernst 113

Dante (Alighieri) 154

Deane, Seamus 152

Debord, Guy 233-234

Derrida, Jacques 49

Dilke, Charles Wentworth 42-45, 48

Dostojewski, Fjodor 212

Dworkin, Ronald 214, 219

Ebeling, Christoph Daniel 114

Eberty, Felix 113

Eiloart, Elizabeth 236

Eliot, T. S. 152

Emerson, Ralph Waldo 52, 58

Engels, Friedrich 1, 46, 211

Ense, Karl August Varnhagen von 113

Epstein Nord, Deborah 227

Fähnders, Walter 122, 125, 129

Fellini, Federico 135

Fichte, J. G. 137, 214

Figal, Günter 247

Flaubert, Gustave 139, 212

Fontane, Theodor 113

Foucault, Michel 132, 226, 229

Friebe, Holm 1

Friedrich der Große 130

Frisch, Max 202-206, 209

Frühsorge, Gotthardt 15

Garve, Christian 7, 13-14, 16

Gass, William H. 156

Gehrmann, Susanne 240

George, Stefan 114

Geßner, Salomon 7, 11-13, 16

Ginzburg, Carlo 227-228

Girardin, Saint-Marc 140 
Goethe, Johann Wolfgang von 8, 17, 95, 139

Gontscharow, Iwan 37-39, 155

Gorz, André 141

Gottsched, Johann Christoph 11

Gumbrecht, Hans Ulrich 122

Habermas, Jürgen 5

Hafftitz, Peter 114

Han, Byung-Chul 144-145

Handke, Peter 245-265

Harvey, David 78

Hasebrink, Burhard 148, 247

Haussmann, Georges-Eugène Baron 102

Hegel, Georg Wilhelm Friedrich 7-8, 10, 17-18, 40, 45, 129, 136-137

Heidegger, Martin 57, 146, 174, 255

Heine, Heinrich 113

Henry, O. (William Sydney Porter) 146

Herder, Johann Gottfried 7, 15-17

Hermann, Georg 114

Hessel, Franz 99-119, 139

Hirschfeld, Christian Cay Lorenz 7, 13, 15-16

Hoffmann, E.T.A. 113, 114

Hofmannsthal, Hugo von 105-106, 208

Horkheimer, Max 40, 124

Howitt, Anna Mary 225-243

Humboldt, Wilhelm von 216

Iser, Wolfgang 16, 238-239

Jakobson, Roman 230

James, Henry 156

Jameson, Fredric 78

Jankélévitch, Vladimir 144

Jeanneret, Charles-Édouard

(Le Corbusier) 57

Jerome, Jerome K. 231

Joubert, Joseph 131-132

Joyce, James 151-152, 156

Jünger, Ernst 180

Kant, Immanuel 7-10, 37, 40-41, 181

Kaulbach, Wilhelm von 230

Kautsky, Karl 46-47

Keynes, John Maynard 187

Klinkert, Thomas 138, 247
Korte, Barbara 231, 237

Koselleck, Reinhart 9

Kracauer, Siegfried 1, 135

Krünitz, Johann Georg 13

Lafargue, Paul 46

Laforgue, Jules 113

Langenscheidt, Gustav 114, 115

Lobo, Sasha 1

Mackowsky, Hans 113, 114

Mahler, Gustav 57

Malinowski, Bronislaw 230

Mallarmé, Stephane 139

Marcus, Sharon 149-151

Marcuse, Herbert 217

Martin, Norbert 2, 122

Marx, Karl 1, 37, 42-46, 48, 129, 132, 211, 214

Menninghaus, Winfried 122

Mill, John Stuart 215, 221

Mix, York-Gothart 11,

Moretti, Franco 149-151

Mozart, Wolfgang Amadeus 157

Müchler, Karl 113

Musil, Robert 5

Neschke-Hentschke, Ada 127

Nicolai, Friedrich 113

Niekisch, Ernst 180

Nietzsche, Friedrich 37, 56-57, 61-74, 146-149, 174, 211

Parks, Fanny 31

Parsons, Deborah 163

Parthey, Lili 113

Pascal, Roy 199-200

Pawson, John 57

Pessoa, Fernando 39

Pfister, Manfred 228

Pieper, Josef 174, 178-185, 191-193

Pietsch, Ludwig 114

Platon 125-126,

Plotin 127

Poe, Edgar Allan 103

Pordzik, Ralph 228

Proust, Marcel 117, 145, 150

Puschkin, Alexander 38 
Raabe, Wilhelm 113

Rawls, John 213, 218

Reich-Ranicki, Marcel 206-209

Rembrandt (van Rijn) 95

Ricardo, David 42-43

Richardson, Dorothy 161-172

Riedl, Peter Philipp 148

Rietfeld, Gerrit van 57

Rifkin, Jeremy 123

Rilke, Rainer Maria 146-147, 246, 255 256

Rohe, Mies van der 57

Rosa, Hartmut 1, 75, 90-92, 144-145, 212

Rousseau, Jean-Jacques 52, 103, 116, 138, 153, 198, 202

Ruda, Frank 40

Russell, Bertrand 174, 185-193

Sackville-West, Vita 227

Saint-Simon, Henri de 129

Sainte-Beuve, Charles-Augustin 131-132

Sand, George 227

Schadow, Johann Gottfried 114

Schäfer, Martin Jörg 122, 130-131

Scheffler, Karl 114

Schiller, Friedrich 7, 9-10, 18, 248

Schlaffer, Hannelore 2

Schlegel, August Wilhelm 42-43, 49

Schlegel, Friedrich 18, 35, 42-43

Schneider, Helmut J. 17

Scholem, Gershom 121

Schoor, Juliet 217

Schopenhauer, Arthur 195-196, 197,

Schuhl, Pierre-Maxime 126-127,

Seneca, Lucius Annaeus 219

Shakespeare, William 49

Shumaker, Wayne 200-201
Sillitoe, Allan 156

Simmel, Georg 75-97, 101

Smith, Adam 43

Sontag, Susan 144

Sophokles 154

Speyer, Wilhelm 113

Spoerhase, Carlos 147

Stern, William 96

Stevenson, Robert Louis 231

Stifter, Adalbert 105-106

Szatmari, Eugen 113

Tally, Robert T. 231

Thomas von Aquin 179, 183

Thoreau, Henry David 51-59

Tiedemann, Rolf 124

Unger, Daniel 137

Varga, Simon 127

Veblen, Thorstein 217

Vermeulen, Pieter 240, 242

Virilio, Paul 78

Vogl, Joseph 8

Voß, Johann Heinrich 18

Wagner, Martin 109

Walser, Robert 35

Weber, Max 40, 131, 134, 180

Wenders, Wim 249-254

Whitman, Walt 58

Wittgenstein, Ludwig 57

Wood, James 242

Woolf, Virginia 151

Wright, Frank Lloyd 58

Zagajewski, Adam 143-145

Zelter, Carl Friedrich 113 



\section{Sachregister}

Arbeit 121-141, 173-194

- Arbeitslosigkeit 186

Autonomie 197

babu 20-22

Beschleunigung 75, 101, 105, 110, 116

- Geschwindigkeit 102, 104, 110, 112

Bildung 193, 214

British Army in India 22

couch-potato 219

Drama 248,252

Einfachheit 51-59

Einsamkeit 52, 54

Elitismus 213

Entfremdung 76, 188

Entschleunigung 105, 116

Erfahrung 121-122, 134-135

Erkennen 184

Erlebnis 134-135, 138-139

Faulheit 35-49, 64, 71-72, 96

Fest 184

- Feiern 185

Flaneur 99-119

flâneuse 163

Freiheit 52-53, 54, 55, 56, 182

Freiraum 53, 56, 58, 257

Freizeit 190, 192-193

Freundschaft 54

Frieden 175

Gelassenheit 55, 59, 101, 107-108, 110, 174

Geldwirtschaft 79

Gerechtigkeit 213

Geschichte 7-10

Geschwindigkeit siehe Beschleunigung

Geselligkeit 54

Glück 186-187, 190
- Glückseligkeit 175

Heterotopie 225-226, 229, 233, 242

hill stations 22, 30-31

Horizont 53

idling 225-226, 231, 233, 243

Interdisziplinarität 2-6, 123

Kapitalismus 1, 124-125, 131, 140-141

Klasse 217

Klima 23, 25, 30

Kontemplation, kontemplativ 176, 178, 181, 184

- theoría 191, 196

Krankheit 25-26, 30

Krise 180

Kult, kultisch 185, 192-193

Kulturgeschichte 122, 125, 135

Kunst 181

Langsames Lesen 143-144, 146, 151-152, 155-157

Leben 51,58

- Landleben 11-15

- Lebensform(en) 177

- Lebensüberdruss 139

Liberalismus 191-192

Makroepoche 5, 122

Moderne, modern 56, 173, 179, 180, 188

- Modernisierung 8,17-18

- Modernetheorie 121-125, 132, 135, 139-140, XY

Muße

- Institutionalisierung von 193-194

- Muße-Praktiken 226, 231, 242-243

- Mußezwang 144, 158-159

- Müßiggang 62, 65, 70-74

- poiesis 76

- praxis 76 
nabob 23-24, 28

Natur 53, 58

otium 196

Philologie 145-149

Philosophie 181

Raum 53, 263

- urbaner Raum 101-102, 104, 107, 109, 116-118

- öffentlicher Raum 222

Rente 218

Schreiben 55

Selbstvergessenheit 52

Selbstüberforderung 212

Spannungsverhältnis 1-2, 4

Stadtleben 2, 6 stream of consciousness 161-162, 164

Subjektivität 196

Tourismus 162, 166

Trägheit 183

Traum 245-265

Tanz 254

Ungleichheit 188, 193, 211-223

Utopie, utopisch 190

Vermögen $37,39,45,47-48$

Widerstand, widerstehen, Widerständigkeit 36, 39, 48-49

Wohnen 59

Zeit 53

- Zeitarmut 212 



